\title{
Pacific Northwest National Laboratory Investigation of Stress Corrosion Cracking in Nickel-Base Alloys, Volume 2
}

Manuscript Completed: February 2012

Date Published: March 2012

Prepared by

S. M. Bruemmer, M. B. Toloczko and M. J. Olszta

Pacific Northwest National Laboratory

Richland, Washington 99352

Darrell Dunn

NRC Project Manager

Prepared for

Office of Nuclear Regulatory Research U.S. Nuclear Regulatory Commission

Washington, DC 20555-0001

NRC Job Code N6872

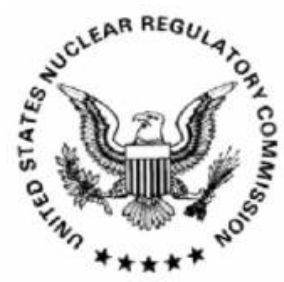




\section{Previous Documents in This Series}

NUREG/CR-7103 Vol. 1: Pacific Northwest National Laboratory Investigation of

Stress Corrosion Cracking in Nickel-Base Alloys, Volume 1 


\begin{abstract}
The objective of this program is to evaluate the primary water stress corrosion cracking (PWSCC) susceptibility of high chromium alloy 690 and its weld metals, establish quantitative measurements of crack-growth rates and determine relationships among cracking susceptibility, environmental conditions and metallurgical characteristics. Stress-corrosion, crack-growth rates have been determined for 12 alloy 690 specimens, 11 alloy 152/52/52M weld metal specimens, 4 alloy $52 \mathrm{M} / 182$ overlay specimens and 2 alloy $52 \mathrm{M} / 82$ inlay specimens in simulated PWR primary water environments. The alloy 690 test materials included three different heats of extruded control-rod-drive mechanism (CRDM) tubing with variations in the initial material condition and degree of cold work for one heat. Two cold-rolled (CR) alloy 690 plate heats were also obtained and evaluated enabling comparisons to the CR CRDM materials. Weld metal, overlay and inlay specimens were machined from industry mock ups to provide plantrepresentative materials for testing. Specimens have been tested for one alloy 152 weld, two alloy 52 welds and three alloy $52 \mathrm{M}$ welds. The overlay and inlay specimens were prepared to propagate stress-corrosion cracks from the alloy 182 or 82 material into the more resistant alloy 52M. In all cases, crack extension was monitored in situ by direct current potential drop (DCPD) with length resolution of about $+1 \mu \mathrm{m}$ making it possible to measure extremely low growth rates approaching $5 \times 10^{-10} \mathrm{~mm} / \mathrm{s}$. Most SCC tests were performed at $325-360^{\circ} \mathrm{C}$ with hydrogen concentrations from 11-29 cc/kg; however, environmental conditions were modified during a few experiments to evaluate the influence of temperature, water chemistry or electrochemical potential on propagation rates. In addition, low-temperature $\left(\sim 50^{\circ} \mathrm{C}\right)$ cracking behavior was examined for selected alloy 690 and weld metal specimens. Extensive characterizations have been performed on material microstructures and stress-corrosion cracks by optical and electron microscopy techniques and linked to crack-growth test results to help define material and environmental parameters controlling SCC susceptibility.
\end{abstract}


This page intentionally left blank. 


\section{Foreword}

Primary water stress corrosion cracking (PWSCC) is a significant issue that has affected nickel base alloy pressurized-water reactor (PWR) components. Observation of PWSCC in the past decade has challenged some assumptions of leak before break (LBB) analyses. These analyses did not consider active degradation mechanisms such as PWSCC that may contribute to potential sources of pipe rupture, and subsequently, a loss of coolant accident (LOCA). In addition, operational experience has shown that PWSCC of reactor pressure vessel head (RPVH) penetrations can lead to boric acid corrosion of low-alloy pressure vessel steels.

The U.S. Nuclear Regulatory Commission (NRC) mandated inspections are required for reactor coolant system components constructed from PWSCC susceptible materials including alloy 600 and its weld metals, alloys 182 and 82 . Proposed methods for PWSCC mitigation include the use of components manufactured from alloy 690 and its weld metals, alloys 152 and 52 . The industry has also proposed PWSCC mitigation on alloy 600/182/82 materials using alloy 52 weld overlays, inlays, and onlays. Although the operational experience of these higher chromium-containing alloys has been favorable, the effects of operating conditions and metallurgical factors on PWSCC susceptibility are not fully understood. Ongoing industry-led research has been conducted to evaluate variables that influence PWSCC resistance. Confirmatory testing sponsored by the NRC has been conducted to verify improvement factors and to support inspection intervals for alloy 690 components and alloy 152/52 welds.

This report documents work conducted by Pacific Northwest National Laboratory (PNNL) during calendar years 2008 to 2010 under contract to the NRC. Stress-corrosion crack-growth rates were measured on multiple materials including as received and cold worked alloy 690 plate and control rod drive mechanism (CRDM) tubing. Specimens produced from industry mock ups included alloy $152 / 52 / 52 \mathrm{M}$ welds, an alloy $52 \mathrm{M} / 182$ overlay, and an alloy $52 \mathrm{M} / 82$ inlay. Crack growth rate tests were performed under conditions typical of an operating pressurized water reactor (PWR). Test conditions were systematically varied to evaluate the influence of temperature, water chemistry, stress intensity and electrochemical potential.

Thermally treated (TT) alloy 690 CRDM tubing heats and alloy 152/52/52M welds were resistant to SCC. High levels of cold work during one-dimensional rolling were found to promote PWSCC and much higher growth rates in alloy 690. Although the highly cold worked specimens were not representative of components in operating reactors these results indicate the high-chromium alloy 690 materials may not be immune to intergranular stress corrosion cracking. Additional tests analyses are planned to understand the effects of fabrication and welding processes.

Michael J. Case, Director

Division of Engineering

Office of Nuclear Regulatory Research

U.S. Nuclear Regulatory Commission 
This page intentionally left blank 


\section{Contents}

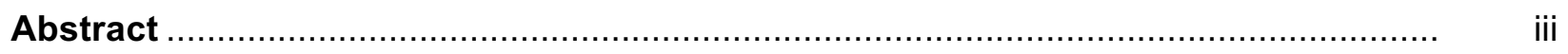

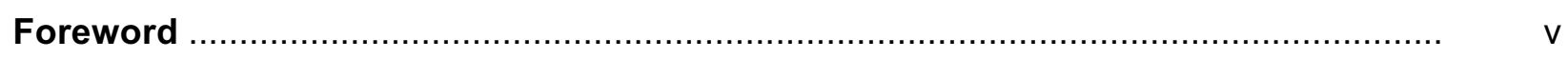

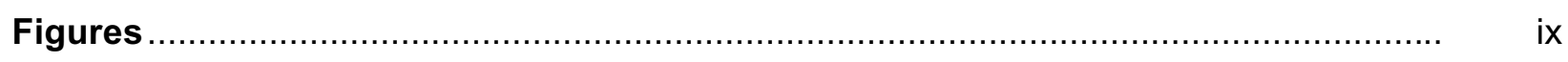

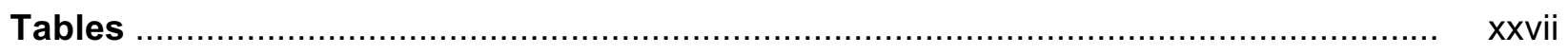

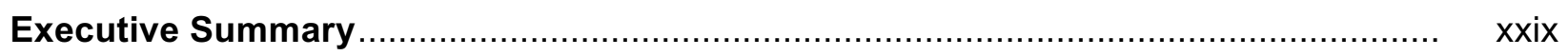

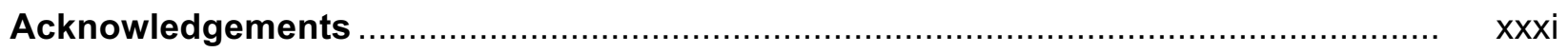

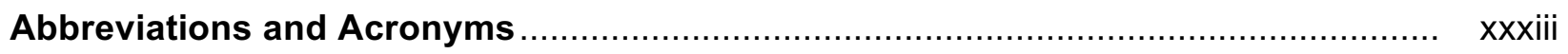

1 Introduction ......................................................................................................... 1

2 SCC Crack-Growth Test Systems and Testing Approach .......................................... 2-1

2.1 Overview of SCC Crack-Growth Test Systems .............................................. 2-1

2.2 General SCC Crack-Growth Testing Approach and Issues ............................... 2-5

2.3 Specific SCC Crack-Growth Testing Approach ........................................... 2-8

3 SCC Crack-Growth Testing on Alloy 152, 52 and 52M Weld Metals ........................... 3-1

3.1 Overview of Weld Mockups and SCC Tests .................................................. $3-1$

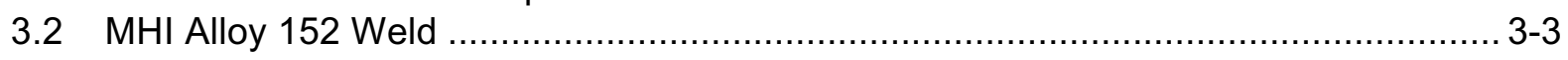

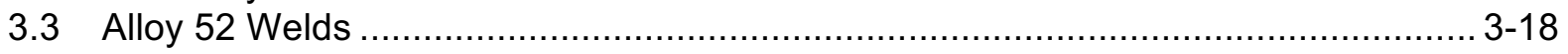

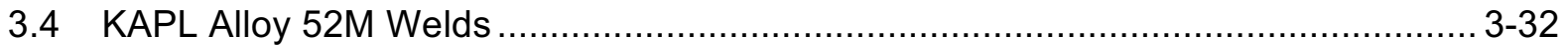

3.5 Alloy 52M/182 Overlay and Alloy 52M/82 Inlay Welds ..................................... 3-50

3.6 Summary and Discussion of SCC Results for Weld Metals ................................ 3-76

4 SCC Crack-Growth-Rate Testing of Alloy 690 CRDM Tubing Materials ...................... 4-1

4.1 Compositions and Microstructures of Alloy 690 CRDM Materials ........................... 4-1

4.2 As-Received Alloy 690TT and Solution-Annealed Alloy 690CM Materials ............... 4-11

4.3 Cold-Rolled Alloy 690 CRDM Materials ...................................................... 4-20

4.4 Summary and Discussion of SCC Results for Alloy 690 CRDM Materials .............. 4-40

5 SCC Crack-Growth-Rate Testing on Cold-Rolled Alloy 690 Plate Materials ................ 5-1

5.1 Compositions and Microstructure of Alloy 690 Plate Materials ............................... 5-1

5.2 High-Resolution Examinations of Cold-Rolling Microstructural Damage .................. 5-18

5.3 SCC Tests on the Cold-Rolled Alloy 690 Plate Materials ..................................... 5-38

5.4 Cold Rolling Effects on Microstructure and SCC ............................................ 5-43 
6 Characterization of SCC Cracks and Crack Tips ................................................... 6-1

6.1 Background for SCC Crack-Tip Characterizations …...................................... 6-1

6.2 Scanning Electron Microscopy Examinations of SCC Cracks and Crack Tips ........... 6-2

6.3 Transmission Electron Microscopy Examinations of SCC Crack Tips .................... 6-23

6.4 Insights into SCC Mechanisms from Crack Tip Characterizations ........................ 6-38

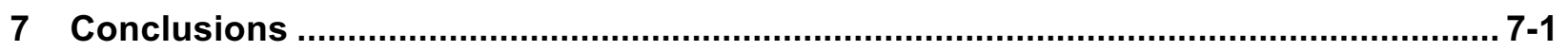

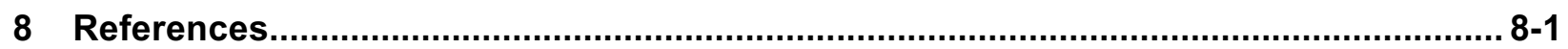




\section{Figures}

Figure 1.1 Summary of SCC growth data reported by Bettis [Ref. 5] on cold-rolled or tensile-strained alloy 690 plate heats. Testing was performed at temperatures of 316,338 and $360^{\circ} \mathrm{C}$ as listed in the legend with a dissolved hydrogen content of $50 \mathrm{cc} / \mathrm{kg} \mathrm{H} \mathrm{H}_{2}$ to ensure electrochemical conditions were within the Ni metal stable regime at $360^{\circ} \mathrm{C}$. Similar results were obtained during selected tests at the lower temperatures using a

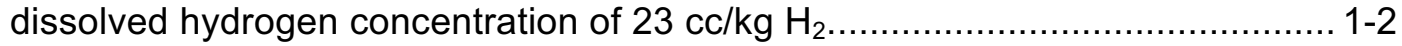

Figure 2.1 General water flow diagram for PNNL SCC crack-growth test systems........... 2-2

Figure 2.2 Typical crack-growth-rate test frame loading system used at PNNL................ 2-3

Figure 2.3 Schematic diagram illustrating the DCPD system to measure crack length in situ.

Figure 2.4 Schematic drawing of a 0.5T CT specimen. Oversized loading holes $(\sim 9.5 \mathrm{~mm}$ diameter) are used to accommodate ceramic inserts that provide electrical isolation between the CT specimen and clevises. Dimensions for 1TCT specimens are approximately double.

Figure 2.5 Example of large uncracked ligament detected in the wake of a crack........

Figure 3.1 Optical image of alloy 152 weld mockup showing U-groove weld in crosssection.

Figure 3.2 Sectioning diagram for the alloy 152 welded block. End sections $X$ and $G$ are $1.3 \mathrm{~cm}$ thick and are used for metallographic observations while sections A-F are $1.9 \mathrm{~cm}$ thick and are to be used for CT samples. There is $\sim 7.6 \mathrm{~cm}$ of welded block in front of section " $X$ "

Figure 3.3 Optical micrograph of section $\mathrm{C}$ showing the location of the machined notch. This same weld pass was selected in section D, while the one just above and to the left was selected in section $\mathrm{E}$.

Figure 3.4 SEM micrographs of the alloy 152 weld showing long dendrites (left) and much smaller, equiaxed dendrites (right). The latter are generally present at the intersection of two weld passes but some of the long dendrites pass through that region uninterrupted.

Figure 3.5 Scanning electron microscope images are shown from the alloy 152 weld metal. The image in (a) was taken using backscattered electrons, (b) and (c) were taken in secondary electron imaging mode.

Figure 3.6 SEM secondary-electron Image is shown along with composition maps for $\mathrm{Mn}, \mathrm{Nb}$ and $\mathrm{Al}$. The $\mathrm{Mn}$ map indicates a slight degree of coring and the other two maps show the locations of the large $\mathrm{NbC}$ and the Ti-Al particles in the microstructure. 
Figure 3.7 An example of a dendritic grain boundary that shows a single large $\mathrm{Cr}$ carbide, with numerous smaller $\mathrm{Nb}$ carbides along the boundary. In this case, Ti was not found associated with the Nb carbides.

Figure 3.8 Compositional maps taken in STEM mode revealed that both $\mathrm{Cr}$ - and $\mathrm{Nb}$ rich carbides are present on the boundary between two dendrites. The bottom image reveals that the two carbide phases can sometimes be superimposed with each other. In this example, $\mathrm{Nb}$ and $\mathrm{Ti}$ were associated with the same particles.

Figure 3.9 Image of $\mathrm{MHI}$ alloy 152 weld showing positioning of $0.5 \mathrm{~T} \mathrm{CT}$ specimens.

Figure 3.10 Crack growth response of MHI alloy 152 specimen CT013 during transitioning and constant $\mathrm{K}$ steps.

Figure 3.11 Side surface profile of MHI alloy 152 sample CT013 showing alignment of crack relative to dendrite structure.

Figure 3.12 Crack growth surface of MHI alloy 152 specimen CT013. Optical image on left reveals local areas of SCC propagation and SEM images on right illustrate IG morphology.

Figure 3.13 Overall crack growth response of $\mathrm{MHI}$ alloy 152 specimens CT017 \& CT018

Figure 3.14 Constant $\mathrm{K}$ crack growth response of MHI alloy 152 specimens CT017 \& CT018 at $30 \mathrm{MPa} \sqrt{\mathrm{m}}$.

Figure 3.15 Crack growth response during cyclic loading conditions of MHI alloy 152 specimens CT017 \& CT018 at $\sim 33 \mathrm{MPa} \sqrt{\mathrm{m}}$ in the second microstructural region examined.

Figure 3.16 Constant $\mathrm{K}$ crack growth response of $\mathrm{MHI}$ alloy 152 specimens CT017 \& CT018 at $\sim 48 \mathrm{MPa} \sqrt{\mathrm{m}}$.

Figure 3.17 Crack growth response of MHI alloy 152 specimens CT017 \& CT018 at $50^{\circ} \mathrm{C}$ in simulated PWR primary water.

Figure 3.18 Detail plot showing DCPD measured crack growth response during cycle + hold loading conditions at $50^{\circ} \mathrm{C}$ in $\mathrm{MHI}$ alloy 152 specimen CT017....

Figure 3.19 Optical image of high temperature crack growth surface of the MHI alloy 152 specimen CT017.

Figure $3.20 \mathrm{SEM}$ images of $350^{\circ} \mathrm{C}$ and $50^{\circ} \mathrm{C}$ crack growth surfaces in MHI alloy 152 specimen CT018.

Figure 3.21 Image of the MHI alloy 52 and AREVA alloy 52 welds showing positioning of the $0.5 \mathrm{~T}$ CT specimens. 
Figure 3.22 Overview of the crack growth response of two alloy 52 welds, one made by AREVA (CT024) and one made by MHI (CT025).

Figure 3.23 Cycle + hold and constant $\mathrm{K}$ response of the AREVA and MHI alloy 52 specimens (CT024 \& CT025) in the second region of each specimen that was examined.

Figure 3.24 Overview of the crack growth response of the AREVA and MHI alloy 52 specimens (CT024 \& CT025) during cyclic loading conditions at $50^{\circ} \mathrm{C}$.

Figure 3.25 Constant $\mathrm{K}$ crack growth response of the $\mathrm{MHI}$ and AREVA alloy 52 specimens (CT024 \& CT025) at $350^{\circ} \mathrm{C}$ after cyclic loading crack extension at $50^{\circ} \mathrm{C}$.

Figure 3.26 Optical image of the crack growth surface of the AREVA alloy 52 specimen (CT024). Four distinct bands are apparent after the air precrack boundary and the only area showing IG growth is indicated by the yellow box in the final band labeled $D$. The smaller blue box identifies the area of the SEM image shown in Figure 3.28.

Figure 3.27 Optical image of the crack growth surface of the MHI alloy 52 specimen (CT025). Yellow boxes indicate regions of IG growth and the blue box identifies the area of the SEM image shown in Figure 3.28.

Figure 3.28 SEM images illustrating IG regions on the crack growth surface for the alloy 52 specimens: (a) isolated IG finger-like area in AREVA sample and (b) typical IG area in MHI sample. For both specimens, some IG cracking was initiated during final growth at $350^{\circ} \mathrm{C}$ and continued during cycling at $50^{\circ} \mathrm{C}$.

Figure 3.29 White lines indicate where crack growth surfaces were sectioned to expose and polish crack side surfaces.

Figure 3.30 Side surface image of the AREVA alloy 52 specimen, CT024.

Figure 3.31 Side surface image of the MHI alloy 52 specimen CT025.

Figure 3.32 Overall response for the second test on the AREVA and MHI alloy 52 specimens CT032 and CT033.

Figure 3.33 Similar crack growth rates were seen during early transitioning between first test (a) CT024/25 and second test (b) CT032/33 on the AREVA and $\mathrm{MHI}$ materials.

Figure 3.34 Cyclic loading response at $50^{\circ} \mathrm{C}$ of AREVA (CT032) and $\mathrm{MHI}$ alloy 52 (CT033).

Figure 3.35 Crack growth response of a second set of AREVA and MHI 52 specimens (CT032 \& CT033) tested at $350^{\circ} \mathrm{C}$ following crack extension at $50^{\circ} \mathrm{C}$. Despite the low $\mathrm{K}$ value of $10 \mathrm{MPa} \sqrt{\mathrm{m}}$, response is nearly identical to the previous test at $30 \mathrm{MPa} \sqrt{\mathrm{m}}$ (see Figure 3.25). 
Figure 3.36 AREVA and MHI alloy 52 crack growth response at $40 \mathrm{MPa} \sqrt{\mathrm{m}}$.

Figure 3.37 Optical image of the crack growth surface of the AREVA alloy 52 specimen (CT032) and the MHI alloy 52 specimen (CT033).

Figure 3.38 Side surface optical image of cracking in the AREVA alloy 52 specimen (CT032) showing both TG and IG growth.

Figure 3.39 Side surface optical image of cracking in the $\mathrm{MHI}$ alloy 52 specimen (CT033) showing both TG and IG growth.

Figure 3.40 Alloy 52M welds from KAPL: (a) dissimilar metal V-groove weld of alloy EN52M joining 304 SS and carbon steel and (b) alloy EN52M narrow gap weld joining alloy 690. The thin rectangular bars at the front of the weld are run-off tabs to help start the weld. The weld itself is between the two large plates. Additional weldment was placed on top of the mockups to create sufficient size to cut CT specimens.

Figure 3.41 Photos of KAPL alloy 52M narrow gap weld blank "A" and CT040 specimen machined from the blank.

Figure 3.42 Photos of KAPL alloy 52M V-groove weld blank "A" and CT041 specimen machined from the blank.

Figure 3.43 Overview of defects in the KAPL alloy 52M weld with known hot cracks.

Figure 3.44 Photos of specimens cut from KAPL alloy 52M narrow gap weld containing hot cracks. Blank A (CT042) is positioned off-center and near the bottom of the weldment to insect a high density of weld cracks, while blank $B$ (CT043) is positioned near the center of the weld where no weld cracks were observed.

Figure 3.45 Overview of the entire test on the KAPL alloy 52M narrow gap (CT040) and V-groove (CT041) specimens.

Figure 3.46 Response during initial cycle + hold transitioning steps on the KAPL alloy 52M narrow gap (CT040) and V-groove (CT041) specimens.

Figure 3.47 Response during initial constant $\mathrm{K}$ step on the KAPL alloy 52M narrow gap (CT040) and V-groove (CT041) specimens.

Figure 3.48 Crack-growth response during the $K$ increase by $\mathrm{dK} / \mathrm{da}$.

Figure 3.49 Crack-growth response from cycle + hold to constant $\mathrm{K}$ for CT040 \& CT041.

Figure 3.50 Crack growth response during constant $\mathrm{K}$ at $360^{\circ} \mathrm{C}$ for the $\mathrm{KAPL}$ alloy $52 \mathrm{M}$ narrow gap (CT040) and V-groove (CT041) weld specimens.

Figure 3.51 Crack growth surface of the KAPL alloy 52M narrow gap specimen, CT040. 
Figure 3.52 Crack growth surface of the KAPL alloy 52M V-groove specimen, CT041...... 3-41

Figure 3.53 Crack profile of the KAPL alloy 52M narrow gap specimen, CT040............... 3-42

Figure 3.54 Crack profile of the KAPL alloy 52M V-groove specimen, CT041................ 3-42

Figure 3.55 Overview of the entire test on the KAPL alloy 52M narrow gap weld specimens (CT042 \& CT043) with known hot cracks................................... 3-43

Figure 3.56 In situ precracking and transitioning of the KAPL alloy 52M narrow gap weld specimens (CT042 \& CT043) with known hot cracks. ........................... 3-43

Figure 3.57 Continued transitioning steps performed on the KAPL alloy 52M narrow gap weld specimens (CT042 \& CT043) with known hot cracks.

Figure 3.58 First observation of constant $\mathrm{K}$ crack growth response on the KAPL alloy 52M narrow gap weld specimens (CT042 \& CT043) with known hot cracks. Slightly lower crack growth rate in the specimen aligned to intersect hot cracks.

Figure 3.59 Second and final observation of constant $\mathrm{K}$ crack growth response of the KAPL alloy 52M narrow gap weld specimens (CT042 \& CT043) with known hot cracks. Specimen aligned to intersect hot cracks has lower crack growth rate, and cracking eventually stalls.

Figure 3.60 Post-test serial sectioning plan for KAPL alloy 52M NG weld specimens with hot cracks (CT042 \& CT043).

Figure 3.61 Crack profile of images from CT042, the weld specimen aligned with hot cracks. The profile images show hot cracks in the region of the SCC crack, but the density is lower than expected.

Figure 3.62 Crack profile of images from CT043, the weld specimen not aligned with hot cracks. The profile images show hot cracks in the region of the SCC crack, however.

Figure 3.63 Crack growth surface from CT042, the weld specimen aligned with hot cracks.

Figure 3.64 Crack growth surface from CT043, the weld specimen not aligned with hot cracks.

Figure 3.65 Overview of the Ringhals alloy 52M overlay and inlay mockups: (a) overlay where alloy $52 \mathrm{M}$ was robotically welded to an alloy 690 plate followed by alloy 182 manually welded onto the alloy $52 \mathrm{M}$. The alloy $52 \mathrm{M}$ layer is $10-\mathrm{mm}$ thick. (b) full-scale, service mockup with alloy 82 fill followed by an alloy 52M inlay. Alloy 152 was welded onto the alloy $52 \mathrm{M}$ by Westinghouse to allow fabrication of CT specimens from the inlay region. 
Figure 3.66 Photographs showing location of specimens to be taken from alloy $182 / 52 / 690$ overlay received from Vattenfall/Ringhals. Machined notch will be approximately $3.0 \mathrm{~mm}$ from the alloy $182-52$ boundary.

Figure 3.67 Compositional profile \#1 across the bottom of an alloy 182 weld puddle and into the alloy $52 \mathrm{M}$ of the Ringhals alloy $52 \mathrm{M} / 182$ overlay material.

Figure 3.68 Compositional profile \#2 across an alloy 182 weld trough and into the alloy $52 \mathrm{M}$ of the Ringhals alloy $52 \mathrm{M} / 182$ overlay material.

Figure 3.69 Initial cycle + hold steps in the alloy 182 portion of the Ringhals alloy $52 \mathrm{M} / 182$ overlay material.

Figure 3.70 First constant $\mathrm{K}$ response of the Ringhals alloy $52 \mathrm{M} / 182$ weld showing very low crack growth rates in the alloy 182 material.

Figure 3.71 Crack extension into new microstructural region and growth response during cycle + hold loading with $R=0.7$ and $R=0.5$.

Figure 3.72 Repeat observation of constant $\mathrm{K}$ and cycle + hold response at $350^{\circ} \mathrm{C}$ in the Ringhals alloy $52 \mathrm{M} / 182$ overlay. Very low CGRs suggest the crack had entered into the alloy $52 \mathrm{M}$ weld.

Figure 3.73 Crack extension in alloy $52 \mathrm{M}$ during cycling at $50^{\circ} \mathrm{C}$ in the Ringhals alloy $52 \mathrm{M} / 182$ overlay.

Figure 3.74 Constant $\mathrm{K}$ crack-growth response in the alloy $52 \mathrm{M}$ weld material after temperature increase from $50^{\circ} \mathrm{C}$ to $350^{\circ} \mathrm{C}$.

Figure 3.75 Optical images showing crack in the side groove (top) and fracture morphology on the crack-growth surface (bottom) for the alloy 182/52 overlay specimen \#1 (CT028).

Figure 3.76 Transitioning steps to constant $\mathrm{K}$ response under BWR oxidizing conditions of the second pair of Ringhals alloy $52 \mathrm{M} / 182$ overlay specimens (CT034 \& CT035).

Figure 3.77 Crack growth response on switching from BWR oxidizing to hydrogenated water in the second pair of Ringhals alloy 52M/182 specimens (CT034 \& CT035).

Figure 3.78 Response during second transitioning phase in BWR oxidizing water of the second pair of Ringhals alloy 52M/182 specimens (CT034 \& CT035).

Figure 3.79 Second observation of constant $\mathrm{K}$ response for the second pair of Ringhals alloy 52M/182 specimens in BWR oxidizing water with sulfate.

Figure 3.80 Final cycle + hold loading response of Ringhals alloy 52M/182 specimen CT035 showing a relatively high rate of $3.2 \times 10^{-8} \mathrm{~mm} / \mathrm{s}$. 
Figure 3.81 Final constant $\mathrm{K}$ response of Ringhals alloy 52M/182 specimen CT035 with final propagation in the alloy $52 \mathrm{M}$.

Figure 3.82 Profile of Ringhals alloy 52M inlay mockup weld received from Westinghouse. Alloy $52 \mathrm{M}$ inlay is $10 \mathrm{~mm}$ thick.

Figure 3.83 Optical images of the alloy 52M/82 inlay sample CT031.

Figure 3.84 Overview of the entire test on the Ringhals alloy $52 \mathrm{M} / 82$ inlay mockups (CT030 \& CT031).

Figure 3.85 Initial cycle + hold and constant $\mathrm{K}$ response in PWR primary water of the Ringhals alloy 52M/82 inlay mockup (CT030 \& CT031)

Figure 3.86 Constant $\mathrm{K}$ and cyclic loading response of the Ringhals alloy 52M/82 inlay mockup (СT030 \& CT031) after switching from PWR primary water to BWR oxidizing water (with sulfate).

Figure 3.87 Alloy 52M response during cycle and cycle + hold loading at $R=0.5$ in the Ringhals alloy 52M/82 inlay mockup specimens (CT030 \& CT031).

Figure 3.88 Alloy $52 \mathrm{M}$ response during constant $\mathrm{K}$ loading in the Ringhals alloy 52M/82 inlay mockup specimens (CT030 \& CT031).

Figure $3.89 \mathrm{dK} / \mathrm{da}$ response going from 30 to $40 \mathrm{MPa} \sqrt{\mathrm{m}}$ of the Ringhals alloy $52 \mathrm{M} / 82$ inlay mockup specimens (CT030 \& CT031).

Figure 3.90 Constant $\mathrm{K}$ response at $40 \mathrm{MPa} \sqrt{\mathrm{m}}$ of the Ringhals alloy $52 \mathrm{M} / 82$ inlay mockup specimens (CT030 \& CT031).

Figure 3.91 Crack growth surface of Ringhals alloy 52M/82 specimen CT030. 3-75

Figure 3.92 Optical image of side surface of crack growing into alloy $52 \mathrm{M}$ in the Ringhals alloy 52M/82 specimen CT031.

Figure 3.93 SEM image of side surface of crack growing into alloy 52M in the Ringhals alloy $52 \mathrm{M} / 82$ specimen CT031.

Figure 3.94 Summary of PNNL-measured constant K SCC crack-growth rates for alloy $152 / 52 / 52 \mathrm{M}$ weld metals.

Figure 4.1 Four of the thick-wall alloy 690 CRDM tubes from Valinox at PNNL

Figure 4.2 Optical metallographs showing grain structures for alloy 690 heat RE243 in the transverse (left), longitudinal (middle), and circumferential (right) orientations.

Figure 4.3 Optical metallographs showing grain structures for alloy 690 heats WP016 (left), WP140 (middle), and RE169 (right).

Figure 4.4 SEM micrographs (SE and backscatter) showing general carbide microstructure of the as received CRDM alloy 690TT heat RE243 material. 
Figure 4.5 SEM micrographs (SE and backscatter) showing cellular carbide structure observed in the as received CRDM alloy 690TT heat RE243 material.

Figure 4.6 STEM/EDS elemental maps showing chemical distributions in various carbide structures in as-received CR CRDM alloy 690TT heat RE243

Figure 4.7 Measurement of $\mathrm{Cr}$ depletion profile across high-energy grain boundary in heat RE243 alloy 690TT material: (a) STEM brightfield showing selected EDS point analyses and the profile location between $\mathrm{Cr}$ carbides and (b) plot documenting concentration changes across the grain boundary.

Figure 4.8 SEM backscatter low magnification images of CRDM alloy 690CM heat RE243 material demonstrating lack of carbides on grain boundaries.

Figure 4.9 SEM backscatter high magnification images of CRDM alloy 690CM heat RE243 material showing absence of $\mathrm{M}_{23} \mathrm{C}_{6}$ and a very low density of TiN on grain boundaries.

Figure 4.10 SEM elemental maps illustrating the low density of Ti-rich precipitates and lack of $\mathrm{M}_{23} \mathrm{C}_{6}$ carbides in the CRDM alloy $690 \mathrm{CM}$ heat RE243 material.

Figure 4.11 Overall crack-growth response of heat RE243 alloy 690TT and CM specimens (CT014 \& CT015) in simulated PWR primary water at $325^{\circ} \mathrm{C}$

Figure 4.12 Response for heat RE243 alloy 690TT and CM specimens (CT014 \& CT015) during transitioning to constant $\mathrm{K}$ in simulated PWR primary water at $325^{\circ} \mathrm{C}$.

Figure 4.13 Crack-growth response of heat RE243 alloy 690TT and CM specimens (CT014 \& CT015) during testing in simulated PWR primary water at $50^{\circ} \mathrm{C}$

Figure 4.14 SEM image showing IG cracking for the RE243 alloy 690 TT specimen during testing at $50^{\circ} \mathrm{C}$ (a) and primarily TG cracking for the RE243 alloy $690 \mathrm{CM}$ specimen (b) although isolated IG facets are identified.

Figure 4.15 Overview of the crack-growth responses for the alloy 690TT CRDM heats WP140 and WP142 specimens (CT026 \& CT027) at $350^{\circ} \mathrm{C}$.

Figure 4.16 Initial constant $\mathrm{K}$ crack-growth responses for alloy 690TT heats WP140 and WP142 specimens (CT026 \& CT027) at $350^{\circ} \mathrm{C}$.

Figure 4.17 Crack-growth response of alloy 690TT heats WP140 and WP142 (CT026 \& CT027) after crack extension during cycling at $50^{\circ} \mathrm{C}$.

Figure 4.18 Optical image of the crack-growth surface of the alloy 690TT CRDM heat WP140 specimen. Color variation is heat tint due to baking the specimen at $600^{\circ} \mathrm{C}$ after fatigue fracture in air. The heat tint and transition lines enables the identification of five separate regions on the crack-growth surface, these are discussed in the text. 
Figure 4.19 Portion of the crack-growth surface of the heat WP140 alloy 690TT specimen. Crack growth in the area between the lines took place during $50^{\circ} \mathrm{C}$ and the subsequent $350^{\circ} \mathrm{C}$ phases of the crack growth rate test.

Figure 4.20 Diagram illustrating the CT sample orientation relation to the rolling direction

Figure 4.21 Hardness measurements on heat RE243 alloy 690 CT specimens as a function of unidirectional cold rolling. Measurements are made on two difference faces from the CT specimens for both the alloy 690TT and $690 \mathrm{CM}$ materials.

Figure 4.22 SEM backscatter micrograph illustrating representative image of $\mathrm{M}_{23} \mathrm{C}_{6}$ damage microstructure in 17\%CR CRDM alloy 690TT material (heat RE243).

Figure 4.23 TEM image and elemental maps showing damage in 17\%CR CRDM alloy 690TT.

Figure 4.24 Low magnification SEM backscatter image showing CR-induced void formation within a cellular carbide microstructure region in the $30 \% \mathrm{CR}$ CRDM alloy 690TT material (heat RE243). The strain contrast in this backscatter image masks the appearance of the $\mathrm{M}_{23} \mathrm{C}_{6}$ carbides, but the voids between carbides are readily apparent.

Figure 4.25 High magnification SEM backscatter micrographs illustrating IG carbide damage microstructures in 30\%CR CRDM alloy 690TT (heat RE243).

Figure 4.26 High magnification SEM backscatter/SE pair micrographs showing carbide damage microstructures in 30\%CR CRDM alloy 690TT (heat RE243).

Figure 4.27 SEM backscatter micrographs illustrating general TiN damage microstructure in 30\%CR CRDM alloy 690CM (heat RE243).

Figure 4.28 Overview of crack-growth responses of the $17 \% \mathrm{CR}$ alloy $690 \mathrm{~S}-\mathrm{L}$ specimens (heat RE243) tested at $325^{\circ} \mathrm{C}$.

Figure 4.29 Crack growth responses of the $17 \%$ CR alloy 690 S-L specimens (heat RE243) during first instance of constant $K$ showing no significant SCC propagation.

Figure 4.30 Optical image of crack-growth surface of the (a) $17 \% \mathrm{CR}$ alloy $690 \mathrm{CM}$ and (b) $17 \%$ CR alloy 690 TT S-L specimens (heat RE243)

Figure 4.31 SEM images of crack-growth surface features in the (a) $17 \% \mathrm{CR}$ alloy $690 \mathrm{CM}$ and (b) 17\%CR alloy 690TT S-L specimens (heat RE243).

Figure 4.32 Overview of the crack growth responses of the alloy 690TT and CM $30 \%$ CR T-L specimens (heat RE243) tested at $325^{\circ} \mathrm{C}$ and $350^{\circ} \mathrm{C}$. 
Figure 4.33 Crack growth responses of the alloy 690TT and CM 30\% CR T-L specimens (heat RE243) during the second assessment of constant $K$ crack growth.

Figure 4.34 Optical images of the crack-growth surface of the 30\% CR T-L specimens (heat RE243). As with the $17 \%$ CR T-L specimens, the CM specimen exhibits a greater amount of crack extension during load cycling.

Figure 4.35 SEM images of crack-growth surfaces for the $30 \% \mathrm{CR}$ alloy $690 \mathrm{~T}-\mathrm{L}$ specimens (heat RE243). IG cracking is observed in both specimens, but with more IG in the TT specimen. Note that IG cracking is on grain boundaries parallel to the rolling plane (transverse plane).

Figure 4.36 Initial constant $\mathrm{K}$ responses for the $31 \% \mathrm{CR}$ alloy 690TT and $\mathrm{CM}$ specimens (heat RE243) at $360^{\circ} \mathrm{C}$ and $25 \mathrm{cc} / \mathrm{kg} \mathrm{H}_{2}$

Figure 4.37 Constant $\mathrm{K}$ responses for the $31 \% \mathrm{CR}$ alloy 690 specimens at 360 and $325^{\circ} \mathrm{C}$.

Figure 4.38 Measured constant $\mathrm{K}$ crack-growth rates as a function of test temperature for the 31\%CR alloy 690TT specimen (heat RE243). The hydrogen concentrations were adjusted at each temperature to keep the ECP at the $\mathrm{Ni} / \mathrm{NiO}$ line.

Figure 4.39 Preliminary results for the influence of hydrogen concentration on the constant $\mathrm{K}$ crack-growth rates for the $31 \% \mathrm{CR}$ alloy 690TT specimen (heat RE243) in simulated PWR primary water at $325^{\circ} \mathrm{C}$. The alloy 690 results are compared to previous PNNL SCC results [Ref. 8] on two alloy 182 welds.

Figure 4.40 Summary plot showing constant K crack-growth results for the alloy 690TT materials either in the as-received, non-CR condition or after cold rolling.

Figure 4.41 Summary of constant K crack-growth results for alloy 690 CRDM heats highlighting differences between the TT and CM materials after extensive 1D cold rolling.

Figure 5.1 Photograph showing the as-received, 26\%CR plate material from ANL (heat NX3297HK12) and sectioning conducted to obtain 3 CT samples for SCC crack-growth testing, slices for metallography corresponding to the CT sample areas, and a top piece for future SCC initiation test samples.

Figure 5.2 Optical micrographs illustrating microstructures in the lower section of the $26 \%$ CR ANL plate (heat NX3297HK12).

Figure 5.3 Optical micrographs illustrating microstructures in the upper section of the $26 \%$ CR ANL plate (heat NX3297HK12). Evidence of banded microstructure can be seen in selected regions ( $a, b$ and $c$ ) above the plate midplane. 
Figure 5.4 Optical and SEM micrographs showing cross-section microstructures in the $26 \%$ CR ANL plate (heat NX3297HK12) at and near the SCC crackgrowth plane for specimen CT036.

Figure 5.5 Optical micrograph showing high density of banded second-phase particles in the GEG $20 \%$ CR alloy 690 plate (heat B25K). The compositional bands in this material were oriented perpendicular to the rolling direction and SCC crack-growth direction for the plate.

Figure 5.6 Low magnification backscattered SEM images illustrating general microstructure in 26\%CR ANL alloy 690 plate (heat NX3297HK12)

Figure 5.7 High magnification backscattered SEM images ( $a, b, c$ and d) illustrating typical grain boundary precipitate microstructures in $26 \%$ CR ANL alloy 690 plate (heat NX3297HK12).

Figure 5.8 TEM EDS elemental maps illustrating the carbide microstructure in $26 \%$ CR ANL alloy 690 plate (heat NX3297HK12).

Figure 5.9 SEM (SE) montage of 26\%CR ANL alloy 690 (heat NX3297HK12) lightly etched to bring out grain structure showing banding of small, $\mathrm{Ti}$ rich particles.

Figure 5.10 Higher magnification (backscattered and SE) SEM images 26\%CR ANL alloy 690 (heat NX3297HK12) lightly etched to bring out grain structure....

Figure 5.11 Brightfield TEM image and corresponding EDS linescan showing $\mathrm{Cr}$ depletion and Ni enrichment at the grain boundary between carbides in the ANL sample. The grain boundary is close to on edge and the minimum measured $\mathrm{Cr}$ concentration is $\sim 22.5 \mathrm{wt} \%$ with a total profile width of $\sim 300 \mathrm{~nm}$.

Figure 5.12 TEM brightfield micrograph and EDS linescans across a high-energy grain boundary revealing $\mathrm{Cr}$ depletion on one side of the boundary. $\mathrm{The} \mathrm{Cr}$ concentration near the boundary drops by $\sim 6 \mathrm{wt} \%$ to $\sim 24 \mathrm{wt} \%$ and the total $\mathrm{Cr}$ depletion width is $\sim 300 \mathrm{~nm}$.

Figure 5.13 TEM brightfield and corresponding linescan across a grain boundary $\mathrm{M}_{23} \mathrm{C}_{6}$ carbide in the ANL sample. Concentration changes at the carbidematrix interfaces show the carbide to primary $\mathrm{Cr}$ rich and the adjacent matrix is depleted by $\sim 8 \mathrm{wt} \%$ in $\mathrm{Cr}$ from the measured bulk $\mathrm{Cr}$ concentration in this region.

Figure 5.14 Low magnification SE and backscattered SEM images illustrating carbide distributions in 20\%CR GEG alloy 690 plate (heat B25K): (a) mostly TG carbides, (b) high density of IG carbides, (c) and (d) low density of primarily TG carbides. 
Figure 5.15 Low magnification backscattered SEM images illustrating carbide and nitride distributions in 20\%CR GEG alloy 690 plate (heat B25K): (a,b,c) areas show mostly TG carbides with some aligned along prior grain boundaries and (d) area with a higher density of both TG and IG carbides. Larger Ti nitride particles can be seen in the matrix.

Figure 5.16 Higher magnification SE and backscattered SEM images illustrating general precipitation microstructure in 20\%CR GEG alloy 690 (heat B25K): (a) well-spaced, TG carbides; (b) high density of IG carbides; (c) well-spaced TG carbides and an elongated TiN inclusion; (d) series of TG carbides apparently formed on a prior grain boundary along with a few small TiN matrix particles.

Figure 5.17 Summary of all hardness measurements for the $26 \%$ CR ANL alloy 690 plate (heat NX3297HK12), hardness units in the plots are $\mathrm{kg} / \mathrm{mm}^{2}$.

Figure 5.18 Measured through-thickness hardness for the $26 \%$ CR ANL alloy 690 plate (heat NX3297HK12), average of 8 data points in $x$ direction. Hardness units in the plots are $\mathrm{kg} / \mathrm{mm}^{2}$.

Figure 5.19 Summary of Vickers hardness measurements obtained on a cross-section sample for the $26 \%$ CR ANL alloy 690 plate (heat NX3297HK12), hardness units are $\mathrm{kg} / \mathrm{mm}^{2}$. Through-thickness measurements in the $y$ direction start at $\sim 10 \mathrm{~mm}$ below the top of the plate.

Figure 5.20 Measured through-thickness hardness for the 26\%CR ANL (heat NX3297HK12) and 20\%CR GEG alloy 690 plates, each point is an average of 3 data points in $\mathrm{x}$ direction.

Figure 5.21 SEM backscatter micrographs illustrating grain boundary damage microstructure in 26\%CR ANL alloy 690 (heat NX3297HK12).....

Figure 5.22 SEM micrographs illustrating general carbide damage microstructure in $26 \%$ CR ANL alloy 690 (heat NX3297HK12).

Figure $5.23(a, b)$ SEM micrographs and EDS maps $(a, b)$ illustrating general carbide microstructure in 26\%CR ANL alloy 690 (heat NX3297HK12).

Figure 5.23 (c) SEM micrographs illustrating general carbide damage microstructure in $26 \%$ CR ANL alloy 690 (heat NX3297HK12).

Figure 5.24 SEM micrographs of a FIB prepared plan view crack-tip sample showing differences in appearance in TiN particles in 26\%CR ANL alloy 690 (heat NX3297HK12).

Figure 5.25 SEM Secondary/backscatter electron image micrographs illustrating general carbide damage microstructure in 26\%CR ANL alloy 690 (heat NX3297HK12).

Figure 5.26 SEM micrographs illustrating general precipitate damage microstructure in $26 \%$ CR ANL alloy 690 (heat NX3297HK12). 
Figure 5.27 SEM micrographs further illustrating general precipitate damage microstructure in 26\%CR ANL alloy 690 (heat NX3297HK12).

Figure 5.28 SEM backscatter images show a highly deformed grain structure with visible slip bands and high local strain at carbides on the grain boundaries....

Figure 5.29 Pattern quality map show poorly indexed grain boundary regions in the ANL $26 \%$ CR material because of high strain and carbides plus similar issue at TiN matrix particles.

Figure 5.30 Misorientation axis map: Blue and red boundaries indicate rotation in the rolling direction, that is, axis of rotation is the sample normal $(\mathrm{N})$. Misorientation profile near TiN particle in the middle region (black arrow) shows the changing degree of misorientation.

Figure 5.31 Comparison of Inverse pole figure maps (RD versus TD): Rolling direction orientation map shows a greater degree of lattice misorientation in terms of the broader range of colors present in the area, whereas from the TD, the grains are colored more uniformly. Boundary map shows boundaries with regions of greater than $>0.75^{\circ}$ misorientation. Note that the central red colored region below the $\mathrm{TiN}$ in the $\mathrm{RD}$ map is outlined by gradients in the misorientation boundaries, but inside the red region there are relatively few boundaries.

Figure 5.32 SEM micrographs illustrating general carbide damage microstructure in 20\%CR GEG alloy 690 (heat B25K).

Figure 5.33 SEM micrographs illustrating general carbide damage microstructure in 20\%CR GEG alloy 690 (heat B25K).

Figure 5.34 SEM micrograph showing void damage near carbides in $20 \%$ CR GEG alloy 690 (heat B25K).

Figure 5.35 SEM backscatter images show a highly deformed grain structure with few visible carbides on the grain boundaries, but moderate density of large TiN particles, in the $20 \%$ CR GEG alloy 690 plate material (heat B25K).

Figure 5.36 Pattern Quality map exhibits more sharply defined grain boundaries in the GEG $20 \%$ CR plate material, presumably because of the lower density of carbides on the boundaries and possible lower localized strain.

Figure 5.37 Misorientation axis map for GEG material: Blue and red boundaries indicate rotation in the rolling direction, that is, axis of rotation is the sample normal $(\mathrm{N})$. Misorientation profile across grain in lower left hand region (black arrow) shows the degree of misorientation from the less deformed matrix region to the grain boundary.

Figure 5.38 Inverse pole figure map (Transverse direction) for GEG material: Nonuniform colors indicated lattice rotation across grains. Boundary map shows boundaries with regions of greater than $>0.75^{\circ}$ misorientation. 
Figure 5.39 SEM micrographs of ANL $26 \%$ CR alloy 690 plate material with grain boundaries decorated with a high density of $\mathrm{M}_{23} \mathrm{C}_{6}$ carbides: (a) Low magnification image illustrating the extent of the carbide decoration throughout the sample, (b) High magnification image with dashed box indicating location of FIB sample preparation across carbided grain boundary and (c) High magnification image illustrating two different sample orientations prepared via FIB in order to examine cracking at $\mathrm{M}_{23} \mathrm{C}_{6}$ interfaces. Orientation 1 is normal the grain boundary and Orientation 2 is $45^{\circ}$ to the grain boundary....

Figure 5.40 SEM micrographs of ion milled sections around selected area for TEM preparation. a) Ion milling trenches illustrate how sample is isolated from remainder of the bulk. b) Composite SEM image showing surface region from Figure 5.39 overlayed with an image showing side of TEM sample which illustrates the orientation of the grain boundary in the final sample. c) U-cut is made underneath the sample to partially free it from the bulk. d) Sample removed from bulk, rotated $180^{\circ}$ from b), and attached to a $\mathrm{Cu}$ TEM grid for final milling. A grain boundary decorated with carbides is present in the middle of the sample.

Figure 5.41 TEM micrograph montages of the 26\%CR ANL alloy 690 sample illustrating $\mathrm{M}_{23} \mathrm{C}_{6}$ carbides along a grain boundary. Top image: Sample taken normal to the grain boundary illustrating cracking between $\mathrm{M}_{23} \mathrm{C}_{6}$ carbides along the grain boundaries. Bottom image: Sample taken $45^{\circ}$ to the grain boundary showing mottled contrast in the bulk and carbide grains indicating high amounts of strain in the sample. The diffraction pattern (inset) from the selected area illustrates that the carbide is oriented in the [112] on the left grain.

Figure 5.42 STEM brightfield micrograph and elemental maps of the $26 \%$ CR ANL alloy 690 illustrating cracks adjacent to $\mathrm{M}_{23} \mathrm{C}_{6}$ carbides that decorate the grain boundary (sample taken normal to boundary). An increased signal for most elements can be seen as a vertical line in the EDS maps as well as a dark line in the STEM image due to specimen thickness differences.

Figure 5.43 STEM brightfield micrograph and elemental maps from the $26 \% \mathrm{CR}$ ANL alloy 690 illustrating cracks adjacent to $\mathrm{M}_{23} \mathrm{C}_{6}$ carbides that decorate another grain boundary (sample taken normal to boundary). The rolling direction has been noted in the STEM image.

Figure 5.44 STEM image and elemental maps of a grain boundary region for FIB-TEM sample taken across a grain boundary along the rolling direction in the $20 \%$ CR GEG sample. An isolated $\mathrm{M}_{23} \mathrm{C}_{6}$ carbide is seen adjacent to the grain boundary.

Figure 5.45 STEM image and elemental maps from a second FIB-TEM sample taken $45^{\circ}$ to a grain boundary along the rolling direction in the $20 \% \mathrm{CR}$ GEG sample. The $\mathrm{Cr}$ composition map suggests that a thin, IG $\mathrm{Cr}$ carbide is present. High-resolution imaging was not possible due to sample thickness. 
Figure 5.46 Overview of SCC test for ANL-CT036 (heat NX3297HK12) and GEGCT037 (heat B25K) alloy 690 specimens.

Figure 5.47 Initial transitioning for ANL (CT036) and GEG (CT037) specimens at $325^{\circ} \mathrm{C}$.

Figure 5.48 Constant K response for ANL 26\%CR (CT036) and GEG 20\%CR (CT037) alloy 690 plate specimens at $360^{\circ} \mathrm{C}$

Figure 5.49 Comparison among reported SCC growth rate measurements at either constant $\mathrm{K}$ or constant load for the $26 \% \mathrm{CR}$ ANL alloy 690 plate (heat NX3297HK12). Data for ANL, GEG and SERCO is from references 16, 17 and 18 , respectively.

Figure 5.50 Summary of constant K crack-growth results for alloy 690 CRDM and plate heats highlighting more recent data on 1D cold-rolled materials. Data from ANL, GEG and SERCO are from references 16, 17 and 18, respectively.

Figure 5.51 Summary of all constant K crack-growth results for alloy 690 CRDM and plate heats including the Bettis data identifying the detrimental effects of 1D rolling and tensile straining. Data from Bettis, ANL, GEG and SERCO are from references $5,16,17$ and 18 , respectively.

Figure 6.1 SEM backscatter micrograph of a crack-tip region in crack-growth sample CT022 for 30\%CR CRDM alloy 690TT (heat RE243).

Figure 6.2 SEM micrographs (SE and backscatter) of thin TEM foil illustrating crack growth tips in 30\%CR CRDM alloy 690TT (CT022) from select regions in Figure 6.1.

Figure 6.3 SEM elemental maps of thin TEM foil showing crack growth around a cellular carbide region in the 30\%CR CRDM alloy 690TT CT022 specimen.

Figure 6.4 SEM backscatter micrographs of various SCC tips (secondary and primary) in 30\% CR CRDM alloy 690TT specimen CT022.

Figure 6.5 SEM backscatter micrographs of a leading SCC tip in 30\%CR CRDM alloy 690TT specimen CT022.

Figure 6.6 SEM backscatter micrograph montage showing SCC cracks in crosssection for the $26 \%$ CR ANL alloy 690 specimen CT036.

Figure 6.7 Low magnification SEM backscatter micrographs of various cracks and secondary crack tip regions in $26 \%$ CR ANL alloy 690 specimen CT036.

Figure 6.8 Higher magnification SEM backscatter micrographs of open cracks and crack walls in $26 \%$ CR ANL alloy 690 specimen CT036.

Figure 6.9 SEM backscatter micrographs of open crack walls in $26 \%$ CR ANL alloy 690. 
Figure 6.10 High magnification SEM backscatter micrographs of open crack walls in $26 \%$ CR ANL alloy 690 specimen CT036.

Figure 6.11 SEM backscatter micrographs of an open IGSCC crack and grain boundary precipitates along one wall in the 26\%CR ANL alloy 690 specimen CT036.

Figure 6.12 SEM backscatter micrographs of a SCC crack tip in the $26 \%$ CR ANL alloy 690 specimen CT036: (a) lower magnification showing an open IG crack ending in a highly branched tip region with a TG (b) and IG (c) characteristics.

Figure 6.13 Lower magnification SEM backscatter micrograph and compositional maps showing the open IGSCC crack in specimen CT036 from Figure 6.12 .

Figure 6.14 SEM backscatter micrographs of open IG crack (a) ending at a rather blunt IG crack tip (b,c) with penetrative wall oxidation in the $26 \% \mathrm{CR}$ ANL alloy 690 specimen CT036.

Figure 6.15 High magnification SEM backscatter micrographs of an IG crack tip in the $26 \%$ CR ANL alloy 690 specimen CT036.

Figure 6.16 Low magnification SEM backscatter micrograph of an ion-milled TEM cross-section sample in $26 \%$ CR ANL alloy 690 specimen CT036.

Figure 6.17 Low magnification SEM backscatter micrographs of open crack walls in $26 \%$ CR ANL alloy 690 specimen CT036.

Figure 6.18 High magnification SEM backscatter micrographs of open crack walls in 26\%CR ANL alloy 690 specimen CT036.

Figure 6.19 High magnification SEM backscatter micrographs of open crack walls in 26\%CR ANL alloy 690 specimen CT036.

Figure 6.20 High magnification SEM backscatter micrographs of open crack walls in $26 \%$ CR ANL alloy 690 specimen CT036.

Figure 6.21 High magnification SEM backscatter micrographs of penetrative wall oxidation as a function of distance behind the SCC crack front in the $26 \%$ CR ANL alloy 690 specimen CT036.

Figure 6.22 Measured crack-growth rate for 26\%CR ANL alloy 690 specimen CT036 along with specific distances where crack wall oxidation depths were determined.

Figure 6.23 Depth of penetration oxidation off SCC crack walls as a function of the estimated time in PWR primary water. 
Figure 6.24 Montages of SEM backscatter (left) and secondary (right) electron micrographs at low magnifications showing the open SCC crack with branching (in and out of plane) to the crack tip in 20\%CR GEG alloy 690 specimen CT037. Several larger matrix TiN particles are identified and careful examination of the backscatter image reveals much smaller TG and IG $\mathrm{M}_{23} \mathrm{C}_{6}$ precipitates.

Figure 6.25 High magnification SEM SE (a) and backscatter (b,c) micrographs of open IGSCC crack ending with two IG crack tips in 20\%CR GEG alloy 690 specimen CT037.

Figure 6.26 SEM backscatter micrographs showing several IGSCC crack tips in $20 \%$ CR GEG alloy 690 specimen CT037.

Figure 6.27 SEM backscatter micrographs of leading IGSCC crack tips in $20 \%$ CR GEG alloy 690 specimen CT037. Few grain boundary precipitates are seen off crack walls, however one of the crack branches ends at a grain boundary triple and a carbide interface.

Figure 6.28 IGSCC crack partially filled with epoxy containing oxide corrosion products from 30\%CR CRDM alloy 690TT specimen CT022.

Figure 6.29 Needle-shaped crystallites are present in a crack from specimen CT022. Diffraction analysis suggests that it is a hydroxide phase, pattern gives fair match to $\mathrm{NiOOH}$ and $\mathrm{CrOOH}$ (poor match to spinel or $\mathrm{Cr}_{2} \mathrm{O}_{3}$ ).

Figure 6.30 STEM image of needle-shaped corrosion product in crack along with EDS results (in wt\%) indicating that the phase is Fe-rich and Cr-poor compared to the metal matrix.

Figure 6.31 Attacked/oxidized region along edge of SCC crack in CT022. (a) brightfield underfocus image showing 'filaments' and interfacial oxidation of $\mathrm{Cr}$ carbide particle. (b) oxide darkfield image taken with $\mathrm{Cr}_{2} \mathrm{O}_{3}$ reflection, showing oxide in filaments.

Figure 6.32 EDS maps of crack edge area in 30\%CR CRDM alloy 690TT specimen CT022 with color composite combining the $\mathrm{O}$ (red), $\mathrm{Cr}$ (green) and $\mathrm{Ni}$ (blue) maps. Cr-rich oxide at carbide interface and in filaments appears orange. Cr carbide particles appear green.

Figure 6.33 Higher magnification EDS maps of crack edge area in Figure 6.32. Color composite combines the $\mathrm{O}$ (red), $\mathrm{Cr}$ (green) and $\mathrm{Ni}$ (blue) maps.

Figure 6.34 STEM/EDS analysis of carbide particles and crack subsurface region.

Figure 6.35 Darkfield image highlighting $\mathrm{Cr}_{2} \mathrm{O}_{3}$ particles in oxidized zone along crack wall in $30 \%$ CR CRDM alloy 690TT specimen CT022.

Figure 6.36 Oxide darkfield images showing particulate $\mathrm{Cr}_{2} \mathrm{O}_{3}$ and MO-type oxide in filaments along crack wall. Different $\mathrm{Cr}_{2} \mathrm{O}_{3}$ spots appear to highlight different orientation variants. 
Figure 6.37 Crack-tip area in the 30\%CR CRDM alloy 690TT specimen CT022. Photo at upper right was taken after thinning was continued. Note very high dislocation density in region. No porosity is observed along grain boundary ahead of crack tip.

Figure 6.38 STEM/EDS maps of CT022 specimen crack tip region shown in Figure 6.36. Color composite of $\mathrm{O}$ (red), $\mathrm{Cr}$ (green) and $\mathrm{Ni}$ (blue) maps shows blocky Cr-carbide particles (green), and Cr-rich oxide (pink-orange). White is open area of crack. Also note Ni-rich regions (dark blue) between carbide particles.

Figure 6.39 TEM brightfield image of an additional crack tip in 30\%CR alloy 690 CRDM specimen CT022.

Figure 6.40 TEM image of a crack tip in the ANL 26\%CR alloy 690 specimen CT036.

Figure 6.41 SEM and STEM images from a secondary crack region in the CT036 specimen (ANL 26\%CR alloy 690). This region is behind the SCC crack front and EDS composition maps are shown illustrating the corrosion microstructure that has developed.

Figure 6.42 SEM (above) and TEM (below) images of a crack tip in the GEG $20 \%$ CR alloy 690 specimen CT037.

Figure 6.43 TEM brightfield and oxide darkfield images indicating wall oxidation in the crack-tip region from Figure 6.42.

Figure 6.44 Brightfield TEM images in the CW316LSS crack-growth sample tested in BWR oxidizing water [Ref. 37]: (a) oxide- and epoxy-filled crack many micrometers behind tip and (b) highly deformed crack tip with narrow oriented spinel present on crack walls to the tip.

Figure 6.45 Open (a) and oxide-filled (b) crack tips in a BWR core shroud sample [Ref. 25]. EDS x-ray maps of oxide-filled tip (c) show Fe/Ni loss in oxide, $\mathrm{Ni}$ concentrated ahead of tip, and Mo segregation along the leading grain boundary.

Figure 6.46 Alloy 600 IG attack in PWR primary water [Ref. 23]: (a) typical extended IG attack region filled with porous oxide and (b) leading edge of oxide penetration along grain boundary.

Figure 6.47 EDS maps showing the leading edge of IG attack ahead in alloy 600 [Ref. 29]. Chromium is enriched in the tip oxide and $\mathrm{Ni}$ is enriched along the boundary ahead of the tip. 


\section{Tables}

Table 3.1 Alloy 152, 152M, 52 and 52M weldments at PNNL.

Table 3.2 Summary of completed alloy 152, 52 and 52M SCC tests.

Table 3.3 Test conditions and corrected specimen response for $\mathrm{MHI}$ alloy 152 specimen CT013.

Table 3.4 Summary of test conditions and corrected response of $\mathrm{MHI}$ alloy 152 specimens CT017 \& CT018.

Table 3.5 Summary of test conditions and corrected response for AREVA and MHI alloy 52 specimens CT024 \& CT025.

Table 3.6 Summary of test conditions and corrected response for AREVA and MHI alloy 52 specimens CT032 \& CT033.

Table 3.7 Corrected data summary for KAPL alloy 52M specimens CT040 \& CT041..... 3-40

Table 3.8 Corrected data summary for KAPL alloy 52M narrow gap weld specimens CT042 \& CT043 with hot cracks.

Table 3.9 Corrected data summary for Ringhals alloy 52M/182 overlay specimens CT028 \& CT029.

Table 3.10 Data summary for Ringhals alloy 52M/182 overlay specimens CT034 \& CT035.

Table 3.11 Corrected data summary for Ringhals alloy 52M/82 inlay specimens \#1 and \#2 (CT030 \& CT031).

Table 4.1 Alloy 690 CRDM tubing materials at PNNL.

Table 4.2 Microstructure, microchemistry and hardness for CRDM alloy 690 (heat RE243).

Table 4.3 Uncorrected data summary for alloy 690 CRDM specimens CT014 \& CT015.

Table 4.4 Uncorrected data summary for alloy 690 CRDM specimens CT026 \& CT027.

Table 4.5 Microstructure, CR damage and hardness for heat RE243 alloy 690 materials.

Table 4.6 Uncorrected data summary for alloy 690 CRDM specimens CT019 \& CT020.

Table 4.7 Uncorrected data summary for alloy 690 CRDM specimens CT022 \& CT023. 
Table 4.8 Data summary for alloy 690 CRDM specimens CT038 \& CT039.

Table 4.9 Microstructure, hardness and SCC rates for heat RE243 alloy 690 materials.

Table 4.10 Microstructure, CR damage and SCC rates for heat RE243 alloy 690 materials.

Table 5.1 Alloy 690 plate materials at PNNL

Table 5.2 Microstructure, microchemistry and hardness for selected CR alloy 690 materials.

Table 5.3 Microstructure, CR damage and hardness for selected CR alloy 690 materials.

Table 5.4 Corrected results for ANL and GEG 1D CR S-L alloy 690 (CT036 \& CT037).

Table 5.5 Microstructure, CR damage and SCC rates for alloy 690 tested at PNNL....... 5-43 


\section{Executive Summary}

Stress-corrosion cracking (SCC) of high-chromium, nickel-base alloys has been evaluated in simulated pressurized water reactor (PWR) environments. This report focuses on material characterizations and test results for alloy 690 and its weld metals (alloy 152, 52 and 52M) conducted at PNNL from January 2009 to June 2010 for NRC project N6782. In addition, selected results are also included from research performed in 2008 for NRC project 6007. Stress-corrosion, crack-growth rates have been determined for 12 alloy 690 specimens, 11 alloy $152 / 52 / 52 \mathrm{M}$ weld metal specimens, 4 alloy 52M/182 overlay specimens and 2 alloy $52 \mathrm{M} / 82$ inlay specimens in simulated PWR primary water environments. The alloy 690 test materials included three different heats of extruded control-rod-drive mechanism (CRDM) tubing with variations in the initial material condition and degree of cold work for one heat. Two cold-rolled (CR) alloy 690 plate heats were also obtained and evaluated enabling comparisons to the CR CRDM materials. Weld metal, overlay and inlay specimens were machined from industry mock ups to provide plant-representative materials for testing. Specimens have been tested for one alloy 152 weld, two alloy 52 welds and three alloy $52 \mathrm{M}$ welds. The overlay and inlay specimens were prepared to propagate stress-corrosion cracks from the alloy 182 or 82 material into the more resistant alloy 52M. In all cases, crack extension was monitored in situ by direct current potential drop (DCPD) with length resolution of about $+1 \mu \mathrm{m}$ making it possible to measure extremely low growth rates approaching $5 \times 10^{-10} \mathrm{~mm} / \mathrm{s}$. Most SCC tests were performed at 325$360^{\circ} \mathrm{C}$ with hydrogen concentrations from $11-29 \mathrm{cc} / \mathrm{kg}$, however environmental conditions were modified during a few experiments to evaluate the influence of temperature, water chemistry or electrochemical potential on propagation rates. In addition, low-temperature $\left(\sim 50^{\circ} \mathrm{C}\right)$ cracking behavior was examined for selected alloy 690 and weld metal specimens.

Important results have been obtained for alloy 690 and its weld metals establishing SCC response as a function of material and environmental parameters. As expected, the as-received and plant representative, thermally treated (TT) alloy $690 \mathrm{CRDM}$ tubing heats were resistant to SCC. Steady propagation and intergranular (IG) cracking was observed under constant stress intensity $(\mathrm{K})$ conditions, but propagation rates were very low $\left(\leq 1 \times 10^{-9} \mathrm{~mm} / \mathrm{s}\right)$ and only isolated regions of IGSCC were produced after long tests in PWR primary water. High levels of cold work during one-dimensional rolling were found to promote IGSCC and much higher ( 100X) growth rates when specimens were tested so propagation occurs in the rolling plane (S-L orientation). These results demonstrate that extruded alloy 690 tubing with an excellent microstructure can become susceptible to IGSCC after unidirectional cold rolling similar to behavior documented for alloy 690 plate materials. It is critical to note that the level and orientation of cold work is not anticipated in light-water-reactor (LWR) service components, however these results clearly demonstrate that the high-chromium alloy 690 materials are not immune to SCC and reasons for enhanced susceptibility are not understood. To that end, the alloy 690 microstructure has been modified through heat treatment, and detailed examinations of cold-rolling damage and SCC cracks have been performed using high-resolution scanning (SEM) and transmission electron microscopy (TEM) techniques. Cold rolling alloy 690 to high reductions produced IG nanometer-scale voids and cracked precipitates particularly when a high density of grain boundary carbides is present. The influence of this permanent damage on IGSCC is unclear, but characterizations of crack tips do not show them playing a controlling role in environment-assisted propagation. An unexpected observation has been the lack of a continuous protective film on SCC crack walls, and instead penetrative internal oxidation into the matrix is seen. 
This project has completed some of the first SCC crack-growth tests on alloy 152, 52 and $52 \mathrm{M}$ weld metals in PWR primary water and helped establish a basis for their behavior. Similar to the previous PNNL test results for the as-received alloy 690 materials, the high-chromium weld metals have consistently shown a high resistance to SCC. Several different weld mockup types have been tested including U-groove, V-groove, butt weld, and narrow gap welds. Unlike the thermally treated alloy 690 base metal, a higher degree of IG engagement is typically seen, but measured propagation rates have been $\leq 1 \times 10^{-8} \mathrm{~mm}$ with most less than $2 \times 10^{-9} \mathrm{~mm}$ at test temperatures from 325 to $360^{\circ} \mathrm{C}$. Despite the higher degree of engagement, transitioning to SCC can be more challenging due to the interdendritic weld metal microstructure and large grain sizes making IG engagement across the crack front difficult. Only a few weld metals have exhibited significant propagation along grain boundaries during long-term tests suggesting a good resistance to IGSCC. In an effort to improve IG engagement, limited testing has also been conducted at $50^{\circ} \mathrm{C}$ in PWR primary water. Hydrogen-induced IG crack growth and higher growth rates were promoted during cycling steps for an alloy 152 weld, but much smaller effects were seen for alloy 52 welds. The environment-induced cracking at low temperature is believed to occur during dynamic straining, and much more experimentation is needed to properly assess this behavior. The influence of preexisting weld cracks on SCC response is also being evaluated in alloy $52 \mathrm{M}$ with preliminary results showing no enhancement of crack growth. However, complete characterizations of the crack path have not yet been completed. The final SCC tests on weld metals have been on industry mockups for an alloy 52M/182 overlay and an alloy $52 \mathrm{M} / 82$ inlay. For both, initial SCC propagation rates in the lower-chromium layer (alloy 182 or 82) were less than expected with only partial IG engagement. Although the growth decreased significantly as the alloy 52M interface was reached, this was due to isolated IGSCC fingers intersecting the interface. A simple assessment of chromium concentration on growth rates through the interface region was not possible without a straight crack front. Additional SCC data was generated for alloy $52 \mathrm{M}$ from the overlay and inlay welds with the highest weld metal constant stress intensity $(\mathrm{K})$ growth rate detected for the alloy 52M overlay material. 


\section{Acknowledgements}

The authors recognize support from PNNL staff for the research performed including Rob Seffens for crack-growth system construction, maintenance and testing, Clyde Chamberlin for optical metallography, Alan Schemer-Kohrt for scanning electron microscopy, Dan Edwards for electron backscatter diffraction, Larry Thomas for analytical transmission electron microscopy of stress-corrosion crack tips and Ed Simonen for document review and helpful discussions. Critical interactions with Peter Andresen of General Electric Global Research are also acknowledged. The work was sponsored by the Office of Nuclear Regulatory Research, U.S. Nuclear Regulatory Commission (NRC) under job code N6782 with Darrell Dunn as the current project manager. In addition, some work conducted under job code N6007 during 2007 and 2008 is also included in this report. Many helpful discussions with NRC staff are recognized including Mr. Dunn and Jay Collins as well as prior project managers Carol Moyer, Samantha Crane and Hipólito Gonzalez. Pacific Northwest National Laboratory is operated by Battelle Memorial Institute for the U.S. Department of Energy. 
This page intentionally left blank. 


\section{Abbreviations and Acronyms}

$\begin{array}{ll}\text { ANL } & \text { Argonne National Laboratory } \\ \text { APT } & \text { atom probe tomography } \\ \text { ASTM } & \text { American Society for Testing and Materials } \\ \text { ATEM } & \text { analytical transmission electron microscopy } \\ \text { BSE } & \text { backscatter electron } \\ \text { BWR } & \text { boiling-water reactor } \\ \text { CGR } & \text { crack-growth rate } \\ \text { CM } & \text { carbide modified } \\ \text { CR } & \text { cold rolled } \\ \text { CRDM } & \text { control rod drive mechanism } \\ \text { CT } & \text { compact tension } \\ \text { CW } & \text { cold worked } \\ \text { DCPD } & \text { direct current potential drop } \\ \text { DOE } & \text { Department of Energy } \\ \text { EBSD } & \text { electron backscatter diffraction } \\ \text { ECP } & \text { electrochemical potential } \\ \text { EDS } & \text { energy-dispersive x-ray spectroscopy } \\ \text { EPRI } & \text { Electric Power Research Institute } \\ \text { FIB } & \text { Materials Reliability Program } \\ \text { focused ion beam } \\ \text { GEG }\end{array}$




\begin{tabular}{|c|c|}
\hline $\mathrm{NRC}$ & U.S. Nuclear Regulatory Commission \\
\hline PEELS & parallel detection electron energy loss spectrometer \\
\hline PNNL & Pacific Northwest National Laboratory \\
\hline PWR & pressurized water reactor \\
\hline PWSCC & primary water stress corrosion cracking \\
\hline $\mathrm{R}$ & load ratio (minimum/maximum) \\
\hline RPV & reactor pressure vessel \\
\hline SA & solution annealed \\
\hline SCC & stress corrosion cracking \\
\hline SE & secondary electron \\
\hline SEM & scanning electron microscopy \\
\hline SMAW & shielded metal arc weld \\
\hline SS & stainless steel \\
\hline STEM & scanning transmission electron microscopy \\
\hline TEM & transmission electron microscopy \\
\hline TG & transgranular \\
\hline TT & thermally treated \\
\hline TTZ & transformation toughened zirconia \\
\hline
\end{tabular}




\section{Introduction}

Primary water stress corrosion cracking (PWSCC) in nickel-base alloy primary pressure boundary components is a degradation mechanism that can affect pressure boundary components in pressurized water reactors (PWRs). PWSCC preferentially occurs in components that operate at high temperatures and pressures. Fabrication and welding processes and especially weld repairs leave residual stresses that promote cracking in susceptible materials. The narrow cracks, which are often located in complex structures either within or adjacent to welds, are difficult to detect and characterize during in service inspections. PWSCC that goes undetected has led to reactor pressure boundary leaks and subsequent boric acid corrosion of low alloy steels at Arkansas Nuclear One-1 in 2001 and Davis-Besse in 2002. Extensive wastage of the Davis-Besse reactor head could have resulted in a loss of coolant accident (LOCA) had reactor operation continued and the damage gone undetected. Circumferential cracks discovered in the V.C. Summer reactor coolant system (RCS) piping welds in 2000 and in pressurizer nozzle welds at Wolf Creek in 2006 have raised concerns that PWSCC in PWR piping also could result in a LOCA.

Increasingly, industry has utilized alloy 690 and associated weld metals, alloy 52 and 152 in both replacement components and in mitigation methods including weld onlays and overlays. Alloy 690 has been used in steam generators since 1989 and more than 30 PWR replacement heads using alloys 690/152/52 have been placed into service. The high chromium nickel-base alloys have also been used in RCS piping, nozzles, and instrument penetrations. While the service history has been favorable [Refs. 1-4], significant industry and international efforts are underway to characterize the PWSCC susceptibility of alloys 690/152/52. Initial results have been reported in document MRP-237. Although the issue of PWSCC susceptibility is being addressed by industry, the U.S. Nuclear Regulatory Commission (NRC) has sought to obtain PWSCC growth rates of these resistant alloys and assess mitigation methods to determine the validity and acceptability of licensee flaw analyses, and to support regulatory inspection requirements. In order to be successful, an improved understanding of the complex interrelations between stresses in the affected components, material microstructure, and the aggressive nature of the PWR environment is necessary.

In the prior testing program (JCN N6007), three test systems were assembled. Initial testing was conducted on 300-series stainless steels, alloy 600 and alloy 182 in BWR and PWR simulated water chemistries. The effect of cold work, electrochemical potential, stress intensity and temperature were examined, and the results obtained were in good agreement with previously reported data. While limited tests were also conducted on alloy 690 and its weld metals, testing of the higher chromium alloys was the focus of the follow-up project (JCN N6782) at PNNL. At the beginning of this project, very few quantitative SCC growth rate measurements had been reported on alloy 690 and even less on its weld metals. Additional SCC propagation data was (and still is) needed to define improvement factors for these materials when compared with alloy 600 and its weldments. One of the biggest challenges for quantitative measurements has been the difficulty in promoting significant SCC in the highchromium material [Refs. 1-4], however modern test systems, proper transitioning and considerable patience makes this possible for most alloys. Questions concerning the inherent resistance of alloy 690 to PWSCC were raised after data on cold-worked alloy 690 plate heats were released by Bettis [Ref. 5]. Extremely high propagation rates were observed for certain heats when cold rolled or tensile strained, then SCC tested in the plane of deformation. This data is summarized in Figure 1.1 and is compared to the SCC growth rate disposition curve for 
alloy 600. While the practical importance of these highly strained materials in PWR applications is in question, clearly alloy 690 is not immune to PWSCC and systematic SCC testing is needed to establish its behavior under a range of material and environmental conditions. As noted, very limited testing had been performed on the weld metals used with alloy 690 including alloys 152, 52 and its many variants. The higher strains associated with the welds and the weld metal complex microstructure provides more issues of concern. These higher chromium weld metals are also more susceptible to segregation and weld cracking including solidification cracking and ductility dip cracking. The role of weld defects on PWSCC susceptibility and crack growth rates are not established and need to be better understood. Additional tests are planned to address the effects of weld defects on PWSCC.

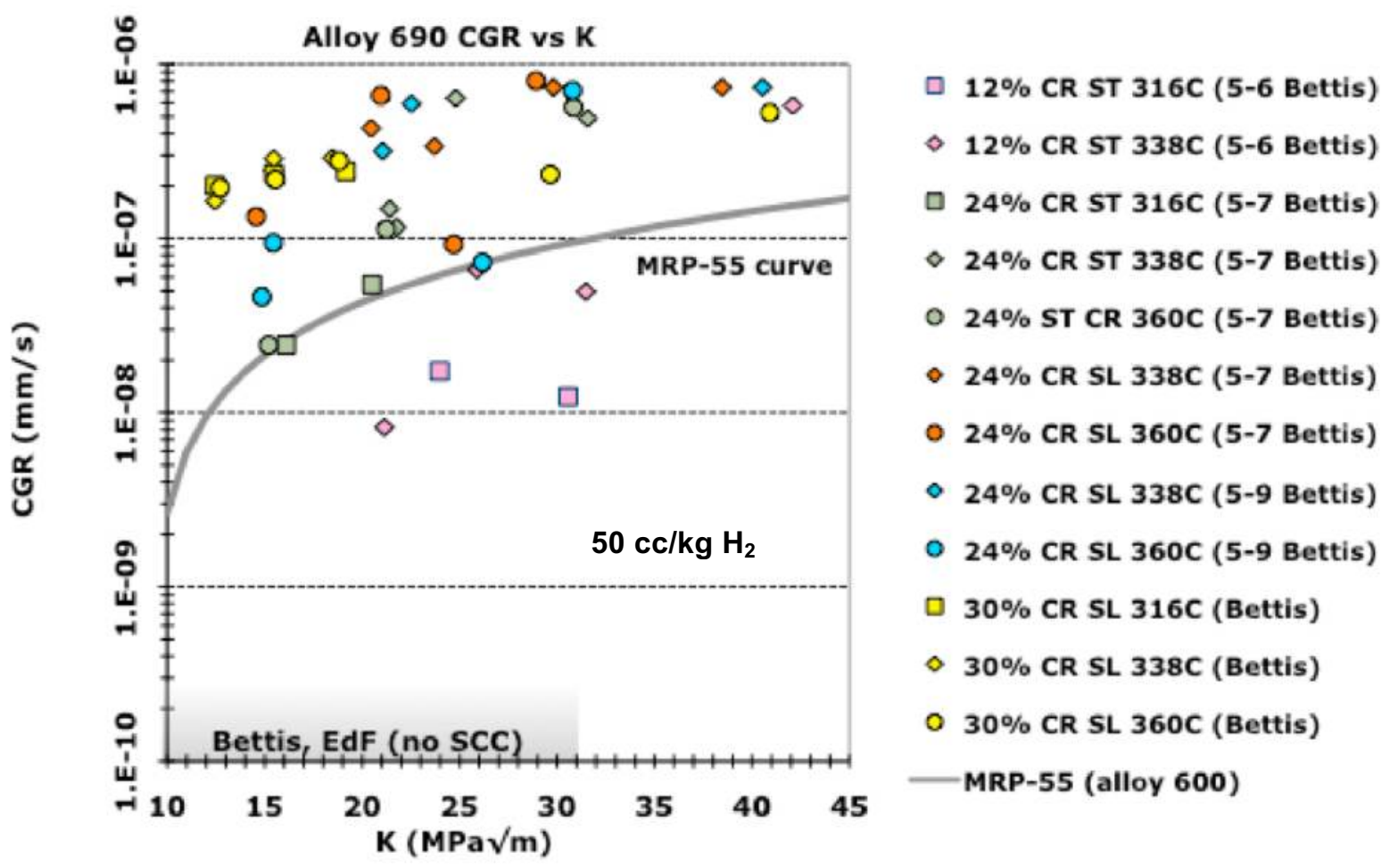

Figure 1.1 Summary of SCC growth data reported by Bettis [Ref. 5] on cold-rolled or tensile-strained alloy 690 plate heats. Testing was performed at temperatures of 316,338 and $360^{\circ} \mathrm{C}$ as listed in the legend with a dissolved hydrogen content of $50 \mathrm{cc} / \mathrm{kg} \mathrm{H}_{2}$ to ensure electrochemical conditions were within the $\mathrm{Ni}$ metal stable regime at $360^{\circ} \mathrm{C}$. Similar results were obtained during selected tests at the lower temperatures using a dissolved hydrogen concentration of $23 \mathrm{cc} / \mathrm{kg} \mathrm{H}$. 


\section{SCC Crack-Growth Test Systems and Testing Approach}

The purposes of the crack-growth systems are to develop, control, and measure stress corrosion cracks under well-defined material and environmental conditions, and ensure that the SCC growth rate response is reproducible and characteristic of the test conditions. Features expected in a good crack-growth system include active constant $\mathrm{K}$ load control, active temperature control, a sensitive crack length measurement apparatus, a recirculating hightemperature water system, control over all aspects of water chemistry, and continuous monitoring of all pertinent test parameters. The options for PNNL in creating a crack growth capability were for PNNL to design crack growth test systems, buy commercial systems, or copy a system at another research institute. It was determined very early in the previous program that the most advanced and reliable crack-growth systems in the world have been designed, developed, and run by Peter Andresen at General Electric Global Research (GEG). His crackgrowth systems have been copied to various degrees by research institutes and commercial companies throughout the world. The decision was made to work closely with Peter Andresen and GEG staff on a crack growth system design. In the process of building the systems, some design aspects were improved, and more up-to-date parts were chosen when advantageous. GEG has incorporated some of these improvements and newer parts into their systems.

\subsection{Overview of SCC Crack-Growth Test Systems}

The key components of these systems are: (1) a servo-electric load control system capable of holding constant load for very long periods of time, (2) a high-pressure piston pump to pressurize and flow water through the high-temperature loop, (3) an autoclave, (4) a custommade water board for water chemistry control, (5) a reversing DCPD system for crack length estimation, and (6) a continuous data acquisition system. Careful consideration went into the selection of each piece of equipment to optimize either test system control or test environment. Some of the most important optimizations were to: (1) make sure that all wetted components release no contamination into the water, (2) have a high water flow rate through the autoclave, (3) have uniform temperature through a large volume of the autoclave, (4) have consistent water pressure, (5) have highly accurate measurements of test environment (temperature, conductivity, $\mathrm{pH}$, load, dissolved gas content), and (6) have a sensitive DCPD measurement system. Each of the subsystems will be discussed in further detail below.

The water flow design of the system is a loop within a loop as shown in Figure 2.1. One loop is at low pressure, and its purpose is to flow water through a water column where selected gases and ionic impurities are dissolved or injected into the water. A side stream is taken off this lowpressure loop and fed into a high-pressure piston pump. The large pressure pulses and flow surges created by the piston pump are dampened by the use of pulsation dampers both at the inlet and outlet of the pump. The high-pressure water flows into a regenerative heat exchanger where hot water leaving the autoclave is used to heat the incoming water. Just prior to the water entering the autoclave, the partially heated water is brought up to test temperature using a preheater. After the water flows through the heated autoclave, it goes back through the regenerative heat exchanger and then through a water cooler that brings the water back down to room temperature. The cooled water then passes through a back-pressure regulator and emerges at $\sim 0.07 \mathrm{MPa}(10 \mathrm{psi})$ of pressure. The water flows through a flow meter, a conductivity sensor, a mixed resin bed demineralizer, and is finally dumped back into the lowpressure chemistry control loop. 


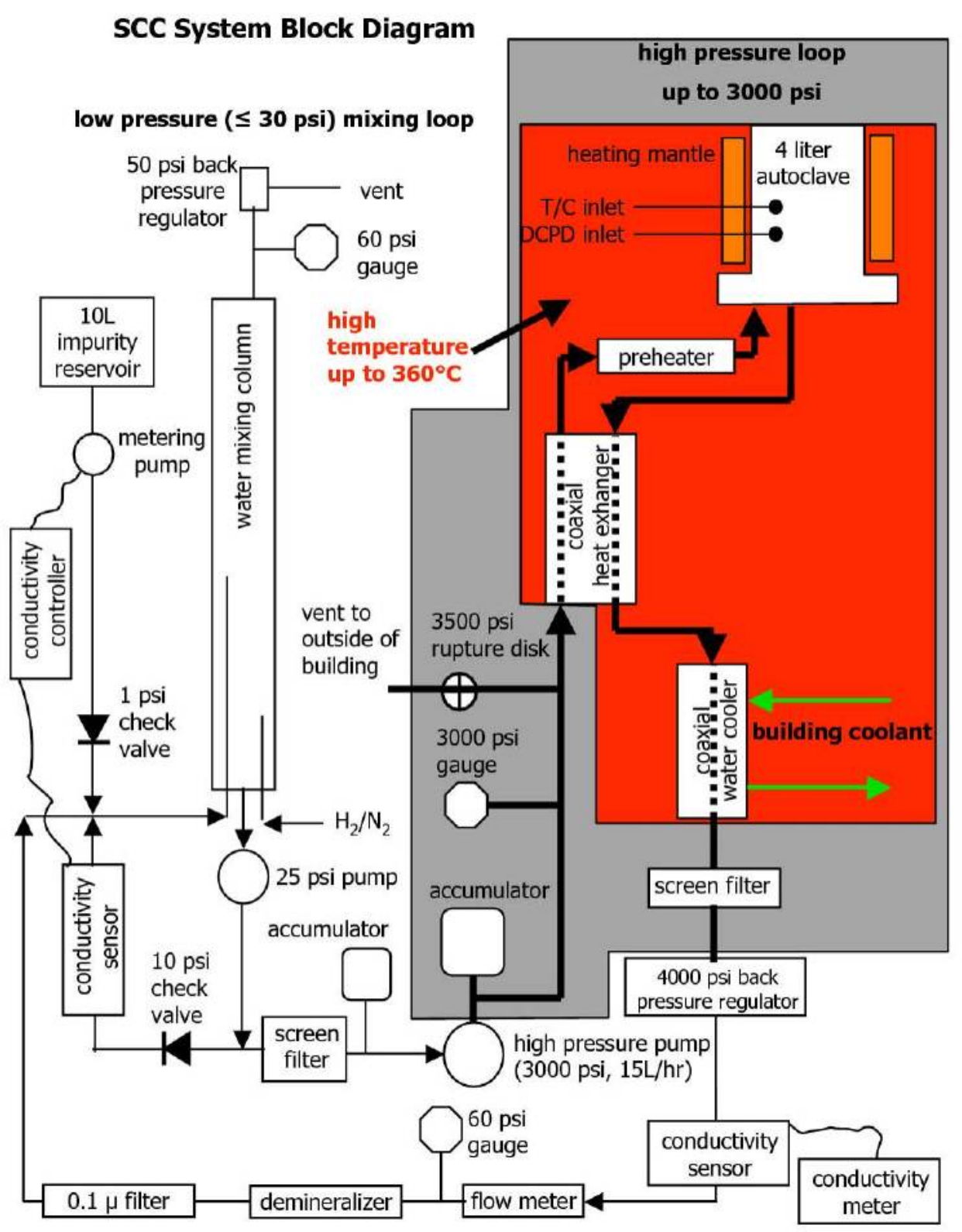

Figure 2.1 General water flow diagram for PNNL SCC crack-growth test systems.

Boron (B) and lithium ( $\mathrm{Li}$ ) levels for PWR water testing are controlled by pre-saturating the mixed resin bed demineralizer with boric acid and lithium hydroxide to specific levels that will result in tailored near-constant $\mathrm{B}$ and $\mathrm{Li}$ content in the water. There is some drift in the Li level in the water because it is singly ionized and is easily displaced from the demineralizer by more highly positively ionized species coming off the autoclave such as chromate. The displaced Li is removed by periodic partial replacement of water in the mixing loop with water having little or no $\mathrm{Li}$ (and some B). Boron and Li levels in the mixing loop are determined from measurements of water conductivity, $\mathrm{pH}$, and temperature using pHSC4 software (obtained from Rick Eaker of Duke Power). Autoclave flow rate is held to at least $125 \mathrm{cc} / \mathrm{min}$ (approximately two autoclave exchanges per hour) to provide a consistent chemistry environment within the autoclave. 
Load is applied to a sample using a servo-electric motor attached to the test frame. The servoelectric motor is controlled using proprietary software from GEG. The servo-electric motor can provide a smooth cyclic loading sine wave up to about $3 \mathrm{~Hz}$, allowing in-situ pre-cracking of a test sample. Using DCPD data, the GEG software can continuously adjust the servo-electric motor to provide constant $\mathrm{K}$ loading conditions. As shown in Figure 2.2, the load from the servo-electric motor is transmitted into the autoclave with a pullrod, and the sample is braced from above by a top plate and 4-bar linkage that transmits load to the baseplate of the autoclave which is bolted to the test frame.

Crack length is estimated using a reversing DCPD system developed by Peter Andresen of GEG. A sketch of the system is shown in Figure 2.3. As with all DC potential drop measurement systems, a constant current is run though the sample, and the voltage across the crack plane is measured and converted into a crack length by means of an empirically derived formula relating
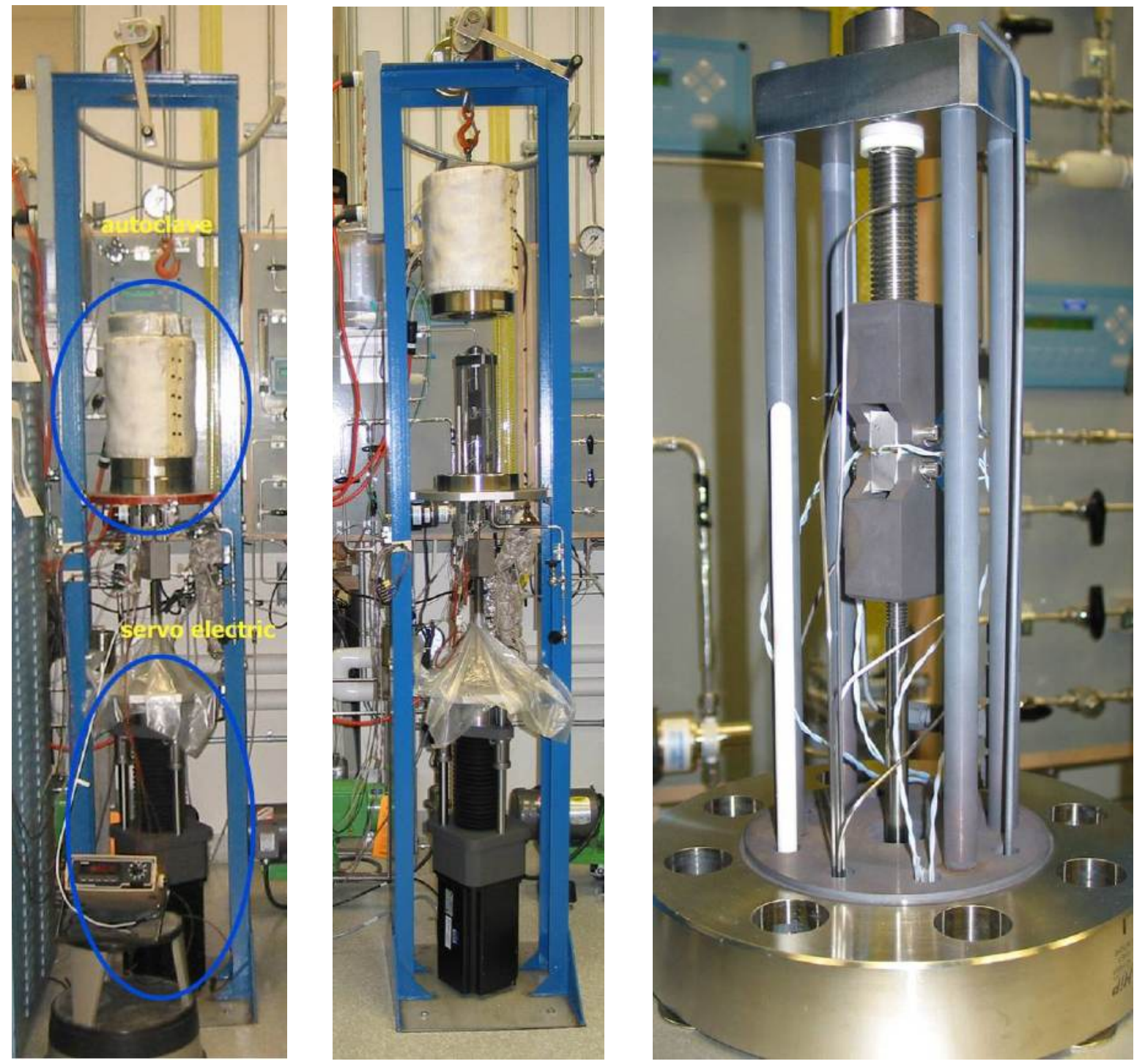

Figure 2.2 Typical crack-growth-rate test frame loading system used at PNNL. 


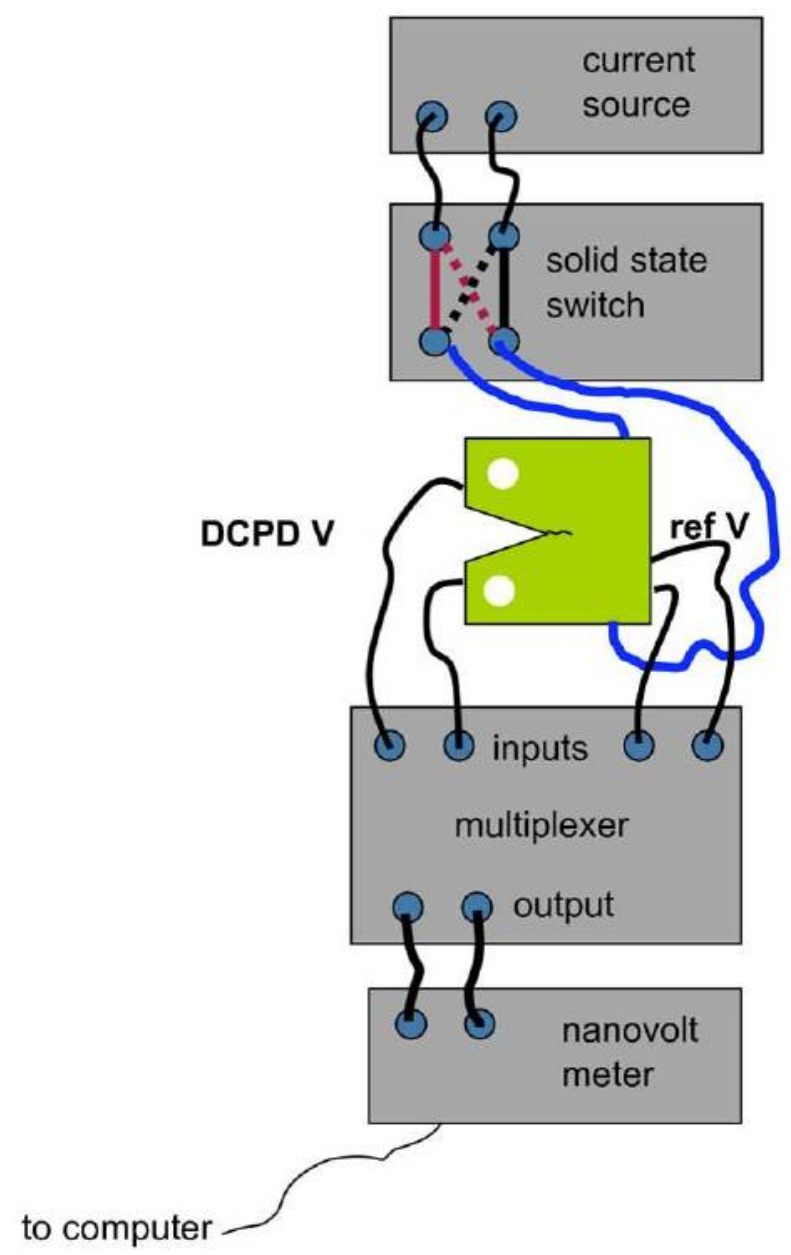

Figure 2.3 Schematic diagram illustrating the DCPD system to measure crack length in situ.

voltage to crack length. A referenced DCPD resistivity is monitored directly on the test specimen using a "back face" potential method developed at GEG. Using a solid-state polarity-reversing switch built into the current path, potential drop is measured in both a forward and reverse current flow condition. By measuring in both directions, the system eliminates contact voltages from the measurement.

The GEG software also controls the operation of the DCPD system and aggregates the data. Platinum wire is used for current and voltage feeds into the autoclave. For PWR water testing, segmented transformation toughened zirconia (TTZ) tubing is used to help prevent shorting of the Pt wires against other wires or any metal surfaces in the autoclave. Some crosstalk in the voltage wires occurs and is minimized by keeping the wires separated as far as reasonably possible from each other. In addition, the current wires are kept away from the voltage measurement wires. The sample is electrically insulated from the load train through a combination of ceramic spacers and sleeves. Spot welding is used to attach the platinum wires to a specimen. The spot weld locations are marked on the sample prior to inserting the sample into the load train. 
The PNNL systems have the capability to monitor autoclave water outlet conductivity, mixing loop water conductivity, autoclave temperature, autoclave water flow rate, sample corrosion potential (via a $\mathrm{ZrO}_{2}$ insulated $\mathrm{Cu} / \mathrm{Cu}_{2} \mathrm{O}$ reference electrode in the autoclave), dissolved oxygen, water pressure, DCPD current, and DCPD voltage. With the exception of water pressure and flow rate, these parameters are recorded in the test data file. Statistical information on temperature and current fluctuations are also recorded. Additionally, messages describing changes in test conditions and other issues are a permanent part of the data record.

\subsection{General SCC Crack-Growth Testing Approach and Issues}

Although systems have been designed for both 1T and 0.5T CT specimens, the primary specimen geometry used in this project is the 0.5T CT with side grooves. The details of the specimen geometry are shown in Figure 2.4. Prior to loading a specimen in the autoclave, the sample thickness, notch depth, $\mathrm{a}_{0}$, and $\mathrm{W}$ values are all measured and recorded into the data record for the test. Using the sample dimensions and the strength of the specimen at the test temperature, in accordance with American Society for Testing and Materials (ASTM) E-1681, an upper limit on $\mathrm{K}_{\mathrm{EAC}}$ value is calculated using the formula:

$$
K_{E A C_{\max }}=\sigma_{y s} \sqrt{D / 1.27}
$$

where $\sigma_{y s}$ is the yield strength at the test temperature, and $D$ is the smaller of the specimen thickness, the remaining uncracked specimen width and the crack length. In the case of materials with large amounts of work hardening (defined as $\sigma_{U T S} / \sigma_{y s}>1.3$ ) such as annealed 300 -series stainless steels and nickel-base alloys, the average of the yield and ultimate stress is used in place of the yield stress as per ASTM guidelines.

After the sample dimensions are measured and spot-weld locations are marked on the sample, it is cleaned and inserted into a test system. Pre-cracking of a sample is done in situ at the test temperature when a single specimen is being tested. Initial pre-cracking of two or more specimens mounted in-series is not possible in situ because the length of time needed to nucleate a pre-crack is not consistent, so precracking two specimens in series would likely lead to specimens with different precrack lengths. The differing precrack lengths would make it impossible to maintain and control the $\mathrm{K}$ level in both specimens during and after pre-cracking. Thus, the approach for testing at PNNL is to nucleate a crack individually on each of the two specimens under fatigue in air ${ }^{\mathrm{a}}$, followed by continued precracking of the two samples loaded together in situ. Crack transitioning steps are carefully selected to grow the pre-crack in hightemperature water using the following stages: (1) fatigue, (2) corrosion fatigue and (3) SCC. Typically, this means producing initial precracks of $\sim 1 \mathrm{~mm}$ in air followed by an additional $\sim 1$ $\mathrm{mm}$ by cycling in situ before transitioning to slow cyclic loading plus hold times to promote SCC. An Instron servohydraulic test frame is used to precrack CT specimens in air, and the same DCPD electronics and system control software used for the crack-growth systems is also used for the Instron test frame.

\footnotetext{
a Practically speaking, CT samples slated for testing in series could be individually precracked in situ. However, this would result in a significant increase in system set-up requirements, sample modifications, test time and expense. The initial precracking in air is now done without impacting the current operation of the available PNNL SCC test systems. This precracking is done under well-controlled conditions, and care is taken to make sure that samples, grips and other components are cleaned before testing.
} 


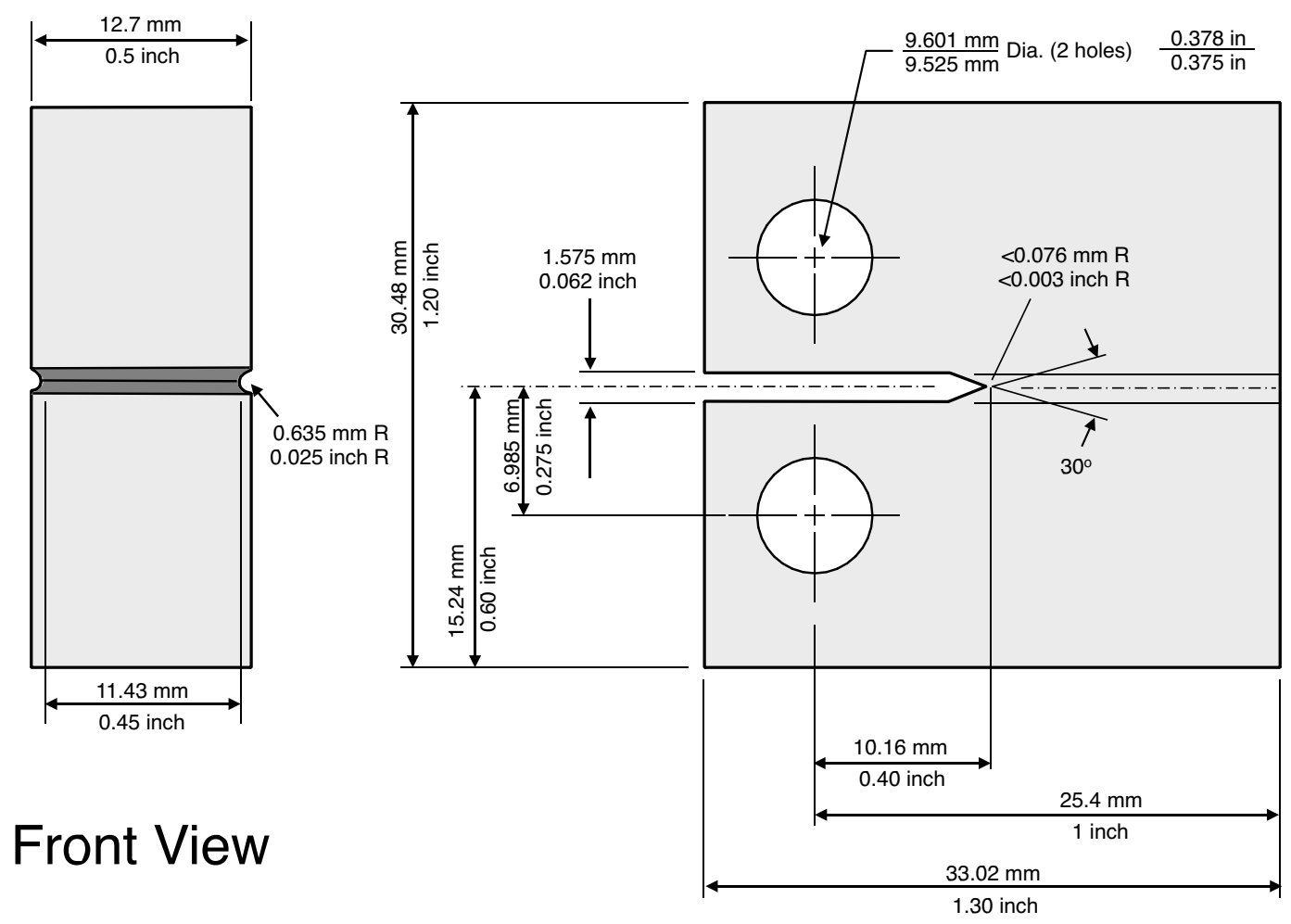

Figure 2.4 Schematic drawing of a 0.5T CT specimen. Oversized loading holes $(\sim 9.5 \mathrm{~mm}$ diameter) are used to accommodate ceramic inserts that provide electrical isolation between the CT specimen and clevises. Dimensions for 1TCT specimens are approximately double.

The first step in pre-cracking is to cycle the sample at a relatively high frequency $(1-20 \mathrm{~Hz})$ with a large load ratio and $\mathrm{K}_{\max }$ less than the $\mathrm{K}$ level chosen for constant $\mathrm{K}$. As the crack begins to grow from the notch, the load ratio and frequency are reduced while the $\mathrm{K}_{\max }$ value is increased. By pre-cracking in this way, each pre-crack segment can grow beyond the plastic zone created by the previous segment. For all samples, cyclic loading steps at frequencies of $0.1 \mathrm{~Hz}$ down to $0.001 \mathrm{~Hz}$ are performed in high-temperature water. The final phase involves crack transitioning by very slow cycling with a hold time ranging from $1 \mathrm{~h}$ to $24 \mathrm{~h}$. This grows the crack beyond the pre-cracking plastic zone and allows the crack to transition from transgranular (TG) fatigue to the crack growth mechanism that occurs for that material under constant $\mathrm{K}$ conditions.

For materials such as cold-worked (CW) 316SS that crack readily in LWR environments, obtaining a steady crack growth rate after transitioning to constant $\mathrm{K}$ can easily be accomplished by following a standard procedure. However, determining a constant $\mathrm{K}$ crack growth rate in highly SCC-resistant materials such as alloy 690 and its welds is more challenging with the main focus on giving the crack adequate opportunity to become an engaged IG crack. For these materials, the use of alternate cyclic and cycle + hold loading conditions, including various load ratio $(R)$ values and modified rise/fall times, are often employed prior to reaching constant $\mathrm{K}$. Tests conducted at PNNL have shown that an R of 0.5 usually produces the best engagement response, and in base metal materials, efforts are made to run the specimen under slow continuous cycling for several grain dimensions prior to the onset of cycle + hold loading. The much larger grain dimensions and more irregular shape of 
the grain boundaries in weld metals makes transitioning to an engaged crack front even more challenging. If extremely slow or inconsistent crack growth rates are observed, cyclic loading is typically restarted to move the crack forward (ten microns to several hundred microns) and then retransition to constant $\mathrm{K}$. This retransitioning procedure may be performed several times. The constant K SCC response is judged on the response of the material to these multiple observations at constant $\mathrm{K}$. Observation of the propagation rate under selected cyclic loading and hold time conditions is also used to judge the crack growth resistance of the material.

The ideal increment of crack length over which to measure a steady crack growth rate would be several grain diameters. However in alloy 690 and its weld metals, this is often an extremely impractical goal that could take more than two years to achieve and so it is necessary to choose an increment based on factors related accuracy and resolution in the DCPD crack length data trend. The most easily quantifiable factor is noise or scatter in the DCPD crack length data. Each PNNL crack growth system has slightly different noise levels. The best system at PNNL has a noise level of $1.0 \mu \mathrm{m}$ peak-to-peak while the "worst" system has $\sim 3 \mu \mathrm{m}$ peak-to-peak noise. Noise creates uncertainty in the measurement. Uncertainty is greatest when only a few measurements are performed, but as the number of measurements is increased, an average value can be resolved along with statistics on the goodness of fit. This is equivalent to fitting a trend line through the data. As long as the noise remains random (e.g., the residuals in the curve fit remain random), trends in the data down to the noise level can be resolved. Other factors contributing to the uncertainty in trends in the data are related to environment, crack morphology effects, and resistivity drift of the material. Environmental parameters such as water temperature, water conductivity, and dissolved hydrogen have been found to affect crack length, and it is important to limit deviations in these parameters. All environmental parameters on PNNL crack growth systems that can lead to phantom changes in crack length are monitored and tightly controlled. The factor affecting crack length accuracy and resolution that is most difficult to control is crack morphology. DCPD is founded on the notion that there is no electrical current conduction behind the crack front. In stress corrosion crack-growth testing (especially in PWSCC testing), it has been found that there is almost always some feature in the crack morphology that allows current conduction behind the crack front. The most easily identifiable feature is an uncracked ligament in the wake of a crack as shown in Figure 2.5. Electric current bridging across very closely spaced crack walls is also thought to contribute to conduction behind the crack front. These features cause underprediction of DCPD-measured crack length and reduce the sensitivity of the DCPD system to detecting movement of the crack front. Crack ligaments can also cause large steps in crack extension when they break. Uneven growth along the crack front also causes crack length underprediction and reduced sensitivity in the same way as ligaments behind the crack front. It is important to recognize that all these morphology effects do not cause falsely high crack growth rates, but instead lead to underprediction of crack extension. The only phenomenon that leads to a falsely high crack growth rate is resistivity change that occurs in Ni-base alloys such as alloy 600 and alloy 690. It is a well-known phenomenon that the resistivity of these alloys will slowly increase with time when testing at PWSCC temperatures. Without compensation, resistivity drift will give the appearance of a slowly increasing crack length. It is typical to compensate for resistivity drift by monitoring the resistivity of a piece of unstressed reference coupon placed in the autoclave environment. The resistivity change of the test specimen is normalized to the resistivity of the reference coupon. Looking at all these factors in aggregate, the test systems at PNNL are designed with a sufficiently high data acquisition rate to allow trends in crack extension to be detected down to the noise level of the DCPD system as long as test conditions are tightly controlled and resistivity drift is properly factored into the crack length measurement. 


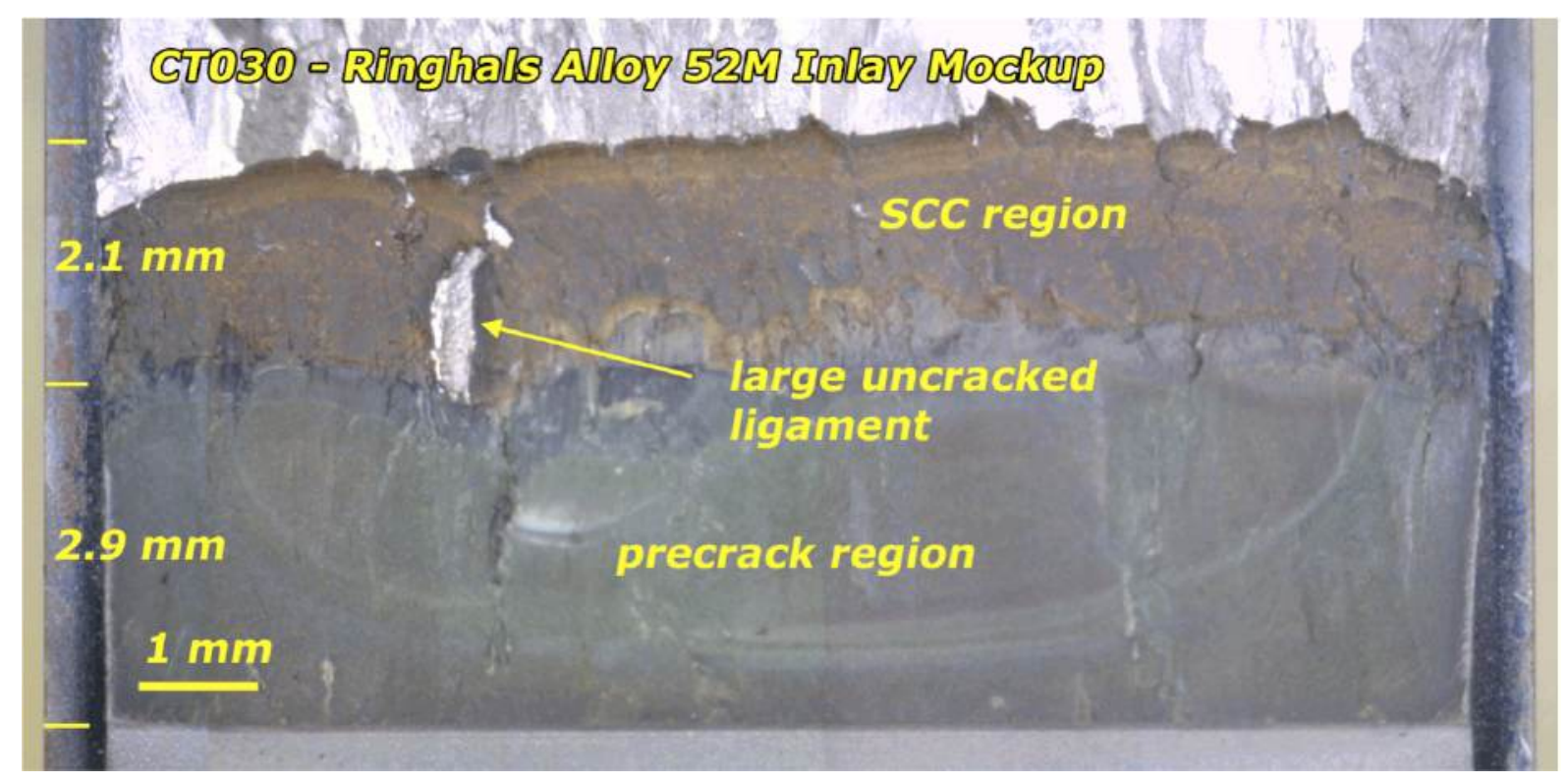

Figure 2.5 Example of large uncracked ligament detected in the wake of a crack.

Effects of current conduction behind the crack front and uneven crack extension will produce crack growth rates that are lower than what are actually occurring, so any crack growth rate that is detectable by DCPD is expected to be an underprediction of the actual rate. There has yet to be a test where crack growth rate has been overpredicted.

\subsection{Specific SCC Crack-Growth Testing Approach}

Unless noted otherwise, experiments were conducted in simulated PWR primary water with $2000 \mathrm{ppm} \mathrm{B}$ and $2 \mathrm{ppm} \mathrm{Li}$. A prototypic simulated PWR primary water environment is considered to be $325^{\circ} \mathrm{C}$ with $29 \mathrm{cc} / \mathrm{kg} \mathrm{H}_{2}$. Tests conducted early in the program were often done at this temperature and hydrogen concentration, however as the program progressed, the desire to better understand the crack growth response of alloy 690 and its welds eventually led to testing at $350^{\circ} \mathrm{C}$, and then later at $360^{\circ} \mathrm{C}$. Testing now is typically conducted at $360^{\circ} \mathrm{C}$. Dissolved hydrogen concentration also evolved over the course of the program with most testing now done at $\mathrm{DH}$ concentrations that place the corrosion potential of the material on the $\mathrm{Ni} / \mathrm{NiO}$ line where crack growth response is known to be greatest in alloy 600 and its weld metals [Ref. 6]. Limited testing was also performed at $50^{\circ} \mathrm{C}$ under primary water conditions. The stress intensity $(\mathrm{K})$ was controlled to a value of $30 \mathrm{MPa} \sqrt{\mathrm{m}}$ under most conditions, however high $\mathrm{K}$ values were often evaluated up to $\sim 40 \mathrm{MPa} \sqrt{\mathrm{m}}$ later in an SCC CGR test. For most experiments, a zirconia membrane reference electrode was utilized to allow corrosion potential measurement of the specimen and a Pt coupon during testing. Crack growth tests were performed with two specimens in series allowing a greater range of material conditions to be examined in a shorter period of time.

Specimens were first precracked in air and followed by further crack extension using aggressive cycling in high temperature water. A variety of loading conditions were used to attempt to transition from the TG precrack to an IGSCC crack front. Loading conditions included R values ranging from 0.5 to 0.9 , the addition of hold times up to $24 \mathrm{~h}$, and various "periodic unload" schemes with a symmetric or a sawtooth wave form (e.g., rapid unload followed by a slow 
reload). Based on the current work and tests on alloy 690, a final cycling step at $0.001 \mathrm{~Hz}$ with $\mathrm{R}=0.5-0.7$ was often used and followed by the addition of hold times before determining crack growth rates at constant $\mathrm{K}$.

The response of the material during transitioning was assessed continuously by comparing current propagation rates to results from earlier tests. As the database of observed crack growth rates and accompanying crack surface morphologies from previous tests grew, higher crack growth rates during transitioning (particularly during cycle + hold loading) could be identified. If a crack growth rate during transitioning was indicative of a non-engaged crack front, then the crack would often be retransitioned in an attempt to improve SCC engagement. For these SCC resistant alloys, several transitioning attempts were typically made before documenting constant K, CGR response.

The general philosophy for assessing CGRs of alloy 690 and its weld metals is to first obtain baseline SCC behavior with the material in the expected plant thermomechanical treatment and then follow with tests on material in off-normal conditions. Testing begins in either simulated PWR primary water or in an aggressive PWR primary water environment (elevated temperature, testing at the $\mathrm{Ni} / \mathrm{NiO}$ line). In some tests, these conditions would eventually be followed by systematic variations in environmental conditions to assess the effects of parameters such as temperature, stress intensity, and corrosion potential on the crack growth rate of these materials.

Alloy 690 thermomechanical conditions that have been examined thus far include solution annealing, cold rolling and a combination of these treatments to alter alloy microstructure and mechanical properties. In cold-rolled materials, specimens were cut in either the T-L or S-L orientation. All weld metals were tested in the as-welded condition with the crack plane aligned along the dendrite growth direction (often referred to as the T-S orientation in weldments). Environmental conditions have included test temperatures from 290 to $360^{\circ} \mathrm{C}$, variable hydrogen content in simulated PWR primary water and the additional of oxygen and minor impurities such as sulfate. With only three NRC test systems and test times ranging from 6 to 12 months, it has been difficult to study a wide range of heats and material conditions. However by testing two samples in series and obtaining access to a fourth SCC test system for almost two years, PNNL has been able to conduct crack-growth tests on seventeen alloy 152/52/52M weld samples and 10 alloy 690 samples as part of this project. 


\section{SCC Crack-Growth Testing on Alloy 152, 52 and 52M Weld Metals}

\subsection{Overview of Weld Mockups and SCC Tests}

Various alloy 152, 52 and 52M weld mockups have been obtained for SCC testing as part of this project. All of these materials were supplied by industry sources and were selected to represent industry practices of direct relevance to PWR service. In most cases, these mockups were produced specifically to qualify a welding approach to be used for plant replacement or repair. Alloy 152 and $52 \mathrm{U}$-groove welds produced by Mitsubishi Heavy Industries (MHI) were obtained from EPRI and were mockups for the pressure vessel head replacement at the Kewanee plant. In addition, an alloy 52 butt weld was obtained from AREVA NP that was produced as part of a testing program. Alloy $52 \mathrm{M}$ and $152 \mathrm{M}$ welds were obtained from George Young at KAPL and supplied as part of an international cooperative program on alloy 690 led by EPRI and the NRC. Finally, alloy $52 \mathrm{M} / 182$ overlay and alloy $52 \mathrm{M} / 82$ inlay weld mockups produced by RinghalsVatenfall were obtained with the help of Pal Efsing. A brief description of the welds, their heat numbers, and compositions are listed in Table 3-1. Weld fabrication method differed for each of the weldments and available information will be provided in the following sections.

Table 3.1 Alloy 152, 152M, 52 and 52M weldments at PNNL.

\begin{tabular}{|c|c|c|}
\hline Material - Source & Heat Number and Description & $\begin{array}{c}\text { Alloy } 152,52 \text { or } 52 \mathrm{M} \\
\text { Weld Metal Composition, wt } \%\end{array}$ \\
\hline Alloy $152-\mathrm{MHI}$ & $\begin{array}{l}\text { Heat } 307380, \text { U-groove mock-up } \\
\text { weld for Kewanee, 304SS plate }\end{array}$ & $\begin{array}{c}\mathrm{Ni}-28.7 \mathrm{Cr}-9.1 \mathrm{Fe}-0.03 \mathrm{C}-3.6 \mathrm{Mn}-0.33 \mathrm{Si}- \\
0.15 \mathrm{Al}-0.12 \mathrm{Ti}-0.003 \mathrm{~S} \\
\text { (independent analysis) }\end{array}$ \\
\hline Alloy $52-\mathrm{MHI}$ & $\begin{array}{l}\text { NX2686JK, U-groove MHI mock-up } \\
\text { weld for Kewanee, 304SS plate }\end{array}$ & $\begin{array}{c}\text { Ni-29.1Cr-10.0Fe-0.024C-0.25Mn- } \\
\text { 0.13Si-0.71Al-0.52Ti-0.01N } \\
\text { (standard comp.) }\end{array}$ \\
\hline Alloy 52 - AREVA NP & $\begin{array}{l}\text { NX3926JK, Mockup butt weld, alloy } \\
690 \text { plate }\end{array}$ & $\begin{array}{l}\text { Ni-29.1Cr-10.0Fe-0.024C-0.25Mn- } \\
0.13 \mathrm{Si}-0.71 \mathrm{Al}-0.52 \mathrm{Ti}-0.01 \mathrm{~N}_{2} \\
\text { (standard comp.) }\end{array}$ \\
\hline Alloy $52 \mathrm{M}-\mathrm{KAPL}$ & $\begin{array}{l}\text { Heat NX5285TK, High constraint, } \\
\text { narrow groove weld, alloy } 690 \text { plate }\end{array}$ & $\begin{array}{l}\text { Ni-30.0Cr-7.9Fe-0.014C-0.75Mn- } \\
0.13 \mathrm{Si}-0.11 \mathrm{Al}-0.21 \mathrm{Ti}-0.81 \mathrm{Nb}+\mathrm{Ta} \\
\text { (mill test report) }\end{array}$ \\
\hline Alloy $52 \mathrm{M}-\mathrm{KAPL}$ & $\begin{array}{l}\text { Heat NX5285TK, V-groove } \\
\text { dissimilar metal weld, carbon steel } \\
\text { and 316SS plate }\end{array}$ & $\begin{array}{l}\text { Ni-30.0Cr-7.9Fe-0.014C-0.75Mn- } \\
0.13 \mathrm{Si}-0.11 \mathrm{Al}-0.21 \mathrm{Ti}-0.81 \mathrm{Nb}+\mathrm{Ta} \\
\text { (mill test report) }\end{array}$ \\
\hline Alloy 52M - KAPL & $\begin{array}{l}\text { Heat NX5285TK, Narrow groove } \\
\text { weld with modified weld conditions } \\
\text { to create hot cracks }\end{array}$ & $\begin{array}{c}\text { Ni-30.0Cr-7.9Fe-0.014C-0.75Mn- } \\
0.13 \mathrm{Si}-0.11 \mathrm{Al}-0.21 \mathrm{Ti}-0.81 \mathrm{Nb}+\mathrm{Ta} \\
\text { (mill test report) }\end{array}$ \\
\hline Alloy $152 \mathrm{M}-\mathrm{KAPL}$ & $\begin{array}{l}\text { Heat WC83F8, V-groove dissimilar } \\
\text { metal (carbon steel, } 316 \text { SS) weld } \\
\text { with known hot cracks }\end{array}$ & $\begin{array}{c}\mathrm{Ni}-30.2 \mathrm{Cr}-8.7 \mathrm{Fe}-<0.005 \mathrm{C}-3.0 \mathrm{Mn}- \\
0.22 \mathrm{Si}-<0.01 \mathrm{Al}-0.03 \mathrm{Ti}-1.176 \mathrm{Nb}- \\
0.002 \mathrm{~S}-0.03 \mathrm{~V} \text { (mill test report) }\end{array}$ \\
\hline $\begin{array}{c}\text { Alloy } 52 \mathrm{M} / 182 \text { Overlay } \\
\text { - Ringhals }\end{array}$ & $\begin{array}{l}\text { Mockup alloy } 52 \mathrm{M} \text { overlay on alloy } \\
690 \text { plate with alloy } 182 \text { overlay } \\
\text { (heat numbers not available) }\end{array}$ & $\begin{array}{l}\mathrm{Ni}-30.0 \mathrm{Cr}-8.4 \mathrm{Fe}-0.020 \mathrm{C}-0.81 \mathrm{Mn}- \\
0.03 \mathrm{Si}-0.10 \mathrm{Al}-0.21 \mathrm{Ti}-0.85 \mathrm{Nb}+\mathrm{Ta} \\
\text { (mill test report) }\end{array}$ \\
\hline $\begin{array}{l}\text { Alloy } 52 \mathrm{M} / 82 \text { Inlay - } \\
\text { Ringhals }\end{array}$ & $\begin{array}{c}\text { Mockup alloy 52M inlay on alloy } 82 \\
\text { weld and A533 pipe } \\
\text { (heat numbers not available) }\end{array}$ & ilable \\
\hline
\end{tabular}


Seventeen SCC crack-growth tests on alloy 152/52/52M weldments were completed. Table 3.2 summarizes the various welds, specimen numbers and general test conditions for each of the weld metal tests. SCC results for these crack-growth tests will be described in detail along with characterizations of the welds.

Table 3.2 Summary of completed alloy 152, 52 and 52M SCC tests.

\begin{tabular}{|c|c|c|c|}
\hline Sample and Test & Material & Test Description & $\begin{array}{l}\text { Completion } \\
\text { Date }\end{array}$ \\
\hline $\begin{array}{c}\text { CT013, 1/2T CT, NRC } \\
\text { System \#1 }\end{array}$ & Alloy $152-\mathrm{MHI}$ & $\begin{array}{l}\text { PWR Primary Water, alloy } \\
152 \text { data }\end{array}$ & $4 / 07$ \\
\hline $\begin{array}{l}\text { CT017, 1/2T CT, } \\
\text { NRC System \#1 }\end{array}$ & Alloy $152-\mathrm{MHI}$, as welded & $\begin{array}{c}\text { PWR Primary Water, } \\
\text { Temp effects, alloy } 152 \text { data }\end{array}$ & $6 / 08$ \\
\hline $\begin{array}{l}\text { CT018, 1/2T CT, } \\
\text { NRC System \#1 }\end{array}$ & $\begin{array}{c}\text { Alloy } 152-\mathrm{MHI}, \text { stress } \\
\text { relieved }\end{array}$ & $\begin{array}{l}\text { PWR Primary Water, } \\
\text { Temp effects, alloy } 152 \text { data }\end{array}$ & $6 / 08$ \\
\hline $\begin{array}{l}\text { CT024, 1/2T CT, } \\
\text { NRC System \#2 }\end{array}$ & $\begin{array}{c}\text { Alloy } 52-\text { AREVA, as } \\
\text { welded }\end{array}$ & $\begin{array}{l}\text { PWR Primary Water, two } \\
\text { alloy } 52 \text { weld metals }\end{array}$ & $1 / 09$ \\
\hline $\begin{array}{l}\text { CT025, 1/2T CT, } \\
\text { NRC System \#2 }\end{array}$ & Alloy $52-\mathrm{MHI}$, as welded & $\begin{array}{l}\text { PWR Primary Water, two } \\
\text { alloy } 52 \text { weld metals }\end{array}$ & $1 / 09$ \\
\hline $\begin{array}{l}\text { CT028, 1/2T CT, } \\
\text { NRC System \#3 }\end{array}$ & $\begin{array}{c}\text { Alloy 52M on Alloy } 182 \\
\text { overlay - Ringhals }\end{array}$ & $\begin{array}{l}\text { PWR Primary Water, alloy } \\
182 \text { into } 52 \mathrm{M} \text {, alloy } 52 \mathrm{M}\end{array}$ & $4 / 09$ \\
\hline $\begin{array}{l}\text { CT029, 1/2T CT, } \\
\text { NRC System \#3 }\end{array}$ & $\begin{array}{c}\text { Alloy } 52 \mathrm{M} \text { on Alloy } 182 \\
\text { overlay - Ringhals }\end{array}$ & $\begin{array}{l}\text { PWR Primary Water, alloy } \\
182 \text { into } 52 \mathrm{M} \text {, alloy } 52 \mathrm{M}\end{array}$ & $4 / 09$ \\
\hline $\begin{array}{l}\text { CT030, 1/2T CT, } \\
\text { NRC System \#1 }\end{array}$ & $\begin{array}{l}\text { Alloy } 52 \mathrm{M} \text { on Alloy } 82 \\
\text { inlay - Ringhals }\end{array}$ & $\begin{array}{l}\text { PWR Primary Water, alloy } \\
82 \text { into } 52 \mathrm{M} \text {, alloy } 52 \mathrm{M}\end{array}$ & $10 / 09$ \\
\hline $\begin{array}{l}\text { CT031, 1/2T CT, } \\
\text { NRC System \#1 }\end{array}$ & $\begin{array}{c}\text { Alloy } 52 \mathrm{M} \text { on Alloy } 82 \\
\text { inlay - Ringhals }\end{array}$ & $\begin{array}{l}\text { PWR Primary Water, alloy } \\
82 \text { into } 52 \mathrm{M} \text {, alloy } 52 \mathrm{M}\end{array}$ & $10 / 09$ \\
\hline $\begin{array}{l}\text { CT032, 1/2T CT, } \\
\text { NRC System \#2 }\end{array}$ & $\begin{array}{c}\text { Alloy } 52-\text { AREVA as } \\
\text { welded }\end{array}$ & $\begin{array}{l}\text { PWR Primary Water, low } \\
\text { temp on high temp CGR }\end{array}$ & $10 / 09$ \\
\hline $\begin{array}{l}\text { CT033, 1/2T CT, } \\
\text { NRC System \#2 }\end{array}$ & Alloy $52-\mathrm{MHI}$ as welded & $\begin{array}{l}\text { PWR Primary Water, low } \\
\text { temp on high temp CGR }\end{array}$ & $10 / 09$ \\
\hline $\begin{array}{l}\text { CT034, 1/2T CT, } \\
\text { PNNL System \#1 }\end{array}$ & $\begin{array}{c}\text { Alloy 52M on Alloy } 182 \\
\text { overlay - Ringhals }\end{array}$ & $\begin{array}{c}\text { PWR Primary Water, alloy } \\
182 \text { into } 52 \mathrm{M} \text {, alloy } 52 \mathrm{M}\end{array}$ & $10 / 09$ \\
\hline $\begin{array}{l}\text { CT035, 1/2T CT, } \\
\text { PNNL System \#1 }\end{array}$ & $\begin{array}{c}\text { Alloy } 52 \mathrm{M} \text { on Alloy } 182 \\
\text { overlay - Ringhals }\end{array}$ & $\begin{array}{l}\text { PWR Primary Water, alloy } \\
182 \text { into } 52 \mathrm{M} \text {, alloy } 52 \mathrm{M}\end{array}$ & $2 / 10$ \\
\hline $\begin{array}{l}\text { CT040, 1/2T CT, } \\
\text { NRC System \#2 }\end{array}$ & $\begin{array}{c}\text { Alloy 52M narrow gap weld } \\
\text { - KAPL }\end{array}$ & $\begin{array}{l}\text { PWR Primary water, alloy } \\
52 \mathrm{M} \text { data }\end{array}$ & $7 / 10$ \\
\hline $\begin{array}{l}\text { CT041, 1/2T CT, } \\
\text { NRC System \#2 }\end{array}$ & $\begin{array}{c}\text { Alloy 52M V-groove weld - } \\
\text { KAPL }\end{array}$ & $\begin{array}{c}\text { PWR Primary water, alloy } \\
52 \mathrm{M} \text { data }\end{array}$ & $7 / 10$ \\
\hline $\begin{array}{l}\text { CT042, 1/2T CT, } \\
\text { NRC System \#1 }\end{array}$ & $\begin{array}{c}\text { Alloy 52M narrow gap weld } \\
\text { with aligned hot cracks - } \\
\text { KAPL }\end{array}$ & $\begin{array}{l}\text { PWR Primary Water, weld } \\
\text { defects/cracks on SCC }\end{array}$ & $7 / 10$ \\
\hline $\begin{array}{l}\text { CT043, 1/2T CT, } \\
\text { NRC System \#1 }\end{array}$ & $\begin{array}{l}\text { Alloy 52M KAPL narrow } \\
\text { gap weld with non-aligned } \\
\text { hot cracks - KAPL }\end{array}$ & $\begin{array}{l}\text { PWR Primary Water, weld } \\
\text { defects/cracks on SCC }\end{array}$ & $7 / 10$ \\
\hline
\end{tabular}




\section{$3.2 \quad$ MHI Alloy 152 Weld}

Initial weld metal SCC testing started with the alloy 152 mockup weld obtained from EPRI. This mockup weld was produced for the Kewaunee reactor pressure vessel head replacement by $\mathrm{MHI}$. It was made using $6.1 \mathrm{~mm}$ (2.4 in.) thick plates of 304SS butted together with a U-groove as shown in Figure 3.1. Alloy 152 (heat 307380) butter passes were applied to each half of the $\mathrm{U}$-groove, the ends of buttering were machined flat, and then the plates were welded together with alloy 152 (heat 307380). Both the buttering and the filler were applied by shielded metal arc welding (SMAW). Welding parameters for the alloy 152 SMAW filler material consisted of a deposition speed of $4-25 \mathrm{~cm} / \mathrm{min}$ and a current of $95-145 \mathrm{~A}$.

A portion of the weldment was sectioned at PNNL into $1.9 \mathrm{~cm}(0.75$-in.) thick blocks (Figure 3.2) and metallographically prepared to reveal the individual weld passes and the butter zone as shown, for example, in Figure 3.1. Sections C, D, and E indicated in Figure 3.2 were selected for fabricating CT samples. After polishing, these blanks were marked for machining so as to locate the end of the pre-crack in a single weld pass and enable $>1 \mathrm{~mm}$ of growth in that weld pass. A close examination was made to select a weld pass where the dendrites would be as parallel as possible to the pre-crack. The machined notch from section $C$ is shown in Figure 3.3. Crack growth testing was performed in the weld pass below the pass where the machined notch is located. The precrack will be located in the same weld pass for sections $C$ and $\mathrm{D}$, but the slight wandering of the welds along the length of the mockup meant that it was necessary to use a different weld pass for crack growth testing (moving one up) of section E.

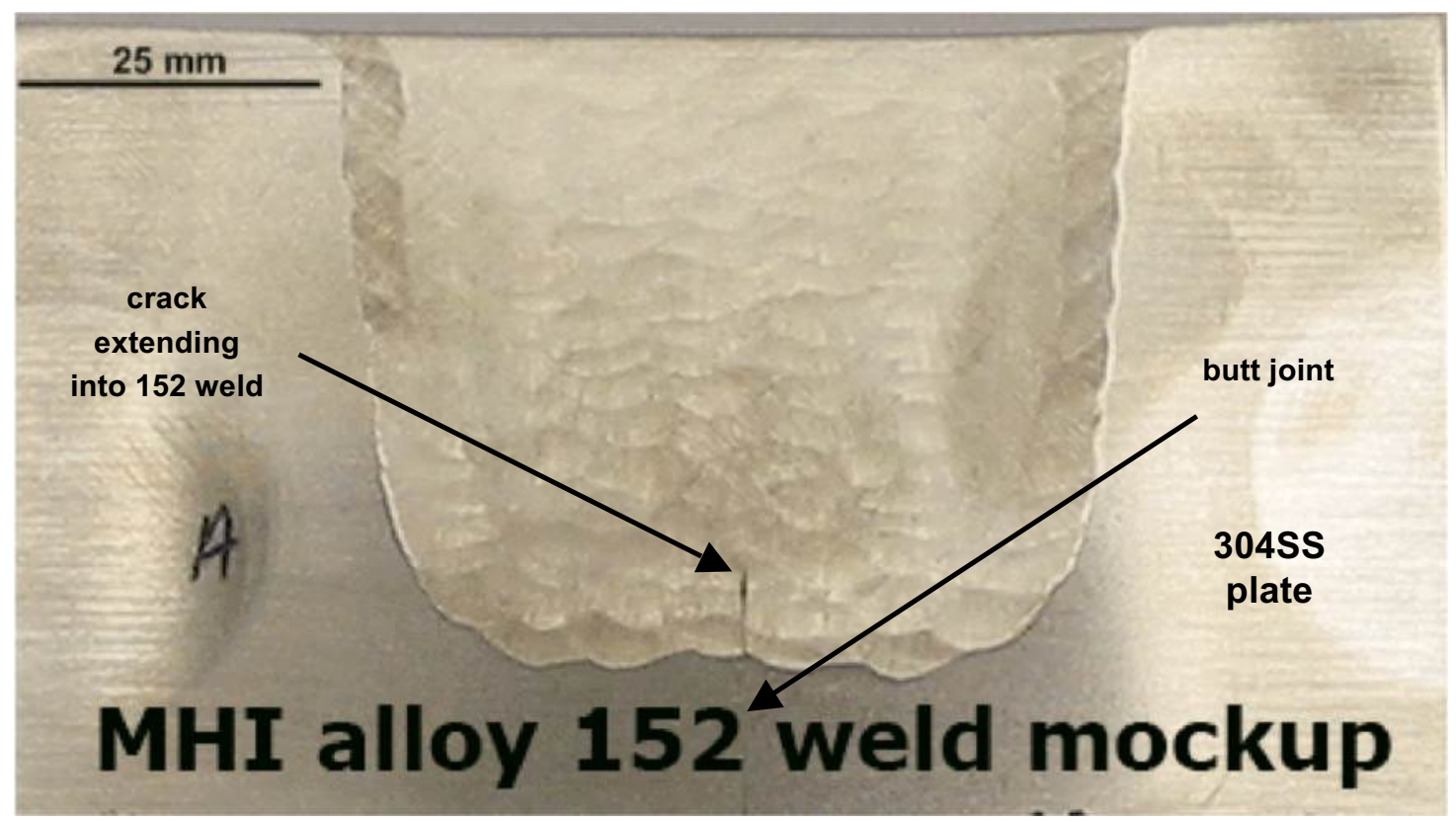

Figure 3.1 Optical image of alloy 152 weld mockup showing U-groove weld in crosssection. 


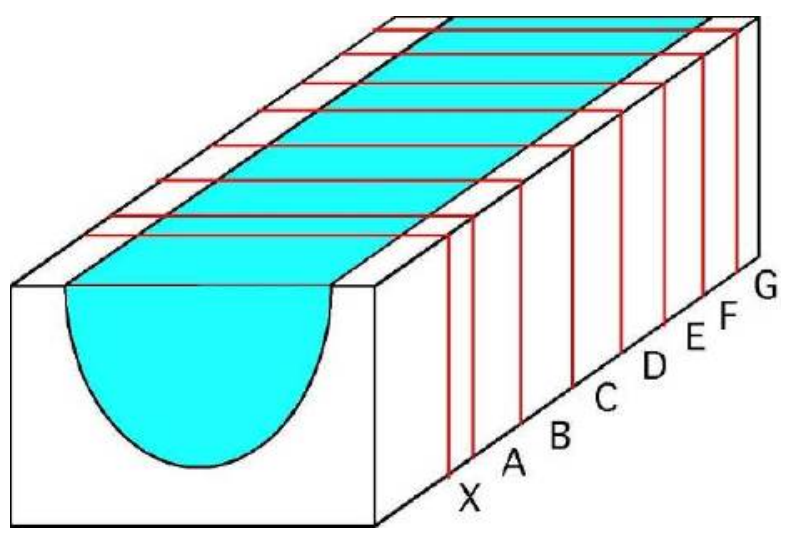

Figure 3.2 Sectioning diagram for the alloy 152 welded block. End sections $X$ and $G$ are $1.3 \mathrm{~cm}$ thick and are used for metallographic observations while sections $\mathrm{A}-\mathrm{F}$ are $1.9 \mathrm{~cm}$ thick and are to be used for CT samples. There is $\sim 7.6 \mathrm{~cm}$ of welded block in front of section "X".

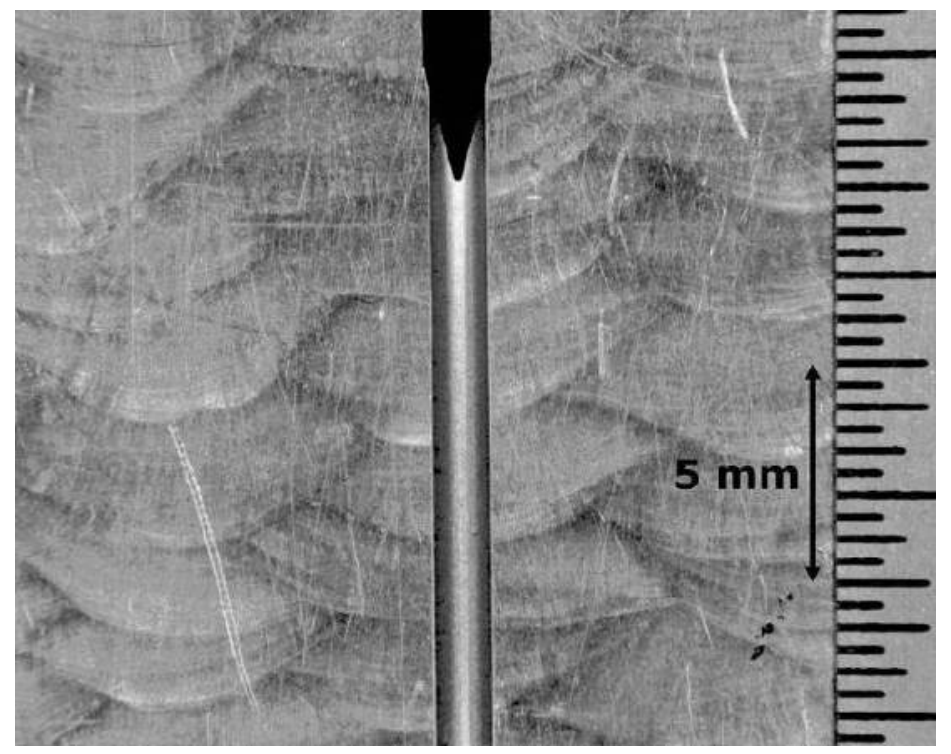

Figure 3.3 Optical micrograph of section $\mathrm{C}$ showing the location of the machined notch. This same weld pass was selected in section $D$, while the one just above and to the left was selected in section $E$.

SEM examinations were carried out in section $X$ and revealed a standard dendritic structure with some long dendrites interspersed with smaller ones at the junctions of the weld passes. The boundaries between dendrites were often wavy. Examples of these are seen in Figures 3.4 and 3.5. Based on SEM examination of the microstructure of the alloy 152 weld, the weld is composed of a mixture of a cellular and columnar dendritic structure with heavy precipitation in both the interiors of the dendrites and the dendritic boundaries. The backscatter electron (BSE) images of the dendrites in Figures 3.4 and 3.5 reveal a mottled contrast that is presumed to arise due to strain in the matrix. Carbides scattered throughout the dendrites show up as dark particles in BSE images, whereas in the secondary electron (SE) images, the particles typically 

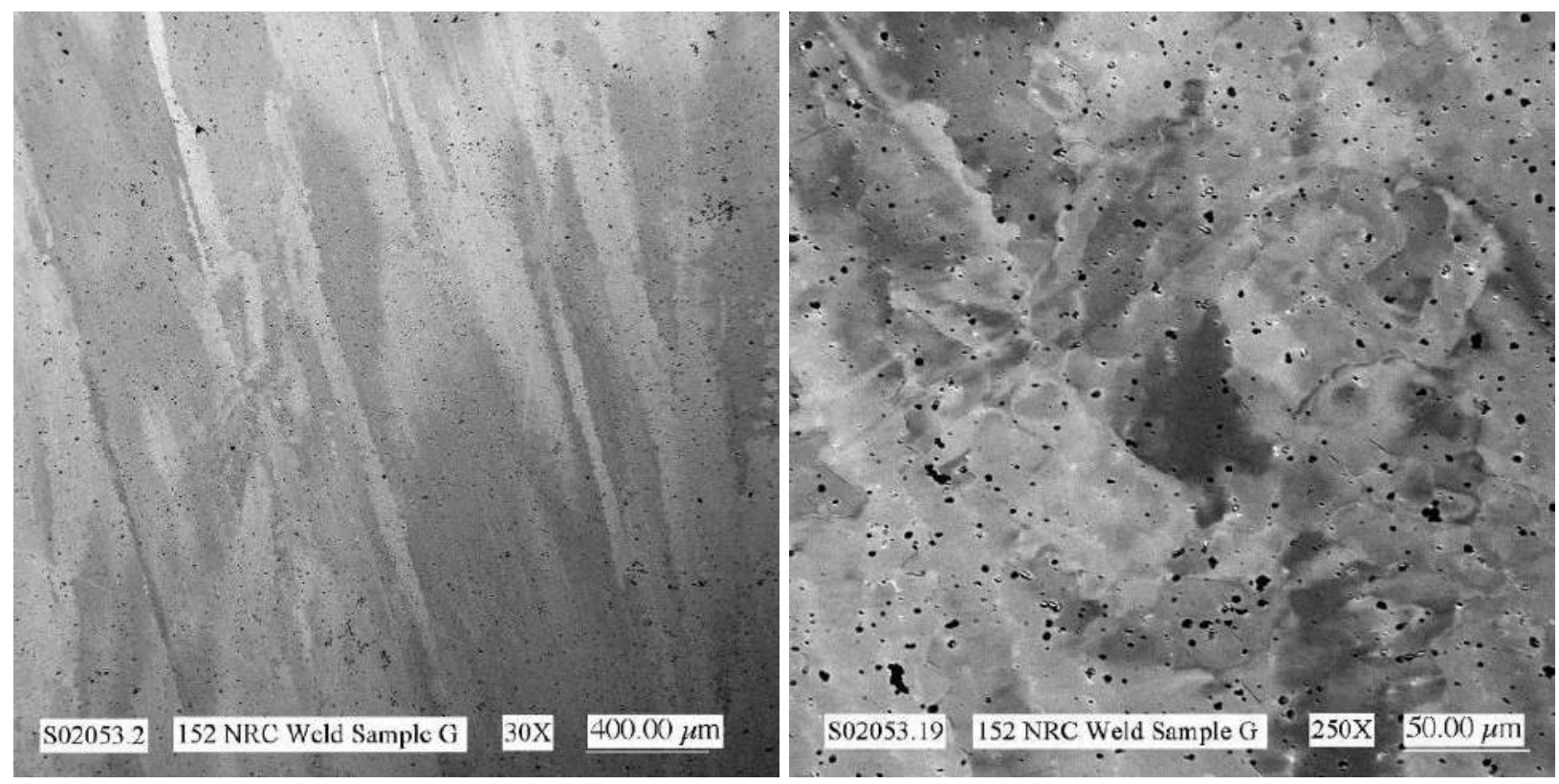

Figure 3.4 SEM micrographs of the alloy 152 weld showing long dendrites (left) and much smaller, equiaxed dendrites (right). The latter are generally present at the intersection of two weld passes but some of the long dendrites pass through that region uninterrupted.

show up as bright particles because they are sticking out from the specimen surface. Some of the dendritic boundaries etched differently than the surrounding matrix, possibly due to either compositional changes or from precipitation on the boundaries. Additionally, EDS composition maps were made to elucidate compositional inhomogeneities in the structure and identify the major second-phase particles. As seen in Figure 3.6, there is a slight amount of coring indicated in the Mn map. Coring profiles in the Fe map (not shown) were complementary to the $\mathrm{Mn}$ map. The primary particles identified were rich in $\mathrm{Nb}$ (likely $\mathrm{NbC}$ ) and Ti-Al-rich particles (likely a Ti-Al-O).

Two more slices ( $\sim 0.6 \mathrm{~cm}$ in thickness) were made from the weld, one being cut up for compositional analysis and the other cut for TEM sample preparation. In both cases, the cutting centered on the same weld pass as for samples C and D. Transmission electron microscopy revealed that many of the dendritic boundaries contain a widely varying distribution of metal carbides. In Figure 3.7, a single large chromium carbide was found along with numerous small $\mathrm{Nb}$ carbides in very close proximity. As shown in Figure 3.8, both $\mathrm{Cr}$ - and $\mathrm{Nb}$-rich carbides have precipitated along the dendritic boundaries. In some cases, Ti was found to coincide with the $\mathrm{Nb}$.

Samples were also cut from the edge of the alloy 152 weld in the "transition region" from the $304 S S$ to the buttering to the main weld. Optical examination of one of the samples that was etched revealed an altered microstructure in the 304SS. A narrow region appears to have been melted and a dilution zone was created between the Fe-base 304SS and the butter passes to the Ni-base alloy 152 material. No apparent difference in defects was noted compared to the main weld. Crack-growth samples have been machined to permit evaluation of SCC susceptibility in this transition zone. Future tests are planned on these materials. 


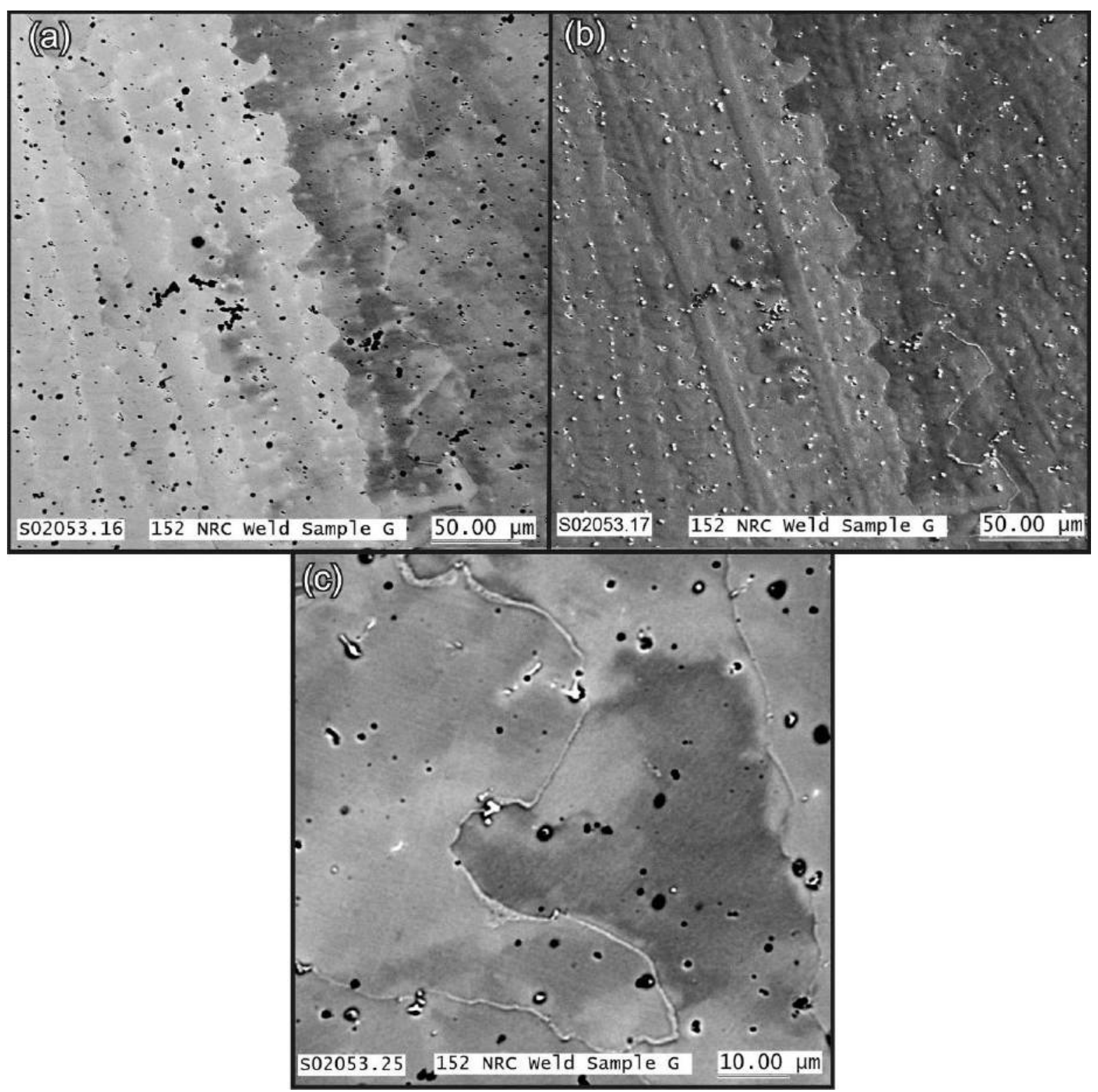

Figure 3.5 Scanning electron microscope images are shown from the alloy 152 weld metal. The image in (a) was taken using backscattered electrons, (b) and (c) were taken in secondary electron imaging mode. 

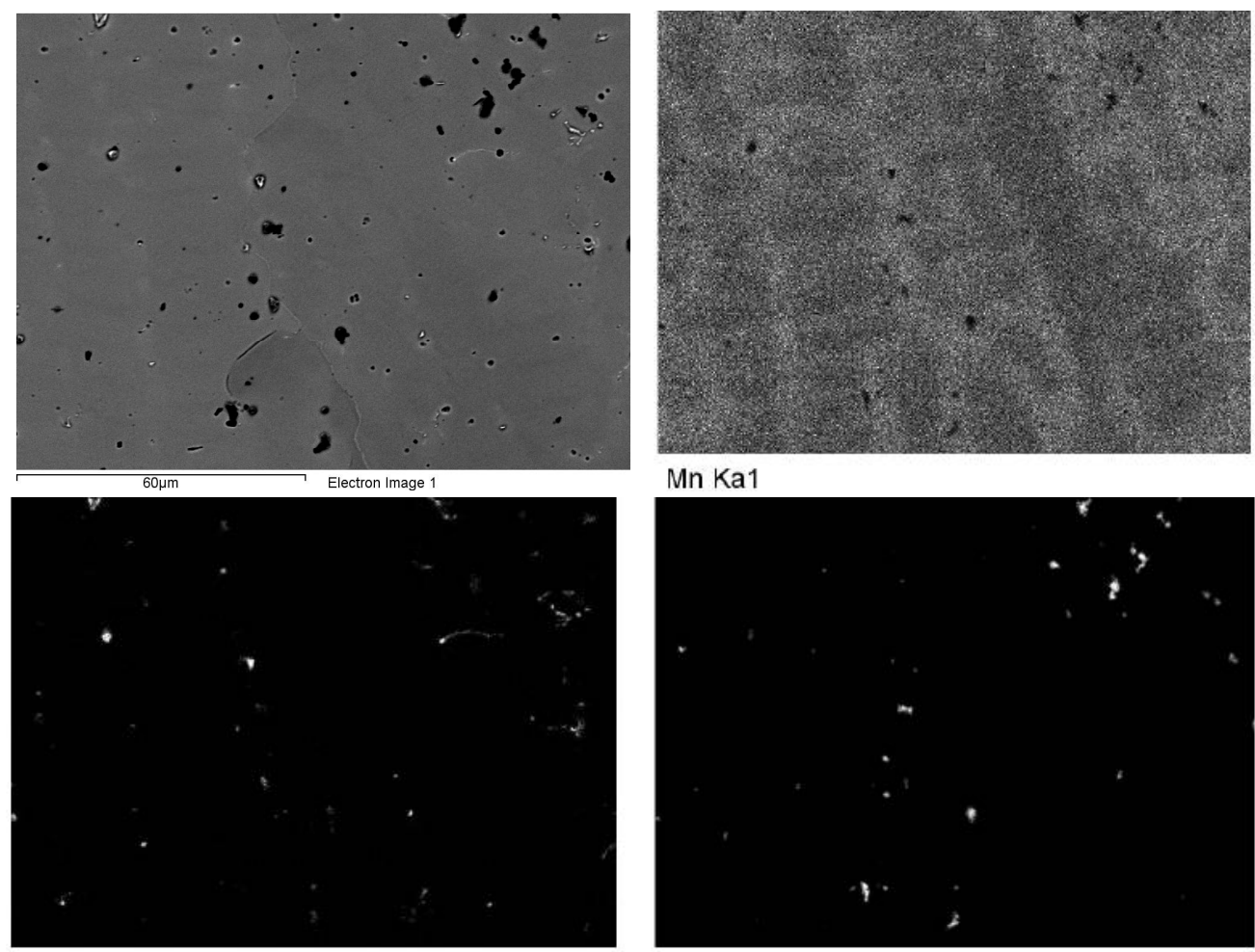

Mn Ka1

Nb La1

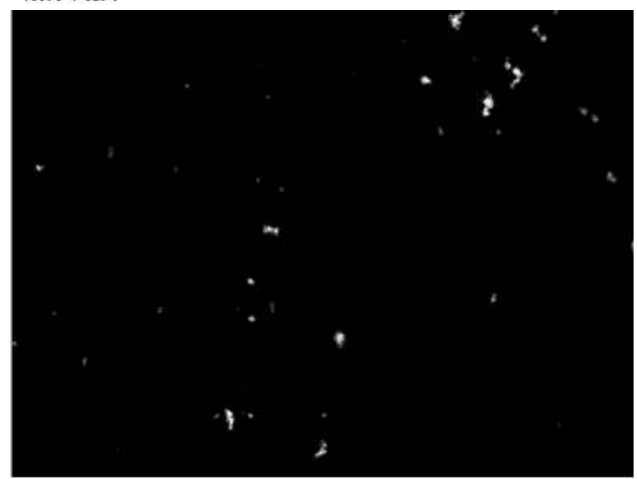

Al Ka1

Figure 3.6 SEM secondary-electron Image is shown along with composition maps for $\mathrm{Mn}, \mathrm{Nb}$ and $\mathrm{Al}$. The $\mathrm{Mn}$ map indicates a slight degree of coring and the other two maps show the locations of the large $\mathrm{NbC}$ and the Ti-Al particles in the microstructure.

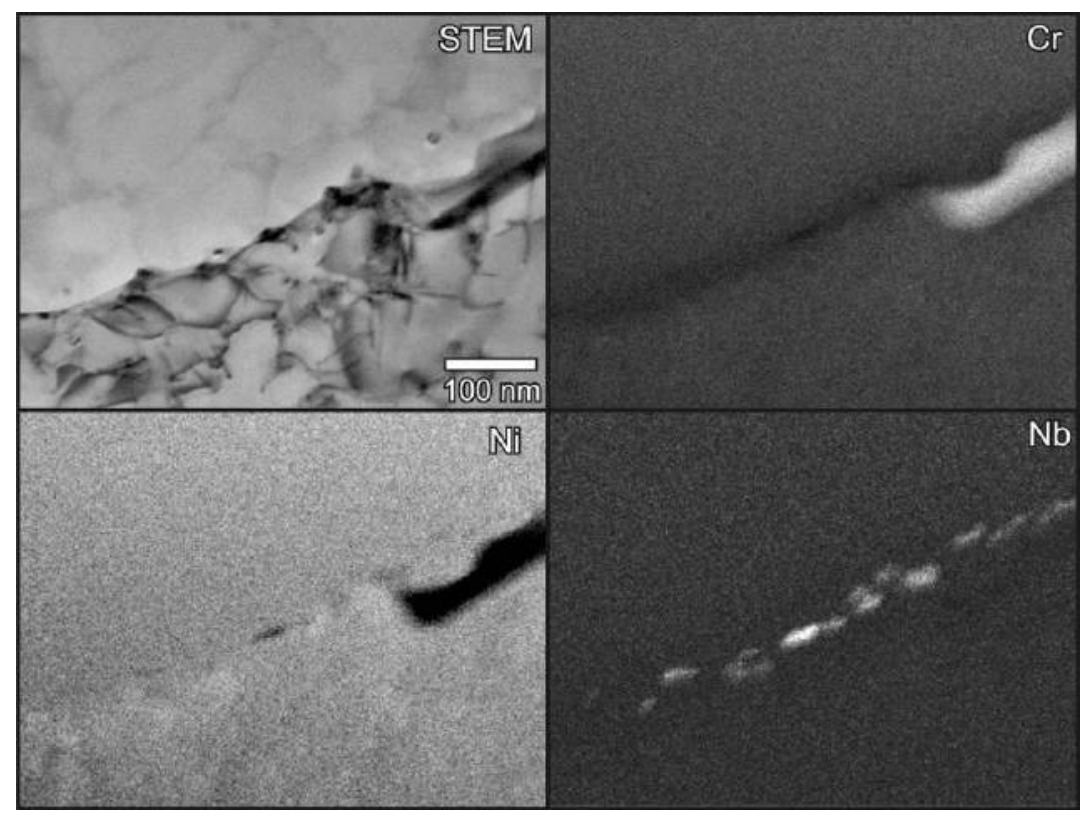

Figure 3.7 An example of a dendritic grain boundary that shows a single large $\mathrm{Cr}$ carbide, with numerous smaller $\mathrm{Nb}$ carbides along the boundary. In this case, $\mathrm{Ti}$ was not found associated with the $\mathrm{Nb}$ carbides. 


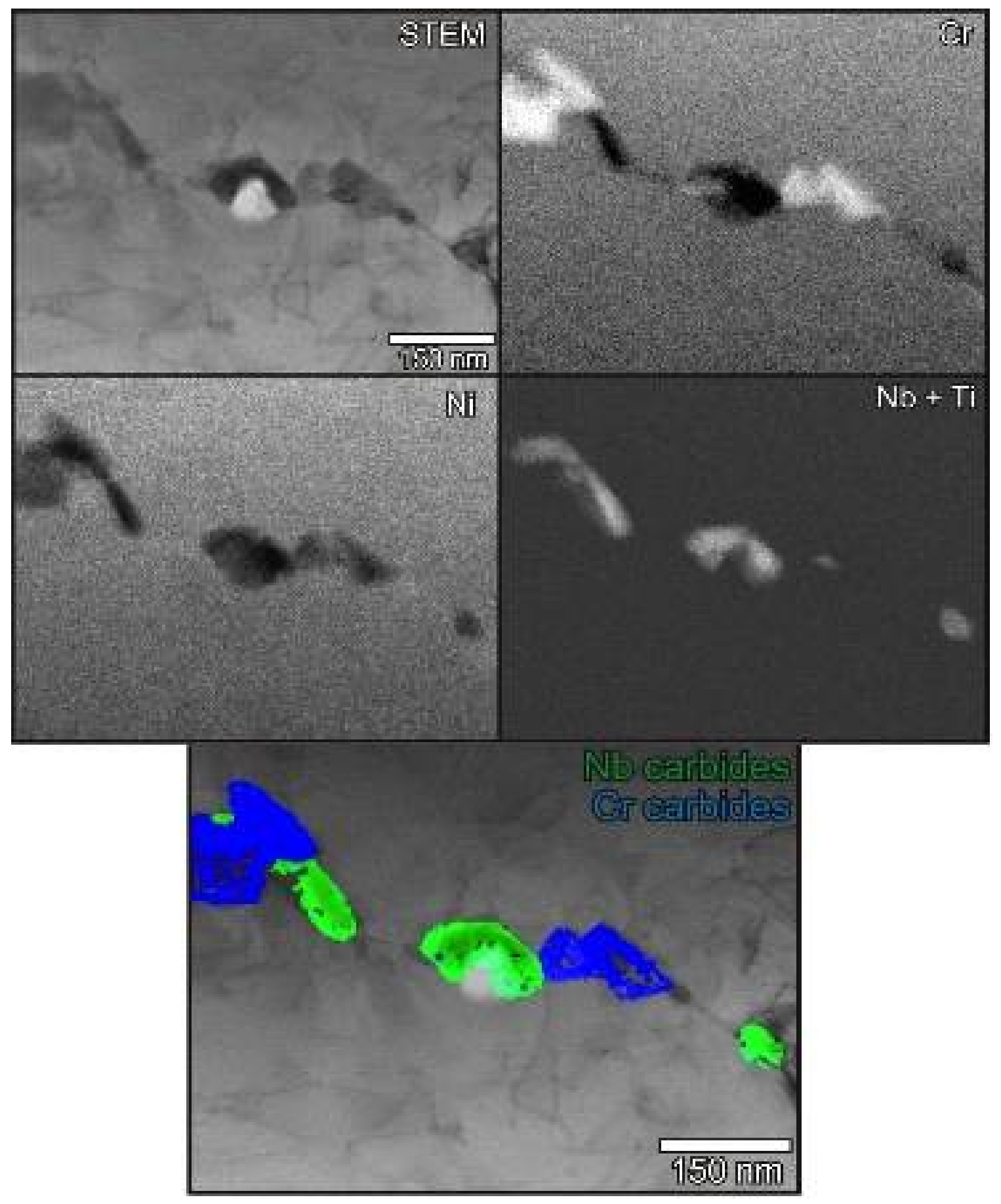

Figure 3.8 Compositional maps taken in STEM mode revealed that both $\mathrm{Cr}$ - and $\mathrm{Nb}$ rich carbides are present on the boundary between two dendrites. The bottom image reveals that the two carbide phases can sometimes be superimposed with each other. In this example, $\mathrm{Nb}$ and $\mathrm{Ti}$ were associated with the same particles. 


\section{MHI Alloy 152 Weld Samples (CT013, CT017 and CT018)}

The welds were tested in the as-welded (AW) condition with the exception of one test that was performed on an $\mathrm{MHI}$ alloy 152 weld that had been given a low-alloy steel (LAS) heat treatment of $610^{\circ} \mathrm{C}$ for $12 \mathrm{~h}$ followed by air cooling. Orientation of the specimens relative to the weld is shown in Figures 3.9. Specimens were machined from the blanks to target the desired crack growth path as was illustrated in Figure 3.3.

The first SCC crack-growth test was performed on a single CT specimen (CT013) of the MHI alloy 152 in the as-welded condition. Crack extension and transitioning were done in $325^{\circ} \mathrm{C}$ PWR primary water by cyclic loading at decreasing frequencies, with an $\mathrm{R}$ value of 0.7 , and a $\mathrm{K}$ of $30 \mathrm{MPa} \sqrt{\mathrm{m}}$. After $>500 \mathrm{~h}$ cycling at $0.001 \mathrm{~Hz}$, hold times of $2.5 \mathrm{~h}$ and then $24 \mathrm{~h}$ were added as shown in Figure 3.10. Extremely low, but stable crack growth rates were observed under these conditions decreasing to $3 \times 10^{-9} \mathrm{~mm} / \mathrm{s}$ after $\sim 1000 \mathrm{~h}$ for the $24 \mathrm{~h}$ hold. Constant $\mathrm{K}$ was established and the measured propagation rate gradually decreased to $<5 \times 10^{-10} \mathrm{~mm} / \mathrm{s}$ over the next few months. After $\sim 2200 \mathrm{~h}$ ( 3 months) at constant $\mathrm{K}$, the test was ended. A summary table of test conditions and corrected specimen response for each test phase is shown in Table 3.3. Post-test examination started by sectioning of the specimen to obtain a crack surface profile and then fatiguing the other piece of the CT specimen to expose the crack growth surface. The crack profile in Figure 3.11 shows that the crack growth direction was not as well aligned with the dendrites as appeared when marking the blank to cut the CT specimen. Nevertheless, regions of IG growth were found on the crack growth surface shown in Figure 3.12. The SEM images indicate that the IG cracking is on dendrite boundaries. The IG growth appeared to begin during the cycle + hold steps and the final crack front was $\sim 35 \%$ IG. Based on this degree of IG engagement, area-averaged propagation rates were determined and are reported in Figure 3.10. If only the maximum IG crack extension was considered, estimated local rates would be $\sim 5 \mathrm{X}$ higher or $\sim 1.5 \times 10^{-9} \mathrm{~mm} / \mathrm{s}$ at constant $\mathrm{K}$.

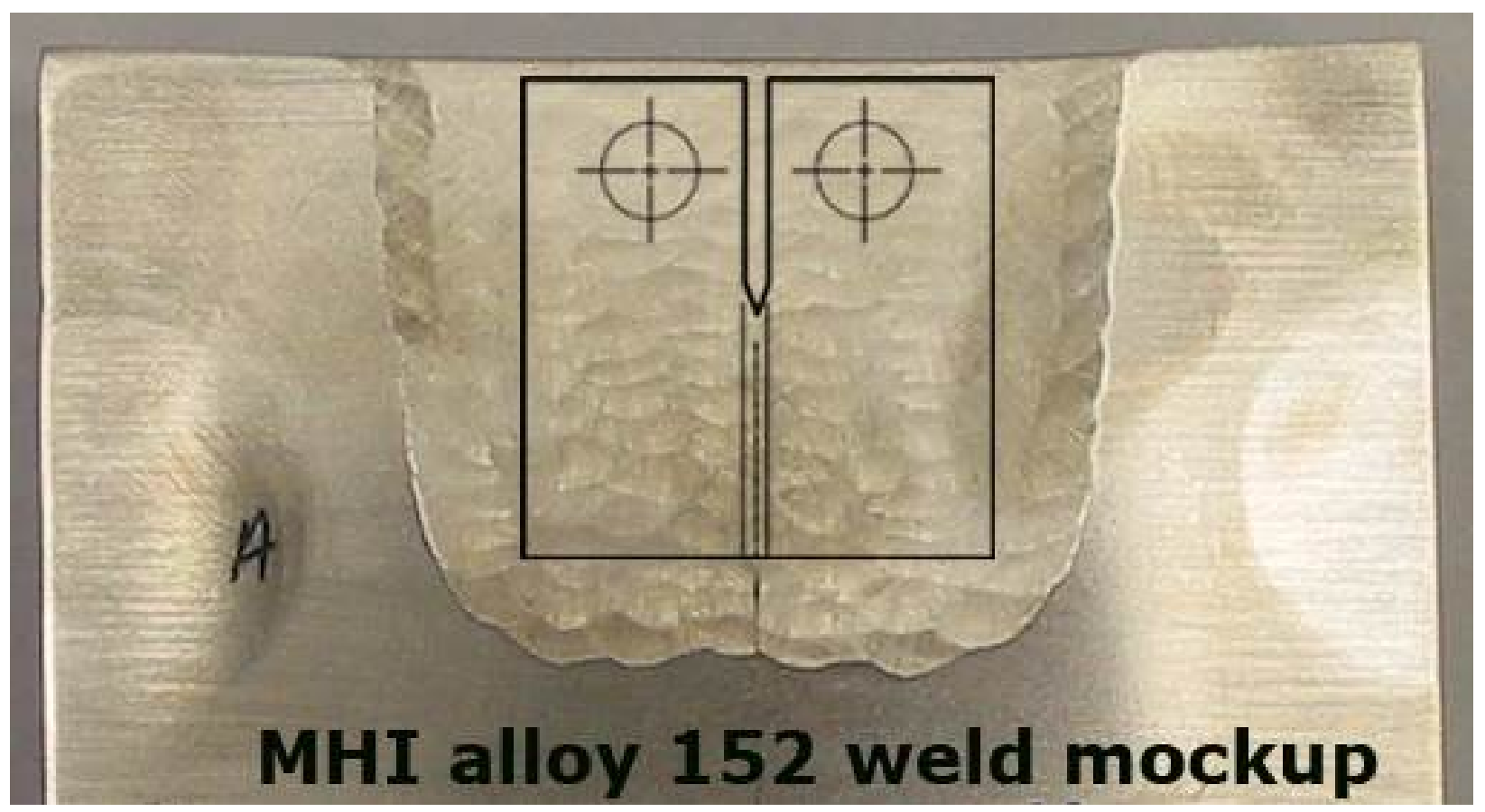

Figure 3.9 Image of $\mathrm{MHI}$ alloy 152 weld showing positioning of 0.5T CT specimens. 


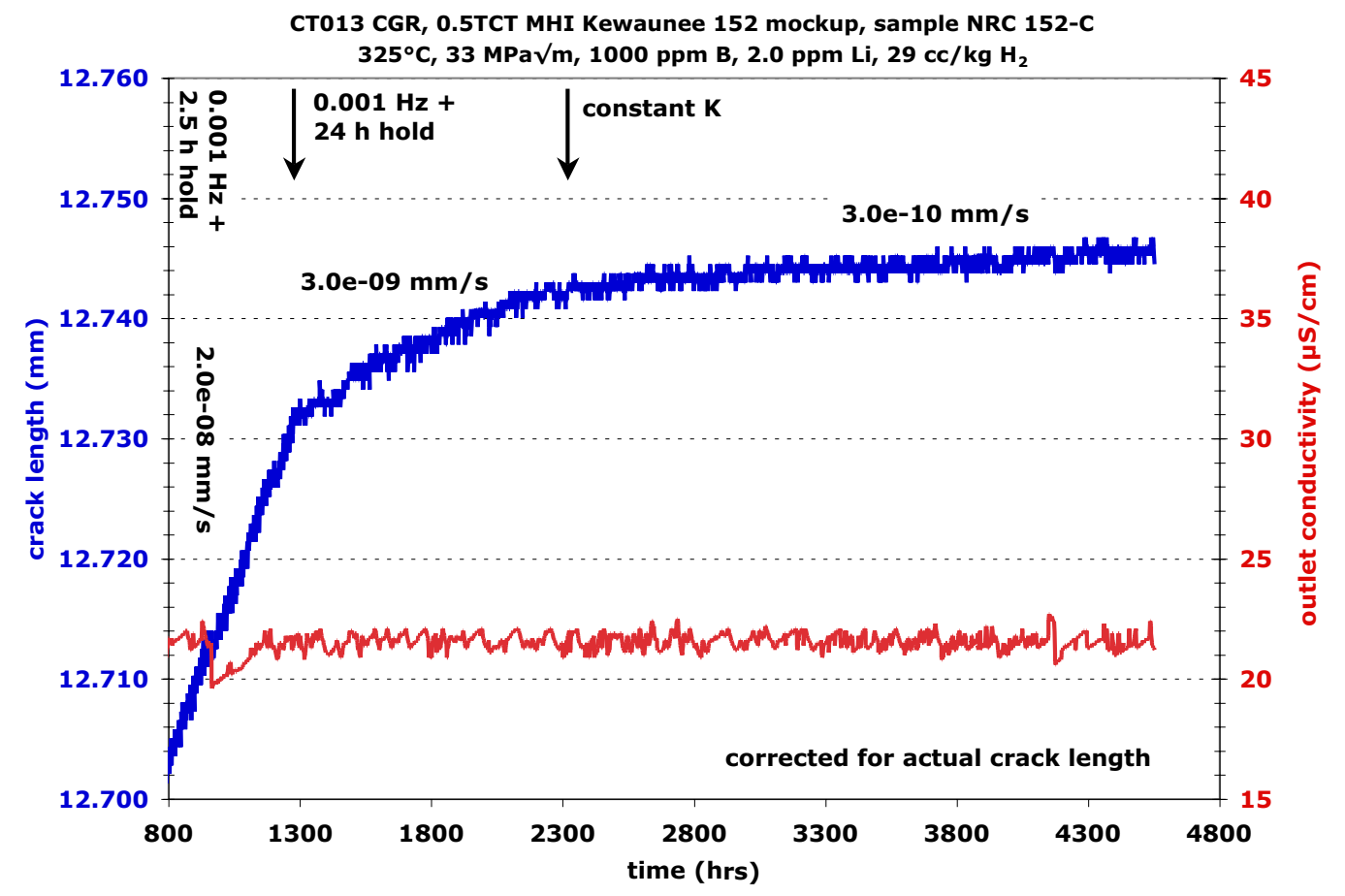

Figure 3.10 Crack growth response of MHI alloy 152 specimen СT013 during transitioning and constant $\mathrm{K}$ steps.

Table 3.3 Test conditions and corrected specimen response for $\mathrm{MHI}$ alloy 152 specimen CT013.

\begin{tabular}{|ccccccc|ccc|}
\hline $\begin{array}{c}\text { Test } \\
\text { Phase }\end{array}$ & $\begin{array}{c}\text { Duration } \\
(\mathrm{h})\end{array}$ & $\mathrm{R}$ & $\begin{array}{c}\text { Freq } \\
(\mathrm{Hz})\end{array}$ & $\begin{array}{c}\text { Hold } \\
(\mathrm{h})\end{array}$ & $\begin{array}{c}\text { Water } \\
\text { Chemistry } \\
\text { Conditions }\end{array}$ & $\begin{array}{c}\text { Temp } \\
\left({ }^{\circ} \mathrm{C}\right)\end{array}$ & $\begin{array}{c}\text { Kmax } \\
(\mathrm{MPa} \sqrt{\mathrm{m}})\end{array}$ & $\begin{array}{c}\text { Avg. } \\
\text { CGR } \\
(\mathrm{mm} / \mathrm{s})\end{array}$ & $\begin{array}{c}\text { Approx. } \\
\text { Crack } \\
\text { Extension } \\
(\mathrm{mm})\end{array}$ \\
\hline 1 & 8.1 & 0.3 & 1 & 0 & $29 \mathrm{cc} / \mathrm{kg} \mathrm{H}_{2}$ & 325 & 26 & $4.8 \mathrm{E}-05$ & 0.936 \\
2 & 4.4 & 0.5 & 1 & 0 & $29 \mathrm{cc} / \mathrm{kg} \mathrm{H}_{2}$ & 325 & 30 & $3.3 \mathrm{E}-05$ & 0.526 \\
3 & 4.6 & 0.6 & 1 & 0 & $29 \mathrm{cc} / \mathrm{kg} \mathrm{H}_{2}$ & 325 & 33 & $2.3 \mathrm{E}-05$ & 0.361 \\
4 & 6.8 & 0.7 & 1 & 0 & $29 \mathrm{cc} / \mathrm{kg} \mathrm{H}_{2}$ & 325 & 33 & $1.4 \mathrm{E}-05$ & 0.335 \\
5 & 26 & 0.7 & 0.1 & 0 & $29 \mathrm{cc} / \mathrm{kg} \mathrm{H}_{2}$ & 325 & 33 & $2.8 \mathrm{E}-06$ & 0.289 \\
6 & 161 & 0.7 & 0.01 & 0 & $29 \mathrm{cc} / \mathrm{kg} \mathrm{H}_{2}$ & 325 & 34 & $6.0 \mathrm{E}-07$ & 0.353 \\
7 & 552 & 0.7 & 0.001 & 0 & $29 \mathrm{cc} / \mathrm{kg} \mathrm{H}_{2}$ & 325 & 34 & $9.4 \mathrm{E}-08$ & 0.171 \\
8 & 520 & 0.7 & 0.001 & 2.5 & $29 \mathrm{cc} / \mathrm{kg} \mathrm{H}_{2}$ & 325 & 34 & $2.0 \mathrm{E}-08$ & 0.032 \\
9 & 855 & 0.7 & 0.001 & 24 & $29 \mathrm{cc} / \mathrm{kg} \mathrm{H}_{2}$ & 325 & 34 & $3.0 \mathrm{E}-09$ & 0.010 \\
10 & 2413 & --- & const K & --- & $29 \mathrm{cc} / \mathrm{kg} \mathrm{H}_{2}$ & 325 & 34 & $3 \mathrm{E}-10$ & 0.004 \\
\hline
\end{tabular}

The next two alloy 152 specimens were tested in series with one in the as-welded condition (CT018) and one given a low alloy steel (LAS) stress-relief heat treatment (CT017). Overall crack growth response is shown in Figure 3.13 with testing performed both at $350^{\circ} \mathrm{C}$ and at $50^{\circ} \mathrm{C}$. Unlike the CT013 test, shorter transitioning intervals were used with more emphasis on sampling the response of the material at several different regions in each specimen and on trying different methods to obtain a more engaged IG crack front. The transitioning conditions 
used in the first region of the specimen were identical to those in the first test on the MHI alloy 152 (CT013) with the exception of shorter duration. The initial crack growth during cycle + hold and constant $\mathrm{K}$ steps were essentially identical to that observed in the previous test (specimen CT013) as shown in Figure 3.14. Stable propagation rates were measured, and slowed to extremely low values under constant $\mathrm{K}$ conditions $\left(<5 \times 10^{-10} \mathrm{~mm} / \mathrm{s}\right)$. A second region of the alloy 152 microstructure was then evaluated by extending the crack $\sim 0.4 \mathrm{~mm}$ in both samples by moderate cycling.

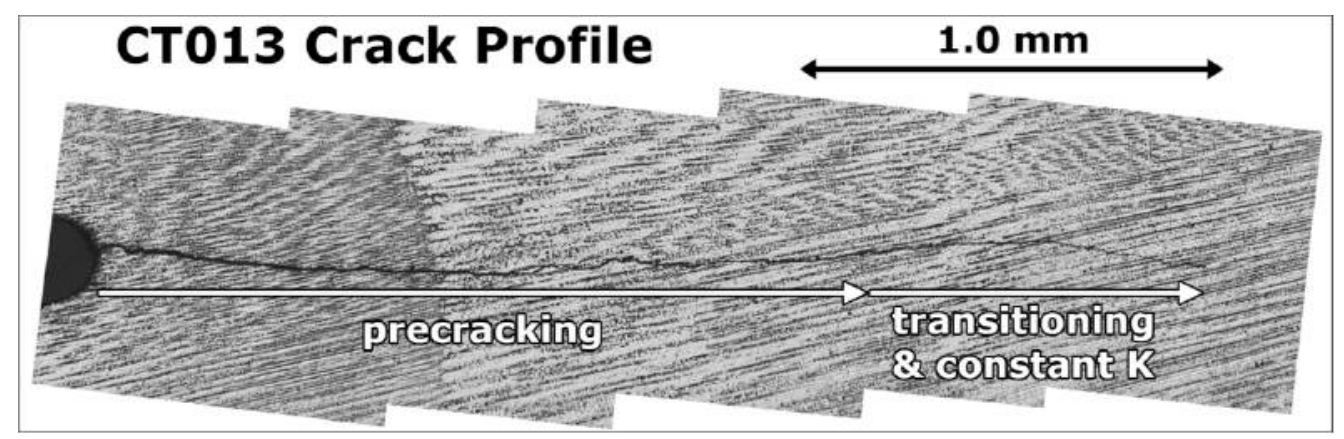

Figure 3.11 Side surface profile of MHI alloy 152 sample CT013 showing alignment of crack relative to dendrite structure.
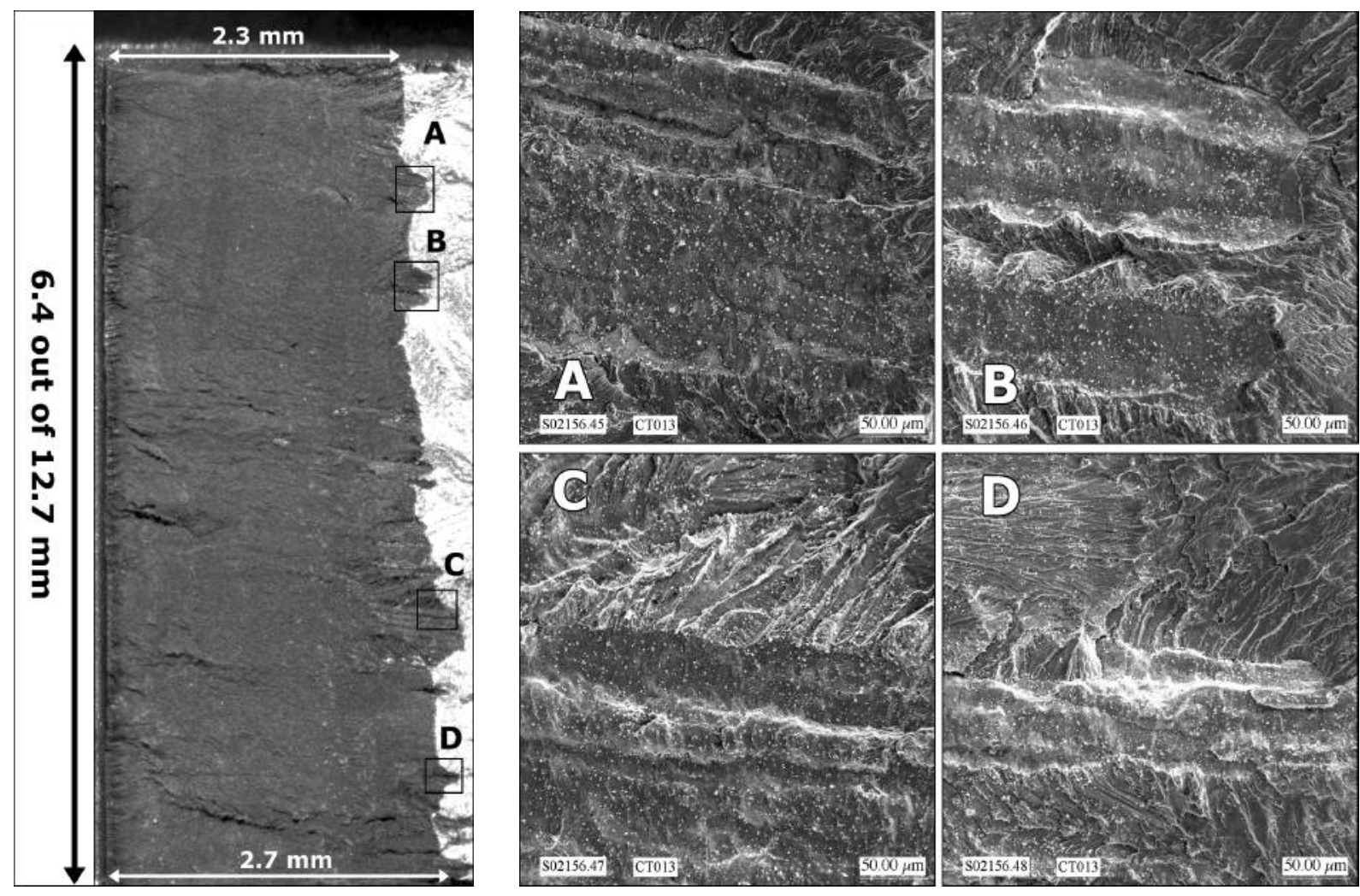

Figure 3.12 Crack growth surface of MHI alloy 152 specimen CT013. Optical image on left reveals local areas of SCC propagation and SEM images on right illustrate IG morphology. 


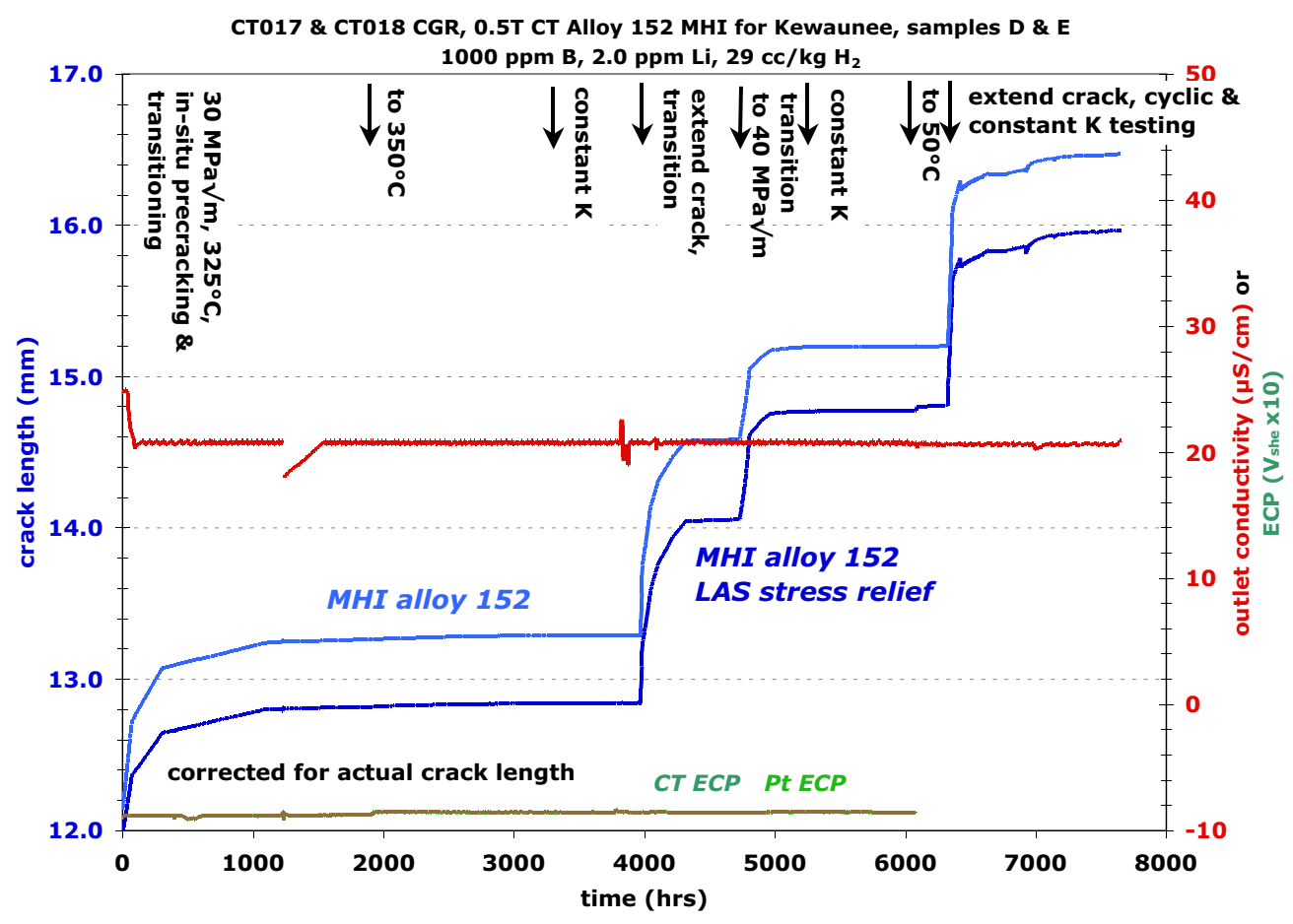

Figure 3.13 Overall crack growth response of MHI alloy 152 specimens CT017 \& CT018.

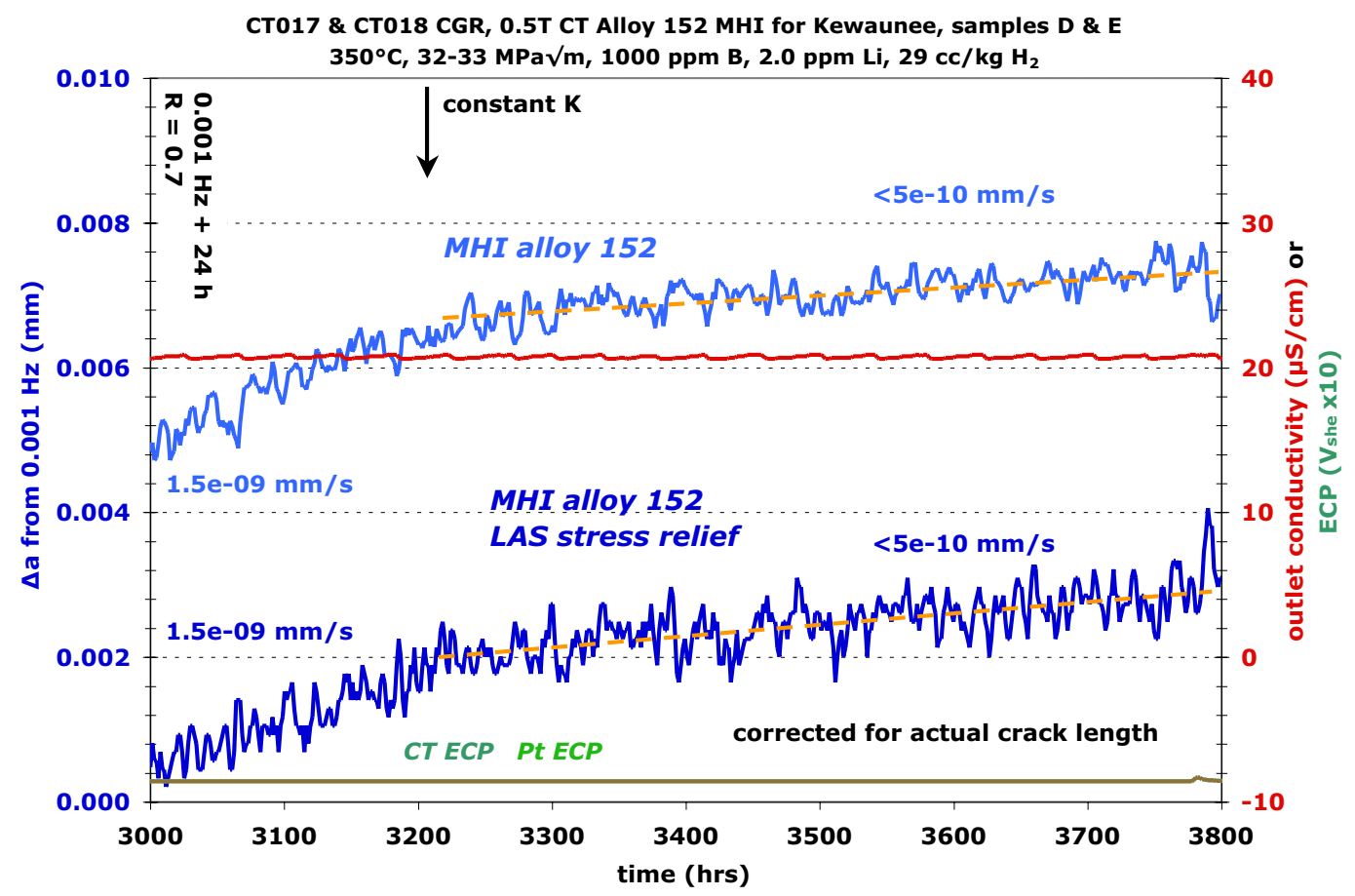

Figure 3.14 Constant $\mathrm{K}$ crack growth response of MHI alloy 152 specimens CT017 \& CT018 at $30 \mathrm{MPa} \sqrt{\mathrm{m}}$. 
An alternate SCC transitioning approach was then used with sawtooth waveforms during cycling with $R=0.5$, a $12 \mathrm{~s}$ unload, and increasingly longer reload time ranging from $300 \mathrm{~s}$ to $1000 \mathrm{~s}$. After $\sim 100 \mu \mathrm{m}$ of growth with the $1000 \mathrm{~s}$ reload time, the $\mathrm{R}$ value was then changed to 0.7 and a $2.5 \mathrm{~h}$ hold was added. Over $\sim 200 \mathrm{~h}$, the crack growth rate was observed to slowly decrease to a rate below $1 \times 10^{-8} \mathrm{~mm} / \mathrm{s}$ as shown in Figure 3.15. The load cycle was then converted from a sawtooth waveform to a $0.001 \mathrm{~Hz}$ symmetric waveform while maintaining the same $2.5 \mathrm{~h}$ hold time and $R$ value of 0.7 . As shown in Figure 3.15, no change in propagation rate occurred upon converting to the symmetric waveform, and the crack growth rate of $\sim 6 \times 10^{-9} \mathrm{~mm} / \mathrm{s}$ was slightly less than that observed when this same cycle + hold condition was used earlier in the test. Since no SCC enhancement was indicated during the cycle + hold loading, it was decided to investigate the crack growth response at a higher $\mathrm{K}$ of $40 \mathrm{MPa} \sqrt{\mathrm{m}}$. This was done for both specimens by extending the crack $0.4 \mathrm{~mm}$ using cyclic loading $(0.01 \mathrm{~Hz}, \mathrm{R}=0.6)$ and a $\mathrm{dK} / \mathrm{da}$ value of $100 \mathrm{MPa} \vee \mathrm{m} / \mathrm{mm}$. Based on post-test correction of the crack length, the actual $\mathrm{K}$ value was $\sim 48 \mathrm{MPa} \sqrt{\mathrm{m}}$ after the $\mathrm{dK} / \mathrm{da}$ transition. After switching to $0.001 \mathrm{~Hz}$ (symmetric waveform) and an $\mathrm{R}$ of 0.7 , propagation rates were evaluated after adding a $2.5 \mathrm{~h}$ hold and finally during constant $\mathrm{K}$ as shown in Figure 3.16. Crack growth rates were 3-4X higher than seen at lower $\mathrm{K}$ levels with values of $1.7-2.1 \times 10^{-8} \mathrm{~mm} / \mathrm{s}$ and $1.0-1.7 \times 10^{-9} \mathrm{~mm} / \mathrm{s}$ for the cycle + hold and constant $\mathrm{K}$ conditions, respectively.

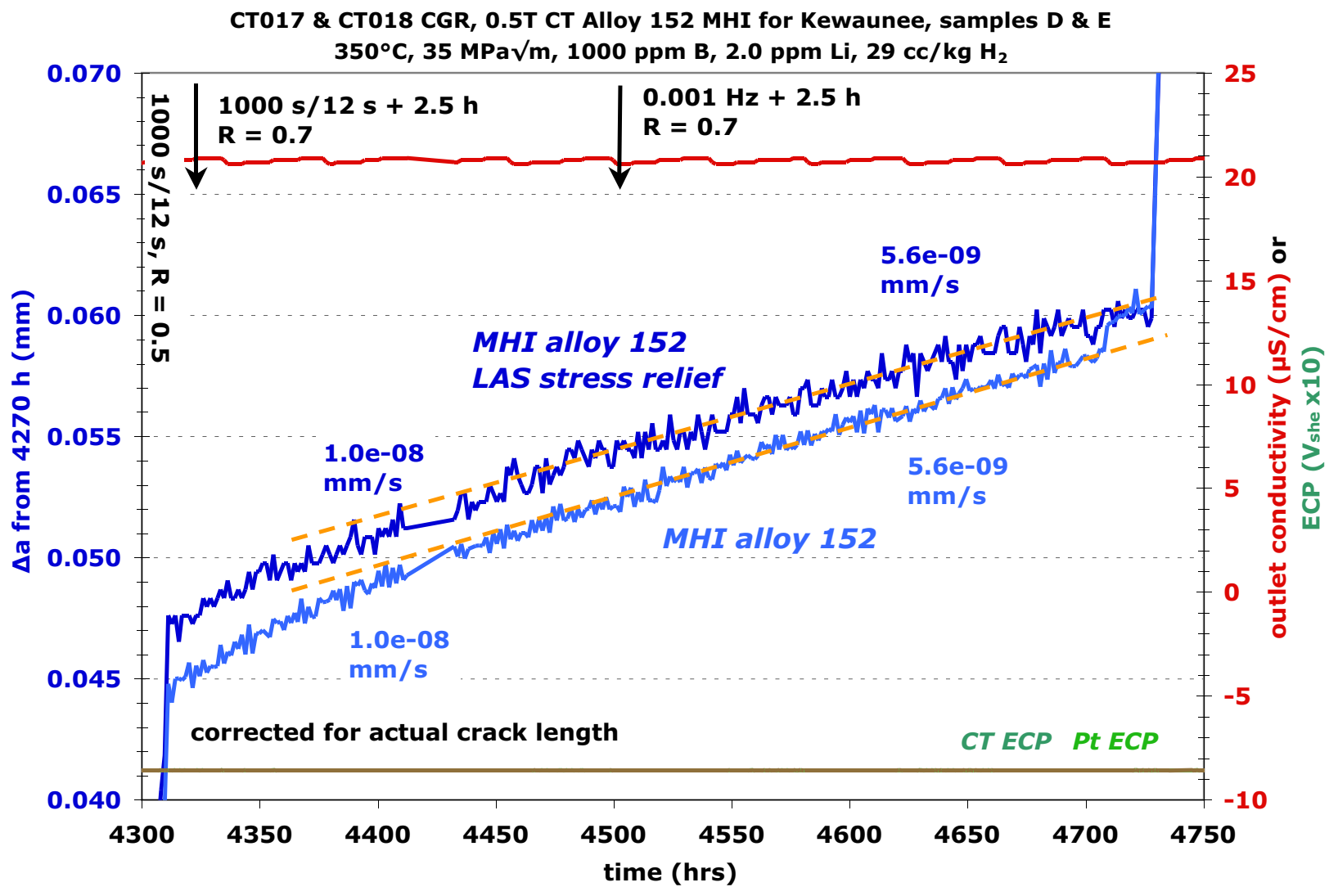

Figure 3.15 Crack growth response during cyclic loading conditions of $\mathrm{MHI}$ alloy 152 specimens CT017 \& CT018 at $\sim 33 \mathrm{MPa} \sqrt{\mathrm{m}}$ in the second microstructural region examined. 


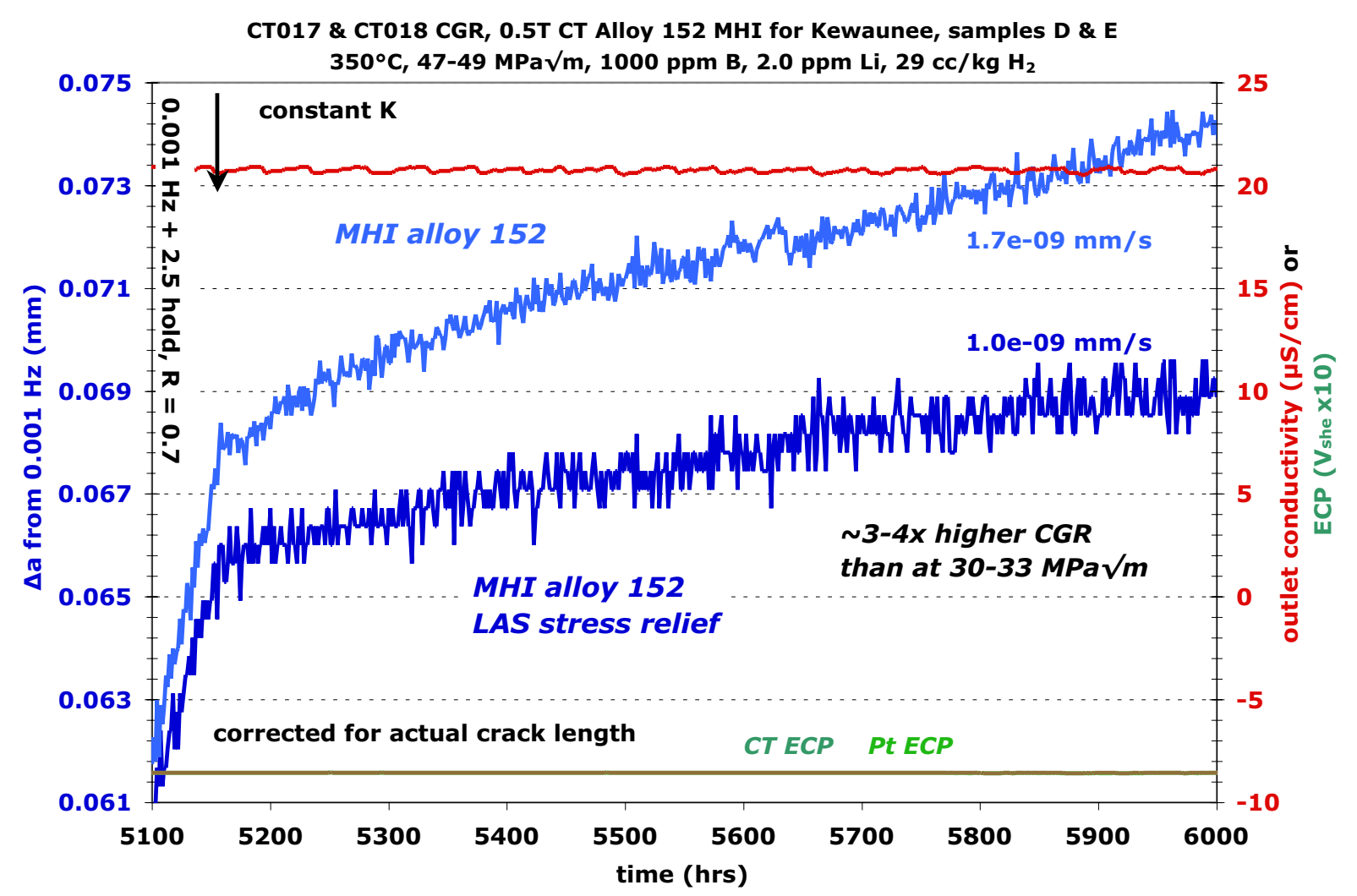

Figure 3.16 Constant $\mathrm{K}$ crack growth response of MHI alloy 152 specimens CT017 \& CT018 at $\sim 48 \mathrm{MPa} \sqrt{\mathrm{m}}$.

The final stage of the test examined crack-growth response at $50^{\circ} \mathrm{C}$ while maintaining PWR primary water chemistry conditions, including a dissolved hydrogen content of $29 \mathrm{cc} / \mathrm{kg}$. After extending the crack $\sim 1 \mathrm{~mm}$ by cycling at $0.01 \mathrm{~Hz}$, transitioning and constant $\mathrm{K}$ steps were performed as shown in Figure 3.17. The crack growth rates during cyclic and cycle + hold loading were found to be $\sim 2-3 \mathrm{X}$ greater than rates observed at $350^{\circ} \mathrm{C}$ at the same stress intensity value and cycling conditions. However when the test was converted to constant $\mathrm{K}$, the crack in both specimens ceased growing entirely, and when cyclic loading conditions were reestablished, crack growth resumed. The test was later converted to constant $\mathrm{K}$ again with the no crack advance. This suggests that dynamic strain during cycling is required for environmentassisted propagation at this low temperature.

One of the characteristic features of the crack growth response at $50^{\circ} \mathrm{C}$ was a relatively large systematic variation in the DCPD-measured crack length during low frequency cyclic loading. To better assess the cause of this, the DCPD response was examined in detail during cycle + hold loading conditions as shown in Figure 3.18. Large spikes in the DCPD-measured crack length were found to occur at the onset of each load cycle with the crack length decaying rapidly to a value slightly higher than existed prior to the load cycle. The spikes in the crack extension are clearly not a real phenomenon, but each load cycle does produce a small increment in crack length. The lack of growth during the hold time is consistent with the constant $\mathrm{K}$ response. It is thought that the spikes in crack length are due to the formation (during constant $\mathrm{K}$ loading) and destruction (during cycling) of "conducting" bridges behind the crack front. These bridges may form in the crack wake due to the electrochemical conditions of the PWR primary water at $50^{\circ} \mathrm{C}$ 
where Ni metal is stable. Enhanced electronic conduction across the crack will result in DCPD underestimating the actual crack length. Dynamic deformation during load cycling is apparently sufficient to break the bridges resulting in an immediate increase in DCPD-measured crack length. However, the bridges across the crack quickly reform once the cycle is complete.

As a final phase of the test, the air fatigue crack growth rate at $50^{\circ} \mathrm{C}$ of these specimens was measured and found to be 3-4X lower than in PWR primary water at the same temperature, further demonstrating that propagation at $50^{\circ} \mathrm{C}$ was an environment-assisted process. A summary of test conditions and corrected response of both specimens for each phase of the entire test is shown in Table 3.4. The specimens were then fatigue fractured in air to expose the crack growth surfaces. An optical image highlighting the crack growth surface created during high temperature testing is shown in Figure 3.19. Lines on the surface separate different phases of the tests. Regions of IGSCC are apparent, especially at the final high temperature crack front with the higher $\mathrm{K}$ level. SEM images in Figure 3.20 better illustrate the degree of IG engagement with the final crack front at $350^{\circ} \mathrm{C}$ having about $40 \%$ IG engagement. Somewhat surprisingly, more than $90 \%$ IG engagement was found to occur during the crack growth testing at $50^{\circ} \mathrm{C}$. This $I G$ growth is consistent with the higher crack growth rates observed during cycling loading of the specimens at $50^{\circ} \mathrm{C}$ in water.

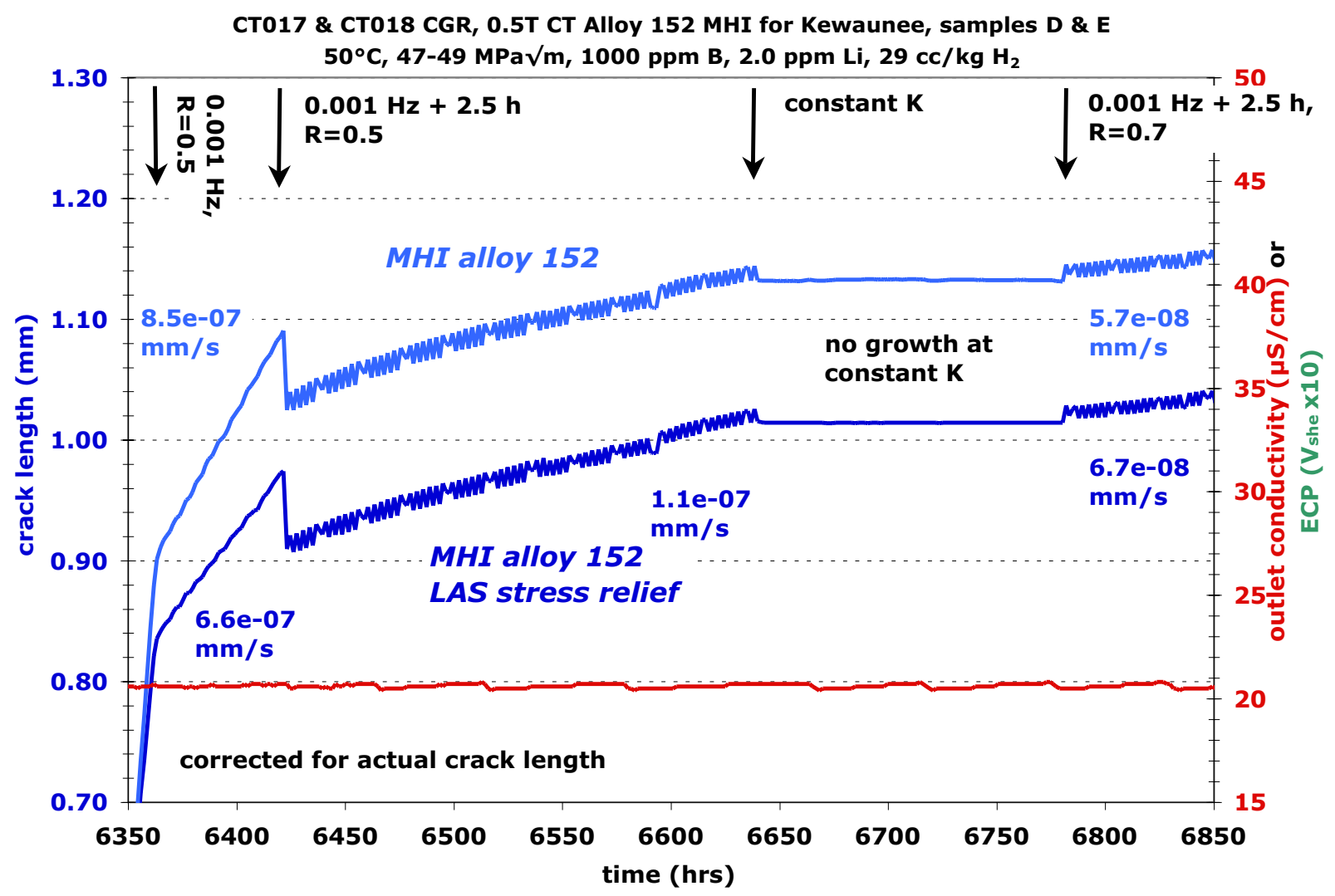

Figure 3.17 Crack growth response of MHI alloy 152 specimens CT017 \& CT018 at $50^{\circ} \mathrm{C}$ in simulated PWR primary water. 


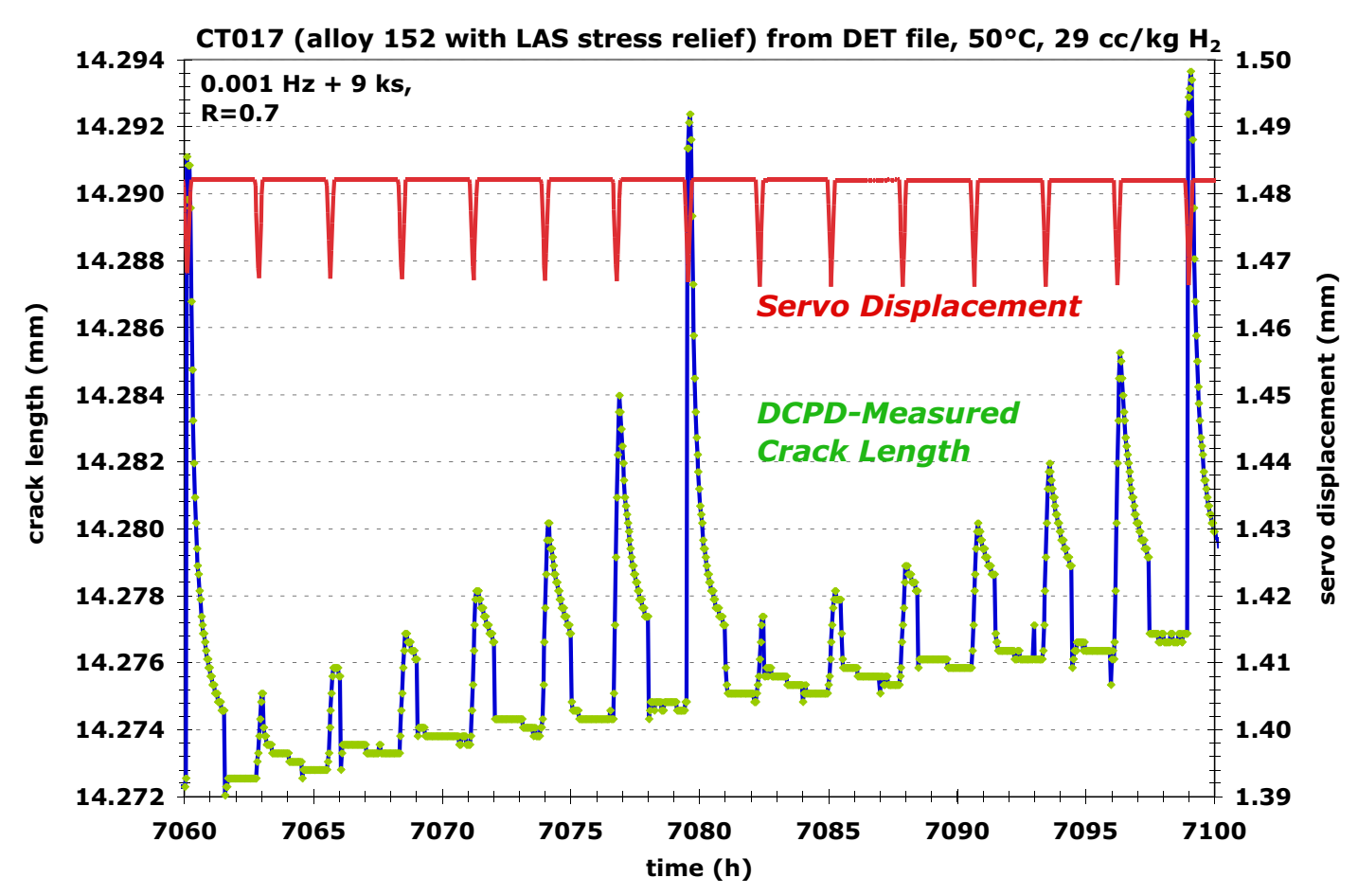

Figure 3.18 Detail plot showing DCPD measured crack growth response during cycle + hold loading conditions at $50^{\circ} \mathrm{C}$ in $\mathrm{MHI}$ alloy 152 specimen CT017.

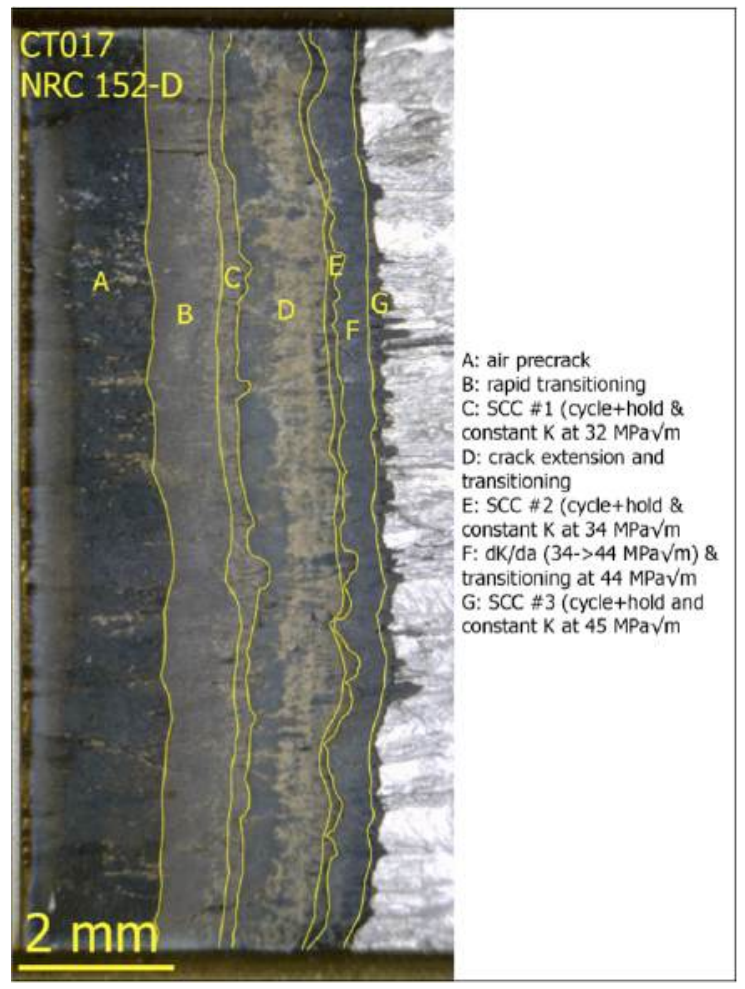

Figure 3.19 Optical image of high temperature crack growth surface of the MHI alloy 152 specimen CT017. 
Table 3.4 Summary of test conditions and corrected response of $\mathrm{MHI}$ alloy 152 specimens CT017 \& CT018.

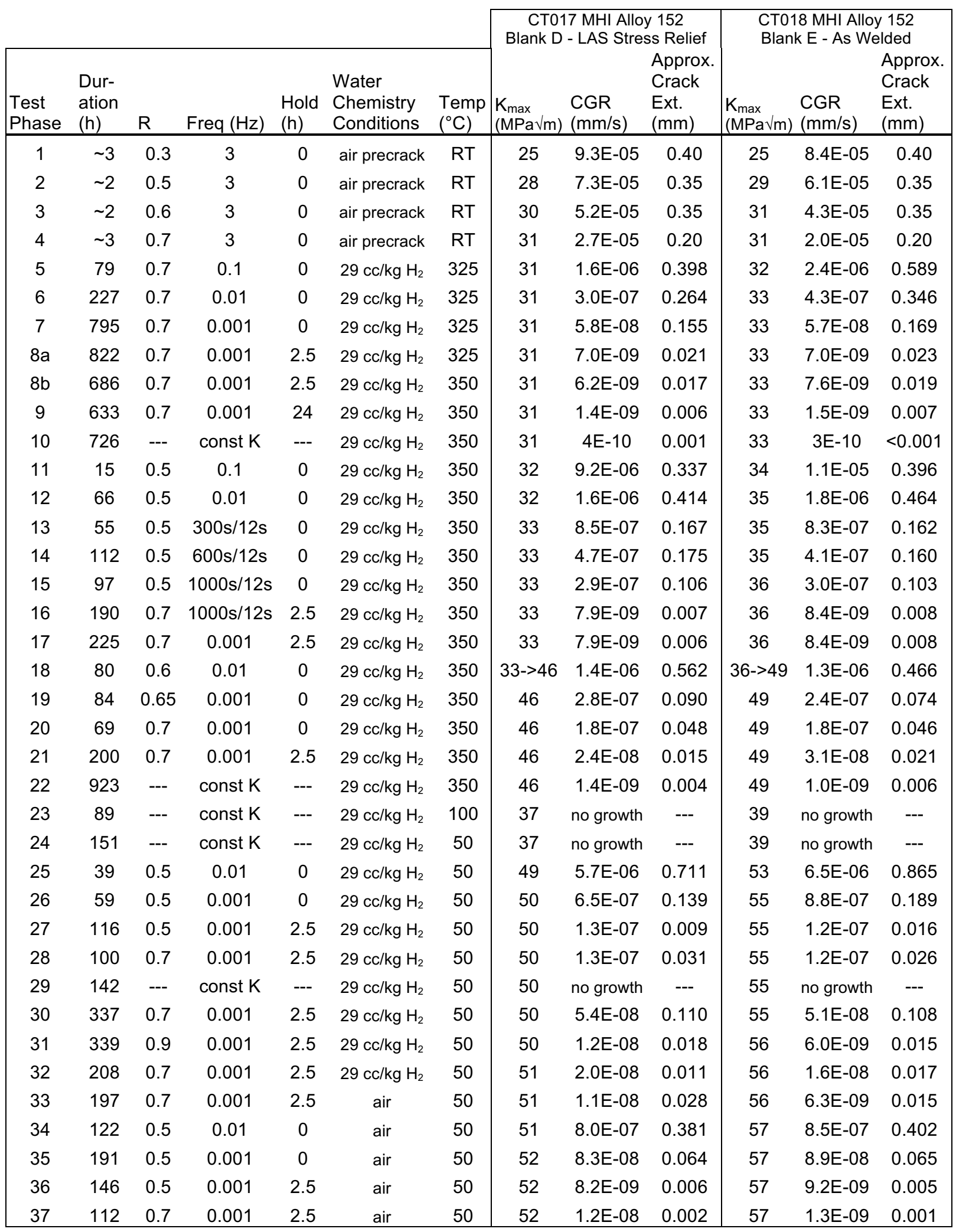



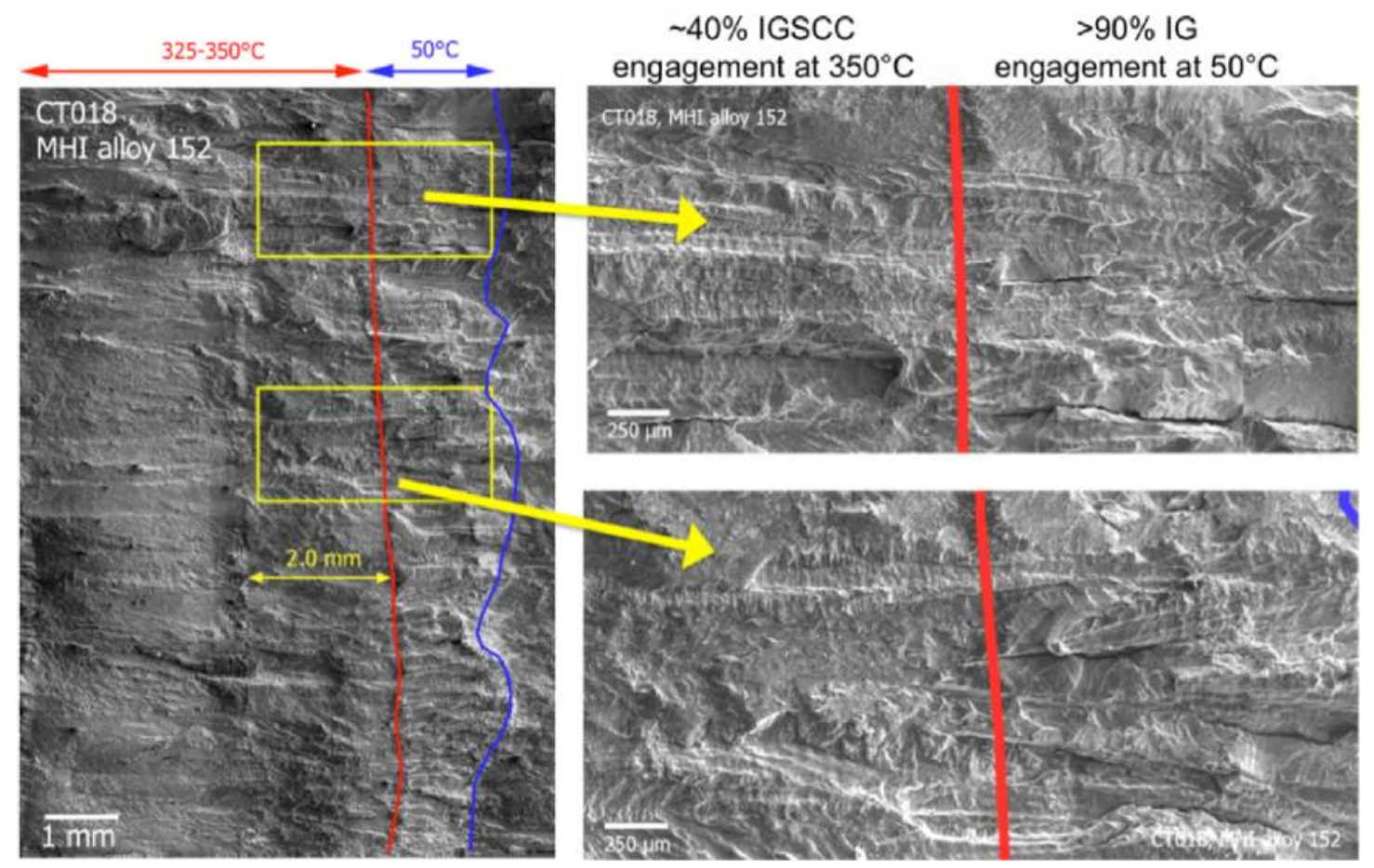

Figure 3.20 SEM images of $350^{\circ} \mathrm{C}$ and $50^{\circ} \mathrm{C}$ crack growth surfaces in $\mathrm{MHI}$ alloy 152 specimen CT018.

\subsection{Alloy 52 Welds}

For the $\mathrm{MHI}$ alloy 52 weld, alloy 152 (heat 307380) was buttered onto the U-groove surface by SMAW, while alloy 52 (heat NX2686JK) was used as the filler and applied by gas tungsten arc welding (GTAW). Welding parameters for the MHI alloy 52 GTAW consisted of a deposition speed of 4-10 $\mathrm{cm} / \mathrm{min}$ and a current of 150-300 amps. Welding parameters for the AREVA alloy 52 butt weld were not provided.

\section{Alloy 52 Weld Samples (CT024, CT025, CT032 and CT033)}

Duplicate tests have been performed on two alloy 52 welds, one made by AREVA (CT024 and CT032) and the other made by MHI (CT025 and CT033). Orientations of these specimens relative to the welds are shown in Figure 3.21. Before machining specimens, the blanks were etched to allow viewing the weld morphology, and a desired crack growth path through specific weld passes was determined. Specimens were again machined from the blanks to target the desired crack growth path, for example, as shown in Figure 3.3.

Two tests were performed with an AREVA alloy 52 sample paired with an MHI alloy 52 sample in both tests. An overview of the first test is shown in Figure 3.22 with CT024 being the AREVA material and CT025 being the $\mathrm{MHI}$ material. The test can be broken up into three phases. The first two phases evaluated crack growth response during transitioning and constant $\mathrm{K}$ at $350^{\circ} \mathrm{C}$ at two different regions in the specimens while the third phase of the test examined the $350^{\circ} \mathrm{C}$ constant $\mathrm{K}$ crack growth response after extending the crack by cyclic loading at $50^{\circ} \mathrm{C}$. This unusual transitioning method was based on the high degree of IG engagement observed in the $\mathrm{MHI}$ alloy 152 specimens during cyclic loading at $50^{\circ} \mathrm{C}$. 

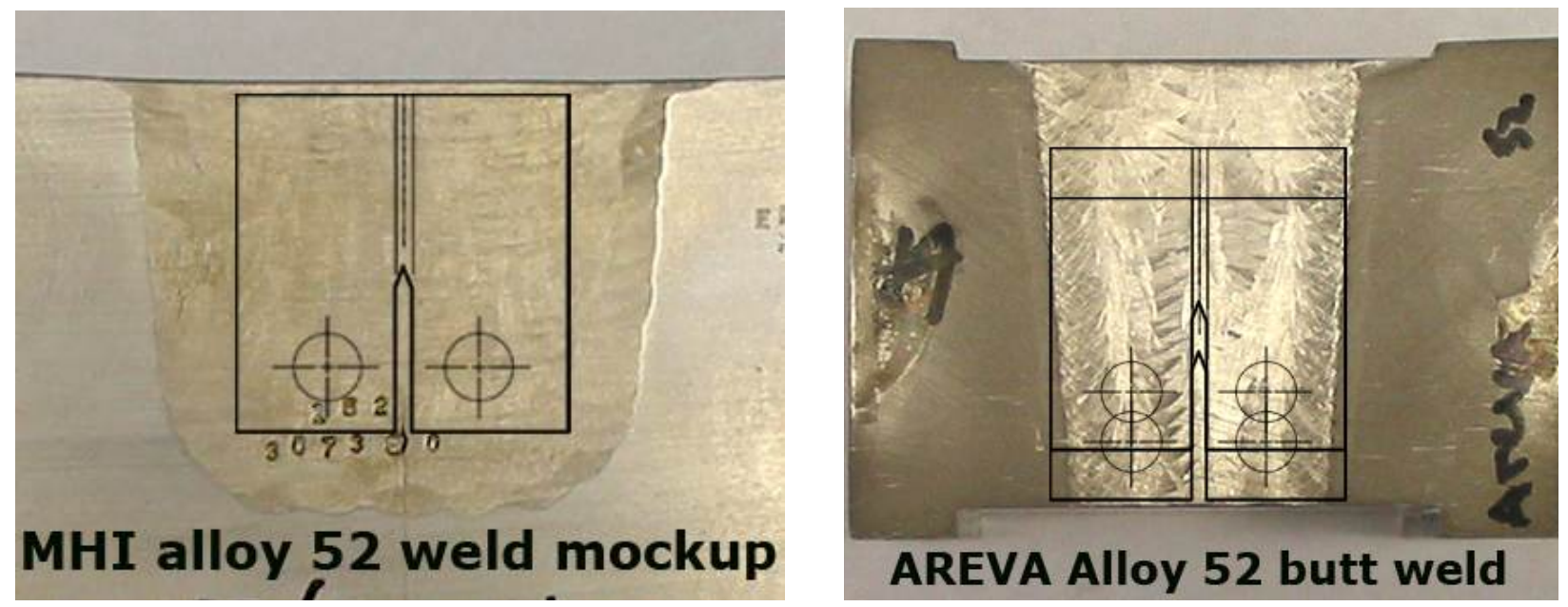

Figure 3.21 Image of the MHI alloy 52 and AREVA alloy 52 welds showing positioning of the $0.5 \mathrm{~T}$ CT specimens.

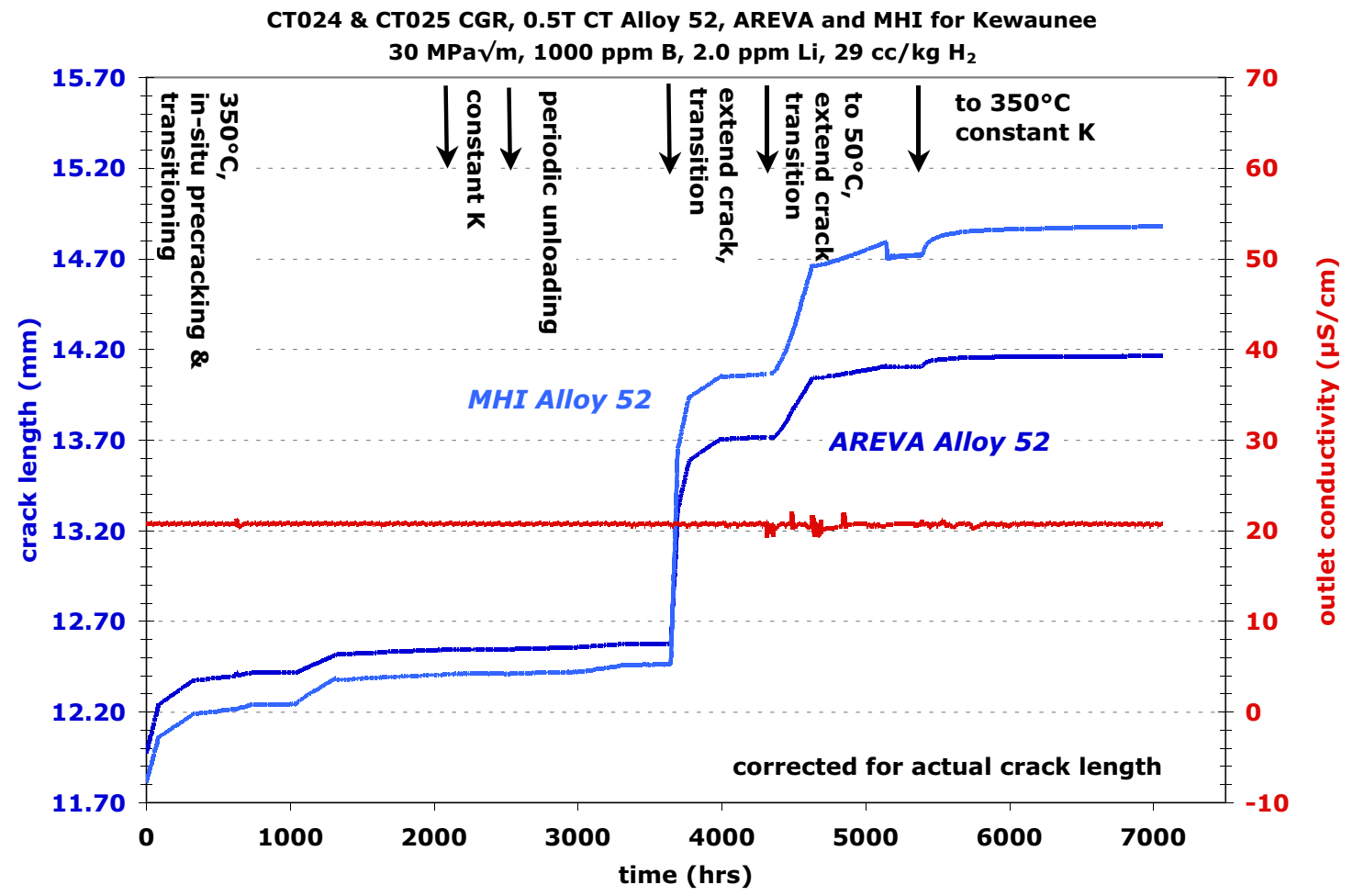

Figure 3.22 Overview of the crack growth response of two alloy 52 welds, one made by AREVA (CT024) and one made by MHI (CT025).

In the first region that was evaluated, crack growth rates during cycle + hold loading with $\mathrm{R}=0.7$ were found to be a factor of 2-5X lower than transitioning crack growth rates in the MHI alloy 152 specimens from previous tests. Additional transitioning steps were applied using an $\mathrm{R}=0.5$ and crack growth rates increased, however propagation rates in the alloy 52 specimens remained a factor of $\sim 2 X$ lower than for the alloy 152 specimens under equivalent gentle load 
cycling. Cycle + hold and constant $\mathrm{K}$ response was then determined as presented in Figure 3.23. The crack growth rate during the extended time at cycle + hold loading was very linear with no suggestion of any change in the degree of engagement. At approximately $2130 \mathrm{~h}$, the loading conditions were set to constant $\mathrm{K}$ and no crack advance was measured over a period of approximately 500 hours. Transitioning was reinitiated using a series of different hold times and periodic unloading steps, but none gave any indication of an increase in engagement, and it was decided to advance the crack in the specimens to a new region. Using moderate cyclic loading conditions, the crack in each specimen was advanced over $0.5 \mathrm{~mm}$, and transitioning was initiated using symmetric waveforms with $R=0.5$. Propagation rates during subsequent cycle + hold conditions were found to be only slightly higher $(40 \%$ higher with rates of $\sim 1.4 \times 10^{-8} \mathrm{~mm} / \mathrm{s}$ ) than the rates observed in the previous region suggesting that constant $\mathrm{K}$ crack growth rate for the specimens would again be well below $1 \times 10^{-9} \mathrm{~mm} / \mathrm{s}$.

For the final phase of the test, transitioning at $50^{\circ} \mathrm{C}$ was performed. In an attempt to generate an engaged IG crack front in the alloy 52 specimens, it was decided to perform similar cycling at $50^{\circ} \mathrm{C}$ in PWR primary water as was done for the alloy 152 specimens where extensive IG cracking was observed. The crack growth response of the alloy 52 specimens at $50^{\circ} \mathrm{C}$ is shown in Figure 3.24.

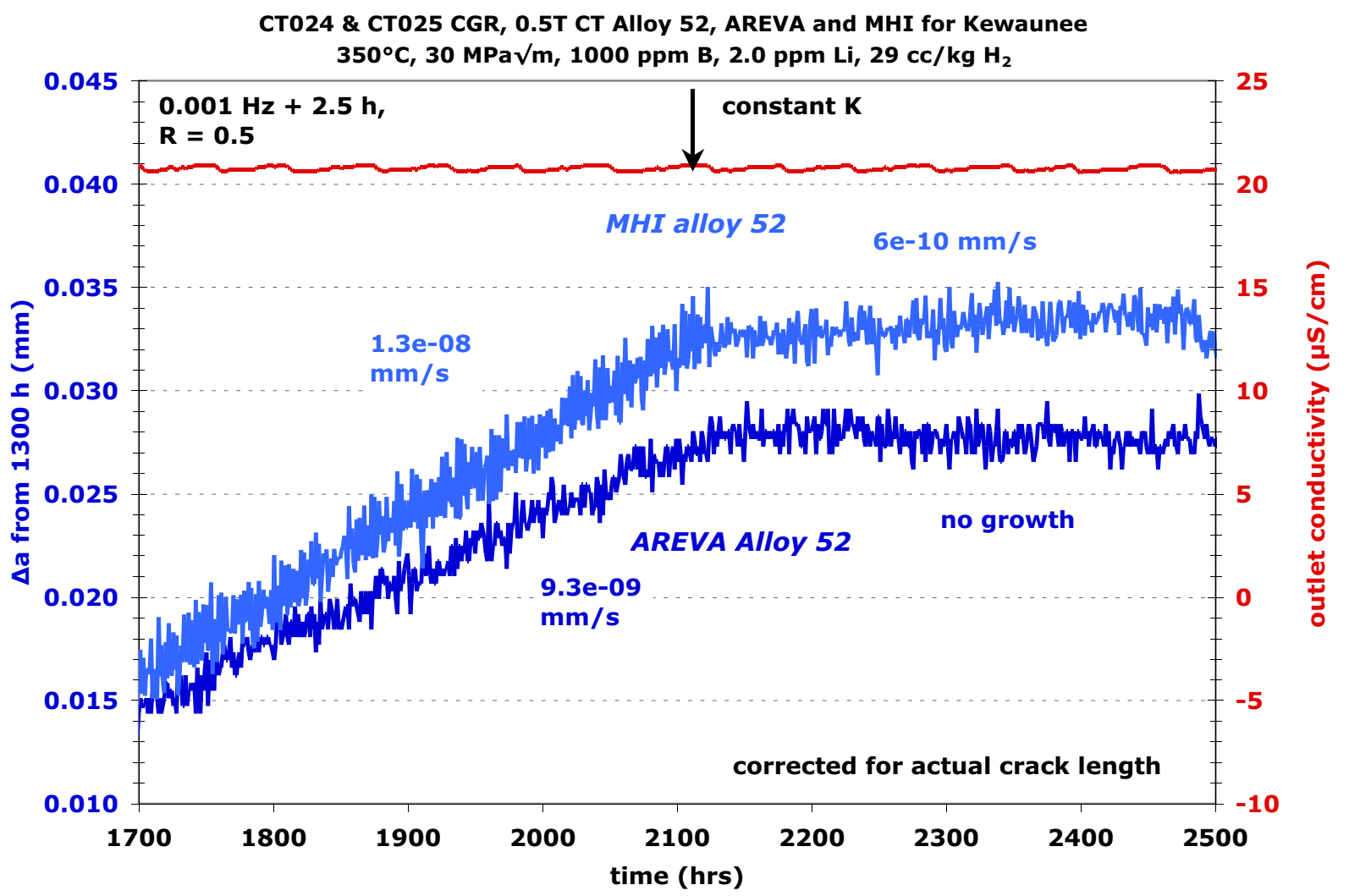

Figure 3.23 Cycle + hold and constant $\mathrm{K}$ response of the AREVA and $\mathrm{MHI}$ alloy 52 specimens (CT024 \& CT025) in the second region of each specimen that was examined. 
While an increase in propagation rate with time during $0.001 \mathrm{~Hz}$ step is suggestive of an improvement in engagement, the crack growth rate in each of the three cyclic loading steps was consistently lower than the rates observed at $350^{\circ} \mathrm{C}$ and much lower than measured for the alloy 152 specimens under equivalent cycling conditions. After $\sim 1000$ hours of crack extension at $50^{\circ} \mathrm{C}$, the loading was converted to constant $\mathrm{K}$, and the test temperature was brought back up to $350^{\circ} \mathrm{C}$. DCPD fluctuations were allowed to settle out for $24 \mathrm{~h}$ before crack length measurements were resumed. The resulting crack length with time response at $350^{\circ} \mathrm{C}$ is shown in Figure 3.25. As can be seen, very high initial crack growth rates in excess of $1 \times 10^{-7} \mathrm{~mm} / \mathrm{s}$ were observed. Over the next 1400 hours (2 months), the propagation rates slowly decreased reaching levels below $1 \times 10^{-9} \mathrm{~mm} / \mathrm{s}$ similar to earlier high-temperature constant $\mathrm{K}$ response for these specimens. The high initial DCPD-measured growth rates is possibly due to the disruption of conducting bridges across the cracks formed at low temperatures and during the temperature increase to $350^{\circ} \mathrm{C}$. As noted previously, electrochemical conditions are very Ni-metal stable at $50^{\circ} \mathrm{C}$ and move closer to the $\mathrm{Ni} / \mathrm{NiO}$ potential as the temperature is increased. The increase in DCPD-measured crack length may be due to oxidation or creep-induced fracture of these bridges in the crack at high temperature. It was not possible to separate this process from actual propagation, but it appears likely that the final constant $\mathrm{K}$ rates after 2 months are more representative of SCC growth rates. A summary of test conditions and corrected specimen response for each phase of the test is shown in Table 3.5.

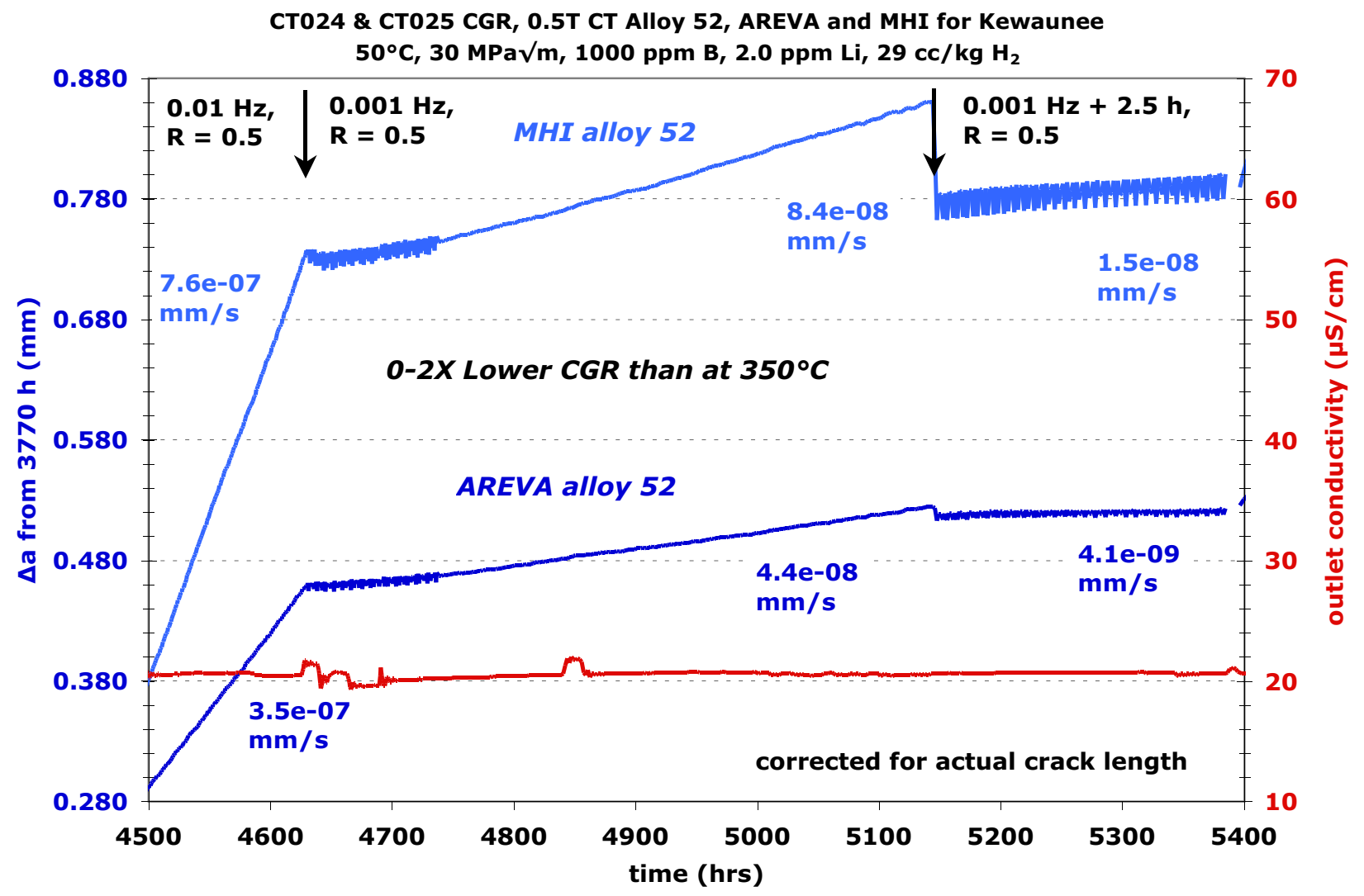

Figure 3.24 Overview of the crack growth response of the AREVA and MHI alloy 52 specimens (CT024 \& CT025) during cyclic loading conditions at $50^{\circ} \mathrm{C}$. 


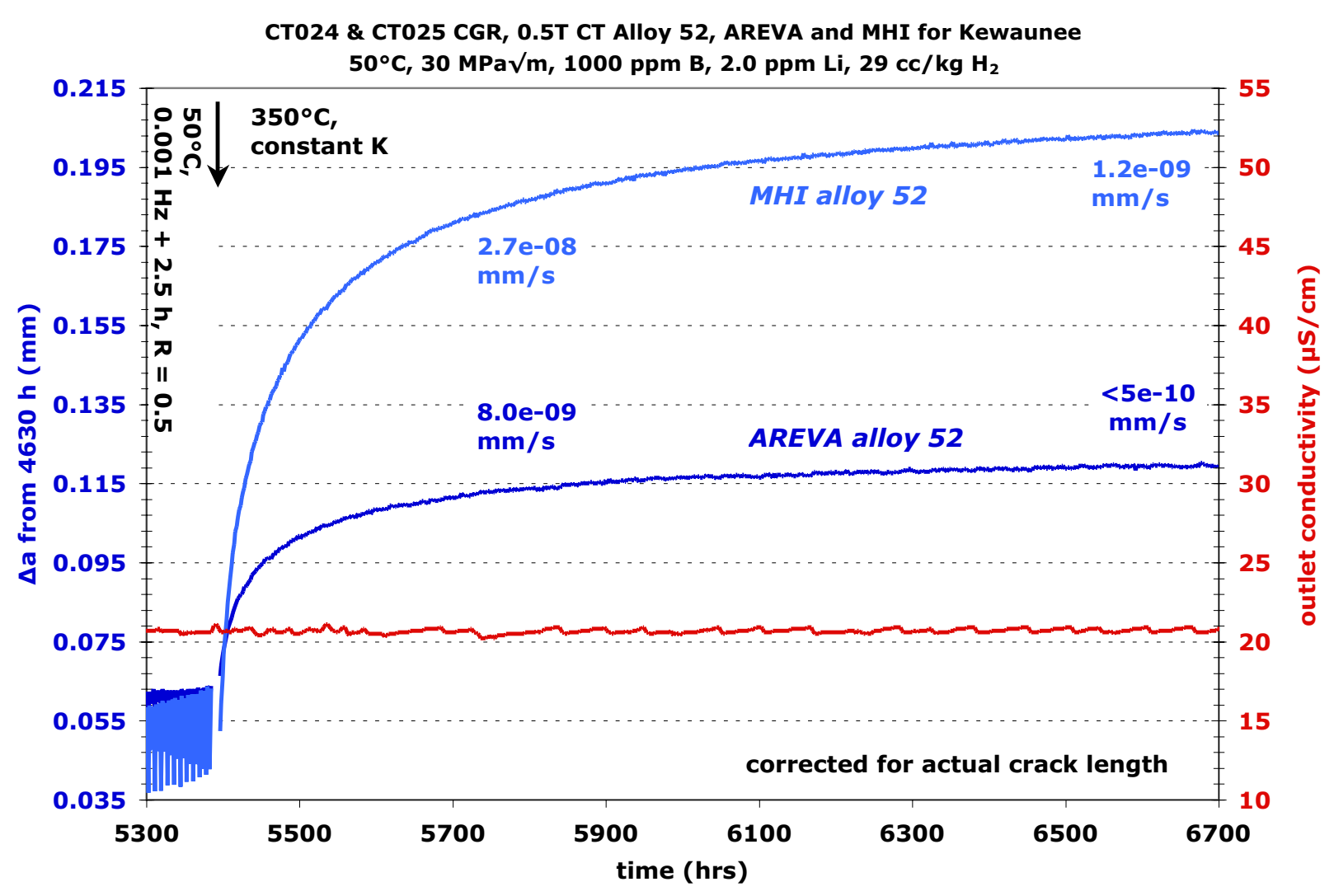

Figure 3.25 Constant $\mathrm{K}$ crack growth response of the $\mathrm{MHI}$ and AREVA alloy 52 specimens (CT024 \& CT025) at $350^{\circ} \mathrm{C}$ after cyclic loading crack extension at $50^{\circ} \mathrm{C}$.

The test was ended and the specimens were fatigued open in air to document the crack growth surfaces. Optical images of the crack growth surfaces for the AREVA and MHI alloy 52 specimens are shown in Figure 3.26 and 3.27, respectively. Several distinct bands are apparent on the surface, and are labeled as A through D in Figure 3.26. Band A corresponds to the transitioning and constant $\mathrm{K}$ testing in the first region that was examined. Band $\mathrm{B}$ corresponds to rapid crack extension performed to move the crack front forward to the next microstructural region of crack-growth testing while $C$ corresponds to the transitioning steps in this region. Finally, band $\mathrm{D}$ corresponds to crack extension at $50^{\circ} \mathrm{C}$ and during the subsequent constant $\mathrm{K}$ phase at $350^{\circ} \mathrm{C}$. SEM examination determined that the crack-growth surface of the AREVA alloy 52 specimen was TG except for two small protrusions of IG growth within the yellow boxed region. An SEM example of this IG morphology is presented in Figure 3.28(a). This IG growth appears to have been initiated and propagated during $50^{\circ} \mathrm{C}$ cycling with no significant IG cracking produced during prior testing at $350^{\circ} \mathrm{C}$. A higher fraction of IG cracking was discovered for the $\mathrm{MHI}$ alloy 52 specimen as indicated by the yellow-boxed regions in Figure 3.27. Whereas the AREVA alloy 52 specimen was less than $5 \%$ IG at the final crack front, the MHI alloy 52 specimen was $\sim 35 \%$ IG. The cracking morphology in one of these IG regions for the $\mathrm{MHI}$ sample is documented in Figure $3.28(\mathrm{~b})$ and again appears to have initiated and propagated during $50^{\circ} \mathrm{C}$ cycling. 
Table 3.5 Summary of test conditions and corrected response for AREVA and MHI alloy 52 specimens CT024 \& CT025.

\begin{tabular}{|c|c|c|c|c|c|c|c|c|c|c|c|c|}
\hline $\begin{array}{c}\text { Test } \\
\text { Phase }\end{array}$ & $\begin{array}{l}\text { Dur- } \\
\text { ation } \\
\text { (h) }\end{array}$ & $\mathrm{R}$ & $\begin{array}{l}\text { Freq } \\
(\mathrm{Hz})\end{array}$ & $\begin{array}{l}\text { Hold } \\
\text { (h) }\end{array}$ & $\begin{array}{c}\text { Water } \\
\text { Chemistry } \\
\text { Conditions }\end{array}$ & $\begin{array}{c}\text { Temp } \\
\left({ }^{\circ} \mathrm{C}\right)\end{array}$ & $\begin{array}{c}\mathrm{K}_{\max } \\
(\mathrm{MPa} \sqrt{\mathrm{m}})\end{array}$ & $\begin{array}{l}4 \text { AREVA A } \\
\text { theld Blan }\end{array}$ & $\begin{array}{l}\text { Alloy } 52 \\
\text { k \#1 } \\
\text { Approx. } \\
\text { Crack } \\
\text { Extension } \\
(\mathrm{mm})\end{array}$ & $\begin{array}{c}\mathrm{K}_{\max } \\
(\mathrm{MPa} \sqrt{\mathrm{m}})\end{array}$ & $\begin{array}{l}25 \mathrm{MHI} \text { Allc } \\
\text { ove Weld BI }\end{array}$ & $\begin{array}{l}\text { loy } 52 \\
\text { Blank \#1 } \\
\text { Approx. } \\
\text { Crack } \\
\text { Extension } \\
(\mathrm{mm})\end{array}$ \\
\hline 1 & $\sim 3$ & 0.3 & 3 & 0 & air precrack & RT & 25 & $1.2 \mathrm{E}-04$ & 0.40 & 25 & 7.6E-05 & 0.40 \\
\hline 2 & $\sim 2$ & 0.5 & 3 & 0 & air precrack & RT & 28 & 7.6E-05 & 0.35 & 28 & 4.6E-05 & 0.35 \\
\hline 3 & $\sim 2$ & 0.6 & 3 & 0 & air precrack & RT & 31 & 5.1E-05 & 0.35 & 30 & 3.1E-05 & 0.35 \\
\hline 4 & $\sim 3$ & 0.7 & 3 & 0 & air precrack & RT & 31 & 2.1E-05 & 0.20 & 30 & $1.5 \mathrm{E}-05$ & 0.20 \\
\hline 5 & 88 & 0.7 & 0.1 & 0 & $29 \mathrm{cc} / \mathrm{kg} \mathrm{H}_{2}$ & 325 & 31 & 8.0E-07 & 0.257 & 30 & 7.5E-07 & 0.235 \\
\hline 6 & 237 & 0.7 & 0.01 & 0 & $29 \mathrm{cc} / \mathrm{kg} \mathrm{H}{ }_{2}$ & 325 & 31 & 1.6E-07 & 0.133 & 30 & $1.5 \mathrm{E}-07$ & 0.128 \\
\hline 7 & 323 & 0.7 & 0.001 & 0 & $29 \mathrm{cc} / \mathrm{kg} \mathrm{H}$ & 325 & 31 & $2.2 \mathrm{E}-08$ & 0.031 & 31 & $2.2 \mathrm{E}-08$ & 0.033 \\
\hline 8 & 82 & 0.7 & 0.001 & 0 & $29 \mathrm{cc} / \mathrm{kg} \mathrm{H}_{2}$ & 350 & 31 & 3.1E-08 & 0.011 & 31 & 5.3E-08 & 0.016 \\
\hline 9 & 314 & 0.7 & 0.001 & 2.5 & $29 \mathrm{cc} / \mathrm{kg} \mathrm{H}_{2}$ & 350 & 31 & 1.4E-09 & 0.004 & 31 & 5.7E-09 & 0.015 \\
\hline 10 & 272 & 0.5 & 0.001 & 0 & $29 \mathrm{cc} / \mathrm{kg} \mathrm{H}_{2}$ & 350 & 31 & $1.0 \mathrm{E}-07$ & 0.098 & 31 & $1.5 \mathrm{E}-07$ & 0.126 \\
\hline 11 & 806 & 0.5 & 0.001 & 2.5 & $29 \mathrm{cc} / \mathrm{kg} \mathrm{H}_{2}$ & 350 & 31 & $1.2 \mathrm{E}-08$ & 0.024 & 31 & 1.0E-08 & 0.028 \\
\hline 12 & 365 & --- & const $\mathrm{K}$ & -- & $29 \mathrm{cc} / \mathrm{kg} \mathrm{H}$ & 350 & 31 & no growth & --- & 31 & $9 \mathrm{E}-10$ & 0.002 \\
\hline 13 & 500 & 0.5 & 0.04 & 2.5 & $29 \mathrm{cc} / \mathrm{kg} \mathrm{H}_{2}$ & 350 & 31 & 4.3E-09 & 0.013 & 31 & $6.1 \mathrm{E}-09$ & 0.012 \\
\hline 14 & 343 & 0.5 & 0.04 & 0.5 & $29 \mathrm{cc} / \mathrm{kg} \mathrm{H}_{2}$ & 350 & 31 & $1.9 \mathrm{E}-08$ & 0.022 & 31 & 3.1E-08 & 0.037 \\
\hline 15 & 313 & 0.5 & 0.04 & 12.5 & $29 \mathrm{cc} / \mathrm{kg} \mathrm{H}_{2}$ & 350 & 31 & $8 \mathrm{E}-10$ & 0.002 & 31 & 2.4E-09 & 0.004 \\
\hline 16 & 49 & 0.5 & 0.1 & 0 & $29 \mathrm{cc} / \mathrm{kg} \mathrm{H}_{2}$ & 350 & 32 & $5.2 \mathrm{E}-06$ & 0.718 & 34 & 7.2E-06 & 1.161 \\
\hline 17 & 78 & 0.5 & 0.01 & 0 & $29 \mathrm{cc} / \mathrm{kg} \mathrm{H}_{2}$ & 350 & 33 & $9.7 \mathrm{E}-07$ & 0.286 & 34 & 1.0E-06 & 0.308 \\
\hline 18 & 225 & 0.5 & 0.001 & 0 & $29 \mathrm{cc} / \mathrm{kg} \mathrm{H}_{2}$ & 350 & 33 & $1.4 \mathrm{E}-07$ & 0.119 & 34 & $1.5 \mathrm{E}-07$ & 0.115 \\
\hline 19 & 341 & 0.5 & 0.001 & 2.5 & $29 \mathrm{cc} / \mathrm{kg} \mathrm{H}_{2}$ & 350 & 33 & $1.4 \mathrm{E}-08$ & 0.038 & 34 & 1.5E-08 & 0.042 \\
\hline 20 & 297 & 0.5 & 0.01 & 0 & $29 \mathrm{cc} / \mathrm{kg} \mathrm{H}_{2}$ & 50 & 33 & $3.5 \mathrm{E}-07$ & 0.306 & 36 & 7.7E-07 & 0.592 \\
\hline 21 & 513 & 0.5 & 0.001 & 0 & $29 \mathrm{cc} / \mathrm{kg} \mathrm{H}_{2}$ & 50 & 34 & 4.3E-08 & 0.051 & 36 & 8.4E-08 & 0.018 \\
\hline 22 & 250 & 0.5 & 0.001 & 2.5 & $29 \mathrm{cc} / \mathrm{kg} \mathrm{H}_{2}$ & 50 & 34 & $4.0 \mathrm{E}-09$ & 0.012 & 36 & 1.6E-08 & 0.023 \\
\hline 23 & 1327 & --- & const $\mathrm{K}$ & -- & $29 \mathrm{cc} / \mathrm{kg} \mathrm{H}_{2}$ & 350 & 34 & $1.4 \mathrm{E}-09$ & 0.053 & 37 & 2.8E-09 & 0.151 \\
\hline 24 & 352 & --- & const $\mathrm{K}$ & --- & $20 \mathrm{cc} / \mathrm{kg} \mathrm{H}_{2}$ & 350 & 34 & 1.2E-09 & 0.003 & 37 & $3.5 \mathrm{E}-09$ & 0.006 \\
\hline
\end{tabular}




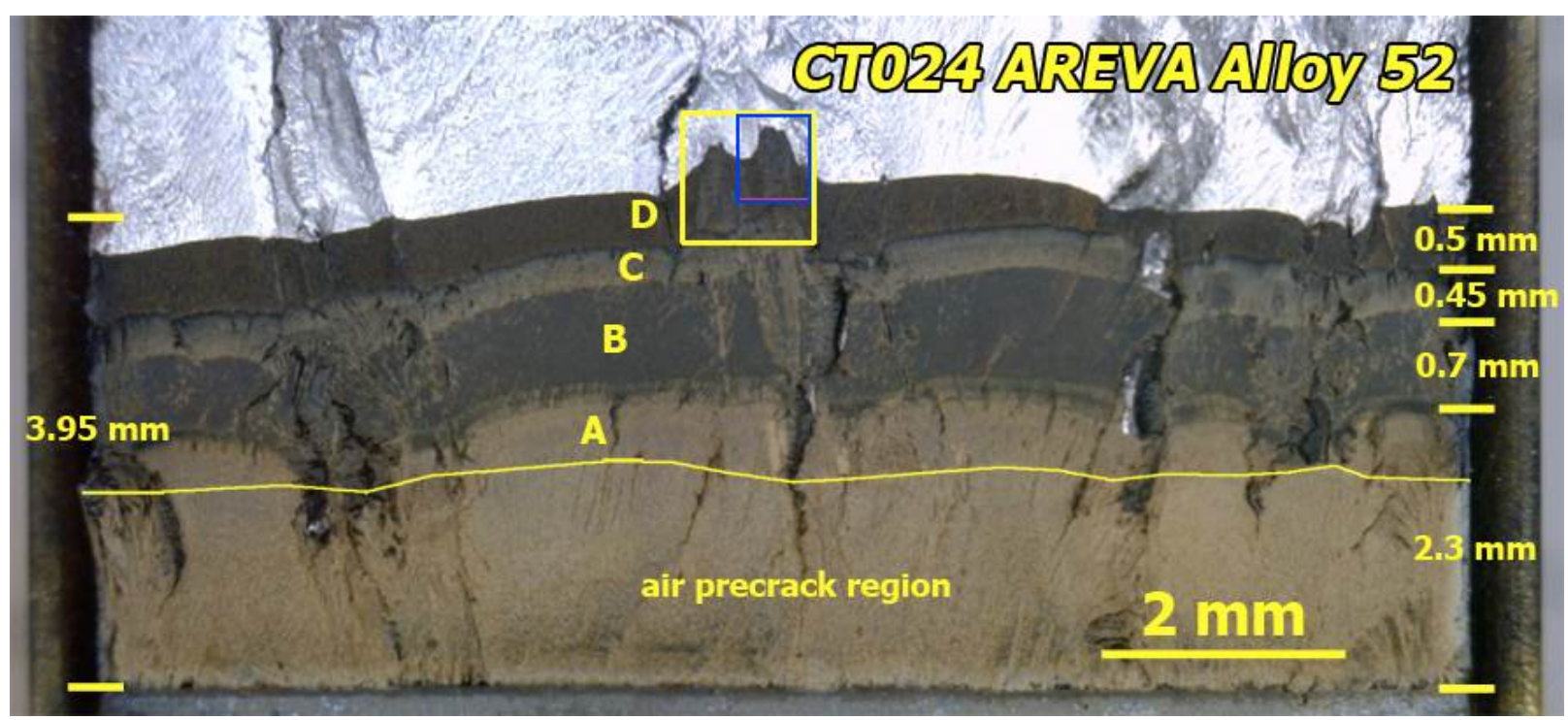

Figure 3.26 Optical image of the crack growth surface of the AREVA alloy 52 specimen (CT024). Four distinct bands are apparent after the air precrack boundary and the only area showing IG growth is indicated by the yellow box in the final band labeled D. The smaller blue box identifies the area of the SEM image shown in Figure 3.28.

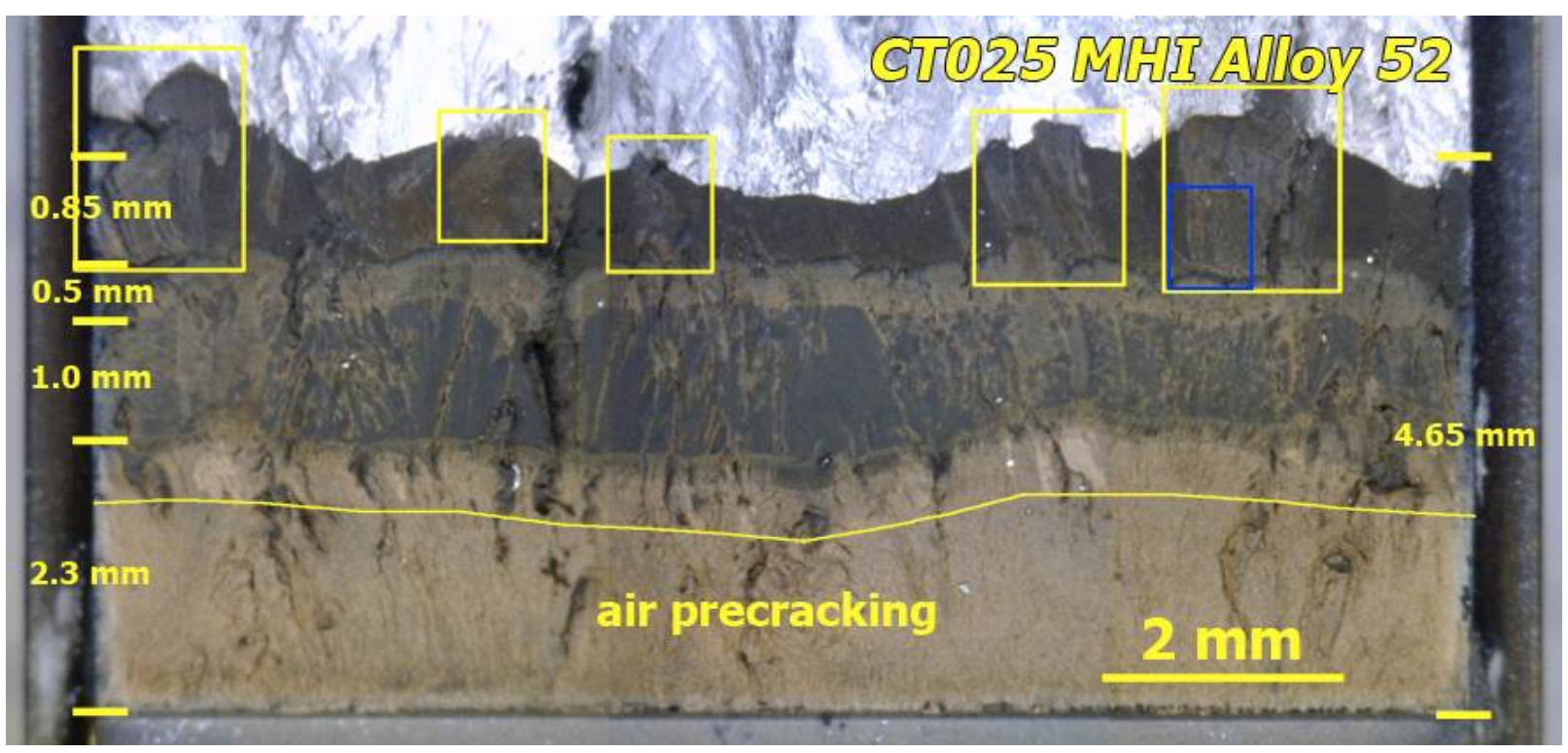

Figure 3.27 Optical image of the crack growth surface of the MHI alloy 52 specimen (CT025). Yellow boxes indicate regions of IG growth and the blue box identifies the area of the SEM image shown in Figure 3.28. 


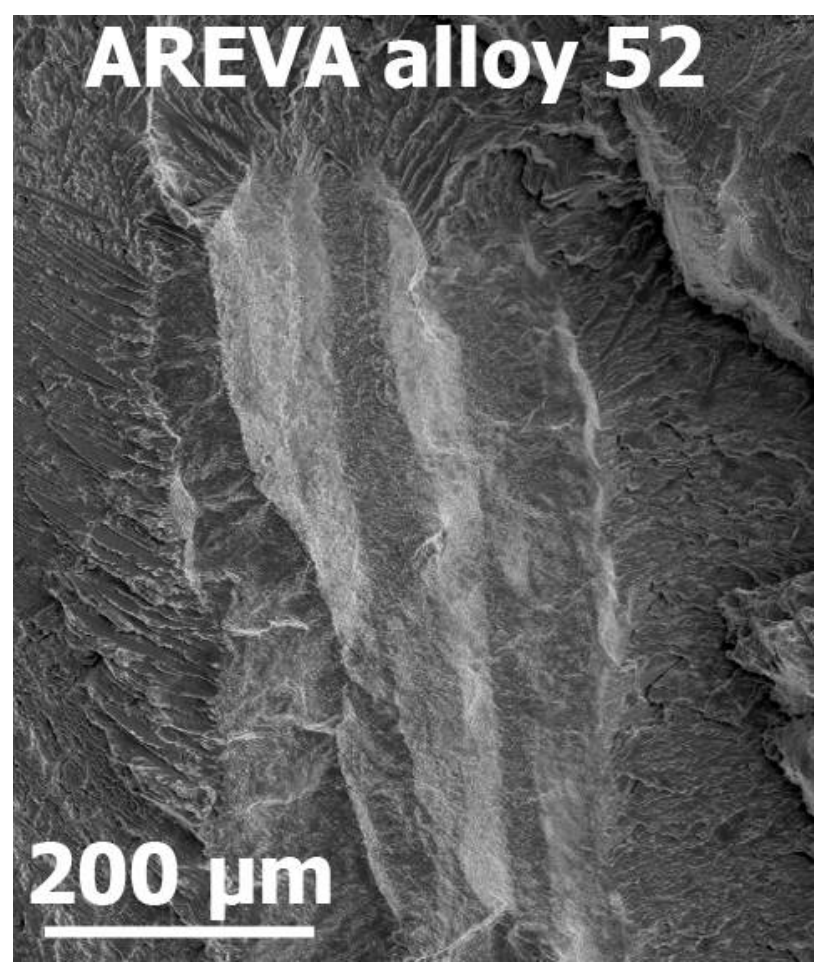

(a)

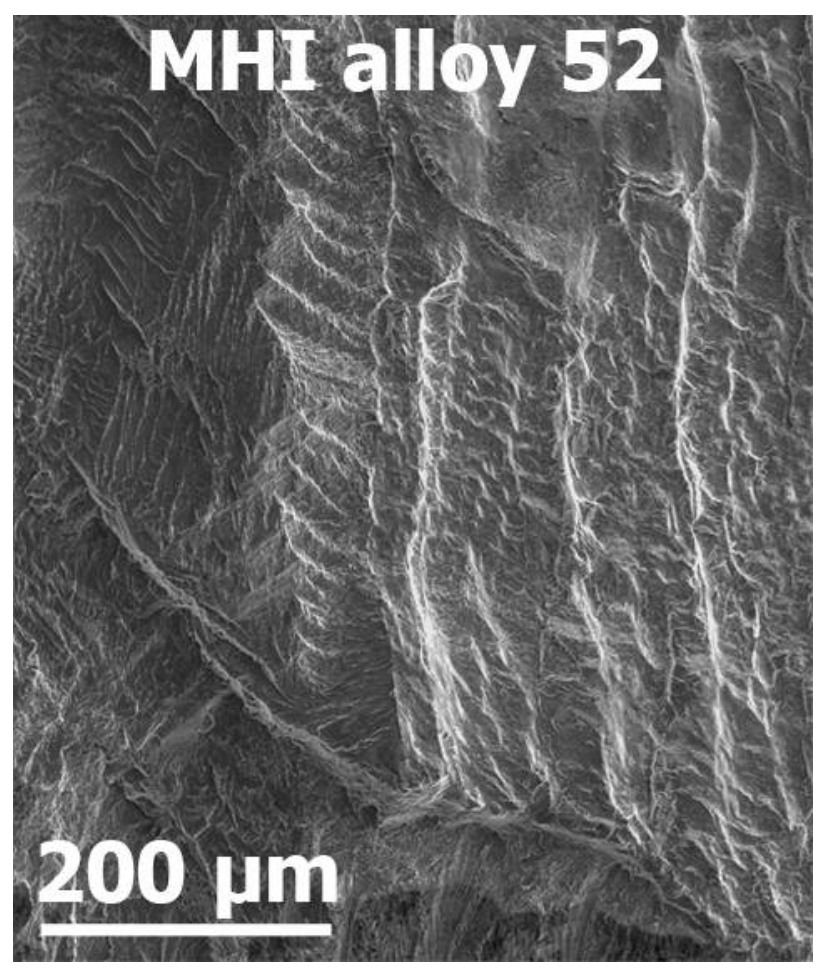

(b)

Figure 3.28 SEM images illustrating IG regions on the crack growth surface for the alloy 52 specimens: (a) isolated IG finger-like area in AREVA sample and (b) typical IG area in $\mathrm{MHI}$ sample. For both specimens, some IG cracking was initiated during final growth at $350^{\circ} \mathrm{C}$ and continued during cycling at $50^{\circ} \mathrm{C}$.

Side surface images of the cracks were also obtained on these specimens with cut lines for both specimens shown in Figure 3.29. Side surfaces where polished and etched to reveal the dendrite and grain structure and are shown in Figures 3.30 and 3.31, respectively for the AREVA and $\mathrm{MHI}$ materials. The edge of the crack wall is feathered over making it somewhat difficult to determine TG or IG growth along the crack front, but comparison with the crack growth surfaces allows the start of IG growth to be identified. Of interest in looking at these side surfaces was the number of opportunities a crack had to intersect a grain boundary. The AREVA material has an extremely large grain size $(500 \mu \mathrm{m}$ to $2000 \mu \mathrm{m})$ that provides little opportunity for a TG crack to intersect a grain boundary while the $\mathrm{MHI}$ material has a wider range of grain size with some falling down into the $200 \mu \mathrm{m}$ range. It is in a region of smaller grain size where the MHI alloy 52 material goes IG. 


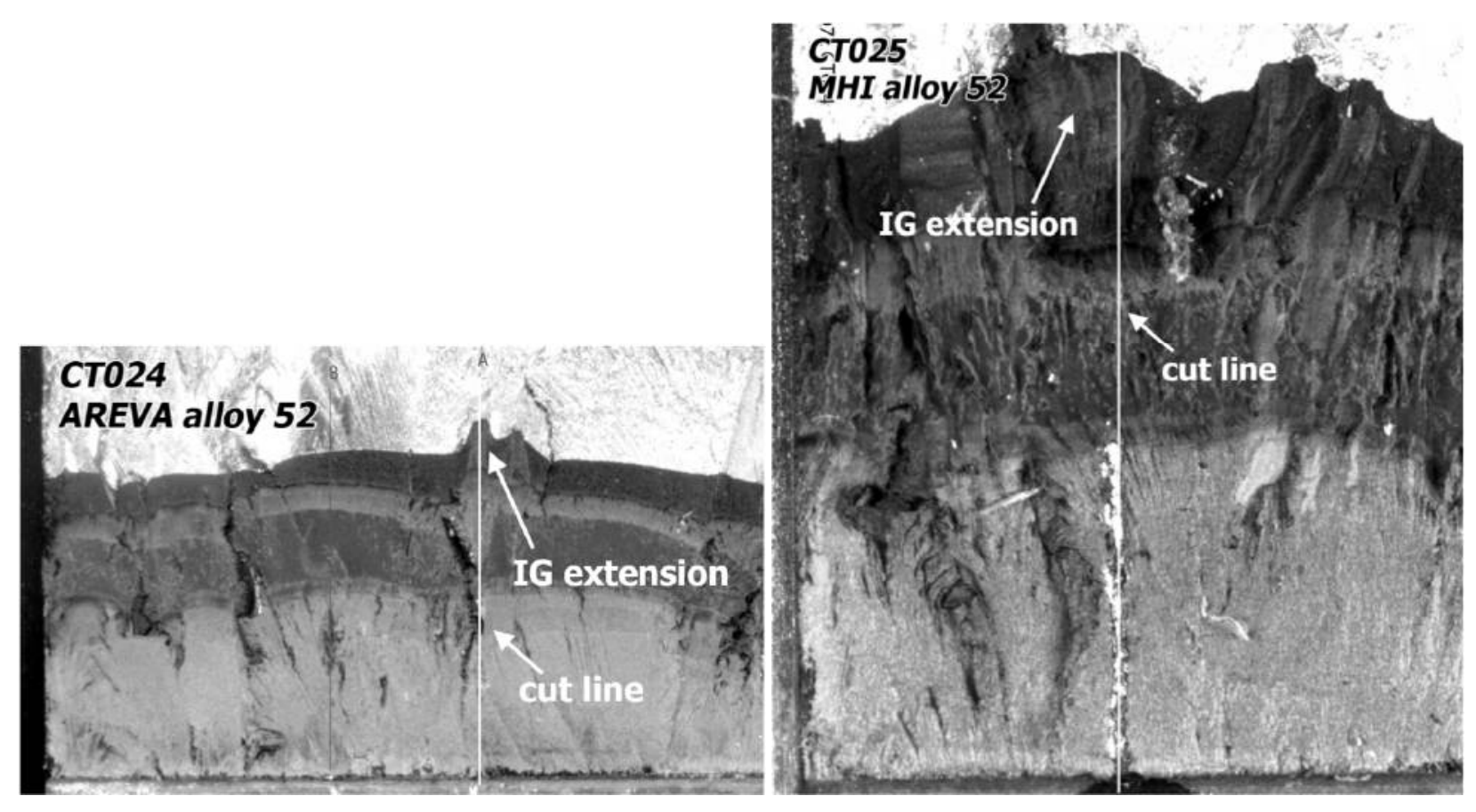

Figure 3.29 White lines indicate where crack growth surfaces were sectioned to expose and polish crack side surfaces.

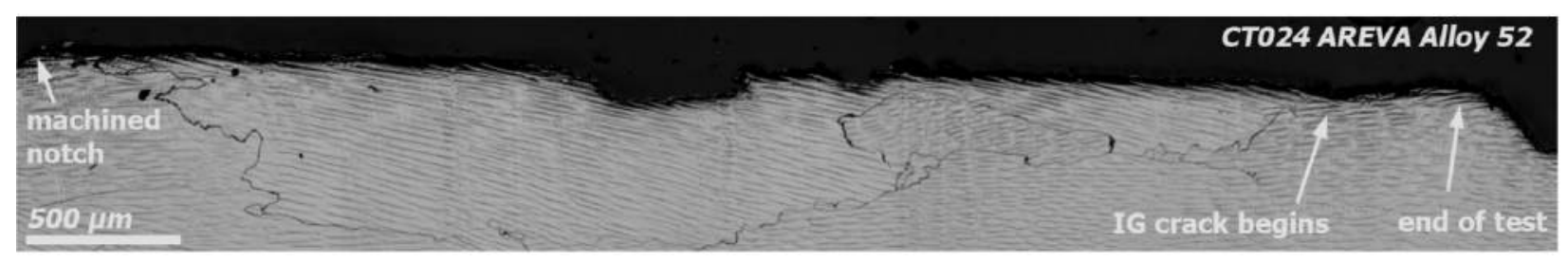

Figure 3.30 Side surface image of the AREVA alloy 52 specimen, CT024.

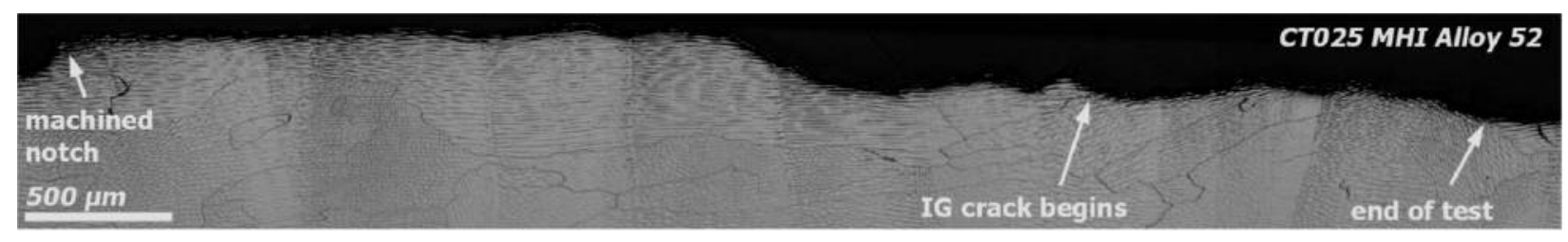

Figure 3.31 Side surface image of the MHI alloy 52 specimen CT025. 
A key issue that remained was whether any significant IGSCC growth occurred during constant $\mathrm{K}$ testing at $350^{\circ} \mathrm{C}$ after crack extension at $50^{\circ} \mathrm{C}$. In order to better assess the effects of the temperature change on the DCPD-measured crack length, tests were performed on a second pair of AREVA (CT032) and MHI (CT033) alloy 52 specimens in simulated PWR primary water. An overview of the entire crack growth test is shown in Figure 3.32. The test can be broken up into four phases. During the first phase, the specimens were transitioned for several weeks at $350^{\circ} \mathrm{C}$ and displayed similar cyclic crack growth response as specimens CT024 and CT025 as illustrated in Figure 3.33. The temperature was then decreased to $50^{\circ} \mathrm{C}$ in the second phase and the crack extended by $\sim 1 \mathrm{~mm}$ using cyclic loading conditions. This is documented in Figure 3.34. Conditions used were similar to those for the first set of alloy 52 specimens. Loading was then converted to constant $\mathrm{K}$ at a low value of $10 \mathrm{MPa} \vee \mathrm{m}$ and the temperature brought back up to $350^{\circ} \mathrm{C}$ in the third phase of the test. Considering the resistance of these materials, no crack growth was expected at this low $\mathrm{K}$ value. However, nearly identical DCPD crack growth response can be seen when comparing Figure 3.35 (CT032/33, low K) to Figure 3.25 (CT024/25, high K). The final phase of the test increased $\mathrm{K}$ values up to $30 \mathrm{MPa} \sqrt{\mathrm{m}}$ and then to $40 \mathrm{MPa} \sqrt{\mathrm{m}}$ using $\mathrm{dK} / \mathrm{da}$ loading. Constant K SCC propagation rates increased slightly at the higher $\mathrm{K}$ values, but remained extremely low (corrected rates of $1.5 \times 10^{-9} \mathrm{~mm} / \mathrm{s}$ for the MHI alloy 52 and $<1 \times 10^{-9} \mathrm{~mm} / \mathrm{s}$ for AREVA) as shown in Figure 3.36 and it was decided to end the test. A summary of test conditions and corrected data for each phase of the test is shown in Table 3.6.

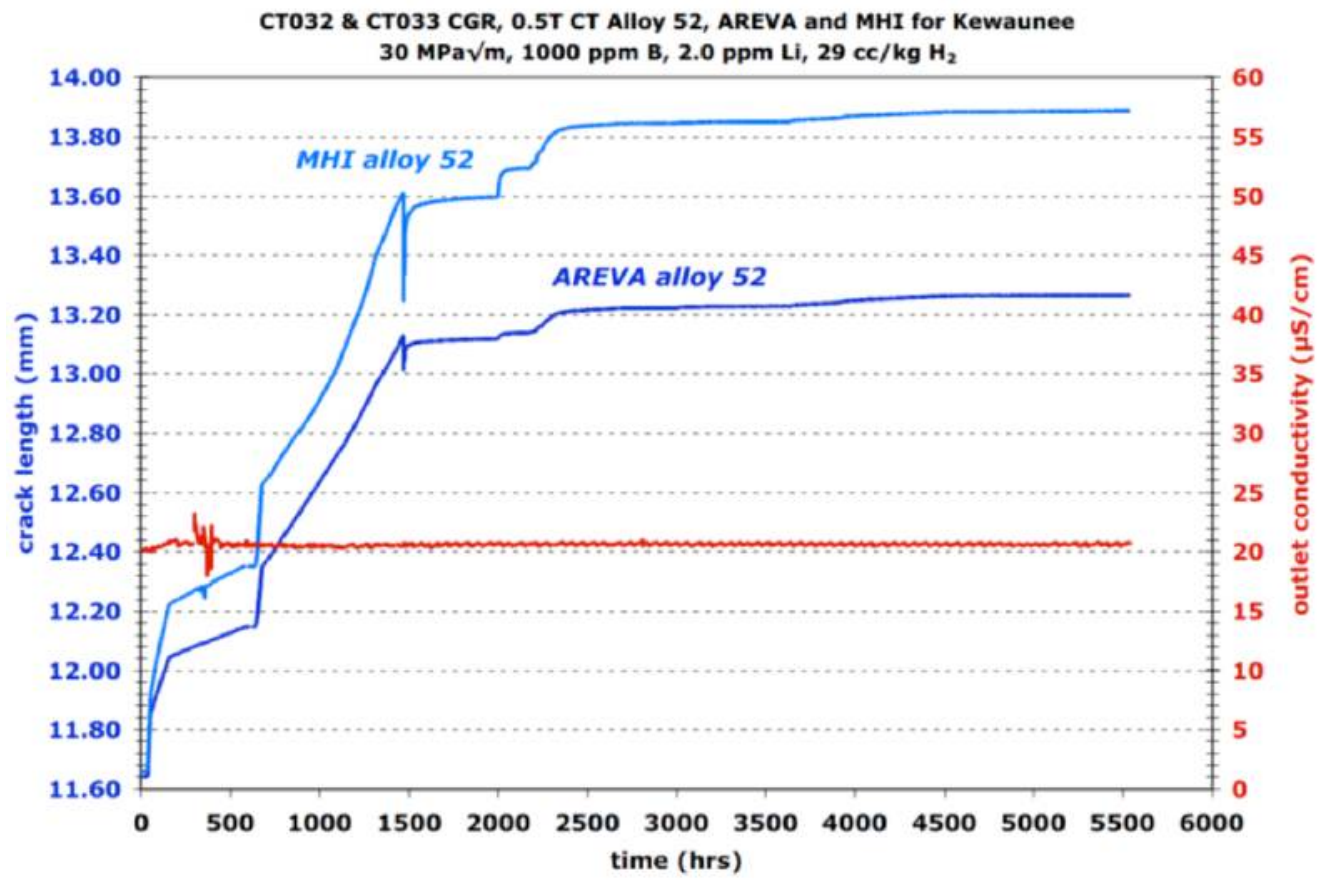

Figure 3.32 Overall response for the second test on the AREVA and $\mathrm{MHI}$ alloy 52 specimens CT032 and CT033. 

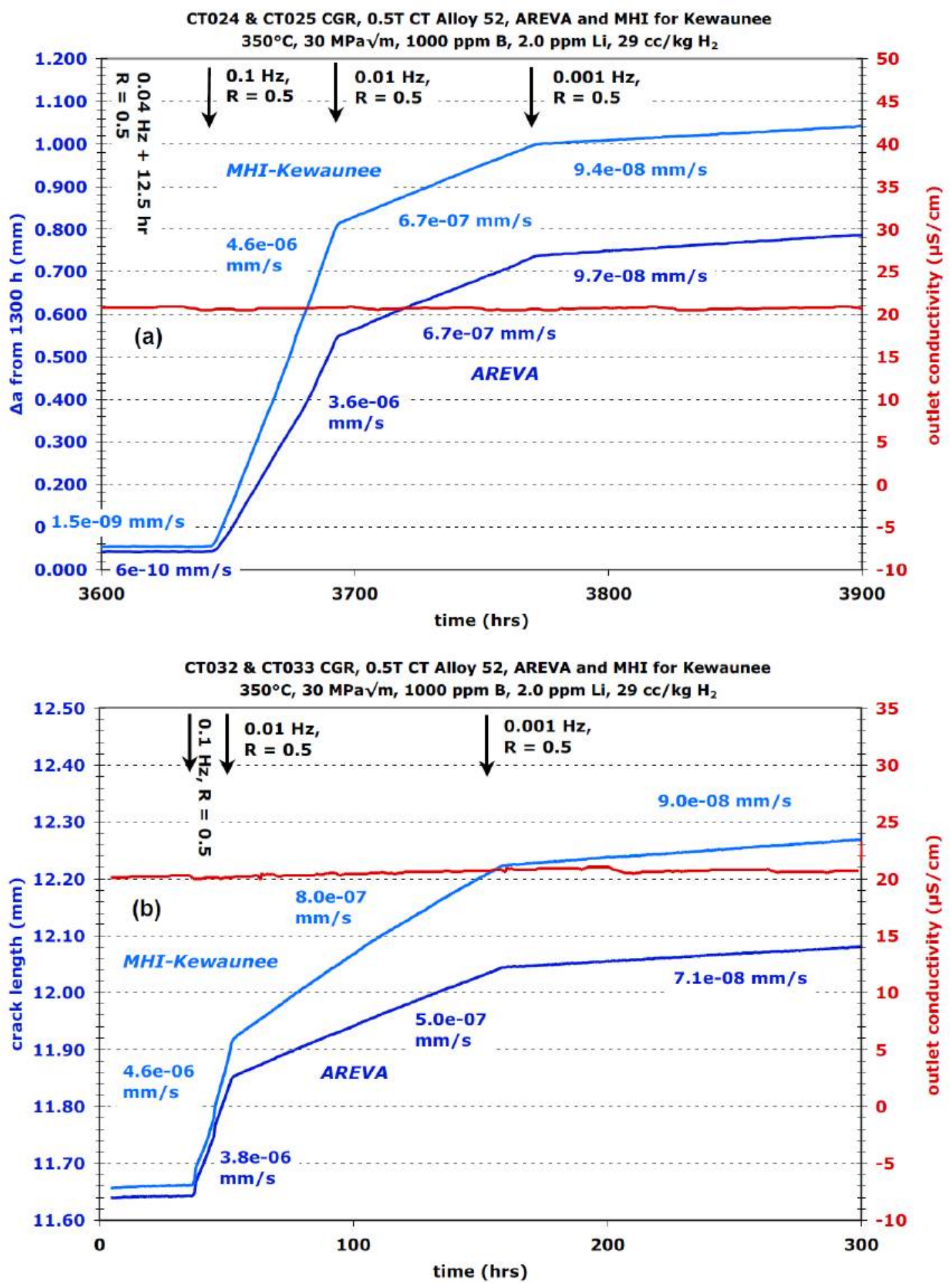

Figure 3.33 Similar crack growth rates were seen during early transitioning between first test (a) CT024/25 and second test (b) CT032/33 on the AREVA and MHI materials. 


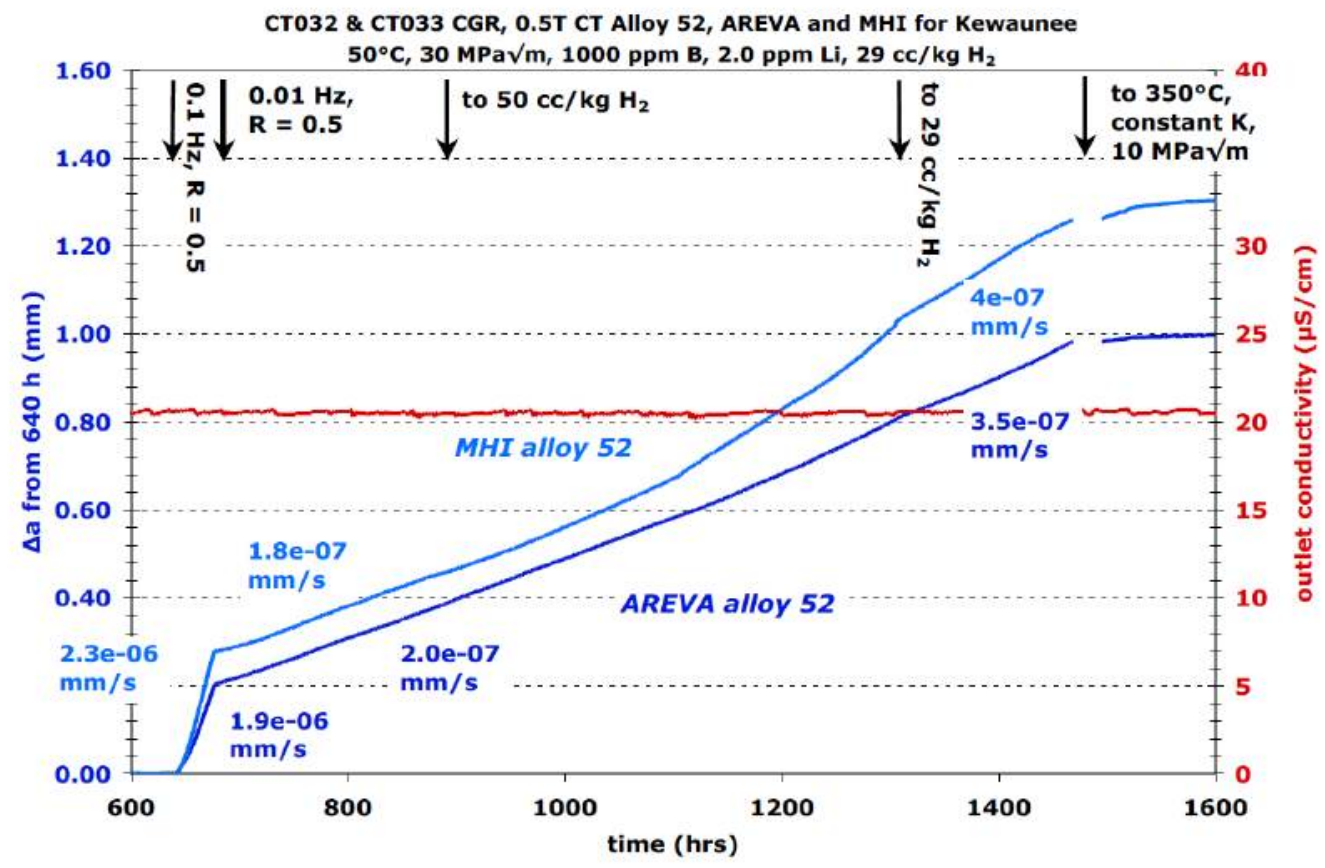

Figure 3.34 Cyclic loading response at $50^{\circ} \mathrm{C}$ of AREVA (CT032) and $\mathrm{MHI}$ alloy 52 (CT033).

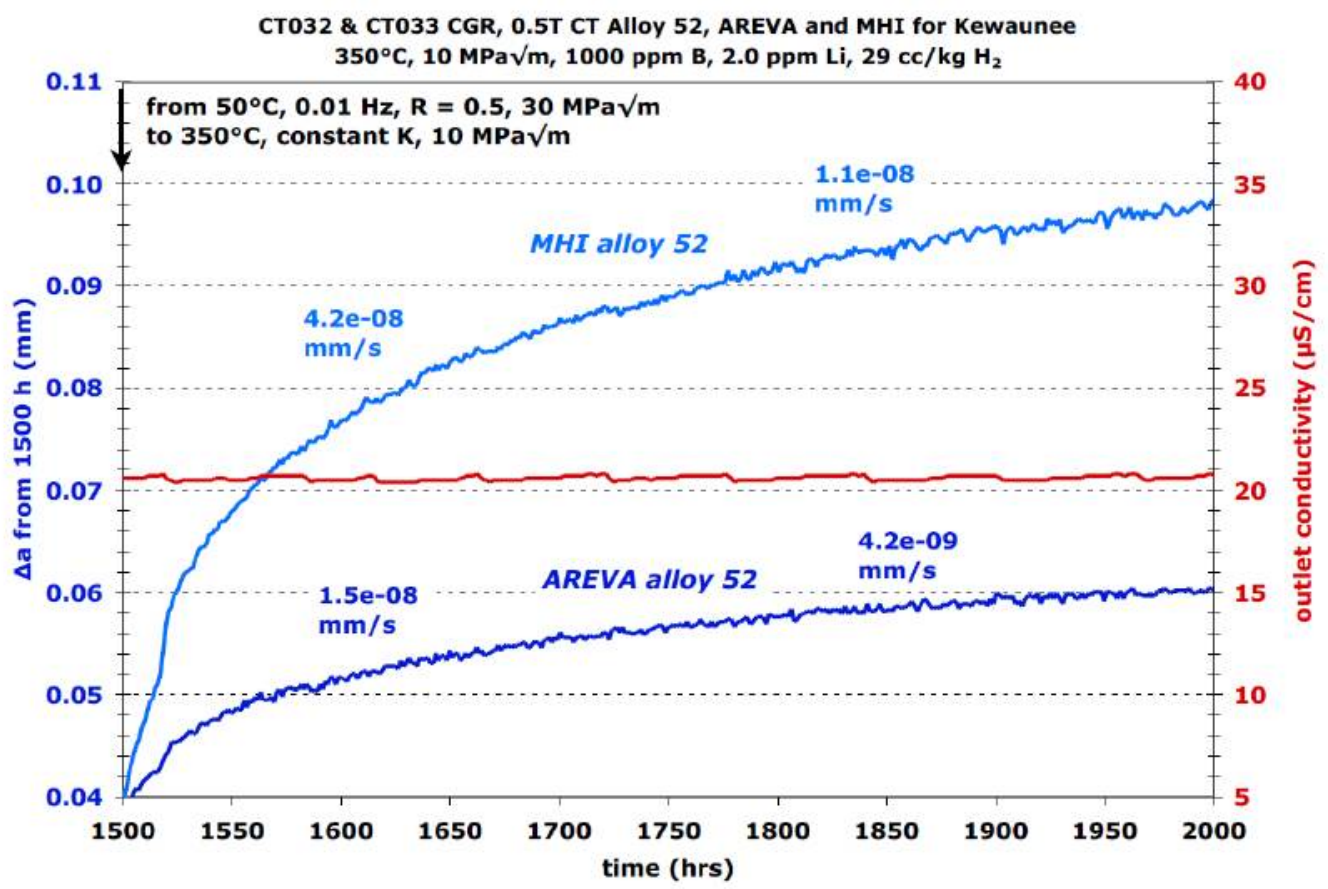

Figure 3.35 Crack growth response of a second set of AREVA and MHI 52 specimens (CT032 \& CT033) tested at $350^{\circ} \mathrm{C}$ following crack extension at $50^{\circ} \mathrm{C}$. Despite the low $\mathrm{K}$ value of $10 \mathrm{MPa} \sqrt{\mathrm{m}}$, response is nearly identical to the previous test at $30 \mathrm{MPa} \sqrt{\mathrm{m}}$ (see Figure 3.25). 


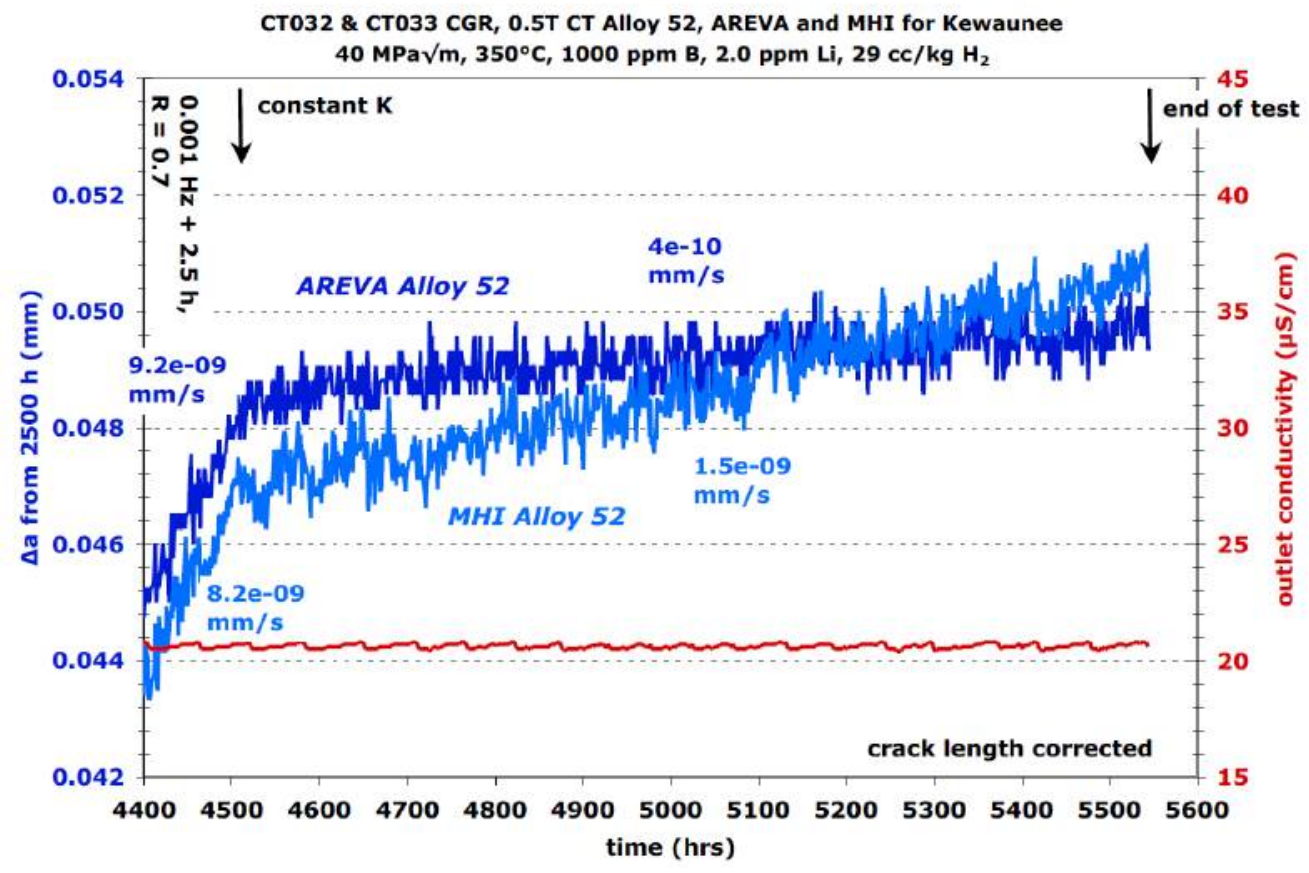

Figure 3.36 AREVA and MHI alloy 52 crack growth response at $40 \mathrm{MPa} \sqrt{\mathrm{m}}$.

After ending the test, the crack was sealed for crack-tip characterization by filling it with resin, and the specimens were each sectioned into two slices with one slice being fatigued open to reveal the crack growth surface, and the side of the other slice being polished to reveal the crack path through the material. The optical images of the crack growth surface, as shown in Figure 3.37, are somewhat difficult to discern because of resin coating the surface, but the large phases of the test are identifiable. It is also clear that there are regions of IG growth on the surface of both specimens. A side surface image of the AREVA (CT032) specimen is shown in Figure 3.38 revealing again that the material has very large grains. In this particular slice through the material, a significant amount of IG cracking was found; essentially the entire in-situ portion of the test appears to be IG along this section through the specimen. The side surface cut corresponds to a large protrusion on the crack growth surface in Figure 3.37. Several other protrusions are apparent indicating a higher degree of engagement than on the previous test (CT024). Figure 3.39 shows the side surface of the MHI (CT033) specimen with its smaller grains. Of interest in this photo is that while the crack eventually finds a grain boundary and cracks along it for some distance, it eventually turns off the boundary. Extensive cracking above and below the main crack is apparent. There is clearly some preference for IG cracking, but it appears that the grains must be well aligned for growth.

These crack growth results along with the crack surface observations support the conclusion that after going up to $350^{\circ} \mathrm{C}$, slow oxidation of $\mathrm{Ni}$-metal bridges are occurring in the crack produced at $50^{\circ} \mathrm{C}$, and this is reducing or removing DCPD current conduction paths behind the crack front causing an artificially high crack growth rate during this oxidation event. The very similar crack growth rates between the tests at 10 and $30 \mathrm{MPa} \sqrt{\mathrm{m}}$ suggest that very little IGSCC growth occurred after returning to $350^{\circ} \mathrm{C}$ even with $\sim 35 \%$ IG engagement in the $\mathrm{MHI}$ specimen and $\sim 20 \%$ IG engagement in the AREVA specimen produced by transitioning at $50^{\circ} \mathrm{C}$. 
Table 3.6 Summary of test conditions and corrected response for AREVA and MHI alloy 52 specimens CT032 \& CT033.

\begin{tabular}{|c|c|c|c|c|c|c|c|c|c|c|c|c|}
\hline $\begin{array}{l}\text { Test } \\
\text { Phase }\end{array}$ & $\begin{array}{l}\text { Dur- } \\
\text { ation } \\
\text { (h) }\end{array}$ & $\mathrm{R}$ & $\begin{array}{c}\text { Freq } \\
(\mathrm{Hz})\end{array}$ & $\begin{array}{l}\text { Hold } \\
\text { (h) }\end{array}$ & $\begin{array}{c}\text { Water } \\
\text { Chemistry } \\
\text { Conditions }\end{array}$ & $\begin{array}{c}\text { Temp } \\
\left({ }^{\circ} \mathrm{C}\right)\end{array}$ & \multicolumn{3}{|c|}{$\begin{array}{rcc}\text { CT032 AREVA Alloy } 52 \\
\text { Butt Weld Blank \#1 } \\
\\
& & \text { Approx. } \\
& & \text { Crack } \\
& & \text { C } \\
\mathrm{K}_{\max } & \text { CGR } & \text { Extension } \\
(\mathrm{MPa} \vee \mathrm{m}) & (\mathrm{mm} / \mathrm{sec}) & (\mathrm{mm})\end{array}$} & \multicolumn{3}{|c|}{\begin{tabular}{|ccc}
\multicolumn{3}{|c}{ CT033 MHI Alloy 52} \\
U-groove Weld Blank \#1 \\
& & Approx. \\
& & Crack \\
& & Extensior \\
$\mathrm{K}_{\max }$ & CGR & Ex \\
$(\mathrm{MPa} \sqrt{\mathrm{m}})$ & $(\mathrm{mm} / \mathrm{sec})$ & $(\mathrm{mm})$
\end{tabular}} \\
\hline 1 & $\sim 2$ & 0.3 & 3 & 0 & air precrack & RT & 25 & $1.5 \mathrm{E}-04$ & 0.58 & 25 & $1.2 \mathrm{E}-04$ & 0.48 \\
\hline 2 & $\sim 2$ & 0.5 & 3 & 0 & air precrack & RT & 28 & 1.1E-04 & 0.46 & 28 & 8.1E-05 & 0.38 \\
\hline 3 & $\sim 2$ & 0.6 & 3 & 0 & air precrack & RT & 31 & $6.8 \mathrm{E}-05$ & 0.35 & 30 & 5.0E-05 & 0.29 \\
\hline 4 & $\sim 3$ & 0.7 & 3 & 0 & air precrack & RT & 31 & $3.4 \mathrm{E}-05$ & 0.35 & 30 & 2.3E-05 & 0.29 \\
\hline 5 & 18 & 0.5 & 0.1 & 0 & $29 \mathrm{cc} / \mathrm{kg} \mathrm{H}$ & 350 & 31 & $6.0 \mathrm{E}-06$ & 0.301 & 30 & 7.9E-06 & 0.457 \\
\hline 6 & 106 & 0.5 & 0.01 & 0 & $29 \mathrm{cc} / \mathrm{kg} \mathrm{H}$ & 350 & 31 & $7.9 \mathrm{E}-07$ & 0.303 & 31 & 1.4E-06 & 0.513 \\
\hline 7 & 421 & 0.5 & 0.001 & 0 & $29 \mathrm{cc} / \mathrm{kg} \mathrm{H}_{2}$ & 350 & 32 & $1.0 \mathrm{E}-07$ & 0.160 & 32 & $1.4 \mathrm{E}-07$ & 0.219 \\
\hline 8 & 60 & --- & const $\mathrm{K}$ & --- & $29 \mathrm{cc} / \mathrm{kg} \mathrm{H}$ & 50 & 32 & not meas & 0.015 & 32 & not meas & 0.007 \\
\hline 9 & 37 & 0.5 & 0.1 & 0 & $29 \mathrm{cc} / \mathrm{kg} \mathrm{H}{ }_{2}$ & 50 & 32 & 2.3E-06 & 0.234 & 32 & $3.4 \mathrm{E}-06$ & 0.410 \\
\hline 10 & 200 & 0.5 & 0.01 & 0 & $29 \mathrm{cc} / \mathrm{kg} \mathrm{H}$ & 50 & 32 & $2.5 \mathrm{E}-07$ & 0.208 & 33 & 2.8E-07 & 0.254 \\
\hline 11 & 425 & 0.5 & 0.01 & 0 & $29 \mathrm{cc} / \mathrm{kg} \mathrm{H}_{2}$ & 50 & 32 & $3.9 \mathrm{E}-07$ & 0.522 & 33 & $6.5 \mathrm{E}-07$ & 0.873 \\
\hline 12 & 192 & 0.5 & 0.01 & 0 & $29 \mathrm{cc} / \mathrm{kg} \mathrm{H}_{2}$ & 50 & 33 & $4.4 \mathrm{E}-07$ & 0.212 & 36 & $4.8 \mathrm{E}-07$ & 0.357 \\
\hline 13 & 504 & --- & const $\mathrm{K}$ & --- & $29 \mathrm{cc} / \mathrm{kg} \mathrm{H}$ & 350 & 11 & decreasing & 0.025 & 12 & decreasing & 0.085 \\
\hline 14 & 186 & 0.78 & 0.001 & 2.5 & $29 \mathrm{cc} / \mathrm{kg} \mathrm{H}_{2}$ & 350 & 11 & 2.7E-09 & 0.024 & 12 & 8.3E-09 & 0.146 \\
\hline 15 & 497 & --- & $\mathrm{dK} / \mathrm{da}$ & --- & $29 \mathrm{cc} / \mathrm{kg} \mathrm{H}$ & 350 & $11->33$ & $1.2 \mathrm{E}-08$ & 0.059 & $12->38$ & 1.3E-08 & 0.104 \\
\hline 16 & 367 & --- & const $\mathrm{K}$ & --- & $29 \mathrm{cc} / \mathrm{kg} \mathrm{H}$ & 350 & 33 & $5 \mathrm{E}-10$ & $<0.001$ & 38 & 1.2E-09 & $<0.001$ \\
\hline 17 & 136 & --- & $\mathrm{dK} / \mathrm{da}$ & --- & $29 \mathrm{cc} / \mathrm{kg} \mathrm{H}$ & 350 & $33->38$ & $2.4 \mathrm{E}-08$ & 0.002 & $38->44$ & 2.9E-08 & 0.003 \\
\hline 18 & 458 & --- & const $\mathrm{K}$ & --- & $29 \mathrm{cc} / \mathrm{kg} \mathrm{H}$ & 350 & 38 & $5 \mathrm{E}-10$ & $<0.001$ & 44 & $8 \mathrm{E}-10$ & $<0.001$ \\
\hline 19 & 216 & 0.7 & 0.001 & 2.5 & $29 \mathrm{cc} / \mathrm{kg} \mathrm{H}_{2}$ & 350 & $38->39$ & $1.1 \mathrm{E}-08$ & 0.009 & $44->45$ & $1.2 \mathrm{E}-08$ & 0.010 \\
\hline 20 & 86 & 0.7 & 0.001 & 2.5 & $29 \mathrm{cc} / \mathrm{kg} \mathrm{H}_{2}$ & 350 & $39->44$ & $5.0 \mathrm{E}-08$ & 0.009 & $45->51$ & $5.4 \mathrm{E}-08$ & 0.009 \\
\hline 21 & 564 & 0.7 & 0.001 & 2.5 & $29 \mathrm{cc} / \mathrm{kg} \mathrm{H}_{2}$ & 350 & 44 & $1.1 \mathrm{E}-08$ & 0.022 & 51 & $1.2 \mathrm{E}-08$ & 0.024 \\
\hline 22 & 1034 & --- & const $\mathrm{K}$ & --- & $29 \mathrm{cc} / \mathrm{kg} \mathrm{H}_{2}$ & 350 & 44 & $4 \mathrm{E}-10$ & 0.001 & 51 & 1.5E-09 & 0.005 \\
\hline
\end{tabular}
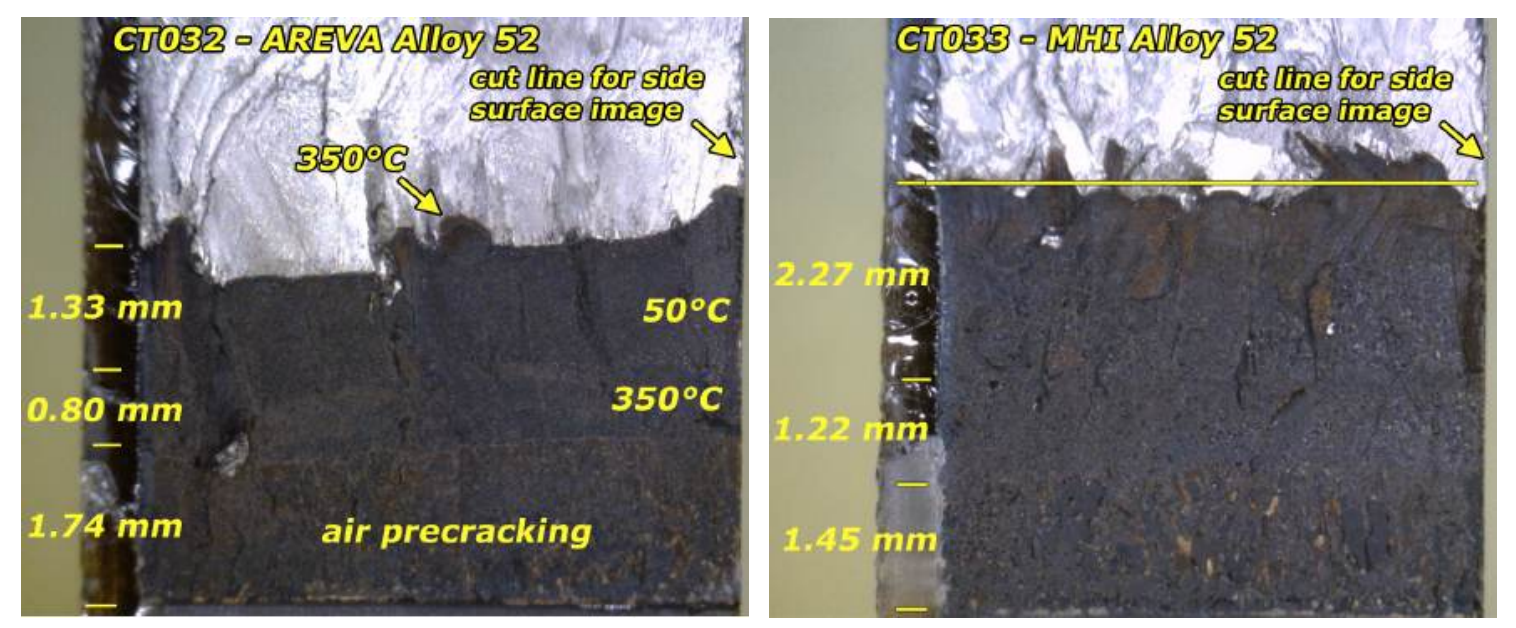

Figure 3.37 Optical image of the crack growth surface of the AREVA alloy 52 specimen (CT032) and the MHI alloy 52 specimen (CT033). 


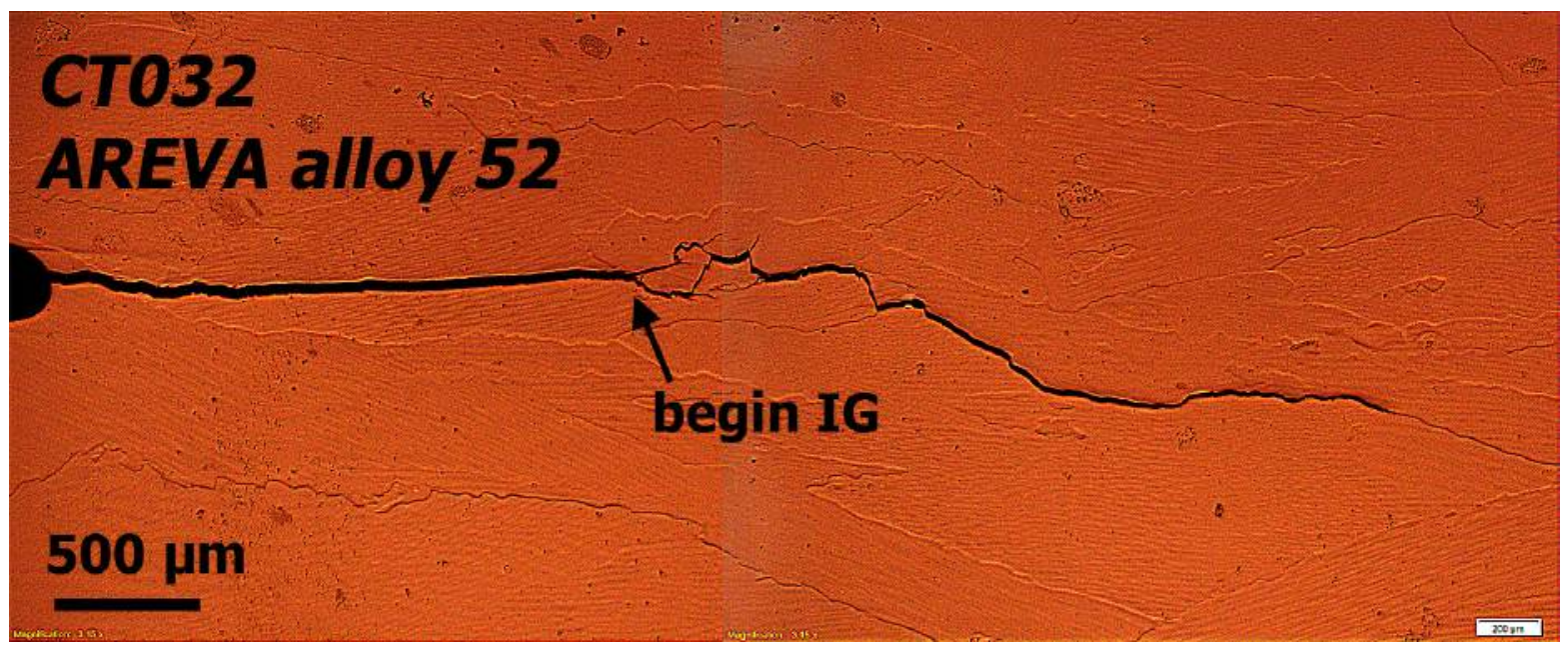

Figure 3.38 Side surface optical image of cracking in the AREVA alloy 52 specimen (CT032) showing both TG and IG growth.

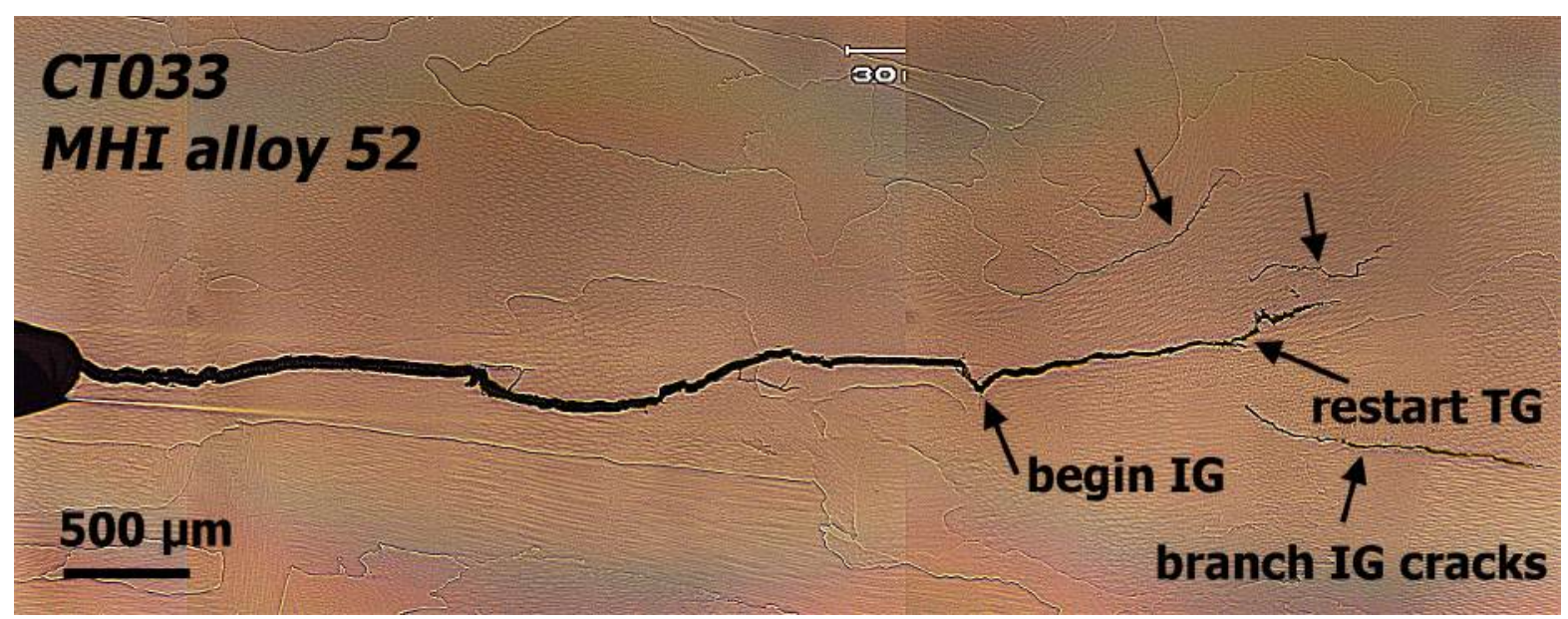

Figure 3.39 Side surface optical image of cracking in the MHI alloy 52 specimen (CT033) showing both TG and IG growth.

\subsection{KAPL Alloy 52M Welds}

Characterizations, sample preparations and testing have been performed on three alloy $52 \mathrm{M}$ weldments received from KAPL. A brief description of the welds and weld metal compositions was given earlier in Table 3.1. Photographs of the $V$-groove and narrow gap mockups are presented in Figure 3.40. These welds were produced under prototypic best practice conditions and welding procedures. The third alloy $52 \mathrm{M}$ weldment was the same weld metal heat and narrow-gap configuration as the prototypic narrow gap weld, but re-fuse passes were applied between each weld pass to intentionally produce hot cracks. Based on metallographic examinations, the individual weld blocks were sectioned by electro-discharge machining to create blanks for CT and thin sheets for more detailed microstructural examinations. Most characterization effort was placed on the alloy 52M weld with known hot cracks. 

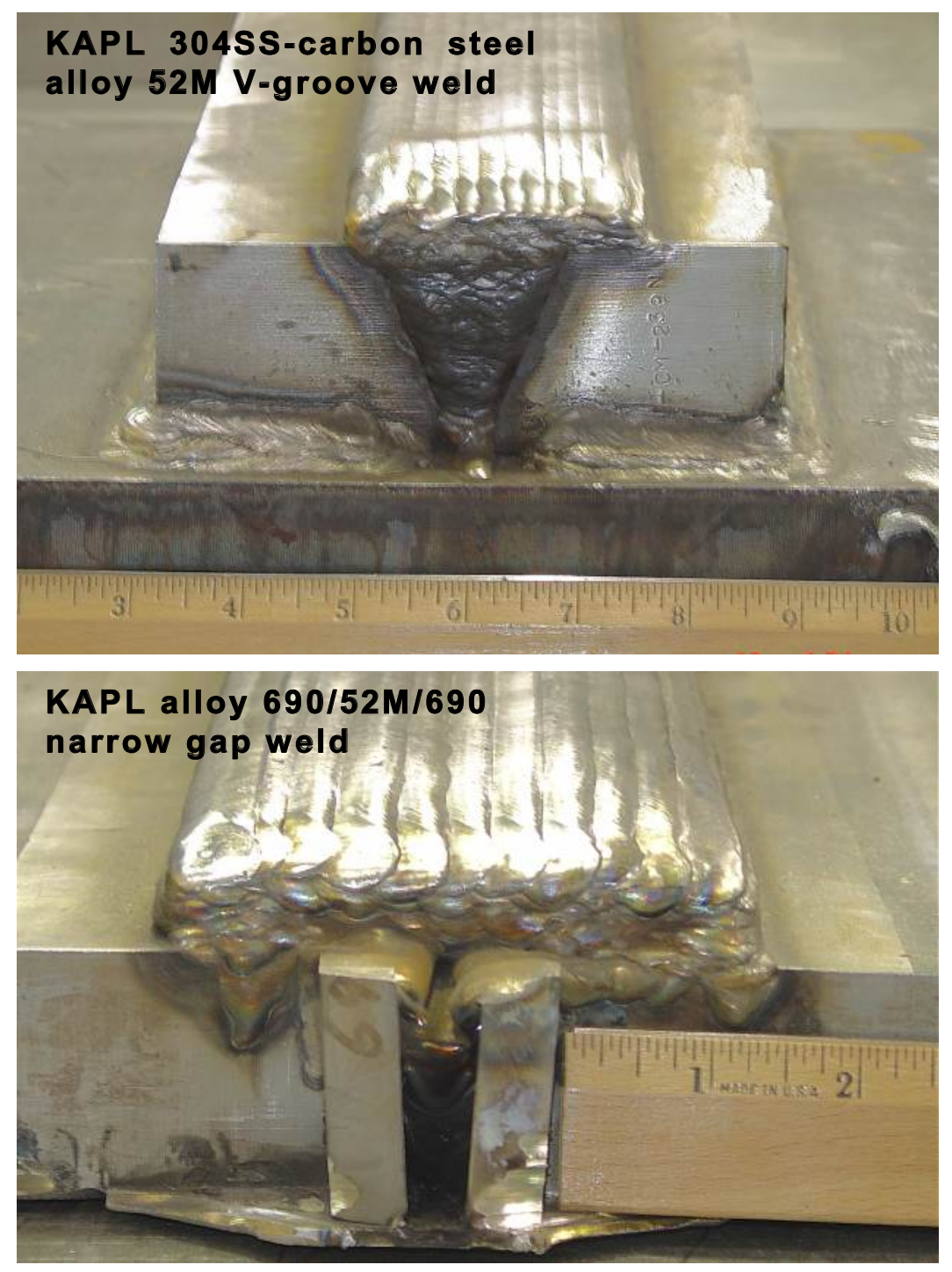

Figure 3.40 Alloy 52M welds from KAPL: (a) dissimilar metal V-groove weld of alloy EN52M joining 304 SS and carbon steel and (b) alloy EN52M narrow gap weld joining alloy 690 . The thin rectangular bars at the front of the weld are run-off tabs to help start the weld. The weld itself is between the two large plates. Additional weldment was placed on top of the mockups to create sufficient size to cut CT specimens.

Specimens CT040 and CT041 were machined from the center of the alloy 52M narrow-gap weld and alloy 52M V-groove weld, respectively. This is illustrated in Figures 3.41 and 3.42. Metallographic and SEM analyses were performed on the alloy 52M weld with hot cracks to determine the location of the hot cracks. Optical imaging was useful in mapping out the location of defects across entire width of the CT blanks while SEM was used to study the defects in greater detail. As shown in Figure 3.43, the majority of the defects were hot cracks along grain boundaries, and the density of these hot cracks was low. Because the cross-sectional area of the as-received weldment was only slightly larger than a $0.5 \mathrm{~T}$ CT specimen, only a few regions of the weld could be selected for crack growth testing. Figure 3.44 shows the positioning of 
specimens СT042 and СT043 on the CT blanks while the yellow boxes in Figure 3.43 show the region of the weldment to be SCC tested relative to the observed weld defects in one of the metallography specimens. Specimen CT042 is positioned off-center to intersect a higher density of weld cracks, while CT043 is positioned near the center where fewer cracks were observed. All four alloy 52M specimens were pre-cracked in air to a depth of $\sim 1.2 \mathrm{~mm}$.
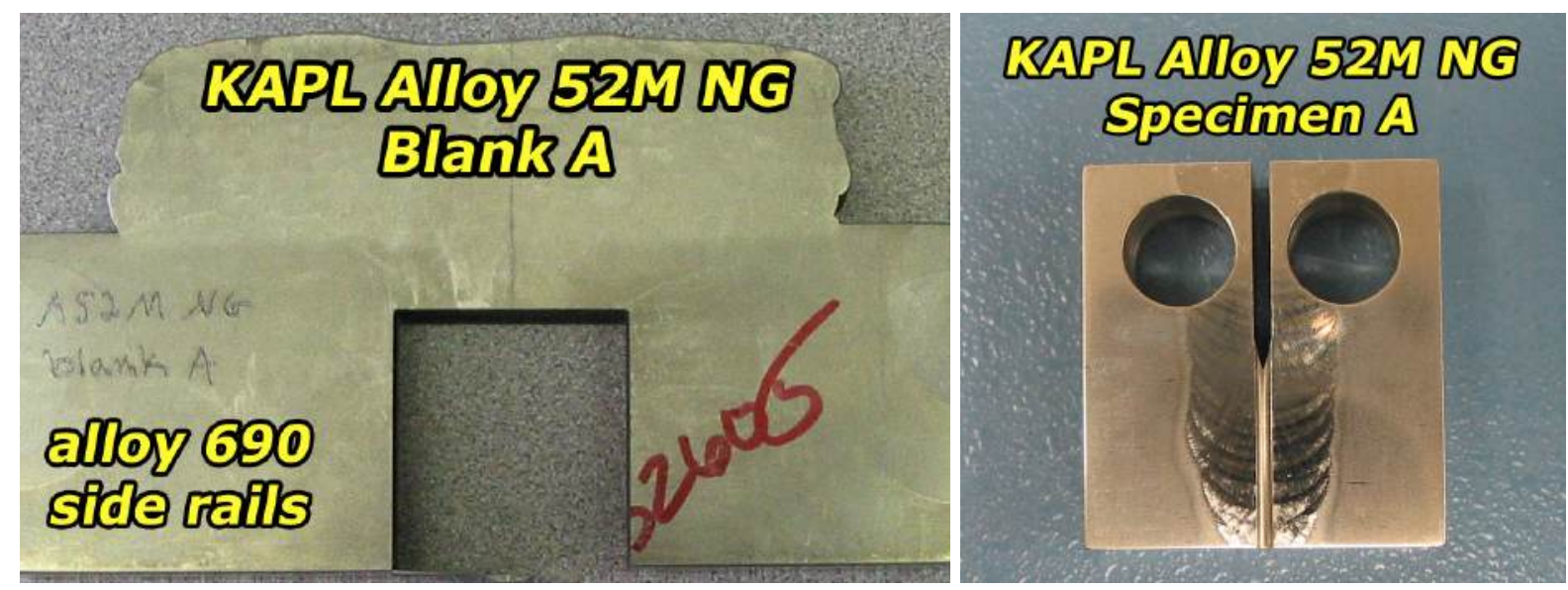

Figure 3.41 Photos of KAPL alloy 52M narrow gap weld blank "A" and CT040 specimen machined from the blank.
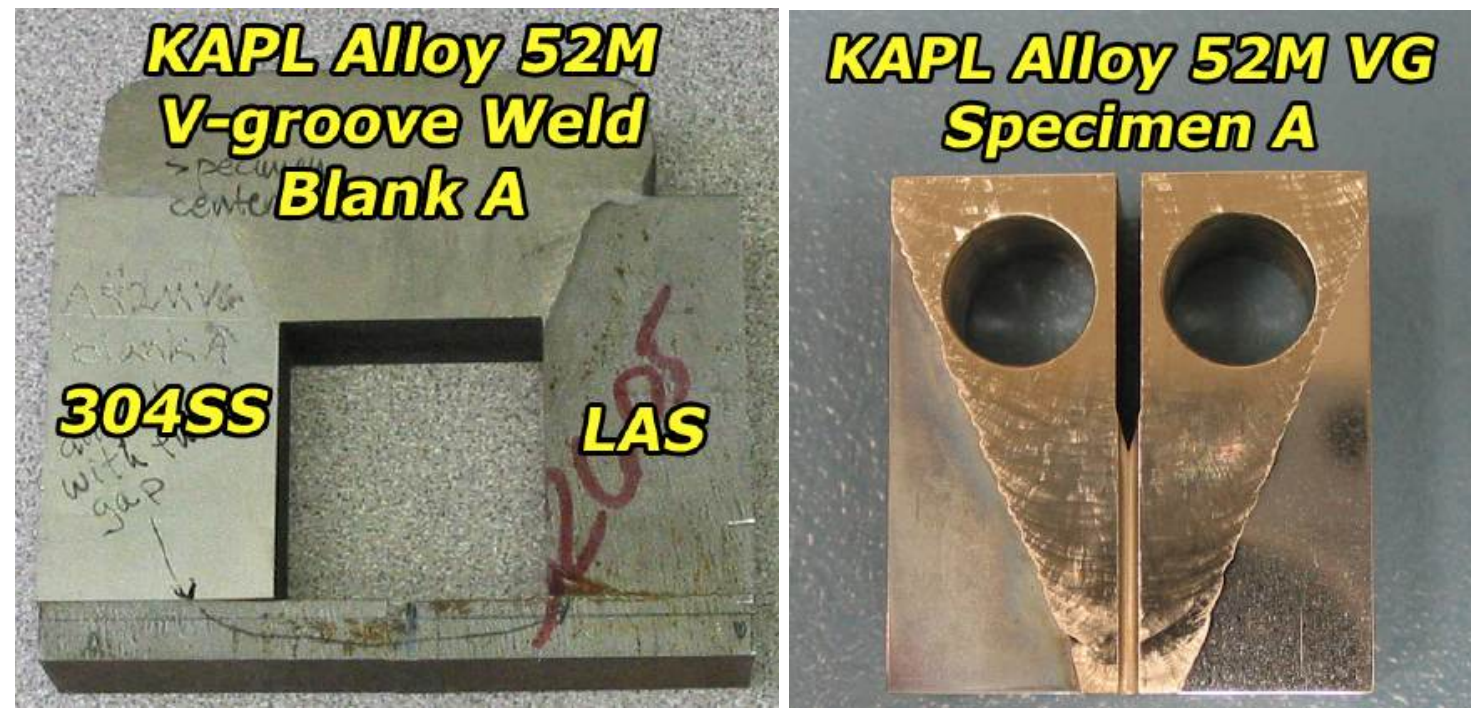

Figure 3.42 Photos of KAPL alloy 52M V-groove weld blank "A" and CT041 specimen machined from the blank. 


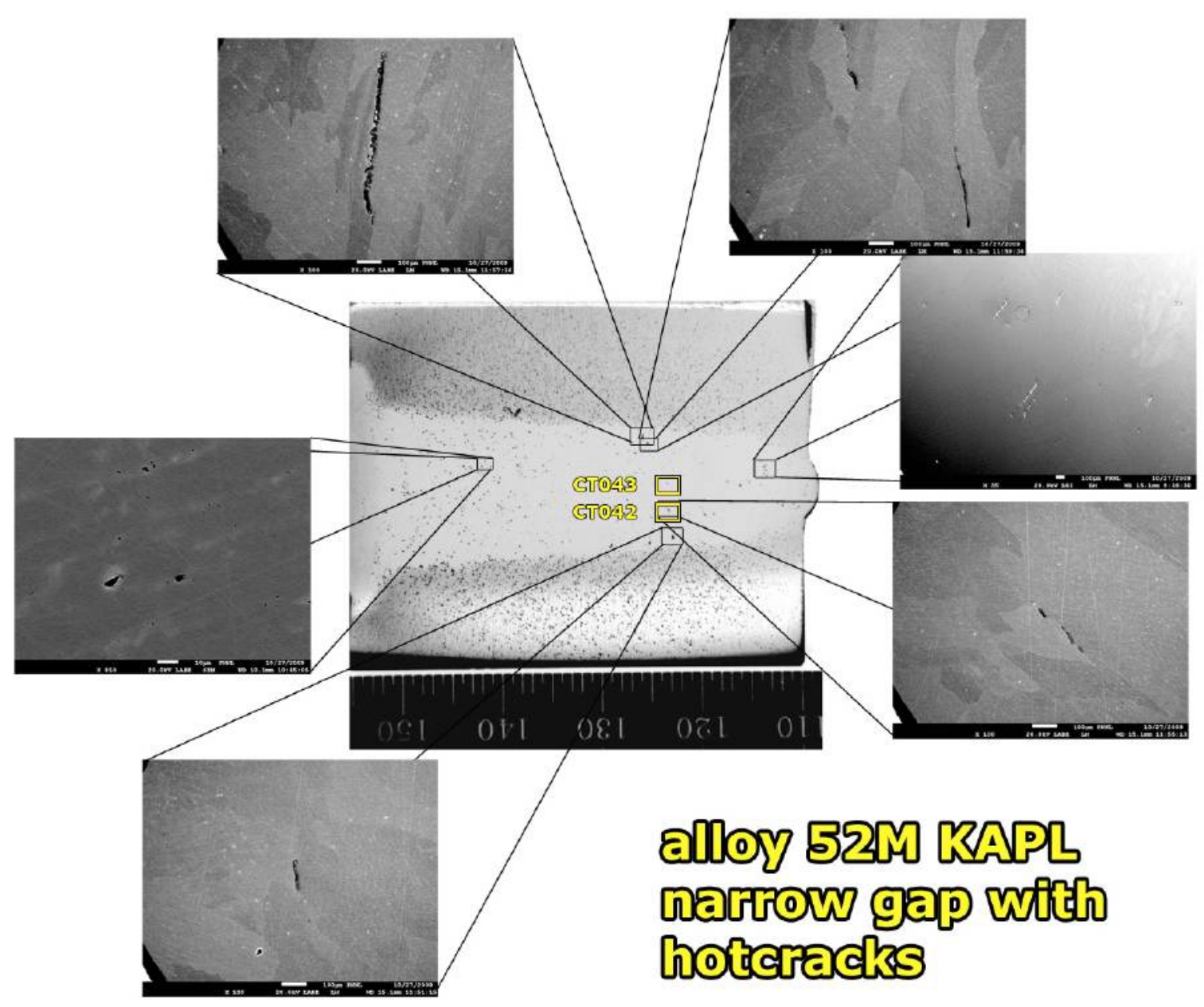

Figure 3.43 Overview of defects in the KAPL alloy 52M weld with known hot cracks.

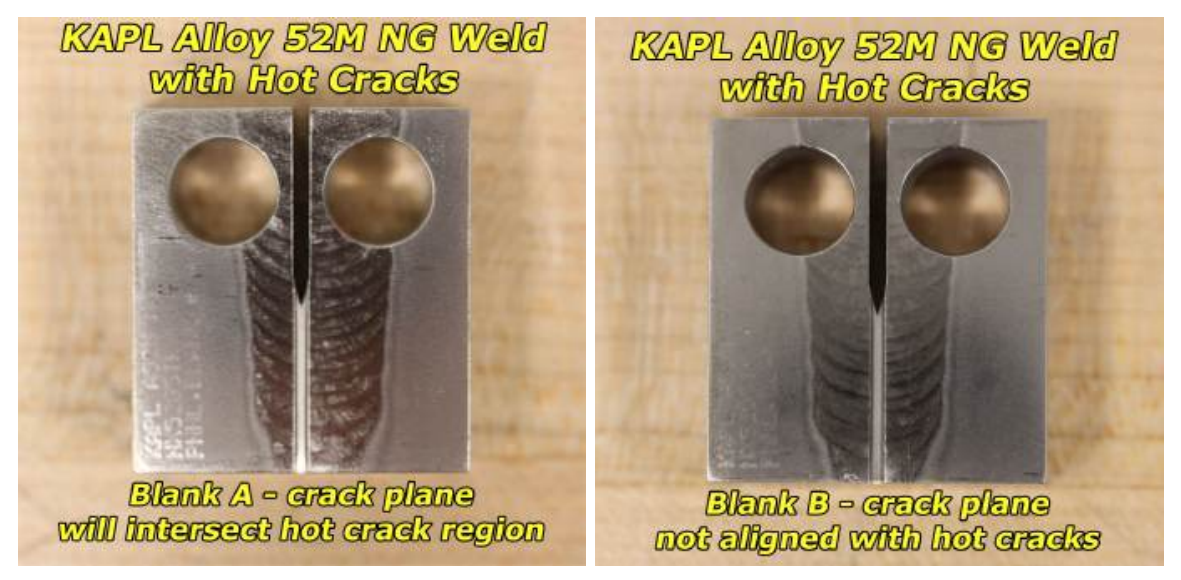

Figure 3.44 Photos of specimens cut from KAPL alloy 52M narrow gap weld containing hot cracks. Blank A (CT042) is positioned off-center and near the bottom of the weldment to insect a high density of weld cracks, while blank B (CT043) is positioned near the center of the weld where no weld cracks were observed. 
KAPL Alloy 52M Narrow Gap and V-Groove Weld Testing (CT040 \& CT041)

Testing was performed in simulated PWR primary water at either $350^{\circ} \mathrm{C}$ with $20 \mathrm{cc} / \mathrm{kg}$ dissolved $\mathrm{H}_{2}$ or, later in the test, $360^{\circ} \mathrm{C}$ and $25 \mathrm{cc} / \mathrm{kg} \mathrm{H}_{2}$. These hydrogen concentrations were selected to obtain ECP conditions at the $\mathrm{Ni} / \mathrm{NiO}$ transition [Ref. 6]. An overview of the entire test is presented in Figure 3.45. During in-situ pre-cracking and initial transitioning steps at $R=0.7$, low CGRs were observed, so steps were duplicated at a more aggressive $R$ of 0.5 starting at $\sim 180 \mathrm{~h}$. CGR response increased significantly with both samples reaching rates $>10^{-6} \mathrm{~mm} / \mathrm{s}$ at $0.1 \mathrm{~Hz}$. The $\mathrm{V}$-groove weld sample exhibited higher CGRs than the narrow-gap weld as the cyclic frequency was reduced first to 0.01 and then to $0.001 \mathrm{~Hz}$.

As transitioning steps continued, higher CGRs continued to be measured in the V-groove weld sample than for the narrow-gap weld sample. This is illustrated in Figure 3.46. Rates during cycle + hold were $1.6 \times 10^{-8} \mathrm{~mm} / \mathrm{s}$ for the V-groove weld, somewhat higher than identified for previous alloy 52 weld metal tests and $\sim 2 X$ higher than the narrow-gap weld. The decision was made to switch to constant $\mathrm{K}$ conditions at $\sim 1130 \mathrm{~h}$ and investigate SCC response. Crackgrowth rates of $3.6 \times 10^{-9} \mathrm{~mm} / \mathrm{s}$ and $\sim 7 \times 10^{-10} \mathrm{~mm} / \mathrm{s}$ can be seen for the V-groove and narrow-gap alloy $52 \mathrm{M}$ weld specimens, respectively. Stable SCC propagation is seen throughout the constant $\mathrm{K}$ period for the $\mathrm{V}$-groove weld specimen in Figure 3.47, while growth, if any, appears to have stalled in the narrow-gap weld specimen.

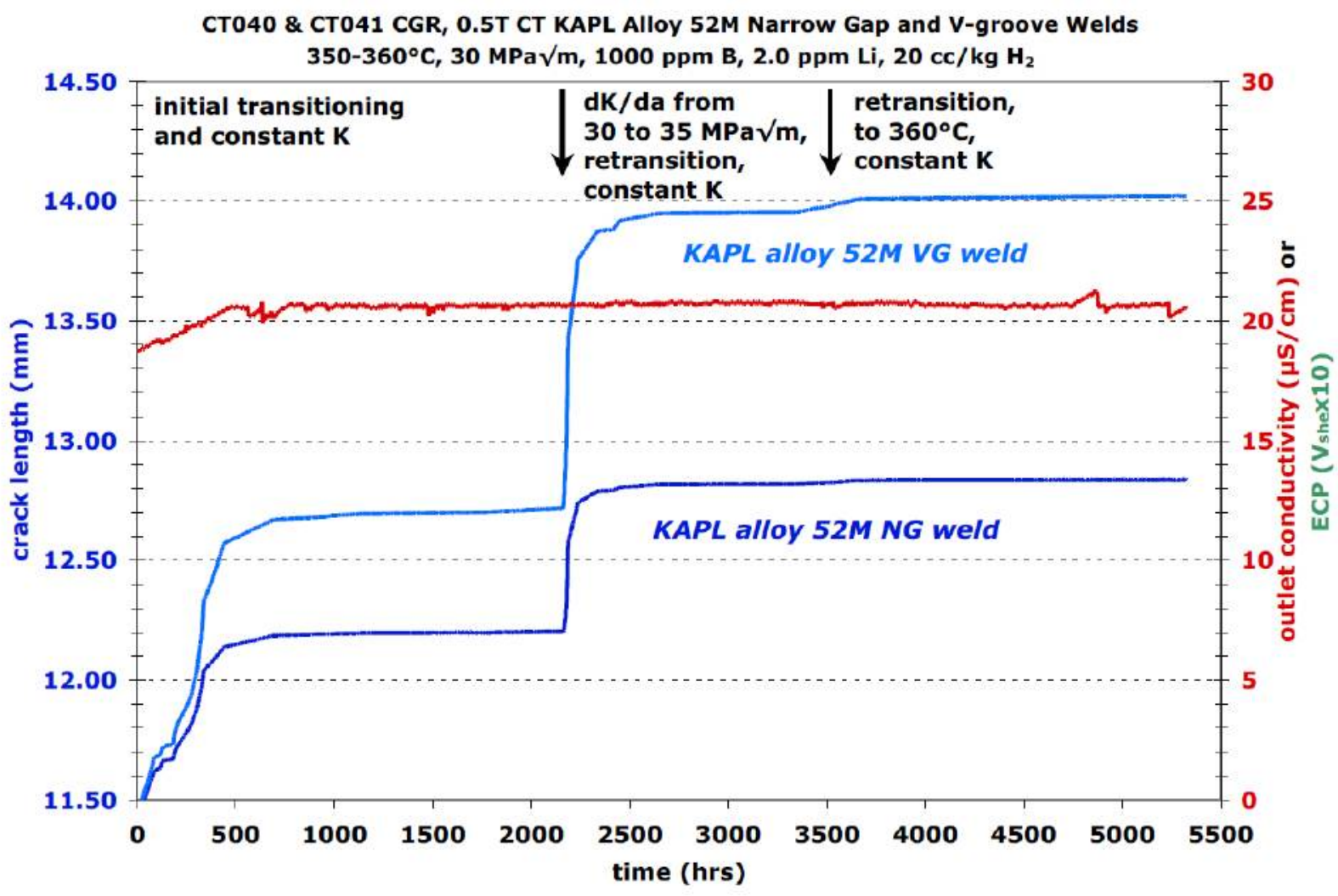

Figure 3.45 Overview of the entire test on the KAPL alloy 52M narrow gap (CT040) and V-groove (CT041) specimens. 


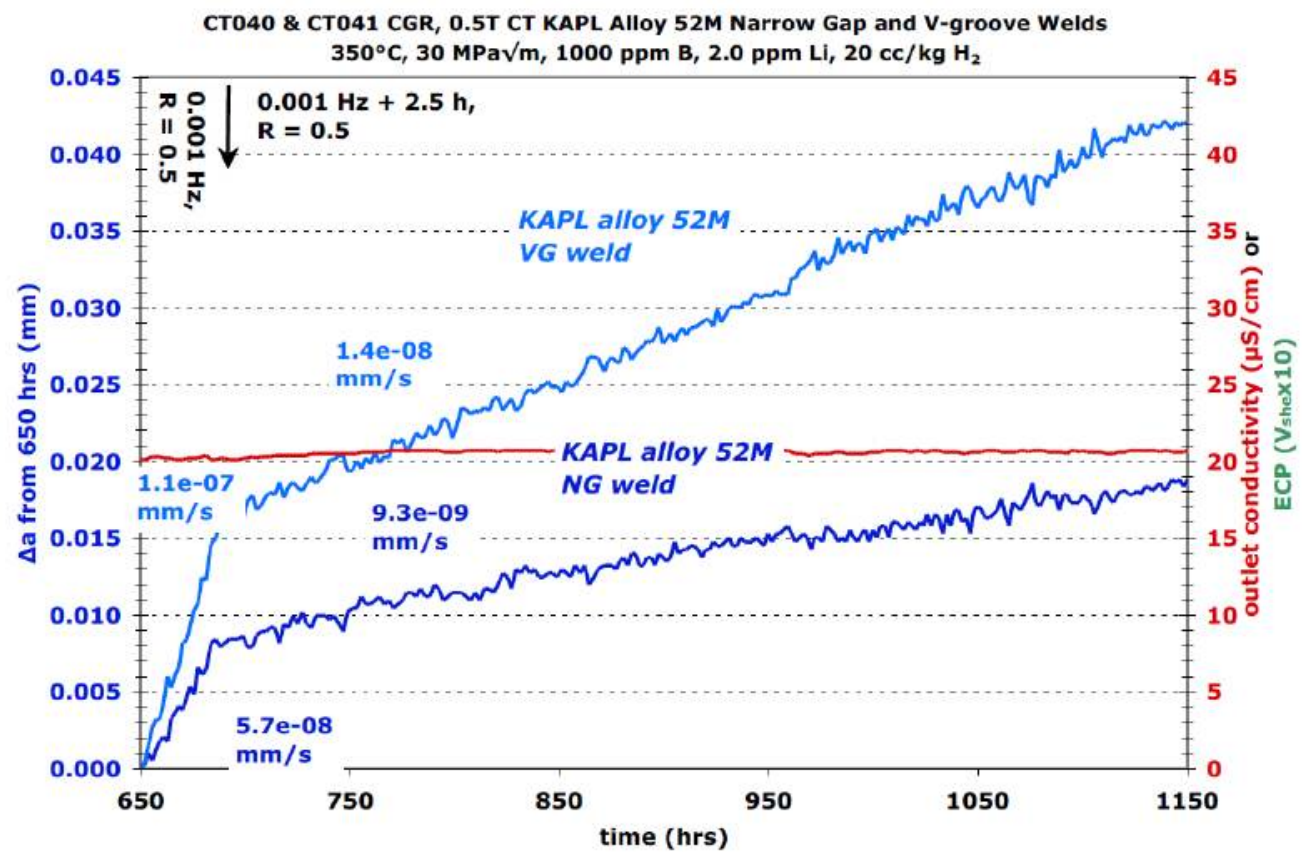

Figure 3.46 Response during initial cycle + hold transitioning steps on the KAPL alloy 52M narrow gap (CT040) and V-groove (CT041) specimens.

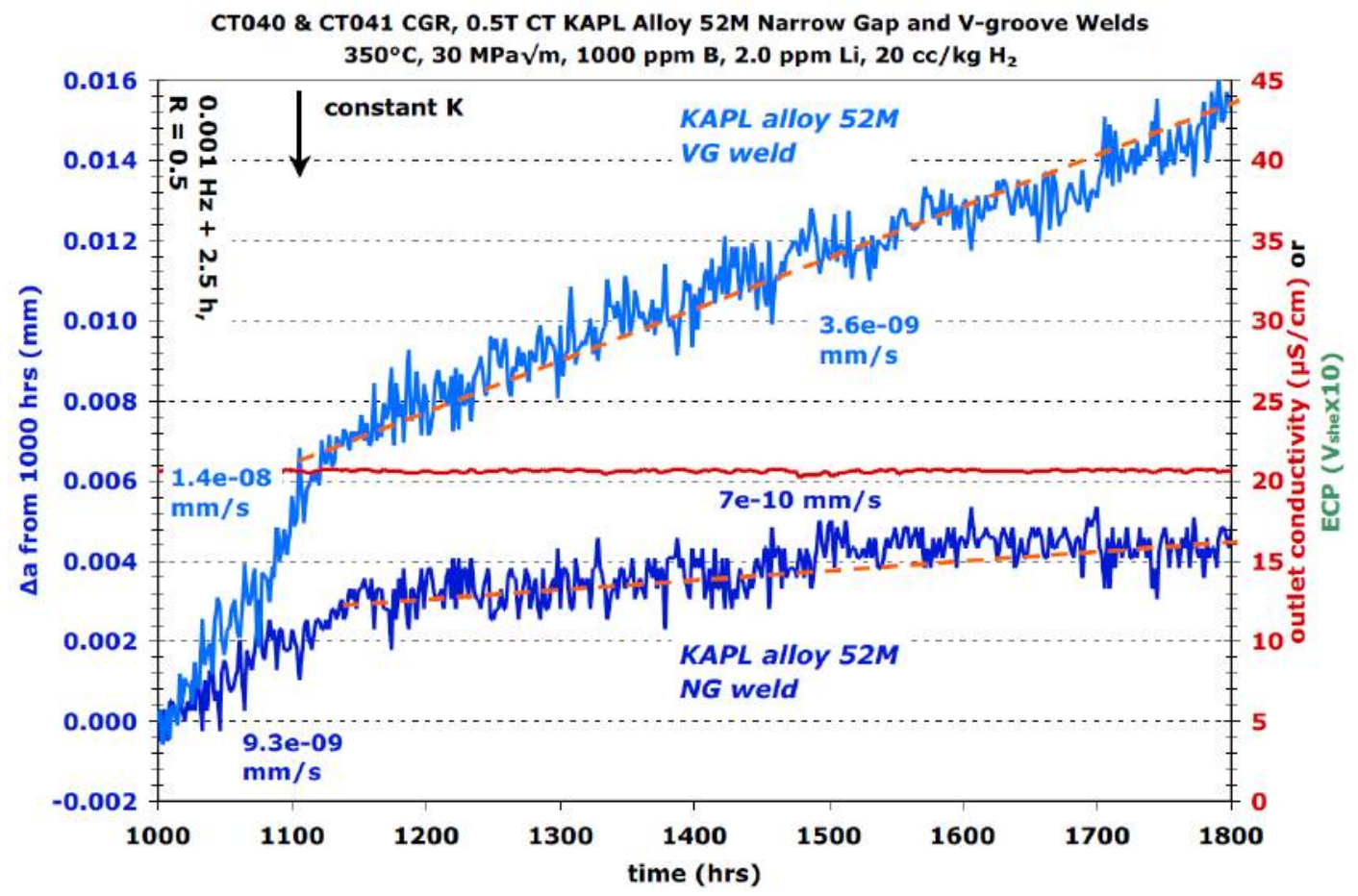

Figure 3.47 Response during initial constant $\mathrm{K}$ step on the KAPL alloy 52M narrow gap (CT040) and V-groove (CT041) specimens. 
Gentle cycling was restarted to move the crack front forward slightly and straighten the crack front, but since higher propagation rates were not observed during retransitioning, the decision was made to increase the $\mathrm{K}$ level for both specimens. Cycling at $0.1 \mathrm{~Hz}(\mathrm{R}=0.5)$ was established under $\mathrm{dK} / \mathrm{da}$ loading at $\sim 2165 \mathrm{~h}$ with the $\mathrm{NG}$ sample increasing from 30 to $35 \mathrm{MPa} \sqrt{\mathrm{m}}$ and the $\mathrm{VG}$ sample increasing from 32 to $39 \mathrm{MPa} \sqrt{\mathrm{m}}$. The CGR response during this step is documented in Figure 3.48 showing $\sim 390$ and $730 \mu \mathrm{m}$ of crack extension respectively for the NG and VG specimens over the 24-h period. Transitioning was then performed by decreasing the cyclic frequency and moving to a cycle + hold at $\sim 2330 \mathrm{~h}$. Higher CGRs were again observed during all loading conditions for the VG than for the NG sample. Transitioning steps were continued until constant $\mathrm{K}$ (35 MPa $\sqrt{\mathrm{m}}$ in the NG sample and $40 \mathrm{MPa} \sqrt{\mathrm{m}}$ in the VG sample) was established at $\sim 2650 \mathrm{~h}$ as shown in Figure 3.49. Propagation rate for the NG specimen was initially stable at $1.3 \times 10^{-9} \mathrm{~mm} / \mathrm{s}$, similar to what has been observed in previous alloy 52M materials tested at PNNL. The V-groove specimen exhibited a higher growth rate of $\sim 3.0 \times 10^{-9} \mathrm{~mm} / \mathrm{s}$ for about $600 \mathrm{~h}$ and then appeared to slow down at $\sim 3200 \mathrm{~h}$. The initial CGR for the $\mathrm{V}$-groove specimen is similar to the value measured at the lower $\mathrm{K}$ value.

To help promote SCC, a cycle + hold loading condition was reestablished and the test temperature increased to $360^{\circ} \mathrm{C}$ while holding the ECP on the $\mathrm{Ni} / \mathrm{NiO}$ line $(25 \mathrm{cc} / \mathrm{kg} \mathrm{H}$ ). Once again, crack growth rates started higher when switching back to constant $\mathrm{K}$ but decreased after $\sim 500 \mathrm{~h}$. This is illustrated in Figure 3.50 with the VG specimen slowing from $3.5 \times 10^{-9} \mathrm{~mm} / \mathrm{s}$ to $2.3 \times 10^{-9} \mathrm{~mm} / \mathrm{s}$. The rate for the NG specimen starts off at $\sim 6 \times 10^{-10} \mathrm{~mm} / \mathrm{s}$, and then appears to stall after $1000 \mathrm{~h}$. This test was ended after $\sim 1700 \mathrm{~h}$ under constant $\mathrm{K}(35-40 \mathrm{MPa} \sqrt{\mathrm{m}})$ conditions at $360^{\circ} \mathrm{C}$ and $25 \mathrm{cc} / \mathrm{kg} \mathrm{H}_{2}$. The CGRs for both samples are similar to the previous measurements at $350^{\circ} \mathrm{C}$ with slightly lower $\mathrm{K}$ values. A summary of the corrected step-by-step data obtained during this test is presented in Table 3.7.

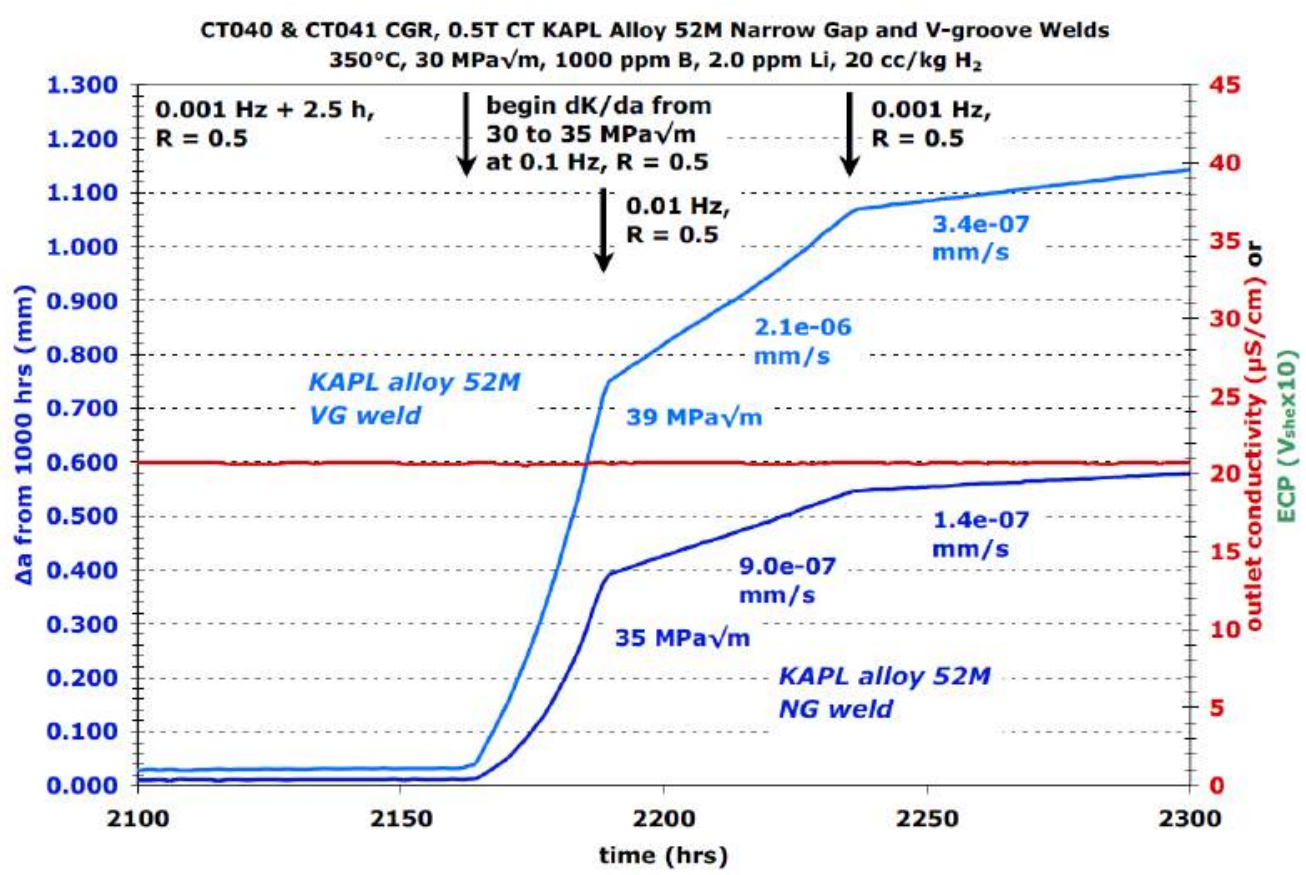

Figure 3.48 Crack-growth response during the $\mathrm{K}$ increase by $\mathrm{dK} / \mathrm{da}$. 


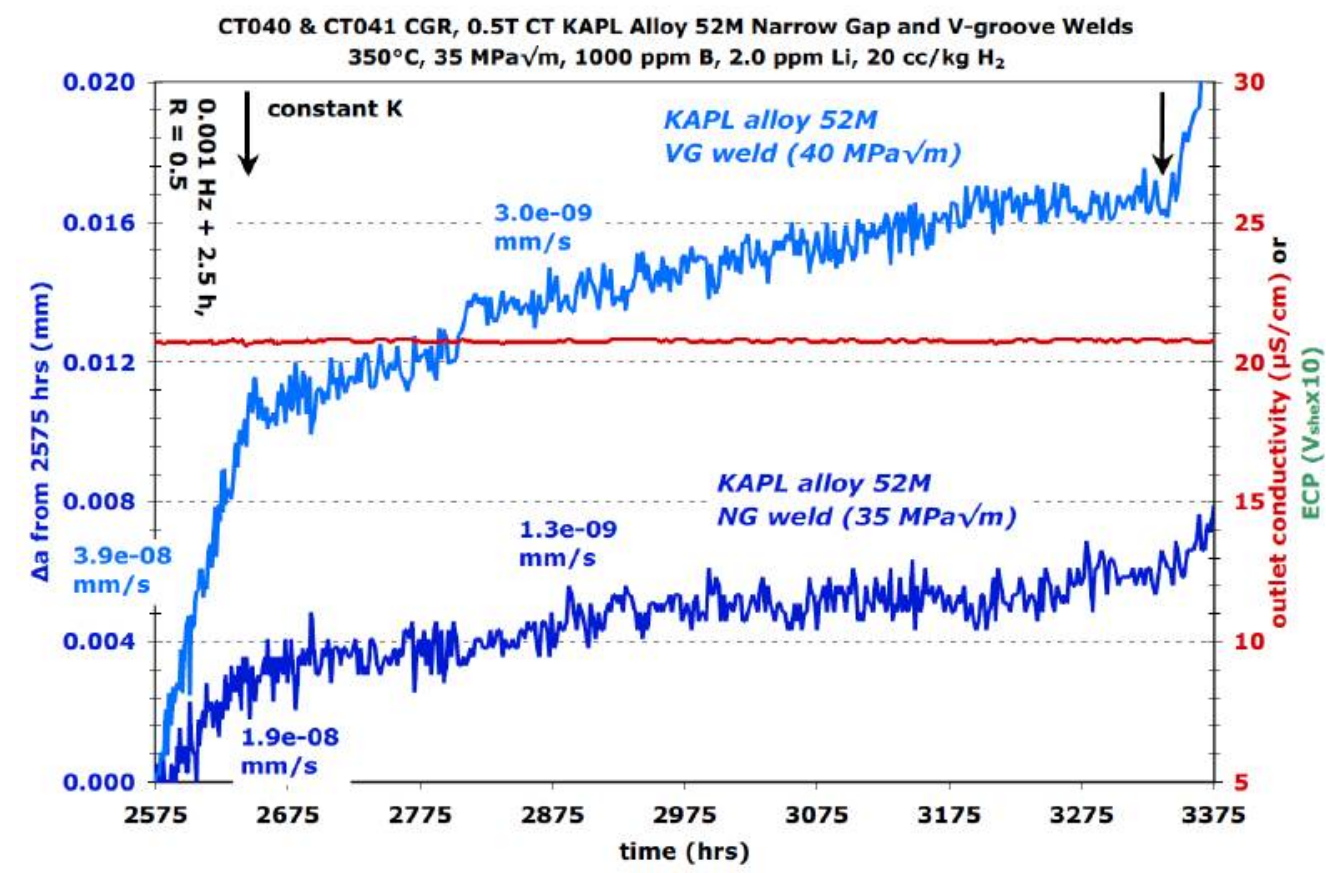

Figure 3.49 Crack-growth response from cycle + hold to constant K for CT040 \& CT041.

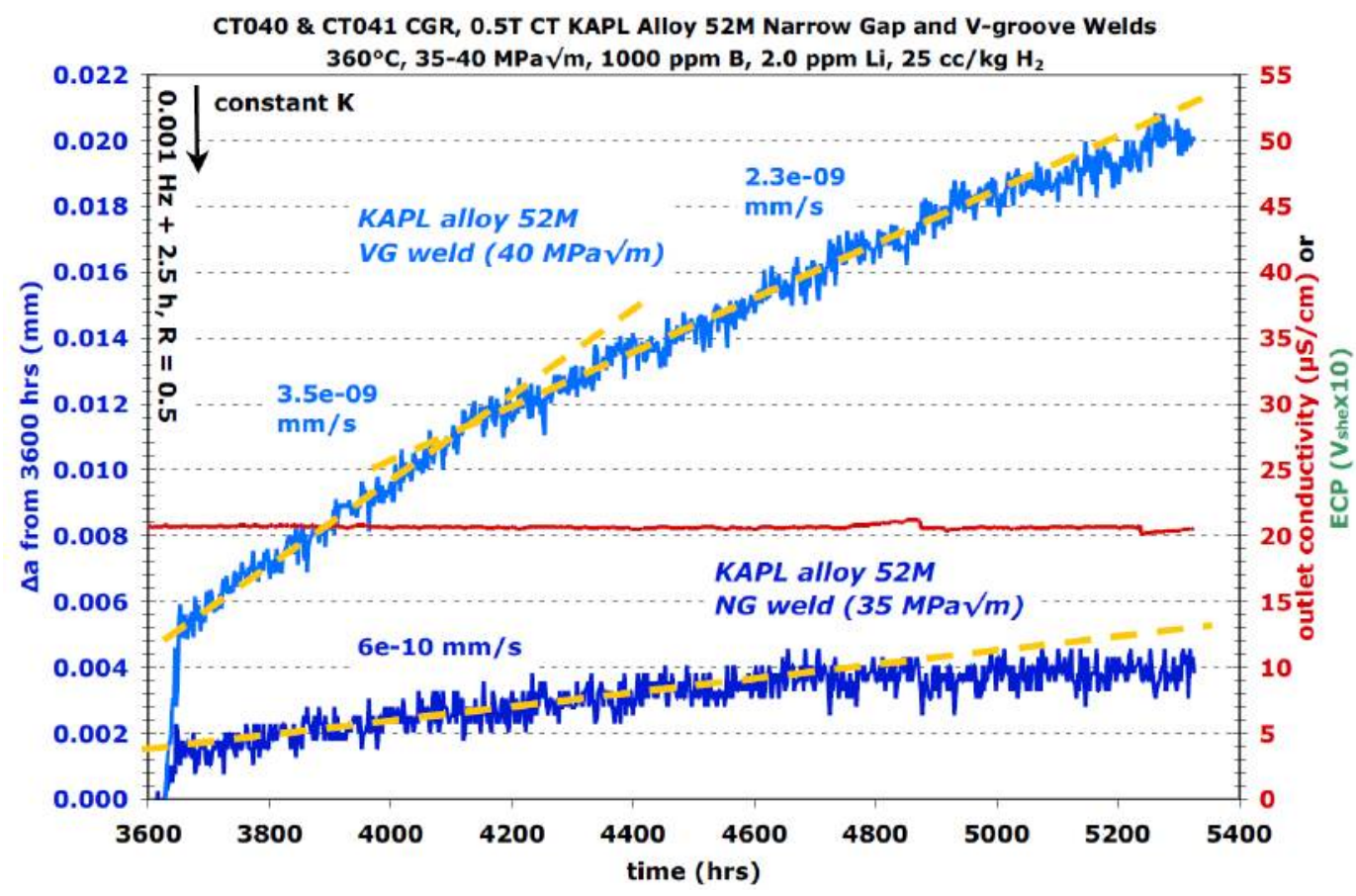

Figure 3.50 Crack growth response during constant $\mathrm{K}$ at $360^{\circ} \mathrm{C}$ for the $\mathrm{KAPL}$ alloy $52 \mathrm{M}$ narrow gap (CT040) and V-groove (CT041) weld specimens. 
Table 3.7 Corrected data summary for KAPL alloy 52M specimens CT040 \& CT041.

\begin{tabular}{|c|c|c|c|c|c|c|c|c|c|c|c|c|}
\hline \begin{tabular}{|c} 
Test \\
Phase \\
\end{tabular} & $\begin{array}{l}\text { Dur- } \\
\text { ation } \\
\text { (h) }\end{array}$ & $\mathrm{R}$ & $\begin{array}{l}\text { Freq } \\
(\mathrm{Hz})\end{array}$ & $\begin{array}{c}\text { Hold } \\
\text { (h) }\end{array}$ & Water & $\begin{array}{c}\text { Temp } \\
\left({ }^{\circ} \mathrm{C}\right) \\
\end{array}$ & $\begin{array}{c}\text { KAPL } \\
\text { Kmax } \\
(\mathrm{MPa} \sqrt{\mathrm{m}})\end{array}$ & $\begin{array}{c}\text { CGR } \\
(\mathrm{mm} / \mathrm{sec})\end{array}$ & $\begin{array}{c}\text { Blank A } \\
\text { Crack } \\
\text { Extension } \\
(\mathrm{mm}) \\
\end{array}$ & $\begin{array}{c}\text { KAPL A5 } \\
\text { Kmax } \\
(\mathrm{MPa} \sqrt{\mathrm{m}})\end{array}$ & $\begin{array}{c}\text { CT041 } \\
\text { 2M V-groove } \\
\text { CGR } \\
(\mathrm{mm} / \mathrm{sec})\end{array}$ & $\begin{array}{c} \\
\text { Ve Blank A } \\
\text { Crack } \\
\text { Extension } \\
(\mathrm{mm}) \\
\end{array}$ \\
\hline 1 & $\sim 3$ & 0.3 & 5 & 0 & air precrack & RT & 21 & $6.8 \mathrm{E}-05$ & 0.40 & 21 & $6.2 \mathrm{E}-05$ & 0.40 \\
\hline 2 & $\sim 2$ & 0.5 & 5 & 0 & air precrack & RT & 23 & 4.0E-05 & 0.35 & 24 & 3.7E-05 & 0.35 \\
\hline 3 & $\sim 2$ & 0.6 & 5 & 0 & air precrack & RT & 26 & 2.6E-05 & 0.35 & 26 & 2.6E-05 & 0.35 \\
\hline 4 & $\sim 3$ & 0.7 & 5 & 0 & air precrack & RT & 26 & 1.3E-05 & 0.20 & 26 & $1.2 \mathrm{E}-05$ & 0.20 \\
\hline 5 & 86 & 0.7 & 0.1 & 0 & $20 \mathrm{cc} / \mathrm{kg} \mathrm{H}_{2}$ & 350 & 31 & $7.8 \mathrm{E}-07$ & 0.241 & 32 & $9.8 \mathrm{E}-07$ & 0.319 \\
\hline 6 & 100 & 0.7 & 0.01 & 0 & $20 \mathrm{cc} / \mathrm{kg} \mathrm{H}_{2}$ & 350 & 31 & $1.3 \mathrm{E}-07$ & 0.062 & 32 & $1.4 \mathrm{E}-07$ & 0.078 \\
\hline 7 & 153 & 0.5 & 0.1 & 0 & $20 \mathrm{cc} / \mathrm{kg} \mathrm{H}_{2}$ & 350 & 31 & $1.6 \mathrm{E}-06$ & 0.443 & 33 & 3.5E-06 & 0.784 \\
\hline 8 & 100 & 0.5 & 0.01 & 0 & $20 \mathrm{cc} / \mathrm{kg} \mathrm{H}_{2}$ & 350 & 31 & $3.5 \mathrm{E}-07$ & 0.116 & 34 & $9.6 \mathrm{E}-07$ & 0.302 \\
\hline 9 & 242 & 0.5 & 0.001 & 0 & $20 \mathrm{cc} / \mathrm{kg} \mathrm{H}_{2}$ & 350 & 31 & $6.9 \mathrm{E}-08$ & 0.055 & 34 & 1.4E-07 & 0.127 \\
\hline 10 & 454 & 0.5 & 0.001 & 2.5 & $20 \mathrm{cc} / \mathrm{kg} \mathrm{H}_{2}$ & 350 & 31 & 1.1E-08 & 0.012 & 34 & $1.8 \mathrm{E}-08$ & 0.033 \\
\hline 11 & 647 & --- & const $\mathrm{K}$ & --- & $20 \mathrm{cc} / \mathrm{kg} \mathrm{H}_{2}$ & 350 & 31 & $\sim 8 \mathrm{E}-10$ & 0.002 & 34 & 4.6E-09 & 0.011 \\
\hline 12 & 380 & 0.5 & 0.001 & 2.5 & $20 \mathrm{cc} / \mathrm{kg} \mathrm{H}_{2}$ & 350 & 31 & $1.8 \mathrm{E}-08$ & 0.007 & 35 & $6.8 \mathrm{E}-09$ & 0.021 \\
\hline 13 & 26 & 0.5 & 0.1 & 0 & $20 \mathrm{cc} / \mathrm{kg} \mathrm{H}_{2}$ & 350 & 31->37 & increasing & 0.439 & $35->45$ & increasing & 0.899 \\
\hline 14 & 47 & 0.5 & 0.01 & 0 & $20 \mathrm{cc} / \mathrm{kg} \mathrm{H}_{2}$ & 350 & 37 & 1.1E-06 & 0.199 & 45 & 2.7E-06 & 0.436 \\
\hline 15 & 94 & 0.5 & 0.001 & 0 & $20 \mathrm{cc} / \mathrm{kg} \mathrm{H}_{2}$ & 350 & 37 & $1.6 \mathrm{E}-07$ & 0.061 & 46 & 4.5E-07 & 0.158 \\
\hline 16 & 84 & 0.5 & 0.001 & 2.5 & $20 \mathrm{cc} / \mathrm{kg} \mathrm{H}_{2}$ & 350 & 37 & 1.3E-08 & 0.007 & 46 & $1.8 \mathrm{E}-08$ & 0.017 \\
\hline 17 & 32 & 0.5 & 0.001 & 0 & $20 \mathrm{cc} / \mathrm{kg} \mathrm{H}_{2}$ & 350 & 37 & $1.4 \mathrm{E}-07$ & 0.013 & 46 & 4.2E-07 & 0.044 \\
\hline 18 & 195 & 0.5 & 0.001 & 2.5 & $20 \mathrm{cc} / \mathrm{kg} \mathrm{H}_{2}$ & 350 & 37 & 2.3E-08 & 0.016 & 46 & $5.1 \mathrm{E}-08$ & 0.041 \\
\hline 19 & 704 & --- & const $\mathrm{K}$ & --- & $20 \mathrm{cc} / \mathrm{kg} \mathrm{H}_{2}$ & 350 & 37 & 1.6E-09 & 0.004 & 46 & 3.8E-09 & 0.010 \\
\hline 20 & 159 & 0.5 & 0.001 & 2.5 & $20 \mathrm{cc} / \mathrm{kg} \mathrm{H}_{2}$ & 350 & 37 & 1.6E-08 & 0.008 & 46 & $5.3 \mathrm{E}-08$ & 0.030 \\
\hline 21 & 146 & 0.5 & 0.001 & 2.5 & $25 \mathrm{cc} / \mathrm{kg} \mathrm{H}_{2}$ & 360 & 37 & 2.1E-08 & 0.010 & 47 & $7.8 \mathrm{E}-08$ & 0.037 \\
\hline $22 \mathrm{~A}$ & 500 & --- & const $\mathrm{K}$ & --- & $25 \mathrm{cc} / \mathrm{kg} \mathrm{H}_{2}$ & 360 & 37 & $\sim 1 \mathrm{E}-09$ & 0.001 & 47 & 4.2E-09 & 0.009 \\
\hline $22 \mathrm{~A}$ & 1176 & --- & const $\mathrm{K}$ & --- & $25 \mathrm{cc} / \mathrm{kg} \mathrm{H}_{2}$ & 360 & 37 & $\sim 5 \mathrm{E}-10$ & 0.001 & 47 & $2.8 \mathrm{E}-09$ & 0.011 \\
\hline
\end{tabular}

After testing, a slice was taken from each of the two CT specimens for preparation of an interior crack profile observation, and the other piece was fatigued open in air to reveal the crack growth surface. Figures 3.51 and 3.52 show the crack growth surface of CT040 and CT041, respectively. Strong changes in loading conditions are apparent along the crack growth surface of both specimens and are indicated by the yellow lines. In comparing the two surfaces the higher crack growth rate of the V-groove specimen is apparent in each major region of the test. While the final crack front of the narrow gap specimen (CT040) is relatively straight with little or no strong SCC protrusions, the V-groove specimen (CT041) appears to have clear SCC protrusions along the entire crack front. The cut line for the crack profile specimens is shown on the crack growth surface images, and the crack profile images are shown in Figures 3.53 and 3.54 for CT040 and CT041, respectively. The final crack front of the narrow gap specimen (CT040) is relatively straight with no obvious indication of IG engagement. The crack profile image shows that along the cut line, the precracking ended in the interior of a grain, and the subsequent crack growth appears to be essentially straight through the grain. Towards the end of the test, a grain boundary is encountered, but the cracking does not appear to be IG as it moves along the boundary. This suggests that the majority of the cracking in the narrow gap specimen is transgranular. While the precracking of the V-groove specimen (CT041) also ends 
in the interior of a grain, the crack does eventually find a grain boundary and grow intergranularly. The crack does wander away from the boundary for a period, but it eventually finds the boundary again. The crack profile reinforces the observations of the crack growth surface that the cracking is predominantly IG. The clear difference in crack growth rate between the two types of welds made using the same wire is an interesting result that warrants further observations and supports the need to study welds made using production welding parameters.

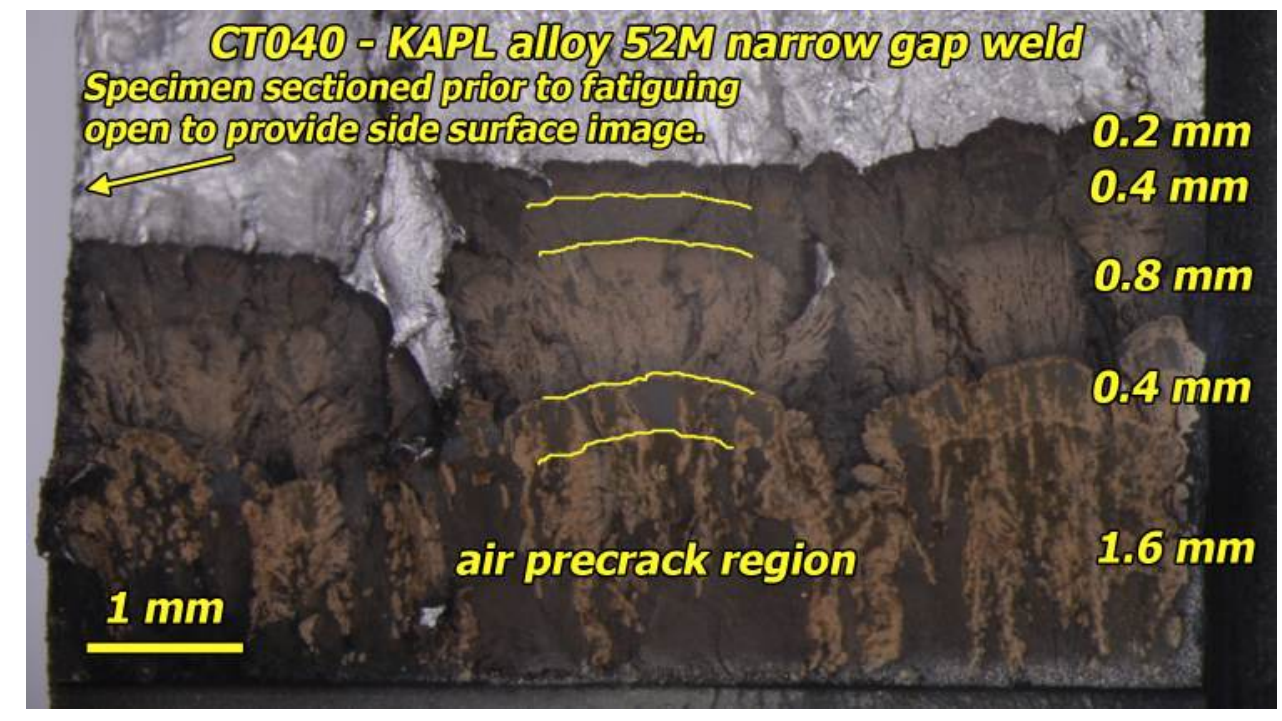

Figure 3.51 Crack growth surface of the KAPL alloy 52M narrow gap specimen, CT040.

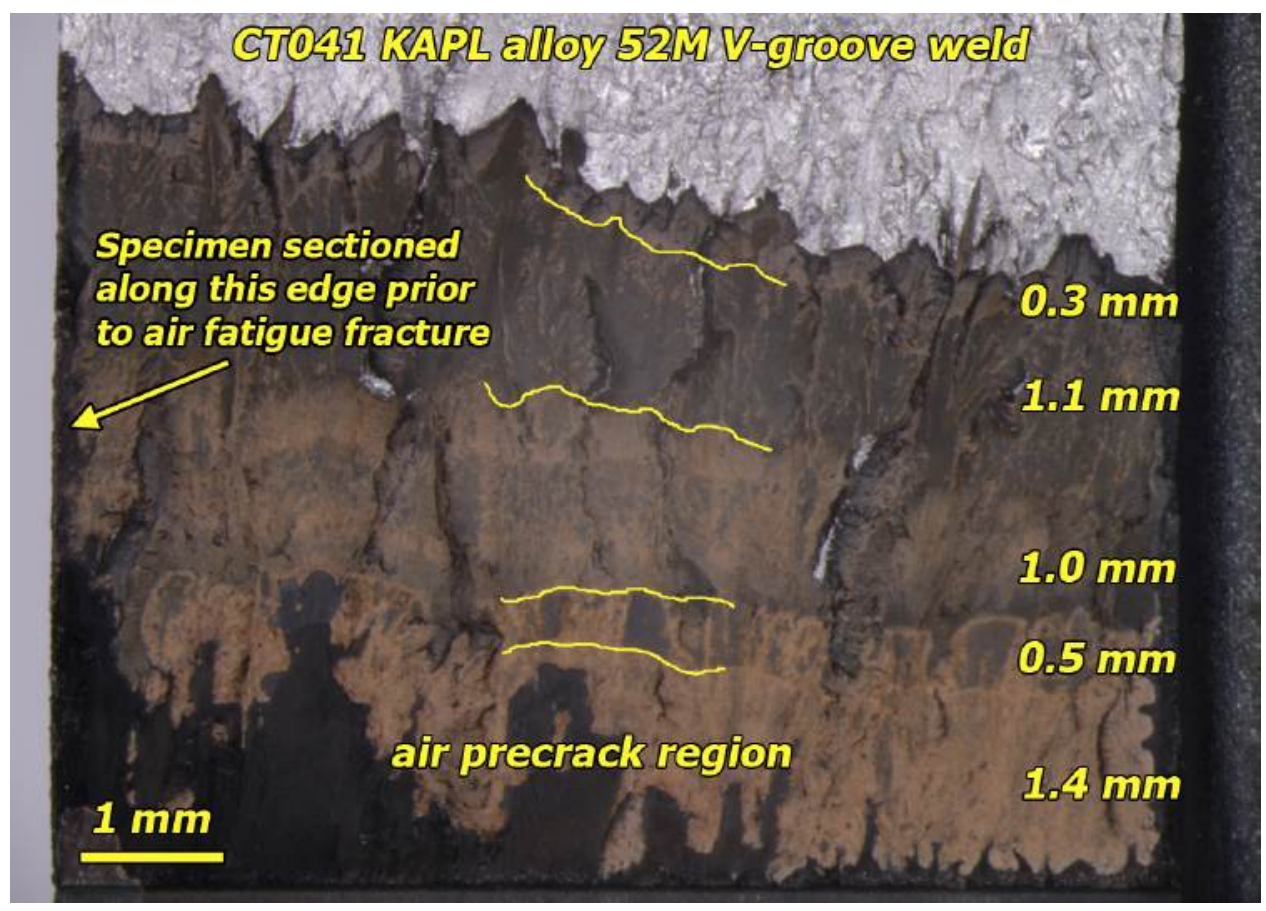

Figure 3.52 Crack growth surface of the KAPL alloy 52M V-groove specimen, CT041. 


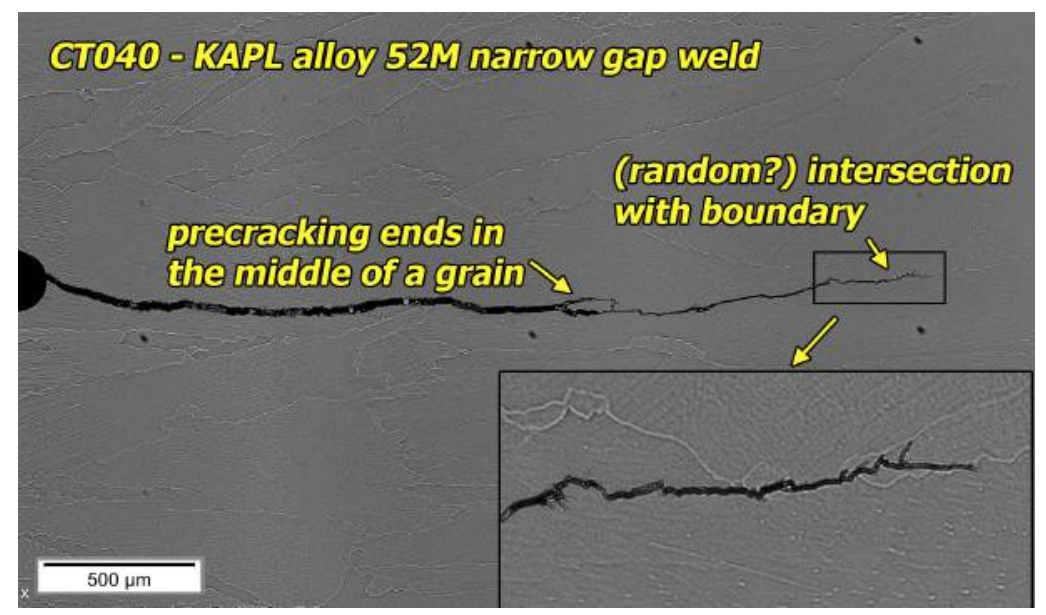

Figure 3.53 Crack profile of the KAPL alloy 52M narrow gap specimen, CT040.

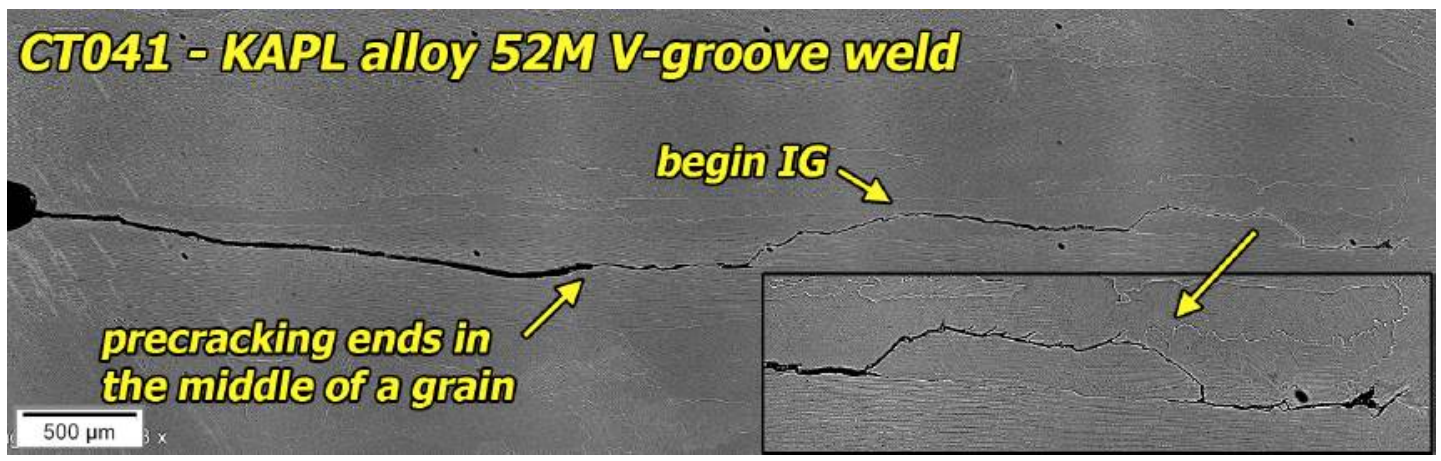

Figure 3.54 Crack profile of the KAPL alloy 52M V-groove specimen, CT041.

\section{KAPL Alloy 52M Narrow Gap Weld with Hot Cracks (CT042 \& CT043)}

The CT specimen aligned with the hot cracks (CT042) was cut from the weld blank so that the crack notch was $\sim 2.8-3.0 \mathrm{~mm}$ from the region thought to contain hot cracks. A standard precracking procedure in air was used to produce a precrack length of $\sim 1.2 \mathrm{~mm}$ in both specimens, thus allowing $\sim 1.6-1.8 \mathrm{~mm}$ of in-situ crack extension before reaching the region of material in CT042 thought to contain hot cracks. The test was initiated in $350^{\circ} \mathrm{C}$ water, and an overview of the entire in-situ test is provided in Figure 3.55. As indicated by the overview plot, several different transitioning steps were applied in the first phase of the test. With no prior information about the cracking susceptibility of the material, it was decided to begin in-situ precracking and transitioning at a conservative $\mathrm{R}$ of 0.7 , however, low crack growth rates indicative of a highly resistant material were obtained, and as shown in Figure 3.56, $\mathrm{R}$ was changed to a more aggressive value of 0.5 at $300 \mathrm{~h}$. CGR values measured at $0.001 \mathrm{~Hz}$ and at this same cyclic frequency with a $2.5 \mathrm{~h}$ hold were typical low values observed in other tests on alloy $152 / 52$ as shown in Figure 3.57. A higher crack growth rate is not seen for the specimen aligned to intersect hot cracks. Continuous cycling at $0.001 \mathrm{~Hz}$ was restarted at $\sim 900 \mathrm{~h}$ and was followed by checking for an increase in susceptibility under two different sawtooth waveforms. The observed propagation rates were consistent with rates observed in prior steps, indicating still typical response from both specimens. 


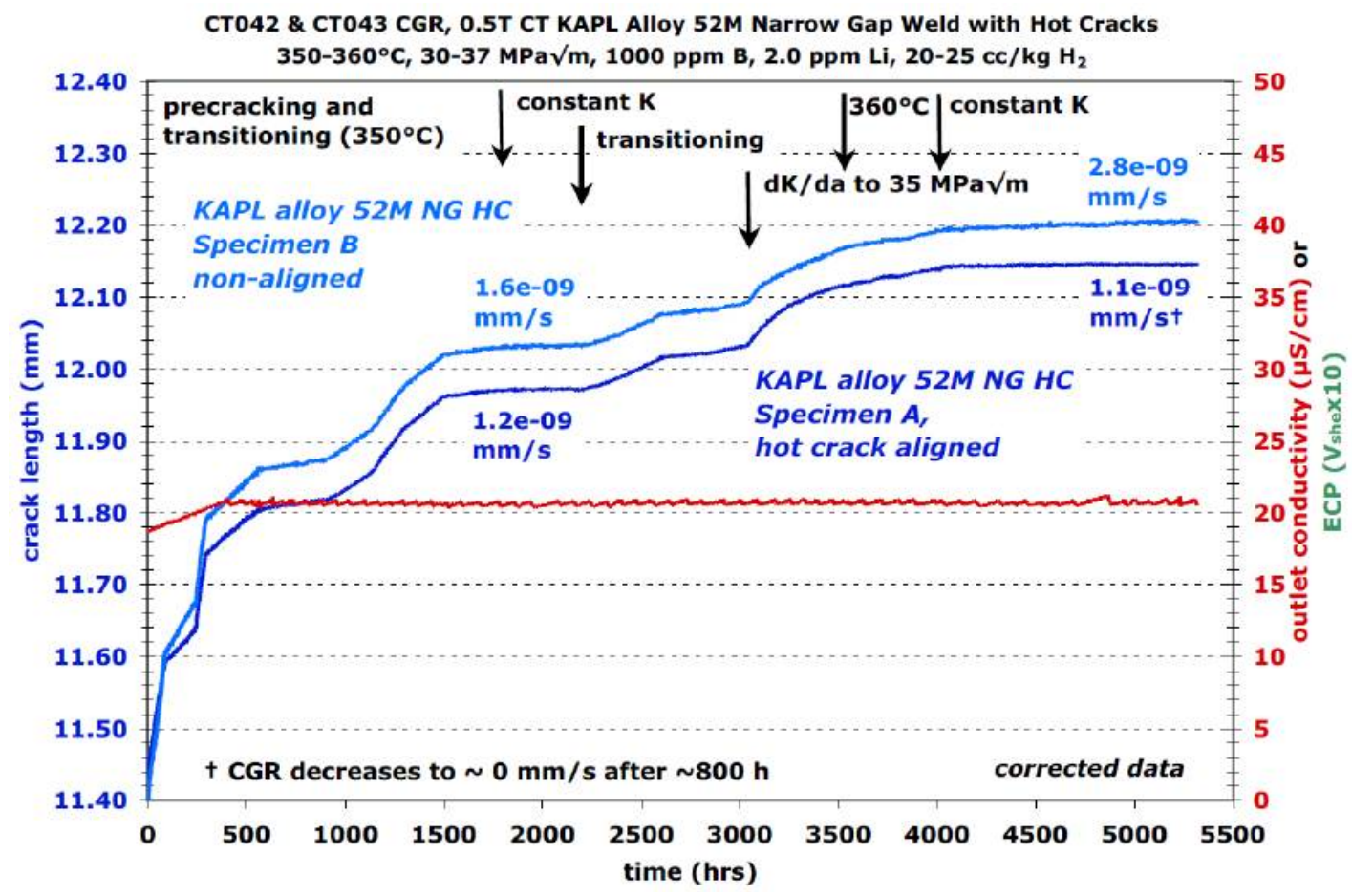

Figure 3.55 Overview of the entire test on the KAPL alloy 52M narrow gap weld specimens (CT042 \& CT043) with known hot cracks.

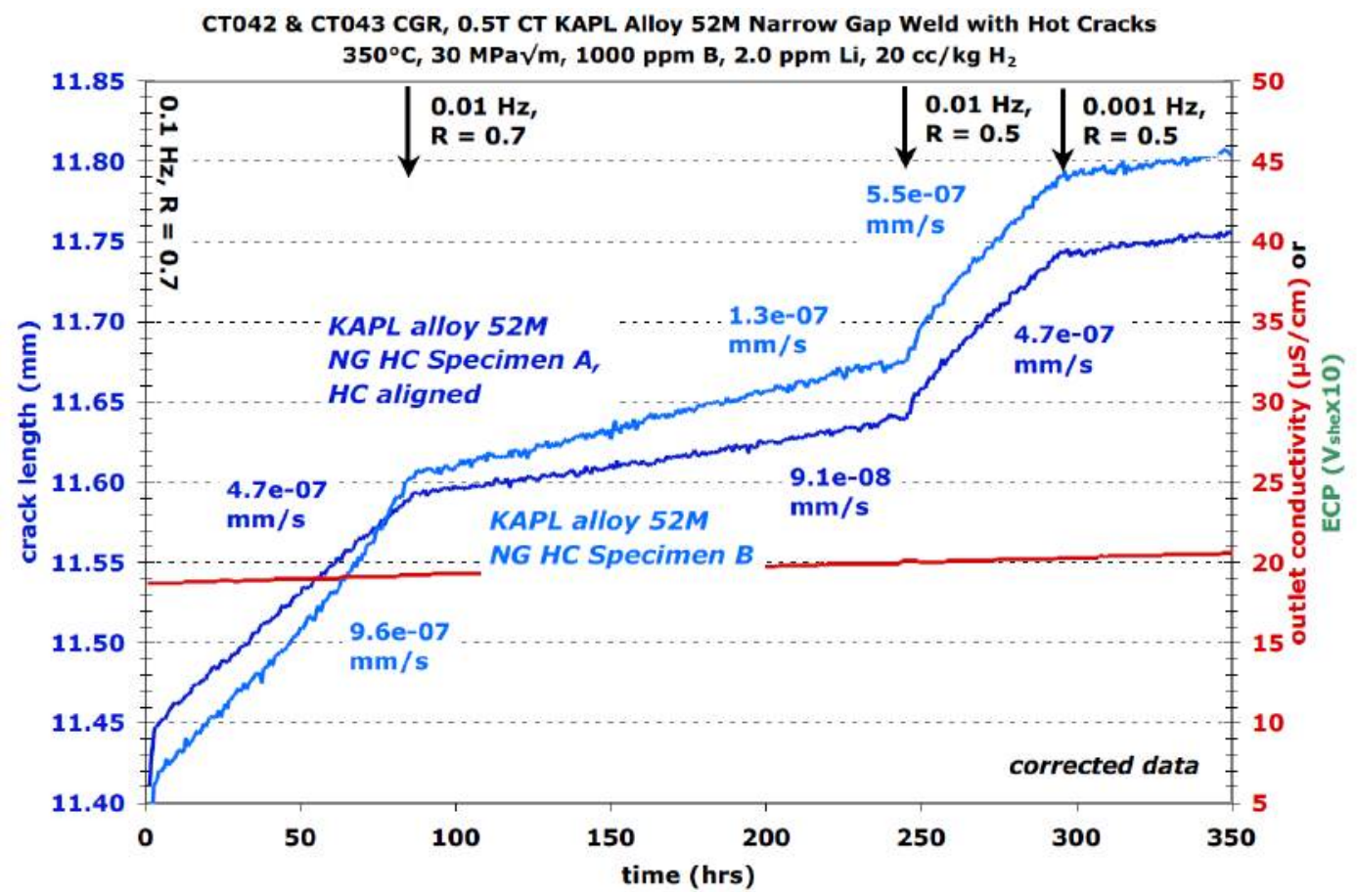

Figure 3.56 In situ precracking and transitioning of the KAPL alloy 52M narrow gap weld specimens (CT042 \& CT043) with known hot cracks. 


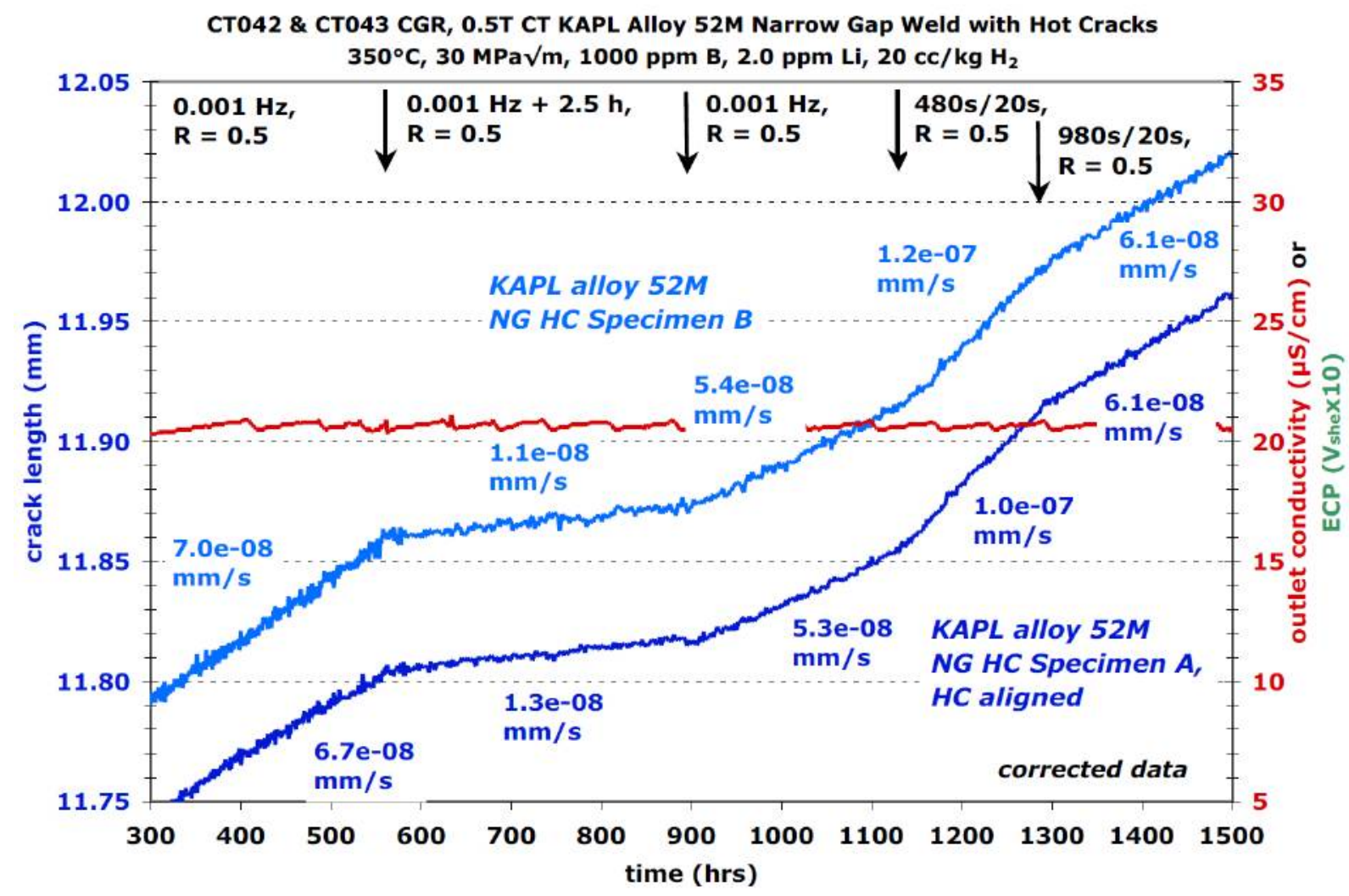

Figure 3.57 Continued transitioning steps performed on the KAPL alloy 52M narrow gap weld specimens (CT042 \& CT043) with known hot cracks.

Having tried several different combinations of frequency and $\mathrm{R}$ during transitioning with typical alloy 152/52 crack growth response, and because the crack length was nearing the region in CT042 thought to contain hot cracks, it was decided to transition to constant $\mathrm{K}$. The sawtooth waveform was converted to $0.001 \mathrm{~Hz}$ symmetric cycle $+2.5 \mathrm{~h}$ hold with $\mathrm{R}$ of 0.5 at $1500 \mathrm{~h}$, and a steady rate of $\sim 1.0 \times 10^{-9} \mathrm{~mm} / \mathrm{s}$ was observed in both specimens as shown in Figure 3.58 . This rate was consistent with crack growth rates observed in other alloy 152/52 specimens, and the test was converted to constant $\mathrm{K}$ at $\sim 1750 \mathrm{~h}$. A steady propagation rate of $\sim 1.4 \times 10^{-9} \mathrm{~mm} / \mathrm{s}$ was observed over the next $\sim 400 \mathrm{~h}$ with no sign of increased propagation rate in the specimen aligned to intersect hot cracks. Transitioning was restarted, and over the next several thousand hours of testing, cyclic loading conditions were varied, the $\mathrm{K}$ level was increase by $5 \mathrm{MPa} \sqrt{\mathrm{m}}$ (by $\mathrm{dK} / \mathrm{da}$ ), and the temperature was brought up to $360^{\circ} \mathrm{C}$ (see overview in Figure 3.55). Cyclic loading conditions were then returned to $0.001 \mathrm{~Hz}+2.5 \mathrm{~h}$ hold where propagation rates of $1.6 \times 10^{-9}$ and $1.9 \times 10^{-9} \mathrm{~mm} / \mathrm{s}$ were observed in the hot crack aligned and non-aligned specimens, respectively. These rates were $\sim 1.7 x$ higher than prior observations at these cyclic loading conditions, and the test was converted to constant K. Over the next $1300 \mathrm{~h}$ of testing, a relatively constant propagation rate of $\sim 2.8 \times 10^{-9} \mathrm{~mm} / \mathrm{s}$ was observed (Figure 3.59) in the specimen not aligned with hot cracks while the specimen aligned to intersect a field of hot cracks showed a steady rate of $\sim 1.1 \times 10^{-9} \mathrm{~mm} / \mathrm{s}$ for 1000 hours and then no further growth was observed for the remaining $300 \mathrm{~h}$. With lower propagation rates consistently observed in the hot crack aligned specimen, it was decided to end the test to examine the specimens. Table 3.8 lists a summary of the corrected step-by-step data obtained during this test. 


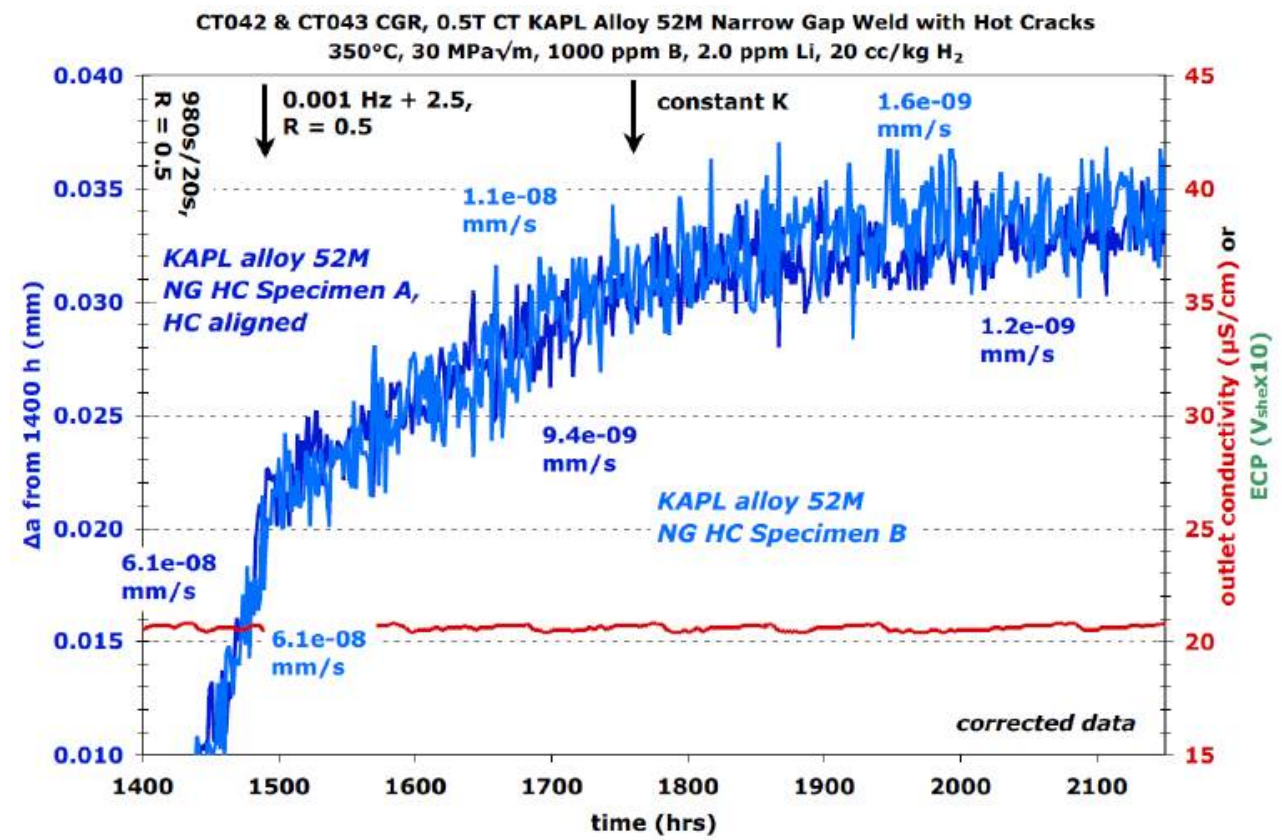

Figure 3.58 First observation of constant $\mathrm{K}$ crack growth response on the KAPL alloy 52M narrow gap weld specimens (CT042 \& CT043) with known hot cracks. Slightly lower crack growth rate in the specimen aligned to intersect hot cracks.

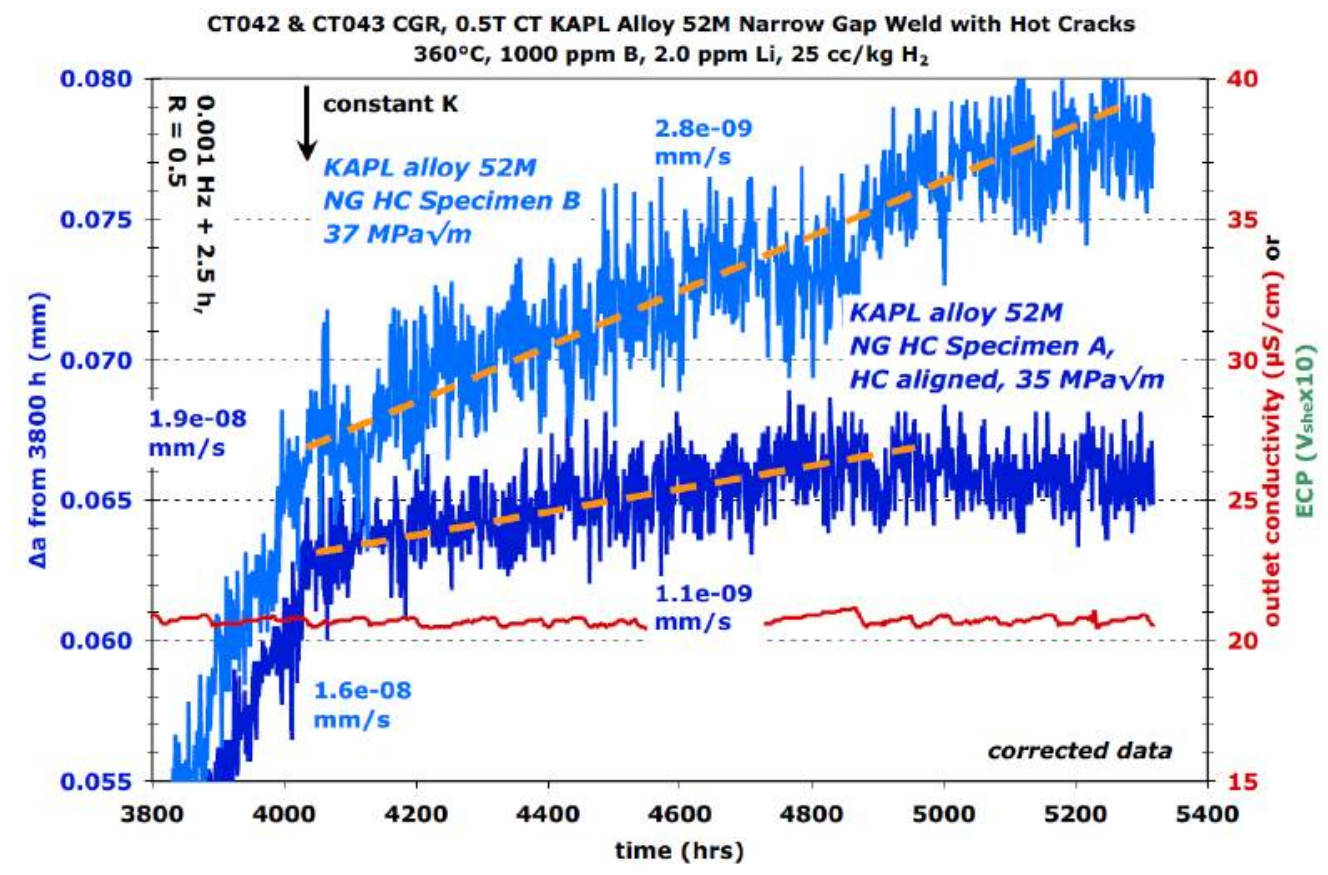

Figure 3.59 Second and final observation of constant $\mathrm{K}$ crack growth response of the KAPL alloy 52M narrow gap weld specimens (CT042 \& CT043) with known hot cracks. Specimen aligned to intersect hot cracks has lower crack growth rate, and cracking eventually stalls. 
Table 3.8 Corrected data summary for KAPL alloy 52M narrow gap weld specimens CT042 \& CT043 with hot cracks.

\begin{tabular}{|c|c|c|c|c|c|c|c|c|c|c|c|c|}
\hline $\begin{array}{l}\text { Test } \\
\text { Phase }\end{array}$ & $\begin{array}{l}\text { Dur- } \\
\text { ation } \\
\text { (h) }\end{array}$ & $\mathrm{R}$ & $\begin{array}{l}\text { Freq } \\
(\mathrm{Hz})\end{array}$ & $\begin{array}{c}\text { Hold } \\
(\mathrm{h})\end{array}$ & & KAPL A & $\begin{array}{c}\text { CT042 } \\
52 \mathrm{M} \mathrm{NG} \mathrm{HC}\end{array}$ & $\begin{array}{c}\text { C aligned } \\
\text { Approx. } \\
\text { Crack } \\
\text { Extension } \\
(\mathrm{mm})\end{array}$ & $\begin{array}{c}\mathrm{Kmax} \\
(\mathrm{MPa} \sqrt{\mathrm{m}})\end{array}$ & $\begin{array}{l}043 \text { KAPL A } \\
\text { HC non-ali }\end{array}$ & $\begin{array}{l}\text { A52M } \\
\text { igned } \\
\text { Approx. } \\
\text { Crack } \\
\text { Extension } \\
(\mathrm{mm}) \\
\end{array}$ \\
\hline 1 & $\sim 3$ & 0.3 & 5 & 0 & air precrack & RT & 21 & 3.7E-05 & 0.40 & 21 & $5.0 \mathrm{E}-05$ & 0.40 \\
\hline 2 & $\sim 2$ & 0.5 & 5 & 0 & air precrack & RT & 23 & 05 & 5 & 2 & 5 & 35 \\
\hline 3 & $\sim 2$ & 0.6 & 5 & 0 & air precrack & RT & 25 & $1.3 \mathrm{E}-05$ & 0.35 & 26 & 2.2E-05 & 0.35 \\
\hline 4 & $\sim 3$ & 0.7 & 5 & 0 & air precrack & RT & 25 & $7.8 \mathrm{E}-06$ & 0.20 & 26 & $E-05$ & 0.20 \\
\hline 5 & 86 & 0.7 & 0.1 & 0 & $20 \mathrm{cc} / \mathrm{kg} \mathrm{H}_{2}$ & 350 & 30 & 4.7E-07 & 0.202 & 31 & $9.6 \mathrm{E}-07$ & 0.281 \\
\hline 6 & 159 & 0.7 & 0.01 & 0 & $20 \mathrm{cc} / \mathrm{kg} \mathrm{H}_{2}$ & 350 & 30 & $9.1 \mathrm{E}-08$ & 0.049 & 31 & 1.3E-07 & 0.107 \\
\hline 7 & 49 & 0.5 & 0.01 & 0 & $20 \mathrm{cc} / \mathrm{kg} \mathrm{H}_{2}$ & 350 & 30 & 4.7E-07 & 0.098 & 31 & $5.5 \mathrm{E}-07$ & 0.145 \\
\hline 8 & 261 & 0.5 & 0.001 & 0 & $20 \mathrm{cc} / \mathrm{kg} \mathrm{H}_{2}$ & 350 & 30 & $6.7 \mathrm{E}-08$ & 0.060 & 32 & 7.0E-08 & 0.105 \\
\hline 9 & 338 & 0.5 & 0.001 & 2.5 & $20 \mathrm{cc} / \mathrm{kg} \mathrm{H} \mathrm{H}_{2}$ & 350 & 30 & 1.3E-08 & 0.019 & 32 & 1.1E-08 & 0.051 \\
\hline 10 & 241 & 0.5 & 0.001 & 0 & $20 \mathrm{cc} / \mathrm{kg} \mathrm{H}$ & 350 & 30 & 5.3E-08 & 0.040 & 32 & 5.4E-08 & 0.076 \\
\hline 11 & 156 & 0.5 & $480 / 20$ & 0 & $20 \mathrm{cc} / \mathrm{kg} \mathrm{H}$ & 350 & 30 & 1.0E-07 & 0.057 & 32 & 1.2E-07 & 0.093 \\
\hline 12 & 193 & 0.5 & $980 / 20$ & 0 & $20 \mathrm{cc} / \mathrm{kg} \mathrm{H}_{2}$ & 350 & 30 & 6.1E-08 & 0.042 & 32 & $6.1 \mathrm{E}-08$ & 0.077 \\
\hline 13 & 280 & 0.5 & 0.001 & 2.5 & $20 \mathrm{cc} / \mathrm{kg} \mathrm{H}_{2}$ & 350 & 30 & 9.4E-09 & 0.012 & 32 & 1.1E-08 & 0.048 \\
\hline 14 & 420 & --- & const $\mathrm{K}$ & --- & $20 \mathrm{cc} / \mathrm{kg} \mathrm{H}$ & 350 & 30 & 1.2E-09 & 0.004 & 32 & 1.6E-09 & 0.038 \\
\hline 15 & 405 & 0.6 & 0.001 & 0 & $20 \mathrm{cc} / \mathrm{kg} \mathrm{H} \mathrm{H}_{2}$ & 350 & 30 & 3.4E-08 & 0.040 & 32 & 3.6E-08 & 0.076 \\
\hline 16 & 265 & 0.6 & 0.001 & 2.5 & $20 \mathrm{cc} / \mathrm{kg} \mathrm{H}_{2}$ & 350 & 30 & 6.3E-09 & 0.010 & 32 & 6.6E-09 & 0.044 \\
\hline 17 & 175 & 0.5 & 0.001 & 1 & $20 \mathrm{cc} / \mathrm{kg} \mathrm{H} \mathrm{H}_{2}$ & 350 & 30 & 1.6E-08 & 0.009 & 32 & 1.6E-08 & 0.045 \\
\hline 18 & 43 & 0.5 & 0.001 & 1 & $20 \mathrm{cc} / \mathrm{kg} \mathrm{H}_{2}$ & 350 & $30->35$ & 1.0E-07 & 0.014 & $32->37$ & $1.2 \mathrm{E}-07$ & 0.045 \\
\hline 19 & 413 & 0.5 & 0.001 & 1 & $20 \mathrm{cc} / \mathrm{kg} \mathrm{H}_{2}$ & 350 & 35 & 3.2E-08 & 0.067 & 37 & 3.7E-08 & 0.095 \\
\hline 20 & 190 & 0.5 & 0.001 & 2.5 & $20 \mathrm{cc} / \mathrm{kg} \mathrm{H} \mathrm{H}_{2}$ & 350 & 35 & 1.4E-08 & 0.010 & 37 & 2.1E-08 & 0.047 \\
\hline 21 & 355 & 0.5 & 0.001 & 2.5 & $25 \mathrm{cc} / \mathrm{kg} \mathrm{H}$ & 360 & 35 & 1.6E-08 & 0.019 & 37 & $1.9 \mathrm{E}-08$ & 0.051 \\
\hline 22 & 1289 & --- & const $\mathrm{K}$ & --- & $25 \mathrm{cc} / \mathrm{kg} \mathrm{H}_{2}$ & 360 & 35 & 1.1E-09 & 0.003 & 37 & $2.8 \mathrm{E}-09$ & 0.047 \\
\hline
\end{tabular}

Post-test examinations consisted of characterizing both the crack growth surface and a series of crack profile obtained from side surfaces of the crack. To accomplish this, both specimens were serially sectioned as shown in Figure 3.60 prior to air fatiguing open the specimens. Five slices were obtained from the CT042 (hot crack aligned), but due to a machining error, only four slices were obtained from CT043. The serial slices were placed in metallography mounts and polished to a high luster using colloidal silica as the final polishing agent. Crack profile images for CT042 and CT043 are shown in Figures 3.61 and 3.62, respectively. The crack profiles of CT042 show that the density of the hot cracks was too low and the distance from the SCC crack was too far for any hot cracks to be intersected by the SCC crack. In addition, the grain boundaries (and hot cracks) were at a steep angle to the geometric crack plane of the specimen, and the steep angle was not allowing the SCC crack to grow favorably along the grain boundaries. Somewhat surprisingly, the crack profile images of the specimen that was not supposed to be aligned with hot cracks shows that a few hot cracks were in the vicinity of the SCC crack. However, as with the hot crack-aligned specimen, only a few hot cracks were present, and they are fairly far from the SCC crack and at a steep angle to it. The grain boundaries are much better aligned with the geometric crack plane of the specimen. Instances of growth along dendrite and grain boundaries are apparent, and the more favorable alignment is likely responsible for the higher constant $\mathrm{K}$ crack growth rate in CT043. 


\section{GTO42- RAPL alloy 52M WG HC alligned Epecinen}

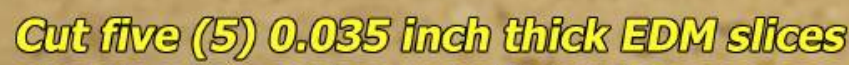
stariting ftrom the minpollished facer

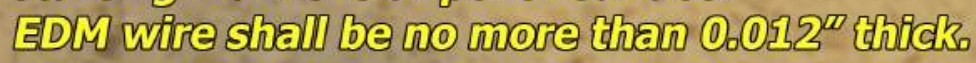

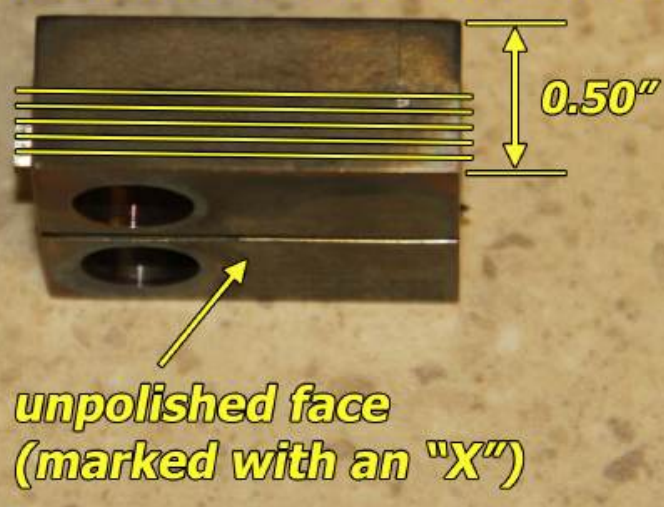

Figure 3.60 Post-test serial sectioning plan for KAPL alloy 52M NG weld specimens with hot cracks (CT042 \& CT043).

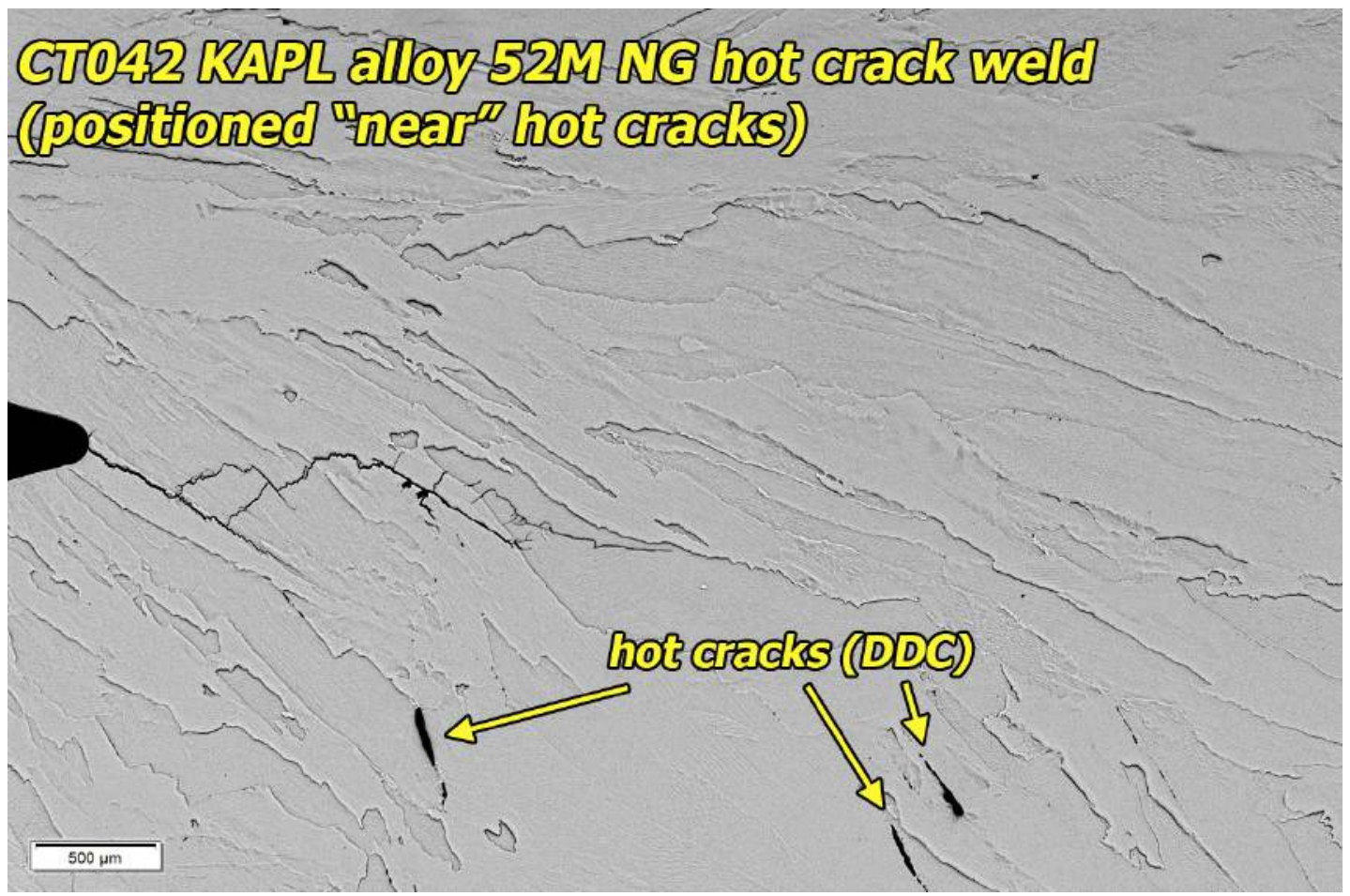

Figure 3.61 Crack profile of images from CT042, the weld specimen aligned with hot cracks. The profile images show hot cracks in the region of the SCC crack, but the density is lower than expected. 


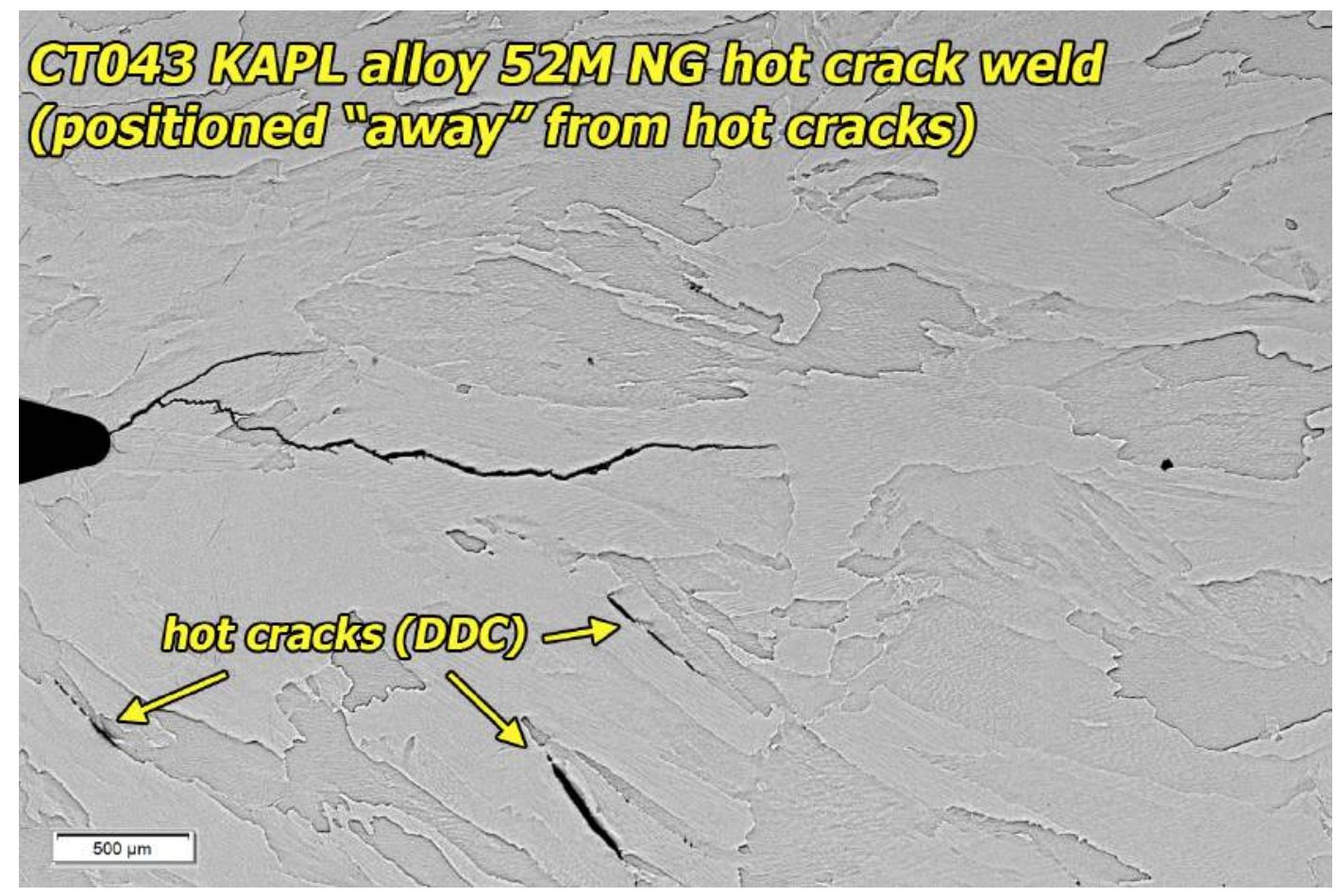

Figure 3.62 Crack profile of images from CT043, the weld specimen not aligned with hot cracks. The profile images show hot cracks in the region of the SCC crack, however.

Figures 3.63 and 3.64 show the crack growth surface of the remaining piece of the CT specimens that was not used for crack profile observations. The edge of the specimen corresponding to the last serial section taken from the specimens is indicated, and the yellow line denotes the boundary between air precracking and in situ testing. The in situ crack growth surface of the hot crack aligned specimen (CT042, Figure 3.63) shows a lower amount of growth. A large number of ridges run along the length of the crack, and it is thought that these indicate jumps in crack growth plane. The areas inside the yellow boxes are the only regions along the crack surface that are clearly IG based on the optical images. No obvious indications of intersected hot cracks are present. While there are no fingers of obvious SCC extension on the crack growth surface of the non-aligned specimen (CT043, Figure 3.65), the greater amount of in situ crack extension and the fewer number of ridges are suggestive of better SCC engagement. As with CT042, there are no obvious indications of intersected hot cracks.

The post test examination of these two specimens has revealed a density of hot cracks too low or too far from the SCC crack plane to provide any insight as to whether hot cracks can affect SCC crack growth. An unintended outcome of the test on these two specimens is, however, a better understanding of the importance of grain boundary orientation relative to the geometric crack plane of the specimens. With these highly resistant welds that have very large, elongated grains with apparently low susceptibility to IG cracking, the difference in the crack growth rate of the two specimens suggests that the highest possible crack growth rate can only be determined if the grain boundaries are well aligned with the geometric crack growth plane of the specimen. 
When considering the effect of poor welding conditions on crack growth rate, there is also the possibility that unfavorable microstructure and/or segregation may be present in this weld containing hot cracks. One method to assess this affect is to compare the crack growth rate of these specimens to the KAPL NG specimen that was fabricated without re-fuse passes (CT040). Since the grain boundaries in CT040 were favorably aligned with the geometric crack plane, CT043 with its favorable grain boundary orientation is the appropriate hot crack weld specimen to use for the comparison. Using the highest constant $\mathrm{K}$ crack growth rate observed, the hot crack specimen (CT043) exhibits a $\sim 2 x$ higher crack growth rate than the standard specimen (CT040). This may indicate a small detrimental effect of chemistry or microstructure on SCC susceptibility in the region of hot cracks, but results are likely within the test reproducibility.

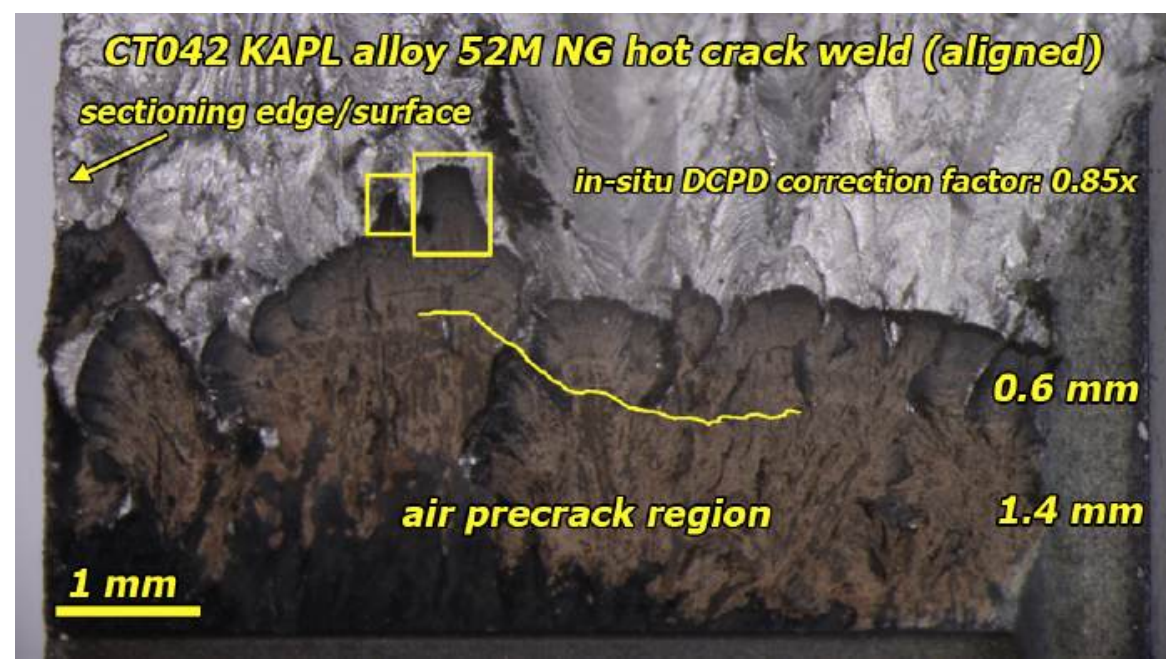

Figure 3.63 Crack growth surface from CT042, the weld specimen aligned with hot cracks.

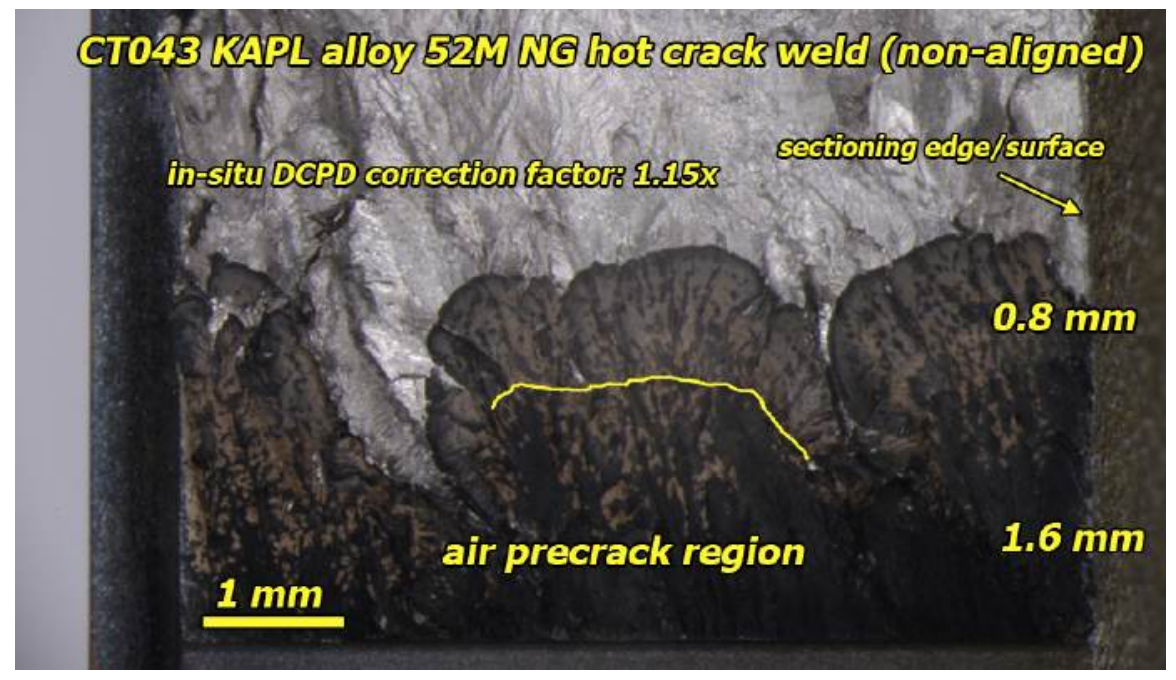

Figure 3.64 Crack growth surface from СT043, the weld specimen not aligned with hot cracks. 


\subsection{Alloy 52M/182 Overlay and Alloy 52M/82 Inlay Welds}

An alloy 52M/182 overlay mockup was obtained from Ringhals and is shown in Figure 3.65(a). It was fabricated by robotically welding a $10-\mathrm{mm}$-thick alloy $52 \mathrm{M}$ layer onto alloy 690 plate and then by manually welding alloy 182 onto the alloy $52 \mathrm{M}$ layer. The alloy $52 \mathrm{M}$ layer was applied by GTAW with a weld speed of $7.5 \mathrm{~cm} / \mathrm{min}$ at a current of $130 \mathrm{~A}$ while the alloy 182 was applied by SMAW with a weld speed of $7-12 \mathrm{~cm} / \mathrm{min}$ at a current of $95-125 \mathrm{~A}$.

An inlay mockup was obtained from Westinghouse and is from a full-scale inlay repair demonstration by Ringhals on a ring of A533 steel pipe. The inlay was fabricated first by carving a boat out of the inner surface of the ring as shown in Figure 3.65(b), and then alloy 82 filler was robotically welded onto the pipe section. This was followed by the robotic application of the alloy $52 \mathrm{M}$ inlay. Lastly, an alloy 152 weld layer was the manually applied by Westinghouse to allow fabrication of compact tension specimens for stress-corrosion testing with an orientation allowing cracks to be grown from the alloy 82 into the alloy $52 \mathrm{M}$.
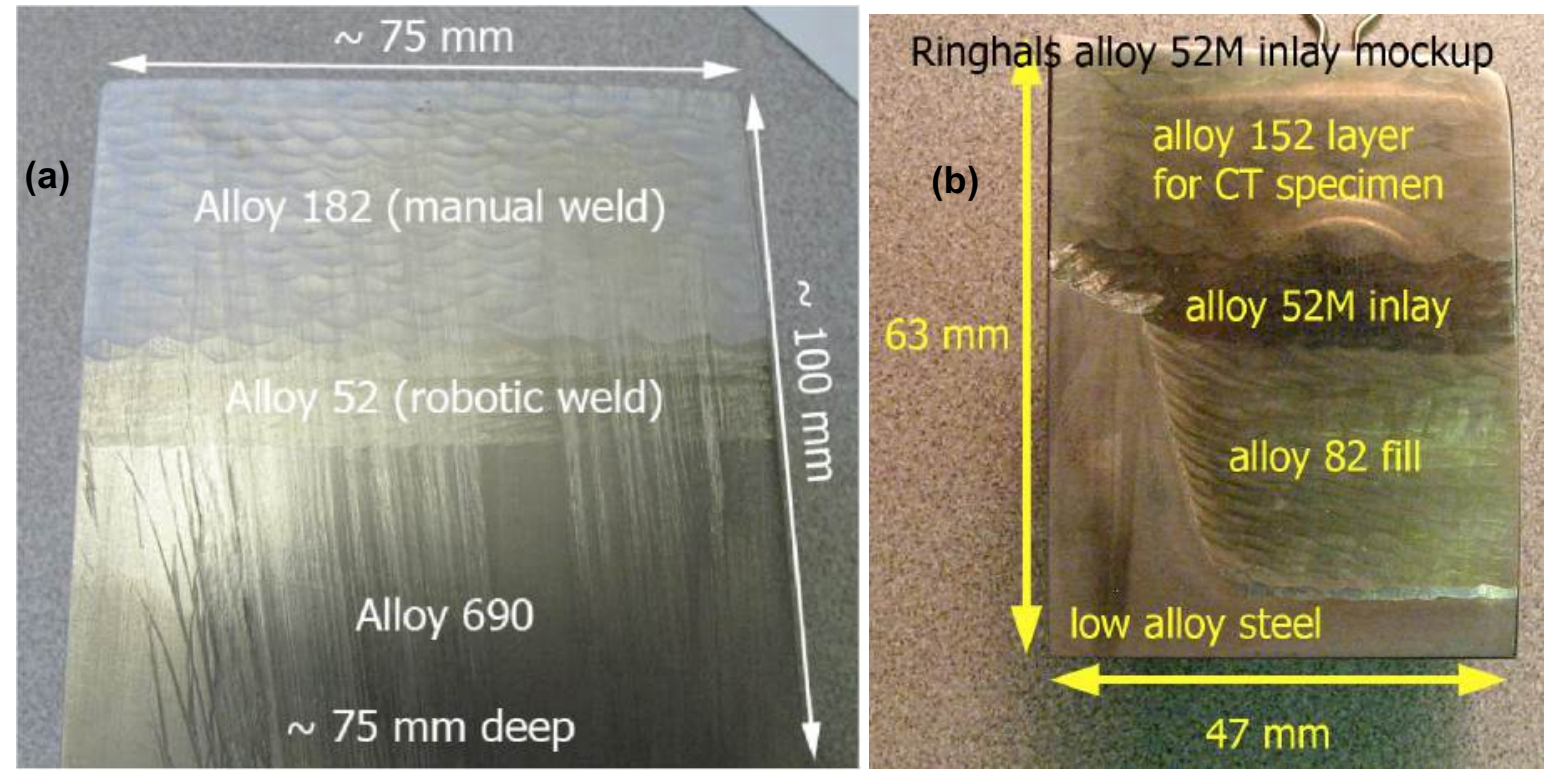

Figure 3.65 Overview of the Ringhals alloy 52M overlay and inlay mockups: (a) overlay where alloy $52 \mathrm{M}$ was robotically welded to an alloy 690 plate followed by alloy 182 manually welded onto the alloy $52 \mathrm{M}$. The alloy $52 \mathrm{M}$ layer is $10-$ $\mathrm{mm}$ thick. (b) full-scale, service mockup with alloy 82 fill followed by an alloy $52 \mathrm{M}$ inlay. Alloy 152 was welded onto the alloy 52M by Westinghouse to allow fabrication of CT specimens from the inlay region.

\section{Alloy 52M/182 Overlay Weld Sample Pair \#1 (CT028 \& CT029)}

Two 0.5T CT samples (CT028 and CT029) of the Ringhals alloy 52M/182 overlay were machined to locate the notch in the alloy 182 weld metal approximately $3 \mathrm{~mm}$ from the alloy $52 \mathrm{M}$ interface. The sample and notch locations are indicated in Figure 3.66. Composition measurements were performed using SEM-EDS at two locations along the interface between the 182 weld and alloy 52 weld as shown in Figures 3.67 and 3.68. Profile \#1 was acquired at 
the bottom of an alloy 182 weld puddle while profile \#2 was acquired at the saddle point between two alloy 182 weld puddles. The two profiles indicate a dilution zone width ranging from $\sim 70 \mu \mathrm{m}$ to $150 \mu \mathrm{m}$ with dilution occurring in both the alloy 182 and alloy 52 welds. These measurements illustrate the complexity of the dilution zone at the alloy $52 \mathrm{M} / 182$ interface and suggest that a simple assessment of $\mathrm{Cr}$ concentration effects on SCC propagation rates will be difficult.

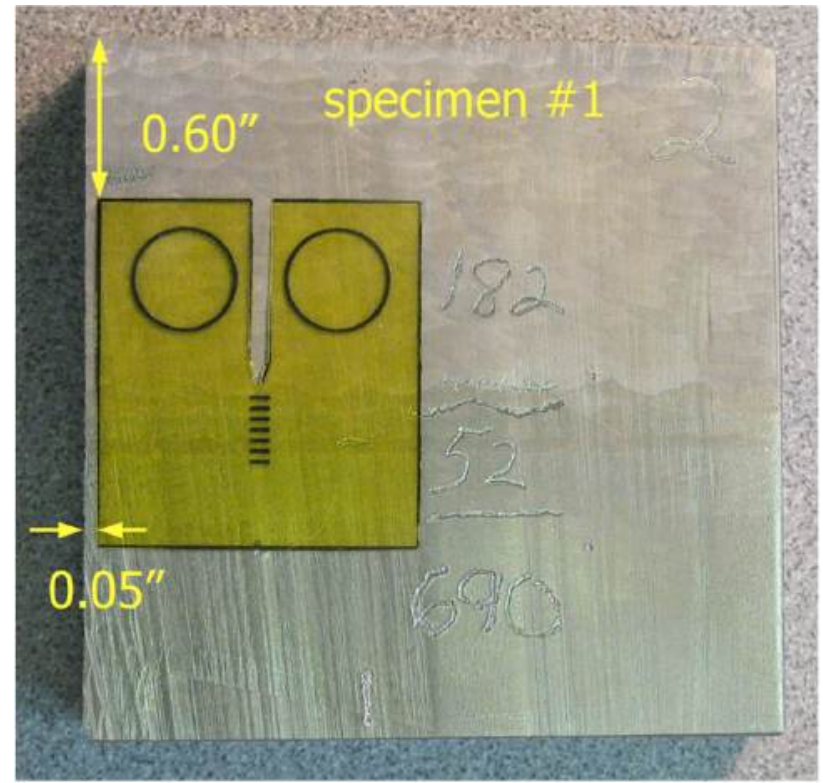

(a)

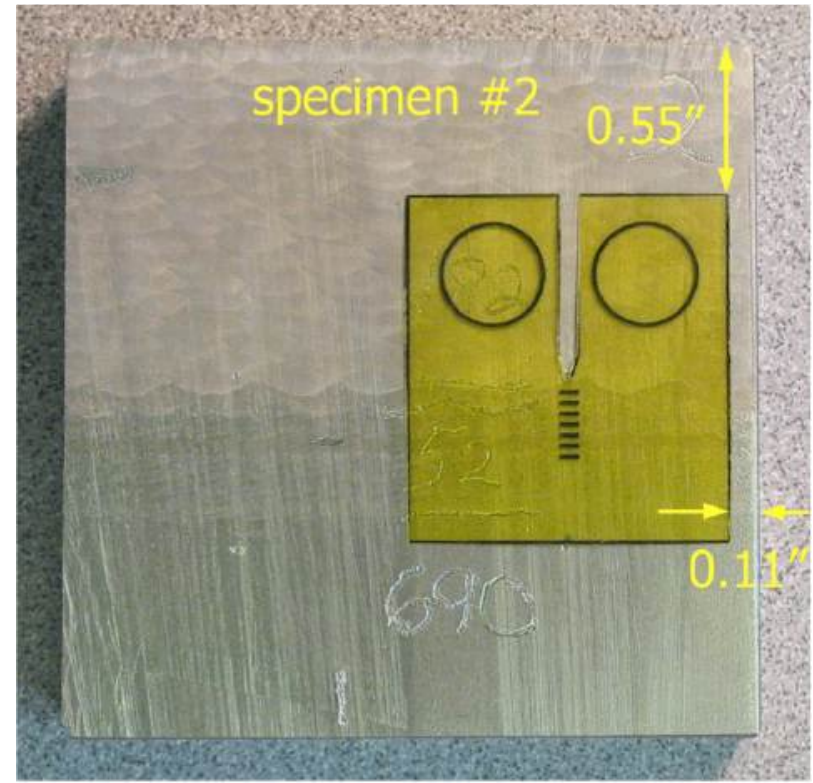

(b)

Figure 3.66 Photographs showing location of specimens to be taken from alloy $182 / 52 / 690$ overlay received from Vattenfall/Ringhals. Machined notch will be approximately $3.0 \mathrm{~mm}$ from the alloy $182-52$ boundary.
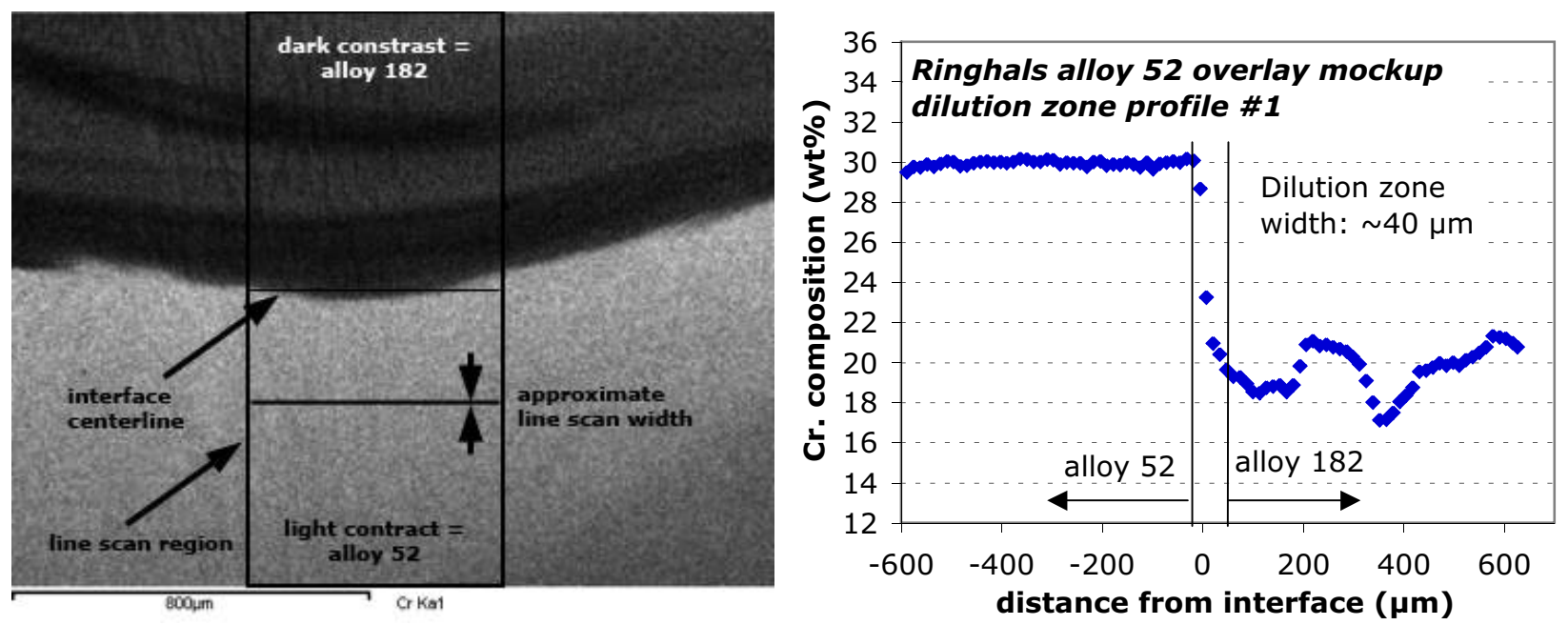

Figure 3.67 Compositional profile \#1 across the bottom of an alloy 182 weld puddle and into the alloy $52 \mathrm{M}$ of the Ringhals alloy $52 \mathrm{M} / 182$ overlay material. 

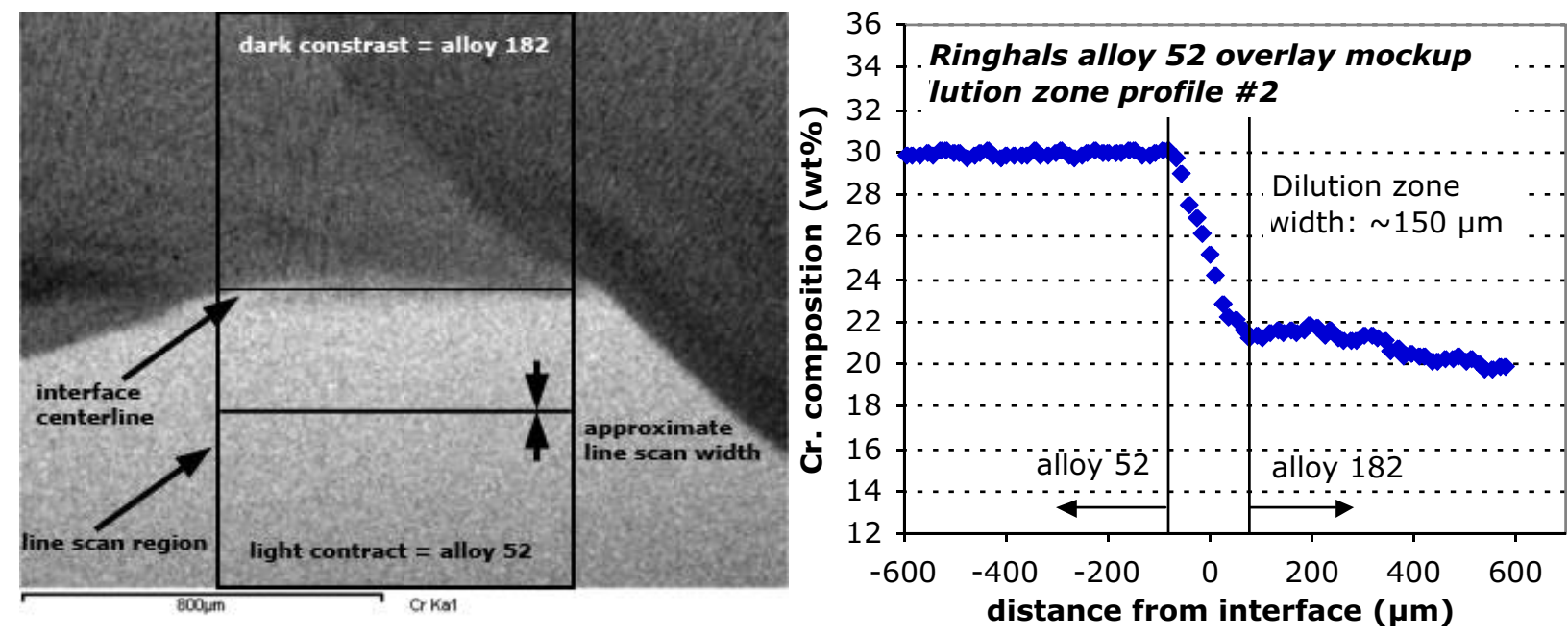

Figure 3.68 Compositional profile \#2 across an alloy 182 weld trough and into the alloy $52 \mathrm{M}$ of the Ringhals alloy $52 \mathrm{M} / 182$ overlay material.

Fatigue pre-cracking was performed in air to produce an initial crack extension of $\sim 1.7 \mathrm{~mm}$ in the alloy 182 material. The overlay samples were mounted in series and tested in simulated PWR primary water at $350^{\circ} \mathrm{C}$. A hydrogen concentration of $20 \mathrm{cc} \mathrm{H}_{2} / \mathrm{kg} \mathrm{H}_{2} \mathrm{O}$ was maintained to produce an electrochemical potential at the $\mathrm{Ni} / \mathrm{NiO}$ line in an attempt to promote maximum CGRs in the alloy 182 weld metal. An initial transitioning sequence was followed for crack growth through the alloy 182 weld metal similar to the test protocol used for two earlier alloy 182 CGR tests. The intent was to produce a fully engaged IGSCC crack front in the alloy 182 at a position that is $\sim 400 \mu \mathrm{m}$ from alloy $182 / 52 \mathrm{M}$ interface and monitor growth under constant $\mathrm{K}$ conditions as it approached the high $\mathrm{Cr}$, alloy 52M weld metal.

After crack extension at 0.01 and $0.001 \mathrm{~Hz}(\mathrm{R}=0.7)$, the crack front is estimated to be $\sim 550 \mu \mathrm{m}$ from the interface and a hold time of $2.5 \mathrm{~h}$ was added at $\sim 670 \mathrm{~h}$. The CGR at $0.001 \mathrm{~Hz}$ with a $2.5 \mathrm{~h}$ hold was $\sim 1.5 \times 10^{-8} \mathrm{~mm} / \mathrm{s}$ for both samples as shown in Figure 3.69. Because of this slower than expected CGRs, the $\mathrm{R}$ value was decreased to 0.5 to promote faster growth. Propagation rates increased to $2.5-3 \times 10^{-8} \mathrm{~mm} / \mathrm{s}$ for both samples, and an initial attempt to evaluate constant $\mathrm{K}$ response was made starting at $\sim 1240 \mathrm{~h}$. Unfortunately, very slow CGRs of $\sim 2 \times 10^{-9} \mathrm{~mm} / \mathrm{s}$ were observed as illustrated in Figure 3.70 . 


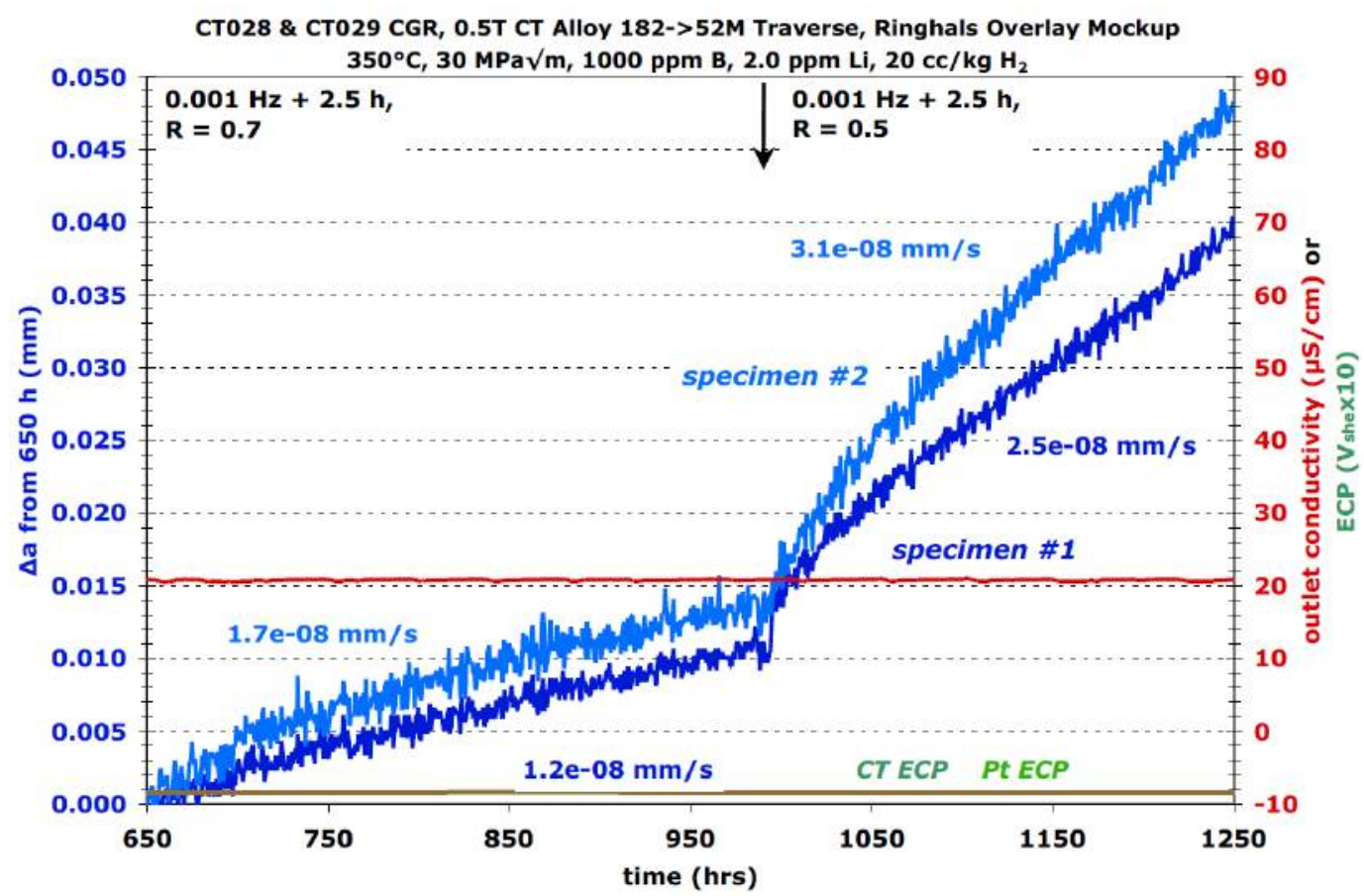

Figure 3.69 Initial cycle + hold steps in the alloy 182 portion of the Ringhals alloy $52 \mathrm{M} / 182$ overlay material.

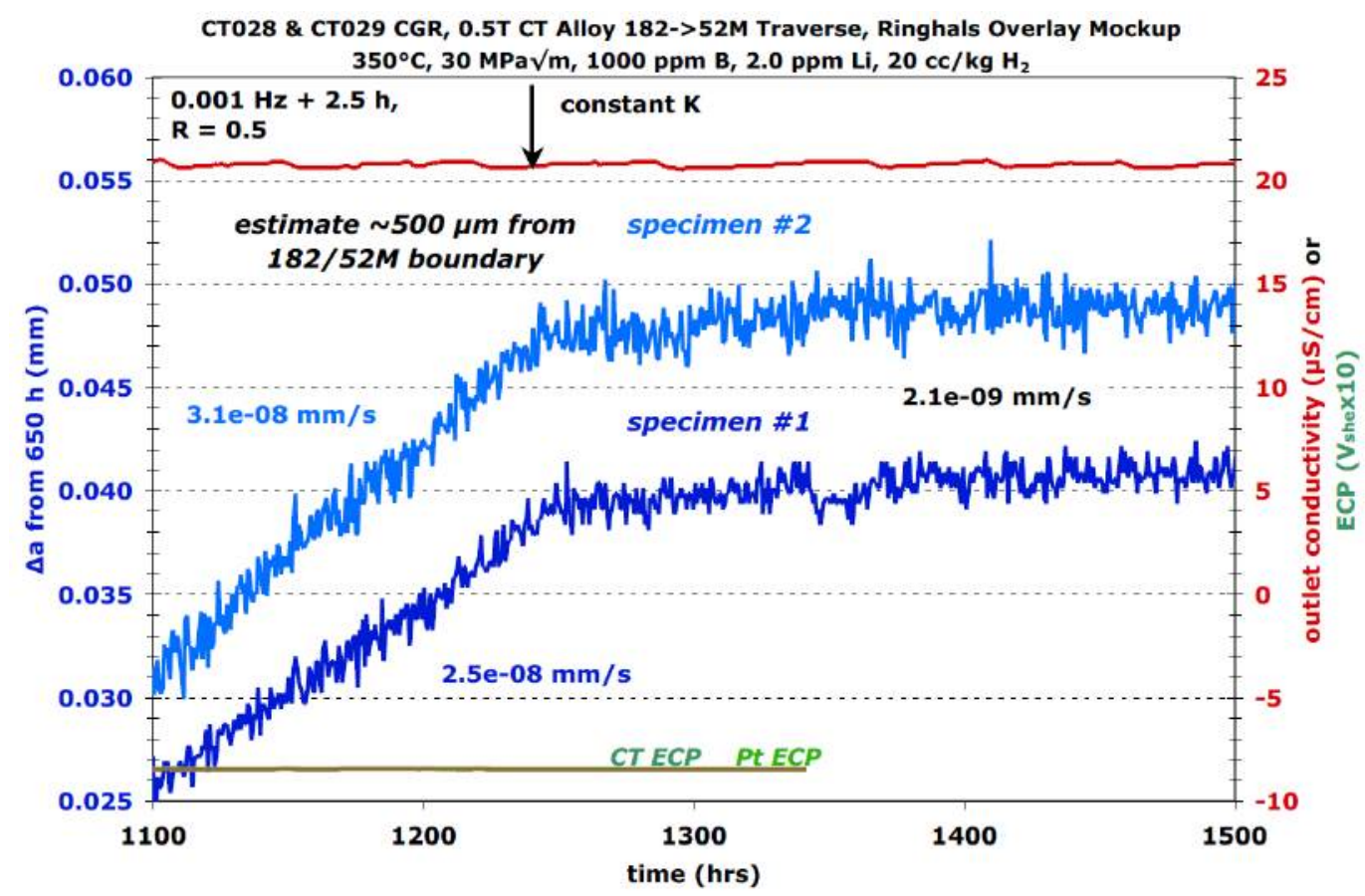

Figure 3.70 First constant $\mathrm{K}$ response of the Ringhals alloy $52 \mathrm{M} / 182$ weld showing very low crack growth rates in the alloy 182 material. 
Since there was no indication of significant SCC growth under cycle + hold or constant K conditions, the decision was made to evaluate another microstructural region closer to the alloy $52 \mathrm{M} / 182$ dilution zone. Cycling at 0.01 and $0.001 \mathrm{~Hz}$ at $\mathrm{R}=0.5$ was applied to straighten and extend the crack front by $\sim 0.2 \mathrm{~mm}$. This should have moved the crack front to within $\sim 0.3 \mathrm{~mm}$ of the dilution zone. The $\mathrm{R}$ value was then increased back to 0.7 and cycling continued at $350^{\circ} \mathrm{C}$ until $\sim 1750 \mathrm{~h}$ as shown in Figure 3.71. Crack-growth rates for the two samples were found to be similar to that established previously.

The low crack growth response for the alloy 182 weld metal was unexpected based on prior SCC test results. Since most of this previous work on alloy 182 was performed at slightly lower temperatures, the decision was made to briefly assess response at $325^{\circ} \mathrm{C}$ at different hydrogen partial pressures (as in prior alloy 182 tests). Although a detailed assessment was not performed, higher CGRs were clearly seen at $11 \mathrm{cc} / \mathrm{kg}$ than for $29 \mathrm{cc} / \mathrm{kg}$ by a factor of $\sim 2 \mathrm{X}$ consistent with the prior tests on the EdF alloy 182 but much less than seen for tests on the ICG-EAC alloy 182 round robin material. In the end, constant $\mathrm{K}$ growth rates were extremely low $\left(<1 \times 10^{-9} \mathrm{~mm} / \mathrm{s}\right)$ at $325^{\circ} \mathrm{C}$, therefore the test temperature and $\mathrm{H}_{2}$ level were increased back to $350^{\circ} \mathrm{C}$ and $20 \mathrm{cc} / \mathrm{kg}$. Propagation rates were initially $\sim 3 \times 10^{-9} \mathrm{~mm} / \mathrm{s}$ under these conditions (still slow for alloy 182) as shown in Figure 3.72, and decreased over the next two weeks to $\sim 1 \times 10^{-9} \mathrm{~mm} / \mathrm{s}$ similar to what was observed previously.

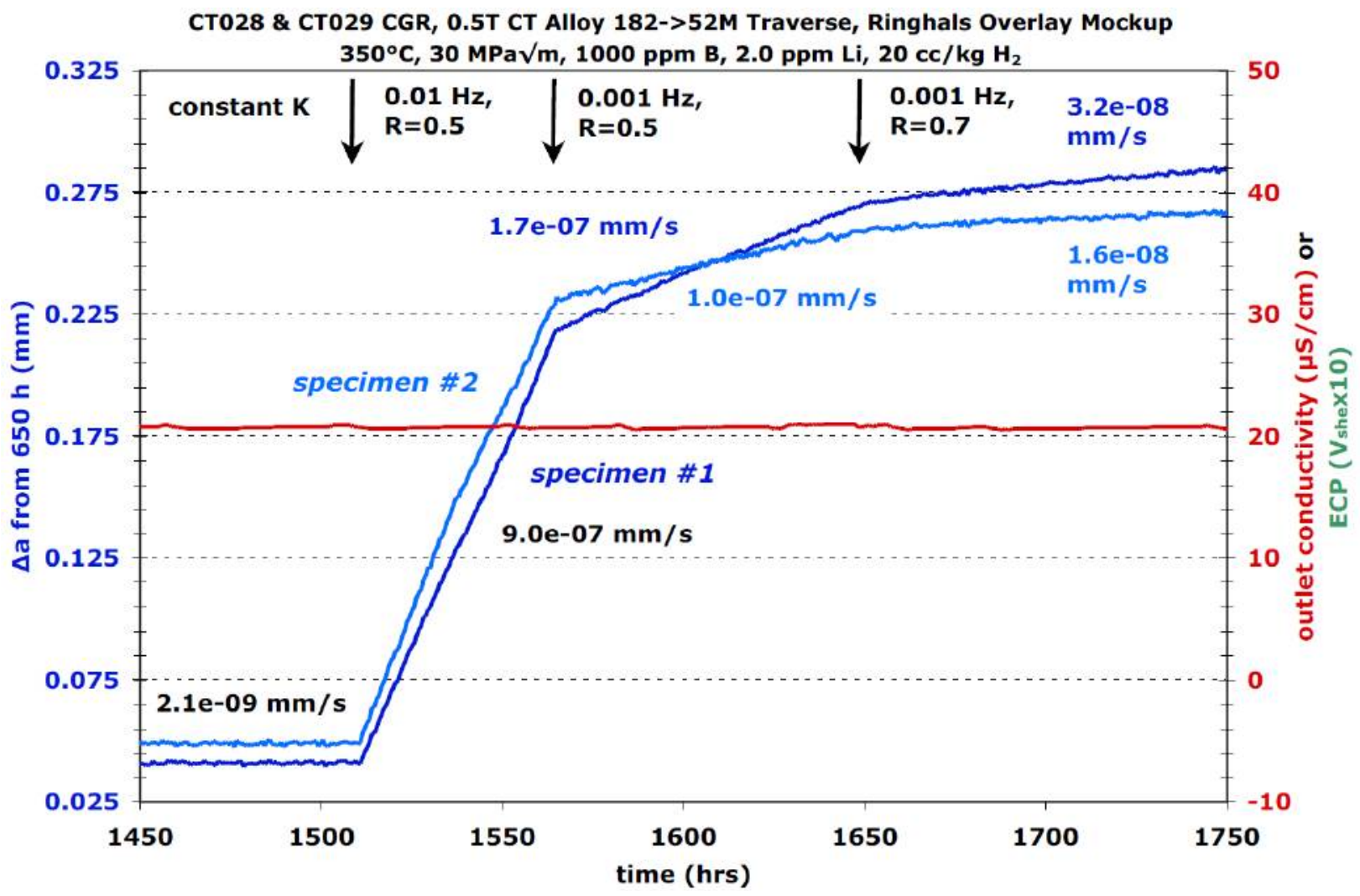

Figure 3.71 Crack extension into new microstructural region and growth response during cycle + hold loading with $\mathrm{R}=0.7$ and $\mathrm{R}=0.5$. 


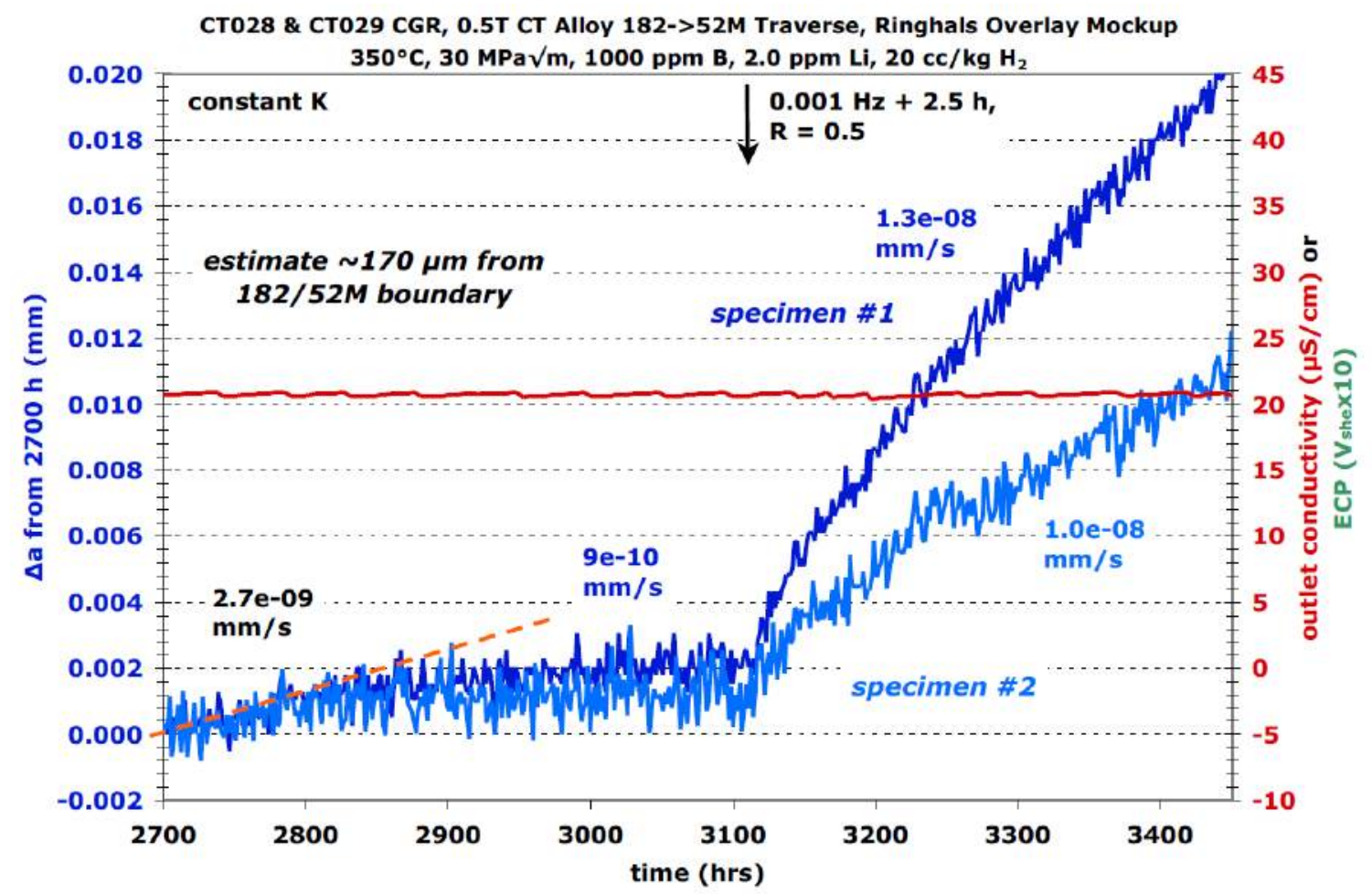

Figure 3.72 Repeat observation of constant $\mathrm{K}$ and cycle + hold response at $350^{\circ} \mathrm{C}$ in the Ringhals alloy $52 \mathrm{M} / 182$ overlay. Very low CGRs suggest the crack had entered into the alloy $52 \mathrm{M}$ weld.

Based on DCPD-measured crack extensions, it was estimated that the alloy 52M should still be a distance of $\sim 150 \mu \mathrm{m}$ away. However, considerable uncertainty exists both for the actual crack length and the position of the interface. The only practical way to determine where the crack front currently is would have been to remove the samples and polish the side surfaces. It was decided to determine CGRs one more time under the standard $0.001 \mathrm{~Hz}+2.5 \mathrm{~h}$ hold condition. As shown in Figure 3.72, this change was made at $3115 \mathrm{~h}$ and new rates stabilized at 1.0 and $1.3 \times 10^{-8} \mathrm{~mm} / \mathrm{s}$. These rates are $3-4 \mathrm{X}$ slower than measured previously under identical conditions and suggested that the crack front has reached the alloy $52 \mathrm{M}$ interface even though it should be $>100 \mu \mathrm{m}$ away from the interface based on DCPD-measured crack extension.

Because of this uncertainty and the importance of evaluating SCC CGRs in the alloy 52M weld metal, the decision was made to drop the temperature and extend the crack well into the alloy $52 \mathrm{M}$ by cycling at $50^{\circ} \mathrm{C}$. A similar cycling sequence was chosen as for the alloy 152 weld metal samples where extensive IG cracking was produced along the crack front. The low-temperature response of the two samples is presented in Figure 3.73. Surprisingly, aggressive cycling at $0.1 \mathrm{~Hz}$ and $\mathrm{R}=0.5$ produced quite different behavior with much more crack extension in overlay specimen CT028 $(\sim 0.75 \mathrm{~mm})$ than for specimen CT029 $(\sim 0.2 \mathrm{~mm})$. This suggests that complex ligaments were present in the overlay specimen СT029 restricting crack growth or masking the true crack length. The decision was made to reduce the cyclic frequency to $0.001 \mathrm{~Hz}$ partially due to the significant crack length difference $(\sim 1.1 \mathrm{~mm})$ between the samples. The applied $\mathrm{K}$ is maintained at $30 \mathrm{MPa} \sqrt{\mathrm{m}}$ based on the DCPD crack length for specimen CT028 and is estimated to be slightly lower for specimen CT029 ( 26 MPa $\sqrt{\mathrm{m}})$. 


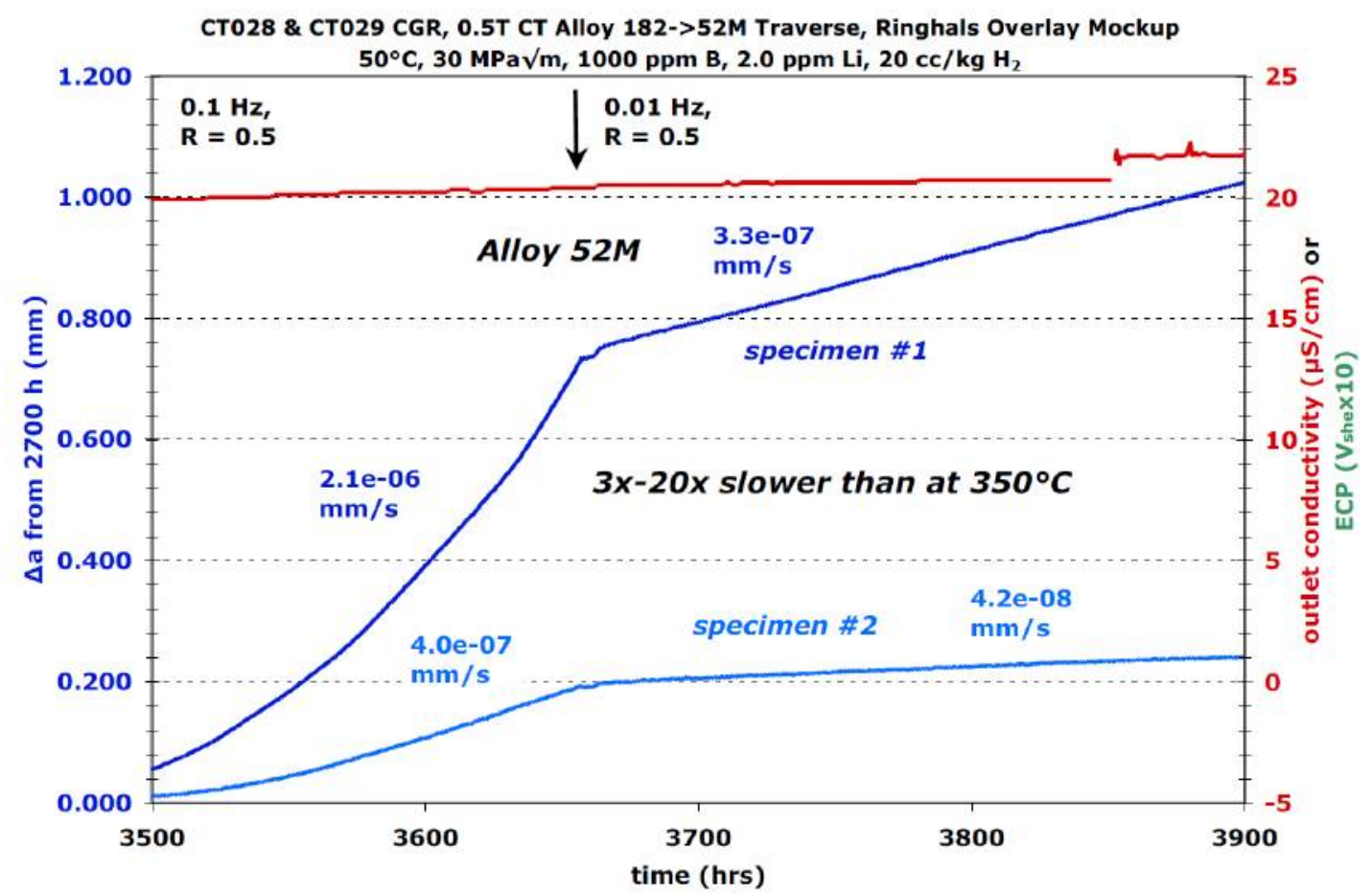

Figure 3.73 Crack extension in alloy $52 \mathrm{M}$ during cycling at $50^{\circ} \mathrm{C}$ in the Ringhals alloy $52 \mathrm{M} / 182$ overlay.

After a crack length increase of $\sim 1.2$ and $0.3 \mathrm{~mm}$ for the specimens CT028 and CT029 at $50^{\circ} \mathrm{C}$, respectively, constant $\mathrm{K}$ conditions were established and the temperature was increased to $350^{\circ} \mathrm{C}$. The crack-growth response at $350^{\circ} \mathrm{C}$ and $20 \mathrm{cc} / \mathrm{kg}$ is shown in Figure 3.74 . As with the previous tests on alloy 152 and alloy 52 , the propagation rates at $350^{\circ} \mathrm{C}$ decreased from relatively high values $\left(>5 \times 10^{-8} \mathrm{~mm} / \mathrm{s}\right)$ to $\sim 4 \times 10^{-9} \mathrm{~mm} / \mathrm{s}$ over the following $600 \mathrm{~h}$ (25 days). While the rates appeared steady over the last $\sim 100$ hours, it is expected that the rates would have continued to decrease slightly over time. In order to help assess the reason for the slowing growth rate, a periodic unload every $2.5 \mathrm{~h}$ was added at $\sim 4750 \mathrm{~h}$ and an immediate jump in DCPD crack length was observed. Expanding the time scale to focus on this rapid increase in length revealed that most of the change $(\sim 0.2 \mathrm{~mm}$ for specimen CT028 and $\sim 0.1 \mathrm{~mm}$ for specimen CT029) occurred during the first three $0.001 \mathrm{~Hz}$ cycles. This suggests that ligaments had developed and were broken by the initial cycles at an $\mathrm{R}$ of 0.5 . Since the growth rate under the cycle + hold condition then reverted to the expected steady-state values, constant $\mathrm{K}$ conditions were resumed at $\sim 4800 \mathrm{~h}$. No indication of SCC propagation was observed over the next few days and the DCPD-measured crack length slightly decreased before the test was ended at $4936 \mathrm{~h}$. A summary of testing conditions, crack extension, and crack growth rate for each phase of the test is shown in Table 3.9. In order to better understand crack-growth response in the alloy 182 and alloy 52M regions, the specimens were removed, their side surfaces examined and then fatigue fractured in air to examine the crack growth surfaces. 


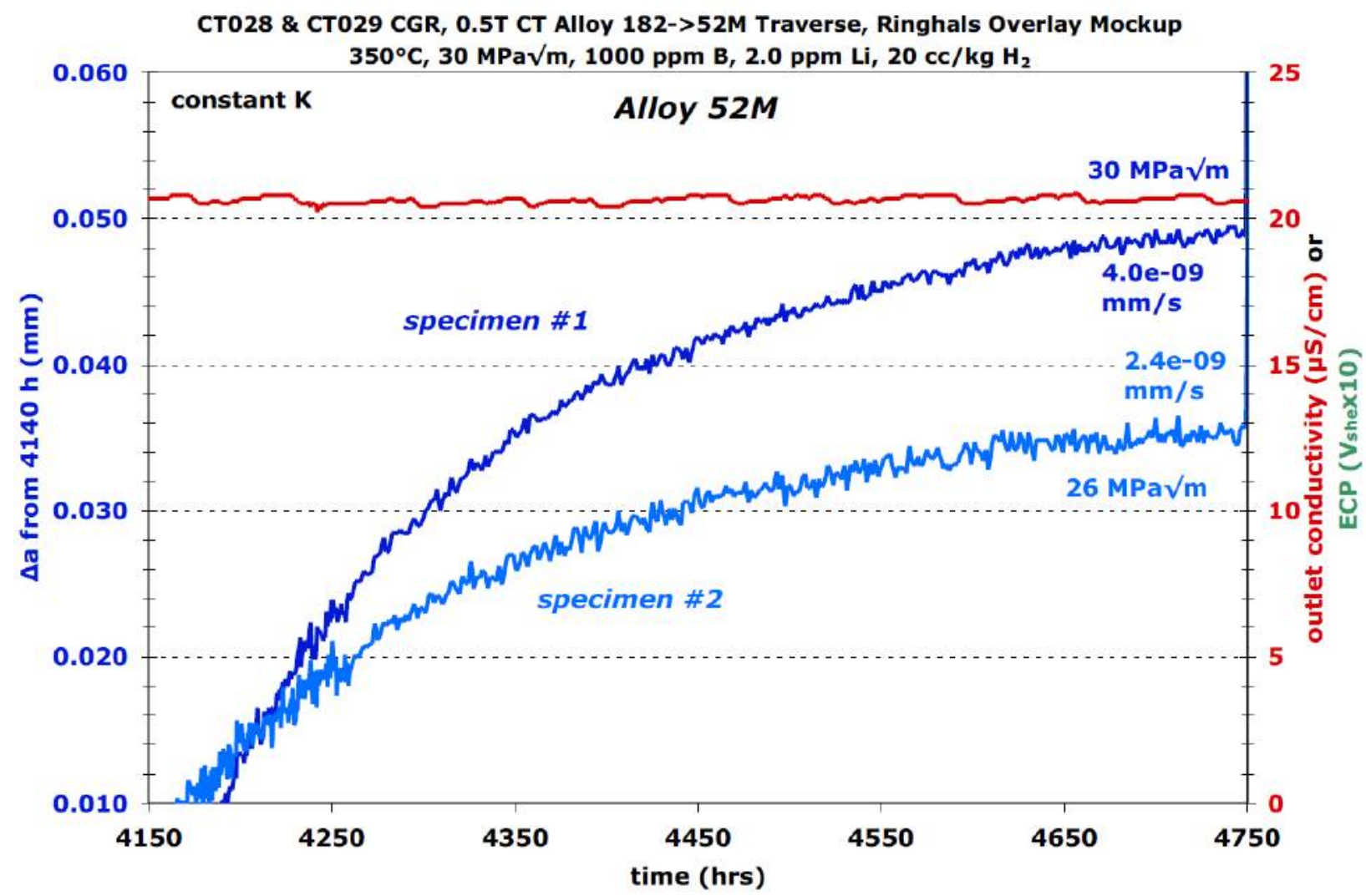

Figure 3.74 Constant $\mathrm{K}$ crack-growth response in the alloy $52 \mathrm{M}$ weld material after temperature increase from $50^{\circ} \mathrm{C}$ to $350^{\circ} \mathrm{C}$.

Side-surface examinations were performed to find the crack front as demonstrated in Figure 3.75(a). The crack can be identified within the side groove of the overlay sample CT028 and distance from the notch estimated as $\sim 4.3 \mathrm{~mm}$. This sample was subsequently removed from the system, the crack was resin impregnated, and then a slice was sectioned off to allow preparing a TEM crack tip specimen. The specimen was then air fatigue fractured and the resin burned off the crack growth surface by baking at $630^{\circ} \mathrm{C}$ followed by ultrasonic cleaning in $\mathrm{DI}$ water. The resulting, tinted crack growth surface is shown in Figure 3.75(b). The change from grey/gold to blue coloration on the crack growth surface results from the transition from crack growth in alloy 182 to alloy 52M. Consistent with the side-surface measurement, the overall crack length was $4.5 \mathrm{~mm}$ with $\sim 2.9 \mathrm{~mm}$ in a water environment. This reveals an underprediction of crack length by DCPD, since it reported a crack length produced in $350^{\circ} \mathrm{C}$ and $50^{\circ} \mathrm{C}$ water of $\sim 2.1 \mathrm{~mm}$. 
Table 3.9 Corrected data summary for Ringhals alloy $52 \mathrm{M} / 182$ overlay specimens CT028 \& CT029.

\begin{tabular}{|c|c|c|c|c|c|c|c|c|c|c|c|c|}
\hline $\begin{array}{c}\text { Test } \\
\text { Phase } \\
\end{array}$ & $\begin{array}{l}\text { Dur- } \\
\text { ation } \\
\text { (h) }\end{array}$ & $\mathrm{R}$ & $\begin{array}{c}\text { Freq } \\
(\mathrm{Hz})\end{array}$ & $\begin{array}{c}\text { Hold } \\
\text { (h) }\end{array}$ & $\begin{array}{c}\text { Water } \\
\text { Chemistry } \\
\text { Conditions }\end{array}$ & $\begin{array}{c}\text { Temp } \\
\left({ }^{\circ} \mathrm{C}\right) \\
\end{array}$ & \multicolumn{3}{|c|}{ 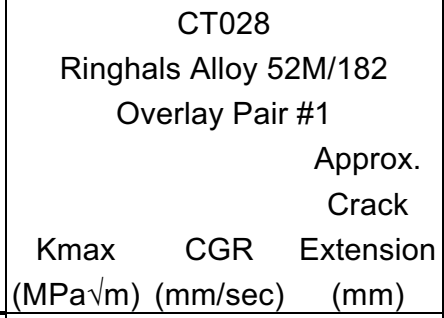 } & \multicolumn{3}{|c|}{ 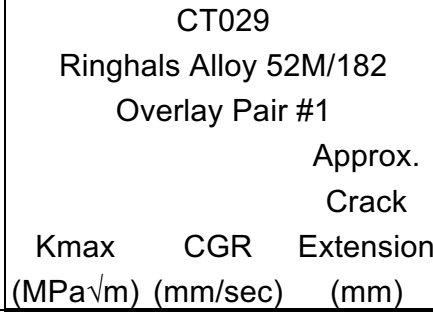 } \\
\hline 1 & $\sim 3$ & 0.3 & 3 & 0 & air & RT & 25 & 1.0E-04 & 0.71 & 25 & 8.1E-05 & 0.57 \\
\hline 2 & $\sim 2$ & 0.5 & 3 & 0 & air & RT & 28 & 5.7E-05 & 0.49 & 28 & 5.4E-05 & 0.38 \\
\hline 3 & $\sim 3$ & 0.6 & 3 & 0 & air & RT & 30 & 3.4E-05 & 0.30 & 30 & $3.1 \mathrm{E}-05$ & 0.28 \\
\hline 4 & $\sim 5$ & 0.7 & 3 & 0 & air & RT & 30 & $1.5 \mathrm{E}-05$ & 0.30 & 30 & $1.4 \mathrm{E}-05$ & 0.32 \\
\hline 5 & 74 & 0.7 & 0.1 & 0 & $20 \mathrm{cc} / \mathrm{kg} \mathrm{H}{ }_{2}$ & 350 & 30 & $1.0 \mathrm{E}-06$ & 0.201 & 30 & $1.0 \mathrm{E}-06$ & 0.236 \\
\hline 6 & 214 & 0.7 & 0.01 & 0 & $20 \mathrm{cc} / \mathrm{kg} \mathrm{H}$ & 350 & 30 & 2.7E-07 & 0.200 & 30 & $2.6 \mathrm{E}-07$ & 0.196 \\
\hline 7 & 359 & 0.7 & 0.001 & 0 & $20 \mathrm{cc} / \mathrm{kg} \mathrm{H}$ & 350 & 30 & 5.3E-08 & 0.066 & 30 & $5.0 \mathrm{E}-08$ & 0.074 \\
\hline 8 & 345 & 0.7 & 0.001 & 2.5 & $20 \mathrm{cc} / \mathrm{kg} \mathrm{H}$ & 350 & 30 & $1.2 \mathrm{E}-08$ & 0.011 & 30 & 1.7E-08 & 0.015 \\
\hline 9 & 518 & 0.5 & 0.001 & 2.5 & $20 \mathrm{cc} / \mathrm{kg} \mathrm{H}$ & 350 & 30 & $2.5 \mathrm{E}-08$ & 0.029 & 30 & $3.1 \mathrm{E}-08$ & 0.033 \\
\hline 10 & 267 & --- & const $\mathrm{K}$ & --- & $20 \mathrm{cc} / \mathrm{kg} \mathrm{H}$ & 350 & 30 & 2.1E-09 & 0.003 & 30 & 2.1E-09 & 0.002 \\
\hline 11 & 55 & 0.5 & 0.01 & 0 & $20 \mathrm{cc} / \mathrm{kg} \mathrm{H}_{2}$ & 350 & 30 & 9.0E-07 & 0.177 & 30 & $9.0 \mathrm{E}-07$ & 0.181 \\
\hline 12 & 84 & 0.5 & 0.001 & 0 & $20 \mathrm{cc} / \mathrm{kg} \mathrm{H}_{2}$ & 350 & 30 & 1.7E-07 & 0.051 & 30 & 9.7E-08 & 0.028 \\
\hline 13 & 119 & 0.7 & 0.001 & 0 & $20 \mathrm{cc} / \mathrm{kg} \mathrm{H}{ }_{2}$ & 350 & 30 & $3.2 \mathrm{E}-08$ & 0.017 & 30 & $1.6 \mathrm{E}-08$ & 0.009 \\
\hline 14 & 77 & 0.7 & 0.001 & 0 & $11 \mathrm{cc} / \mathrm{kg} \mathrm{H}_{2}$ & 325 & 30 & 2.6E-08 & 0.007 & 30 & 8.3E-09 & 0.004 \\
\hline 15 & 410 & 0.7 & 0.001 & 2.5 & $11 \mathrm{cc} / \mathrm{kg} \mathrm{H}{ }_{2}$ & 325 & 30 & 6.3E-09 & 0.009 & 30 & 2.4E-09 & 0.004 \\
\hline 16 & 170 & 0.7 & 0.001 & 2.5 & $29 \mathrm{cc} / \mathrm{kg} \mathrm{H}$ & 325 & 30 & 3.3E-09 & 0.002 & 30 & $1.9 \mathrm{E}-09$ & 0.000 \\
\hline 17 & 181 & 0.7 & 0.001 & 2.5 & $11 \mathrm{cc} / \mathrm{kg} \mathrm{H}_{2}$ & 325 & 30 & 4.5E-09 & 0.003 & 30 & 2.4E-09 & 0.003 \\
\hline 18 & 82 & --- & const $\mathrm{K}$ & --- & $11 \mathrm{cc} / \mathrm{kg} \mathrm{H}_{2}$ & 325 & 30 & no growth & 0.001 & 30 & no growth & 0.000 \\
\hline 19 & 422 & --- & const $\mathrm{K}$ & --- & $20 \mathrm{cc} / \mathrm{kg} \mathrm{H}_{2}$ & 350 & 30 & $9 \mathrm{E}-10$ & 0.004 & 30 & no growth & 0.000 \\
\hline 20 & 365 & 0.5 & 0.001 & 2.5 & $20 \mathrm{cc} / \mathrm{kg} \mathrm{H}_{2}$ & 350 & 30 & $1.3 \mathrm{E}-08$ & 0.034 & 30 & $1.0 \mathrm{E}-08$ & 0.010 \\
\hline 21 & 184 & 0.5 & 0.1 & 0 & $20 \mathrm{cc} / \mathrm{kg} \mathrm{H}$ & 50 & 30 & 2.0E-06 & 0.700 & 30 & 4.0E-07 & 0.179 \\
\hline 22 & 249 & 0.5 & 0.01 & 0 & $20 \mathrm{cc} / \mathrm{kg} \mathrm{H}$ & 50 & 30 & $3.2 \mathrm{E}-07$ & 0.302 & 30 & 4.4E-08 & 0.052 \\
\hline 23 & 239 & 0.5 & 0.001 & 0 & $20 \mathrm{cc} / \mathrm{kg} \mathrm{H}{ }_{2}$ & 50 & 30 & 4.3E-08 & 0.071 & 30 & 6.9E-09 & 0.010 \\
\hline 24 & 602 & --- & const $\mathrm{K}$ & --- & $20 \mathrm{cc} / \mathrm{kg} \mathrm{H}$ & 350 & 30 & 4.0E-09 & 0.039 & 30 & 2.4E-09 & 0.027 \\
\hline
\end{tabular}



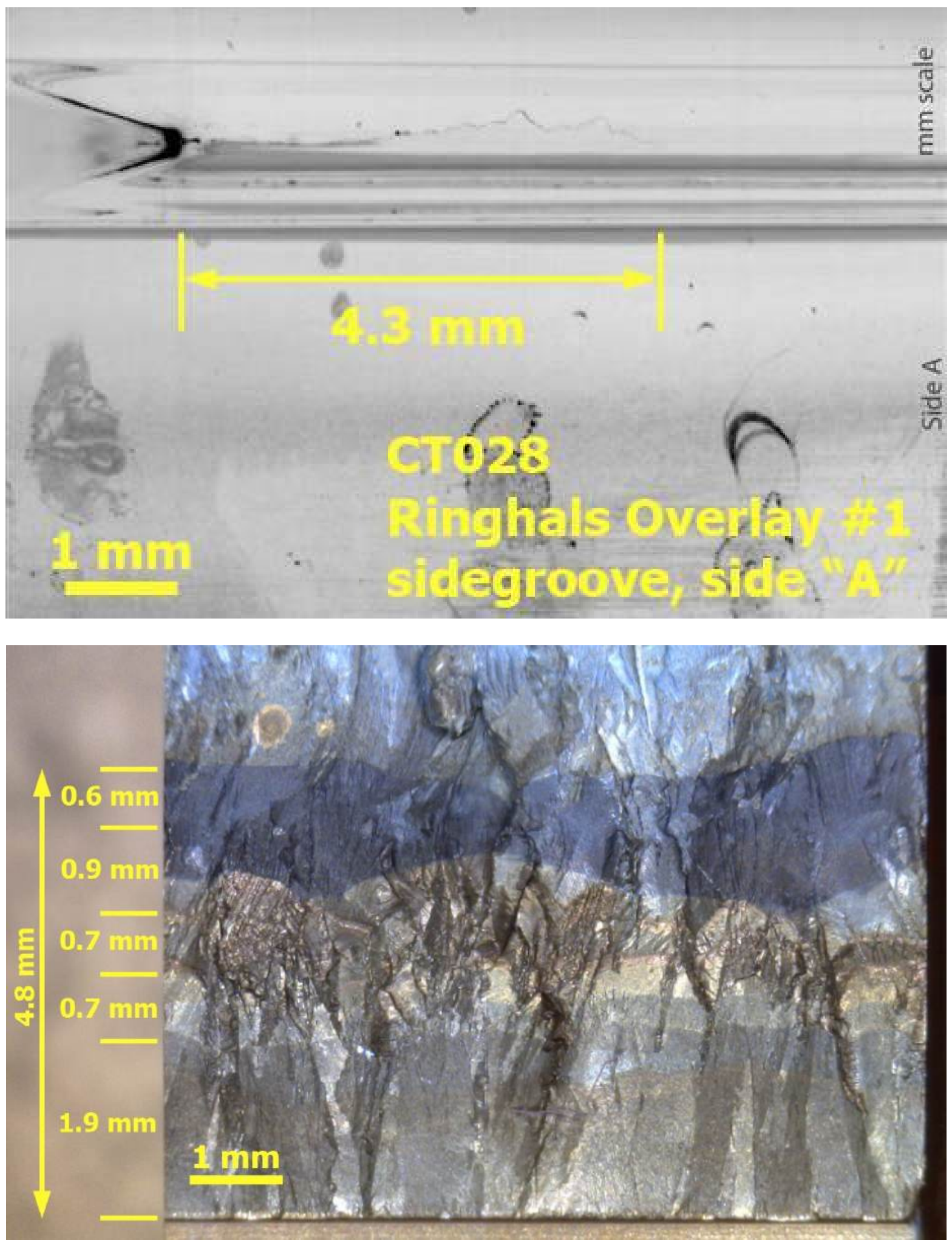

Figure 3.75 Optical images showing crack in the side groove (top) and fracture morphology on the crack-growth surface (bottom) for the alloy 182/52 overlay specimen \#1 (CT028). 
Based on previous experience obtained with the alloy 182 weld metal in the overlay samples CT028 and CT029, the decision was made to begin SCC transitioning at $30 \mathrm{MPa} \sqrt{\mathrm{m}}$ under oxidizing BWR water conditions $\left(288^{\circ} \mathrm{C}\right.$ high purity water with $\left.2 \mathrm{ppm} \mathrm{O}_{2}\right)$ with $30 \mathrm{ppb}$ sulfate. This environment has been shown to give much more consistent SCC response for alloy 182 weld metals [Ref. 7], and the intent was to promote maximum IGSCC crack-front engagement before switching to simulated PWR primary water. Initial transitioning steps were performed at an $R$ value on 0.7 to reach constant $K$ with the crack front a little more than $1 \mathrm{~mm}$ away from the alloy 182 - alloy $52 \mathrm{M}$ interface. The initial constant $\mathrm{K}$ growth rates were $\sim 2 \times 10^{-8} \mathrm{~mm} / \mathrm{s}$ for both samples as shown in Figure 3.76. These rates were again lower than anticipated, but it was expected that the rate would increase with time as has been observed in previous tests on alloy 600 and alloy 182 under BWR oxidizing water conditions. However, the CGRs slowed slightly after $\sim 300 \mathrm{~h}$ at constant K. A cycle + hold loading step with $\mathrm{R}=0.7$ was initiated at $\sim 1220 \mathrm{~h}$ to explore whether crack ligaments in the wake of the crack were affecting the DCPD measurement of crack length. The lack of a significant jump in crack extension suggested little or no breakage of ligaments, and the test was returned to constant K. Unfortunately, the propagation rates remained at somewhat low values for this aggressive oxidizing environment, so a second application of cycle + hold loading, but at $R=0.5$ was applied with similar results. While these rates indicate that IGSCC is occurring, the rates are $\sim 10 \mathrm{X}$ lower than other tests on alloy 182.

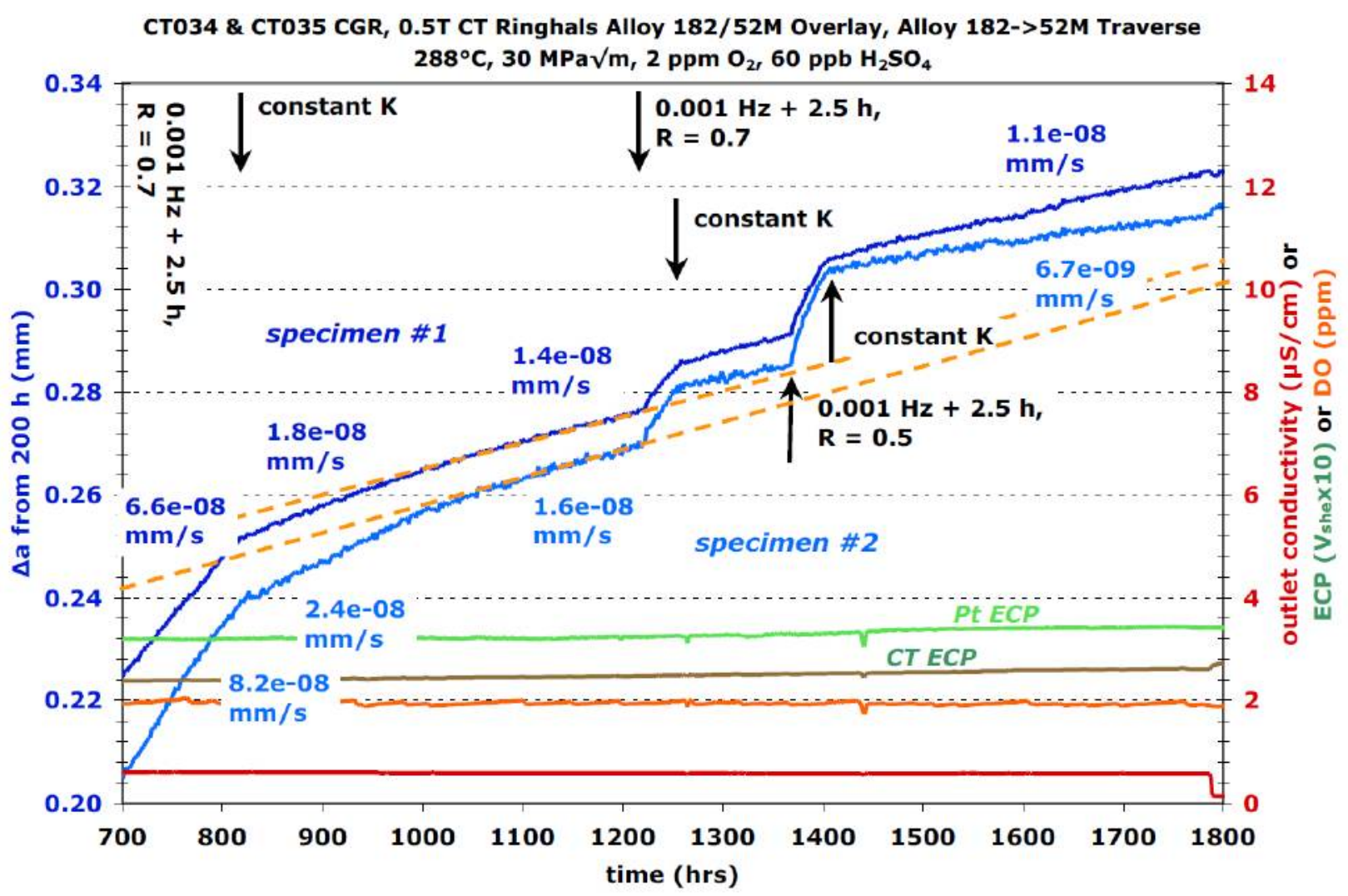

Figure 3.76 Transitioning steps to constant $\mathrm{K}$ response under BWR oxidizing conditions of the second pair of Ringhals alloy 52M/182 overlay specimens (CT034 \& CT035). 
The decision was made to convert this test to PWR primary water conditions. As a first step, sulfate additions were stopped at $\sim 1790 \mathrm{~h}$ and propagation rates slowly dropped by $25 \%$ in specimen \#1 and $35 \%$ in specimen \#2 over a period of $\sim 375 \mathrm{~h}$. Oxygen was then removed, hydrogen added, and the temperature increased to $350^{\circ} \mathrm{C}$ at $\sim 2150 \mathrm{~h}$. A dissolved hydrogen level of $20 \mathrm{cc} / \mathrm{kg}$ (near the $\mathrm{Ni} / \mathrm{NiO}$ line) was used to promote maximum SCC susceptibility. Boron and Li were not added to fully simulate PWR primary water conditions, but this difference is not believed to have a strong influence on SCC. Over the following $3+$ weeks, measured CGRs for the two overlay samples slowly decreased as illustrated in Figure 3.77. CT035 revealed a more significant drop by more than 3 times and appears to be approaching a steadystate CGR of $<1 \times 10^{-9} \mathrm{~mm} / \mathrm{s}$. CT034 remained slightly higher, but its propagation rate was still extremely low. As was the case during the test of the first pair of overlay samples, the alloy 182 is very resistant to SCC. Even though transitioning in oxidizing water + sulfate should have promoted IGSCC, subsequent growth in hydrogenated water was difficult. As a result, it was again impractical to propagate SCC from the alloy 182 to the alloy $52 \mathrm{M}$ interface under these conditions. Even assuming a significant error ( 40\%) in the actual crack length, the required time to reach the interface under constant $\mathrm{K}$ or cycle + hold conditions in hydrogenated water would be greater than one year. Therefore, the decision was made to advance the crack front by $0.3-0.4 \mathrm{~mm}$ by aggressive cycling (hopefully removing any ligaments that may be present), then go through transitioning steps again in $288^{\circ} \mathrm{C}$ oxidizing water + sulfate.

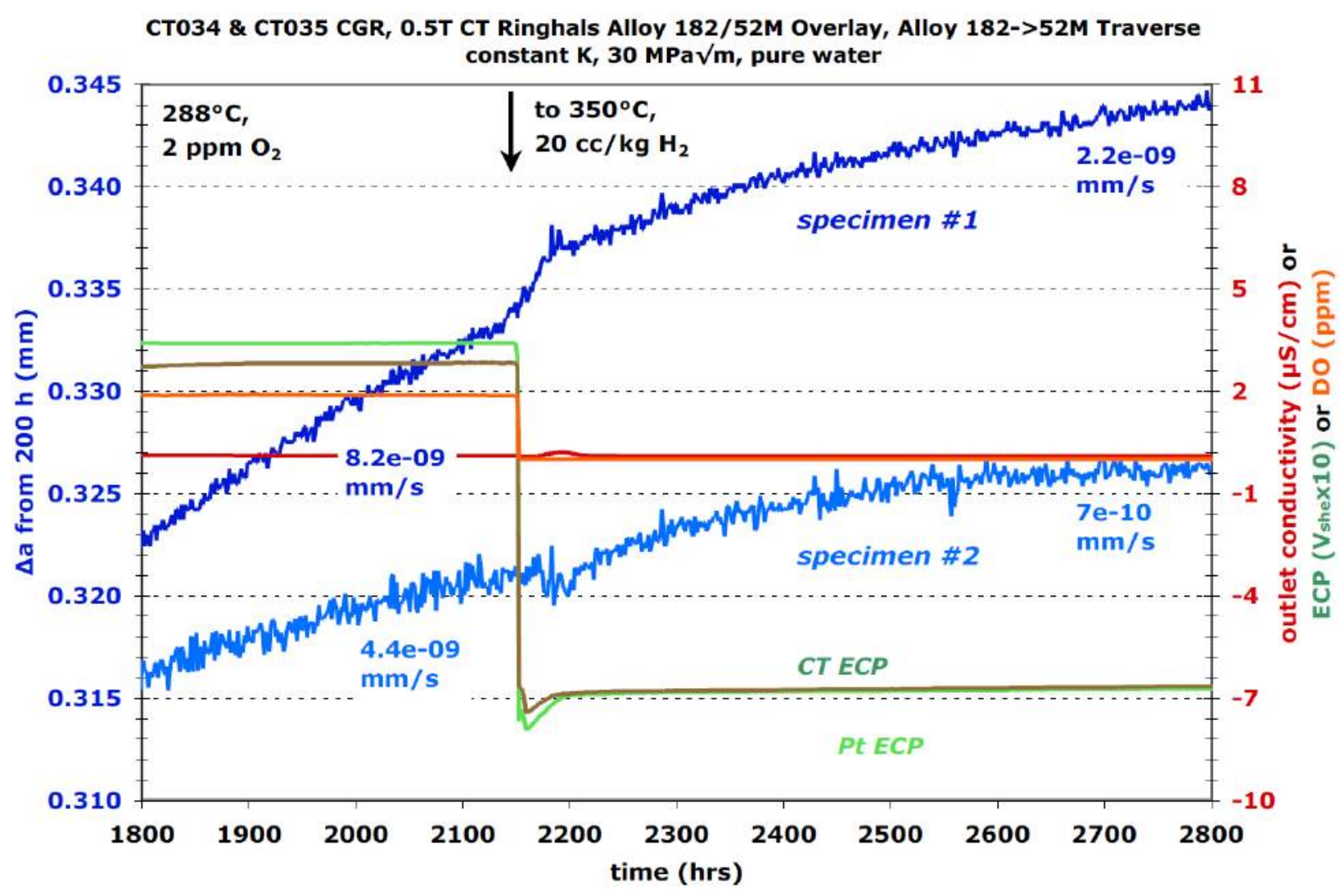

Figure 3.77 Crack growth response on switching from BWR oxidizing to hydrogenated water in the second pair of Ringhals alloy 52M/182 specimens (CT034 \& CT035). 
Initial cycling was conducted at $0.1 \mathrm{~Hz}, \mathrm{R}=0.5$ beginning at $\sim 2960 \mathrm{~h}$ and revealed a reasonably rapid increase in DCPD-measured crack length of $>100 \mu \mathrm{m}$ in $\sim 5 \mathrm{~h}$ before increasing the $\mathrm{R}$ value to 0.7 for another $50 \mu \mathrm{m}$. The transitioning sequence was continued at $\sim 2975 \mathrm{~h}$ by decreasing the cyclic frequency to $0.01 \mathrm{~Hz}$ and then to $0.001 \mathrm{~Hz}$ at $\sim 3015 \mathrm{~h}$. Somewhat surprisingly, the measured cyclic CGRs were 2-4X lower than measured under identical conditions at the beginning of the test. To confirm this response, cycle + hold conditions were established at $\sim 3180 \mathrm{~h}$ showing a CGR of $\sim 3 \times 10^{-8} \mathrm{~mm} / \mathrm{s}$ in Figure 3.78 . Once again, this is more than $2 X$ lower than measured earlier in this test. Since the mockup was created by overlaying alloy 182 on top of alloy $52 \mathrm{M}$, a compressive residual stress is not expected in the alloy 182. Therefore, a more likely explanation for the lower propagation rate is the presence of ligaments behind the crack front or a highly uneven crack front with areas already intersecting the alloy $52 \mathrm{M}$ interface. Loading conditions were briefly changed to a periodic unload at $\mathrm{R}=0.3$ producing a high $\Delta \mathrm{K}$ of $21 \mathrm{MPa} \sqrt{\mathrm{m}}$. The lack of a significant jump in crack length and the small increase in CGR suggests that no ligaments are being removed. Returning to the cycle + hold condition produced a similar CGR and indicates that the periodic unload had no effect. The test was converted to constant $\mathrm{K}$ at $\sim 3660 \mathrm{~h}$ as shown in Figure 3.79. Specimen CT034 continued to exhibit low values with the propagation rate decreasing to $1 \times 10^{-9} \mathrm{~mm} / \mathrm{s}$. However, specimen CT035 slowed only slightly, stabilizing at a rate of $1.0 \times 10^{-8} \mathrm{~mm} / \mathrm{s}$ and is comparable to the constant $\mathrm{K}$ propagation rates measured in earlier steps of the test.

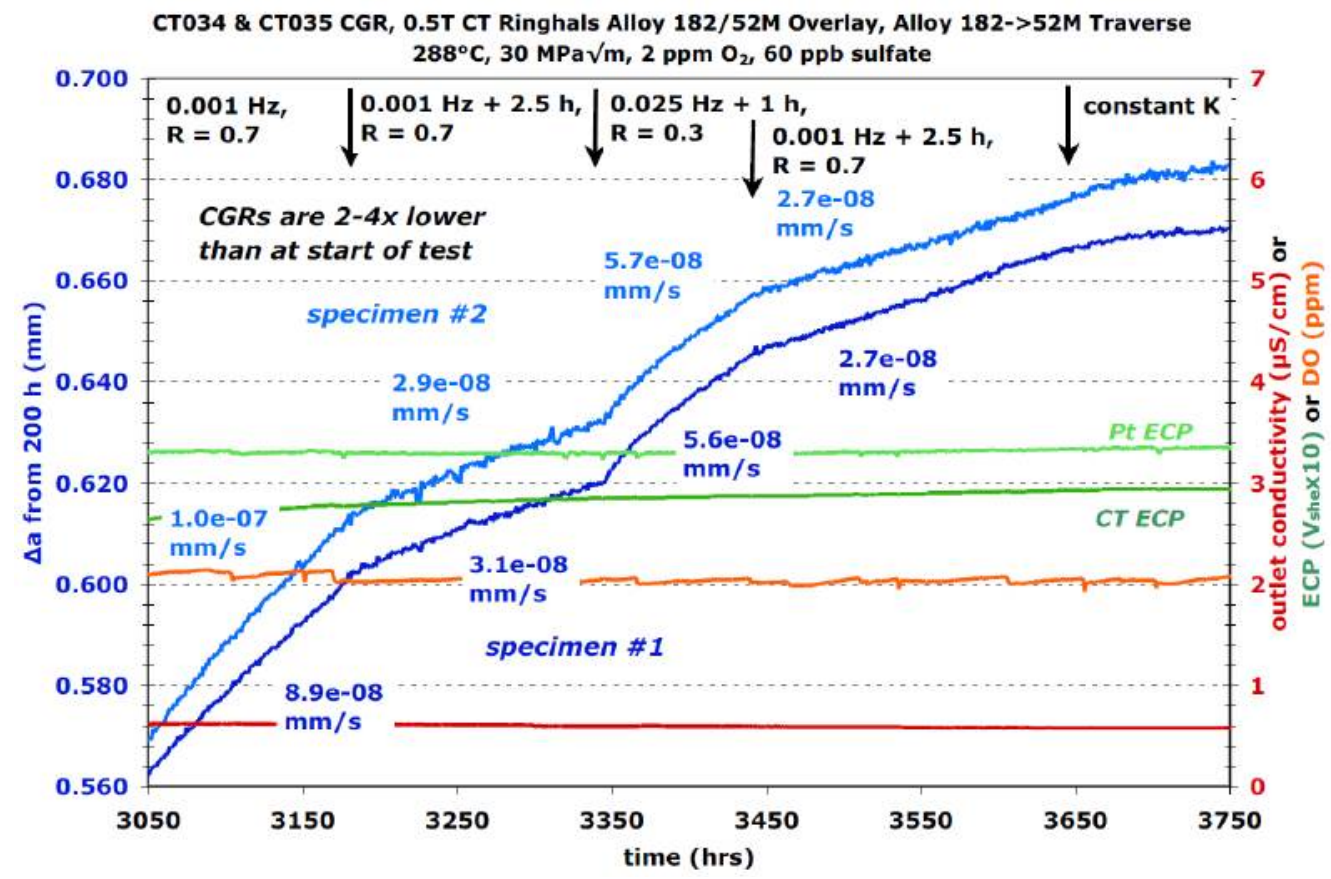

Figure 3.78 Response during second transitioning phase in BWR oxidizing water of the second pair of Ringhals alloy 52M/182 specimens (CT034 \& CT035). 


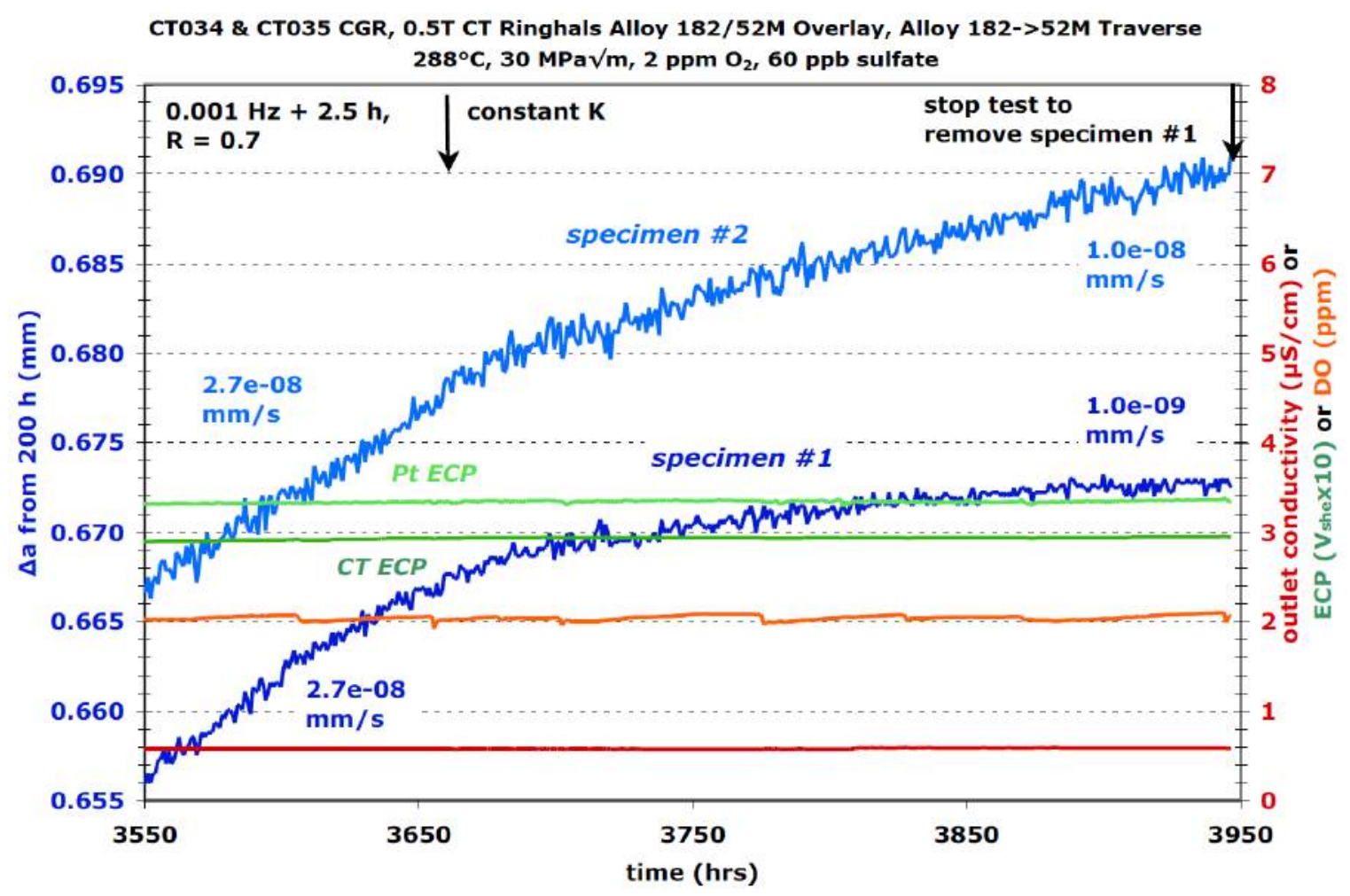

Figure 3.79 Second observation of constant $\mathrm{K}$ response for the second pair of Ringhals alloy $52 \mathrm{M} / 182$ specimens in BWR oxidizing water with sulfate.

The lower SCC CGRs being observed in the alloy 182 under aggressive oxidizing conditions creates even more doubt whether a useful evaluation of the alloy 182/52M interface can be obtained from this material. If sustained higher SCC CGRs cannot be produced in the alloy 182, it will be impossible to assess crack growth rate changes during the final approach to the interface. PNNL results on four separate Ringhals overlay mockup samples clearly show the high SCC resistance of this alloy 182 weld metal in high-temperature hydrogenated water. The current measurements confirm this result and also reveal that the alloy 182 is also somewhat resistant to SCC in oxidizing BWR water. While the measured CGRs suggest that IGSCC is occurring, rates are still $>5 X$ lower than expected in oxidizing water plus sulfate.

After discussion with the NRC project manager, it was decided to stop the test to remove specimen CT034 for examination of first the crack front location at side surfaces and then to fracture and document the crack-growth surface. These characterizations clearly showed that the crack front had intersected the alloy $52 \mathrm{M}$ prompting the decrease in propagation rates. The decision was made to restart the test on specimen CT035 under simulated PWR primary water conditions and apply aggressive cycling to advance the crack front moving it completely into the alloy $52 \mathrm{M}$. 
After crack extension at $0.1 \mathrm{~Hz}$ and $0.01 \mathrm{~Hz}$, a number of transitioning steps were applied with variations in $\mathrm{R}$ and hold time. A rate of $3.2 \times 10^{-8} \mathrm{~mm} / \mathrm{s}$ was eventually established under cycle + hold loading at $R=0.5$ as shown in Figure 3.80. This rate is approximately $3 x$ higher than has been observed in the previous tests on alloy $152 / 52 / 52 \mathrm{M}$, and decision was made to evaluate constant $\mathrm{K}$ at this time. A small step increase in DCPD-measured crack length $(\sim 10 \mu \mathrm{m})$ was detected when constant $\mathrm{K}$ was established at $5825 \mathrm{~h}$, similar to that seen when switching from cycling to cycle + hold conditions previously obtained. A stable CGR of $9.4 \times 10^{-9} \mathrm{~mm} / \mathrm{s}$ was seen over the first $300 \mathrm{~h}$ at constant $\mathrm{K}$ and then decreased slightly to $7.6 \times 10^{-9} \mathrm{~mm} / \mathrm{s}$ over the next $400 \mathrm{~h}$. This final constant $\mathrm{K}$ response is shown in Figure 3.81. A summary of test conditions, crack extension, and growth rate for each phase of the test is shown in Table 3.10. These uncorrected propagation rates are $\sim 6-20 \mathrm{X}$ higher than those previously measured for the alloy 52 welds from AREVA and MHI.

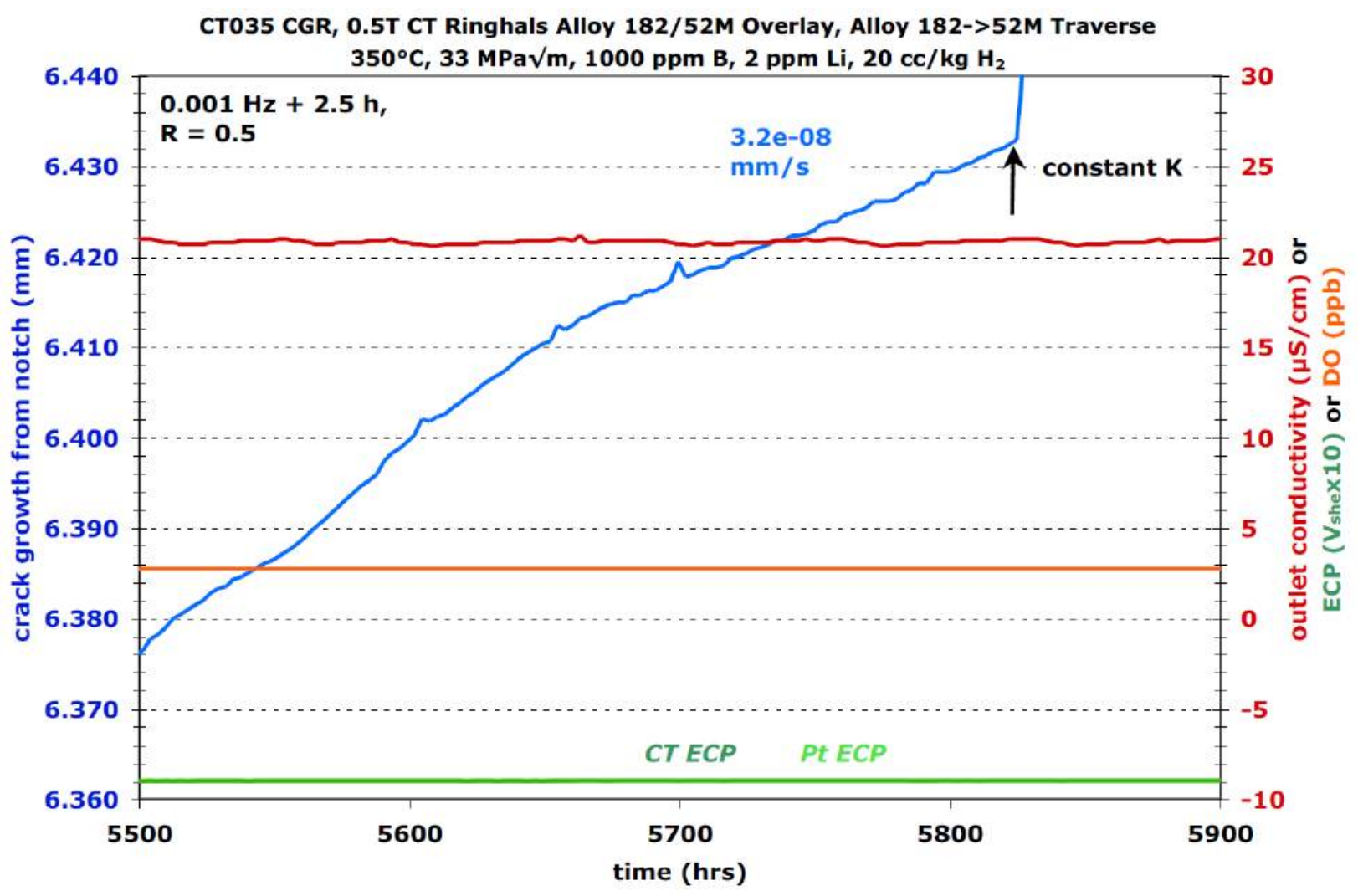

Figure 3.80 Final cycle + hold loading response of Ringhals alloy 52M/182 specimen CT035 showing a relatively high rate of $3.2 \times 10^{-8} \mathrm{~mm} / \mathrm{s}$. 


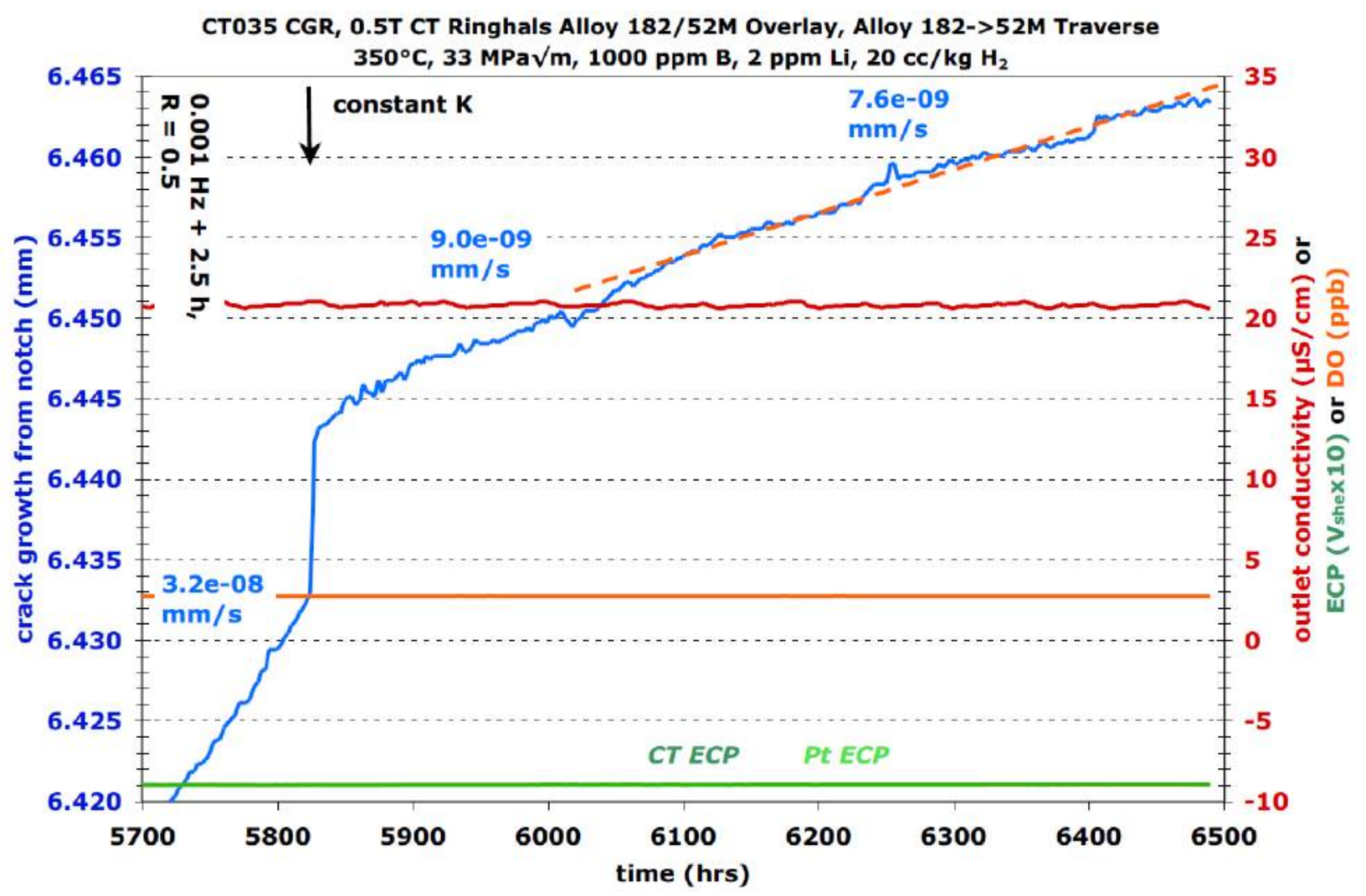

Figure 3.81 Final constant $\mathrm{K}$ response of Ringhals alloy 52M/182 specimen CT035 with final propagation in the alloy $52 \mathrm{M}$.

Alloy 52M/82 Inlay Mockup (CT031 \& CT032)

A section of an alloy $52 \mathrm{M}$ weld inlay mockup produced for Ringhals/Vattenfall was obtained from Rich Jacko of Westinghouse. As briefly described in Section 3.1, it consists of alloy 82 robotically deposited onto a low-alloy steel ring followed by a robotically deposited $10 \mathrm{~mm}$ thick inlay of alloy 52M. A layer of alloy 152 was manually welded on top of the inlay by Westinghouse to provide sufficient material to obtain CT specimens from the mockup. The approximate location of the 0.5T CT specimens (CT031 and CT032) is shown in the Figure 3.82. The notch was positioned to enable the precrack to be placed in the alloy 82 approximately $0.5 \mathrm{~mm}$ from the alloy $52 \mathrm{M}$ interface. Both sides of the machined samples were polished and etched to reveal the alloy 82 inlay and the alloy $52 \mathrm{M}$ interface. Examples of these regions are shown in Figure 3.83 along with specifics of the planned precrack locations. 
Table 3.10 Data summary for Ringhals alloy 52M/182 overlay specimens CT034 \& CT035.

\begin{tabular}{|c|c|c|c|c|c|c|c|c|c|c|c|c|}
\hline $\begin{array}{l}\text { Test } \\
\text { Phase }\end{array}$ & $\begin{array}{l}\text { Dur- } \\
\text { ation } \\
\text { (h) }\end{array}$ & $\mathrm{R}$ & $\begin{array}{l}\text { Freq } \\
(\mathrm{Hz})\end{array}$ & $\begin{array}{l}\text { Hold } \\
\text { (h) }\end{array}$ & $\begin{array}{c}\text { Water } \\
\text { Chemistry } \\
\text { Conditions }\end{array}$ & $\begin{array}{c}\text { Temp } \\
\left({ }^{\circ} \mathrm{C}\right)\end{array}$ & $\begin{array}{r}\text { Ringh } \\
\mathrm{O}\end{array}$ & $\begin{array}{c}\text { СТ034 } \\
\text { als Alloy } 52 \\
\text { verlay Pair }\end{array}$ & $\begin{array}{l}\text { 2M/182 } \\
\# 2 \\
\text { Approx. } \\
\text { Crack } \\
\text { Extension } \\
\text { (mm) }\end{array}$ & $\begin{array}{r}\text { Ringh } \\
\mathrm{O}\end{array}$ & $\begin{array}{l}\text { CT035 } \\
\text { als Alloy } 52 \\
\text { verlay Pair }\end{array}$ & $\begin{array}{l}\text { 2M/182 } \\
\text { A2 } \\
\text { Approx. } \\
\text { Crack } \\
\text { Extension } \\
(\mathrm{mm})\end{array}$ \\
\hline 1 & $\sim 2$ & 0.3 & 5 & 0 & air precrack & RT & 25 & 2.3E-04 & 0.50 & 25 & $9.5 \mathrm{E}-05$ & 0.50 \\
\hline 2 & $\sim 2$ & 0.5 & 5 & 0 & air precrack & RT & 28 & $6.0 \mathrm{E}-05$ & 0.30 & 28 & $6.5 \mathrm{E}-05$ & 0.30 \\
\hline 3 & $\sim 2$ & 0.6 & 5 & 0 & air precrack & $\mathrm{RT}$ & 30 & 4.3E-05 & 0.20 & 30 & 4.3E-05 & 0.20 \\
\hline 4 & $\sim 2$ & 0.7 & 5 & 0 & air precrack & RT & 30 & $2.2 \mathrm{E}-05$ & 0.20 & 30 & 2.1E-05 & 0.20 \\
\hline 5 & 8 & 0.7 & 0.1 & 0 & $\mathrm{O} 2+\mathrm{SO}^{4}{ }^{\mathrm{A}}$ & 288 & 30 & 2.1E-06 & 0.057 & 30 & $3.8 \mathrm{E}-06$ & 0.090 \\
\hline 6 & 69 & 0.7 & 0.01 & 0 & $\mathrm{O} 2+\mathrm{SO}^{\mathrm{A}}$ & 288 & 30 & $6.4 \mathrm{E}-07$ & 0.163 & 30 & 1.3E-06 & 0.311 \\
\hline 7 & 138 & 0.7 & 0.001 & 0 & $\mathrm{O} 2+\mathrm{SO} 4{ }^{\mathrm{A}}$ & 288 & 30 & $2.2 \mathrm{E}-07$ & 0.135 & 30 & $4.2 \mathrm{E}-07$ & 0.269 \\
\hline 8 & 415 & 0.7 & 0.001 & 2.5 & $\mathrm{O} 2+\mathrm{SO}^{\mathrm{A}}$ & 288 & 30 & 7.1E-08 & 0.176 & 30 & $6.6 \mathrm{E}-08$ & 0.127 \\
\hline 9 & 23 & 0.5 & 0.001 & 2.5 & $\mathrm{O} 2+\mathrm{SO}_{4}{ }^{\mathrm{A}}$ & 288 & 30 & not meas & 0.012 & 30 & not meas & 0.015 \\
\hline 10 & 140 & 0.7 & 0.001 & 2.5 & $\mathrm{O} 2+\mathrm{SO}^{\mathrm{B}}$ & 288 & 30 & 6.6E-08 & 0.033 & 30 & $8.2 \mathrm{E}-08$ & 0.039 \\
\hline 11 & 402 & --- & const $\mathrm{K}$ & --- & $\mathrm{O} 2+\mathrm{SO}^{\mathrm{B}}$ & 288 & 30 & 1.4E-08 & 0.025 & 30 & 1.6E-08 & 0.030 \\
\hline 12 & 31 & 0.7 & 0.001 & 2.5 & $\mathrm{O} 2+\mathrm{SO}^{\mathrm{B}}$ & 288 & 30 & $6.1 \mathrm{E}-08$ & 0.009 & 30 & 7.5E-08 & 0.011 \\
\hline 13 & 116 & --- & const $\mathrm{K}$ & --- & $\mathrm{O} 2+\mathrm{SO}^{\mathrm{B}}$ & 288 & 30 & $1.3 \mathrm{E}-08$ & 0.006 & 30 & $1.1 \mathrm{E}-08$ & 0.005 \\
\hline 14 & 32 & 0.5 & 0.001 & 2.5 & $\mathrm{O} 2+\mathrm{SO}^{\mathrm{B}}$ & 288 & 30 & 1.1E-07 & 0.014 & 30 & $1.2 \mathrm{E}-07$ & 0.018 \\
\hline 15 & 387 & -- & const $\mathrm{K}$ & --- & $\mathrm{O} 2+\mathrm{SO}^{\mathrm{B}}$ & 288 & 30 & $1.1 \mathrm{E}-08$ & 0.018 & 30 & 6.7E-09 & 0.011 \\
\hline 16 & 363 & --- & const $\mathrm{K}$ & --- & 2 ppm O2 & 288 & 30 & 8.1E-09 & 0.012 & 30 & 4.4E-09 & 0.006 \\
\hline 17 & 813 & --- & const $\mathrm{K}$ & --- & $20 \mathrm{cc} / \mathrm{kg} \mathrm{H} 2$ & 350 & 30 & $2.2 \mathrm{E}-09$ & 0.013 & 30 & $6.9 \mathrm{E}-10$ & 0.001 \\
\hline 18 & 5 & 0.5 & 0.1 & 0 & $\mathrm{O} 2+\mathrm{SO}^{\mathrm{B}}$ & 288 & 30 & not meas & 0.110 & 30 & not meas & 0.134 \\
\hline 19 & 7 & 0.7 & 0.1 & 0 & $\mathrm{O} 2+\mathrm{SO} 4^{\mathrm{B}}$ & 288 & 30 & not meas & 0.042 & 30 & not meas & 0.043 \\
\hline 20 & 43 & 0.7 & 0.01 & 0 & $\mathrm{O} 2+\mathrm{SO} 4^{\mathrm{B}}$ & 288 & 30 & 3.1E-07 & 0.050 & 30 & $3.8 \mathrm{E}-07$ & 0.056 \\
\hline 21 & 160 & 0.7 & 0.001 & 0 & $\mathrm{O} 2+\mathrm{SO}^{\mathrm{B}}$ & 288 & 30 & 8.9E-08 & 0.050 & 30 & $1.0 \mathrm{E}-07$ & 0.059 \\
\hline 22 & 168 & 0.7 & 0.001 & 2.5 & $\mathrm{O} 2+\mathrm{SO}^{\mathrm{B}}$ & 288 & 30 & $3.1 \mathrm{E}-08$ & 0.018 & 30 & $2.9 \mathrm{E}-08$ & 0.018 \\
\hline 23 & 95 & 0.7 & 0.025 & 1 & $\mathrm{O} 2+\mathrm{SO} 4^{\mathrm{B}}$ & 288 & 30 & 5.6E-08 & 0.026 & 30 & 5.7E-08 & 0.026 \\
\hline 24 & 218 & 0.7 & 0.001 & 2.5 & $\mathrm{O} 2+\mathrm{SO}^{\mathrm{B}}$ & 288 & 30 & 2.7E-08 & 0.020 & 30 & 2.7E-08 & 0.020 \\
\hline 25 & 288 & --- & const $\mathrm{K}$ & --- & $\mathrm{O} 2+\mathrm{SO}^{\mathrm{B}}$ & 288 & 30 & 1.0E-09 & 0.006 & 30 & $1.0 \mathrm{E}-08$ & 0.013 \\
\hline 26 & 52 & 0.7 & 0.001 & 0 & $20 \mathrm{cc} / \mathrm{kg} \mathrm{H} 2$ & 350 & specime & n removed & from test & 32 & 6.9E-09 & 0.016 \\
\hline 27 & 21 & 0.3 & 0.2 & 0 & $20 \mathrm{cc} / \mathrm{kg} \mathrm{H} 2$ & 350 & & $"$ & & 33 & $1.9 \mathrm{E}-05$ & 2.049 \\
\hline 28 & 230 & 0.5 & 0.1 & 0 & $20 \mathrm{cc} / \mathrm{kg} \mathrm{H} 2$ & 350 & & $"$ & & 33 & $6.0 \mathrm{E}-06$ & 0.461 \\
\hline 29 & 184 & 0.7 & 0.01 & 0 & $20 \mathrm{cc} / \mathrm{kg} \mathrm{H} 2$ & 350 & & $"$ & & 33 & 5.8E-07 & 0.396 \\
\hline 30 & 395 & 0.7 & 0.001 & 0 & $20 \mathrm{cc} / \mathrm{kg} \mathrm{H} 2$ & 350 & & $"$ & & 33 & $6.7 \mathrm{E}-08$ & 0.032 \\
\hline 31 & 64 & 0.7 & 0.001 & 2.5 & $20 \mathrm{cc} / \mathrm{kg} \mathrm{H} 2$ & 350 & & $"$ & & 33 & 5.9E-09 & 0.008 \\
\hline 32 & 115 & 0.5 & 0.001 & 2.5 & $20 \mathrm{cc} / \mathrm{kg} \mathrm{H} 2$ & 350 & & $"$ & & 33 & not meas & not meas \\
\hline 33 & 427 & 0.5 & 0.001 & 0 & $20 \mathrm{cc} / \mathrm{kg} \mathrm{H} 2$ & 350 & & $"$ & & 33 & 4.9E-07 & 0.168 \\
\hline 34 & 668 & 0.5 & 0.001 & 2.5 & $20 \mathrm{cc} / \mathrm{kg} \mathrm{H} 2$ & 350 & & $"$ & & 33 & $3.2 \mathrm{E}-08$ & 0.061 \\
\hline 35 & 52 & --- & const $\mathrm{K}$ & --- & $20 \mathrm{cc} / \mathrm{kg} \mathrm{H} 2$ & 350 & & $"$ & & 33 & 7.6E-09 & 0.021 \\
\hline
\end{tabular}

${ }^{\mathrm{A}} 2 \mathrm{ppm} \mathrm{O}_{2}+30 \mathrm{ppb} \mathrm{SO}_{4}^{-} ;{ }^{\mathrm{B}} 2 \mathrm{ppm} \mathrm{O}_{2}+60 \mathrm{ppb} \mathrm{SO}_{4}{ }^{-}$ 


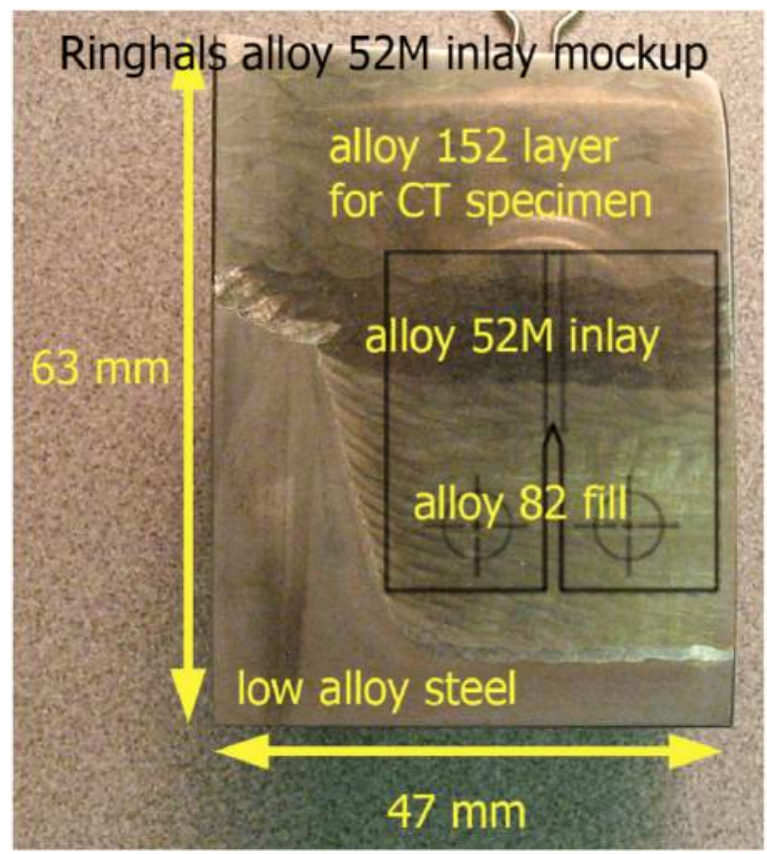

Figure 3.82 Profile of Ringhals alloy 52M inlay mockup weld received from Westinghouse. Alloy $52 \mathrm{M}$ inlay is $10 \mathrm{~mm}$ thick.

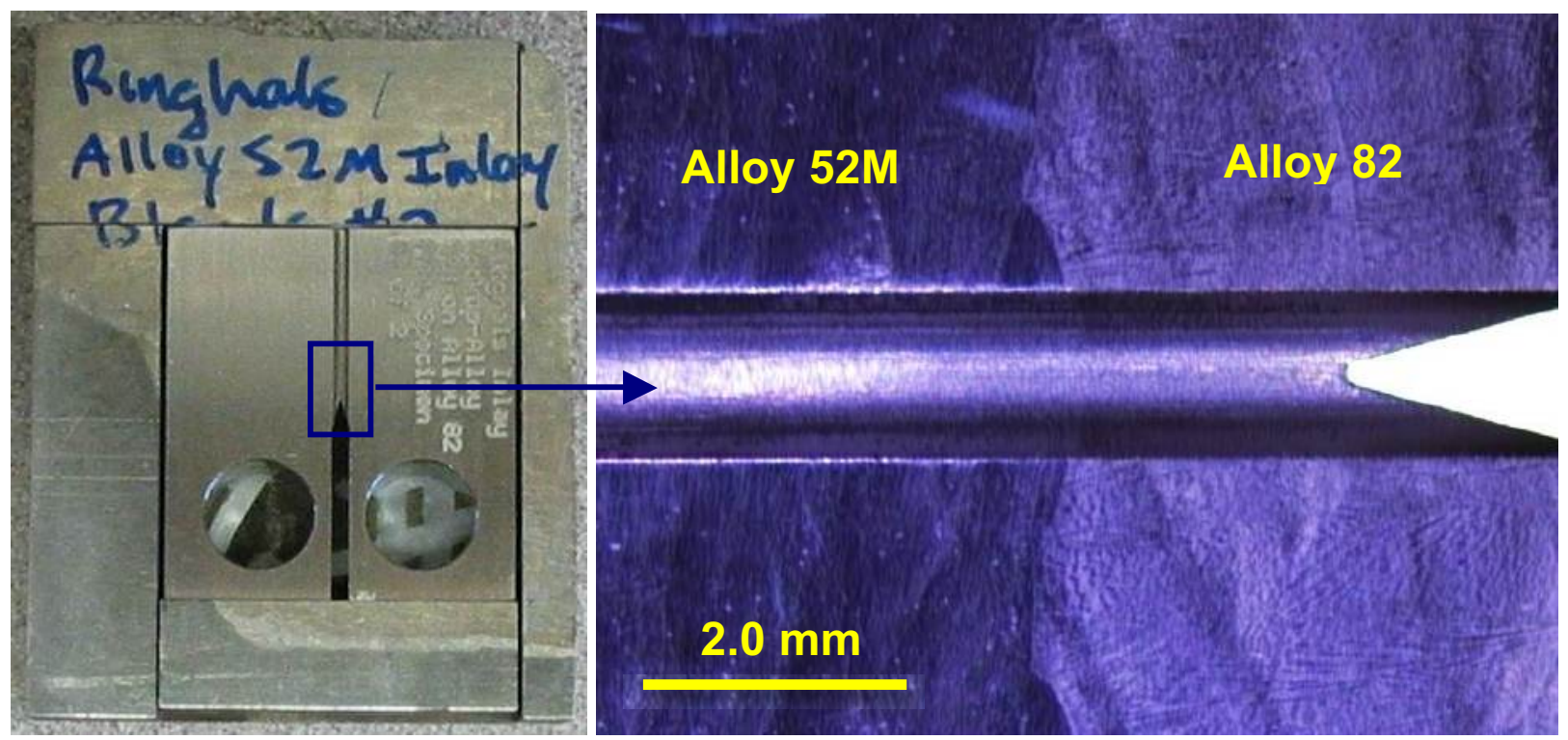

Figure 3.83 Optical images of the alloy 52M/82 inlay sample CT031. 
The goal of this test on the inlay samples was similar to that for the overlay samples; produce a fully engaged IGSCC crack front in the more susceptible alloy 82 and monitor growth under constant $\mathrm{K}$ conditions as it approaches the alloy $52 \mathrm{M}$ interface. An overview of the entire test is shown in Figure 3.84. Testing began at $350^{\circ} \mathrm{C}$ and $29 \mathrm{cc} / \mathrm{kg} \mathrm{H}_{2}$ and was switched to $20 \mathrm{cc} / \mathrm{kg}$ (ECP at $\mathrm{Ni} / \mathrm{NiO}$ transition for expected maximum SCC growth rate [Refs. 6,8]) at $\sim 130 \mathrm{~h}$ during the gentle cycling at $0.001 \mathrm{~Hz}$. Surprisingly, the change to a hydrogen level near the $\mathrm{Ni} / \mathrm{NiO}$ line prompted a small decrease in propagation rates. A 2.5-h hold time was added at $\sim 220 \mathrm{~h}$ and the propagation rates dropped to $\sim 5.4$ and $2.2 \times 10^{-8} \mathrm{~mm} / \mathrm{s}$ for the two inlay specimens. After $\sim 100 \mathrm{~h}$ in this cycle + hold condition, the rates stabilized at 2.9 and $2.1 \times 10^{-8} \mathrm{~mm} / \mathrm{s}$. Based on prior alloy 82 results by GE Global [Ref. 7], the $R$ value was increased from 0.5 to 0.7 to help promote SCC. Propagation rates decreased by $2-3 X$ after this change to values $<10^{-8} \mathrm{~mm} / \mathrm{s}$ suggesting limited SCC engagement across the crack front. Consistent with this interpretation, rates further decreased to $\sim 3 \times 10^{-9} \mathrm{~mm} / \mathrm{s}$ or lower when switching to constant $\mathrm{K}$ conditions as illustrated in Figure 3.85 .

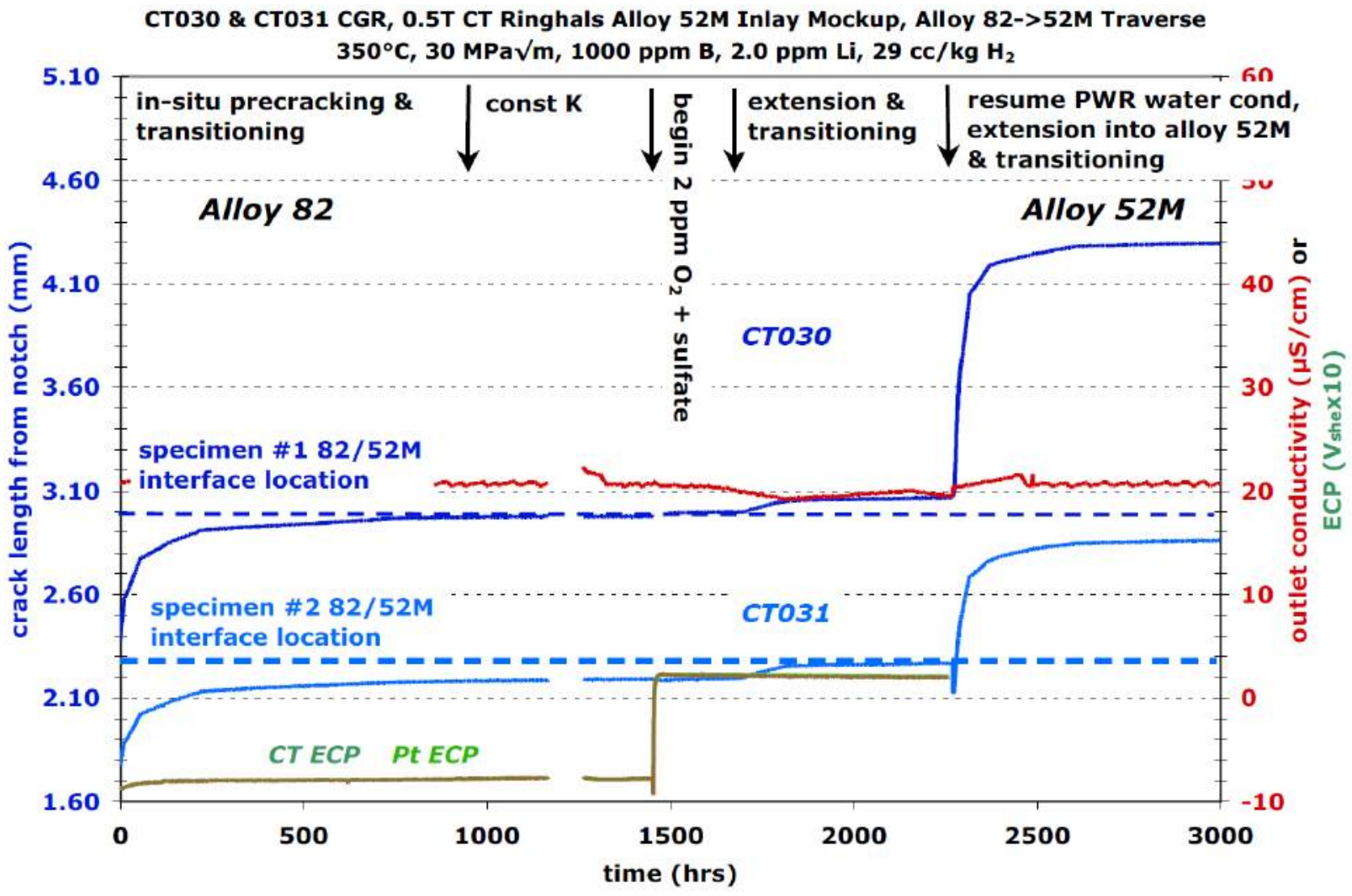

Figure 3.84 Overview of the entire test on the Ringhals alloy $52 \mathrm{M} / 82$ inlay mockups (CT030 \& CT031). 


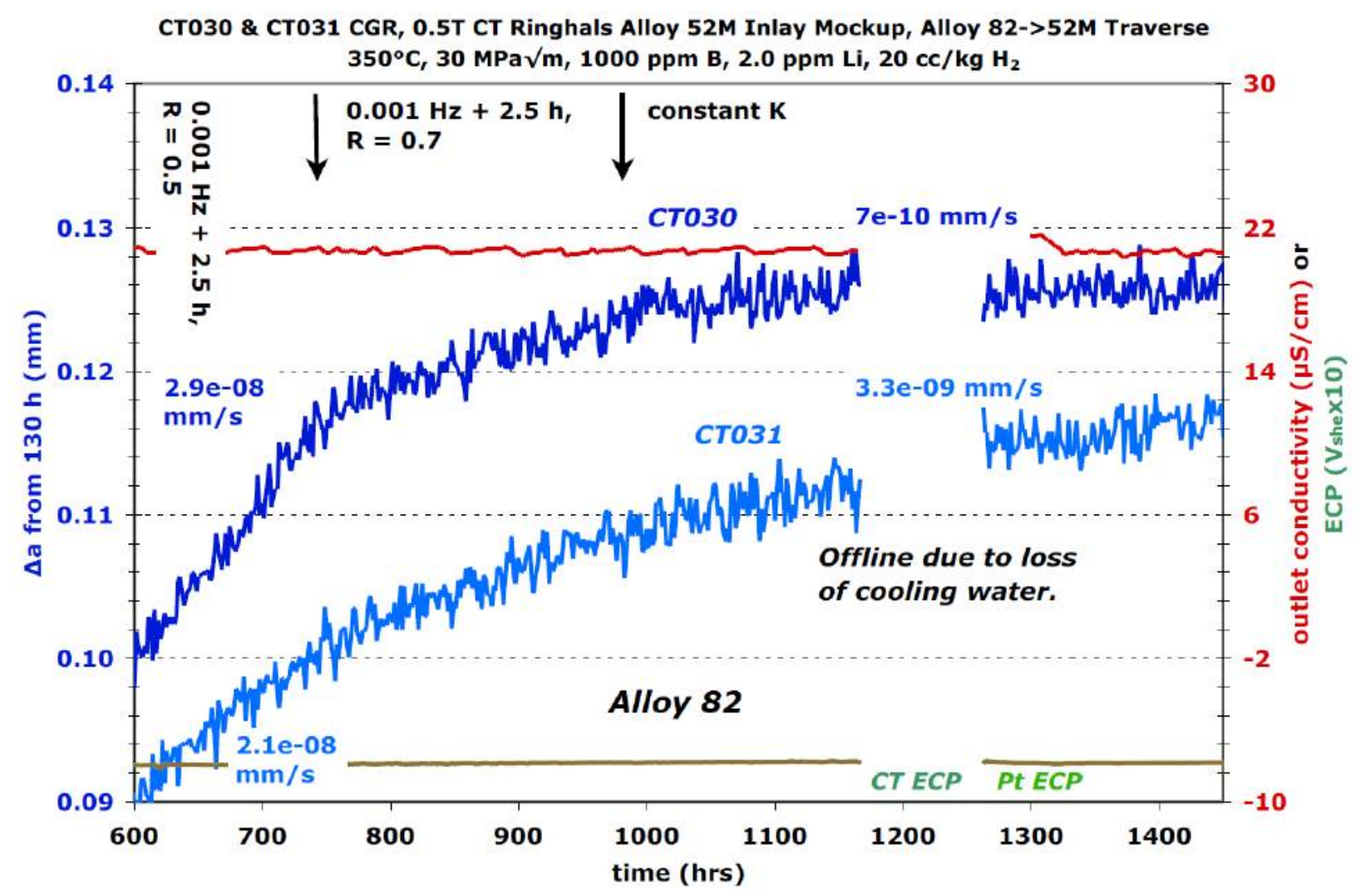

Figure 3.85 Initial cycle + hold and constant $\mathrm{K}$ response in PWR primary water of the Ringhals alloy 52M/82 inlay mockup (CT030 \& CT031).

In an attempt to promote IGSCC, environmental conditions were switched from hydrogenated to oxygenated and the temperature reduced to $290^{\circ} \mathrm{C}$. Under these BWR-like water conditions, a higher IGSCC susceptibility has been observed for alloy 82 particularly with a low level sulfate addition. The goal was again to improve SCC engagement across the crack front under oxidizing conditions and then determine whether more rapid IGSCC rates could be maintained when returning to PWR primary water. Figure 3.86 shows that the crack growth rate was relatively unaffected by the more BWR-like water conditions, suggesting a tortuous crack front, and at $1700 \mathrm{~h}, \sim 60 \mathrm{ppb}$ sulfate was introduced to the water and gentle cycling was performed at 0.01 and $0.001 \mathrm{~Hz}(\mathrm{R}=0.7)$ to help restart crack advance followed by the addition of a $2.5 \mathrm{~h}$ hold. Unfortunately, rates during these transitioning steps (shown in Figure 3.86) were significantly lower than anticipated based on reported alloy 82 behavior in BWR oxidizing water with sulfate additions. The decision was made to stop the test and exam side surfaces to estimate the crack front location. Surprisingly, the cracks were determined to have reached the alloy $52 \mathrm{M}$ interface. 


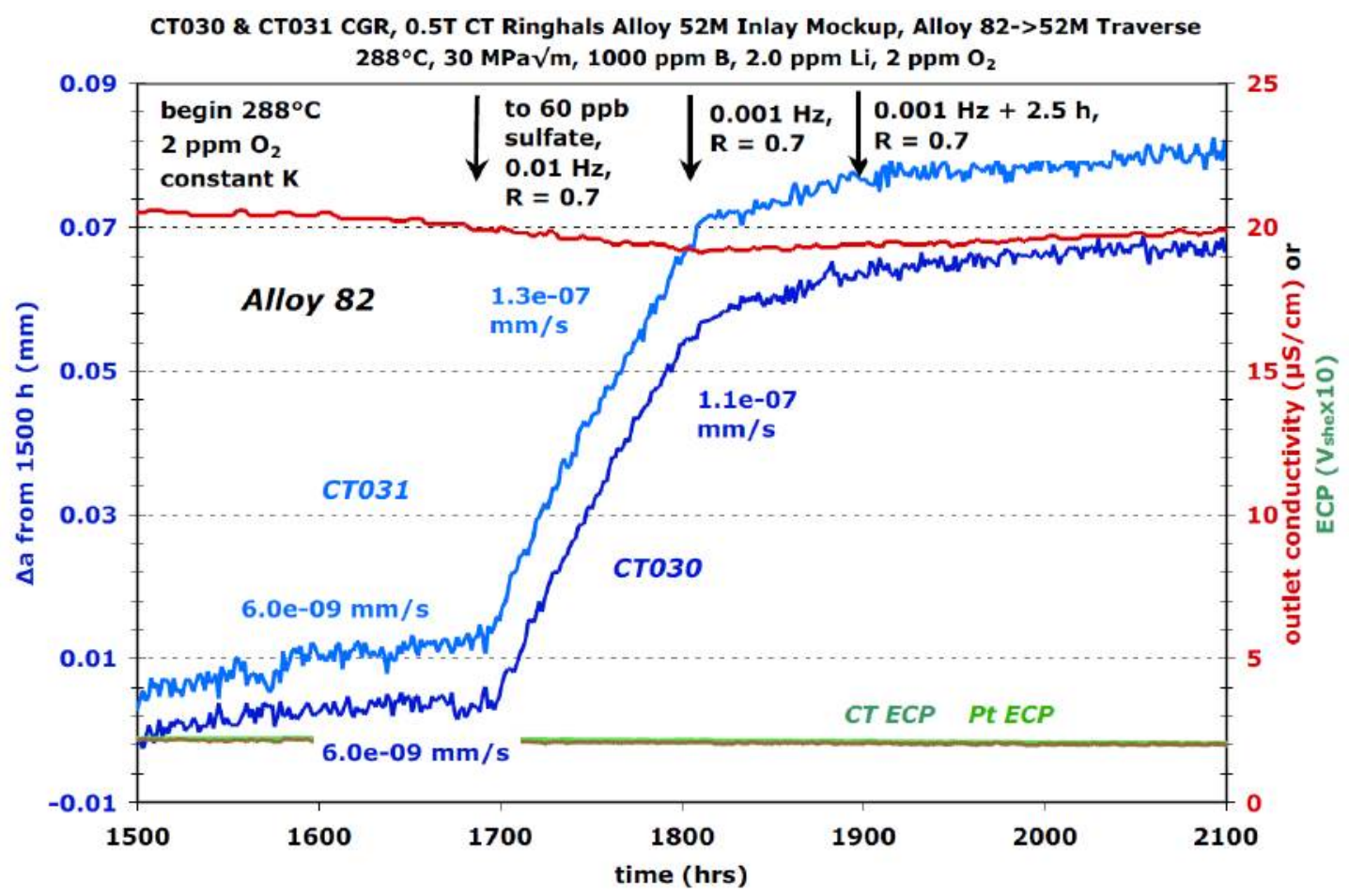

Figure 3.86 Constant $\mathrm{K}$ and cyclic loading response of the Ringhals alloy 52M/82 inlay mockup (CT030 \& CT031) after switching from PWR primary water to BWR oxidizing water (with sulfate).

Crack-growth testing continued for the two Ringhals alloy 52M/82 inlay mockup samples after the restart at a test accumulated time of $\sim 2275 \mathrm{~h}$. Aggressive cycling was initiated to extend the crack well into the alloy $52 \mathrm{M}$ inlay region and evaluate SCC CGR response in the alloy 52M weld metal. A typical transitioning sequence was used and the cyclic frequency was reduced over multiple steps. Propagation rates during cycling at an $\mathrm{R}$ of 0.5 were very similar to those measured previously for the alloy 52 weld metal samples (CT024, CT025, CT032 and CT033) and somewhat lower than for seen for the alloy 82 weld metal under identical loading and environmental conditions. A $2.5-\mathrm{h}$ hold time was added at $\sim 2600 \mathrm{~h}$ and a CGR of $1 \times 10^{-8} \mathrm{~mm} / \mathrm{s}$ was observed (Figure 3.87). Once again, this propagation rate matched that documented previously for the alloy 52 samples suggesting that limited SCC engagement had been created and constant $\mathrm{K}$ propagation rates would probably be $<1 \times 10^{-9} \mathrm{~mm} / \mathrm{s}$. It was then decided to examine the crack growth response with a less aggressive load ratio. Cyclic loading was changed to continuous cycling at $0.001 \mathrm{~Hz}, \mathrm{R}=0.7$ for $\sim 200 \mathrm{~h}$, and then a $2.5 \mathrm{~h}$ hold was added. Propagation rates for both specimens under these loading conditions are similar to the $\mathrm{MHI}$ alloy 52 material (CT025 and CT033) where limited (if any) IGSCC was observed at $350^{\circ} \mathrm{C}$.

Loading was changed to constant $\mathrm{K}$ at $\sim 3820 \mathrm{~h}$ and low propagation rates of $\sim 1 \times 10^{-9} \mathrm{~mm} / \mathrm{s}$ were observed for both samples as illustrated in Figure 3.88. Since limited crack-growth data exists for alloy $52 \mathrm{M}$, the test was continued at constant $\mathrm{K}$ to help build confidence in the measured rates. For these low rates, the measured crack extension under constant $\mathrm{K}$ loading was $\sim 5 \mu \mathrm{m}$ over approximately 1 month. 


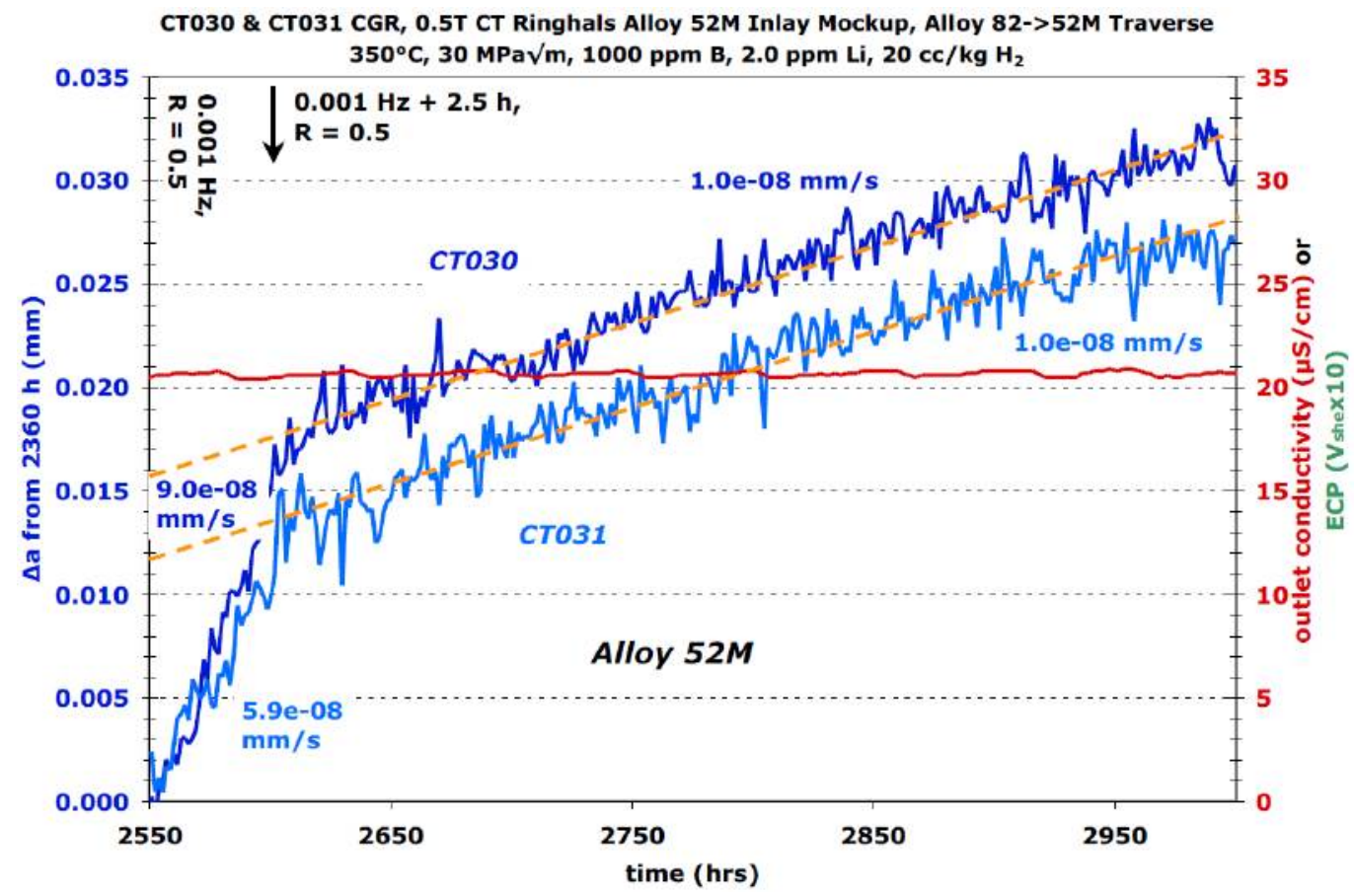

Figure 3.87 Alloy 52M response during cycle and cycle + hold loading at $\mathrm{R}=0.5$ in the Ringhals alloy 52M/82 inlay mockup specimens (CT030 \& CT031).

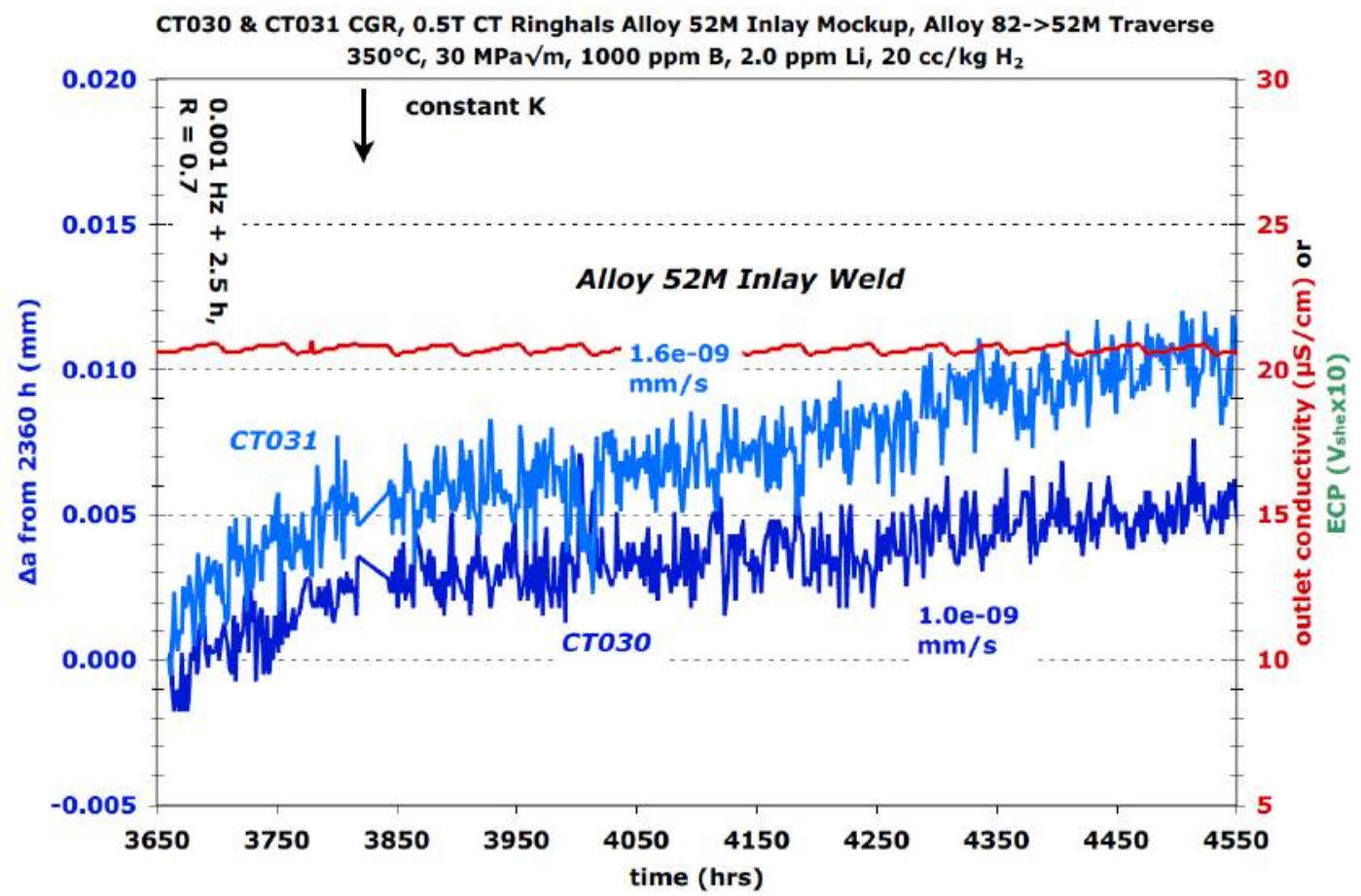

Figure 3.88 Alloy 52M response during constant $\mathrm{K}$ loading in the Ringhals alloy $52 \mathrm{M} / 82$ inlay mockup specimens (CT030 \& CT031). 
The decision was made at $\sim 4600 \mathrm{~h}$ to change back to cycle + hold loading and increase the applied $\mathrm{K}$ value from 30 to $40 \mathrm{MPa} \vee \mathrm{m}$ using a programmed $\mathrm{dK} / \mathrm{da}$ response. The initial $\mathrm{dK} / \mathrm{da}$ rate was $\sim 0.05 \mathrm{MPa} \sqrt{\mathrm{m}} / \mu \mathrm{m}$, giving growth rates of $\sim 6.5 \times 10^{-9} \mathrm{~mm} / \mathrm{s}$ during the $0.001 \mathrm{~Hz}$ cycle + $2.5 \mathrm{~h}$ condition with $\mathrm{R}=0.7$. At these slow propagation rates, the increase to $40 \mathrm{MPa} \sqrt{\mathrm{m}}$ would have taken months, and therefore, the $\mathrm{dK} / \mathrm{da}$ was changed to $0.80 \mathrm{MPa} / \mathrm{m} / \mu \mathrm{m}$ at $\sim 4950 \mathrm{~h}$ producing a $\sim 5$ times increase in rate (to $\sim 3 \times 10^{-8} \mathrm{~mm} / \mathrm{s}$ ) as documented in Figure 3.89 . Although systematic evaluations of $\mathrm{dK} / \mathrm{da}$ effects were not being attempted, it is clear that the gradual increase in $\mathrm{K}$ and delta-K accelerates crack growth. It is important to note that while $\mathrm{K}$ is slowly increasing with time, the actual $\mathrm{dK} / \mathrm{da}$ is high compared with what may be expected in actual piping components. In this case, $\mathrm{K}$ is being changed over $\mu \mathrm{m}$ dimensions whereas similar changes in $\mathrm{K}$ might be expected over $\mathrm{mm}$ dimensions in a component.

Final steps for this test were to evaluate SCC CGRs in the alloy 52M inlay at a higher K level of $40 \mathrm{MPa} \sqrt{\mathrm{m}}$. The cycle + hold response was $1.3 \times 10^{-8} \mathrm{~mm} / \mathrm{s}$ for the two samples as shown in Figure 3.89. This compares to rates of 4.5 and $2 \times 10^{-9} \mathrm{~mm} / \mathrm{s}(3-4 X$ lower) under this loading condition at $30 \mathrm{MPa} \sqrt{\mathrm{m}}$ earlier in this test. The higher CGRs at $40 \mathrm{MPa} \sqrt{\mathrm{m}}$ are similar to that measured for the $\mathrm{MHI}$ alloy 152 weld metal where localized regions of IGSCC were observed. Constant $\mathrm{K}$ conditions were established at $\sim 5495 \mathrm{~h}$ and steady growth was observed in both specimens during this period with uncorrected crack growth rates of $1.0 \times 10^{-9}$ and $1.6 \times 10^{-9} \mathrm{~mm} / \mathrm{s}$ as shown in Figure 3.90. These rates are identical to those obtained on these specimens at $30 \mathrm{MPa} \sqrt{\mathrm{m}}$, and the test was ended at $6500 \mathrm{~h}$. A summary of test condition and corrected specimen response for each phase of the test is shown in Table 3.11.

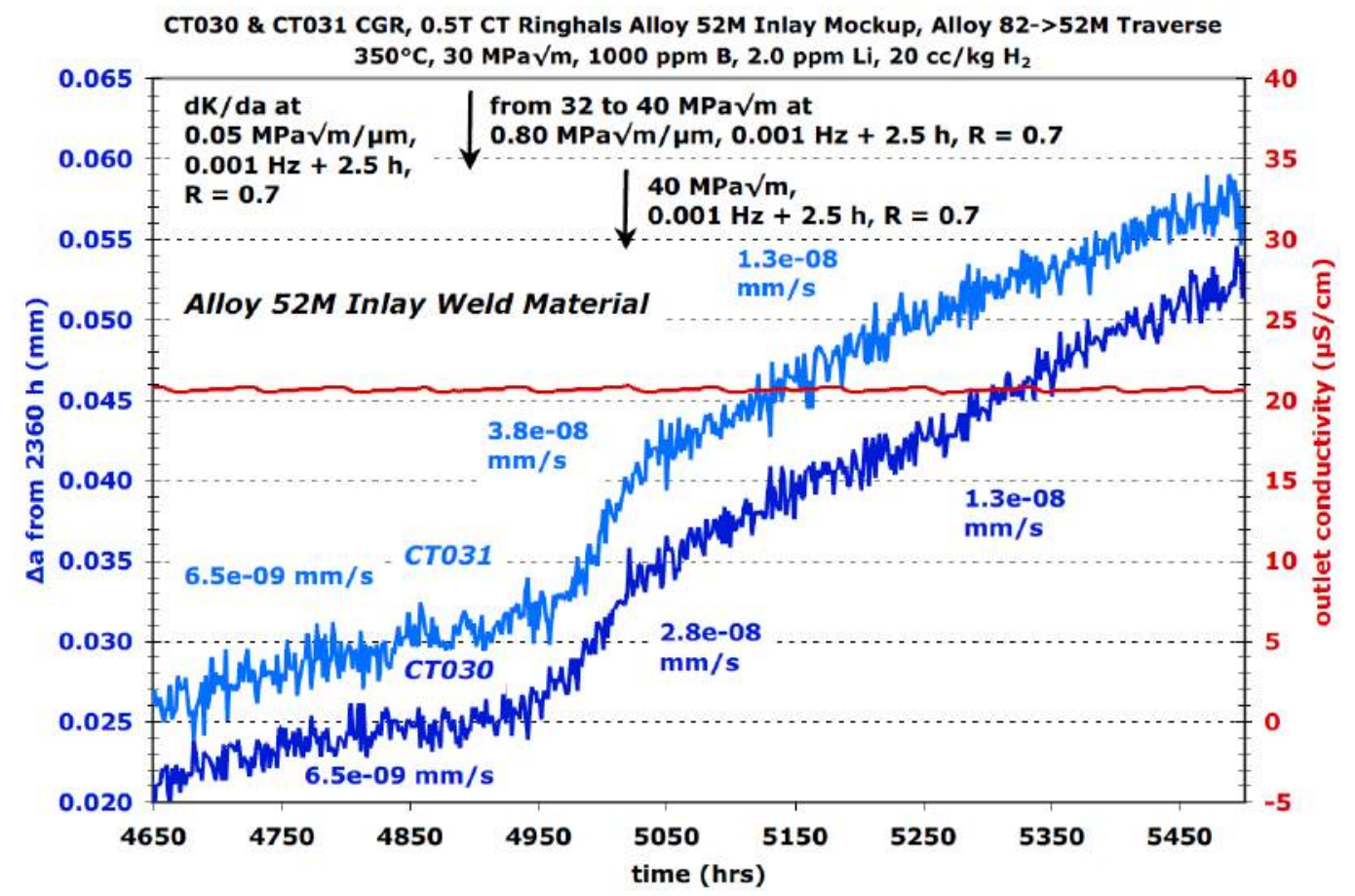

Figure $3.89 \mathrm{dK} / \mathrm{da}$ response going from 30 to $40 \mathrm{MPa} \sqrt{\mathrm{m}}$ of the Ringhals alloy $52 \mathrm{M} / 82$ inlay mockup specimens (CT030 \& CT031). 


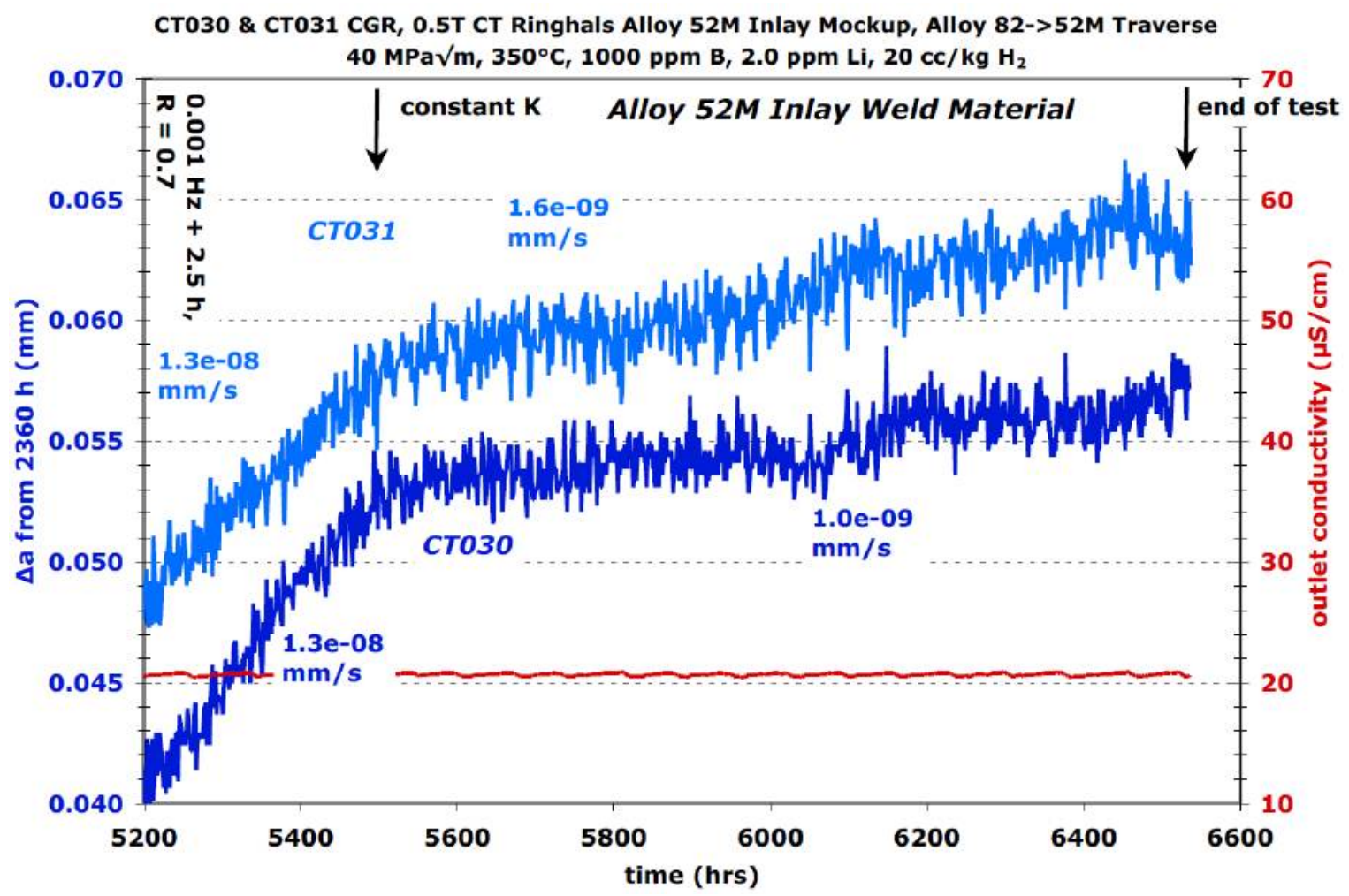

Figure 3.90 Constant $\mathrm{K}$ response at $40 \mathrm{MPa} \sqrt{\mathrm{m}}$ of the Ringhals alloy $52 \mathrm{M} / 82$ inlay mockup specimens (CT030 \& CT031).

After ending the test, СT030 was fatigue fractured in air whereas CT031 was first backfilled with resin, sectioned into two pieces, and then one side was fatigue fractured in air while the other side was set aside for crack tip examinations. The most apparent feature of the crack growth surface of CT030 in Figure 3.91 is the very large uncracked ligament in the wake of the crack. This ligament formed at the onset of high temperature water testing, and was never broken during the entire test. Another feature of interest in the crack growth surface of CT030 is the rather uniform tan layer along the final crack front. This is likely representative of the final transitioning and constant $\mathrm{K}$ at $40 \mathrm{MPa} \sqrt{\mathrm{m}}$. The jagged, uneven final crack front suggests a relatively high degree of engagement (but still with a very slow crack growth rate). The side surface image of the crack growing in the CT031 alloy 52M material in Figure 3.92 shows evidence of a large crack resulting from rapid extension with a narrower cracking extending out. The narrower crack, likely forming during cycle + hold and constant $\mathrm{K}$, shows some preference for cracking along dendrites. This can be better seen in the SEM image of the same region in Figure 3.93 . 
Table 3.11 Corrected data summary for Ringhals alloy 52M/82 inlay specimens \#1 and \#2 (CT030 \& CT031).

\begin{tabular}{|c|c|c|c|c|c|c|c|c|c|c|c|c|}
\hline $\begin{array}{c}\text { Test } \\
\text { Phase } \\
\end{array}$ & $\begin{array}{l}\text { Dur- } \\
\text { ation } \\
\text { (h) }\end{array}$ & $\mathrm{R}$ & $\begin{array}{l}\text { Freq } \\
(\mathrm{Hz})\end{array}$ & $\begin{array}{l}\text { Hold } \\
\text { (h) }\end{array}$ & Water & $\begin{array}{c}\text { Temp } \\
\left({ }^{\circ} \mathrm{C}\right)\end{array}$ & Ringhals & $\begin{array}{c}\text { СТ030 } \\
\text { Alloy } 52 \mathrm{M} \\
\text { specimen \# }\end{array}$ & $\begin{array}{l}\text { 1/182 Inlay } \\
\# 1 \\
\text { Approx. } \\
\text { Crack } \\
\text { Extension } \\
(\mathrm{mm})\end{array}$ & Ringhals & $\begin{array}{c}\text { CT031 } \\
\text { s Alloy } 52 \mathrm{M} \\
\text { Specimen \# } \\
\text { CGR } \\
(\mathrm{mm} / \mathrm{sec})\end{array}$ & $\begin{array}{l}\text { 1/82 Inlay } \\
\text { \$2 } \\
\text { Approx. } \\
\text { Crack } \\
\text { Extension } \\
(\mathrm{mm})\end{array}$ \\
\hline 1 & $\sim 3$ & 0.3 & 5 & 0 & air precrack & RT & 25 & 2.1E-04 & 0.40 & 25 & 1.7E-04 & 0.40 \\
\hline 2 & $\sim 2$ & 0.5 & 5 & 0 & air precrack & RT & 29 & 1.2E-04 & 0.35 & 28 & $9.7 \mathrm{E}-05$ & 0.35 \\
\hline 3 & $\sim 2$ & 0.6 & 5 & 0 & air precrack & RT & 31 & 8.1E-05 & 0.35 & 31 & $5.6 \mathrm{E}-05$ & 0.35 \\
\hline 4 & $\sim 3$ & 0.7 & 5 & 0 & air precrack & RT & 31 & $2.4 \mathrm{E}-05$ & 0.20 & 31 & $2.2 \mathrm{E}-05$ & 0.20 \\
\hline 5 & 11 & 0.5 & 0.1 & 0 & $29 \mathrm{cc} / \mathrm{kg} \mathrm{H}_{2}$ & 350 & 31 & $5.5 \mathrm{E}-06$ & 0.218 & 29 & $3.4 \mathrm{E}-06$ & 0.108 \\
\hline 6 & 43 & 0.5 & 0.01 & 0 & $29 \mathrm{cc} / \mathrm{kg} \mathrm{H}$ & 350 & 31 & 1.4E-06 & 0.209 & 28 & 1.1E-06 & 0.173 \\
\hline 7 & 60 & 0.5 & 0.001 & 0 & $29 \mathrm{cc} / \mathrm{kg} \mathrm{H}_{2}$ & 350 & 31 & $2.8 \mathrm{E}-07$ & 0.067 & 28 & $2.5 \mathrm{E}-07$ & 0.052 \\
\hline 8 & 101 & 0.5 & 0.001 & 0 & $20 \mathrm{cc} / \mathrm{kg} \mathrm{H}_{2}$ & 350 & 31 & $1.8 \mathrm{E}-07$ & 0.086 & 28 & $2.5 \mathrm{E}-07$ & 0.084 \\
\hline 9 & 568 & 0.5 & 0.001 & 2.5 & $20 \mathrm{cc} / \mathrm{kg} \mathrm{H}_{2}$ & 350 & 31 & $3.2 \mathrm{E}-08$ & 0.063 & 28 & 2.7E-08 & 0.058 \\
\hline 10 & 183 & 0.7 & 0.001 & 2.5 & $20 \mathrm{cc} / \mathrm{kg} \mathrm{H}_{2}$ & 350 & 31 & $3.2 \mathrm{E}-08$ & 0.006 & 28 & 2.7E-08 & 0.007 \\
\hline 11 & 534 & --- & const $\mathrm{K}$ & --- & $20 \mathrm{cc} / \mathrm{kg} \mathrm{H}_{2}$ & 350 & 31 & 7.3E-10 & 0.021 & 28 & 4.3E-09 & 0.006 \\
\hline 12 & 197 & --- & const $\mathrm{K}$ & --- & $2 \mathrm{ppm} \mathrm{O}$ & 288 & 31 & 6.6E-09 & 0.006 & 28 & 7.7E-09 & 0.011 \\
\hline 13 & 111 & 0.7 & 0.01 & 0 & $2 \underset{\mathrm{ppm} \mathrm{O}_{4}}{2}+$ & 288 & 31 & $1.2 \mathrm{E}-07$ & 0.055 & 28 & $1.6 \mathrm{E}-07$ & 0.072 \\
\hline 14 & 95 & 0.7 & 0.001 & 0 & $2 \underset{\mathrm{SO}_{4-}}{2 \mathrm{ppm}_{2}}+$ & 288 & 31 & $2.4 \mathrm{E}-08$ & 0.010 & 28 & $2.8 \mathrm{E}-08$ & 0.008 \\
\hline 15 & 209 & 0.7 & 0.001 & 2.5 & $2 \mathrm{ppm} \mathrm{O}_{\mathrm{SO}_{4^{-}}}+$ & 288 & 31 & $5.2 \mathrm{E}-09$ & 0.005 & 28 & $6.0 \mathrm{E}-09$ & 0.005 \\
\hline 16 & 161 & 0.5 & 0.001 & 2.5 & $2 \underset{\mathrm{ppm} \mathrm{O}_{4}}{2}+$ & 288 & 31 & $1.3 \mathrm{E}-08$ & 0.008 & 28 & 1.3E-08 & 0.006 \\
\hline 17 & 14 & 0.4 & 0.2 & 0 & $29 \mathrm{cc} / \mathrm{kg} \mathrm{H}_{2}$ & 350 & 32 & $1.2 \mathrm{E}-05$ & 0.640 & 27 & 7.7E-06 & 0.198 \\
\hline 18 & 31 & 0.5 & 0.1 & 0 & $29 \mathrm{cc} / \mathrm{kg} \mathrm{H}_{2}$ & 350 & 32 & $4.2 \mathrm{E}-06$ & 0.445 & 27 & $2.9 \mathrm{E}-06$ & 0.339 \\
\hline 19 & 52 & 0.5 & 0.01 & 0 & $29 \mathrm{cc} / \mathrm{kg} \mathrm{H}_{2}$ & 350 & 32 & 7.6E-07 & 0.148 & 27 & 4.9E-07 & 0.097 \\
\hline 20 & 232 & 0.5 & 0.001 & 0 & $29 \mathrm{cc} / \mathrm{kg} \mathrm{H}_{2}$ & 350 & 32 & $9.9 \mathrm{E}-08$ & 0.100 & 27 & 7.6E-08 & 0.109 \\
\hline 21 & 390 & 0.5 & 0.001 & 2.5 & $29 \mathrm{cc} / \mathrm{kg} \mathrm{H}$ & 350 & 32 & 1.1E-08 & 0.018 & 27 & 1.3E-08 & 0.016 \\
\hline 22 & 163 & 0.7 & 0.001 & 0 & $29 \mathrm{cc} / \mathrm{kg} \mathrm{H}_{2}$ & 350 & 32 & $3.4 \mathrm{E}-08$ & 0.015 & 27 & 2.3E-08 & 0.007 \\
\hline 23 & 649 & 0.7 & 0.001 & 2.5 & $29 \mathrm{cc} / \mathrm{kg} \mathrm{H}_{2}$ & 350 & 32 & 4.6E-09 & 0.019 & 27 & 4.4E-09 & 0.021 \\
\hline 24 & 846 & -- & const $\mathrm{K}$ & --- & $29 \mathrm{cc} / \mathrm{kg} \mathrm{H}$ & 350 & 32 & 1.1E-09 & 0.021 & 27 & 2.0E-09 & 0.027 \\
\hline 25 & 257 & 0.7 & 0.001 & 2.5 & $29 \mathrm{cc} / \mathrm{kg} \mathrm{H}_{2}$ & 350 & $32->34$ & 7.1E-09 & 0.004 & $27->28$ & 8.3E-09 & 0.006 \\
\hline 26 & 112 & 0.7 & 0.001 & 2.5 & $29 \mathrm{cc} / \mathrm{kg} \mathrm{H}{ }_{2}$ & 350 & $34->43$ & 3.1E-08 & 0.010 & $28->35$ & $4.8 \mathrm{E}-08$ & 0.012 \\
\hline 27 & 484 & 0.7 & 0.001 & 2.5 & $29 \mathrm{cc} / \mathrm{kg} \mathrm{H}_{2}$ & 350 & 43 & $1.4 \mathrm{E}-08$ & 0.021 & 35 & 1.6E-08 & 0.024 \\
\hline 28 & 1033 & --- & const $\mathrm{K}$ & --- & $29 \mathrm{cc} / \mathrm{kg} \mathrm{H}_{2}$ & 350 & 43 & 1.1E-09 & 0.005 & 35 & 2.0E-09 & 0.005 \\
\hline
\end{tabular}




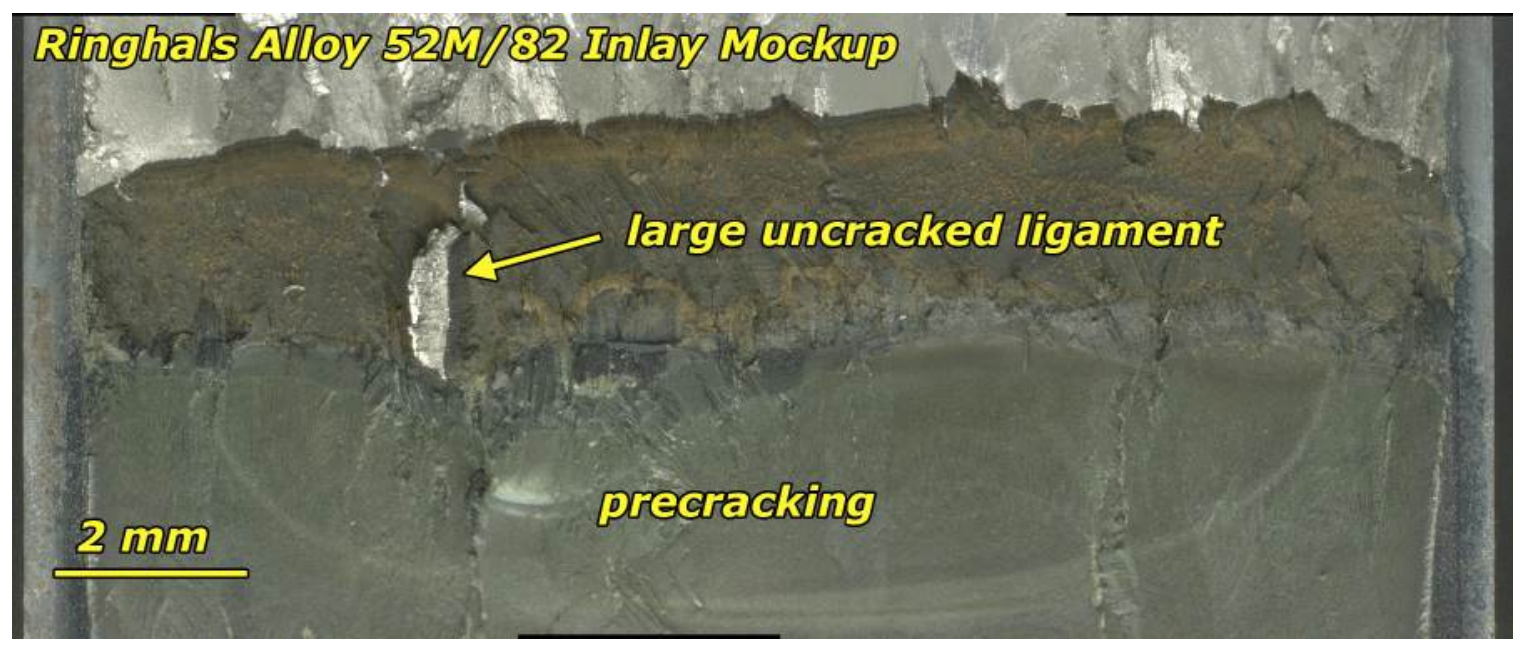

Figure 3.91 Crack growth surface of Ringhals alloy 52M/82 specimen CT030.

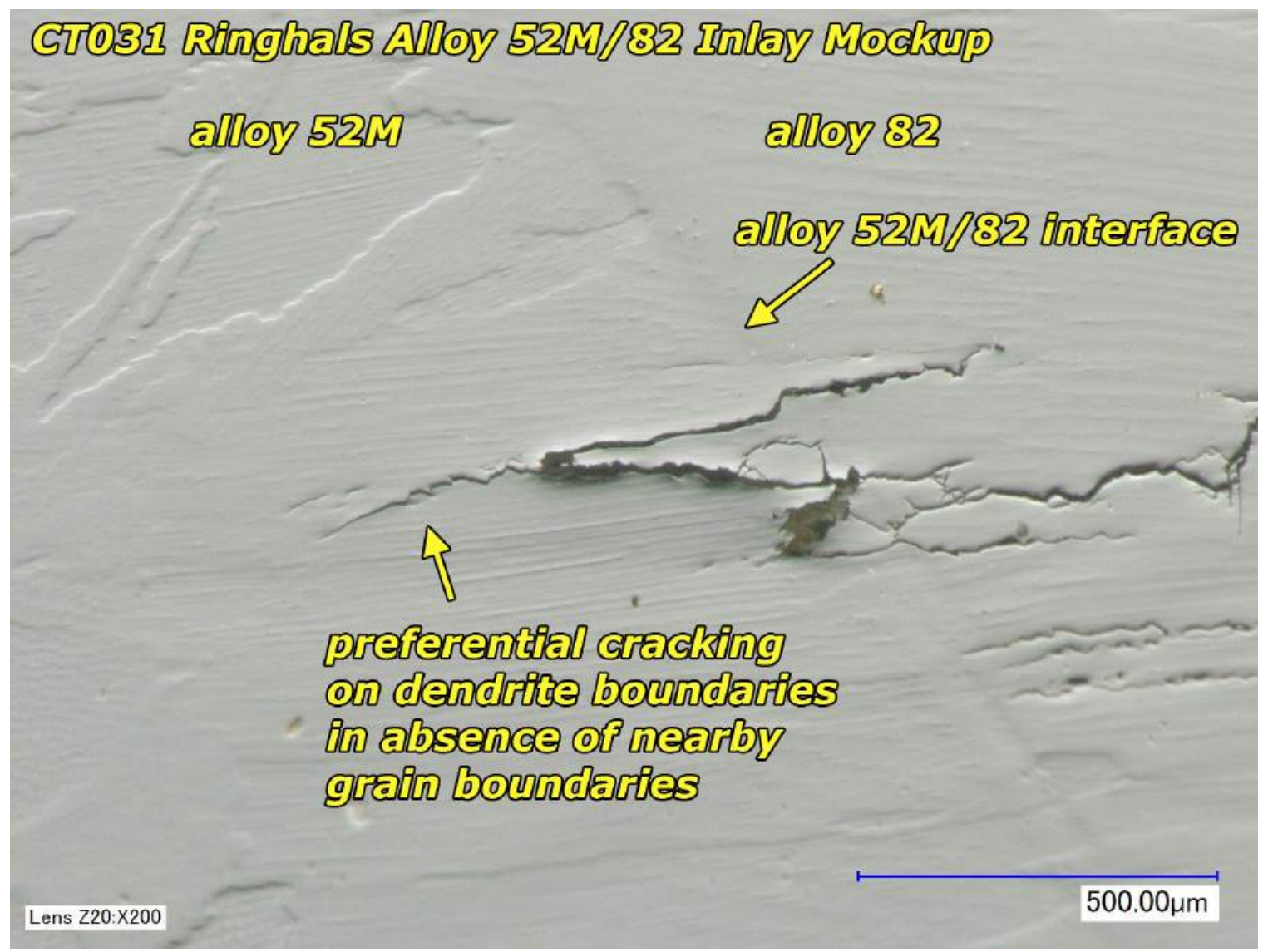

Figure 3.92 Optical image of side surface of crack growing into alloy $52 \mathrm{M}$ in the Ringhals alloy $52 \mathrm{M} / 82$ specimen CT031. 


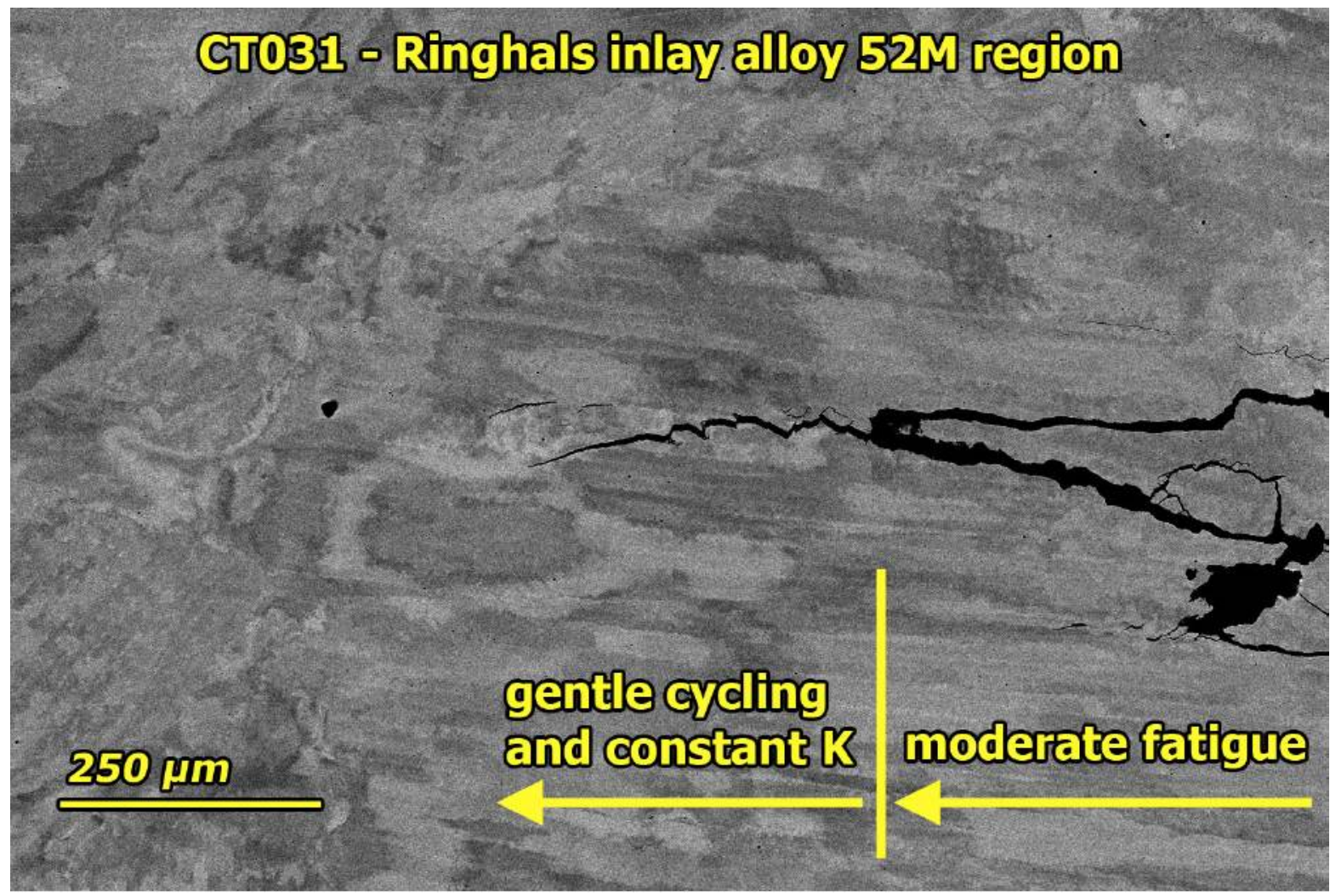

Figure 3.93 SEM image of side surface of crack growing into alloy $52 \mathrm{M}$ in the Ringhals alloy 52M/82 specimen CT031.

\subsection{Summary and Discussion of SCC Results for Weld Metals}

The crack growth rate response of industry-made alloy 152 and alloy 52 weld mockups was investigated in simulated PWR primary water. Several different transitioning conditions were used in each of the tests in an attempt to create an engaged IG crack front at $325-360^{\circ} \mathrm{C}$. For the crack growth surfaces that have been examined, the degree of engagement reached as high as $\sim 80 \%$ (KAPL alloy $52 \mathrm{M}$ V-groove) during testing in high temperature water. The AREVA alloy 52 material, with $<10 \%$ engagement had the least. Although such low degrees of engagement were observed, out of plane branch cracks were observed in side surface examinations of several specimens. Side surface examinations of the cracks suggest that with these resistant materials, the degree of engagement will be strongly dependent on grain size and grain orientation relative to the target crack plane. Smaller grain sizes increase the interaction frequency with a growing crack, and grain boundaries aligned with the target crack growth direction reduce the tendency for cracks to go off boundary. "Engaged" cracking may not be completed limited to a grain boundaries path. The side surface of alloy $52 \mathrm{M}$ cracking in the Ringhals alloy $52 \mathrm{M} / 82$ inlay mockup showed that when there was no grain boundary nearby, there was a small preference for cracks to run on dendrite boundaries. Side surfaces of other materials did not show this as clearly. Based on the degree of IG engagement, the KAPL alloy $52 \mathrm{M} \mathrm{V}$-groove and the $\mathrm{MHI}$ alloy $152 \mathrm{U}$-groove welds might be considered the most susceptible materials. 
A summary of the measured constant K CGR response for the weld metal specimens is shown in Figure 3.94. The highest recorded rate of $\sim 1 \times 10^{-8} \mathrm{~mm} / \mathrm{s}$ was on alloy $52 \mathrm{M}$ in one of the Ringhals alloy $52 \mathrm{M} / 182$ overlay specimens. Tests on KAPL alloy $52 \mathrm{M}$ produced the second highest constant K CGR of $\sim 4 \times 10^{-9} \mathrm{~mm} / \mathrm{s}$ for the V-groove specimen, but significantly lower rates for the narrow gap specimens using the same weld wire. Interestingly, the MHI alloy 152 exhibited one of the lowest SCC propagation rates (at least at $\sim 30 \mathrm{MPa} \sqrt{\mathrm{m}}$ ) even though it had a relatively high degree of IG engagement. The most resistant material tested thus far has been the AREVA alloy 52 weld metal. This material had a very large grain size (more than $1 \mathrm{~mm}$ ) with few opportunities for a crack to intersect grain boundaries. Relative to the alloy 182/132 disposition curve in Figure 3.94, nearly all measured SCC propagation rates for the high- $\mathrm{Cr}$ welds are less than $1 \times 10^{-8} \mathrm{~mm} / \mathrm{s}$ with most $<3 \times 10^{-9} \mathrm{~mm} / \mathrm{s}$. It is important to note that although these reported CGRs have been adjusted for SCC engagement, localized regions or fingers of IG extension have been seen in certain specimens suggesting maximum rates up to $5 X$ higher perhaps due to more optimized alignment with the weld metal grain boundaries. Continued examination of the crack growth and side surfaces from these tests will provide further insight on the resistance of these weld metals and the relationship between microstructure and SCC.

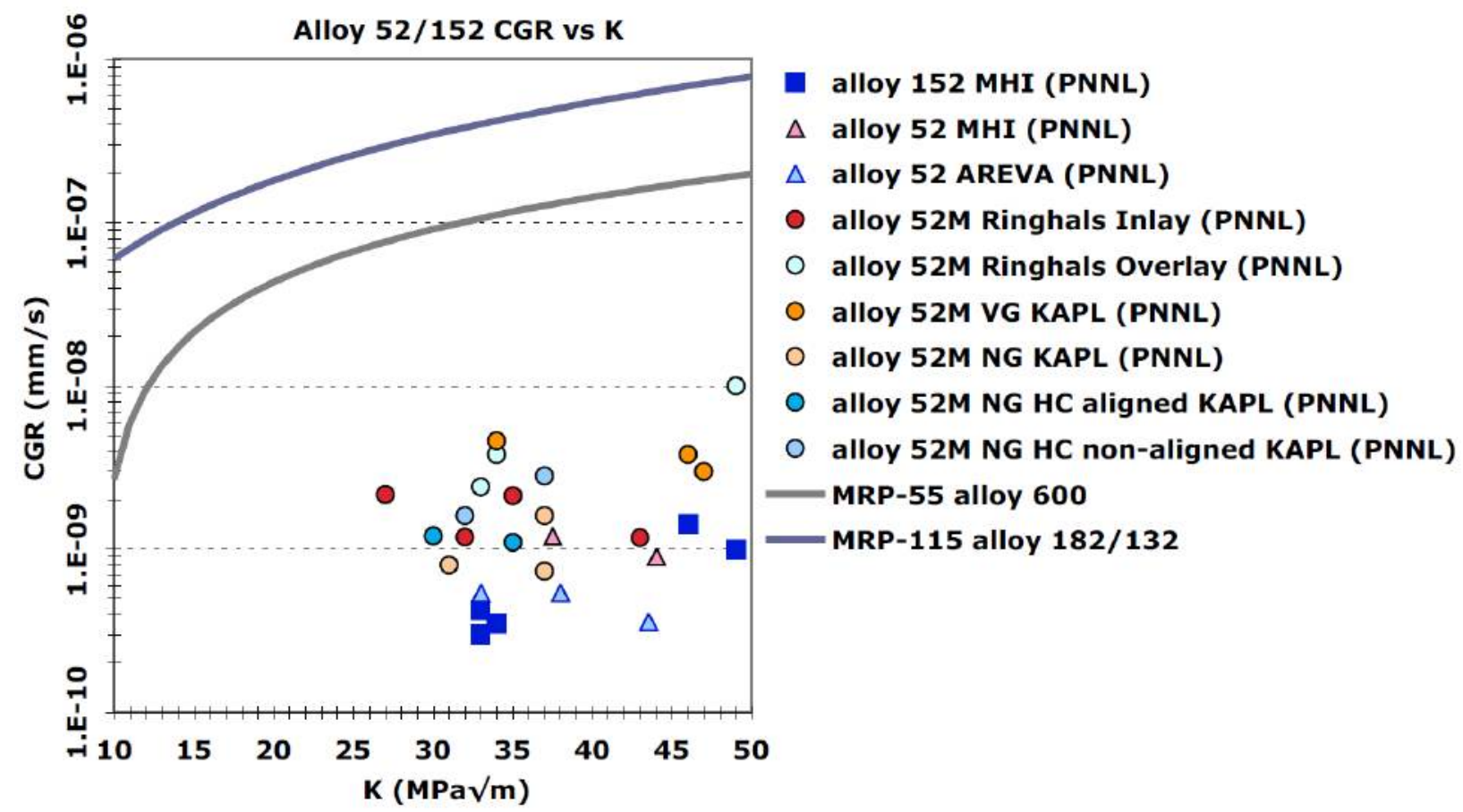

Figure 3.94 Summary of PNNL-measured constant K SCC crack-growth rates for alloy 152/52/52M weld metals.

Crack growth testing was also performed at $50^{\circ} \mathrm{C}$ in simulated PWR primary water in some of the specimens. The $\mathrm{MHI}$ alloy 152 tested at $48 \mathrm{MPa} \sqrt{\mathrm{m}}$ was found to be very susceptible to IG cracking during cyclic loading at $50^{\circ} \mathrm{C}$, having a final crack front that was $\sim 90 \%$ IG. Propagation rates under cyclic and cycle + hold conditions were $2-3 x$ greater at $50^{\circ} \mathrm{C}$ than at equivalent loading conditions at $350^{\circ} \mathrm{C}$. No crack extension was observed at constant $\mathrm{K}$ loading at $50^{\circ} \mathrm{C}$ suggesting that dynamic strain at the crack tip during cycling is required for what is likely hydrogen-assisted crack growth at this low temperature. The $\mathrm{MHI}$ alloy 52 weld metal was also 
found to be more susceptible to IG cracking at $50^{\circ} \mathrm{C}$ than at $350^{\circ} \mathrm{C}$. An $\sim 35 \%$ IG crack front was obtained during cyclic loading at $50^{\circ} \mathrm{C}$ and $30-33 \mathrm{MPa} \sqrt{\mathrm{m}}$. Despite this IG cracking, measured crack growth rates at $50^{\circ} \mathrm{C}$ were equal or somewhat less than values observed at $350^{\circ} \mathrm{C}$. Similar differences in cyclic propagations rates were found for the AREVA alloy 52 with rates at $50^{\circ} \mathrm{C} 50 \%$ less than at $350^{\circ} \mathrm{C}$. Contrary to the other weldments, only isolated IG cracking was seen for the AREVA alloy 52 during cycling at $\sim 30-33 \mathrm{MPa} \sqrt{\mathrm{m}}$ in $50^{\circ} \mathrm{C}$ water. Tests and examinations are ongoing to help determine why the alloy 52 weldments did not show the same susceptibility to IG cracking as the alloy 152 weldment at $50^{\circ} \mathrm{C}$. One possible reason is the higher $\mathrm{K}(\sim 50 \mathrm{MPa} \sqrt{\mathrm{m}})$ and delta-K levels used for the alloy 152 which influences the magnitude of dynamic stain during cyclic loading.

In an attempt to improve IG engagement, crack extension was produced at $50^{\circ} \mathrm{C}$ in the alloy 52 weld specimens, and the test was then set to constant $K$ and the temperature brought up to $350^{\circ} \mathrm{C}$. DCPD-measured crack growth rates were initially quite high and decayed with time to low values over several months. Nearly identical DCPD response was observed at very low $\mathrm{K}$ and at $30 \mathrm{MPa} \sqrt{\mathrm{m}}$ indicating that the initial changes at $350^{\circ} \mathrm{C}$ were due to slow oxidation of conducting paths across the crack behind the crack front. Even though the $\mathrm{MHI}$ alloy 52 exhibited significant IG engagement at $50^{\circ} \mathrm{C}$, subsequent IGSCC propagation at $350^{\circ} \mathrm{C}$ appears to be quite limited. This supports the general conclusion that the high-Cr alloy 52, 52M and 152 weld metals have excellent SCC resistance in high-temperature PWR primary water. 


\section{SCC Crack-Growth-Rate Testing of Alloy 690 CRDM Tubing Materials}

\subsection{Compositions and Microstructures of Alloy 690 CRDM Materials}

Multiple heats of alloy 690 CRDM tubing were purchased from Valinox Nucleaire including five tubes from different heats, plus two tubes of different wall thicknesses made from a sixth heat (RE243). General information on the six heats is summarized in Table 4.1 and is based on the data supplied by Valinox. Independent composition measurements were obtained for three of the heats (RE243, WP140 and WP142) selected for crack-growth rate testing. All tubing pieces were obtained in $\sim 2 \mathrm{ft}$ lengths with each tube having sufficient wall thickness for 0.5T CT samples in several possible orientations. Several of the alloy 690 CRDM tubing sections are shown in Figure 4.1 after receipt at PNNL. The as-received tubing materials were in the thermally treated (TT) condition that consisted of a short high-temperature anneal near $1100^{\circ} \mathrm{C}$, water quenched (WQ) and then annealed at $\sim 720^{\circ} \mathrm{C}$ for $\sim 10 \mathrm{~h}$. The specific heat treatments are given in Table 4.1. The reported room temperature yield strength (YS), ultimate tensile strength (UTS) and total elongation (TE) are very consistent among the materials.

Optical metallography was performed on the six heats of alloy 690 CRDM tubing obtained from Valinox in the longitudinal, transverse, and circumferential orientations to document grain structures, inclusions, and precipitates. Grain size and shape were reasonably consistent for all three orientations among the six heats. In addition, alloy 690 heat RE243 showed similar structures in the two different tubing thicknesses (1.0-in. and 1.4-in. thick wall) obtained.

Table 4.1 Alloy 690 CRDM tubing materials at PNNL.

\begin{tabular}{|c|c|c|c|}
\hline $\begin{array}{c}\text { Material and } \\
\text { Heat \# }\end{array}$ & $\begin{array}{l}\text { CRDM Tube \# } \\
\text { and Description }\end{array}$ & Composition, wt $\%$ & $\begin{array}{l}\text { Heat Treatments and Room } \\
\text { Temp. Mechanical Properties }\end{array}$ \\
\hline $\begin{array}{l}\text { Alloy 690TT } \\
\text { RE243 }\end{array}$ & Tube 2360 (1.4" wall) & $\begin{array}{c}\mathrm{Ni}-28.9 \mathrm{Cr}-10.4 \mathrm{Fe}-0.02 \mathrm{C}- \\
0.3 \mathrm{Mn}-0.35 \mathrm{Si}-0.14 \mathrm{Al}-0.23 \mathrm{Ti}- \\
0.024 \mathrm{~N}-0.008 \mathrm{P}-0.0005 \mathrm{~S}\end{array}$ & $\begin{array}{c}1122^{\circ} \mathrm{C} / \sim 1 \mathrm{~min}, \mathrm{WQ}+ \\
716-725^{\circ} \mathrm{C} / 10.5 \mathrm{~h}, \text { Air cool } \\
\text { YS/UTS = 37/89 ksi; TE = 54\% }\end{array}$ \\
\hline $\begin{array}{l}\text { Alloy 690TT } \\
\text { RE243 }\end{array}$ & Tube 2216 (1.0" wall) & $\begin{array}{c}\mathrm{Ni}-28.9 \mathrm{Cr}-9.6 \mathrm{Fe}-0.018 \mathrm{C}- \\
0.3 \mathrm{Mn}-0.28 \mathrm{Si}-0.11 \mathrm{Al}-0.25 \mathrm{Ti}- \\
0.018 \mathrm{~N}-0.008 \mathrm{P},<0.001 \mathrm{~S}\end{array}$ & $\begin{array}{c}1110^{\circ} \mathrm{C} / \sim 1 \mathrm{~min}, \mathrm{WQ}+ \\
710-720^{\circ} \mathrm{C} / 11.25 \mathrm{~h}, \text { Air cool } \\
\text { YS/UTS = 40/93 ksi; TE = 48\% }\end{array}$ \\
\hline $\begin{array}{l}\text { Alloy 690TT } \\
\text { WP140 }\end{array}$ & $\begin{array}{l}\text { WP140, CRDM Tube } \\
2502 \text { (1.2" wall) }\end{array}$ & $\begin{array}{c}\mathrm{Ni}-29.0 \mathrm{Cr}-10.4 \mathrm{Fe}-0.03 \mathrm{C}- \\
0.3 \mathrm{Mn}-0.33 \mathrm{Si}-0.18 \mathrm{Al}-0.3 \mathrm{Ti}- \\
0.005 \mathrm{P},<0.001 \mathrm{~S}\end{array}$ & $\begin{array}{c}1120^{\circ} \mathrm{C} / \sim 1 \mathrm{~min}, \mathrm{WQ}+ \\
716-722^{\circ} \mathrm{C} / 10.2 \mathrm{~h}, \text { Air cool } \\
\text { YS/UTS = 40/93 ksi; TE = 51\% }\end{array}$ \\
\hline $\begin{array}{l}\text { Alloy 690TT } \\
\text { WP142 }\end{array}$ & $\begin{array}{l}\text { WP142, CRDM Tube } \\
2541 \text { (1.2" wall) }\end{array}$ & $\begin{array}{c}\mathrm{Ni}-29.0 \mathrm{Cr}-10.5 \mathrm{Fe}-0.02 \mathrm{C}- \\
0.3 \mathrm{Mn}-0.35 \mathrm{Si}-0.47 \mathrm{Ti}- \\
0.01 \mathrm{Nb}-0.001 \mathrm{~S}-0.003 \mathrm{P}\end{array}$ & $\begin{array}{c}1096^{\circ} \mathrm{C} / \sim 1 \mathrm{~min}, \mathrm{WQ}+ \\
716-722^{\circ} \mathrm{C} / 10.2 \mathrm{~h}, \text { Air cool } \\
\text { YS/UTS = 39/92 ksi; TE = 50\% }\end{array}$ \\
\hline $\begin{array}{l}\text { Alloy 690TT } \\
\text { WP016 }\end{array}$ & $\begin{array}{l}\text { WP016, CRDM Tube } \\
2422 \text { (1.1" wall) }\end{array}$ & $\begin{array}{c}\mathrm{Ni}-29.3 \mathrm{Cr}-10.3 \mathrm{Fe}-0.020 \mathrm{C}- \\
0.32 \mathrm{Mn}-0.28 \mathrm{Si}-0.14 \mathrm{Al}- \\
0.21 \mathrm{Ti}-0.025 \mathrm{~N}-0.008 \mathrm{P}\end{array}$ & $\begin{array}{c}1085-1128^{\circ} \mathrm{C} / \sim 1 \mathrm{~min}, \mathrm{WQ}+ \\
716-729^{\circ} \mathrm{C} / 10.5 \mathrm{~h}, \text { Air cool } \\
\text { YS/UTS = 39/92 ksi; TE = 51\% }\end{array}$ \\
\hline $\begin{array}{l}\text { Alloy 690TT } \\
\text { RE076 }\end{array}$ & $\begin{array}{c}\text { RE076, CRDM Tube } \\
2146 \text { (1.1" wall) }\end{array}$ & $\begin{array}{c}\text { Ni-28.5Cr-10.2Fe-0.021C- } \\
0.4 \mathrm{Mn}-0.35 \mathrm{Si}-0.23 \mathrm{Al}-0.26 \mathrm{Ti}- \\
0.022 \mathrm{~N}-0.009 \mathrm{P},<0.001 \mathrm{~S}\end{array}$ & $\begin{array}{c}1065-1120^{\circ} \mathrm{C} / \sim 1 \mathrm{~min}, \mathrm{WQ}+ \\
705-710^{\circ} \mathrm{C} / 5.8 \mathrm{~h}, \text { Air cool } \\
\text { YS/UTS = 39/92 ksi; TE = 52\% }\end{array}$ \\
\hline $\begin{array}{l}\text { Alloy 690TT } \\
\text { RE169 }\end{array}$ & $\begin{array}{l}\text { RE169, CRDM Tube } \\
2175 \text { (1.0" wall) }\end{array}$ & $\begin{array}{c}\mathrm{Ni}-29.2 \mathrm{Cr}-10.1 \mathrm{Fe}-0.023 \mathrm{C}- \\
0.3 \mathrm{Mn}-0.30 \mathrm{Si}-0.17 \mathrm{Al}-0.22 \mathrm{Ti}- \\
0.026 \mathrm{~N}-0.009 \mathrm{P},<0.001 \mathrm{~S}\end{array}$ & $\begin{array}{c}1115^{\circ} \mathrm{C} / \sim 1 \mathrm{~min}, \mathrm{WQ}+ \\
715-723^{\circ} \mathrm{C} / 10.5 \mathrm{~h}, \text { Air cool } \\
\mathrm{YS} / \mathrm{UTS}=41 / 95 \mathrm{ksi} ; \text { TE }=52 \%\end{array}$ \\
\hline
\end{tabular}




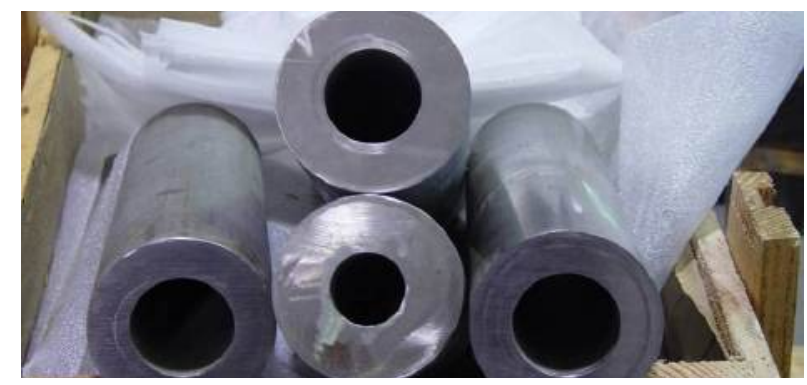

Figure 4.1 Four of the thick-wall alloy 690 CRDM tubes from Valinox at PNNL.

Microstructure examples for several of the heats are shown in Figures 4.2 and 4.3. Typical average grain sizes are somewhat large at $\sim 100 \mu \mathrm{m}$ in diameter. Grain boundary precipitation can be seen in the etched samples, but higher resolution examinations by SEM were required to better estimate precipitate morphologies and distributions. The three heats (RE243, WP140 and WP142) selected for initial crack-growth testing were examined in more detail with most work performed on heat RE243. This particular heat was chosen because of the larger wall thickness for tube 2360 enabling flexibility for subsequent processing (i.e., cold rolling). Tests on the other three CRDM heats (WP016, RE076, and RE169) may be performed in the future and described in subsequent reports.
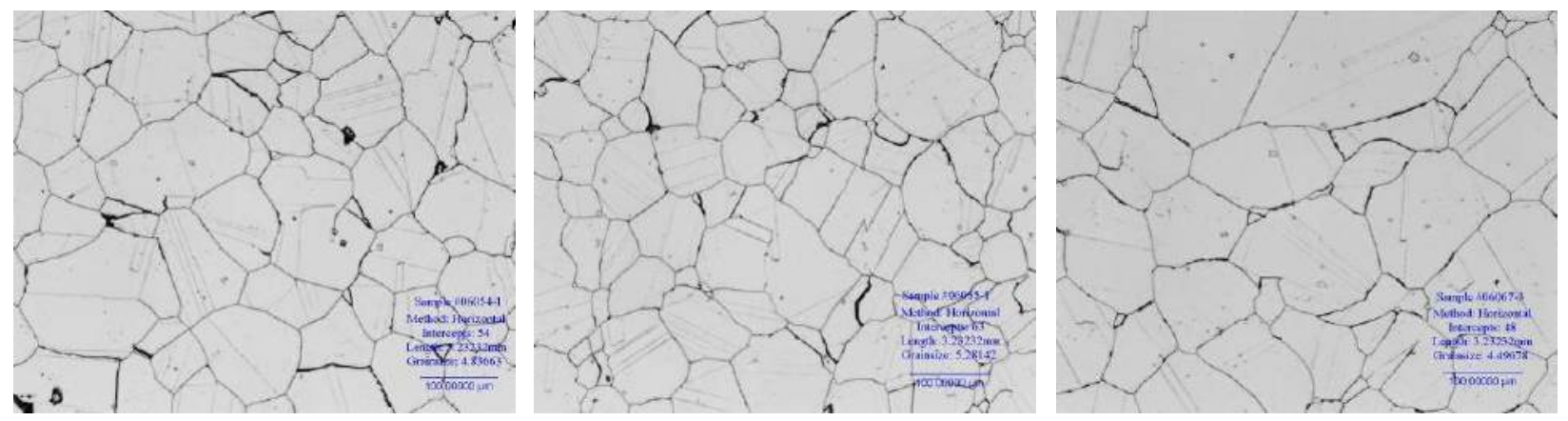

Figure 4.2 Optical metallographs showing grain structures for alloy 690 heat RE243 in the transverse (left), longitudinal (middle), and circumferential (right) orientations.
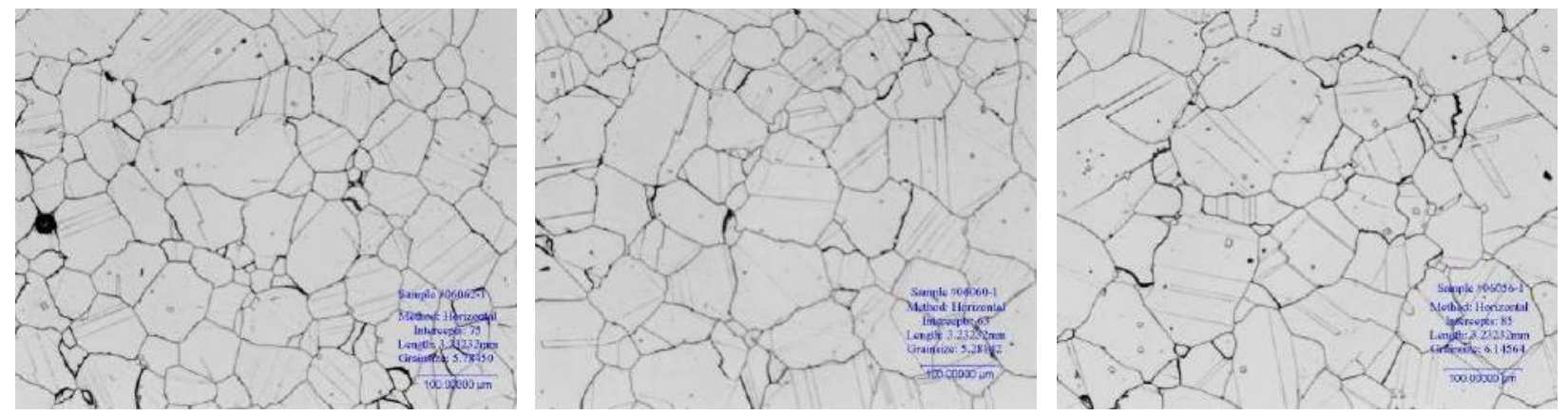

Figure 4.3 Optical metallographs showing grain structures for alloy 690 heats WP016 (left), WP140 (middle), and RE169 (right). 
Scanning electron microscopy (SEM), both in secondary and backscatter modes, was performed to investigate the distribution of second phases in the CRDM alloy 690TT material microstructures. Using low $\mathrm{kV}$ imaging, image analysis is concentrated within the first $50 \mathrm{~nm}$ of the surface thereby providing high surface sensitivity and better resolution of small precipitates.

As expected for a material in the TT condition (final heat treatment at $\sim 720^{\circ} \mathrm{C}$ for $10.5 \mathrm{~h}$ ), the $\mathrm{M}_{23} \mathrm{C}_{6}$ carbide distribution along high-energy, random grain boundaries was very high $(<50 \mathrm{~nm}$ spacing). Carbides were present primarily as semi-continuous discrete precipitates (Figure 4.4), but many boundary regions show cellular or discontinuous carbide morphologies (Figure 4.5). Grain boundary migration has clearly occurred during the discontinuous precipitation process and results in the boundary locally bulged into the matrix ahead of the carbides. These $\mathrm{Cr}$ carbide precipitation characteristics are consistent with that documented by Angeliu and Was [Ref. 9] during isothermal heat treatment of alloy 690.

The discrete $\mathrm{M}_{23} \mathrm{C}_{6}$ ranged in size from about 100 to $200 \mathrm{~nm}$ with variable shapes ranging from equiaxed to slightly elongated. The elemental distributions of the $\mathrm{M}_{23} \mathrm{C}_{6}$ carbides are illustrated in Figure 4.6. These elemental maps, obtained using energy dispersive x-ray spectroscopy (EDS), were collected in the FEG-SEM on thin foil transmission electron microscopy (TEM) samples and show the carbides as highly $\mathrm{Cr}$ rich, and in most cases, the grain boundary region (or surrounding matrix in the case of the cellular carbides) is depleted in $\mathrm{Cr}$. The extent of $\mathrm{Cr}$ depletion is highly variable in regions of cellular carbide precipitation, but is much more consistent along grain boundaries with discrete particles. Limited TEM analyses have shown a relatively broad $\mathrm{Cr}$ depletion profile with that the grain boundary $\mathrm{Cr}$ concentration (measured between $\mathrm{M}_{23} \mathrm{C}_{6}$ carbides) decreasing by 6 to $9 \mathrm{wt} \%$ balanced by an increase in Ni concentration. The depletion profile is affected by the adjacent carbide morphology and spacing, but the total width appears to be on the order of 300 to $400 \mathrm{~nm}$. A typical analysis on the RE243 alloy 690TT material is presented in Figure 4.7.

In addition to the $\mathrm{Cr}$ carbides, Ti-rich precipitates were found along grain boundaries in the alloy 690TT materials as identified in Figures 4.4(a) and (d). TEM analyses indicated that most of these IG particles were Ti nitrides. The TiN precipitates at grain boundaries were slightly larger in size, but much fewer in number than the $\mathrm{M}_{23} \mathrm{C}_{6}$. Somewhat larger TG TiN or carbonitride particles reaching $\sim 1 \mu \mathrm{m}$ in size were seen (Figure $4.5 \mathrm{a}$ ) randomly distributed in the matrix.

Examples were shown here from examinations on the heat RE243 material and these are believed to be representative of the other CRDM heats. In general, all of the as-received Valinox alloy 690TT tubing materials have similar grain sizes and extensive grain boundary carbide precipitation. However, more detailed characterizations are needed to establish and effectively compare heat-to-heat microstructures.

In order to assess the possible influence of alloy 690 microstructure on SCC susceptibility, heat treatments were performed on the RE243 material. The first microstructural variable of interest was the grain boundary carbide distribution, since it is known to be a factor in the IGSCC behavior of alloy 600 in PWR primary water environments. An attempt to modify the carbide distribution without altering the grain size was made through heat treatments at 1050,1100 and $1150^{\circ} \mathrm{C}$ followed by water quenching. Grain growth was observed after a short time anneal at $1150^{\circ} \mathrm{C}$, but not after anneals up to $1 \mathrm{~h}$ at the lower temperatures. As a result, the decision was made to anneal the as-received alloy $690 \mathrm{TT}$ material at $1100^{\circ} \mathrm{C}$ for $1 \mathrm{~h}$ and water quench to produce a carbide-modified (CM) alloy 690 microstructural condition. 


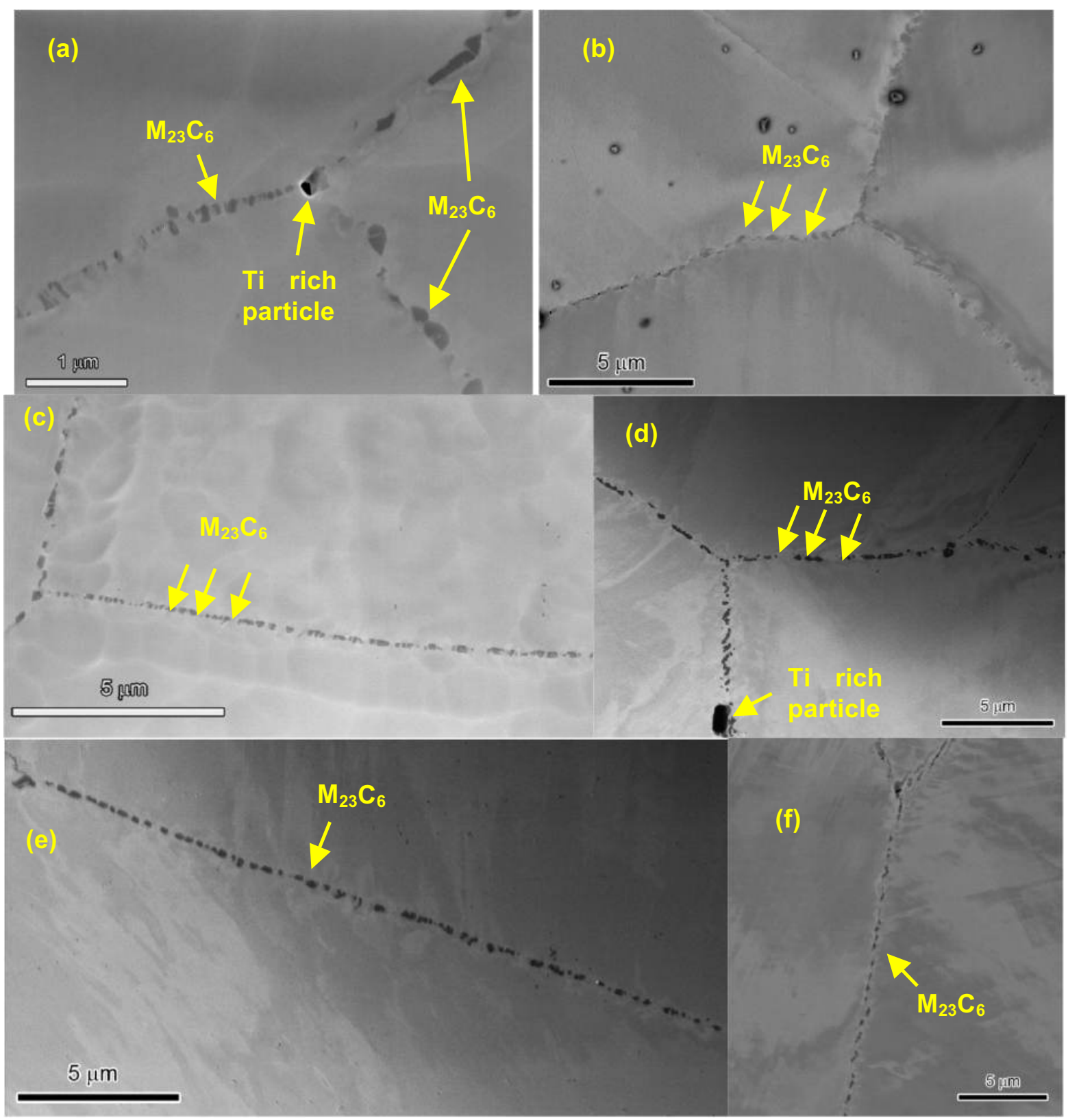

Figure 4.4 SEM micrographs (SE and backscatter) showing general carbide microstructure of the as received CRDM alloy 690TT heat RE243 material. 


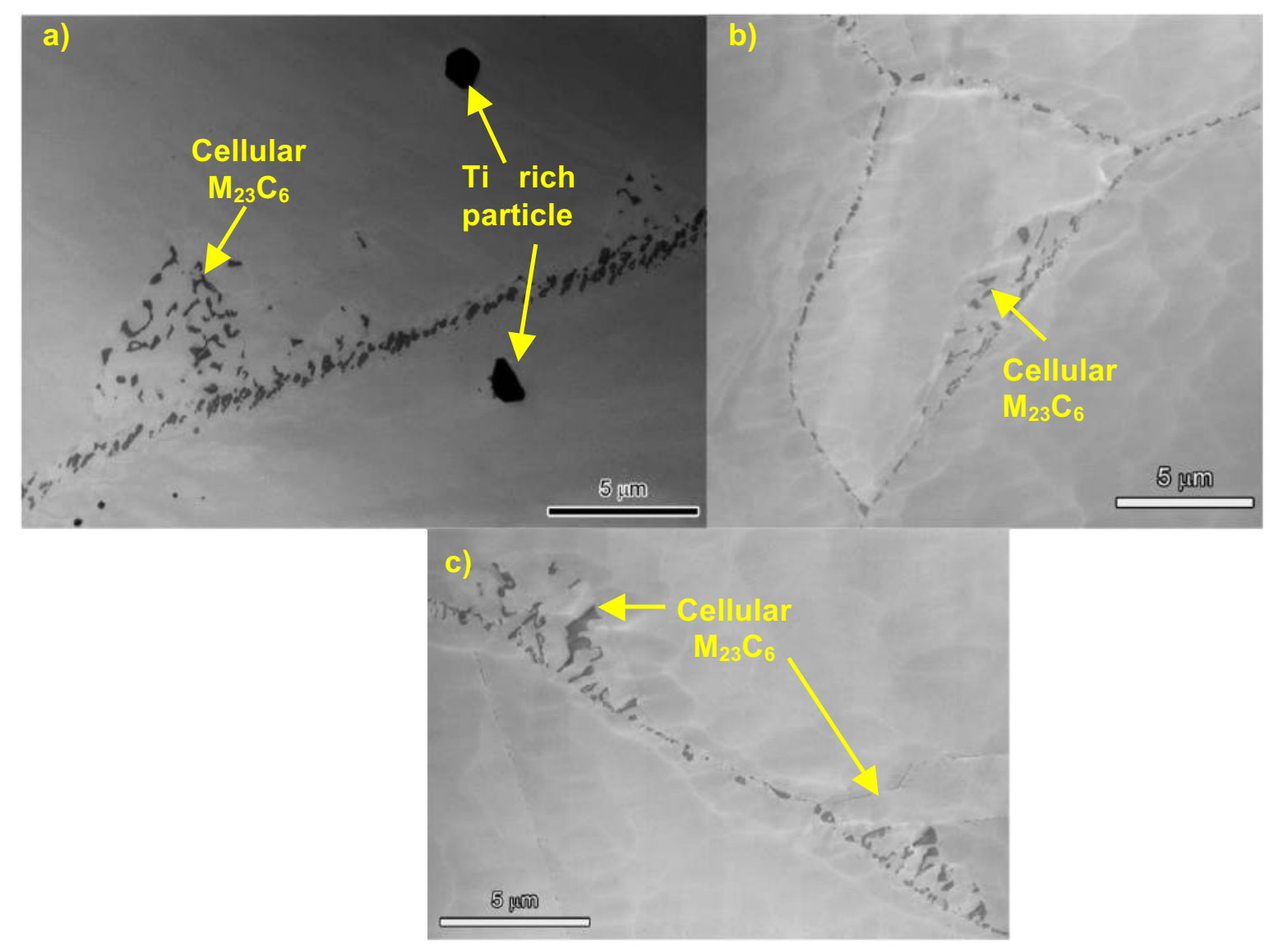

Figure 4.5 SEM micrographs (SE and backscatter) showing cellular carbide structure observed in the as received CRDM alloy 690TT heat RE243 material.

SEM examinations confirmed that the $1100^{\circ} \mathrm{C}$ anneal removed most $\mathrm{Cr}$ carbide precipitates from the microstructure. Very few $\mathrm{M}_{23} \mathrm{C}_{6}$ carbides could be found during characterizations on the CRDM alloy $690 \mathrm{CM}$ materials as illustrated in Figures 4.8 and 4.9. In fact, nearly all grain boundaries show only well-spaced TiN particles and no carbide precipitates. Low magnification micrographs (Figure 4.8) identify larger TG Ti-rich particles as well as smaller IG TiN precipitates. Figure 4.9 reveals that the morphology of these IG Ti-rich particles is often platelike reaching sized $\sim 100 \mathrm{~nm}$ thick and $500-800 \mathrm{~nm}$ long. This suggests that the TiN precipitates have grown in size as a result of the $1100^{\circ} \mathrm{C}$ heat treatment. Their spacing remains similar ranging from micrometers apart to tens of micrometers apart (Figure 4.9). Elemental EDS mapping (Figure 4.10) demonstrates the general distribution of these Ti-rich particles and the lack of $\mathrm{Cr}$-rich $\mathrm{M}_{23} \mathrm{C}_{6}$ precipitates in the alloy $690 \mathrm{CM}$ material. Because the high-temperature solution anneal has removed IG $\mathrm{Cr}$ carbides, there is no significant composition gradient (e.g., $\mathrm{Cr}$ depletion) at grain boundaries. Hardness measurements were also obtained for the RE243 alloy 690TT and alloy $690 \mathrm{CM}$ materials and indicated slightly lower values for the solutionannealed CM material of $\sim 165 \mathrm{~kg} / \mathrm{mm}^{2}$ compared to $\sim 175 \mathrm{~kg} / \mathrm{mm}^{2}$ for the as-received TT material. 

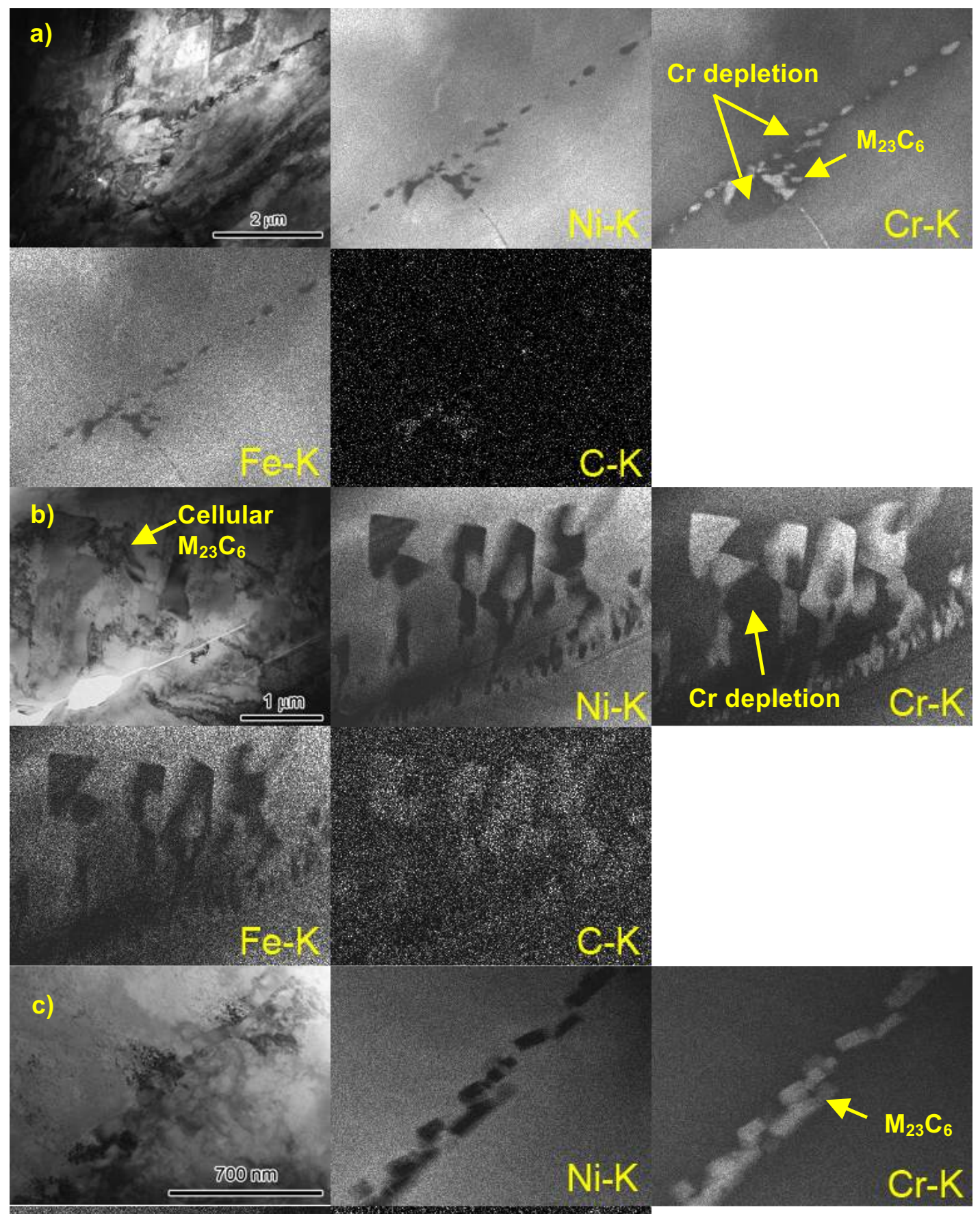

Figure 4.6 STEM/EDS elemental maps showing chemical distributions in various carbide structures in as-received CR CRDM alloy 690TT heat RE243. 


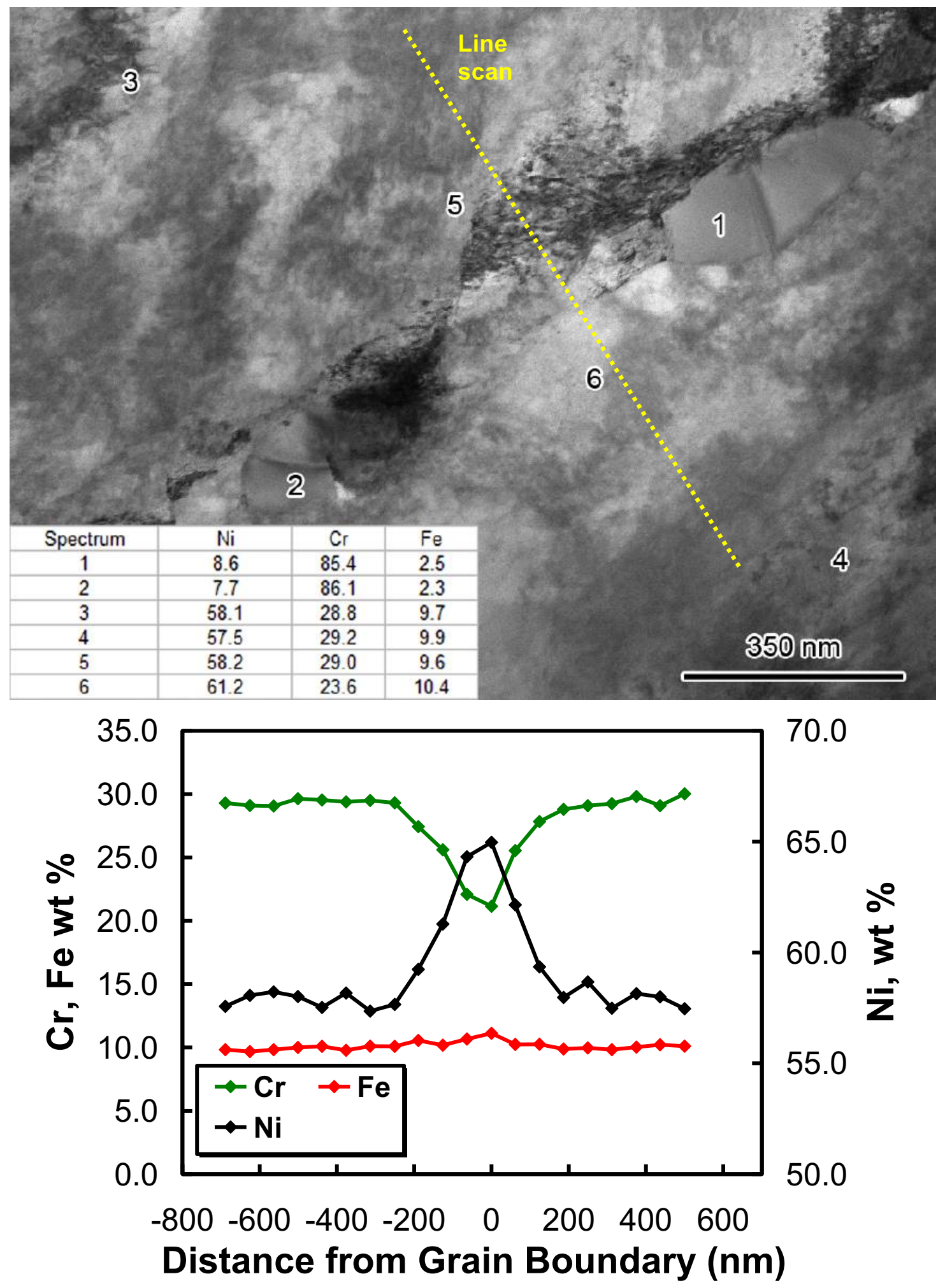

Figure 4.7 Measurement of $\mathrm{Cr}$ depletion profile across high-energy grain boundary in heat RE243 alloy 690TT material: (a) STEM brightfield showing selected EDS point analyses and the profile location between $\mathrm{Cr}$ carbides and (b) plot documenting concentration changes across the grain boundary. 


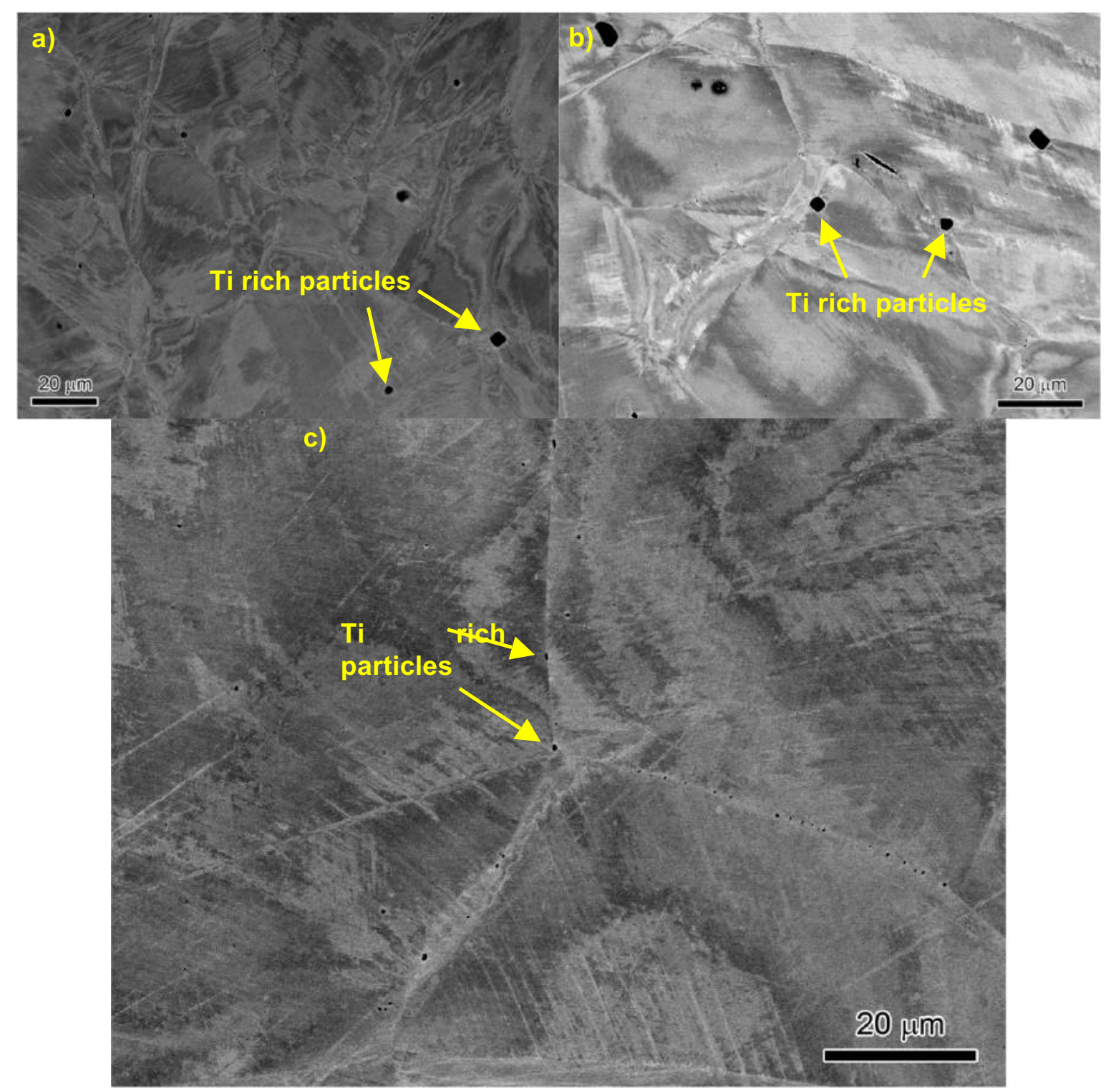

Figure 4.8 SEM backscatter low magnification images of CRDM alloy 690CM heat RE243 material demonstrating lack of carbides on grain boundaries. 


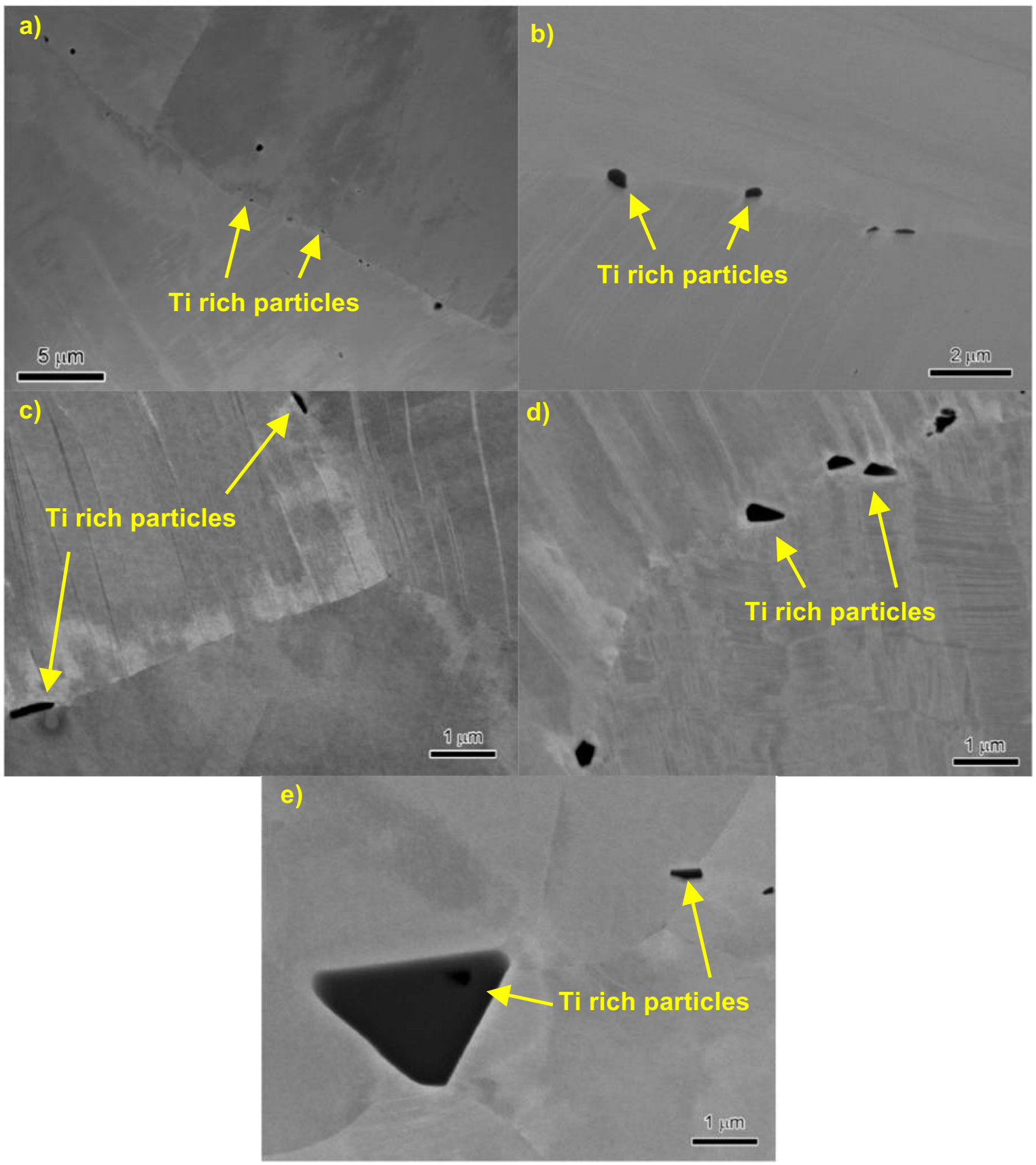

Figure 4.9 SEM backscatter high magnification images of CRDM alloy 690CM heat RE243 material showing absence of $\mathrm{M}_{23} \mathrm{C}_{6}$ and a very low density of TiN on grain boundaries. 


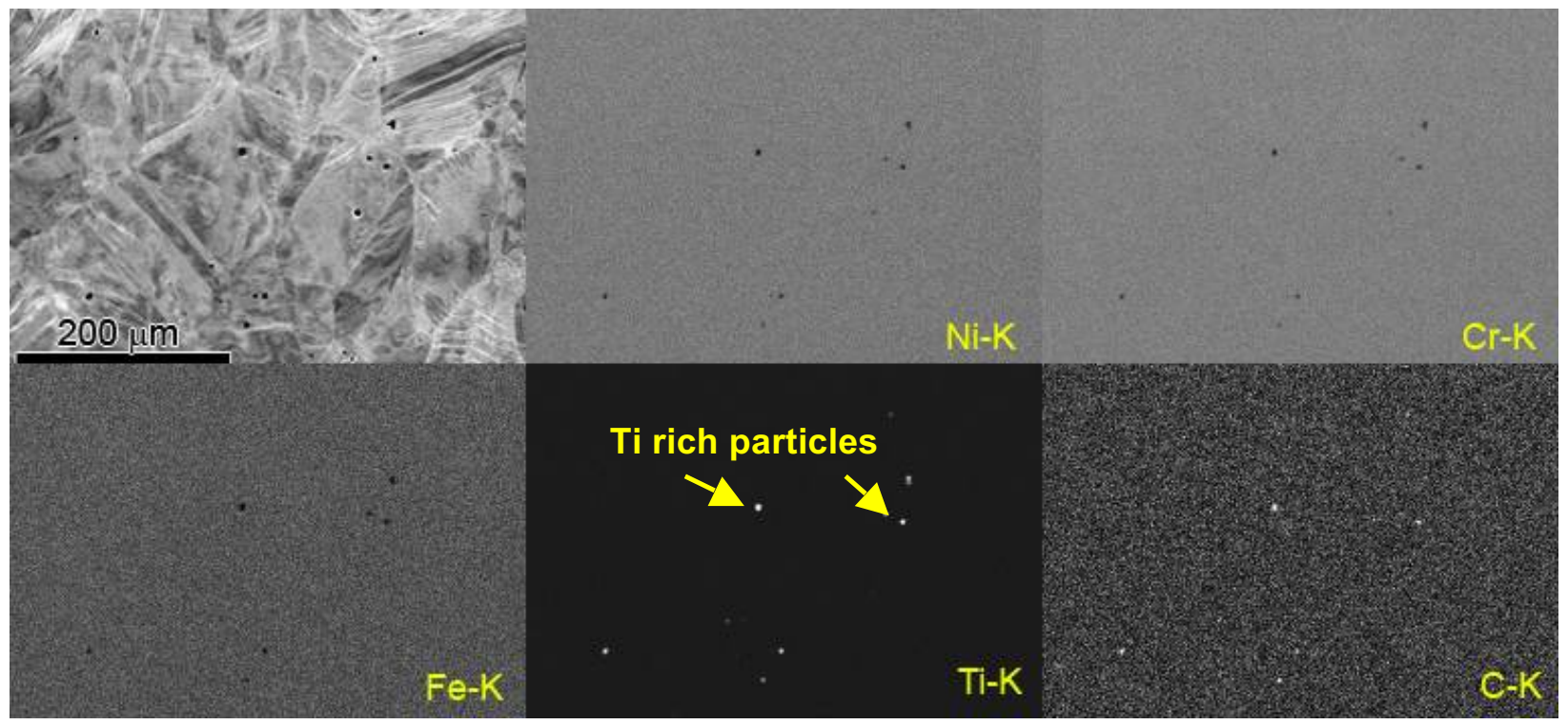

Figure 4.10 SEM elemental maps illustrating the low density of Ti-rich precipitates and lack of $\mathrm{M}_{23} \mathrm{C}_{6}$ carbides in the CRDM alloy $690 \mathrm{CM}$ heat RE243 material.

The characterization results on the as-received alloy 690TT and solution-annealed alloy 690CM CRDM materials are summarized in Table 4.2. The alloy $690 \mathrm{CM}$ material can be seen to have a similar grain size, Ti-rich particle distribution and hardness as for the as-received alloy 690TT material. The most significant differences are the removal of the semi-continuous $\mathrm{Cr}$-rich $\mathrm{M}_{23} \mathrm{C}_{6}$ precipitation on grain boundaries and the Cr-depleted region in the adjacent matrix. In addition, the dissolution of the carbides at $1100^{\circ} \mathrm{C}$ will put some carbon back into solution. The solutionannealed CM material represents a first step in assessing material microstructural variability and enables the influence of IG carbide precipitation on SCC response to be investigated on the same heat of alloy 690 by comparisons to the as-received TT material. Crack-growth rate results for these materials in various cold-rolled conditions will be presented later in this Chapter.

Table 4.2 Microstructure, microchemistry and hardness for CRDM alloy 690 (heat RE243).

\begin{tabular}{|c|c|c|c|}
\hline Sample & Microstructure & GB Microchemistry & Hardness \\
\hline $\begin{array}{l}\text { (0 - TT) PNNL } \\
\text { CRDM alloy } \\
\text { 690TT; Test } \\
\text { sample CT014 }\end{array}$ & $\begin{array}{l}\text { Semi-continuous (small } \\
\text { discrete + cellular) carbides on } \\
\text { GBs, occasional TiN at GBs } \\
\text { and in matrix; equiaxed grains }\end{array}$ & $\begin{array}{l}\mathrm{Cr} \text { depletion to } 21-24 \mathrm{wt} \% \\
\text { at GBs between carbides } \\
\text { along with Ni enrichment, } \\
\text { total width of } 300-400 \mathrm{~nm}\end{array}$ & 175 \\
\hline $\begin{array}{l}\text { (0 - CM) PNNL } \\
\text { CRDM alloy } \\
\text { 690CM; Test } \\
\text { sample CT015 }\end{array}$ & $\begin{array}{c}\text { Few carbides and well-spaced } \\
\text { TiN on GBs, occasional TiN in } \\
\text { matrix, slightly elongated } \\
\text { grains }\end{array}$ & $\begin{array}{l}\text { No measured enrichment or } \\
\text { depletion of alloying or } \\
\text { impurity elements at GBs }\end{array}$ & $165 \mathrm{~kg} / \mathrm{mm}^{2}$ \\
\hline
\end{tabular}




\subsection{As-Received Alloy 690TT and Solution-Annealed Alloy 690CM Materials}

When SCC tests were initiated at PNNL in 2007 on alloy 690 materials, limited crack-growthrate data on cold-worked alloy 690 had been reported but essentially there were no results on alloy 690 without cold work. Many tests had been performed and the final result characterized as showing "no SCC." It is important to note that most of these experiments were on statically loaded samples and represented a combined initiation and propagation test. However, cracking was not observed even on specimens loaded to high $\mathrm{K}$ levels and some with fatigue precracks. The approach at PNNL was to evaluate several alloy 690TT CRDM tubing heats in the asreceived condition along with one heat (RE243) heat treated to modify the IG carbide density. These materials and conditions were described in the previous section.

Three as-received alloy 690 CRDM specimens were tested, one each from RE243, WP140, and WP142 heats. In the first test, and specimen of as-received TT material was paired with a specimen of CM material, both from heat RE243. An overall plot of the crack growth for the heat RE243 specimens is shown in Figure 4.11 and the step-by-step test history is summarized in Table 4.3. Very similar behavior can be seen for the TT and CM specimens over the yearlong experiment. The first transitioning sequence spent a very long time under "gentle" cycle + hold conditions before going to constant $\mathrm{K}$ as shown in Figure 4.12. It was hoped that IGSCC would be promoted during these conditions; however crack growth rates decreased with time for both the 2.5 and $24 \mathrm{~h}$ hold conditions indicating a lack of engagement. Although there was no clear indication of environment-enhanced crack growth, constant K was established at $\sim 5200 \mathrm{~h}$ and extremely small crack extensions $(1-2 \mu \mathrm{m})$ were measured by DCPD over the next $1000 \mathrm{~h}$. Since this extension does not represent a meaningful propagation distance, the crack growth rates are simply assumed to be $<5 \times 10^{-10} \mathrm{~mm} / \mathrm{s}$. The crack fronts were then moved forward into different microstructural regions by cycling and a second transitioning sequence was initiated.

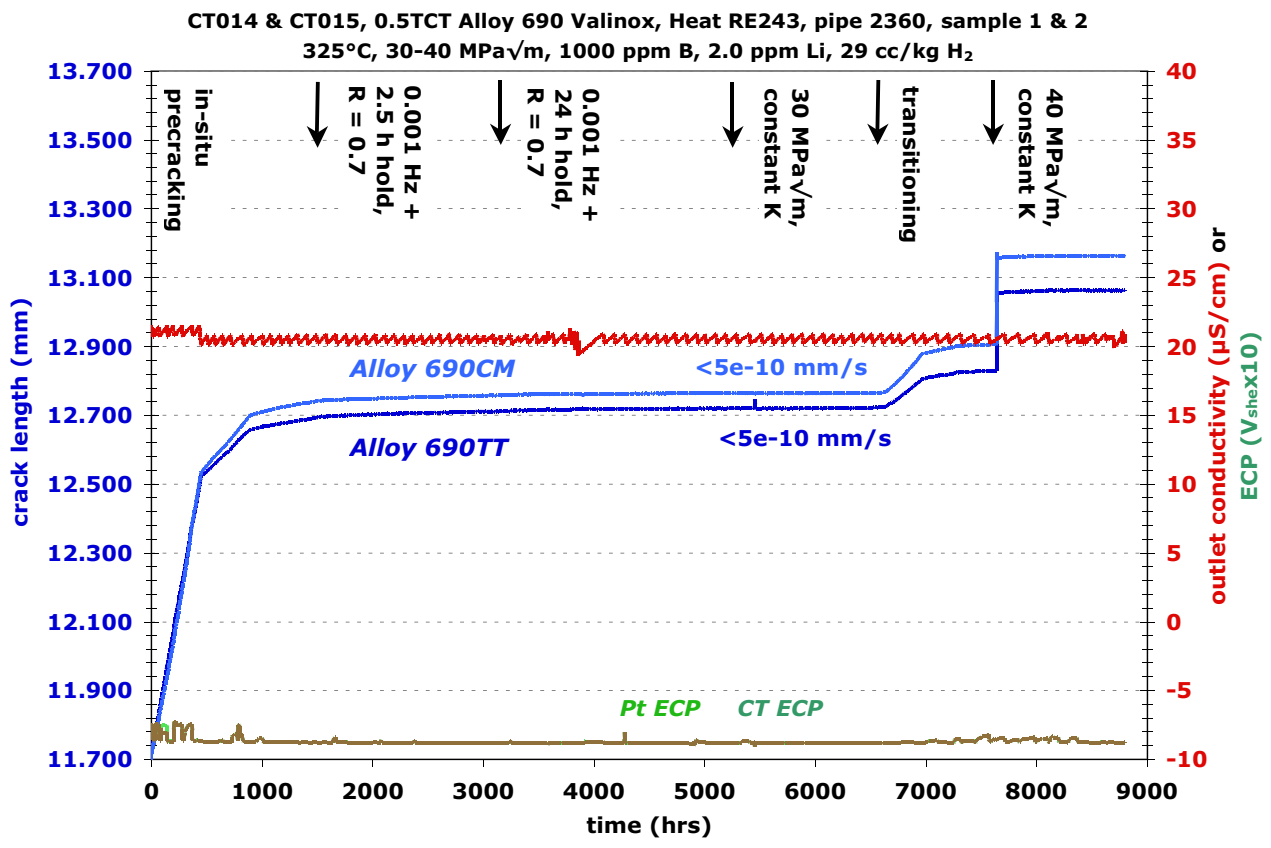

Figure 4.11 Overall crack-growth response of heat RE243 alloy 690TT and CM specimens (CT014 \& CT015) in simulated PWR primary water at $325^{\circ} \mathrm{C}$. 
Table 4.3 Uncorrected data summary for alloy 690 CRDM specimens CT014 \& CT015.

\begin{tabular}{|c|c|c|c|c|c|c|c|c|c|c|c|c|}
\hline \multirow[b]{2}{*}{$\begin{array}{l}\text { Test } \\
\text { Phase }\end{array}$} & \multirow[b]{2}{*}{$\begin{array}{l}\text { Dur- } \\
\text { ation } \\
\text { (h) }\end{array}$} & \multirow[b]{2}{*}{$\mathrm{R}$} & \multirow[b]{2}{*}{ Freq $(\mathrm{Hz})$} & \multirow[b]{2}{*}{$\begin{array}{c}\text { Hold } \\
(\mathrm{h})\end{array}$} & \multirow[b]{2}{*}{$\begin{array}{c}\text { Water } \\
\text { Chemistry } \\
\text { Conditions }\end{array}$} & \multirow[b]{2}{*}{$\begin{array}{l}\text { Temp } \\
\left({ }^{\circ} \mathrm{C}\right)\end{array}$} & \multirow[b]{2}{*}{$\begin{array}{r}\mathrm{Kmax} \\
(\mathrm{MPa} \sqrt{\mathrm{m}}\end{array}$} & \multicolumn{2}{|c|}{$\begin{array}{c}\text { CT014 } \\
\text { Alloy 690TT }\end{array}$} & \multicolumn{3}{|c|}{$\begin{array}{c}\text { CT015 } \\
\text { Alloy } 690 \mathrm{CM}\end{array}$} \\
\hline & & & & & & & & $\begin{array}{c}\mathrm{CGR} \\
(\mathrm{mm} / \mathrm{sec})\end{array}$ & $\begin{array}{c}\text { Crack } \\
\text { Extension } \\
(\mathrm{mm})\end{array}$ & $\begin{array}{c}\mathrm{Kmax} \\
(\mathrm{MPa} \sqrt{ } \mathrm{m})\end{array}$ & $\begin{array}{c}\text { CGR } \\
(\mathrm{mm} / \mathrm{sec})\end{array}$ & $\begin{array}{c}\text { Crack } \\
\text { Extension } \\
(\mathrm{mm})\end{array}$ \\
\hline 1 & 3.5 & 0.3 & 3 & 0 & air & RT & 25 & & 0.50 & 25 & & 0.50 \\
\hline 2 & 1.5 & 0.5 & 3 & 0 & air & RT & 28 & & 0.30 & 28 & & 0.30 \\
\hline 3 & 2.0 & 0.6 & 3 & 0 & air & RT & 30 & & 0.30 & 30 & & 0.30 \\
\hline 4 & 12.0 & 0.7 & 3 & 0 & air & RT & 30 & & 0.30 & 30 & & 0.30 \\
\hline 5 & 455 & 0.7 & 0.1 & 0 & $29 \mathrm{cc} / \mathrm{kg} \mathrm{H}_{2}$ & 325 & 30 & 5.1E-07 & 0.813 & 30 & $5.1 \mathrm{E}-07$ & 0.816 \\
\hline 6 & 450 & 0.7 & 0.01 & 0 & $29 \mathrm{cc} / \mathrm{kg} \mathrm{H}_{2}$ & 325 & 30 & 8.6E-08 & 0.150 & 30 & $1.0 \mathrm{E}-07$ & 0.160 \\
\hline 7 & 600 & 0.7 & 0.001 & 0 & $29 \mathrm{cc} / \mathrm{kg} \mathrm{H}_{2}$ & 325 & 30 & $1.4 \mathrm{E}-08$ & 0.035 & 30 & 1.6E-08 & 0.039 \\
\hline 8 & 1500 & 0.7 & 0.001 & 2.5 & $29 \mathrm{cc} / \mathrm{kg} \mathrm{H}_{2}$ & 325 & 30 & 2.6E-09 & 0.002 & 30 & 2.1E-09 & 0.002 \\
\hline 9 & 2000 & 0.7 & 0.001 & 24 & $29 \mathrm{cc} / \mathrm{kg} \mathrm{H}_{2}$ & 325 & 30 & $\sim 6 \mathrm{E}-10$ & 0.005 & 30 & $\sim 5 \mathrm{E}-10$ & 0.004 \\
\hline 10 & 1400 & & const $\mathrm{K}$ & & $29 \mathrm{cc} / \mathrm{kg} \mathrm{H}{ }_{2}$ & 325 & 30 & $<5 \mathrm{E}-10$ & 0.0015 & 30 & $<5 \mathrm{E}-10$ & 0.001 \\
\hline 11 & 325 & 0.7 & 0.01 & 0 & $29 \mathrm{cc} / \mathrm{kg} \mathrm{H}_{2}$ & 325 & 30 & 8.6E-08 & 0.009 & 30 & $1.0 \mathrm{E}-07$ & 0.011 \\
\hline 12 & 325 & 0.7 & 0.001 & 0 & $29 \mathrm{cc} / \mathrm{kg} \mathrm{H}_{2}$ & 325 & 30 & $1.4 \mathrm{E}-08$ & 0.002 & 30 & 1.6E-08 & 0.002 \\
\hline 13 & 375 & 0.7 & 0.001 & 2.5 & $29 \mathrm{cc} / \mathrm{kg} \mathrm{H}_{2}$ & 325 & 30 & 4.0E-09 & 0.005 & 30 & 4.0E-09 & 0.005 \\
\hline 14 & 475 & 0.7 & 0.001 & 2.5 & $29 \mathrm{cc} / \mathrm{kg} \mathrm{H}$ & 325 & 40 & 3.5E-09 & 0.005 & 40 & $1.8 \mathrm{E}-09$ & 0.003 \\
\hline 15 & 675 & & const $\mathrm{K}$ & & $29 \mathrm{cc} / \mathrm{kg} \mathrm{H}_{2}$ & 325 & 40 & $<5 \mathrm{E}-10$ & $\sim 0$ & 40 & $<5 \mathrm{E}-10$ & 0.0015 \\
\hline
\end{tabular}


CT014 \& CT015 CGR, 0.5TCT Alloy 690 Valinox, Heat RE243, pipe 2360, sample 1 \& 2 $325^{\circ} \mathrm{C}, 30 \mathrm{MPa} / \mathrm{m}, 1000 \mathrm{ppm}$ B, $2.0 \mathrm{ppm} \mathrm{Li}, 29 \mathrm{cc} / \mathrm{kg} \mathrm{H}_{2}$

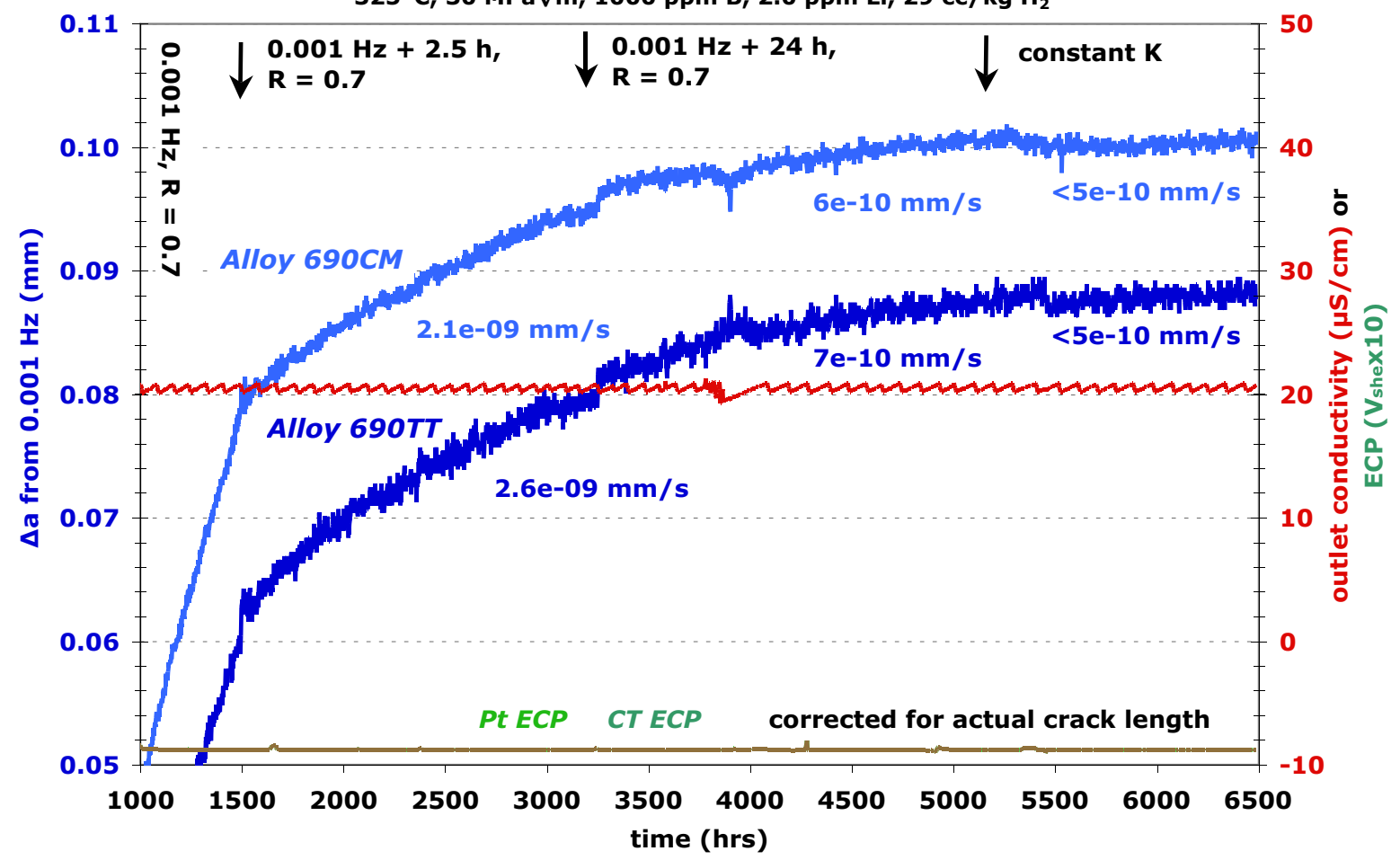

Figure 4.12 Response for heat RE243 alloy 690TT and CM specimens (CT014 \& CT015) during transitioning to constant $\mathrm{K}$ in simulated PWR primary water at $325^{\circ} \mathrm{C}$.

Crack-growth response was nearly identical during cycle + hold conditions to that in the first sequence, and it was decided to increase the $\mathrm{K}$ level to $40 \mathrm{MPa} \sqrt{\mathrm{m}}$ under gentle cycling at $0.001 \mathrm{~Hz}$. As noted in Figure 4.11, a large jump in crack length was observed likely due to the breaking of ligaments in the wake of the crack front. No discernable increase in constant $\mathrm{K}$, crack-growth rates were found at $40 \mathrm{MPa} \sqrt{\mathrm{m}}$ and rates were estimated to be $<5 \times 10^{-10} \mathrm{~mm} / \mathrm{s}$.

The high-temperature portion of the test was ended and the temperature was decreased to first $100^{\circ} \mathrm{C}$ and then to $50^{\circ} \mathrm{C}$. No indication of crack extension was detected under constant $\mathrm{K}$, so cyclic loading was applied as documented in Figure 4.13. The crack growth rates at $50^{\circ} \mathrm{C}$ were similar to that observed during testing at $325^{\circ} \mathrm{C}$, however somewhat higher rates were noted for the TT specimen. 


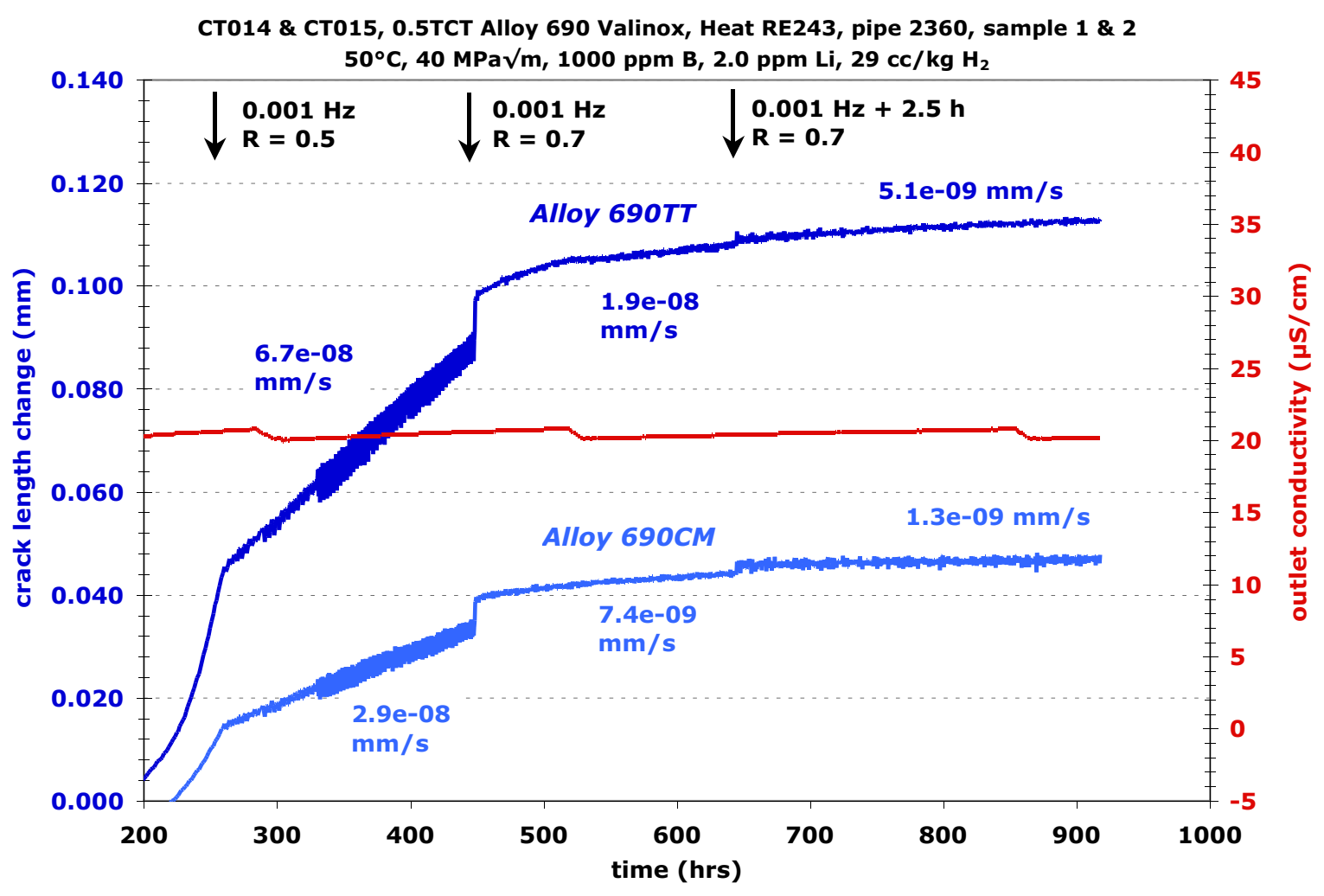

Figure 4.13 Crack-growth response of heat RE243 alloy 690TT and CM specimens (CT014 \& CT015) during testing in simulated PWR primary water at $50^{\circ} \mathrm{C}$.

Post-test examination of the $325^{\circ} \mathrm{C}$ crack-growth surfaces revealed predominately TG features for both the TT and CM specimens as illustrated in Figure 4.14. Only a few isolated IG facets could be identified near final high-temperature crack front and were most likely produced during the cycle + hold and constant $\mathrm{K}$ steps at 1500-6500 h. More significant IG cracking was found in the $50^{\circ} \mathrm{C}$ crack-growth surface for the TT specimen (Figure $4.14 \mathrm{a}$ ), while the CM specimen remained TG (Figure 4.14b). The higher fraction of IG cracking $(\sim 15 \%)$ in the TT material was consistent with the higher propagation rates measured during cycling at $50^{\circ} \mathrm{C}$. Grain boundary carbides may help promote hydrogen-induced IG cracking during dynamic straining at this low temperature [Refs. 10,11]. 

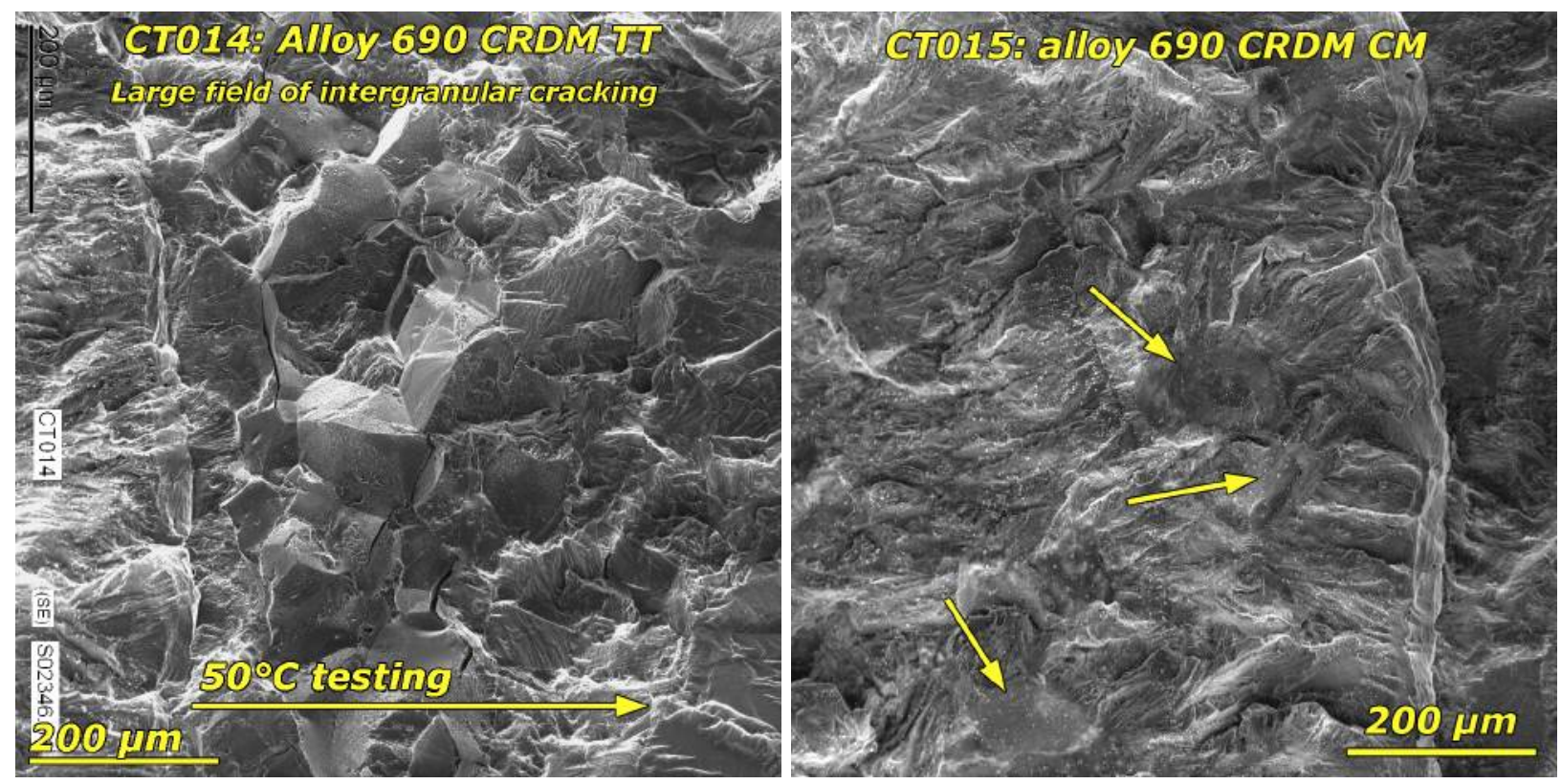

Figure 4.14 SEM image showing IG cracking for the RE243 alloy 690 TT specimen during testing at $50^{\circ} \mathrm{C}$ (a) and primarily TG cracking for the RE243 alloy $690 \mathrm{CM}$ specimen (b) although isolated IG facets are identified.

Heat-to-heat response was evaluated in the next test on alloy 690 CRDM heats WP140 and WP142 both in the as-received, TT condition. Once again, the test was conducted under simulated PWR primary water but at a slightly higher temperature of $350^{\circ} \mathrm{C}$. Four transitioning sequences were performed to improve SCC engagement as shown in the overview of the entire test in Table 4.4 and Figure 4.15. The first three transitioning attempts done at $350^{\circ} \mathrm{C}$ resulted in very low constant $\mathrm{K}$ crack-growth rates. Although these may be slightly higher than seen for the alloy 690 heat RE243 specimens, they remain below $1 \times 10^{-9} \mathrm{~mm} / \mathrm{s}$. For each attempt, somewhat different cycling and periodic unloading parameters were used during transitioning to constant $\mathrm{K}$ conditions. An example of the low-growth rates at constant $\mathrm{K}$ is presented in Figure 4.16 where DCPD-measured crack extension is only $\sim 1.5 \mu \mathrm{m}$ over a period of $600 \mathrm{~h}$. 
Table 4.4 Uncorrected data summary for alloy 690 CRDM specimens CT026 \& CT027.

\begin{tabular}{|c|c|c|c|c|c|c|c|c|c|c|c|c|}
\hline \multirow[b]{2}{*}{$\begin{array}{c}\text { Test } \\
\text { Phase }\end{array}$} & \multirow[b]{2}{*}{$\begin{array}{c}\text { Duration } \\
\text { (h) }\end{array}$} & \multirow[b]{2}{*}{$\mathrm{R}$} & \multirow[b]{2}{*}{ Freq $(\mathrm{Hz})$} & \multirow[b]{2}{*}{$\begin{array}{c}\text { Hold } \\
(\mathrm{h})\end{array}$} & \multirow[b]{2}{*}{$\begin{array}{l}\text { Water } \\
\text { Chemistry } \\
\text { Conditions }\end{array}$} & \multirow[b]{2}{*}{$\begin{array}{r}\text { Temp } \\
\quad\left({ }^{\circ} \mathrm{C}\right) \\
\end{array}$} & \multicolumn{3}{|c|}{$\begin{array}{c}\text { CT026 } \\
\text { Alloy 690TT WP142 } \\
\quad \text { Crack }\end{array}$} & \multicolumn{3}{|c|}{$\begin{array}{c}\text { CT027 } \\
\text { Alloy 690TT WP140 }\end{array}$} \\
\hline & & & & & & & $\begin{array}{c}\mathrm{Kmax} \\
(\mathrm{MPa} \sqrt{\mathrm{m}})\end{array}$ & $\begin{array}{c}\mathrm{CGR} \\
(\mathrm{mm} / \mathrm{sec})\end{array}$ & $\begin{array}{c}\text { Crack } \\
\text { Extension } \\
(\mathrm{mm})\end{array}$ & $\begin{array}{c}\mathrm{Kmax} \\
(\mathrm{MPa} \sqrt{\mathrm{m}})\end{array}$ & $\begin{array}{c}\text { CGR } \\
(\mathrm{mm} / \mathrm{sec}) \\
\end{array}$ & $\begin{array}{c}\text { Crack } \\
\text { Extension } \\
(\mathrm{mm}) \\
\end{array}$ \\
\hline 1 & $\sim 6$ & 0.3 & 3 & 0 & air & RT & 25 & 4.1E-05 & 0.54 & 25 & $5.0 \mathrm{E}-05$ & 0.63 \\
\hline 2 & $\sim 3$ & 0.5 & 3 & 0 & air & RT & 28 & 3.4E-05 & 0.43 & 28 & 3.6E-05 & 0.41 \\
\hline 3 & $\sim 3$ & 0.6 & 3 & 0 & air & RT & 30 & 2.4E-05 & 0.28 & 30 & 2.6E-05 & 0.28 \\
\hline 4 & $\sim 7$ & 0.7 & 3 & 0 & air & RT & 30 & 1.2E-05 & 0.29 & 30 & $1.1 \mathrm{E}-05$ & 0.29 \\
\hline 5 & 19 & 0.5 & 0.1 & 0 & $29 \mathrm{cc} / \mathrm{kg} \mathrm{H}_{2}$ & 325 & 30 & 2.6E-06 & 0.202 & 30 & 2.2E-06 & 0.183 \\
\hline 6 & 124 & 0.5 & 0.01 & 0 & $29 \mathrm{cc} / \mathrm{kg} \mathrm{H}_{2}$ & 325 & 30 & 4.4E-07 & 0.195 & 30 & 4.5E-07 & 0.191 \\
\hline 7 & 169 & 0.5 & 0.00 & 0 & $29 \mathrm{cc} / \mathrm{kg} \mathrm{H}_{2}$ & 32 & 30 & 8.1E-08 & 0.053 & 30 & $8.2 \mathrm{E}-08$ & 0.054 \\
\hline 8 & 163 & 0.5 & 0.001 & 0 & $29 \mathrm{cc} / \mathrm{kg} \mathrm{H}_{2}$ & 350 & 30 & 9.0E-08 & 0.056 & 30 & $9.5 \mathrm{E}-08$ & 0.064 \\
\hline 9 & 555 & 0.5 & 0.001 & 2.5 & $29 \mathrm{cc} / \mathrm{kg} \mathrm{H}_{2}$ & 350 & 30 & 1.0E-08 & 0.020 & 30 & $1.0 \mathrm{E}-08$ & 0.014 \\
\hline 10 & 196 & 0.5 & 0.001 & 1 & $29 \mathrm{cc} / \mathrm{kg} \mathrm{H}_{2}$ & 350 & 30 & 1.9E-08 & 0.011 & 30 & $1.9 \mathrm{E}-08$ & 0.012 \\
\hline 11 & 429 & 0.5 & 0.04 & 12.5 & $29 \mathrm{cc} / \mathrm{kg} \mathrm{H}_{2}$ & 350 & 30 & 5.0E-09 & 0.009 & 30 & $5.1 \mathrm{E}-09$ & 0.008 \\
\hline 12 & 763 & --- & --- & --- & $29 \mathrm{cc} / \mathrm{kg} \mathrm{H}_{2}$ & 350 & 30 & $<5 \mathrm{E}-10$ & $\sim 0$ & 30 & $\sim 7$ & 0.001 \\
\hline 13 & 123 & 0.6 & 0.01 & 0 & $29 \mathrm{cc} / \mathrm{kg} \mathrm{H}_{2}$ & 350 & 30 & 2.8E-07 & 0.102 & 30 & $2.8 \mathrm{E}-07$ & 0.104 \\
\hline 14 & 193 & 0.6 & 0.001 & 0 & $29 \mathrm{cc} / \mathrm{kg} \mathrm{H}_{2}$ & 350 & 30 & 4.3E-08 & 0.037 & 30 & 4.7E-08 & 0.033 \\
\hline 15 & 432 & 0.6 & 0.001 & 2.5 & $29 \mathrm{cc} / \mathrm{kg} \mathrm{H}_{2}$ & 350 & 30 & 8.3E-09 & 0.010 & 30 & 8.3E-09 & 0.009 \\
\hline 16 & 342 & --- & const $\mathrm{K}$ & --- & $29 \mathrm{cc} / \mathrm{kg} \mathrm{H}_{2}$ & 350 & 30 & $<5 \mathrm{E}-10$ & 0.000 & 30 & $\sim 9 \mathrm{E}-10$ & 0.001 \\
\hline 17 & 107 & 0.5 & $80 \mathrm{~s} / 20 \mathrm{~s}$ & 0 & $29 \mathrm{cc} / \mathrm{kg} \mathrm{H}{ }_{2}$ & 350 & 3 & 5.4E-07 & 0.202 & 30 & $5.4 \mathrm{E}-07$ & 0.213 \\
\hline 18 & 61 & 0.5 & $980 \mathrm{~s} / 20 \mathrm{~s}$ & 0 & $29 \mathrm{cc} / \mathrm{kg} \mathrm{H}_{2}$ & 350 & 30 & 8.6E-08 & 0.024 & 30 & 8.6E-08 & 0.022 \\
\hline 19 & 475 & 0.5 & 0.001 & 9000 & $29 \mathrm{cc} / \mathrm{kg} \mathrm{H}_{2}$ & 350 & 30 & 1.9E-08 & 0.017 & 30 & $2.0 \mathrm{E}-08$ & 0.020 \\
\hline 20 & 717 & --- & const $\mathrm{K}$ & --- & $29 \mathrm{cc} / \mathrm{kg} \mathrm{H}_{2}$ & 350 & 30 & $\sim 9 \mathrm{E}-10$ & 0.001 & 30 & $\sim 6 \mathrm{E}-10$ & 0.0015 \\
\hline 21 & 531 & --- & const $\mathrm{K}$ & --- & $20 \mathrm{cc} / \mathrm{kg} \mathrm{H}_{2}$ & 350 & 30 & $<5 \mathrm{E}-10$ & $\sim 0$ & 30 & $\sim 6 \mathrm{E}-10$ & 0.001 \\
\hline 22 & 50 & 0.5 & 0.01 & 0 & $20 \mathrm{cc} / \mathrm{kg} \mathrm{H}_{2}$ & 50 & 30 & 1.9E-08 & 0.005 & 30 & 2.4E-08 & 0.006 \\
\hline 23 & 45 & 0.5 & 0 & 0 & $20 \mathrm{cc} / \mathrm{kg} \mathrm{H}_{2}$ & 50 & 30 & 2.1E-06 & 0.204 & 30 & $1.8 \mathrm{E}-06$ & 0.210 \\
\hline 24 & 86 & 0.5 & 0.01 & 0 & $20 \mathrm{cc} / \mathrm{kg} \mathrm{H}{ }_{2}$ & 50 & 30 & 2.9E-07 & 0.094 & 30 & 2.4E-07 & 0.075 \\
\hline 25 & 478 & 0.5 & 0.001 & 0 & $20 \mathrm{cc} / \mathrm{kg} \mathrm{H}_{2}$ & 50 & 30 & $3.5 \mathrm{E}-08$ & 0.050 & 30 & $1.9 \mathrm{E}-08$ & 0.049 \\
\hline 26 & 705 & --- & const $\mathrm{K}$ & --- & $20 \mathrm{cc} / \mathrm{kg} \mathrm{H}_{2}$ & 350 & 30 & 3.4E-09 & 0.034 & 30 & 3.4E-09 & 0.040 \\
\hline 27 & 92 & 0.5 & 0.001 & 2.5 & $20 \mathrm{cc} / \mathrm{kg} \mathrm{H}_{2}$ & 350 & 30 & 1.9E-08 & 0.038 & 30 & 2.4E-08 & 0.037 \\
\hline
\end{tabular}




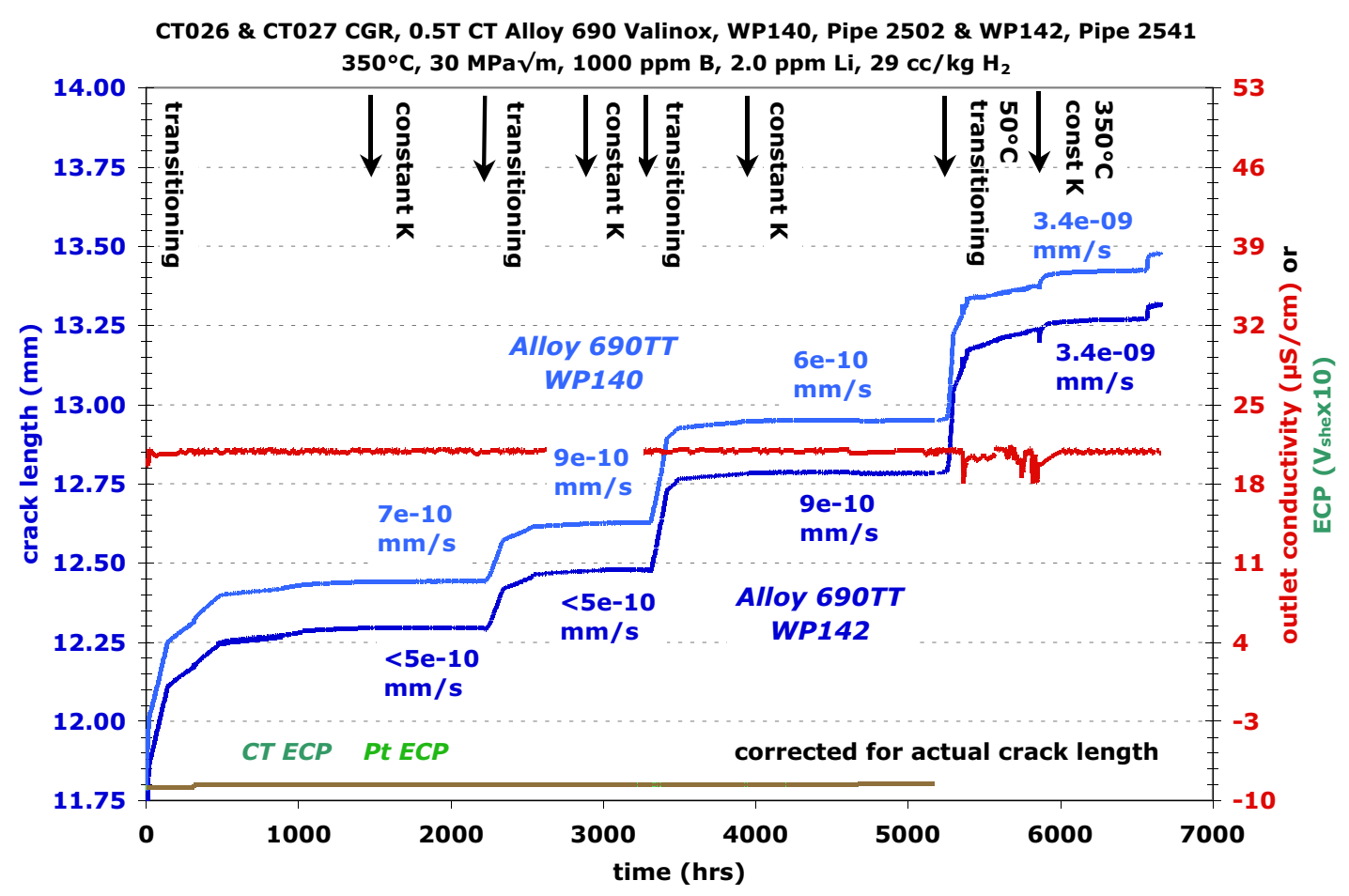

Figure 4.15 Overview of the crack-growth responses for the alloy 690TT CRDM heats WP140 and WP142 specimens (CT026 \& CT027) at $350^{\circ} \mathrm{C}$.

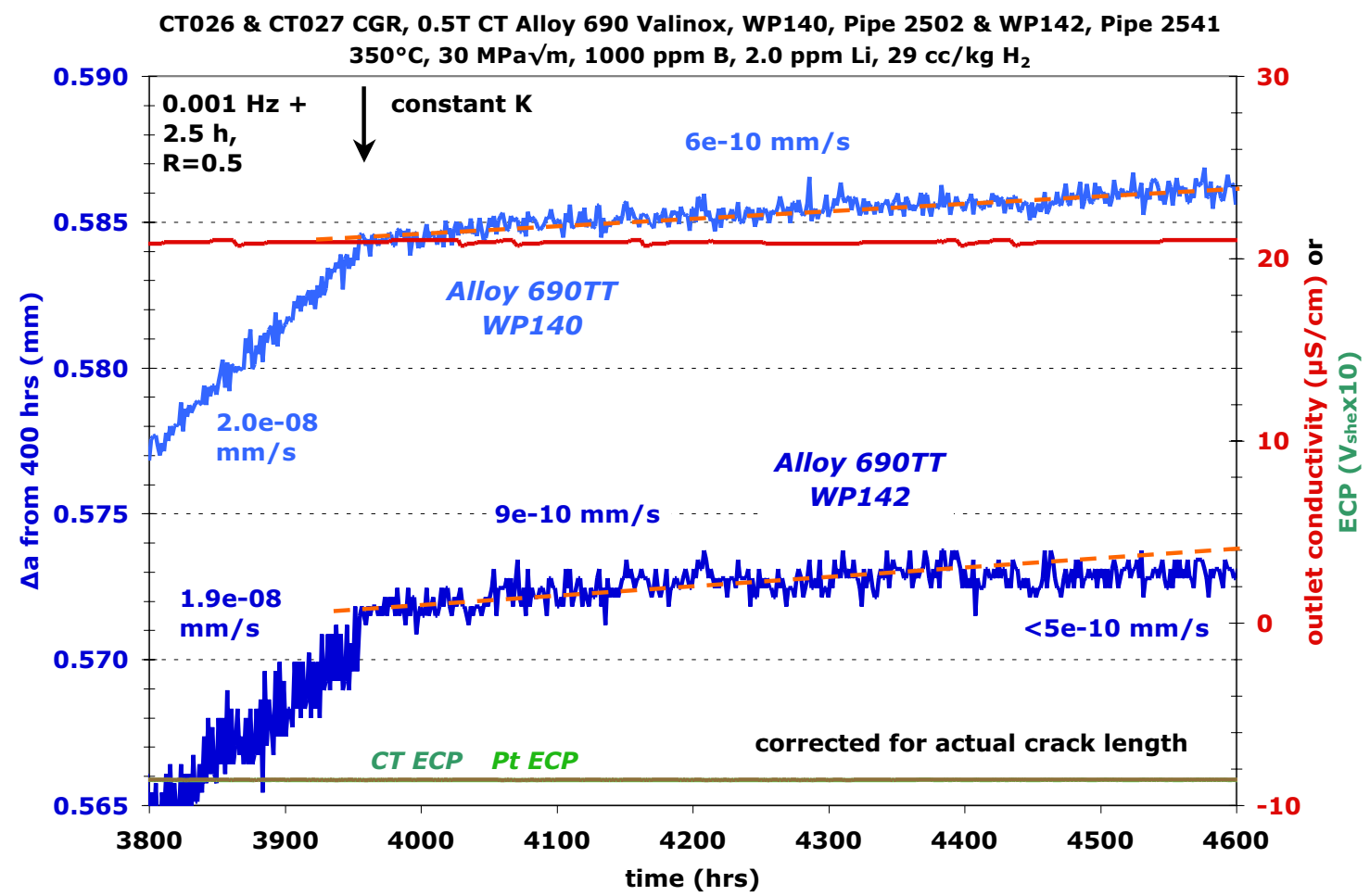

Figure 4.16 Initial constant K crack-growth responses for alloy 690TT heats WP140 and WP142 specimens (CT026 \& CT027) at $350^{\circ} \mathrm{C}$. 
Crack transitioning at $50^{\circ} \mathrm{C}$ was used in the last attempt to generate an IG crack front. Based on the IG cracking produced during $50^{\circ} \mathrm{C}$ cycling in the previous test on the TT material, it was decided to use this approach to generate a more IG crack front for subsequent SCC evaluation at $350^{\circ} \mathrm{C}$. Cycling was performed at $50^{\circ} \mathrm{C}$ over a period of $\sim 650 \mathrm{~h}$ using an $\mathrm{R}$ value of 0.5 with a progressive reduction in frequency to $0.001 \mathrm{~Hz}$ for the final step. Loading was then changed to constant $\mathrm{K}$ and the temperature increased back to $350^{\circ} \mathrm{C}$. The specimen was allowed to sit for $\sim 24 \mathrm{~h}$ at $350^{\circ} \mathrm{C}$ before resuming DCPD crack length measurements. Initial crack-growth rates exceeded $1 \times 10^{-8} \mathrm{~mm} / \mathrm{s}$ as shown in Figure 4.17 , but slowly decreased to $\sim 3 \times 10^{-9} \mathrm{~mm} / \mathrm{s}$ over the next $500 \mathrm{~h}$. A variety of reasons for the slowly dropping rate were considered, and among the possibilities was that ligaments or bridges were being left in the wake of the advancing crack. To explore this possibility, a periodic unload every $2.5 \mathrm{~h}$ was added at $6750 \mathrm{~h}$. An immediate $\sim 30 \mu \mathrm{m}$ increase in DCPD-measured crack length was observed at the onset of cycling followed by rates stabilizing at $\sim 2 \times 10^{-8} \mathrm{~mm} / \mathrm{s}$ during this cycle + hold loading (similar to that recorded earlier in the test). At this point it was decided to end the test, and examine the crack-growth surfaces for evidence of IGSCC.

After air fatigue fracturing the specimens, the specimens were heat tinted at $600^{\circ} \mathrm{C}$ and ultrasonically cleaned. The resulting tinted crack-growth surface of the WP140 specimen is shown in Figure 4.18. Five regions were identified through surface tint and transition lines on the surface, and then matched to DCPD measurements of crack length. Starting from the crack notch, the first region with the darkest blue tint is the air fatigue pre-cracking surface. The next three regions are crack growth during gentle cycling and constant $\mathrm{K}$ conditions at $350^{\circ} \mathrm{C}$. The final region with a mix of blue and gold tint represents $\sim 0.5 \mathrm{~mm}$ of growth at 50 and $350^{\circ} \mathrm{C}$.

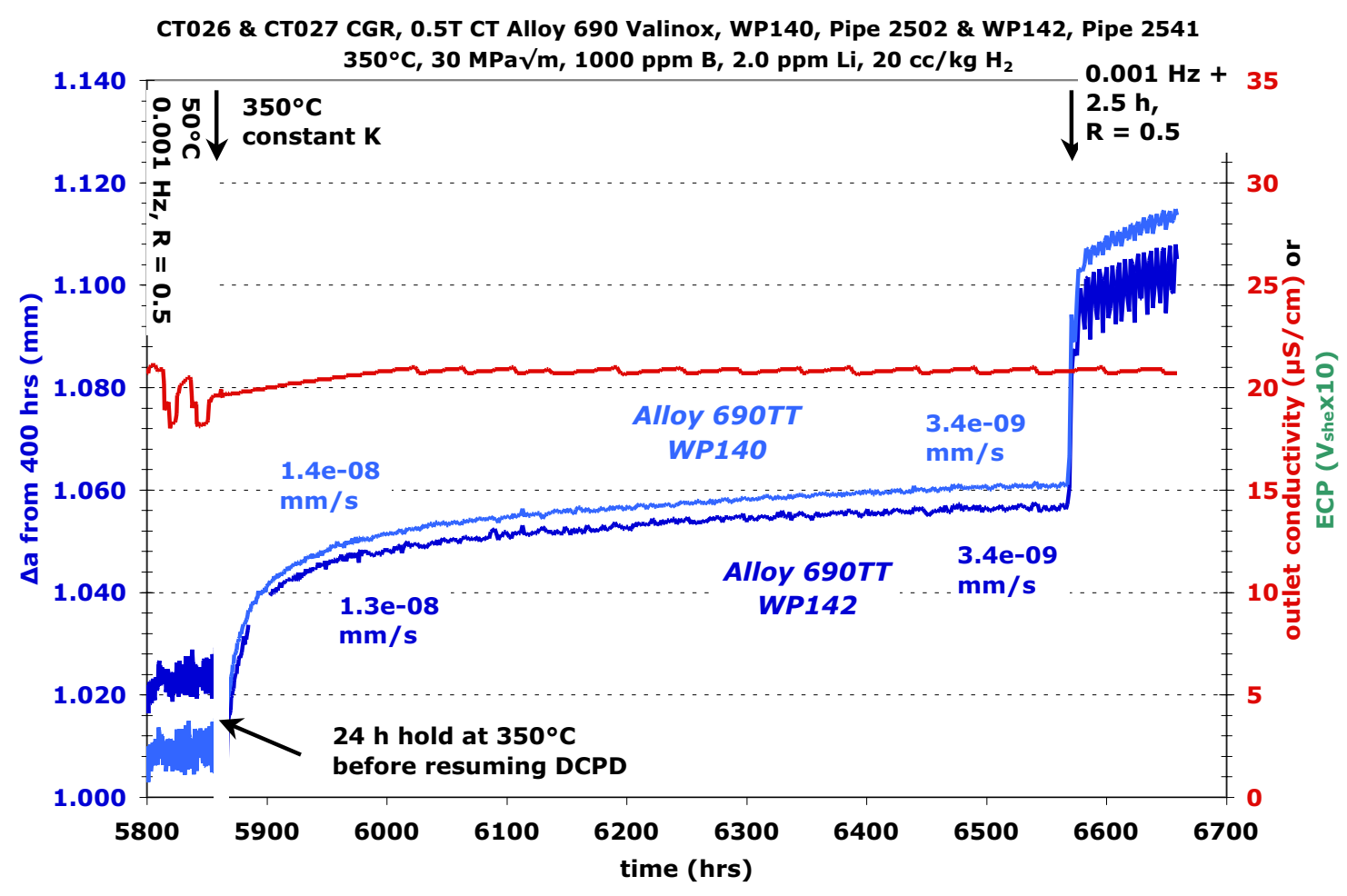

Figure 4.17 Crack-growth response of alloy 690TT heats WP140 and WP142 (CT026 \& CT027) after crack extension during cycling at $50^{\circ} \mathrm{C}$. 


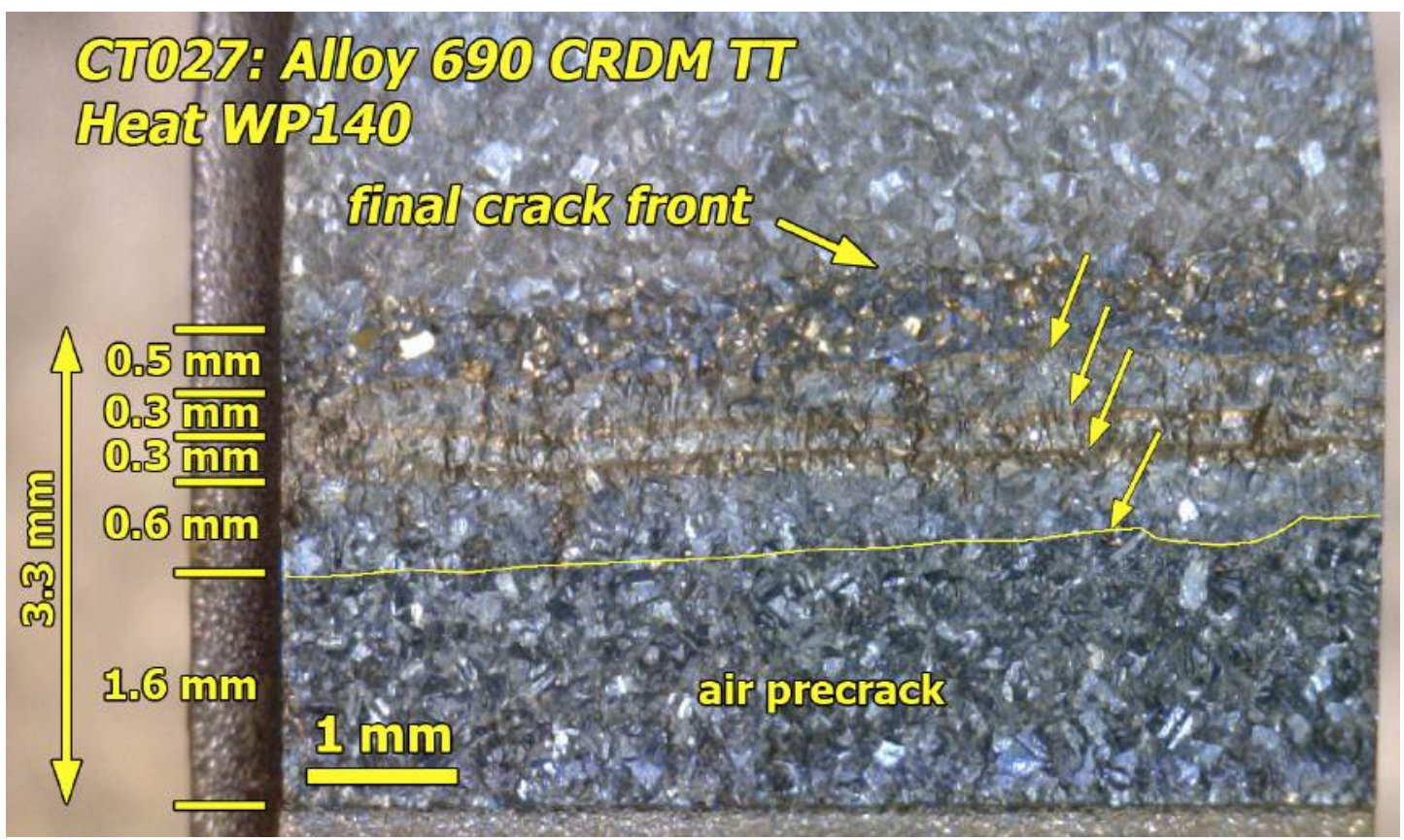

Figure 4.18 Optical image of the crack-growth surface of the alloy 690TT CRDM heat WP140 specimen. Color variation is heat tint due to baking the specimen at $600^{\circ} \mathrm{C}$ after fatigue fracture in air. The heat tint and transition lines enables the identification of five separate regions on the crack-growth surface, these are discussed in the text.

SEM of the crack growth surface (Figure 4.19) revealed nearly 100\% TG crack growth everywhere except for the final $50 / 350^{\circ} \mathrm{C}$ region where $\sim 50 \%$ of the surface is IG. At the time, it was not clear what portion of this region represents constant K IGSCC propagation at $350^{\circ} \mathrm{C}$. Neither optical nor SEM observations show the presence of a final band that might be expected based on the $\sim 90 \mu \mathrm{m}$ extension on the crack growth plot. The high initial crack growth rate at this last step at $350^{\circ} \mathrm{C}$ suggested that this initial response may have been due to oxide formation in cracks influencing the DCPD measurement [Ref. 6]. The hydrogen concentration of $20 \mathrm{cc} / \mathrm{kg}$ produces an electrochemical potential well into the region of Ni metal stability at $50^{\circ} \mathrm{C}$, while it is near the $\mathrm{Ni} / \mathrm{NiO}$ stability line at $350^{\circ} \mathrm{C}$. Subsequent SCC experiments on alloy 52 weld metals (described in Chapter 3 ) confirmed that the initial DCPD changes at $350^{\circ} \mathrm{C}$ were driven by oxidation in the cracks formed at $50^{\circ} \mathrm{C}$ and low propagation rates were quickly established after increasing the temperature to $350^{\circ} \mathrm{C}$. Therefore, it is believed that very little SCC crack growth occurred for the alloy $690 \mathrm{CRDM}$ materials during this final step at $350^{\circ} \mathrm{C}$ and actual propagation rates may have been similar to that measured earlier in the test. This result supports the excellent SCC resistance for the as-received alloy 690 CRDM materials in hightemperature PWR primary water. Even when a high degree of IG engagement is produced at low temperatures, grain boundaries do not appear to be a highly susceptible path for SCC under more prototypic PWR conditions. 


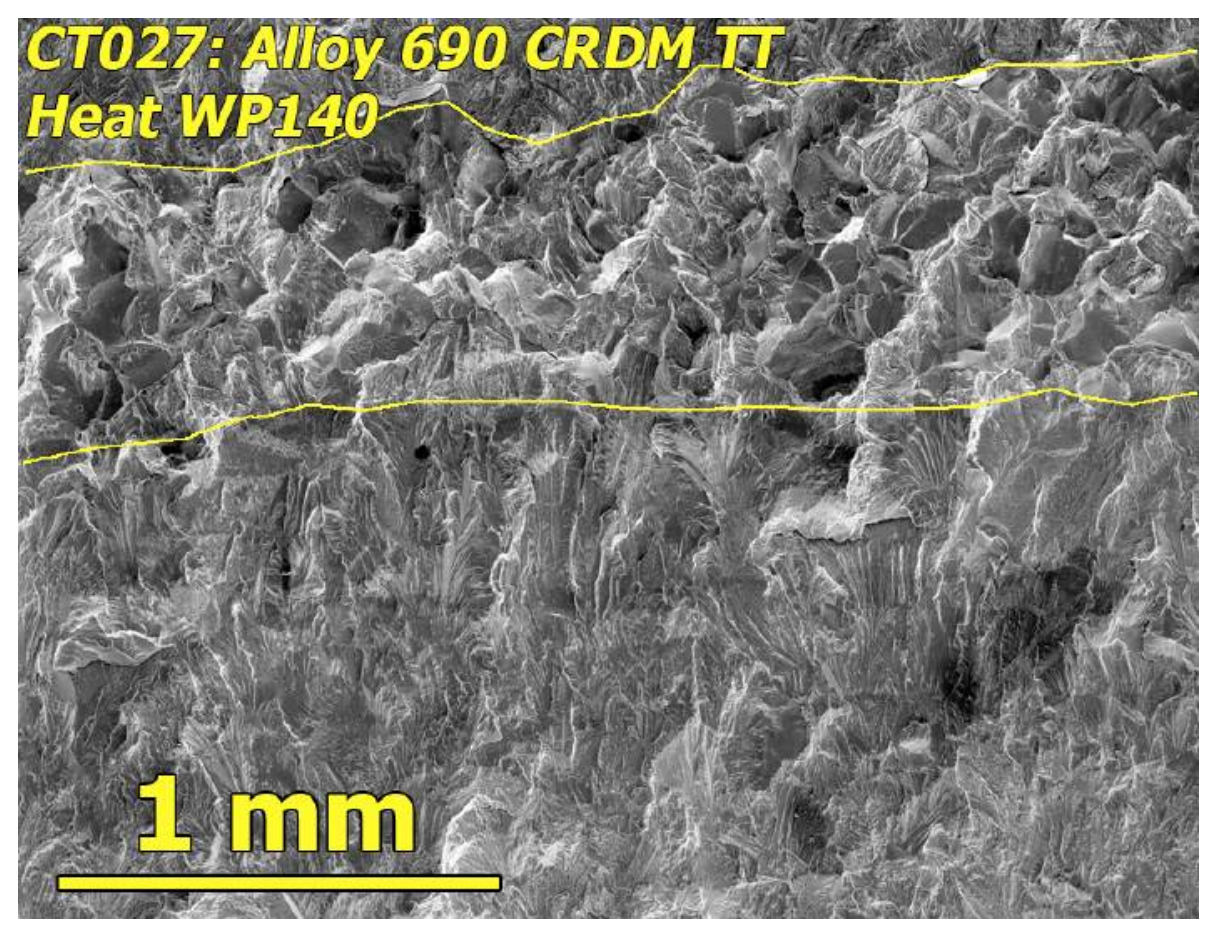

Figure 4.19 Portion of the crack-growth surface of the heat WP140 alloy 690TT specimen. Crack growth in the area between the lines took place during $50^{\circ} \mathrm{C}$ and the subsequent $350^{\circ} \mathrm{C}$ phases of the crack growth rate test.

\subsection{Cold-Rolled Alloy 690 CRDM Materials}

The as-received alloy 690TT and the solution-annealed alloy 690CM materials from heat RE243 were unidirectionally cold rolled $(\mathrm{CR})$ at room temperature. Three different reductions have been produced for the TT and CM starting materials: (1) $17 \%$ reduction in 2 passes SCC tested in the S-L orientation: (2) $30 \%$ reduction in 6 passes tested in the T-L orientation and (3) $31 \%$ reduction in 3 passes being tested in the S-L orientation. Because of the tubing wall thickness, the maximum reduction possible for an S-L oriented specimen using rolling equipment at PNNL was $17 \%$. As a result, the $30 \%$ CR material rolled at PNNL was SCC tested in the lesssusceptible T-L orientation. Subsequent interactions with General Electric Global Research (GEG) made it possible to achieve higher reduction levels and a $31 \% \mathrm{CR}$ material was produced for testing in the S-L orientation. A diagram illustrating the CT specimen test orientations with respect to the rolling direction is presented in Figure 4.20.

Hardness measurements were taken across the alloy 690 CT samples after different levels of cold rolling. Data was obtained from both the back face and a side face from the CTs as shown in Figure 4.21. A lower hardness was indicated near the midplane for the $17 \% \mathrm{CR}$ samples, but uniform hardness was seen across the 30 and $31 \%$ CR samples. The alloy 690TT material showed average midplane hardness values of $175,250,300$ and $298 \mathrm{~kg} / \mathrm{mm}^{2}$ for $0 \%, 17 \%$, $30 \%$ and $31 \% \mathrm{Cr}$, respectively. For these same \%CR conditions, the alloy $690 \mathrm{CM}$ exhibited similar hardness values of $165,235,290$ and $290 \mathrm{~kg} / \mathrm{mm}^{2}$. Consistent with the higher directional damage, grains were noticeably elongated along the rolling plane in the 30 and $31 \% \mathrm{CR}$ materials but no obvious change was identified for the $17 \%$ CR materials. 


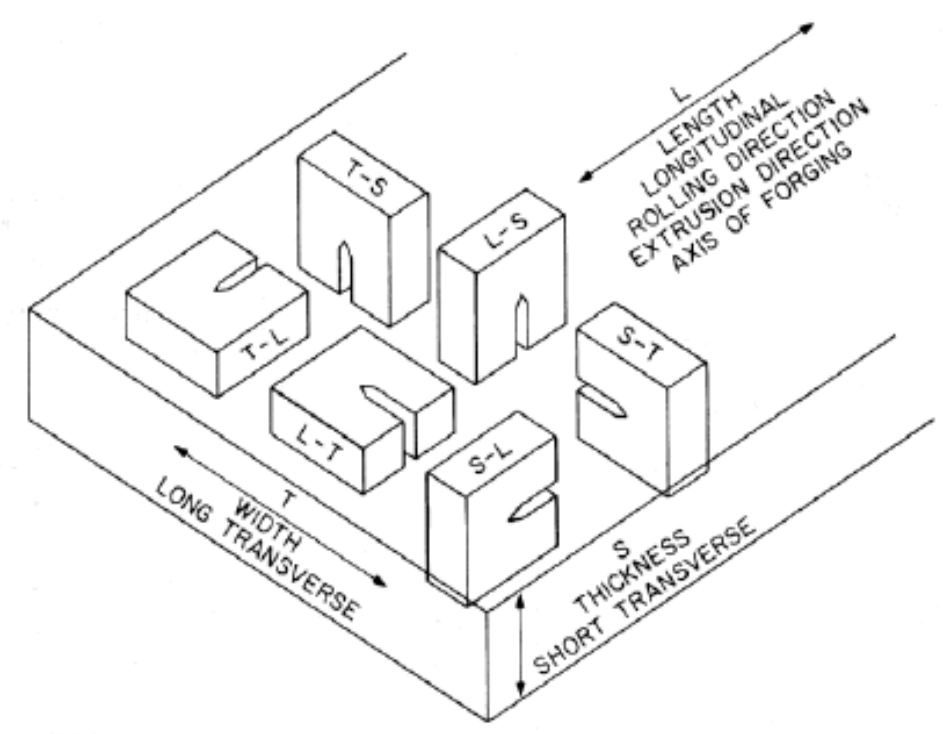

Figure 4.20 Diagram illustrating the CT sample orientation relation to the rolling direction.

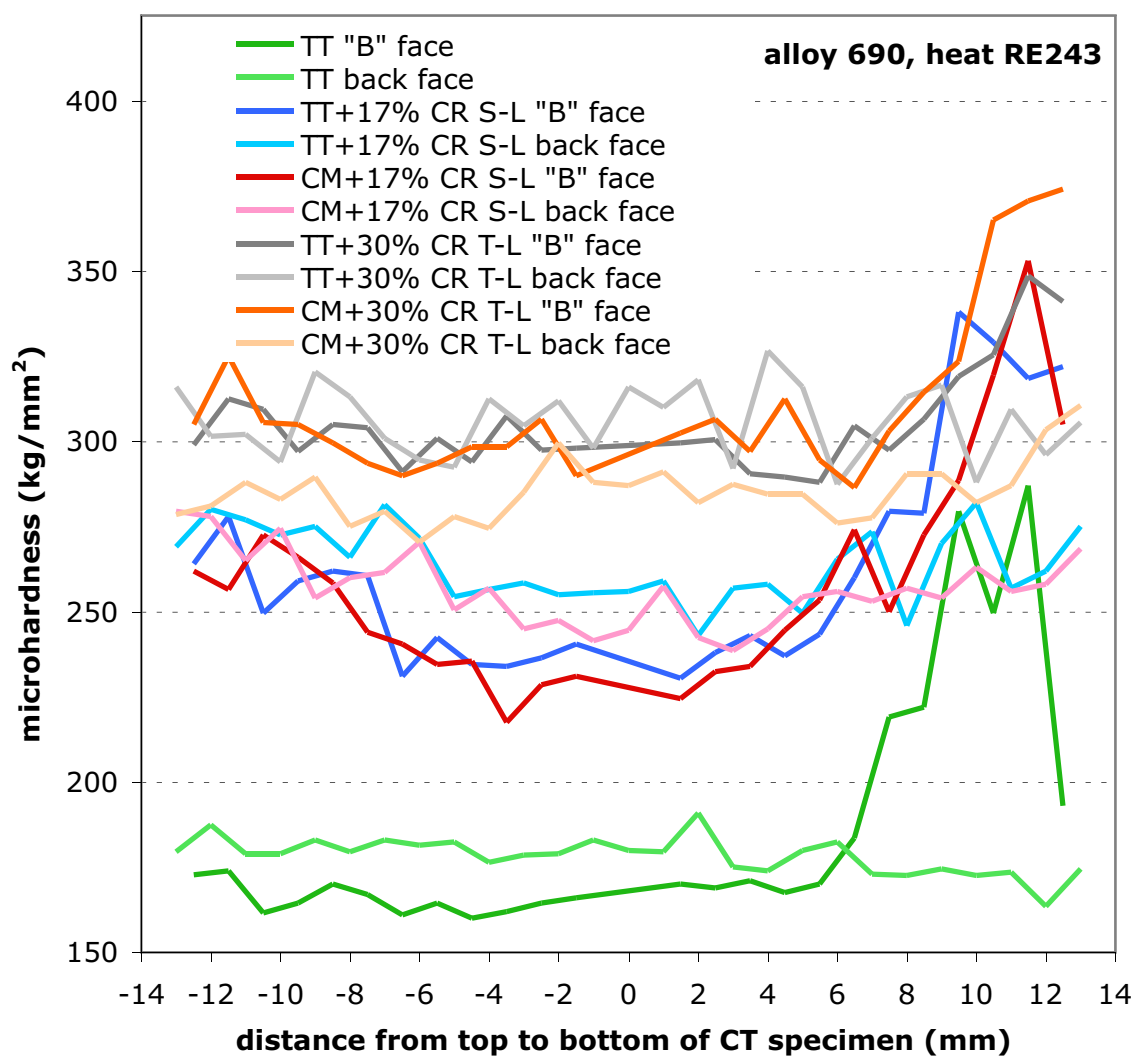

Figure 4.21 Hardness measurements on heat RE243 alloy 690 CT specimens as a function of unidirectional cold rolling. Measurements are made on two difference faces from the CT specimens for both the alloy 690TT and $690 \mathrm{CM}$ materials. 
As employed for the microstructural characterizations on the starting CRDM materials, SEM (secondary and backscatter electron), TEM and EDS elemental composition maps were utilized to examine the various types of CR-induced damage. SEM was used to obtain a global perspective of the damage throughout the sample, whereas TEM and EDS mapping provided a more detailed, localized examination. It should be noted that in SEM the identification of a void versus a crack was often challenging in the TT samples due to their high IG carbide distribution. A void between two overlapping carbides may easily appear as a crack. In addition, TiN particles have a very low backscatter yield as compared to the remainder of the alloy and their contrast can be difficult to separate from that for a void. SEM secondary and backscatter image pairs were collected in many cases to help discriminate between TiN particles and voids.

The $17 \%$ CR CRDM alloy 690 TT and CM materials showed significant strain contrast in SEM images and limited TEM exams documented the expected high dislocation densities. There is evidence that deformation is localized at grain boundaries particularly for the TT materials with a semi-continuous distribution of small carbides. Isolated voids and cracked carbides were observed in the $17 \% \mathrm{CR}$ alloy $690 \mathrm{TT}$ material as illustrated in Figures 4.22 and 4.23. SEM exams indicated that the most common permanent damage in this material was small, wellspaced voids. Only a few cracked carbides were found, however a TEM sample prepared via focused ion beam (FIB) milling (Figure 4.23) revealed two cracks as well as a void along a carbided grain boundary in less than a 2- $\mu \mathrm{m}$ region. It can be difficult to discriminate between the formation of a crack or void in the scanning TEM image, but examination of the Cr-K elemental map shows that the cracks disrupt two continuous carbides. A secondary point of note in the $\mathrm{Cr}$ elemental map is the overlap of two carbides in this section. Because TEM samples have a finite thickness, overlap of carbides on the grain boundaries is expected. Unfortunately, this brings into question as to whether observations on overlapping, faceted carbides signify a crack or a void. Often in SEM and TEM images, there are high contrast objects between carbides that appear angled, and thus complicating the identification. The easiest determination of void formation is seen by its shape and relationship to adjacent carbides in both Figure 4.22 and 4.23. While there were observations of permanent damage in $17 \%$ CR alloy 690 TT material, no voids or cracked TiN particles were detected in the $17 \% \mathrm{CR}$ alloy 690CM material. 


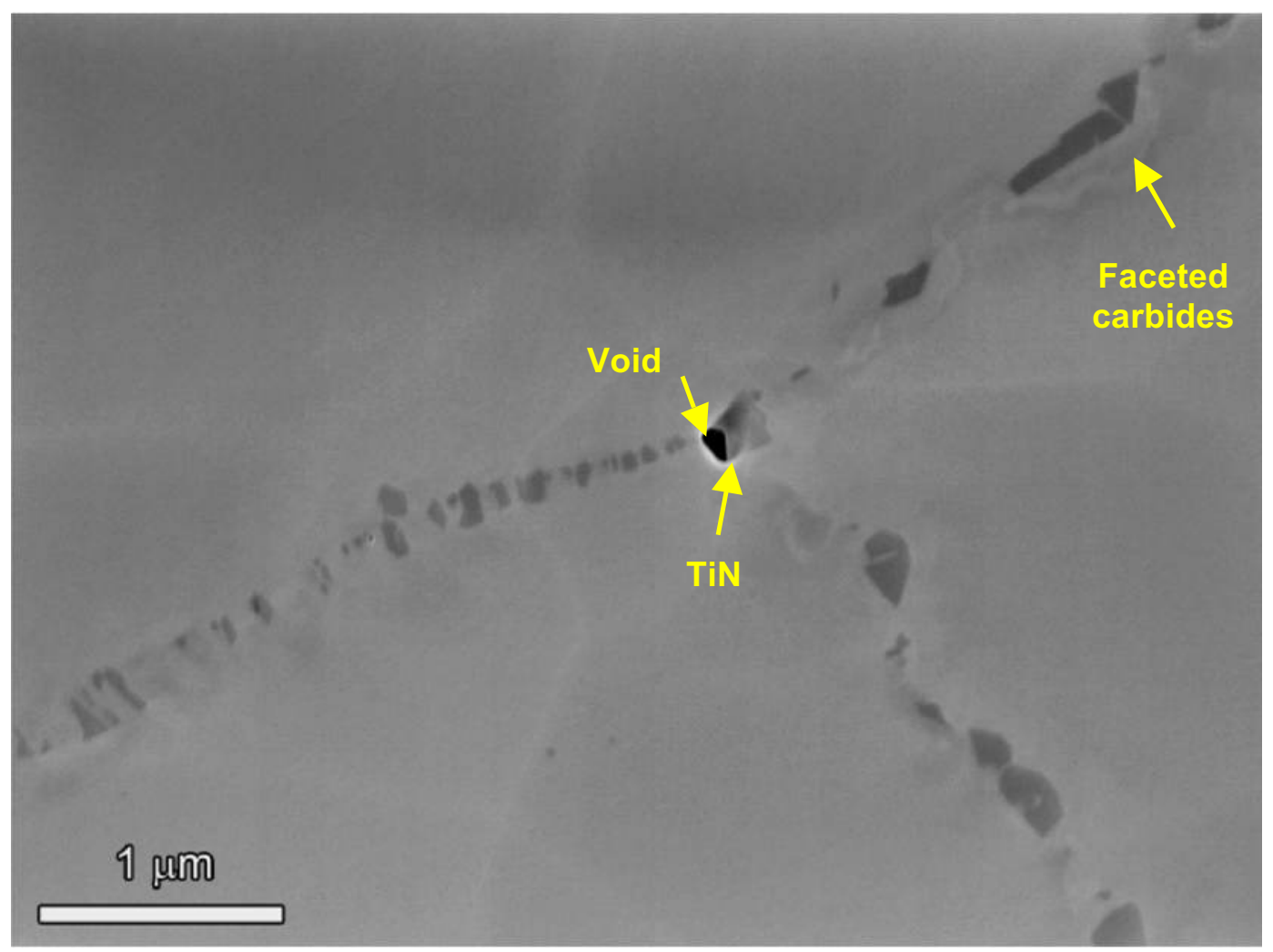

Figure 4.22 SEM backscatter micrograph illustrating representative image of $\mathrm{M}_{23} \mathrm{C}_{6}$ damage microstructure in $17 \% \mathrm{CR}$ CRDM alloy 690TT material (heat RE243).

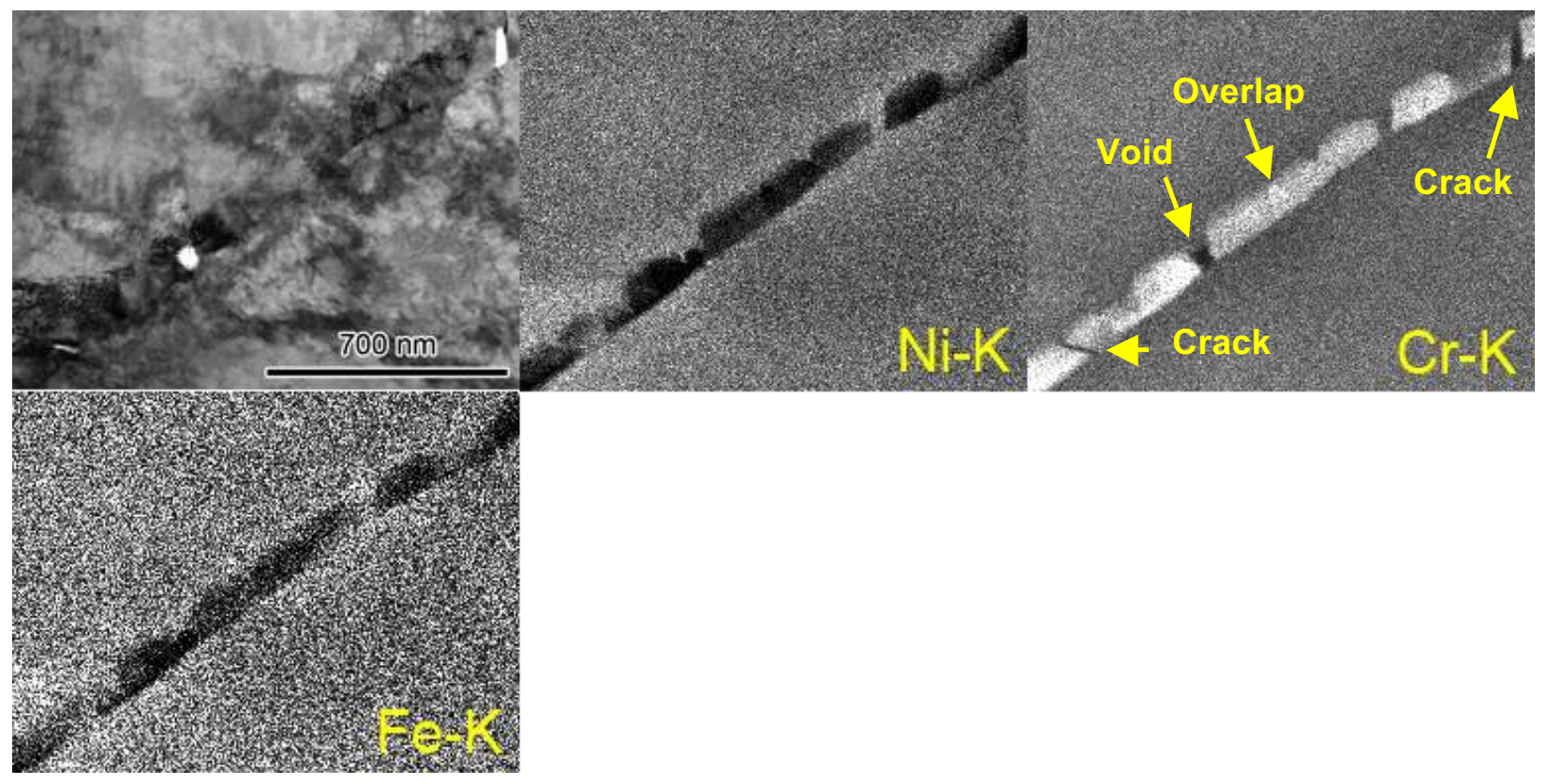

Figure 4.23 TEM image and elemental maps showing damage in 17\%CR CRDM alloy 690TT. 
The 30\%CR CRDM alloy 690TT again showed an extremely high dislocation density and much larger amount of localized permanent damage at grain boundaries as compared to the $17 \% \mathrm{CR}$ alloy 690TT material. SEM analyses identified a large number of voids in both cellular carbide (Figure 4.24) and discrete carbide (Figures 4.25 and 4.26) regions. Cellular carbide regions typically exhibited an array of various sized voids adjacent to $\mathrm{M}_{23} \mathrm{C}_{6}$ interfaces within the boundary migrated area. A much lower density of cracked carbides than voids were present in these structures. More importantly, there also appeared to be more voids than cracked carbides along boundaries with discrete $\mathrm{M}_{23} \mathrm{C}_{6}$ particles. As previously discussed, differentiating between the sporadic TiN particles, cracked carbides, and voids can be difficult. Examples of highly damaged grain boundary regions are presented in Figure 4.25 and a high density of local "dark" features can be seen resulting from low backscatter electron yield. After careful examination (often comparing BSE and SE images), it was determined that most of the small $(<75 \mathrm{~nm})$ equiaxed and the elongated features (formed at the interfaces of faceted carbides) were voids. These elongated cavities appear to abruptly change in shape as the void grows between faceted carbides as seen in Figures 4.24, 4.25(b) and 4.25(c).

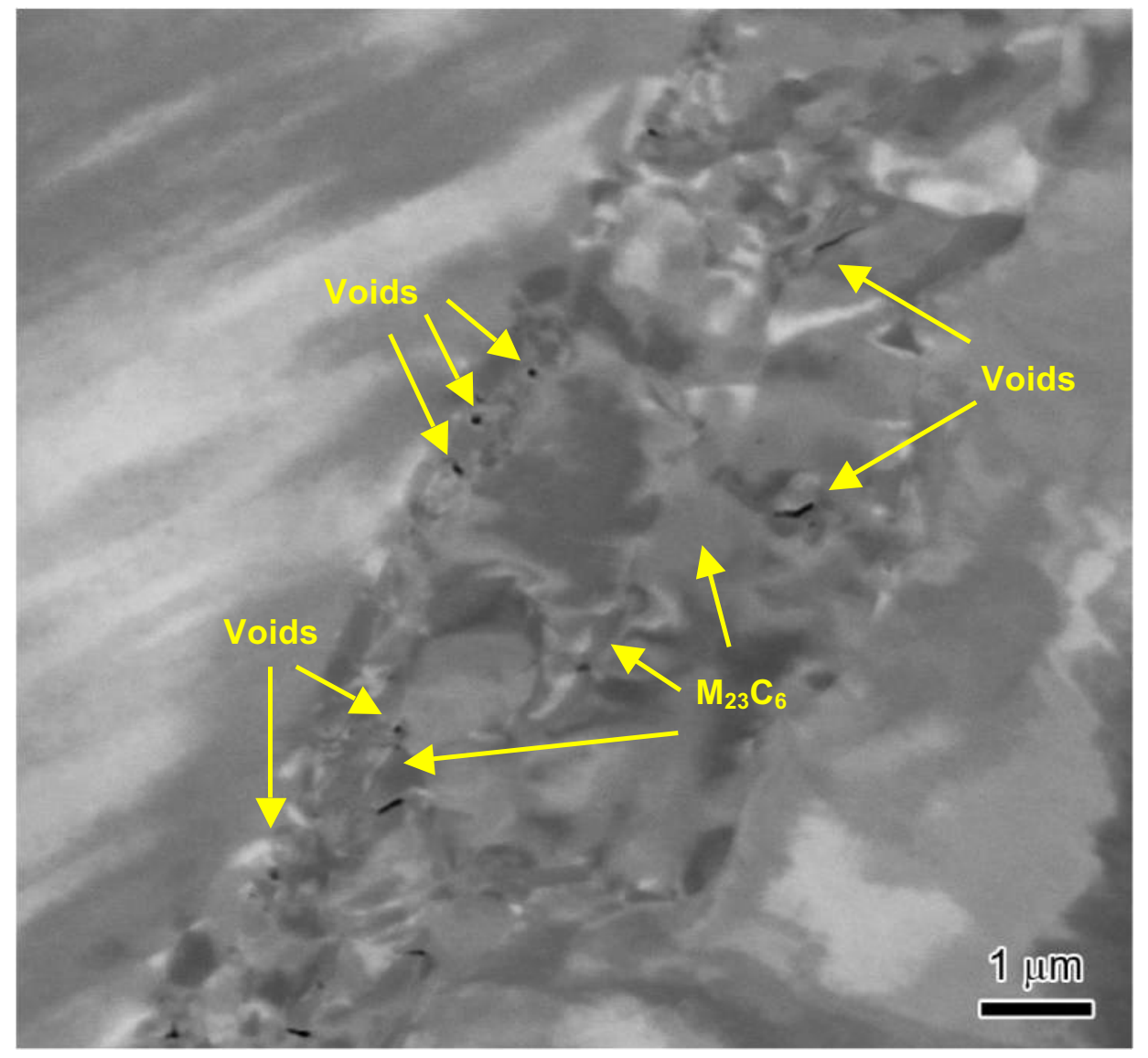

Figure 4.24 Low magnification SEM backscatter image showing CR-induced void formation within a cellular carbide microstructure region in the $30 \% \mathrm{CR}$ CRDM alloy 690TT material (heat RE243). The strain contrast in this backscatter image masks the appearance of the $\mathrm{M}_{23} \mathrm{C}_{6}$ carbides, but the voids between carbides are readily apparent. 


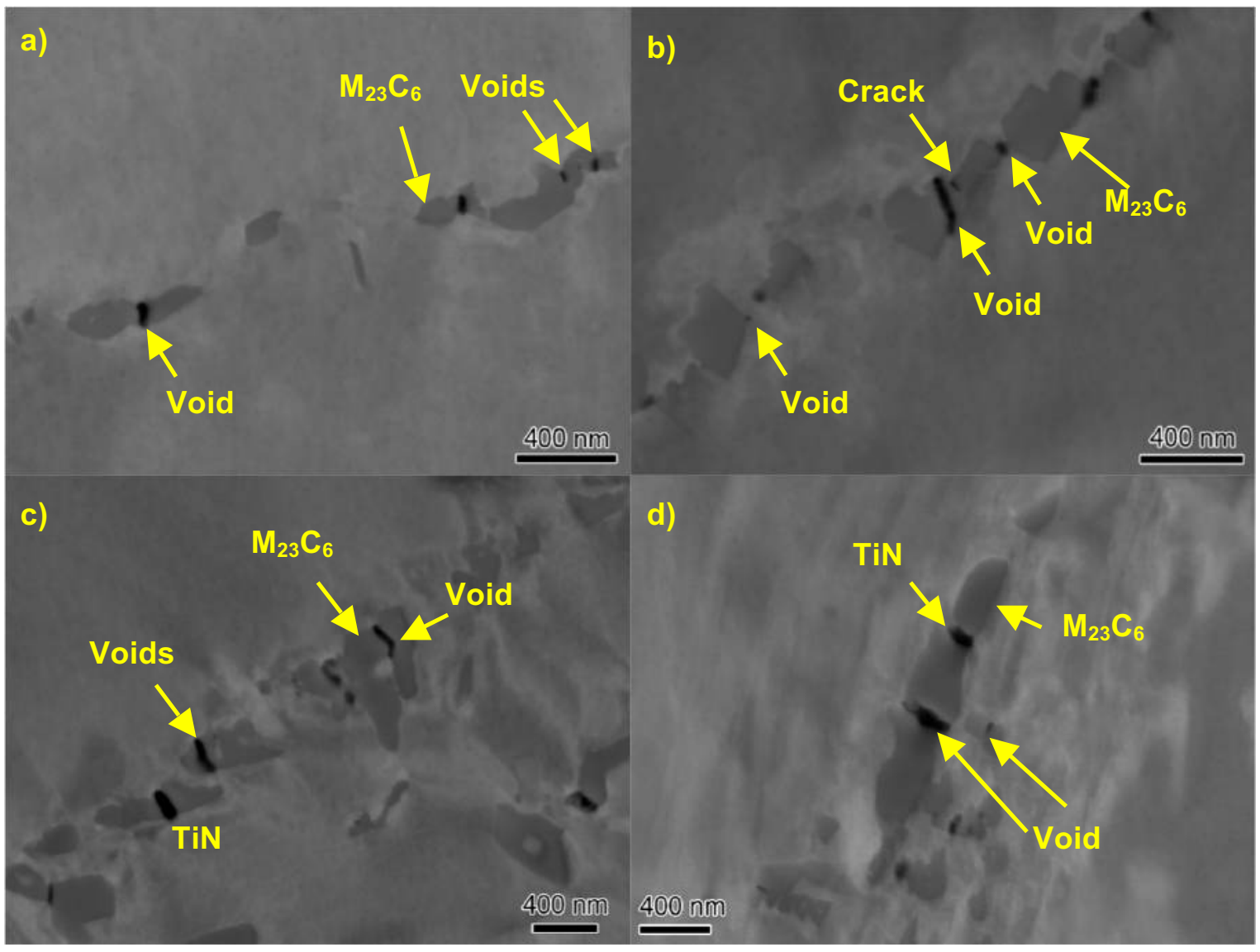

Figure 4.25 High magnification SEM backscatter micrographs illustrating IG carbide damage microstructures in 30\%CR CRDM alloy 690TT (heat RE243).

The higher density of small voids at grain boundaries in the 30\%CR alloy 690TT material makes it even more important to identify them versus the TiN particles. In most cases, this required both backscatter and secondary electron imaging. Figure 4.26 shows three SEM secondary/backscatter pairs (a-b, c-d, e-f), which assist in determining the differences at higher magnifications. Utilizing the high-resolution capabilities of the JEOL 7600 field emission SEM, collection of data on the length scales in TEM images (e.g., Figure 4.23) has been possible. SEM pair images are taken because of the different information gathered from each. Secondary electron (SE) contrast in Figures 4.26(a), (c) and (d) very easily distinguishes between voids, cracks and TiN particles. The increased surface area around a void or crack provides a higher secondary yield, whereas the TiN particles do not have this contrast. Figure 4.26(a) highlights this perfectly, as a void and a TiN particle appear close together in the middle of the micrograph. At a certain point though, SE contrast is not as useful for imaging cracks versus voids as backscatter contrast illustrated in Figures 4.26(a) and (b). In the upper right hand corner, the $\mathrm{M}_{23} \mathrm{C}_{6}$ carbide appears to be continuous but in the SE image the slight crack is tight enough that the additional surface area does not provide extra contrast. The complimentary backscatter contrast in Figure 4.26(b) identifies that this is indeed a crack. Similar comparisons can be seen in the remaining image pairs in Figures 4.26(c), (d) and (e). 


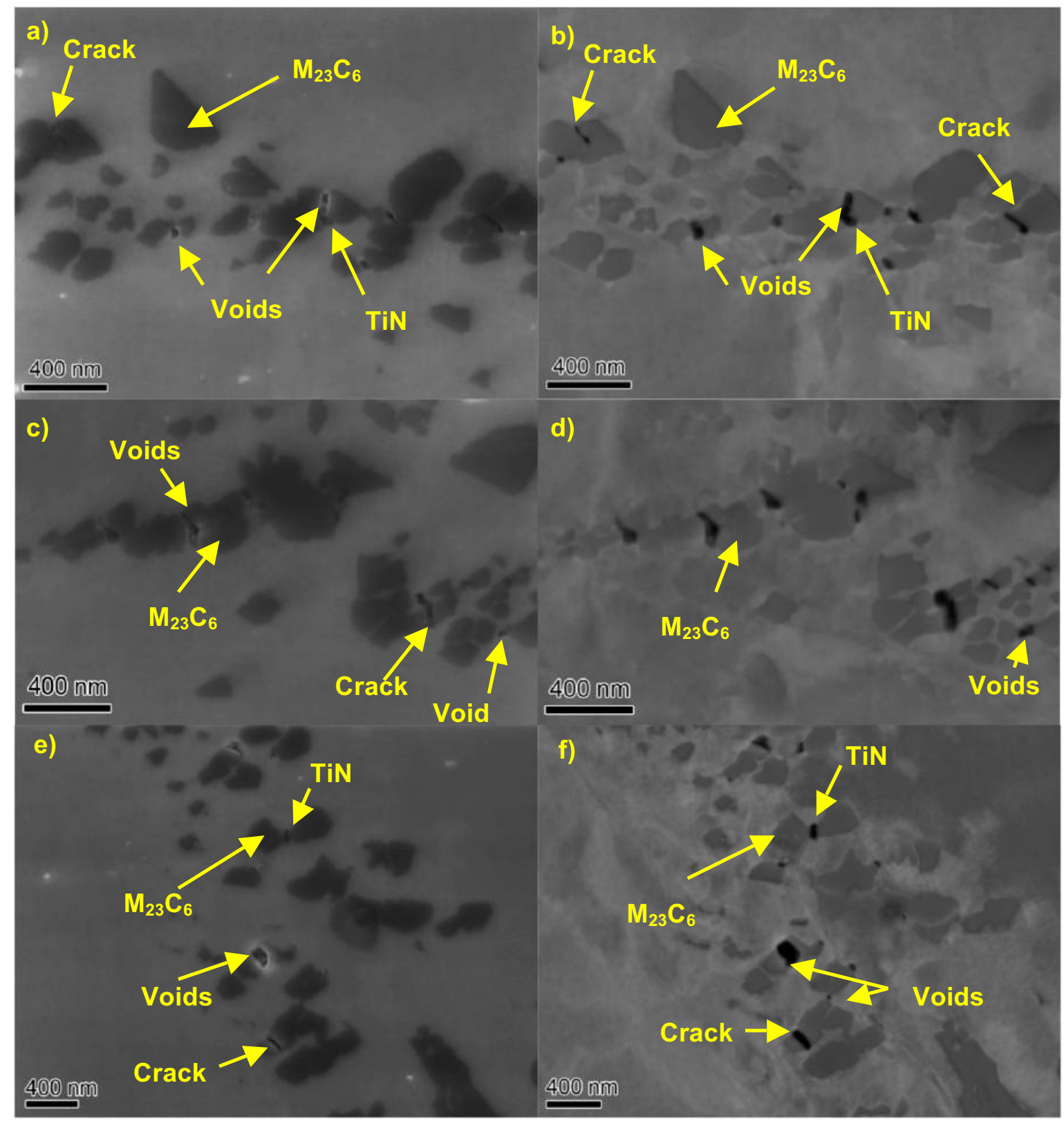

Figure 4.26 High magnification SEM backscatter/SE pair micrographs showing carbide damage microstructures in 30\%CR CRDM alloy 690TT (heat RE243).

General conclusions can be made about the CR-induced damage microstructure from SEM and limited TEM examinations on 30\%CR alloy 690TT material. Most grain boundaries in the TT material have a semi-continuous distribution of discrete carbides and these boundaries will have the controlling influence on IGSCC behavior. A significant difference in the permanent damage distributions is seen between the cellular and discrete carbide regions although both show a moderate density of small voids and a limited number of cracked carbides. The primary CRinduced damage is the presence of small voids at IG carbide interfaces with a typical void spacing along the boundary of $\sim 1-2 \mu \mathrm{m}$. Along with this permanent damage, cold rolling also produces high dislocation densities and localized strains at the boundaries (see Section 5.2). 
The $30 \%$ CR alloy $690 \mathrm{CM}$ material exhibited quite different permanent damage characteristics apparently due the lack of $\mathrm{M}_{23} \mathrm{C}_{6}$ carbides at grain boundaries (as described in an earlier section). This material did not exhibit cracked carbides, since the only IG precipitates were wellspaced TiN particles. Some of these Ti-rich particles were cracked in the 30\%CR material both along grain boundaries and in the matrix as illustrated in Figure 4.27. Voids were not found in the cross-sections examined except for an isolated example at a grain boundary triple point. Therefore, the degree damage was significantly less for the CM versus the TT materials after cold rolling. Limited TEM examinations have documented extremely high dislocation densities in the $30 \% \mathrm{CR}$ alloy $690 \mathrm{CM}$ material similar to that observed in the $30 \% \mathrm{CR}$ alloy $690 \mathrm{TT}$ material and evidence for localized deformation associated with the TiN particles.

A brief summary of characterization results for the heat RE243, alloy 690TT and CM materials as a function of the degree of cold rolling is presented in Table 4.5. Grain boundary precipitate distributions and associated matrix compositions do not change with cold rolling for the two different starting conditions, but the amount of damage microstructure increases.
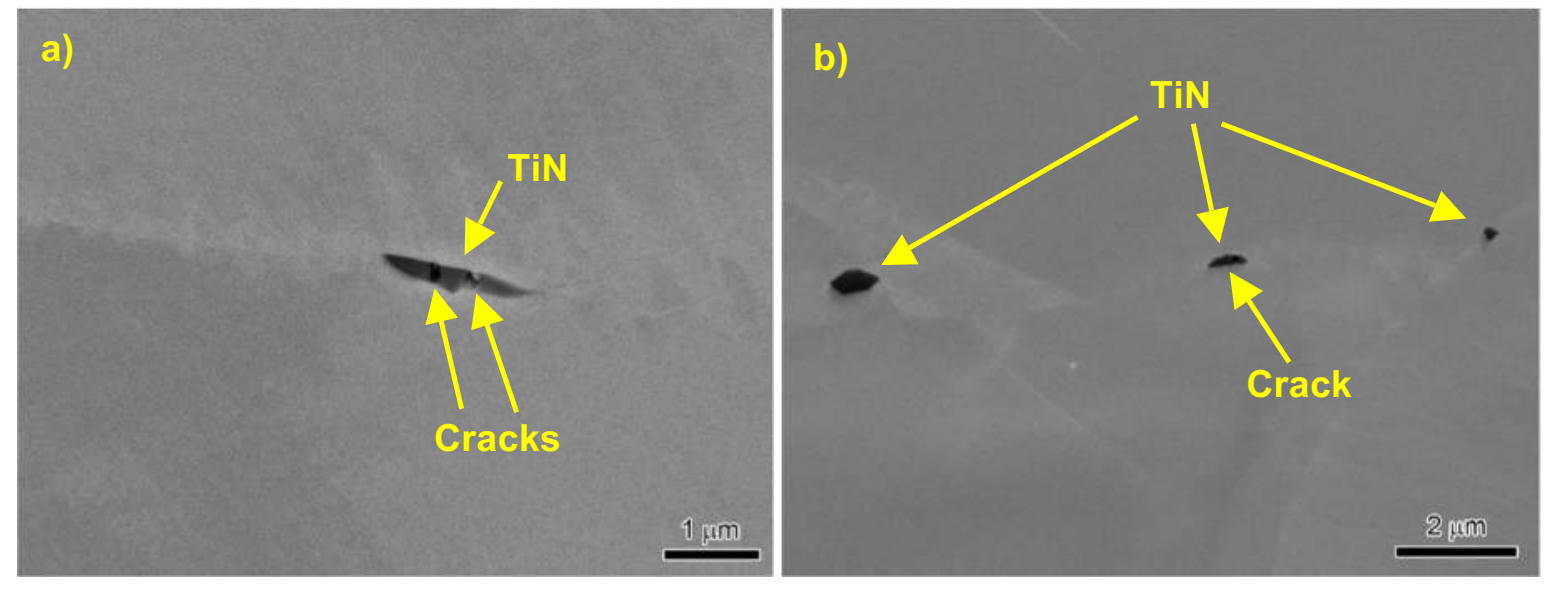

Figure 4.27 SEM backscatter micrographs illustrating general TiN damage microstructure in 30\%CR CRDM alloy 690CM (heat RE243). 
Table 4.5 Microstructure, CR damage and hardness for heat RE243 alloy 690 materials.

\begin{tabular}{|c|c|c|c|}
\hline Sample & Microstructure & CR Damage & Hardness \\
\hline $\begin{array}{c}0-\text { TT) PNNL } \\
\text { CRDM alloy } \\
\text { 690TT; Test } \\
\text { sample CT014 }\end{array}$ & $\begin{array}{c}\text { Semi-continuous (small discrete } \\
\text { + cellular) carbides on GBs, } \\
\text { occasional TiN at GBs and in } \\
\text { matrix; equiaxed grains }\end{array}$ & $\begin{array}{l}\text { No voids and cracked } \\
\text { carbides on GBs, nor } \\
\text { cracked TiN in matrix }\end{array}$ & $175 \mathrm{~kg} / \mathrm{mm}^{2}$ \\
\hline $\begin{array}{c}0-\text { CM) PNNL } \\
\text { CRDM alloy } \\
690 \mathrm{CM} \text {; Test } \\
\text { sample CT015 } \\
\end{array}$ & $\begin{array}{l}\text { Few carbides and well-spaced } \\
\text { TiN on GBs, occasional TiN in } \\
\text { matrix; equiaxed grains }\end{array}$ & $\begin{array}{l}\text { No voids and cracked } \\
\text { particles on GBs, nor } \\
\text { cracked TiN in matrix }\end{array}$ & $165 \mathrm{~kg} / \mathrm{mm}^{2}$ \\
\hline $\begin{array}{c}(1-\mathrm{TT}) \mathrm{PNNL} \\
\text { CRDM alloy } 690 \mathrm{TT} \\
17 \% \text { CR; Test } \\
\text { sample CT019 }\end{array}$ & As for CT014 (0-TT) above & $\begin{array}{c}\text { Low density of voids } \\
\text { and cracked carbides } \\
\text { on GBs, few cracked } \\
\text { TiN in matrix }\end{array}$ & $250 \mathrm{~kg} / \mathrm{mm}^{2}$ \\
\hline $\begin{array}{c}\text { (1 - CM) PNNL } \\
\text { CRDM alloy } \\
\text { 690CM 17\%CR; } \\
\text { Test sample } \\
\text { CT020 }\end{array}$ & As for CT015 (0-CM) above & $\begin{array}{l}\text { No voids and cracked } \\
\text { particles on GBs, nor } \\
\text { cracked TiN in matrix }\end{array}$ & $235 \mathrm{~kg} / \mathrm{mm}^{2}$ \\
\hline $\begin{array}{c}\text { (2 - TT) PNNL } \\
\text { CRDM alloy 690TT } \\
\text { 30\%CR; Test } \\
\text { sample CT022 } \\
\end{array}$ & $\begin{array}{c}\text { As for CT014 }(0-\text { TT) above }+ \\
\text { slightly elongated grains }\end{array}$ & $\begin{array}{l}\text { Moderate density of } \\
\text { voids and some } \\
\text { cracked carbides on } \\
\text { GBs \& TiN in matrix }\end{array}$ & $300 \mathrm{~kg} / \mathrm{mm}^{2}$ \\
\hline $\begin{array}{l}\text { (2 - CM) PNNL } \\
\text { CRDM alloy } \\
\text { 690CM 30\%CR; } \\
\text { Test sample } \\
\text { CT023 }\end{array}$ & $\begin{array}{l}\text { As for CT015 }(0-\mathrm{CM}) \text { above }+ \\
\text { slightly elongated grains }\end{array}$ & $\begin{array}{l}\text { Low density of cracked } \\
\text { TiN on GBs and in } \\
\text { matrix, isolated void at } \\
\text { triple pt. }\end{array}$ & $290 \mathrm{~kg} / \mathrm{mm}^{2}$ \\
\hline
\end{tabular}

\section{Crack-Growth Results for 17\%CR Alloy 690 CRDM Materials}

An overview of results for the $17 \% \mathrm{CR}$ alloy $690 \mathrm{TT}$ and CM materials tested in the S-L orientation is presented in Table 4.6 and Figure 4.28. Four measurements of constant $\mathrm{K}$ crack growth rate in $325^{\circ} \mathrm{C}$ PWR primary water were made, and propagation rates were consistently at or below $1 \times 10^{-9} \mathrm{~mm} / \mathrm{s}$. A higher resolution crack growth plot showing this steady, but extremely slow propagation at constant $\mathrm{K}$ is shown in Figure 4.29. Several attempts were made to promote higher growth rates using different transitioning steps modifying cycling and hold time conditions, but all resulted in similar growth rates under PWR primary water conditions. In an attempt to promote SCC and improve IG engagement, $\mathrm{H}_{2}$ injection was stopped and replaced with $2400 \mathrm{ppb} \mathrm{O}_{2}$ plus $45 \mathrm{ppb}$ sulfate. While the oxidizing environment did increase propagation rates by $\sim 3 X$, they remained very low under constant $K$ loading $\left(<2 \times 10^{-9} \mathrm{~mm} / \mathrm{s}\right)$. PWR primary water conditions were re-established for the final part of the test and $\mathrm{K}$ was slowly increased to $40 \mathrm{MPa} \sqrt{\mathrm{m}}$ via a dK/da technique. DCPD-measured crack length showed that the higher $\mathrm{K}$ promoted slightly increased growth rates during cycle + hold loading, but did not appear to promote SCC at constant K. In comparing the overall response of the two material conditions, the CM specimen exhibited slightly higher growth rates during cycling than the TT specimen but both $17 \% \mathrm{CR}$ specimens showed similar low growth rates at constant $\mathrm{K}$. 
Table 4.6 Uncorrected data summary for alloy 690 CRDM specimens CT019 \& CT020.

\begin{tabular}{|c|c|c|c|c|c|c|c|c|c|c|c|c|}
\hline \multirow[b]{2}{*}{$\begin{array}{l}\text { Test } \\
\text { Phase }\end{array}$} & \multirow[b]{2}{*}{$\begin{array}{l}\text { Dur- } \\
\text { ation } \\
\text { (h) }\end{array}$} & \multirow[b]{2}{*}{$\mathrm{R}$} & \multirow[b]{2}{*}{ Freq $(\mathrm{Hz})$} & \multirow[b]{2}{*}{$\begin{array}{c}\text { Hold } \\
(\mathrm{h})\end{array}$} & \multirow[b]{2}{*}{$\begin{array}{c}\text { Water } \\
\text { Chemistry } \\
\text { Conditions }\end{array}$} & \multirow[b]{2}{*}{$\begin{array}{l}\text { Temp } \\
\left({ }^{\circ} \mathrm{C}\right)\end{array}$} & \multicolumn{3}{|c|}{$\begin{array}{c}\text { CT019 } \\
\text { Alloy } 690 \mathrm{CM}+17 \% \text { CR S-L }\end{array}$} & \multicolumn{3}{|c|}{$\begin{array}{c}\text { CT020 } \\
\text { Alloy } 690 \mathrm{TT}+17 \% \text { CR S-L }\end{array}$} \\
\hline & & & & & & & $\begin{array}{c}\mathrm{Kmax} \\
(\mathrm{MPa} \sqrt{\mathrm{m}})\end{array}$ & $\begin{array}{c}\mathrm{CGR} \\
(\mathrm{mm} / \mathrm{sec})\end{array}$ & $\begin{array}{l}\text { Crack } \\
\text { Extension } \\
(\mathrm{mm})\end{array}$ & $\begin{array}{c}\mathrm{Kmax} \\
(\mathrm{MPa} \sqrt{\mathrm{m}})\end{array}$ & $\begin{array}{c}\text { CGR } \\
(\mathrm{mm} / \mathrm{sec})\end{array}$ & $\begin{array}{c}\text { Crack } \\
\text { Extension } \\
(\mathrm{mm})\end{array}$ \\
\hline 1 & 3.5 & 0.3 & 3 & 0 & air & RT & 25 & & 0.50 & 25 & & 0.50 \\
\hline 2 & 1.5 & 0.5 & 3 & 0 & air & RT & 28 & & 0.30 & 28 & & 0.30 \\
\hline 3 & 2.0 & 0.6 & 3 & 0 & air & RT & 30 & & 0.30 & 30 & & 0.30 \\
\hline 4 & 12.0 & 0.7 & 3 & 0 & air & RT & 30 & & 0.30 & 30 & & 0.30 \\
\hline 5 & 134 & 0.7 & 0.1 & 0 & $29 \mathrm{cc} / \mathrm{kg} \mathrm{H}_{2}$ & 325 & 30 & 6.3E-07 & 0.288 & 30 & $5.8 \mathrm{E}-07$ & 0.238 \\
\hline 6 & 341 & 0.7 & 0.01 & 0 & $29 \mathrm{cc} / \mathrm{kg} \mathrm{H}_{2}$ & 325 & 30 & 1.7E-07 & 0.199 & 30 & 9.9E-08 & 0.117 \\
\hline 7 & 711 & 0.7 & 0.001 & 0 & $29 \mathrm{cc} / \mathrm{kg} \mathrm{H}_{2}$ & 325 & 30 & $1.9 \mathrm{E}-08$ & 0.059 & 30 & $1.5 \mathrm{E}-08$ & 0.042 \\
\hline 8 & 224 & 0.7 & 0.001 & 2.5 & $29 \mathrm{cc} / \mathrm{kg} \mathrm{H}$ & 325 & 30 & 3.1E-09 & 0.002 & 30 & 2.6E-09 & 0.002 \\
\hline 9 & 107 & 0.6 & 0.001 & 2.5 & $29 \mathrm{cc} / \mathrm{kg} \mathrm{H}_{2}$ & 325 & 30 & 8.6E-09 & 0.003 & 30 & 4.9E-09 & 0.002 \\
\hline 10 & 91 & 0.6 & 0.001 & 0 & $29 \mathrm{cc} / \mathrm{kg} \mathrm{H}{ }_{2}$ & 325 & 30 & 4.5E-08 & 0.014 & 30 & $3.5 \mathrm{E}-08$ & 0.013 \\
\hline 11 & 166 & 0.5 & 0.001 & 2.5 & $29 \mathrm{cc} / \mathrm{kg} \mathrm{H}_{2}$ & 325 & 30 & $9.8 \mathrm{E}-08$ & 0.064 & 30 & 8.7E-08 & 0.046 \\
\hline 12 & 275 & 0.7 & 0.001 & 2.5 & $29 \mathrm{cc} / \mathrm{kg} \mathrm{H}{ }_{2}$ & 325 & 30 & 5.1E-09 & 0.004 & 30 & $3.4 \mathrm{E}-09$ & 0.003 \\
\hline 13 & 380 & 1 & const $\mathrm{K}$ & --- & $29 \mathrm{cc} / \mathrm{kg} \mathrm{H}_{2}$ & 325 & 30 & $<5 \mathrm{E}-10$ & 0.0003 & 30 & $<5 \mathrm{E}-10$ & 0.0006 \\
\hline 14 & 90 & 0.5 & 0.1 & 0 & $29 \mathrm{cc} / \mathrm{kg} \mathrm{H}_{2}$ & 325 & 30 & 2.3E-06 & 0.185 & 30 & 2.0E-06 & 0.165 \\
\hline 15 & 70 & 0.5 & 0.01 & 0 & $29 \mathrm{cc} / \mathrm{kg} \mathrm{H}_{2}$ & 325 & 30 & 5.6E-07 & 0.135 & 0 & 4.0E-07 & 0.101 \\
\hline 16 & 78 & 0.5 & $300 \mathrm{~s} / 12 \mathrm{~s}$ & 0 & $29 \mathrm{cc} / \mathrm{kg} \mathrm{H}$ & 325 & 30 & $3.2 \mathrm{E}-07$ & 0.088 & 30 & $2.2 \mathrm{E}-07$ & 0.061 \\
\hline 17 & 306 & 0.5 & $600 \mathrm{~s} / 12 \mathrm{~s}$ & 0 & $29 \mathrm{cc} / \mathrm{kg} \mathrm{H}_{2}$ & 325 & 30 & 2.1E-07 & 0.188 & 30 & $1.4 \mathrm{E}-07$ & 0.131 \\
\hline 18 & 187 & 0.5 & $1000 \mathrm{~s} / 12 \mathrm{~s}$ & 2.5 & $29 \mathrm{cc} / \mathrm{kg} \mathrm{H}_{2}$ & 325 & 30 & $1.3 \mathrm{E}-07$ & 0.084 & 30 & 9.3E-08 & 0.060 \\
\hline 19 & 263 & 0.7 & $1000 \mathrm{~s} / 12 \mathrm{~s}$ & 2.5 & $29 \mathrm{cc} / \mathrm{kg} \mathrm{H}_{2}$ & 325 & 30 & 5.7E-09 & 0.006 & 30 & 3.0E-09 & 0.004 \\
\hline 20 & 241 & 0.7 & 0.001 & 2.5 & $29 \mathrm{cc} / \mathrm{kg} \mathrm{H}_{2}$ & 325 & 30 & 5.3E-09 & 0.004 & 30 & 3.3E-09 & 0.003 \\
\hline 21 & 338 & 0.7 & 0.001 & 2.5 & $2.4 \mathrm{ppm} \mathrm{O} \mathrm{O}_{2}$ & 325 & 30 & 2.5E-09 & 0.003 & 30 & 4.0E-09 & 0.019 \\
\hline 22 & 212 & 0.7 & 0.001 & 2.5 & $\begin{array}{l}2.4 \mathrm{ppm} \mathrm{O}_{2} \\
+\mathrm{H}_{2} \mathrm{SO}_{4}\end{array}$ & 325 & 30 & 4.8E-09 & 0.003 & 30 & 5.1E-09 & 0.004 \\
\hline 23 & 667 & 1 & const $\mathrm{K}$ & --- & $\begin{array}{l}2.4 \mathrm{ppm} \mathrm{O}_{2} \\
+\mathrm{H}_{2} \mathrm{SO}_{4}\end{array}$ & 325 & 30 & $5.6 \mathrm{E}-10$ & 0.0013 & 30 & 8.7E-10 & 0.002 \\
\hline 24 & 135 & 1 & const $\mathrm{K}$ & --- & $29 \mathrm{cc} / \mathrm{kg} \mathrm{H}_{2}$ & 325 & 30 & $<5 \mathrm{E}-10$ & $\sim 0$ & 30 & $<5 \mathrm{E}-10$ & $\sim 0$ \\
\hline 25 & 156 & 0.6 & 0.01 & 0 & $29 \mathrm{cc} / \mathrm{kg} \mathrm{H}_{2}$ & 325 & $30->40$ & - & 0.246 & $30->40$ & - & 0.144 \\
\hline 26 & 45 & 0.5 & 0.01 & 0 & $29 \mathrm{cc} / \mathrm{kg} \mathrm{H}_{2}$ & 325 & $30->40$ & 1.1E-06 & 0.161 & $30->40$ & $8.1 \mathrm{E}-07$ & 0.126 \\
\hline 27 & 147 & 0.7 & 0.001 & 2.5 & $29 \mathrm{cc} / \mathrm{kg} \mathrm{H}_{2}$ & 325 & 40 & 5.1E-08 & 0.028 & 40 & $3.2 \mathrm{E}-08$ & 0.018 \\
\hline 28 & 102 & 0.7 & 0.001 & 2.5 & $29 \mathrm{cc} / \mathrm{kg} \mathrm{H}_{2}$ & 325 & 40 & 5.6E-09 & 0.004 & 40 & 8.3E-09 & 0.002 \\
\hline 29 & 112 & 1 & const $\mathrm{K}$ & --- & $29 \mathrm{cc} / \mathrm{kg} \mathrm{H}_{2}$ & 325 & 40 & $<5 \mathrm{E}-10$ & $\sim 0$ & 40 & $<5 \mathrm{E}-10$ & $\sim 0$ \\
\hline
\end{tabular}


CT019 \& CT020 CGR, 0.5T CT Alloy 690 Valinox, Heat RE243, Pipe 2360, 17\% CW S-L $325^{\circ} \mathrm{C}, 30 \mathrm{MPa} \sqrt{\mathrm{m}}, 1000 \mathrm{ppm} \mathrm{B}, 2.0 \mathrm{ppm} \mathrm{Li}, 29 \mathrm{cc} / \mathrm{kg} \mathrm{H}_{2}$

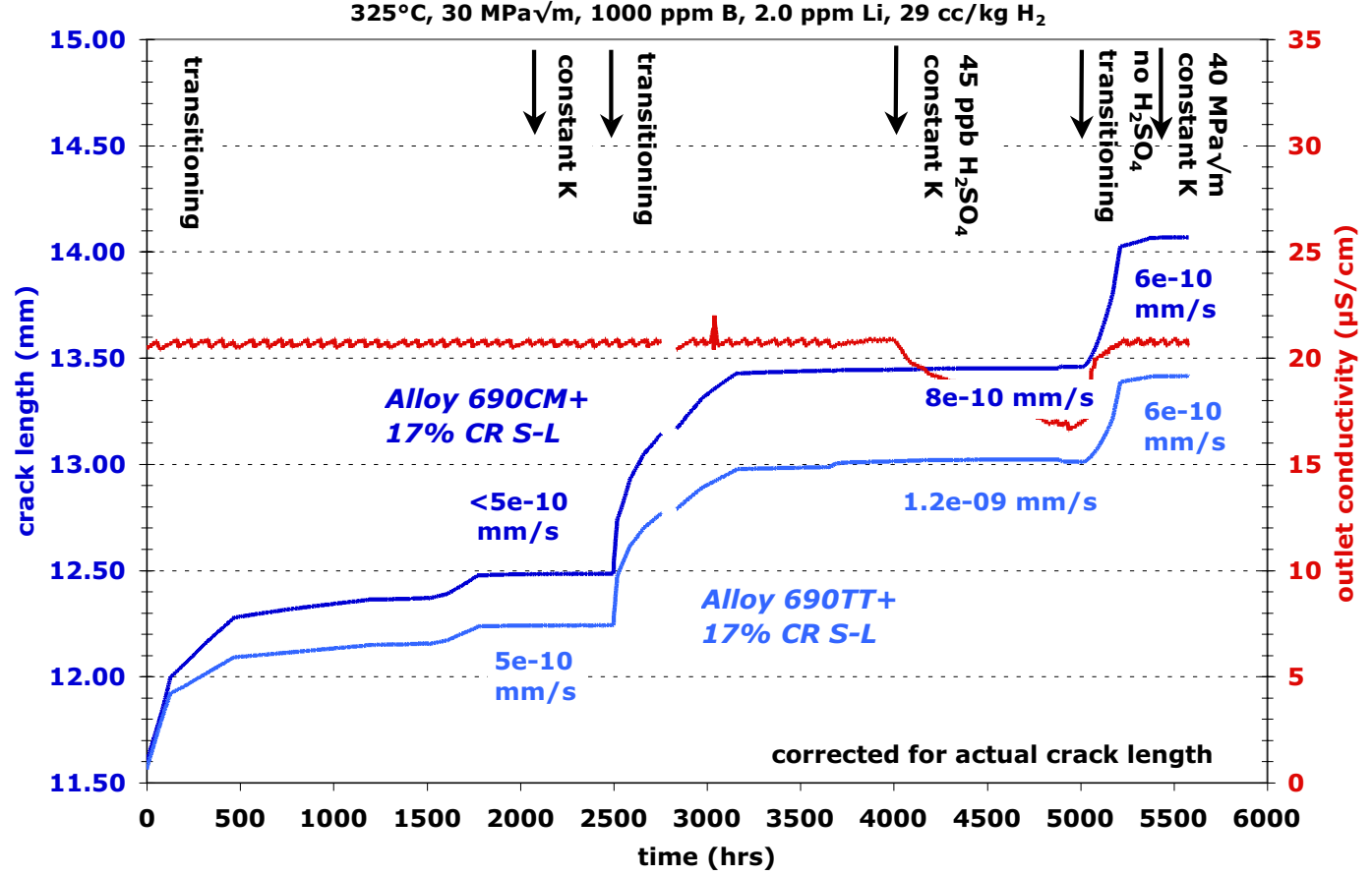

Figure 4.28 Overview of crack-growth responses of the $17 \% \mathrm{CR}$ alloy $690 \mathrm{~S}-\mathrm{L}$ specimens (heat RE243) tested at $325^{\circ} \mathrm{C}$.

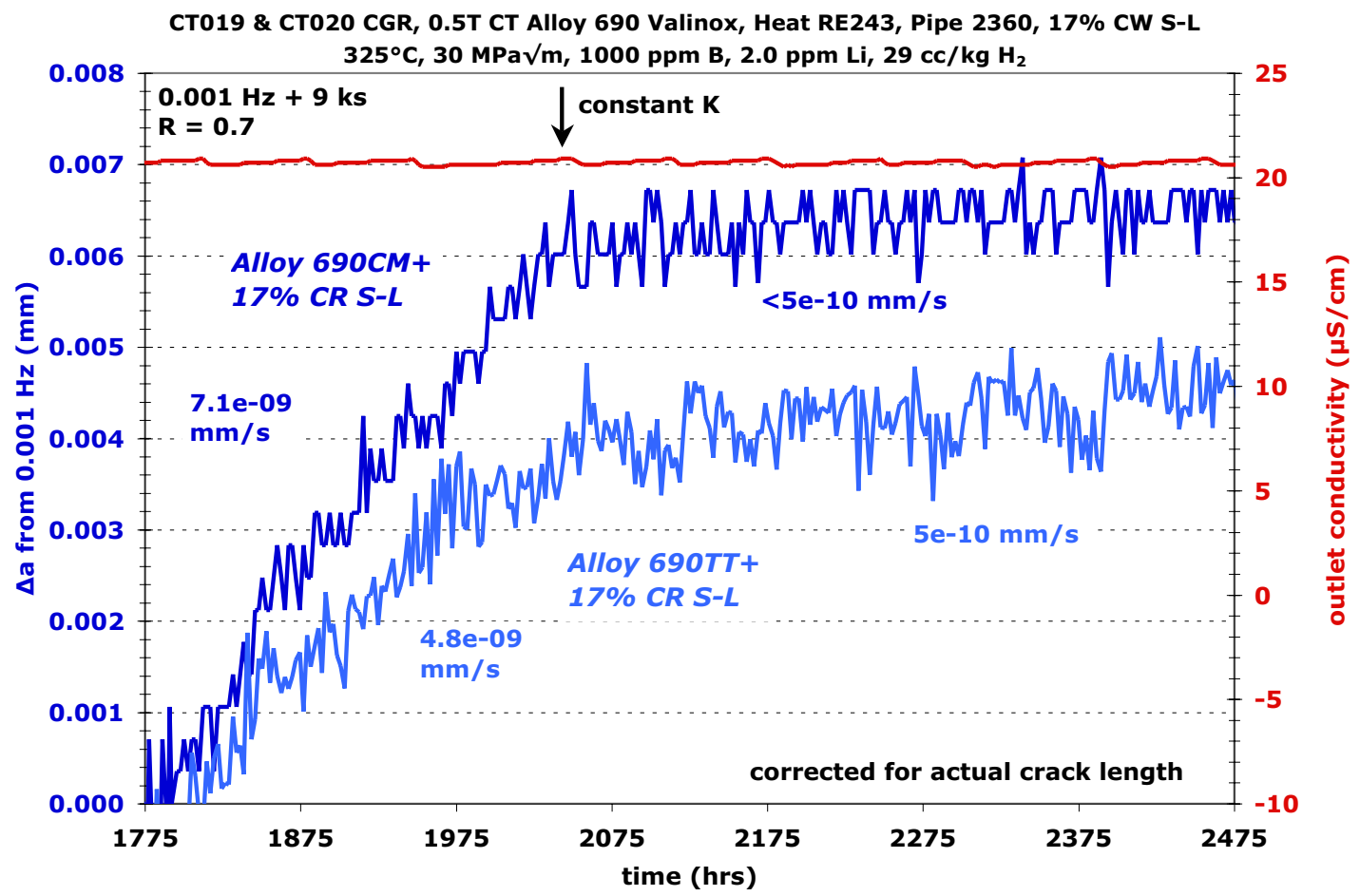

Figure 4.29 Crack growth responses of the 17\%CR alloy 690 S-L specimens (heat RE243) during first instance of constant $K$ showing no significant SCC propagation. 
Post-test optical images of the crack-growth surfaces are shown in Figure 4.30. The greater amount of crack extension measured by DCPD in the CM specimen is confirmed by these images showing the CM specimen to have cracked $\sim 0.5 \mathrm{~mm}$ further than the TT specimen. For both specimens, three distinct regions of crack growth after the precracking phase are apparent with the regions corresponding to the three different phases of the test. The more reflective surface of the CM specimen suggests the possibility of IG cracking, and this was confirmed by SEM observations as shown in Figure 4.31(a). These regions have $\sim 15 \%$ IG features and correspond to phases of the test where cycle + hold or constant $\mathrm{K}$ loading was performed. The TT specimen exhibited primary TG cracking with isolated IG facets as shown in Figure 4.31(b).

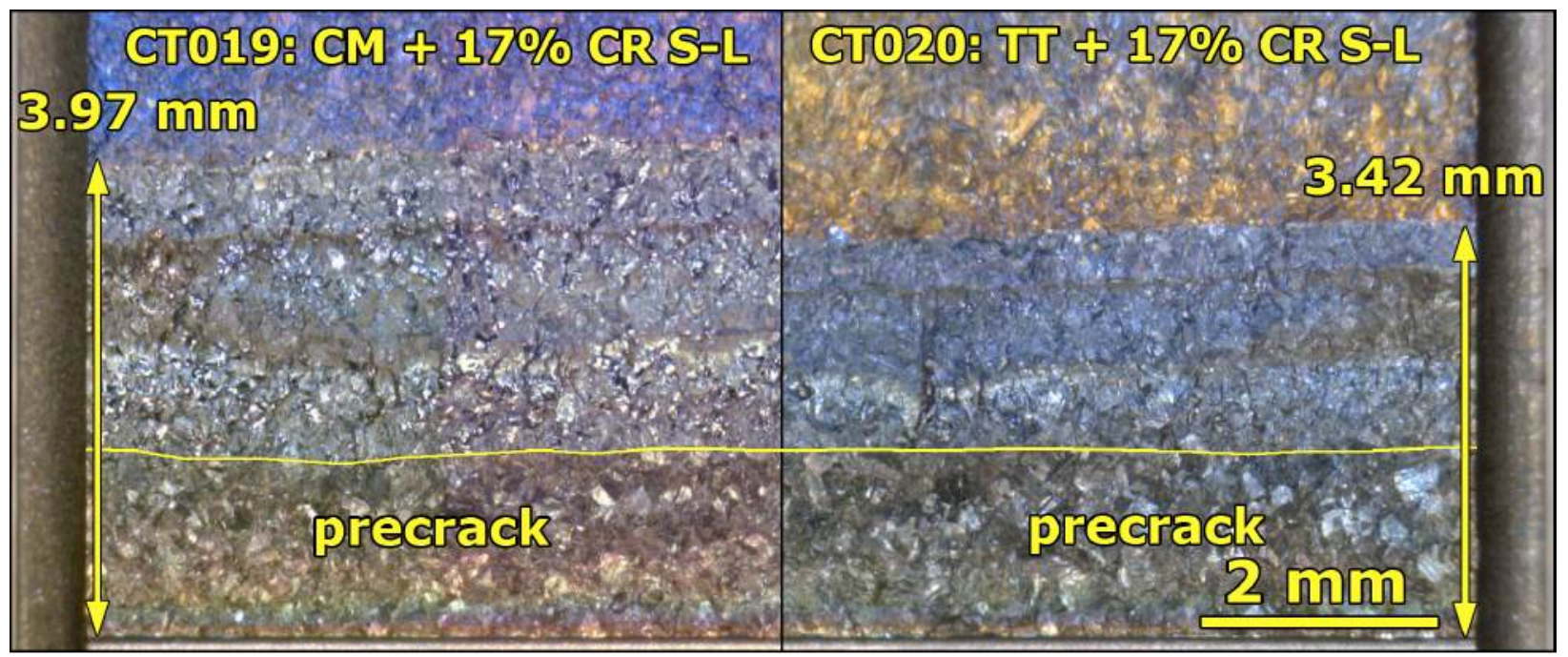

(a)

(b)

Figure 4.30 Optical image of crack-growth surface of the (a) $17 \% \mathrm{CR}$ alloy $690 \mathrm{CM}$ and (b) $17 \%$ CR alloy $690 T T$ S-L specimens (heat RE243).

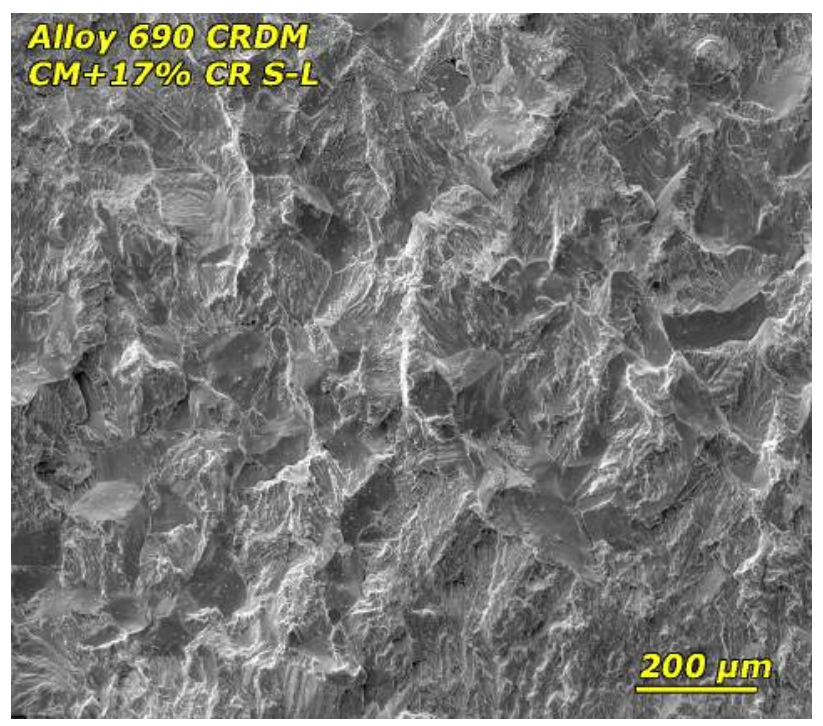

(a)

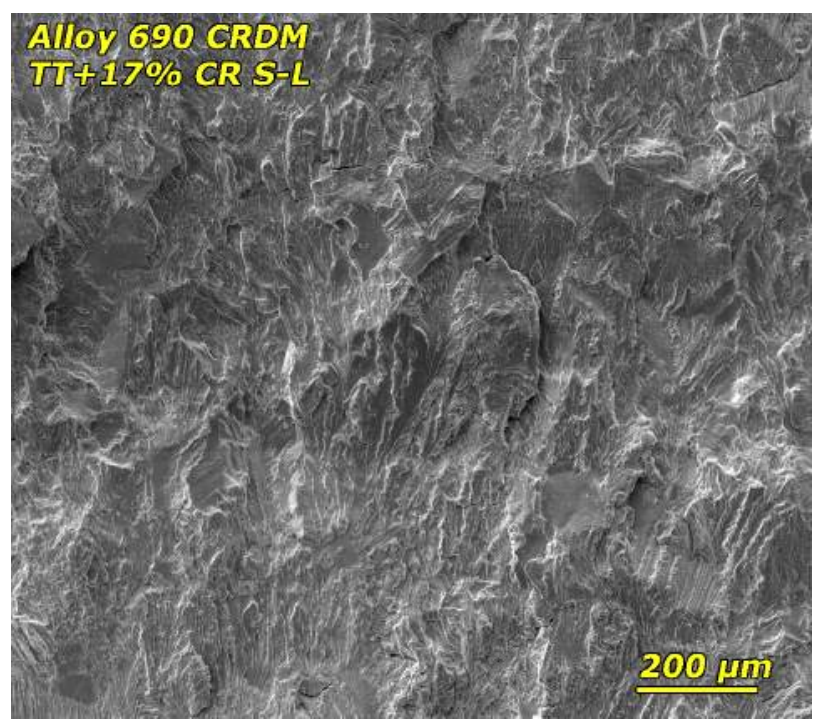

(b)

Figure 4.31 SEM images of crack-growth surface features in the (a) $17 \% \mathrm{CR}$ alloy $690 \mathrm{CM}$ and (b) $17 \% \mathrm{CR}$ alloy $690 \mathrm{TT}$ S-L specimens (heat RE243). 
It is interesting to note that IG cracking was increased in the $17 \%$ CR S-L specimens over the non-CR specimens, but the amount of IG cracking was still quite low. Several possible reasons exist for the lack of extensive IGSCC in these 1D CR S-L alloy 690 CRDM materials. One possibility is that the extruded CRDM tubing microstructures are more resistant to the 1D damage than other alloy 690 materials that show very high SCC crack growth rates after cold rolling. It is also possible that there may have been insufficient cold work in the crack-growth plane to accelerate SCC. Although the total reduction for the CRDM material was $17 \%$, the hardness was slightly lower in the center of the sample (where propagation occurred). Another possible reason for lower growth rates was the lower test temperature, and an additional test on the $17 \% \mathrm{CR}$ is planned at $360^{\circ} \mathrm{C}$.

The first test evaluating higher levels of reduction in these CRDM tubes was done on specimens in the T-L orientation. An overview of the crack growth response of the $30 \% \mathrm{CR}$ T-L specimens is shown in Figure 4.32 and listed in Table 4.7. As with 17\%CR S-L specimens, several transitioning sequences were performed leading to three observations of constant $\mathrm{K}$ crackgrowth response. The first instance of constant $\mathrm{K}$ at $\sim 1500 \mathrm{~h}$ produced propagation rates that were higher than the $17 \% \mathrm{CR}$ S-L material, but decreasing with time. After temperature was raised to $350^{\circ} \mathrm{C}$ and cycle + hold steps were applied, the TT and CM specimens exhibited steady crack-growth rates of $1.0 \times 10^{-8}$ and $1.0 \times 10^{-9} \mathrm{~mm} / \mathrm{s}$, respectively (Figure 4.33). With the higher observed rate in the TT specimen, the test was allowed to continue at constant $K$ for $1000 \mathrm{~h}$ producing a crack extension of $\sim 40 \mu \mathrm{m}$ in the TT specimen. As a final step, $\mathrm{K}$ was increased to $40 \mathrm{MPa} \sqrt{\mathrm{m}}$ by $\mathrm{dK} / \mathrm{da}$ and transitioned back to constant $\mathrm{K}$ where a mild enhancement of SCC was again indicated in the TT specimen.

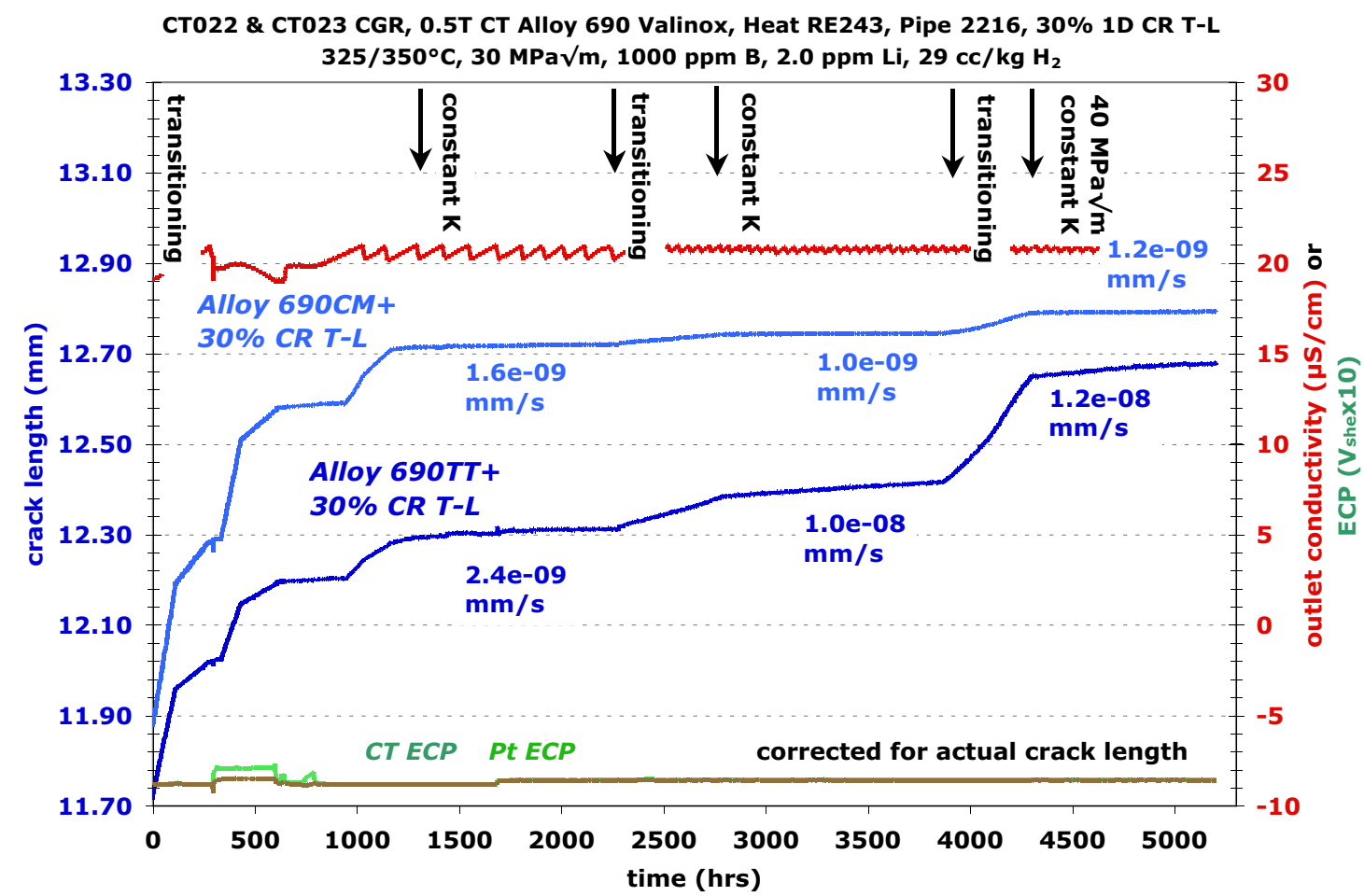

Figure 4.32 Overview of the crack growth responses of the alloy 690TT and CM $30 \%$ CR $\mathrm{T}$-L specimens (heat RE243) tested at $325^{\circ} \mathrm{C}$ and $350^{\circ} \mathrm{C}$. 
Table 4.7 Uncorrected data summary for alloy 690 CRDM specimens CT022 \& CT023.

\begin{tabular}{|c|c|c|c|c|c|c|c|c|c|c|c|c|}
\hline $\begin{array}{c}\text { Test } \\
\text { Phase } \\
\end{array}$ & $\begin{array}{l}\text { Dur- } \\
\text { ation } \\
\text { (h) }\end{array}$ & $\mathrm{R}$ & Freq $(\mathrm{Hz})$ & $\begin{array}{c}\text { Hold } \\
(\mathrm{h})\end{array}$ & $\begin{array}{c}\text { Water } \\
\text { Chemistry } \\
\text { Conditions } \\
\end{array}$ & $\begin{array}{c}\text { Temp } \\
\left({ }^{\circ} \mathrm{C}\right) \\
\end{array}$ & $\begin{array}{c}\text { Alloy } 6 \\
\text { Kmax } \\
(\mathrm{MPa} \sqrt{ })\end{array}$ & $\begin{array}{c}\text { CT022 } \\
90 \mathrm{TT}+30 \% \\
\text { CGR } \\
(\mathrm{mm} / \mathrm{sec})\end{array}$ & $\begin{array}{c}\text { CR T-L } \\
\text { Crack } \\
\text { Extension } \\
(\mathrm{mm}) \\
\end{array}$ & $\begin{array}{c}\text { Alloy } 69 \\
\text { Kmax } \\
(\mathrm{MPa} \sqrt{\mathrm{m}}) \\
\end{array}$ & $\begin{array}{c}\text { CT023 } \\
90 \mathrm{CM}+30 \% \\
\text { CGR } \\
(\mathrm{mm} / \mathrm{sec}) \\
\end{array}$ & $\begin{array}{c}\text { \% CR T-L } \\
\text { Crack } \\
\text { Extension } \\
(\mathrm{mm}) \\
\end{array}$ \\
\hline 1 & $\sim 3$ & 0.3 & 3 & 0 & air & RT & 25 & $4.9 \mathrm{E}-05$ & 0.550 & 25 & 5.7E-05 & 0.540 \\
\hline 2 & $\sim 2$ & 0.5 & 3 & 0 & air & RT & 28 & 3.6E-05 & 0.428 & 28 & $3.8 \mathrm{E}-05$ & 0.426 \\
\hline 3 & $\sim 3$ & 0.6 & 3 & 0 & air & RT & 30 & $2.5 \mathrm{E}-05$ & 0.300 & 30 & $2.8 \mathrm{E}-05$ & 0.250 \\
\hline 4 & $\sim 5$ & 0.7 & 3 & 0 & air & RT & 30 & 1.4E-05 & 0.281 & 30 & 1.3E-05 & 0.285 \\
\hline 5 & 113 & 0.7 & 0.1 & 0 & $29 \mathrm{cc} / \mathrm{kg} \mathrm{H} 2$ & 325 & 30 & 4.5E-07 & 0.176 & 30 & $6.0 \mathrm{E}-07$ & 0.230 \\
\hline 6 & 162 & 0.7 & 0.01 & 0 & $29 \mathrm{cc} / \mathrm{kg} \mathrm{H} 2$ & 325 & 30 & $6.9 \mathrm{E}-08$ & 0.043 & 30 & $1.2 \mathrm{E}-07$ & 0.066 \\
\hline 7 & 62 & 0.7 & 0.001 & 0 & $29 \mathrm{cc} / \mathrm{kg} \mathrm{H} 2$ & 325 & 30 & - & 0.008 & 30 & - & 0.017 \\
\hline 8 & 96 & 0.5 & & 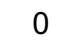 & $29 \mathrm{cc} / \mathrm{kg} \mathrm{H} 2$ & 5 & 30 & 2.7 & 0.092 & 30 & 4.7E-07 & 162 \\
\hline 9 & 406 & 0.5 & 0.001 & 0 & $29 \mathrm{cc} / \mathrm{kg} \mathrm{H} 2$ & 325 & 30 & 5.7E-08 & 0.034 & 30 & $9.1 \mathrm{E}-08$ & 0.053 \\
\hline 10 & 231 & 0.5 & 0.001 & 2.5 & $29 \mathrm{cc} / \mathrm{kg} \mathrm{H} 2$ & 325 & 30 & 4.4E-09 & 0.007 & 30 & 8.1E-09 & 0.005 \\
\hline 11 & 97 & 0.7 & 0.001 & 2.5 & $29 \mathrm{cc} / \mathrm{kg} \mathrm{H} 2$ & 325 & 30 & - & 0 & 30 & - & 0.001 \\
\hline 12 & 95 & 0.5 & $480 / 20$ & 0 & $29 \mathrm{cc} / \mathrm{kg} \mathrm{H} 2$ & 325 & 30 & 1.0E-07 & 0.034 & 30 & 1.7E-07 & 0.050 \\
\hline 13 & 130 & 0.5 & $980 / 20$ & 0 & $29 \mathrm{cc} / \mathrm{kg} \mathrm{H} 2$ & 32 & 30 & 5.6E-08 & 0.029 & 0 & $8.6 \mathrm{E}-08$ & 0.042 \\
\hline 14 & 117 & 0.5 & 0.001 & 2.5 & $29 \mathrm{cc} / \mathrm{kg} \mathrm{H} 2$ & 325 & 30 & 7.4E-09 & 0.002 & 30 & $1.1 \mathrm{E}-08$ & 0.004 \\
\hline 15 & 416 & --- & const $\mathrm{K}$ & --- & $29 \mathrm{cc} / \mathrm{kg} \mathrm{H} 2$ & 325 & 30 & $<5 e-10$ & 0.0018 & 30 & $<5 e-10$ & 0.0026 \\
\hline 16 & 590 & --- & const $\mathrm{K}$ & --- & $29 \mathrm{cc} / \mathrm{kg} \mathrm{H} 2$ & 350 & 30 & 1.2E-09 & 0.0026 & 30 & $5.8 \mathrm{E}-10$ & 0.0026 \\
\hline 17 & 526 & 0.5 & 0.001 & 2.5 & $29 \mathrm{cc} / \mathrm{kg} \mathrm{H} 2$ & 350 & 30 & 1.2E-08 & 0.019 & 30 & 9.3E-09 & 0.018 \\
\hline 18 & 890 & --- & const $\mathrm{K}$ & --- & $29 \mathrm{cc} / \mathrm{kg} \mathrm{H} 2$ & 350 & 30 & 2.7E-09 & 0.0068 & 30 & $7.8 \mathrm{E}-10$ & 0.0017 \\
\hline 19 & 517 & 0.5 & 0.001 & 2.5 & $29 \mathrm{cc} / \mathrm{kg} \mathrm{H} 2$ & 350 & $30->40$ & - & 0.048 & $30->40$ & - & 0.027 \\
\hline 20 & 81 & 0.5 & 0.001 & 2.5 & $29 \mathrm{cc} / \mathrm{kg} \mathrm{H} 2$ & 350 & 40 & 3.8E-08 & 0.012 & 40 & 2.4E-08 & 0.007 \\
\hline 21 & 904 & --- & const $\mathrm{K}$ & --- & $29 \mathrm{cc} / \mathrm{kg} \mathrm{H} 2$ & 350 & 40 & 1.4E-09 & 0.0066 & 40 & $9.3 E-10$ & 0.0033 \\
\hline
\end{tabular}




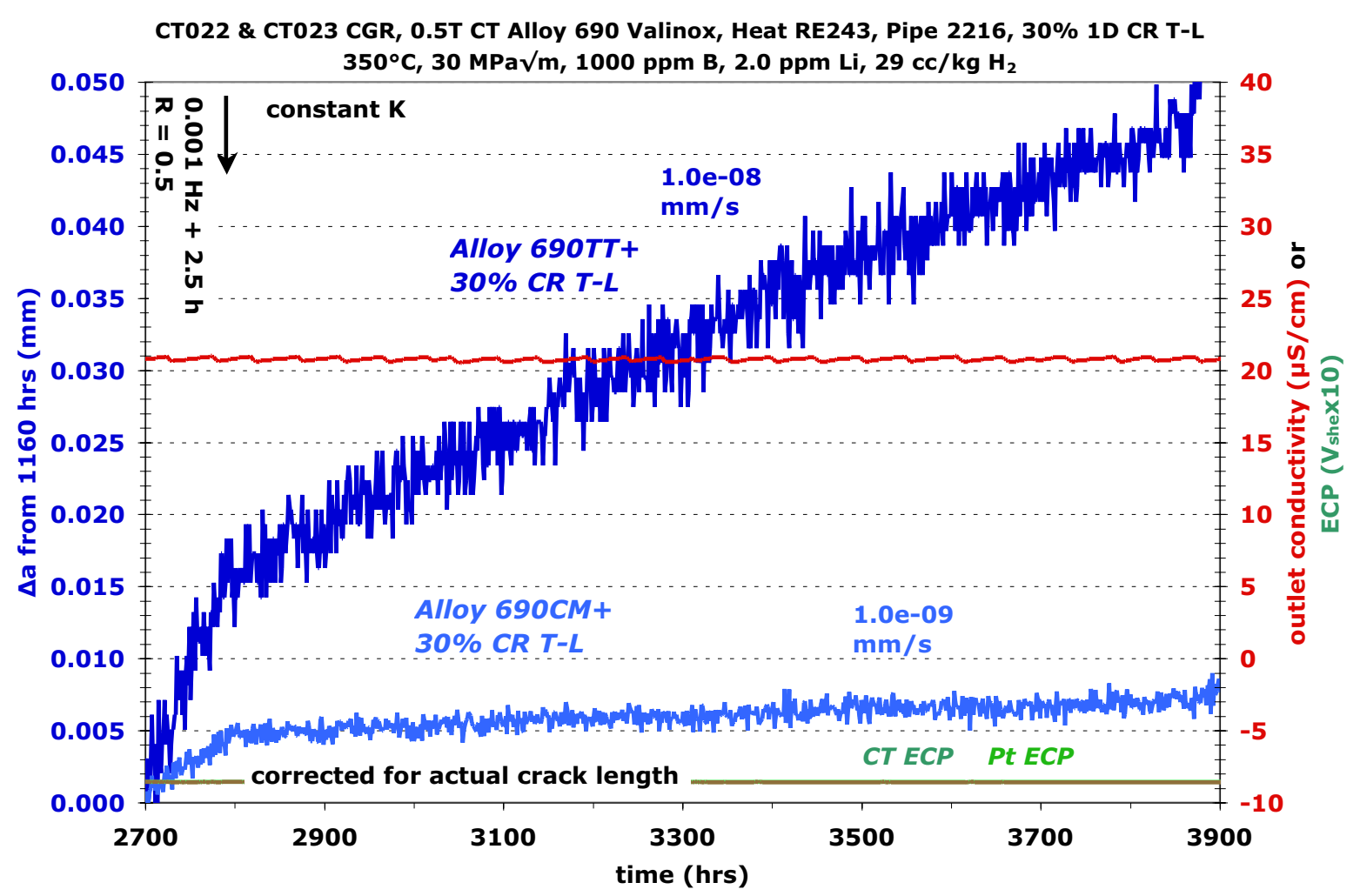

Figure 4.33 Crack growth responses of the alloy 690TT and CM 30\% CR T-L specimens (heat RE243) during the second assessment of constant K crack growth.

Figure 4.34 presents optical images of the crack-growth surface for the $30 \%$ CR T-L specimens. The three phases of the test are not easily resolved probably due to the shorter amount of crack extension during transitioning attempts and the less aggressive transitioning steps employed. The most striking difference between the specimens is that the CM specimen has a relatively flat crack front across the width, while the TT specimen has an uneven crack front with a large number of protrusions. SEM images (Figure 4.35) reveal that IG cracking occurred at the crack front for both specimens with a much higher fraction of IG facets for the TT specimen. For both materials, nearly all the cracked grain boundaries were oriented approximately parallel to the rolling plane and would have sustained the most damage from the cold-rolling operation. Despite the less favorable orientation relative to the crack-growth plane, IG cracking was promoted on many of these boundaries. The different IG growth between the TT and CM specimens suggests that the grain boundary carbide density may influence rolling-induced damage and SCC response. Grain boundary $\mathrm{Cr}$ depletion is also different between these materials, but it is not thought to influence PWSCC susceptibility [Refs. 9, 12, 13].

In order to more effectively evaluate the influence of cold rolling on the SCC behavior of the CRDM alloy 690 RE243 heat, additional rolling was performed at GEG as described earlier. Using their equipment, it was possible to achieve a $31 \% \mathrm{CR}$ condition on the TT and CM materials and machine 0.5T CT specimens in the S-L orientation. SCC growth-rate tests were initiated at PNNL and GEG. The first 29 stages of the PNNL tests CT038 (31\%CR alloy 690TT) and CT039 (31\%CR alloy 690CM) have been completed and the preliminary DCPD-measured results will be described. 


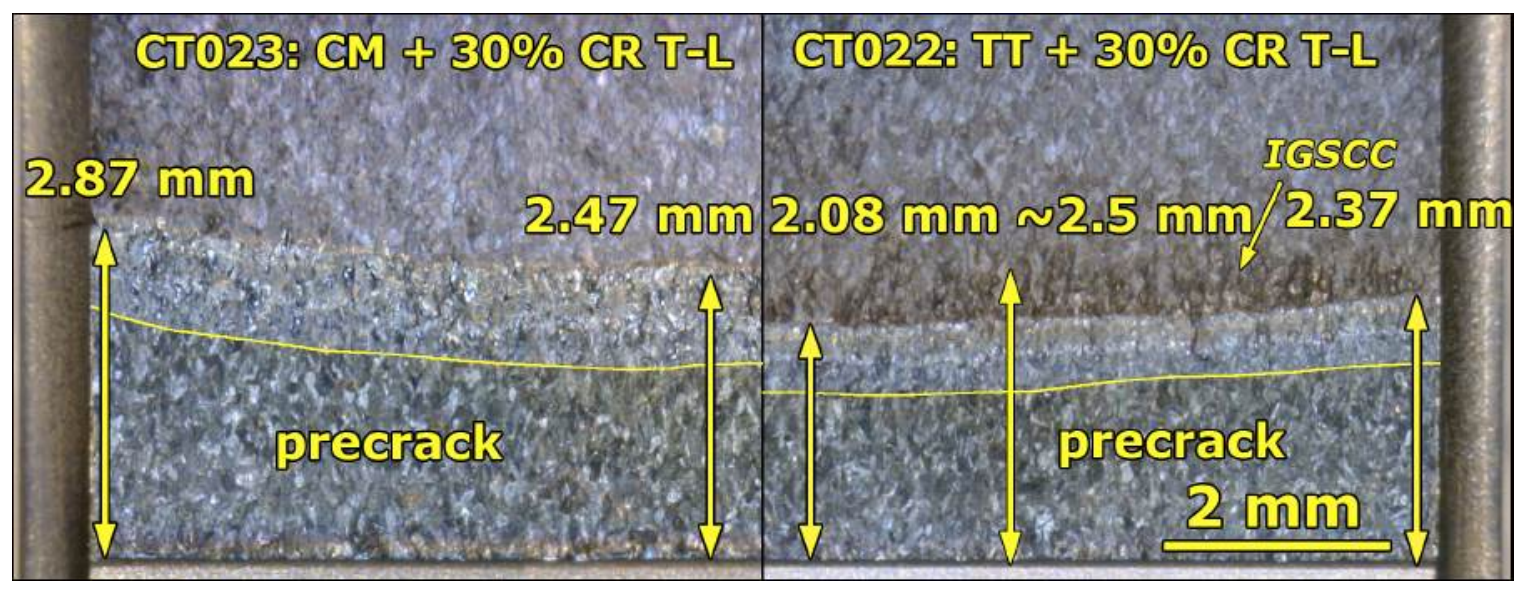

Figure 4.34 Optical images of the crack-growth surface of the $30 \%$ CR T-L specimens (heat RE243). As with the 17\% CR T-L specimens, the CM specimen exhibits a greater amount of crack extension during load cycling.
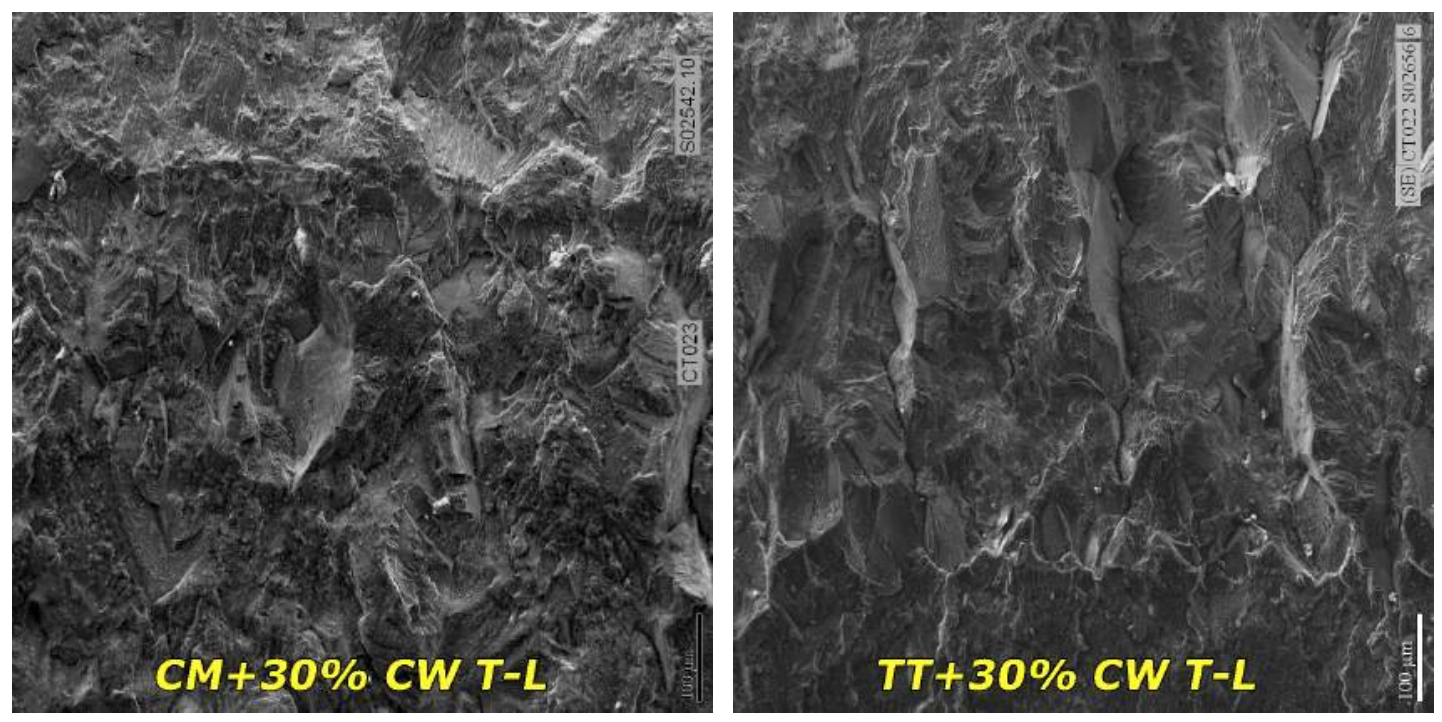

Figure 4.35 SEM images of crack-growth surfaces for the $30 \% \mathrm{CR}$ alloy $690 \mathrm{~T}-\mathrm{L}$ specimens (heat RE243). IG cracking is observed in both specimens, but with more IG in the TT specimen. Note that IG cracking is on grain boundaries parallel to the rolling plane (transverse plane).

Significant differences were seen between the 31\%CR alloy 690TT and CM materials during cycle + hold transitioning and constant $\mathrm{K}$ exposures as listed in Table 4.8. These differences are highlighted by the constant $\mathrm{K}$ response at $360^{\circ} \mathrm{C}$ and $25 \mathrm{cc} / \mathrm{kg} \mathrm{H}$. These $\mathrm{SCC}$ results are presented in Figure 4.36 showing rates of $\sim 8 \times 10^{-8} \mathrm{~mm} / \mathrm{s}$ for the TT material and $\sim 8 \times 10^{-9} \mathrm{~mm} / \mathrm{s}$ for the $\mathrm{CM}$ material. After the observation of moderate-to-high propagation rates at $360^{\circ} \mathrm{C}$ for the TT sample, temperature dependence was explored by observing constant $\mathrm{K}$ response at 325 and $290^{\circ} \mathrm{C}$ (Figure 4.37). To ensure maximum IGSCC engagement for each temperature, the test temperature was returned to $360^{\circ} \mathrm{C}$ and higher rates of propagation reestablished between each temperature change. 
Table 4.8 Data summary for alloy 690 CRDM specimens CT038 \& CT039.

\begin{tabular}{|c|c|c|c|c|c|c|c|c|c|c|c|c|}
\hline $\begin{array}{c}\text { Test } \\
\text { Phase } \\
\end{array}$ & $\begin{array}{l}\text { Duration } \\
\text { (h) }\end{array}$ & $\mathrm{R}$ & $\begin{array}{l}\text { Freq } \\
(\mathrm{Hz})\end{array}$ & $\begin{array}{l}\text { Hold } \\
\text { (h) }\end{array}$ & $\begin{array}{c}\text { Water } \\
\text { Chemistry } \\
\text { Conditions }\end{array}$ & $\begin{array}{c}\text { Temp } \\
\left({ }^{\circ} \mathrm{C}\right) \\
\end{array}$ & $\begin{array}{c}\text { Alloy } 69 \\
\text { Kmax } \\
(\mathrm{MPa} \sqrt{\mathrm{m}})\end{array}$ & $\begin{array}{c}\text { CT038 } \\
0 \mathrm{TT}+31 \% \\
\text { CGR } \\
(\mathrm{mm} / \mathrm{sec})\end{array}$ & $\begin{array}{c}\text { CR S-L } \\
\text { Crack } \\
\text { Extension } \\
(\mathrm{mm})\end{array}$ & $\begin{array}{c}\text { Alloy } 690 \\
\text { Kmax } \\
(\mathrm{MPa} \sqrt{\mathrm{m}})\end{array}$ & $\begin{array}{c}\text { CT039 } \\
\text { 0CM+31\% } \\
\text { CGR } \\
(\mathrm{mm} / \mathrm{sec}) \\
\end{array}$ & $\begin{array}{l}\text { CR S-L } \\
\text { Crack } \\
\text { Extension } \\
(\mathrm{mm})\end{array}$ \\
\hline 1 & $\sim 3$ & 0.3 & 5 & 0 & air & RT & 21.0 & 8.3E-05 & 0.43 & 21.0 & 7.9E-05 & 0.41 \\
\hline 2 & $\sim 2$ & 0.5 & 5 & 0 & air & RT & 23.0 & 4.5E-05 & 0.28 & 23.0 & 4.5E-05 & 0.30 \\
\hline 3 & $\sim 2$ & 0.6 & 5 & 0 & air & RT & 25.0 & 3.6E-05 & 0.30 & 25.0 & 3.3E-05 & 0.28 \\
\hline 4 & $\sim 3$ & 0.7 & 5 & 0 & air & RT & 25.0 & $1.8 \mathrm{E}-05$ & 0.19 & 25.0 & $1.9 \mathrm{E}-05$ & 0.19 \\
\hline 5 & 13 & 0.5 & 0.1 & 0 & $25 \mathrm{cc} / \mathrm{kg} \mathrm{H}{ }_{2}$ & 360 & 27.5 & 4.6E-06 & 0.203 & 27.6 & 7.7E-06 & 0.325 \\
\hline 6 & 35 & 0.5 & 0.01 & 0 & $25 \mathrm{cc} / \mathrm{kg} \mathrm{H} \mathrm{H}_{2}$ & 360 & 27.5 & 1.3E-06 & 0.145 & 27.8 & 1.5E-06 & 0.196 \\
\hline 7 & 84 & 0.5 & 0.001 & 0 & $25 \mathrm{cc} / \mathrm{kg} \mathrm{H} \mathrm{H}_{2}$ & 360 & 27.5 & $2.6 \mathrm{E}-07$ & 0.073 & 27.7 & $1.8 \mathrm{E}-07$ & 0.056 \\
\hline 8 & 278 & 0.5 & 0.001 & 2.5 & $25 \mathrm{cc} / \mathrm{kg} \mathrm{H} \mathrm{H}_{2}$ & 360 & 27.5 & $2.2 \mathrm{E}-07$ & 0.175 & 27.3 & 3.0E-08 & 0.034 \\
\hline $9 a$ & 350 & --- & $\begin{array}{c}\text { const } \\
\mathrm{K}\end{array}$ & --- & $25 \mathrm{cc} / \mathrm{kg} \mathrm{H} \mathrm{H}_{2}$ & 360 & 27.5 & 8.1E-08 & 0.093 & 27.1 & 8.3E-09 & 0.010 \\
\hline $9 b$ & 135 & --- & $\begin{array}{c}\text { const } \\
\mathrm{K}\end{array}$ & --- & $25 \mathrm{cc} / \mathrm{kg} \mathrm{H}$ & 360 & 27.5 & 7.0E-08 & 0.032 & 27.0 & 7.9E-09 & 0.005 \\
\hline 10 & 550 & --- & $\begin{array}{c}\text { const } \\
\mathrm{K}\end{array}$ & --- & $11 \mathrm{cc} / \mathrm{kg} \mathrm{H}_{2}$ & 325 & 27.5 & 2.8E-08 & 0.054 & 26.8 & $<5 \mathrm{E}-10$ & 0.000 \\
\hline 11 & 37 & 0.5 & 0.001 & 0 & $11 \mathrm{cc} / \mathrm{kg} \mathrm{H} \mathrm{H}_{2}$ & 325 & 27.5 & 1.4E-06 & 0.237 & 26.2 & 2.6E-07 & 0.007 \\
\hline 12 & 85 & 0.5 & 0.001 & 2.5 & $11 \mathrm{cc} / \mathrm{kg} \mathrm{H}{ }_{2}$ & 325 & 27.5 & 1.6E-07 & 0.072 & 26.0 & $2.2 \mathrm{E}-08$ & 0.006 \\
\hline 13 & 38 & 0.5 & 0.001 & 2.5 & $25 \mathrm{cc} / \mathrm{kg} \mathrm{H} \mathrm{H}_{2}$ & 360 & 27.5 & $2.4 \mathrm{E}-07$ & 0.032 & 25.9 & $2.8 \mathrm{E}-08$ & 0.004 \\
\hline 14 & 267 & --- & $\begin{array}{c}\text { const } \\
\mathrm{K}\end{array}$ & --- & $25 \mathrm{cc} / \mathrm{kg} \mathrm{H} \mathrm{H}_{2}$ & 360 & 27.5 & 3.3E-08 & 0.032 & 25.8 & 5.6E-09 & 0.005 \\
\hline 15 & 87 & 0.6 & 0.001 & 2.5 & $25 \mathrm{cc} / \mathrm{kg} \mathrm{H} 2$ & 360 & 27.5 & 1.9E-07 & 0.075 & 25.6 & 1.7E-08 & 0.005 \\
\hline 16 & 206 & --- & $\underset{\mathrm{K}}{\mathrm{const}}$ & --- & $25 \mathrm{cc} / \mathrm{kg} \mathrm{H}{ }_{2}$ & 360 & 27.5 & 4.7E-08 & 0.035 & 25.5 & 4.9E-09 & 0.005 \\
\hline 17 & 669 & ---- & $\begin{array}{c}\text { const } \\
\mathrm{K}\end{array}$ & --- & $4 \mathrm{cc} / \mathrm{kg} \mathrm{H} \mathrm{H}_{2}$ & 290 & 27.5 & 6.1E-09 & 0.090 & 25.3 & $<5 E-10$ & 0.005 \\
\hline 18 & 37 & 0.6 & 0.001 & 2.5 & $4 \mathrm{cc} / \mathrm{kg} \mathrm{H} 2$ & 290 & 27.5 & 2.1E-07 & 0.053 & 25.1 & $\begin{array}{c}\sim 1.6 \mathrm{E}- \\
08\end{array}$ & 0.001 \\
\hline 19 & 100 & --- & $\begin{array}{c}\text { const } \\
\mathrm{K}\end{array}$ & --- & 4 cc/kg H2 & 290 & 27.5 & 1.8E-09 & 0.003 & 25.1 & $<5 \mathrm{E}-10$ & 0.001 \\
\hline 20 & 197 & 0.6 & 0.001 & 0 & $4 \mathrm{cc} / \mathrm{kg} \mathrm{H} \mathrm{H}_{2}$ & 290 & 27.5 & 2.7E-07 & 0.390 & 24.2 & 7.4E-08 & 0.058 \\
\hline 21 & 137 & 0.6 & 0.001 & 2.5 & $4 \mathrm{cc} / \mathrm{kg} \mathrm{H} \mathrm{H}_{2}$ & 290 & 27.5 & 3.1E-08 & 0.017 & 24.2 & 9.7E-09 & 0.008 \\
\hline 22 & 317 & --- & $\begin{array}{c}\text { const } \\
\mathrm{K}\end{array}$ & --- & $4 \mathrm{cc} / \mathrm{kg} \mathrm{H}$ & 290 & 27.5 & 1.9E-09 & 0.003 & 24.2 & 1.0E-09 & 0.002 \\
\hline 23 & 136 & 0.6 & 0.001 & 2.5 & $11 \mathrm{cc} / \mathrm{kg} \mathrm{H} \mathrm{H}_{2}$ & 325 & 27.5 & 5.6E-08 & 0.028 & 211 & $1.5 \mathrm{E}-08$ & 0.007 \\
\hline 24 & 154 & 0.5 & 0.001 & 2.5 & $11 \mathrm{cc} / \mathrm{kg} \mathrm{H} \mathrm{H}_{2}$ & 325 & 27.5 & 1.7E-07 & 0.061 & 24.0 & 2.6E-08 & 0.012 \\
\hline 25 & 348 & --- & $\underset{\mathrm{K}}{\mathrm{const}}$ & --- & $11 \mathrm{cc} / \mathrm{kg} \mathrm{H}_{2}$ & 325 & 27.5 & 1.1E-08 & 0.014 & 24.0 & $\sim 6 \mathrm{E}-10$ & 0.001 \\
\hline 26 & 317 & --- & $\begin{array}{c}\text { const } \\
\mathrm{K}\end{array}$ & --- & $50 \mathrm{cc} / \mathrm{kg} \mathrm{H}$ & 325 & 27.5 & 1.1E-08 & 0.013 & 24.0 & $\sim 6 \mathrm{E}-10$ & 0.002 \\
\hline 27 & 188 & --- & $\begin{array}{c}\text { const } \\
\mathrm{K}\end{array}$ & --- & $11 \mathrm{cc} / \mathrm{kg} \mathrm{H}{ }_{2}$ & 325 & 27.5 & $1.2 \mathrm{E}-08$ & 0.007 & 23.9 & 1E-09 & 0.001 \\
\hline 28 & 685 & --- & $\begin{array}{c}\text { const } \\
\mathrm{K}\end{array}$ & --- & $1 \mathrm{cc} / \mathrm{kg} \mathrm{H}{ }_{2}$ & 325 & 27.5 & 4.1E-09 & 0.009 & 23.9 & 〜1E-09 & 0.002 \\
\hline 29 & going & --- & $\begin{array}{c}\text { const } \\
\mathrm{K}\end{array}$ & --- & $11 \mathrm{cc} / \mathrm{kg} \mathrm{H}_{2}$ & 325 & 27.5 & 1E-08 & ongoing & 23.9 & 1E-09 & ongoing \\
\hline
\end{tabular}




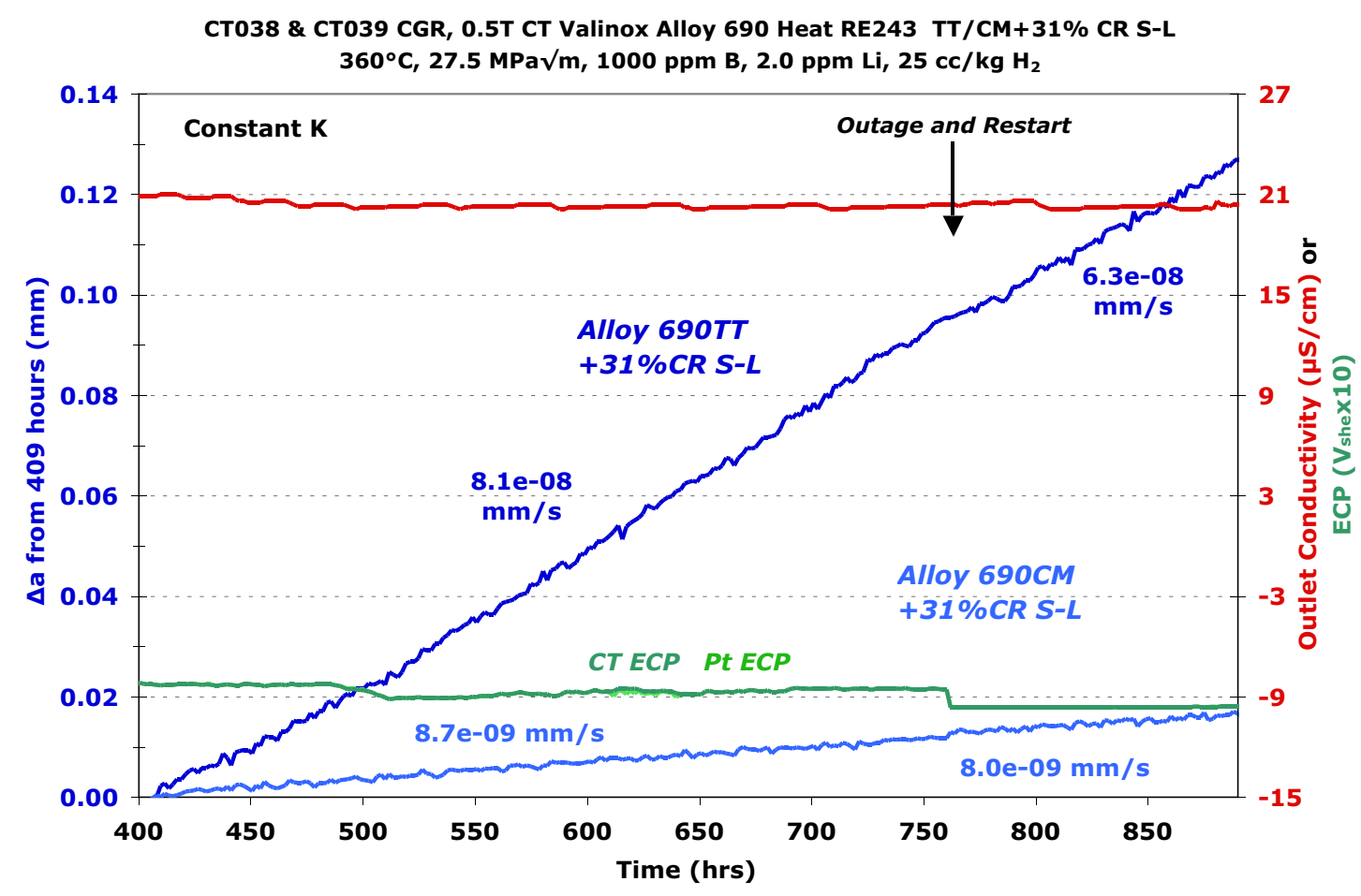

Figure 4.36 Initial constant $\mathrm{K}$ responses for the $31 \% \mathrm{CR}$ alloy $690 \mathrm{TT}$ and $\mathrm{CM}$ specimens (heat RE243) at $360^{\circ} \mathrm{C}$ and $25 \mathrm{cc} / \mathrm{kg} \mathrm{H}_{2}$.

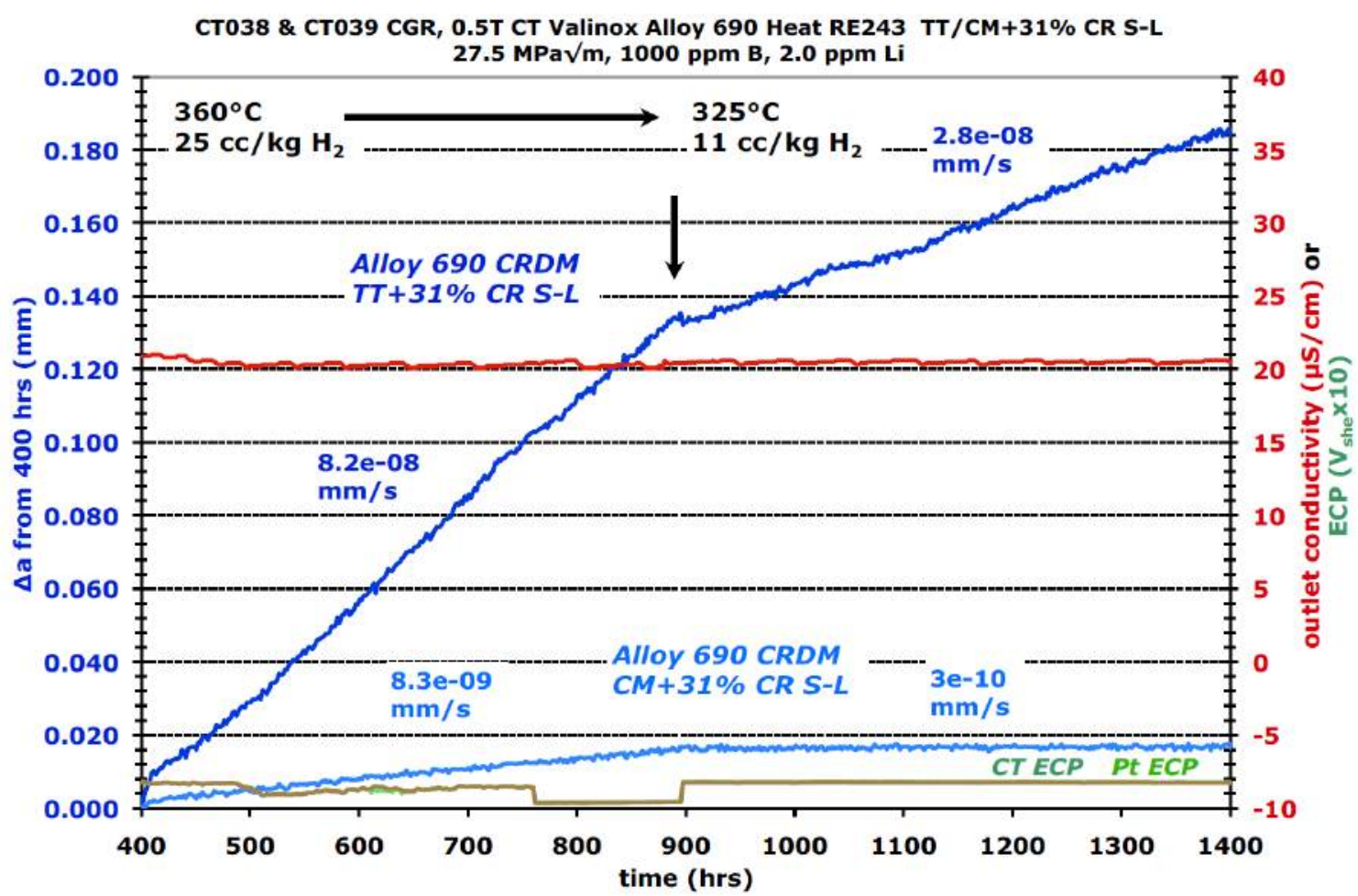

Figure 4.37 Constant $\mathrm{K}$ responses for the $31 \% \mathrm{CR}$ alloy 690 specimens at 360 and $325^{\circ} \mathrm{C}$. 
The hydrogen content at each temperature was altered with each temperature change to maintain the ECP at the $\mathrm{Ni} / \mathrm{NiO}$ stability line. Propagation rates for the TT material decreased consistently with decreasing temperature producing an activation energy of $\sim 110 \mathrm{~kJ} / \mathrm{mole}$ as shown in Figure 4.38. As indicated in this plot and listed in Table 4.8, constant $\mathrm{K}$ growth rates have been evaluated several times at each temperature building confidence in the results. The $31 \% \mathrm{CR}$ alloy $690 \mathrm{CM}$ specimen essentially stopped propagating as the temperature was dropped from $360^{\circ} \mathrm{C}$ to $325^{\circ} \mathrm{C}$. Since no significant DCPD-measured crack extension was observed at the lower temperatures, it was not possible to assess an activation energy for the $\mathrm{CM}$ material using the common exponential representation.

One final environmental parameter examined as part of the tests on the 31\%CR S-L specimens was the effect of hydrogen concentration and ECP. Hydrogen concentrations was varied at a temperature of $325^{\circ} \mathrm{C}$, matching prior PNNL work [Ref. 8] conducted on alloy 182. No change in the propagations rates was detected at a higher content of $50 \mathrm{cc} / \mathrm{kg}$ in the Ni stable regime, but the TT material clearly shows a decrease in rate when the dissolved hydrogen level is reduced to $1 \mathrm{cc} / \mathrm{kg}$ (well into the $\mathrm{NiO}$ stable regime). This behavior is documented in Figure 4.39. The experiment on the $31 \% \mathrm{CR}$ specimens is continuing and additional data is needed to confirm the influence of hydrogen on the SCC behavior.

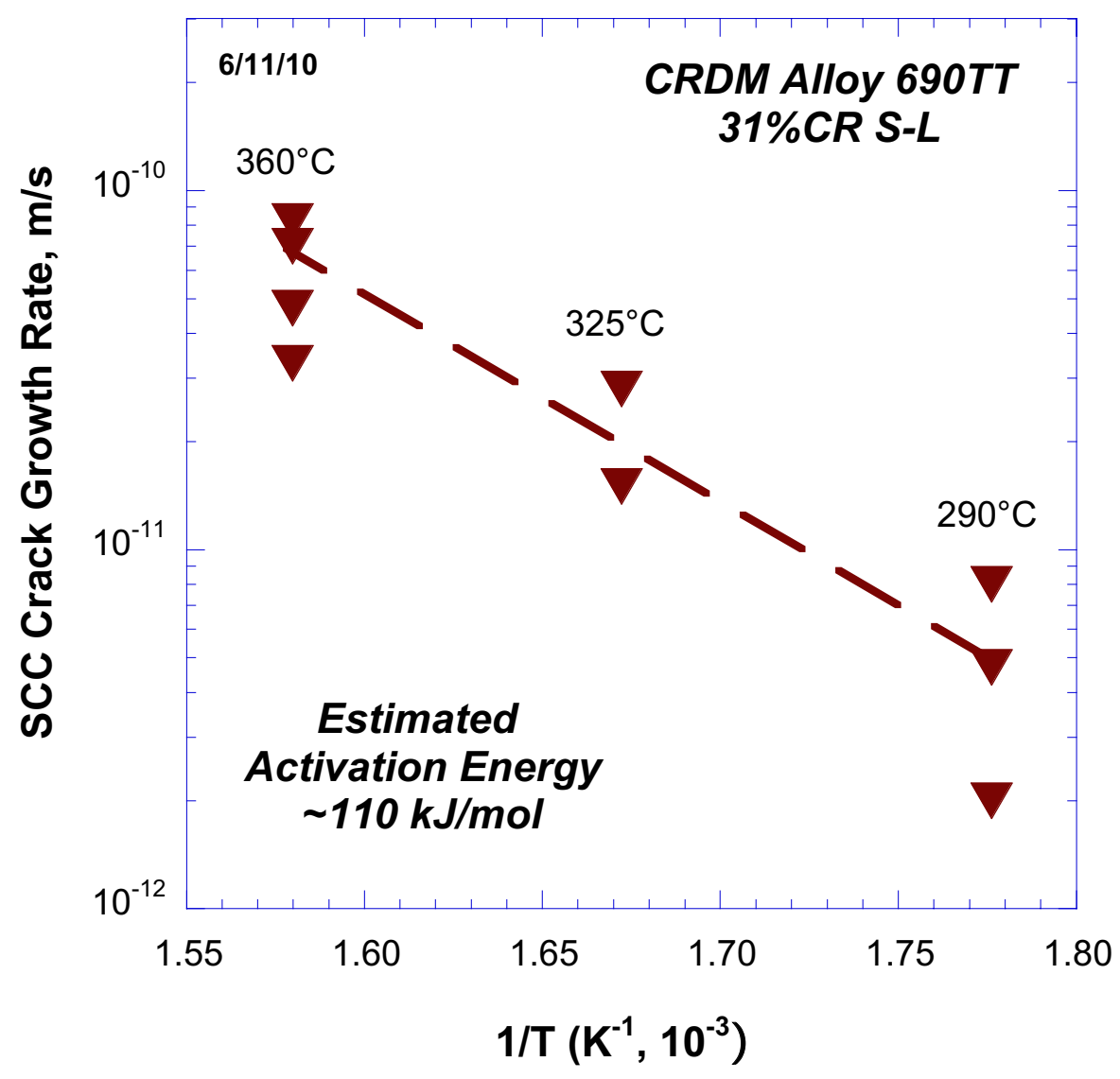

Figure 4.38 Measured constant $\mathrm{K}$ crack-growth rates as a function of test temperature for the 31\%CR alloy 690TT specimen (heat RE243). The hydrogen concentrations were adjusted at each temperature to keep the ECP at the $\mathrm{Ni} / \mathrm{NiO}$ line. 


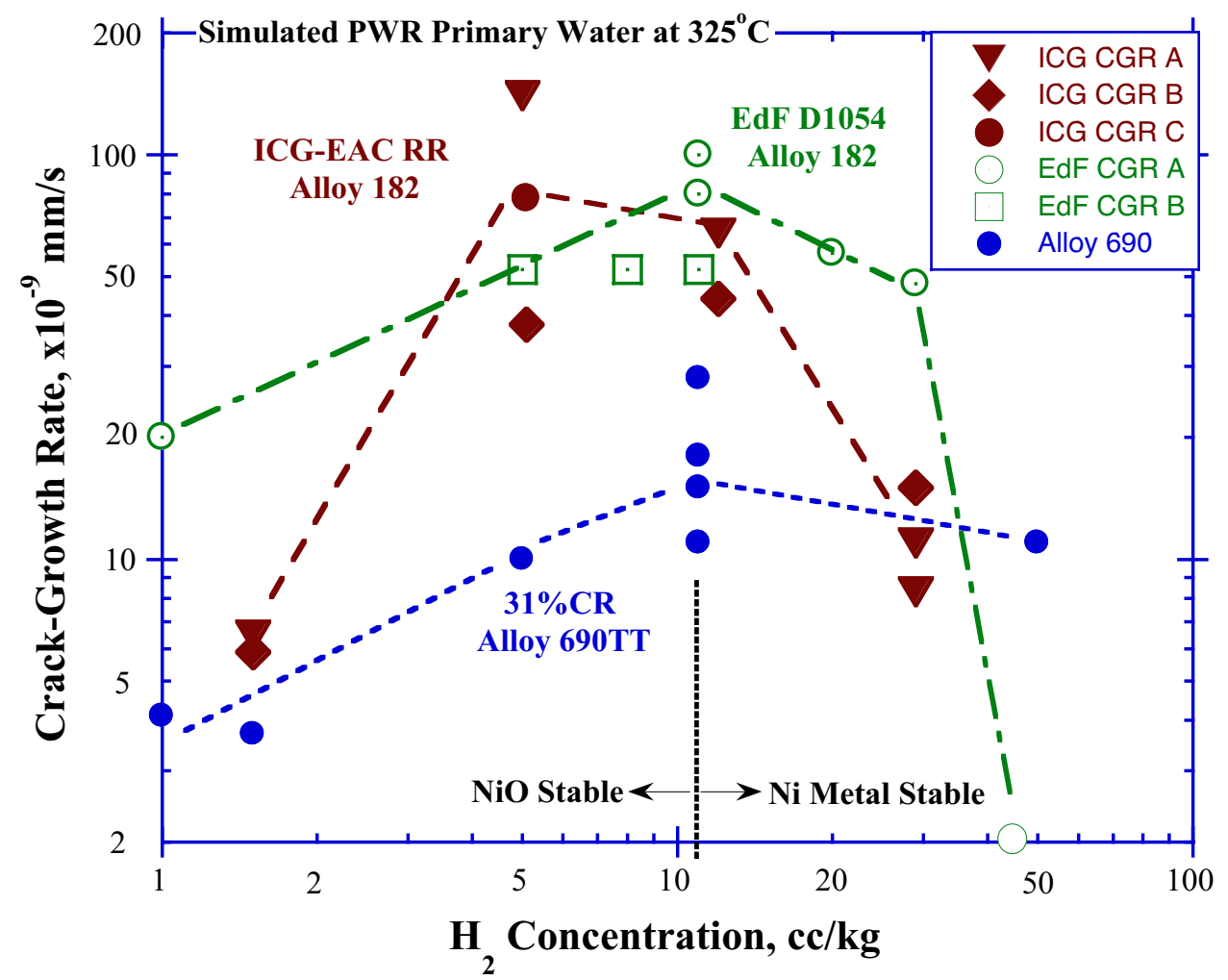

Figure 4.39 Preliminary results for the influence of hydrogen concentration on the constant $\mathrm{K}$ crack-growth rates for the $31 \% \mathrm{CR}$ alloy 690TT specimen (heat RE243) in simulated PWR primary water at $325^{\circ} \mathrm{C}$. The alloy 690 results are compared to previous PNNL SCC results [Ref. 8] on two alloy 182 welds. 


\subsection{Summary and Discussion of SCC Results for Alloy 690 CRDM Materials}

Representative alloy 690 CRDM plant materials were studied to investigate the SCC crackgrowth response in the as-received TT and several modified conditions. A variety of different transitioning methods were employed in an attempt to promote SCC engagement and effectively measure propagation rates under constant $\mathrm{K}$ conditions. None of the transitioning methods were found to produce significant IG cracking in PWR primary water for the non-CR materials. Crack-growth response for three different alloy 690 heats in the as-received TT condition, and one heat also in the CM condition, was essentially the same. Steady propagation was observed at constant $\mathrm{K}$, but only at extremely low rates $\left(\leq 1 \times 10^{-9} \mathrm{~mm} / \mathrm{s}\right)$. This data is summarized in Figure 4.40.

Crack-growth-rate testing of the $17 \%$ CR S-L specimens showed similarly low propagation rates at $325^{\circ} \mathrm{C}$ during both cycle + hold and constant $\mathrm{K}$ phases. Despite having rates similar to the non-CR materials, SEM observations of the crack-growth surfaces revealed noticeable IG cracking. This suggests that the $17 \% \mathrm{CR}$ condition does influence grain boundary susceptibility to SCC, but the amount of damage was not sufficient to degrade overall SCC resistance even for the S-L orientation. Increasing the $1 D$ CR to a reduction of $\sim 30 \%$ significantly increased the IGSCC susceptibility. The alloy $690 \mathrm{TT}+30 \% \mathrm{CR}$ specimen in the less-favorable T-L orientation $\left(350^{\circ} \mathrm{C}\right.$ ) and $\mathrm{TT}+31 \% \mathrm{CR}$ specimen in the S-L orientation (up to $360^{\circ} \mathrm{C}$ ) showed much higher constant $\mathrm{K}$ crack-growth rate as shown in Figure 4.40 and listed in Table 4.9. An increase in IGSCC propagation rates of $\sim 100 \mathrm{X}$ is indicated due to $31 \% 1 \mathrm{D}$ cold rolling for the alloy $690 \mathrm{TT}$ material.

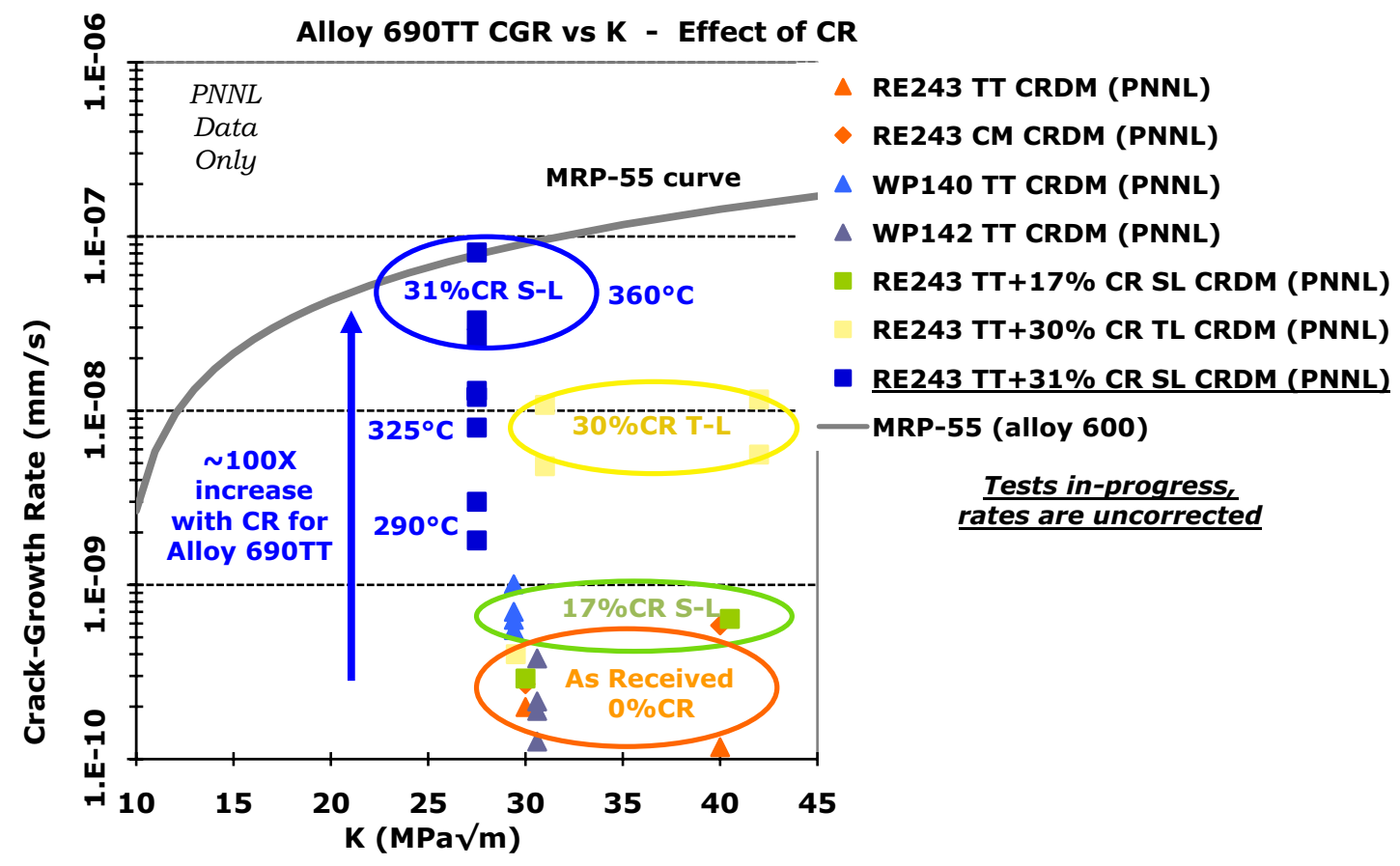

Figure 4.40 Summary plot showing constant K crack-growth results for the alloy 690TT materials either in the as-received, non-CR condition or after cold rolling. 
Table 4.9 Microstructure, hardness and SCC rates for heat RE243 alloy 690 materials.

\begin{tabular}{|c|c|c|c|}
\hline Sample & Microstructure & $\begin{array}{l}\text { Mid-Plane } \\
\text { Hardness }\end{array}$ & $\begin{array}{l}\text { PNNL } \\
\text { CGRs }\end{array}$ \\
\hline $\begin{array}{l}\text { (0 - TT) PNNL CRDM } \\
\text { alloy } 690 T T ; \text { Test } \\
\text { sample CT014 }\end{array}$ & $\begin{array}{l}\text { Semi-continuous (small discrete + cellular) } \\
\text { carbides on GBs plus Cr depletion, few TiN } \\
\text { at GBs and in matrix; equiaxed grains }\end{array}$ & $\begin{array}{c}175 \\
\mathrm{~kg} / \mathrm{mm}^{2}\end{array}$ & $\begin{array}{c}<5 \times 10^{-10} \\
\mathrm{~mm} / \mathrm{s}\end{array}$ \\
\hline $\begin{array}{l}(0-\mathrm{CM}) \mathrm{PNNL} \\
\text { CRDM alloy 690CM; } \\
\text { Test sample CT015 }\end{array}$ & $\begin{array}{c}\text { Few carbides and well-spaced TiN on GBs } \\
\text { with no Cr depletion; few TiN in matrix; } \\
\text { equiaxed grains }\end{array}$ & $\begin{array}{c}165 \\
\mathrm{~kg} / \mathrm{mm}^{2}\end{array}$ & $\begin{array}{c}<5 \times 10^{-10} \\
\mathrm{~mm} / \mathrm{s}\end{array}$ \\
\hline $\begin{array}{l}1 \text { - TT) PNNL CRDM } \\
\text { alloy } 690 T T 17 \% \text { CR; } \\
\text { Test sample CT019 }\end{array}$ & $\begin{array}{l}\text { As for CT014 (0-TT) above + very low } \\
\text { density of GB voids and cracked carbides }\end{array}$ & $\begin{array}{c}250 \\
\mathrm{~kg} / \mathrm{mm}^{2}\end{array}$ & $\begin{array}{l}\sim 6 \times 10^{-10} \\
\mathrm{~mm} / \mathrm{s} \\
(\mathrm{S}-\mathrm{L})\end{array}$ \\
\hline $\begin{array}{c}(1-\mathrm{CM}) \mathrm{PNNL} \\
\text { CRDM alloy } 690 \mathrm{CM} \\
\text { 17\%CR; Test sample } \\
\text { CT020 }\end{array}$ & $\begin{array}{c}\text { As for CT015 }(0-\mathrm{CM}) \text { above }+ \text { no obvious } \\
\text { permanent damage }\end{array}$ & $\begin{array}{c}235 \\
\mathrm{~kg} / \mathrm{mm}^{2}\end{array}$ & $\begin{array}{c}\sim 6 \times 10^{-10} \\
\mathrm{~mm} / \mathrm{s} \\
(\mathrm{S}-\mathrm{L})\end{array}$ \\
\hline $\begin{array}{l}\text { (2 - TT) PNNL CRDM } \\
\text { alloy } 690 T T 30 \% \text { CR; } \\
\text { Test sample CT022 }\end{array}$ & $\begin{array}{l}\text { As for CT014 (0 -TT) above + slightly } \\
\text { elongated grains; moderate density of GB } \\
\text { voids and some cracked carbides, low } \\
\text { density of cracked TiN at GBs and in matrix }\end{array}$ & $\begin{array}{c}300 \\
\mathrm{~kg} / \mathrm{mm}^{2}\end{array}$ & $\begin{array}{l}1.2 \times 10^{-8} \\
\mathrm{~mm} / \mathrm{s} \\
(\mathrm{T}-\mathrm{L})\end{array}$ \\
\hline $\begin{array}{c}\text { (2 - CM) PNNL } \\
\text { CRDM alloy 690CM } \\
\text { 30\%CR; Test sample } \\
\text { CT023 }\end{array}$ & $\begin{array}{l}\text { As for CT015 (0 -CM) above + slightly } \\
\text { elongated grains; low density of cracked TiN } \\
\text { at GBs and in matrix, few isolated GB voids }\end{array}$ & $\begin{array}{c}290 \\
\mathrm{~kg} / \mathrm{mm}^{2}\end{array}$ & $\begin{array}{l}1.0 \times 10^{-9} \\
\mathrm{~mm} / \mathrm{s} \\
(\mathrm{T}-\mathrm{L})\end{array}$ \\
\hline $\begin{array}{l}\text { (3 - TT) PNNL CRDM } \\
\text { alloy } 690 T T 31 \% \text { CR; } \\
\text { Test sample CT038 }\end{array}$ & As for CT022 (2 -TT) above & $\begin{array}{c}298 \\
\mathrm{~kg} / \mathrm{mm}^{2}\end{array}$ & $\begin{array}{c}4-8 \times 10^{-8} \\
\mathrm{~mm} / \mathrm{s} \\
(\mathrm{S}-\mathrm{L})\end{array}$ \\
\hline $\begin{array}{c}\text { (3 - CM) PNNL } \\
\text { CRDM alloy 690CM } \\
\text { 31\%CR; Test sample } \\
\text { CT039 }\end{array}$ & As for CT023 (2-CM) above & $\begin{array}{c}290 \\
\mathrm{~kg} / \mathrm{mm}^{2}\end{array}$ & $\begin{array}{c}5-9 \times 10^{-9} \\
\mathrm{~mm} / \mathrm{s} \\
(\mathrm{S}-\mathrm{L})\end{array}$ \\
\hline
\end{tabular}

The test results on the $31 \% \mathrm{CR}$ alloy $690 \mathrm{TT}$ CRDM material demonstrates that $1 \mathrm{D}$ cold rolling is clearly detrimental to SCC resistance even for extruded tubing with a homogeneous starting microstructure. This is contrary to previous assertions that the high SCC susceptibility may be related to non-homogeneous plate microstructures where compositional banding is present. The current work on the CRDM heat RE243 also provides some additional insights into material condition and microstructural effects on SCC susceptibility through the tests on the solutionannealed alloy $690 \mathrm{CM}$ specimens. While no significant crack growth rate differences were observed between TT and CM for the non-CR and the 17\%CR materials, the $30-31 \%$ CR alloy $690 \mathrm{CM}$ specimens revealed consistently lower SCC propagation rates than the alloy 690TT specimens. Figure 4.41 summarizes this data and reveals growth rates $\sim 10 \mathrm{X}$ higher for the TT materials than the CM materials even though the hardness levels were similar between these CR materials as shown in Table 4.9. The most significant microstructural difference is the grain boundary precipitate distributions with a semi-continuous distribution of $\mathrm{Cr}_{23} \mathrm{C}_{6}$ carbides in the TT condition and only isolated carbides in the solution-annealed CM condition. However in addition to dissolving IG $\mathrm{Cr}_{23} \mathrm{C}_{6}$ carbides, the solution anneal also removed the grain boundary $\mathrm{Cr}$ depletion present in the TT material and puts carbon back into solution for the CM material. 


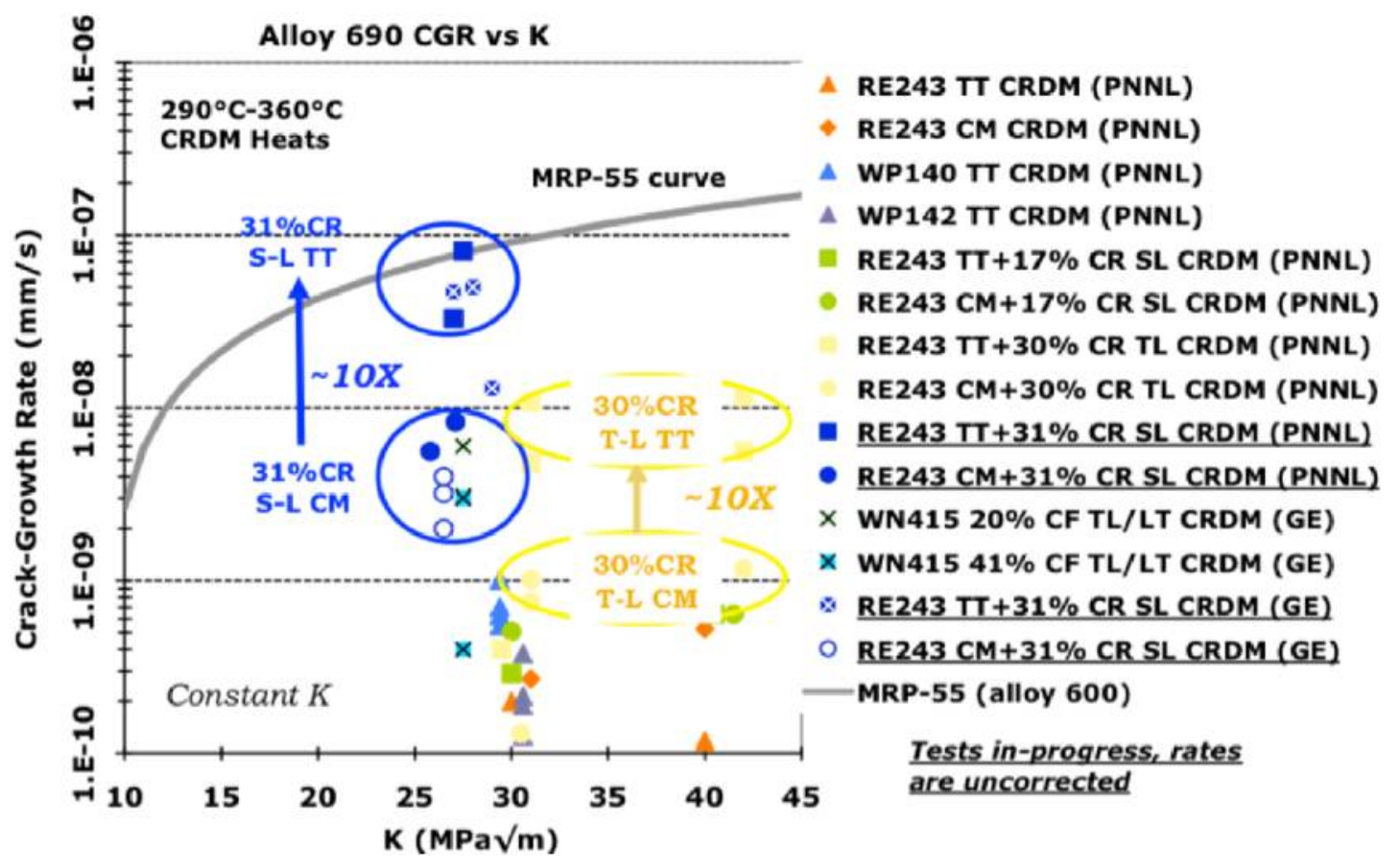

Figure 4.41 Summary of constant K crack-growth results for alloy 690 CRDM heats highlighting differences between the TT and CM materials after extensive 1D cold rolling.

Important results have been obtained investigating grain boundary damage in the alloy 690TT and CM materials after cold rolling. Each of the $17 \% \mathrm{CR}$ and $30 \% \mathrm{CR}$ materials are heavily deformed as documented by high strain contrast in SEM images and extremely high dislocation densities in TEM images. Qualitatively, these observations also indicate enhanced deformation localized at grain boundaries particularly for the alloy 690TT material. Consistent with this apparent higher boundary damage for the TT materials is the formation of small voids adjacent to IG carbides along with a lower density of cracked $\mathrm{Cr}$ carbides after $30 \% \mathrm{CR}$. Very little permanent damage of this type is seen in the $30 \% \mathrm{CR}$ alloy $690 \mathrm{CM}$ material. Table 4.10 includes the observed CR-induced damage and links it to the measured SCC crack-growth rates. Higher SCC propagation rates are only seen in the $30-31 \%$ CR condition where significant permanent damage is found at grain boundaries. A key question is what CR-induced microstructural change promotes IGSCC susceptibility and the high growth rates under PWR primary water conditions. Clearly, the presence of grain boundary carbides in the TT material leads to more extensive grain boundary deformation, voids and cracked carbides than for the CM material. Additional insights have been obtained from SEM and TEM examinations of SCC cracks and crack tips in the 30\%CR alloy 690TT specimen (CT022) and these will be described and discussed in Chapter 5. 
Table 4.10 Microstructure, CR damage and SCC rates for heat RE243 alloy 690 materials.

\begin{tabular}{|c|c|c|c|}
\hline Sample & Microstructure & CR Damage & $\begin{array}{l}\text { PNNL } \\
\text { CGRs }\end{array}$ \\
\hline $\begin{array}{l}\text { (0) PNNL CRDM } \\
\text { alloy } 690 T T ; \text { Test } \\
\text { sample CT014 }\end{array}$ & $\begin{array}{l}\text { Semi-continuous (small discrete }+ \\
\text { cellular) carbides on GBs plus } \mathrm{Cr} \\
\text { depletion, few TiN at GBs and in } \\
\text { matrix; equiaxed grains }\end{array}$ & $\begin{array}{l}\text { No voids and cracked } \\
\text { carbides on GBs, nor } \\
\text { cracked TiN in matrix }\end{array}$ & $\begin{array}{c}<5 \times 10^{-10} \\
\mathrm{~mm} / \mathrm{s}\end{array}$ \\
\hline $\begin{array}{l}\text { (1) PNNL CRDM } \\
\text { alloy } 690 T T 17 \% \text { CR; } \\
\text { Test sample CT019 }\end{array}$ & $\begin{array}{c}\text { Semi-continuous (small discrete }+ \\
\text { cellular) carbides on GBs, few } \\
\text { TiN at GBs and in matrix; slightly } \\
\text { elongated grains }\end{array}$ & $\begin{array}{c}\text { Low density of voids } \\
\text { and cracked carbides } \\
\text { on GBs, few cracked } \\
\text { TiN in matrix } \\
\end{array}$ & $\begin{array}{l}\sim 6 \times 10^{-10} \\
\mathrm{~mm} / \mathrm{s} \\
(\mathrm{S}-\mathrm{L})\end{array}$ \\
\hline $\begin{array}{l}(2-\mathrm{TT}) \text { PNNL CRDM } \\
\text { alloy } 690 \mathrm{TT} 30 \% \mathrm{CR} ; \\
\text { Test sample CT022 }\end{array}$ & $\begin{array}{l}\text { Semi-continuous (small discrete }+ \\
\text { cellular) carbides on GBs plus } \mathrm{Cr} \\
\text { depletion, few TiN at GBs and in } \\
\text { matrix; slightly elongated grains }\end{array}$ & $\begin{array}{l}\text { Moderate density of } \\
\text { voids and some } \\
\text { cracked carbides on } \\
\text { GBs \& TiN in matrix }\end{array}$ & $\begin{array}{c}1.2 \times 10^{-8} \\
\mathrm{~mm} / \mathrm{s} \\
(\mathrm{T}-\mathrm{L})\end{array}$ \\
\hline $\begin{array}{c}\text { (2 - CM) PNNL } \\
\text { CRDM alloy 690CM } \\
\text { 30\%CR; Test sample } \\
\text { CT023 } \\
\end{array}$ & $\begin{array}{l}\text { Few carbides and well-spaced } \\
\text { TiN on GBs, few TiN in matrix; } \\
\text { slightly elongated grains }\end{array}$ & $\begin{array}{l}\text { Low density of } \\
\text { cracked TiN on GBs } \\
\& \text { in matrix, isolated } \\
\text { void at triple pt. } \\
\end{array}$ & $\begin{array}{c}1.0 \times 10^{-9} \\
\mathrm{~mm} / \mathrm{s} \\
(\mathrm{T}-\mathrm{L})\end{array}$ \\
\hline $\begin{array}{l}\text { (3) PNNL CRDM } \\
\text { alloy } 690 T T 31 \% \text { CR; } \\
\text { Test sample CT038 }\end{array}$ & $\begin{array}{l}\text { Semi-continuous (small discrete }+ \\
\text { cellular) carbides on GBs plus } \mathrm{Cr} \\
\text { depletion, few TiN at GBs and in } \\
\text { matrix; slightly elongated grains }\end{array}$ & $\begin{array}{l}\text { Measurements in } \\
\text { progress, expected } \\
\text { similar to }(2-\mathrm{TT}) \\
30 \% \mathrm{CR} \text { alloy } 690 \mathrm{TT} \\
\end{array}$ & $\begin{array}{c}4-8 \times 10^{-8} \\
\mathrm{~mm} / \mathrm{s} \\
(\mathrm{S}-\mathrm{L})\end{array}$ \\
\hline $\begin{array}{c}\text { (3 - CM) PNNL } \\
\text { CRDM alloy 690CM } \\
31 \% \text { CR; Test sample } \\
\text { CT039 } \\
\end{array}$ & $\begin{array}{l}\text { Few carbides and well-spaced } \\
\text { TiN on GBs, few TiN in matrix; } \\
\text { slightly elongated grains }\end{array}$ & $\begin{array}{c}\text { Measurements in } \\
\text { progress, expected } \\
\text { similar to }(2-\mathrm{CM}) \\
30 \% \mathrm{CR} \text { alloy } 690 \mathrm{CM} \\
\end{array}$ & $\begin{array}{c}5-9 \times 10^{-9} \\
\mathrm{~mm} / \mathrm{s} \\
(\mathrm{S}-\mathrm{L})\end{array}$ \\
\hline
\end{tabular}




\section{SCC Crack-Growth-Rate Testing on Cold-Rolled Alloy 690 Plate Materials}

\subsection{Compositions and Microstructure of Alloy 690 Plate Materials}

Three different alloy 690 plate materials have been obtained at PNNL with a large section received from EPRI and small, cold-rolled pieces from Argonne National Laboratory (ANL) and GEG Research. Information available on these three heats is summarized in Table 5.1. It is important to note that the ANL and GEG plate materials were in the mill-annealed condition. The final annealing was reported at either 1038 or $996^{\circ} \mathrm{C}$ followed by an air cool.

Table 5.1 Alloy 690 plate materials at PNNL.

\begin{tabular}{|c|c|c|c|}
\hline $\begin{array}{l}\text { Material and } \\
\text { Source }\end{array}$ & $\begin{array}{l}\text { Heat Number } \\
\text { \& Description }\end{array}$ & Composition, wt $\%$ & Material Condition \\
\hline $\begin{array}{l}\text { EPRI Alloy 690TT } \\
\text { Huntington Alloys }\end{array}$ & $\begin{array}{c}\text { NX8625HG21 } \\
\text { 1.34" Plate } \\
\end{array}$ & $\mathrm{Ni}-30.3 \mathrm{Cr}-10.0 \mathrm{Fe}-0.027 \mathrm{C}$ & $\begin{array}{c}\text { Mill Anneal }+718-727^{\circ} \mathrm{C} \\
\text { thermal treatment }\end{array}$ \\
\hline $\begin{array}{l}\text { ANL Alloy } 690 \\
\text { ATI Wah Chang }\end{array}$ & $\begin{array}{l}\text { NX3297HK12 } \\
\text { 2.125" Flat Bar }\end{array}$ & $\begin{array}{c}\text { Ni-30.8Cr-8.5Fe-0.04C- } \\
0.33 \mathrm{Mn}-0.02 \mathrm{Si}-0.18 \mathrm{Al}-0.27 \mathrm{Ti}- \\
0.037 \mathrm{~N}-0.0006 \mathrm{~S}-0.006 \mathrm{P}\end{array}$ & $\begin{array}{l}1038^{\circ} \mathrm{C} \text { for } 2 \mathrm{~h} \text { and air cooled } \\
\text { (MIL-DTL-24802), } \\
\text { unidirectional CR to } 26 \% \\
\text { reduction, } 3 \text { passes }\end{array}$ \\
\hline $\begin{array}{l}\text { GEG Alloy } 690 \\
\text { ATI Allvac }\end{array}$ & $\begin{array}{c}\text { B25K } \\
3.25 " \text { Bar }\end{array}$ & $\begin{array}{c}\mathrm{Ni}-29.3 \mathrm{Cr}-9.2 \mathrm{Fe}-0.034 \mathrm{C}- \\
0.22 \mathrm{Mn}-0.06 \mathrm{Si}-0.26 \mathrm{Al}-0.37 \mathrm{Ti}- \\
0.026 \mathrm{~N}-0.006 \mathrm{P}-<0.0003 \mathrm{~S}\end{array}$ & $\begin{array}{l}996^{\circ} \mathrm{C} \text { for } 0.33 \mathrm{~h} \text { and air } \\
\text { cooled, unidirectional } \mathrm{CR} \text { to } \\
20 \% \text { reduction, } 2 \text { passes }\end{array}$ \\
\hline
\end{tabular}

Optical Metallography on ANL 26\%CR and GEG 20\%CR Alloy 690 Plate Materials

A photo of the piece of the $26 \%$ CR plate section obtained from ANL (heat NX3297HK12) is shown in Figure 5.1 along with the positioning of the CT specimens. Microstructural examinations were conducted using a single through-thickness slice (shown in Figure 5.2) and a CT test sample (CT036) after SCC testing in simulated PWR primary water. Optical metallography was employed to map the microstructure across the entire thickness of the plate as illustrated in Figures 5.2 and 5.3. Examples from the lower section of the plate are presented in Figure 5.2 revealing a region of extremely large grains. Beyond these unique features, the grain size appeared to be reasonably consistent with no evidence for bands of finer and larger grains. In addition, regions with obviously higher densities of $\mathrm{Cr}$ carbides or Ti-rich precipitates were not identified during initial optical examinations. The areas identified as (d) and (e) in Figure 5.2 are just below the midplate and correspond to the crack-growth plane for the PNNL CT samples. They show no evidence for microstructural banding. The uniform microstructure extended through the plate midplane and into the upper section of the plate shown in Figure 5.3. Careful examination did identify several regions with bands of finer and larger grains starting at about 3-4 mm from the plate midplane. In addition, a higher density of small IG and TG $\mathrm{Cr}$ carbides $(<1 \mu \mathrm{m})$ were found in the finer-grain bands along with a higher density small and large $\mathrm{Ti}$ nitrides or carbonitrides. This microstructural variation is consistent with compositional banding and is similar to the GEG observations [Refs. 14,15] on the ANL plate material they tested. It is possible that GEG machined their CT samples from the top of the ANL plate and could have intersected these banded regions. 


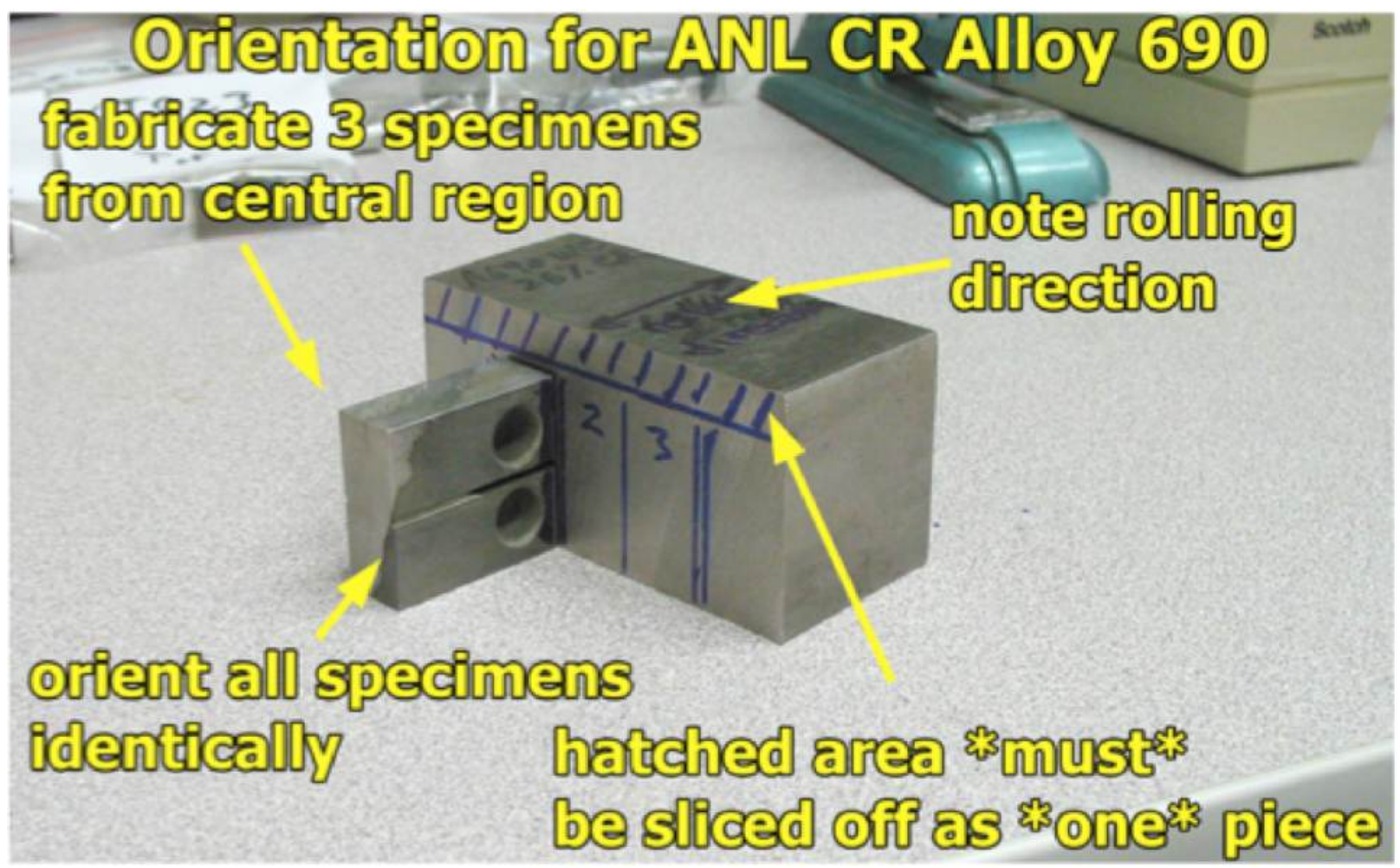

Figure 5.1 Photograph showing the as-received, 26\%CR plate material from ANL (heat NX3297HK12) and sectioning conducted to obtain 3 CT samples for SCC crack-growth testing, slices for metallography corresponding to the CT sample areas, and a top piece for future SCC initiation test samples.

Further confirmation of the SCC crack-growth plane microstructure is presented in Figure 5.4 by examination of the PNNL CT036 test sample. Cross-sections were prepared for high-resolution characterizations of the SCC cracks and crack tips (described in Chapter 6). Before final preparation steps for TEM characterization by ion milling, optical metallography and SEM were used to document the general microstructure in the region surrounding the SCC cracks. Consistent with the prior observations in Figure 5.2, there was no evidence for banding at or near the crack-growth plane. 


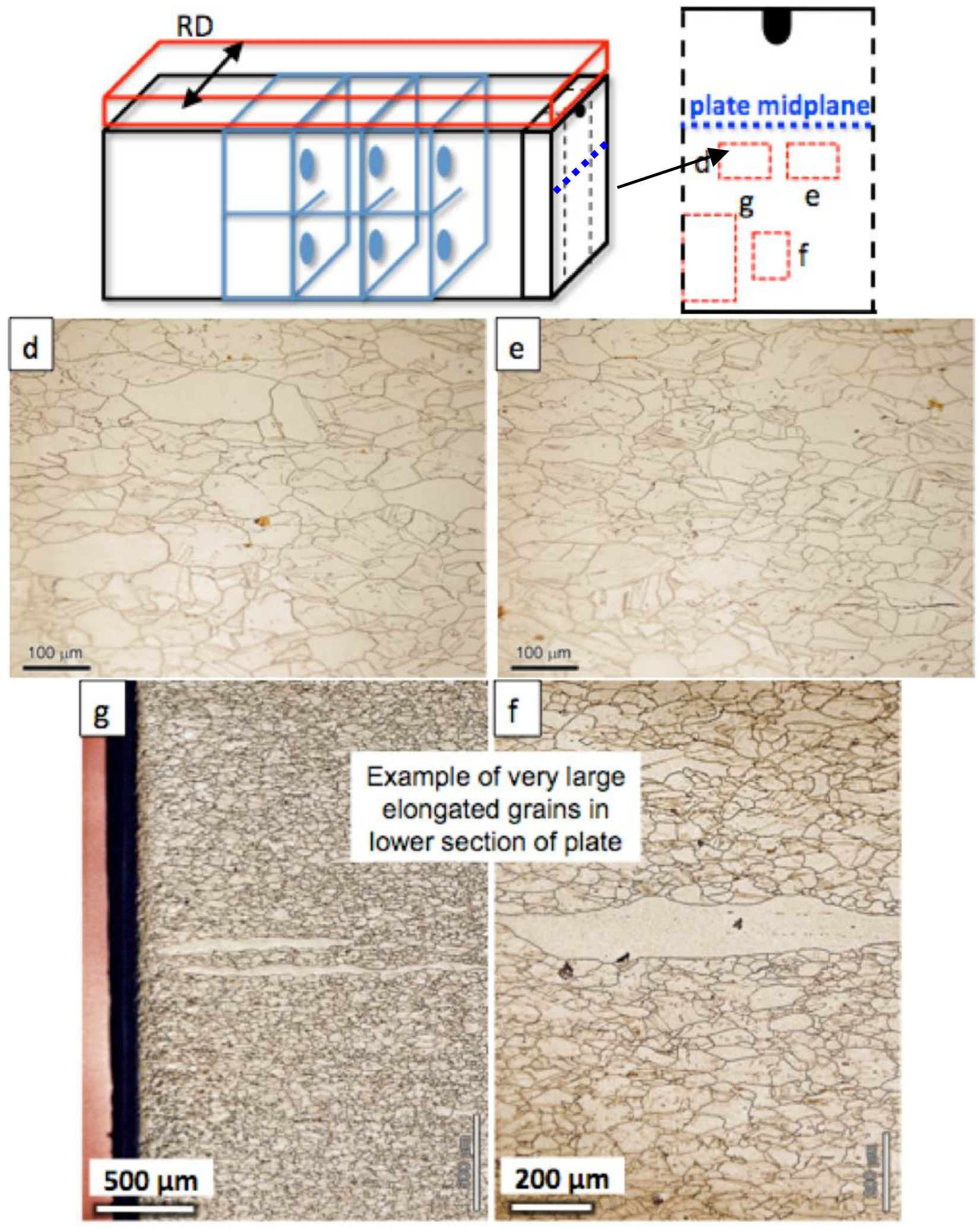

Figure 5.2 Optical micrographs illustrating microstructures in the lower section of the $26 \%$ CR ANL plate (heat NX3297HK12). 

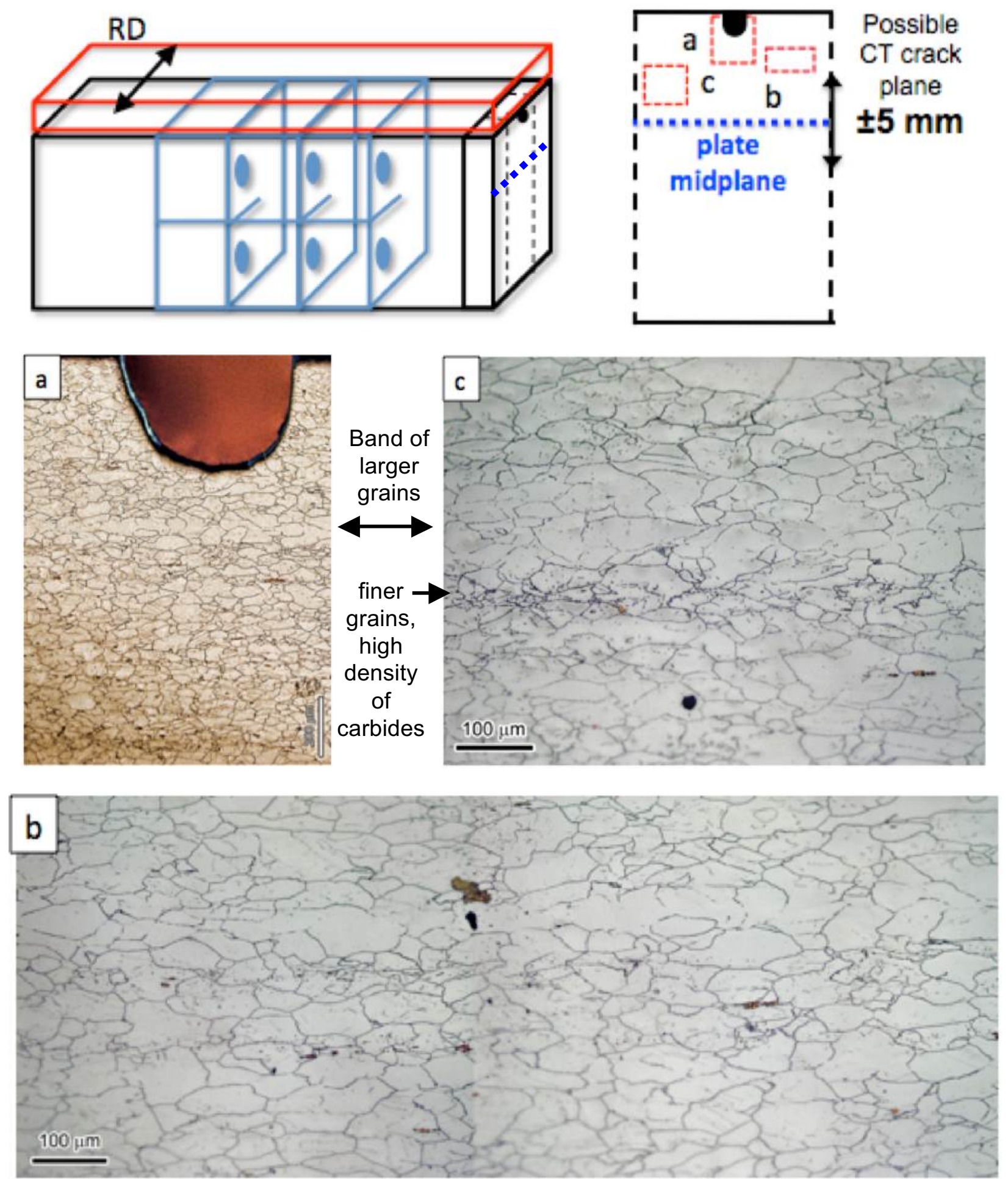

Figure 5.3 Optical micrographs illustrating microstructures in the upper section of the $26 \%$ CR ANL plate (heat NX3297HK12). Evidence of banded microstructure can be seen in selected regions $(a, b$ and $c)$ above the plate midplane. 


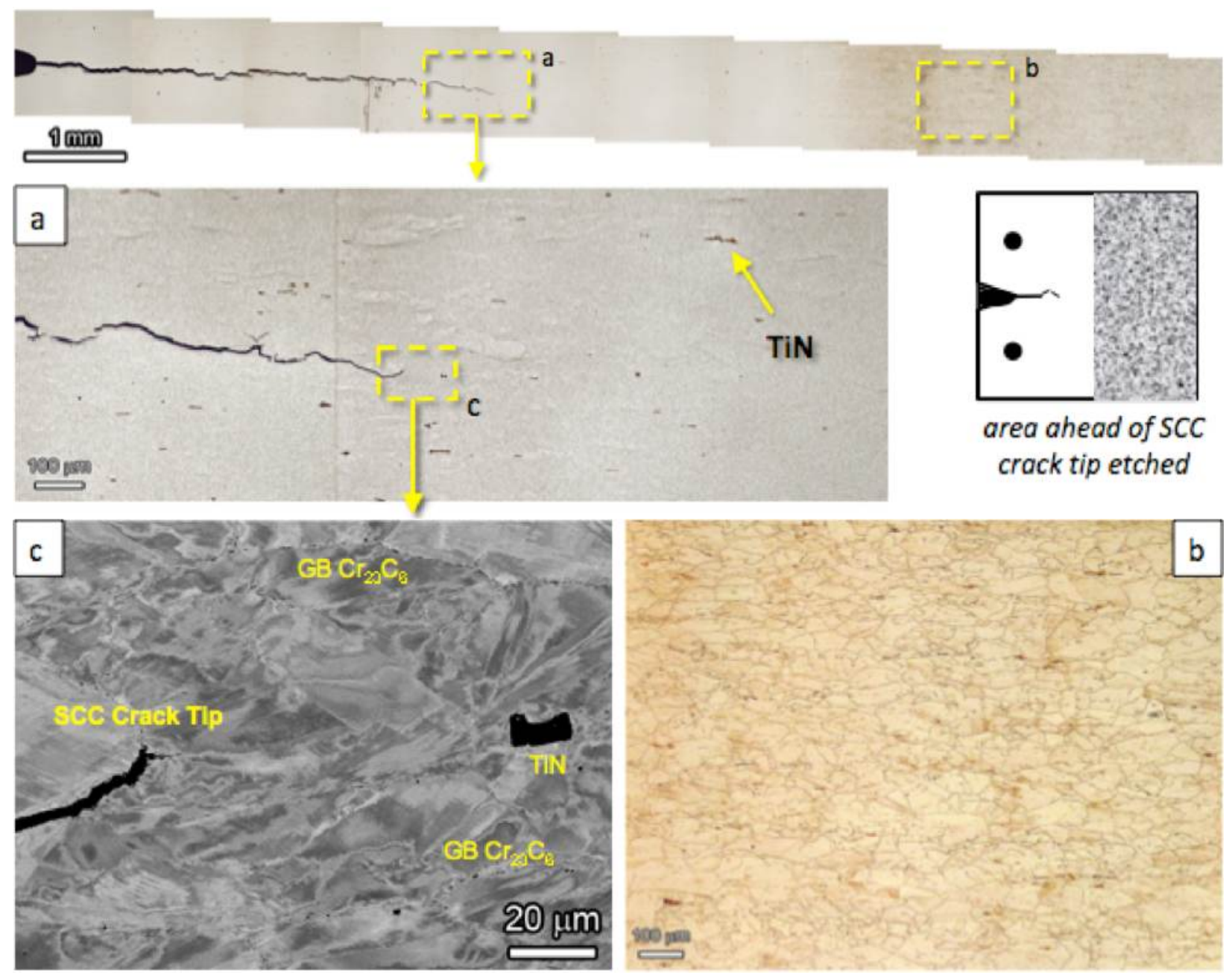

Figure 5.4 Optical and SEM micrographs showing cross-section microstructures in the $26 \%$ CR ANL plate (heat NX3297HK12) at and near the SCC crack-growth plane for specimen CT036.

In summary, optical examinations of etched samples for the $26 \%$ CR ANL plate have revealed: (1) no evidence of banded microstructures in the thickness location corresponding to the crackgrowth plane in PNNL SCC test samples (just below the CR plate midplane); (2) bands of larger and finer grains (typically with a higher density of precipitates) were identified in the "upper" half of the plate; and (3) regions of very large, elongated grains were found in the lower third of the plate. Based on the observation for this through-thickness plate location, the ANL plate is not extensively banded and contains only isolated regions where such non-uniform microstructure is present. This assessment is consistent with that reported by Alexandreanu [Ref. 16]. It appears to be possible that $0.5 \mathrm{~T} \mathrm{CT}$ test samples machined from the top section of the ANL CR plate might intersect the banded microstructure documented above the plate midplane and be more consistent with results from Andresen [Ref. 14]. This is important for comparisons made later in this chapter to SCC tests performed at other laboratories on the $26 \%$ CR ANL plate. 
Optical metallography was also performed on the 20\%CR GEG plate (heat B25K), but examinations were very limited in comparison to that for the ANL material. Microstructural characterizations focused on the area near the crack-growth plane in the CT specimens. A highly variable distribution of second-phase particles was observed with clear evidence for compositional banding. An extreme example showing clusters of particles grouped in bands is shown in Figure 5.5. Based on the SEM and TEM results (presented in the following section), most particles revealed by the etchant are $\mathrm{Cr}$ carbides, $\mathrm{Ti}$ nitrides or $\mathrm{Ti}$ carbonitrides. Occasionally particles are seen on grain boundaries, but most are arrayed through the matrix. The compositional banding in this material was oriented perpendicular to the CR direction and to the SCC crack-growth direction. These microstructural observations are generally consistent with those reported by Andresen [Refs. 15,17] on this CR plate material.

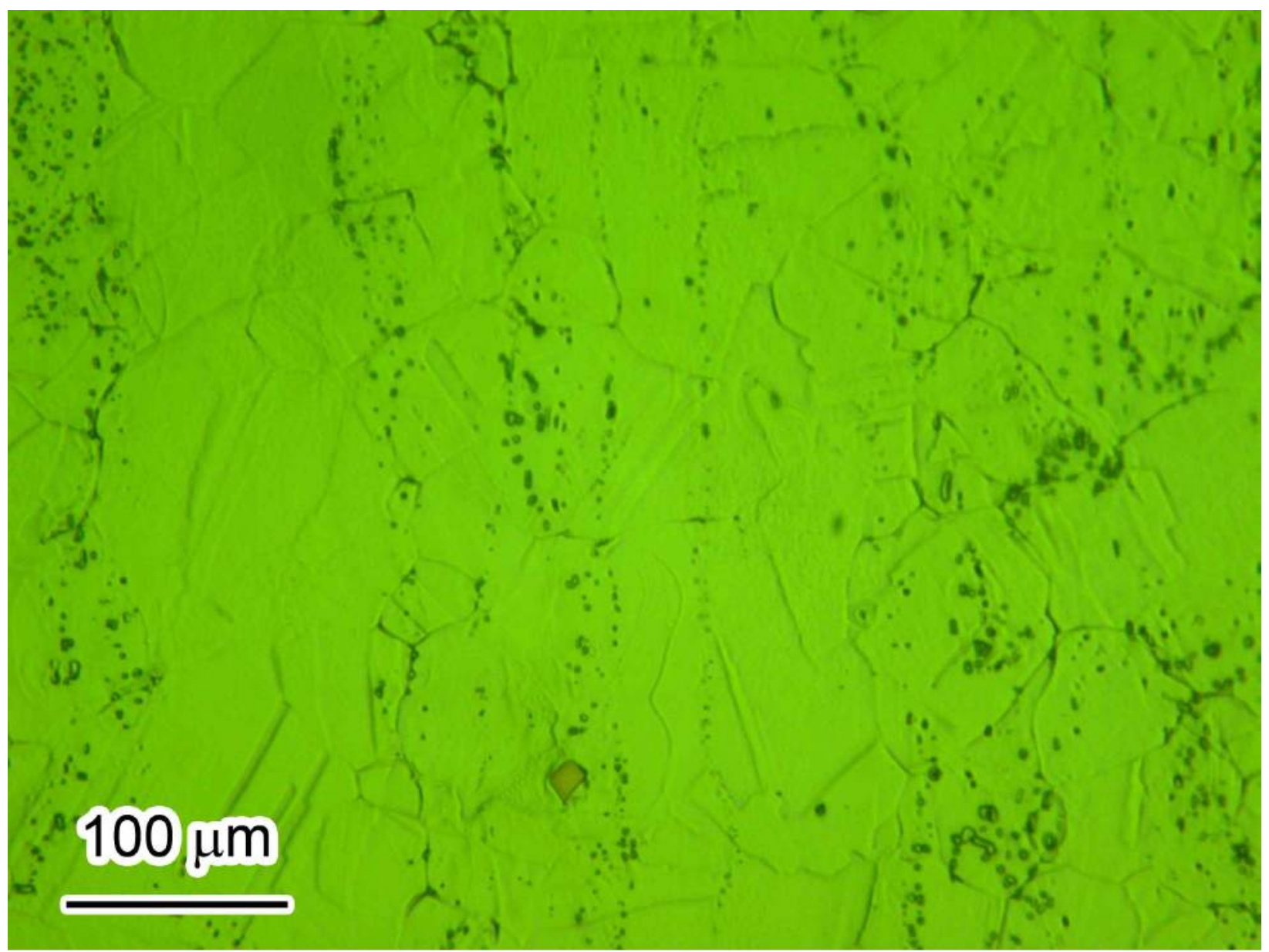

Figure 5.5 Optical micrograph showing high density of banded second-phase particles in the GEG $20 \%$ CR alloy 690 plate (heat B25K). The compositional bands in this material were oriented perpendicular to the rolling direction and SCC crack-growth direction for the plate. 
Characterizations on the $26 \%$ CR ANL and $20 \%$ CR GEG alloy 690 materials by SEM and TEM methods will be presented in this section to better elucidate the general grain and precipitate structures. More detailed examinations focused on the CR damage microstructures will be described in Section 5.2 using many of these same techniques.

The ANL alloy 690 (heat NX3297HK12) material had a high density of $\mathrm{M}_{23} \mathrm{C}_{6}$ carbides on most high-energy grain boundaries as illustrated in Figure 5.6. Higher magnification of these grain boundaries (Figure 5.7) showed that carbides were slightly elongated and $\sim 400-500 \mathrm{~nm}$ in size with an average carbide separation along high-energy grain boundaries of $\sim 300-500 \mathrm{~nm}$. EDS elemental maps in Figure 5.8 shows the distribution of the $\mathrm{Cr}$-rich $\mathrm{M}_{23} \mathrm{C}_{6}$ carbides along a grain boundary at a slightly higher magnification. Small $(\sim 200 \mathrm{~nm})$, slightly elongated TiN particles were also observed sporadically along the grain boundaries as shown by the example in Figure $5.7(\mathrm{~d})$. In addition, a higher density of Ti-rich particles (nitrides and carbonitrides) was found in bands in several regions as documented in Figures 5.9 and 5.10.

Limited TEM analyses were performed to investigate the grain boundary composition in the ANL material. Asymmetric $\mathrm{Cr}$ depletion profiles were detected at high-energy boundaries between carbides as illustrated in Figures 5.11 and 5.12. The $\mathrm{Cr}$ concentrations typically decreased by 5 to $8 \mathrm{wt} \%$ at grain boundary regions to a corrected values of $22-25 \mathrm{wt} \%$ between carbides and $\mathrm{Ni}$ was enriched by a similar amount, while the Fe concentration remained relatively constant across the grain boundaries. Some variability in these measured depletion profiles was observed among the finite number of grain boundaries examined and appeared to depend on the density/spacing of IG carbides. The observed asymmetry in the composition profiles may result from the heat treatment with carbide precipitation and depletion apparently developing during cooling from the mill-anneal temperature $\left(1038^{\circ} \mathrm{C}\right)$. A final example of a measured compositional profile is presented in Figure 5.13 taken across the matrix/carbide interface. For the profile spacing employed, the carbide interfaces show an abrupt step change in elemental composition with a $\mathrm{Cr}$ depletion region in the adjacent matrix.

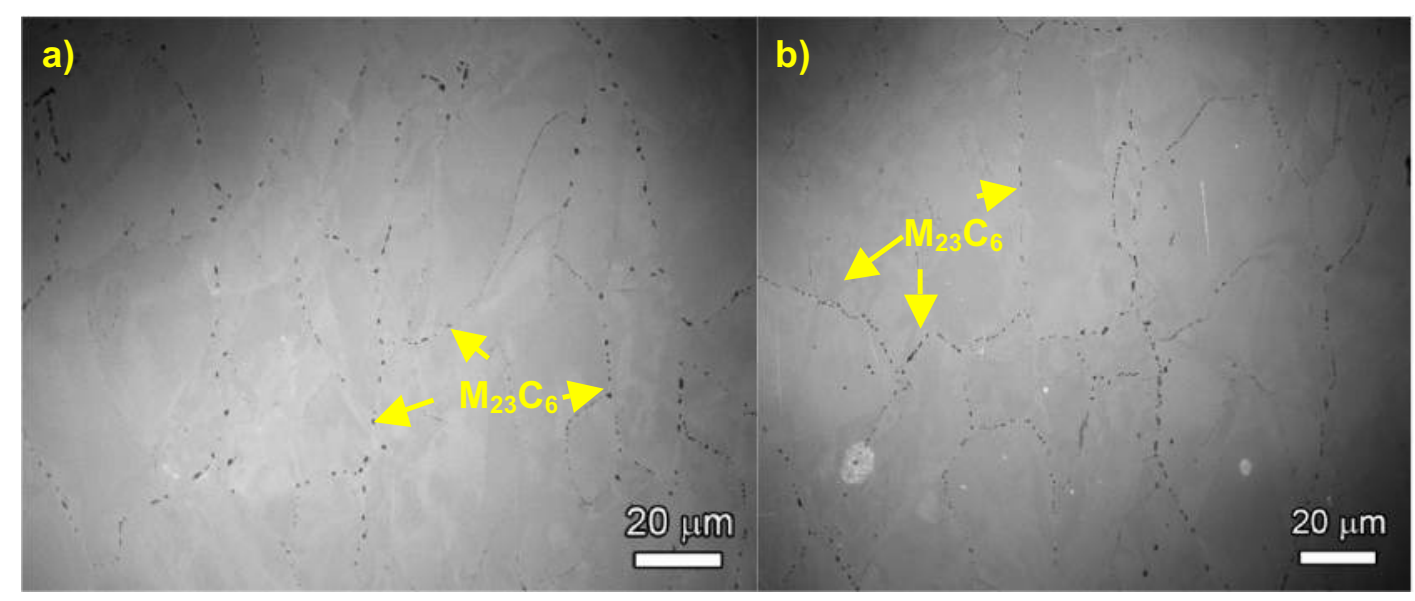

Figure 5.6 Low magnification backscattered SEM images illustrating general microstructure in $26 \% \mathrm{CR}$ ANL alloy 690 plate (heat NX3297HK12). 


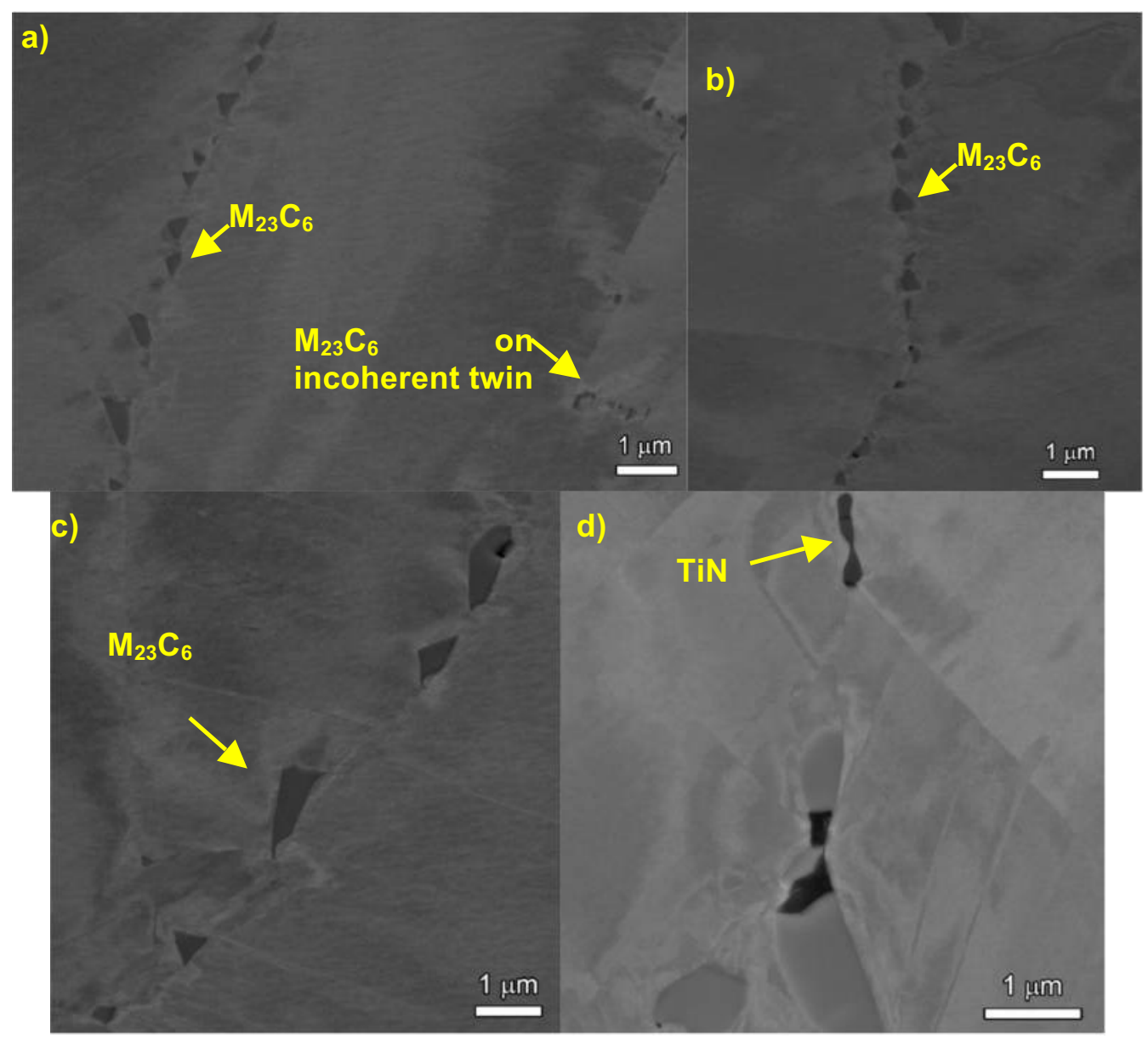

Figure 5.7 High magnification backscattered SEM images (a, b, c and d) illustrating typical grain boundary precipitate microstructures in $26 \%$ CR ANL alloy 690 plate (heat NX3297HK12).

The alloy 690 (heat B25K) material received from GEG was found to have a varied carbide microstructure throughout the sample with a higher density of TG than IG carbides as illustrated in Figures 5.14, 5.15 and 5.16. The majority of grain boundaries had a low density of irregularly spaced carbides as illustrated in Figures 5.14(a,c,d), 5.15(a,b,c) and 5.16(c,d). However, a higher density of evenly spaced, discrete carbides ( $\sim 500 \mathrm{~nm}$ in diameter) was observed on several boundaries as can be seen in Figures 5.14(b), 5.15(d) and 5.16(b). The carbide spacing on these boundaries is $\sim 500 \mathrm{~nm}$ apart, while boundaries with isolated carbides had spacings closer to $10 \mu \mathrm{m}$. Limited TEM examinations revealed no significant $\mathrm{Cr}$ depletion on the highenergy grain boundaries analyzed, but all had a low density of carbides. Additional TEM samples would need to be prepared to locate and analyze grain boundaries with a higher density of carbides where $\mathrm{Cr}$ depletion might be expected. Transgranular $\mathrm{M}_{23} \mathrm{C}_{6}$ carbides with similar dimensions to those of the IG carbides were present throughout the sample and their distribution often suggests that they had probably formed on prior grain boundaries. Examples of these matrix carbides are presented in Figures 5.14(d), 5.15(a,b,c,d) and 5.16(c,d). Lastly, elongated TiN inclusions on the order of micrometers wide and 5-10 $\mu \mathrm{m}$ long were observed in the grains (Figure 5.15 and $5.16 \mathrm{c})$ as well as small $(200-300 \mathrm{~nm})$ TiN at grain boundaries and in the matrix. 


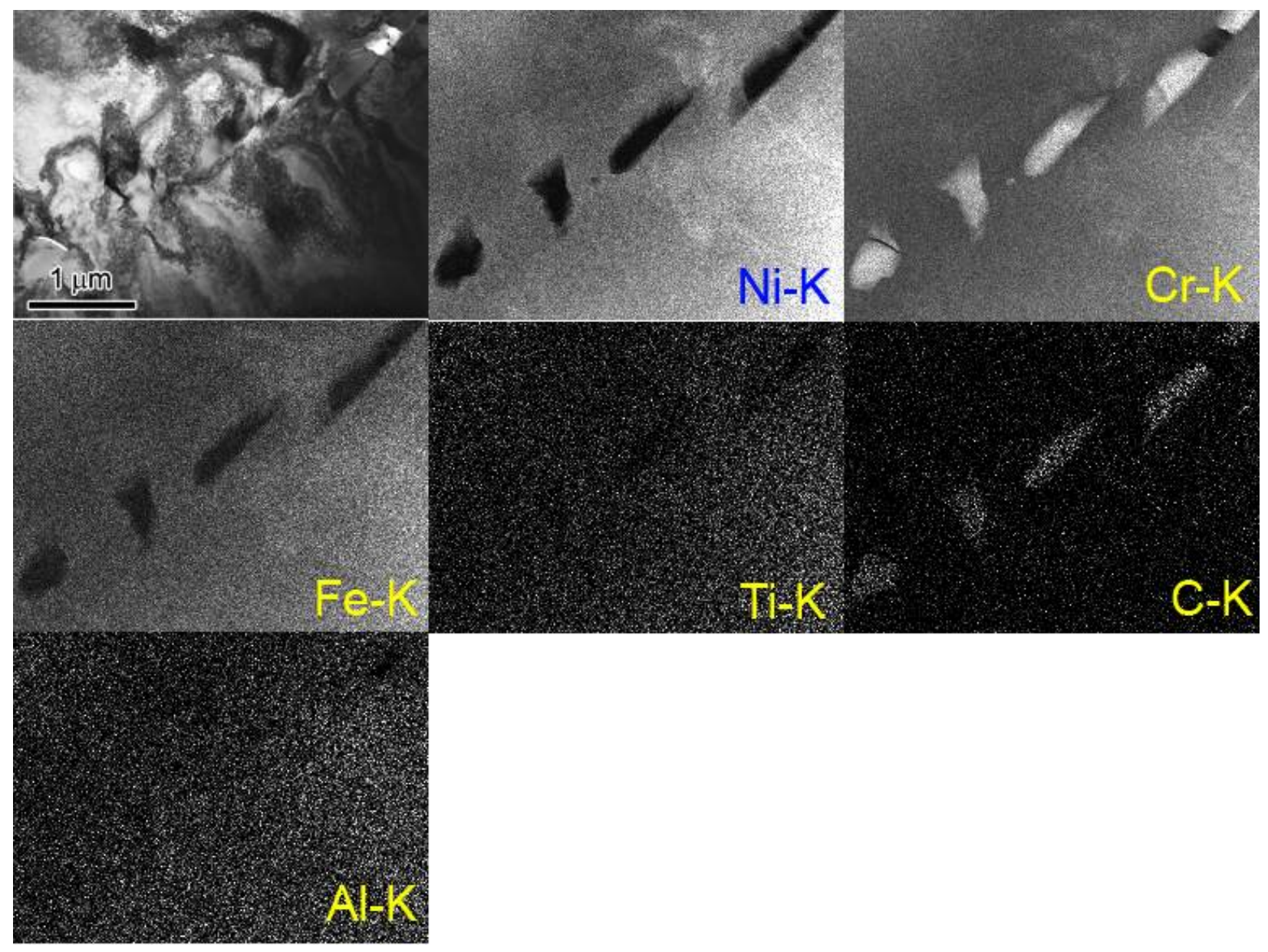

Figure 5.8 TEM EDS elemental maps illustrating the carbide microstructure in $26 \% \mathrm{CR}$ ANL alloy 690 plate (heat NX3297HK12).

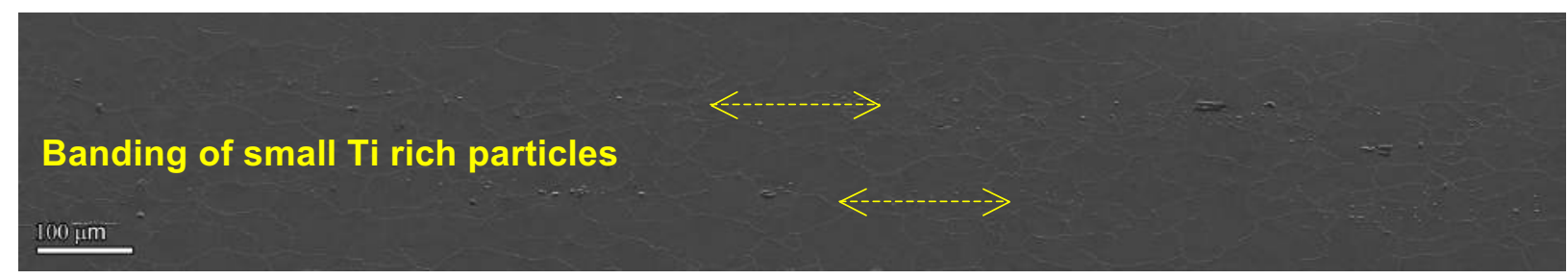

Figure 5.9 SEM (SE) montage of $26 \%$ CR ANL alloy 690 (heat NX3297HK12) lightly etched to bring out grain structure showing banding of small, $\mathrm{Ti}$ rich particles. 


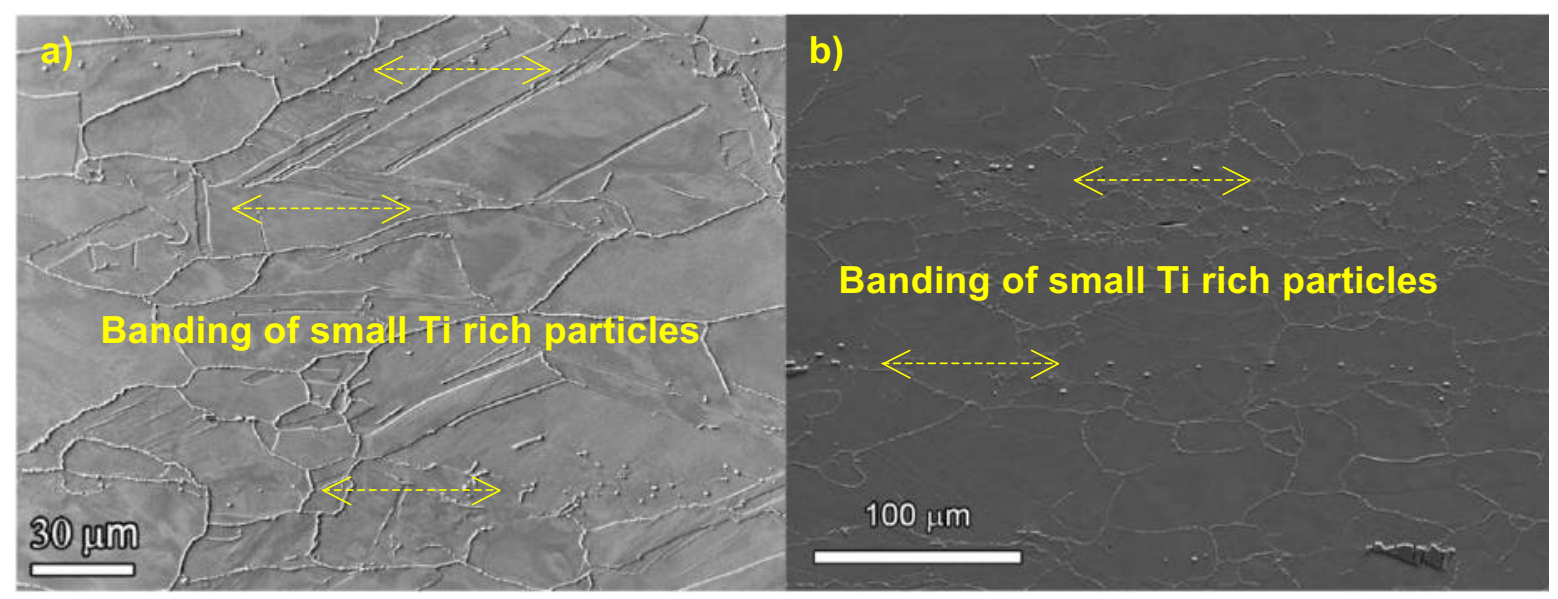

Figure 5.10 Higher magnification (backscattered and SE) SEM images 26\%CR ANL alloy 690 (heat NX3297HK12) lightly etched to bring out grain structure.
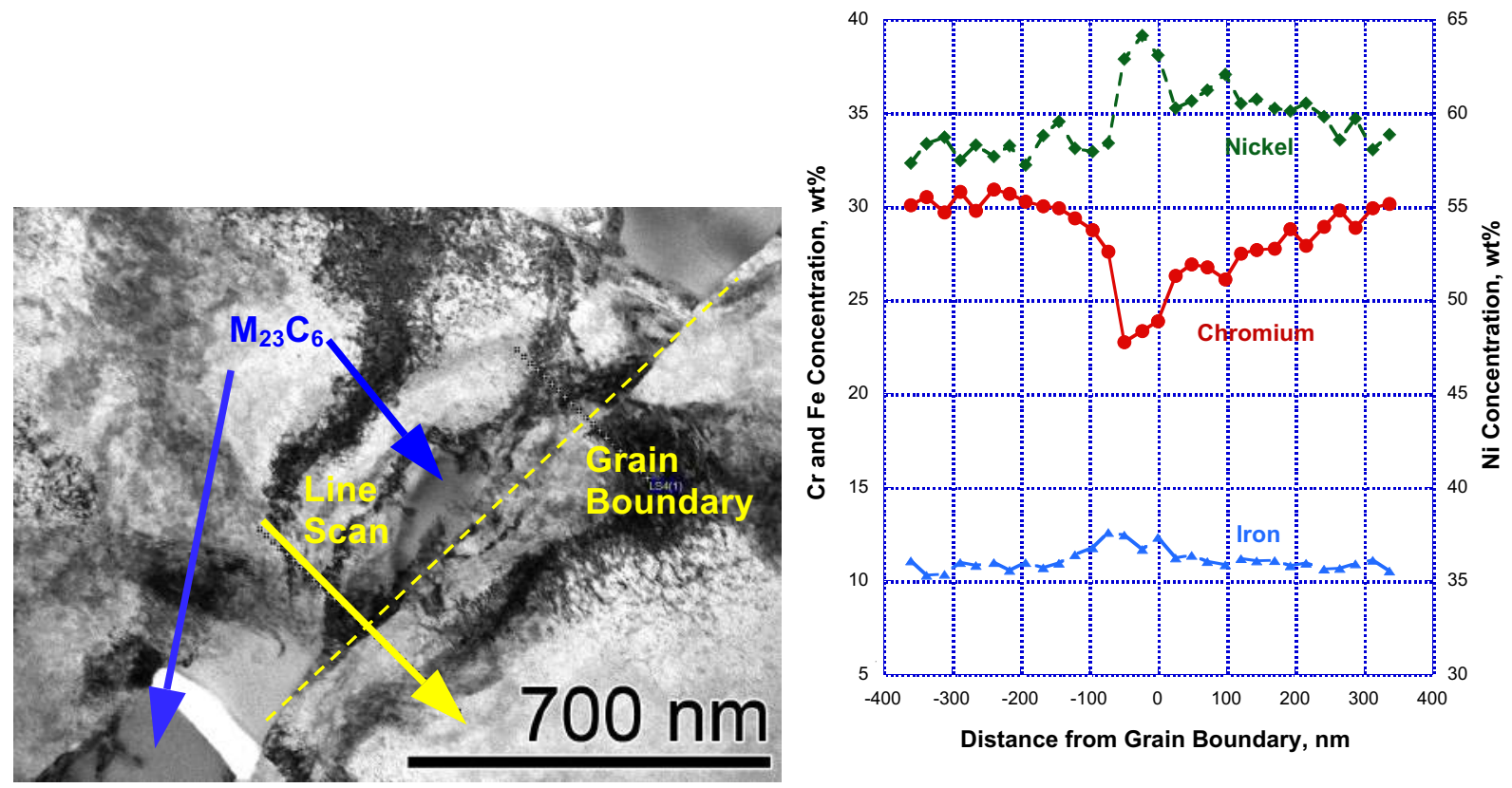

Figure 5.11 Brightfield TEM image and corresponding EDS linescan showing $\mathrm{Cr}$ depletion and $\mathrm{Ni}$ enrichment at the grain boundary between carbides in the ANL sample. The grain boundary is close to on edge and the minimum measured $\mathrm{Cr}$ concentration is $\sim 22.5 \mathrm{wt} \%$ with a total profile width of $\sim 300 \mathrm{~nm}$. 

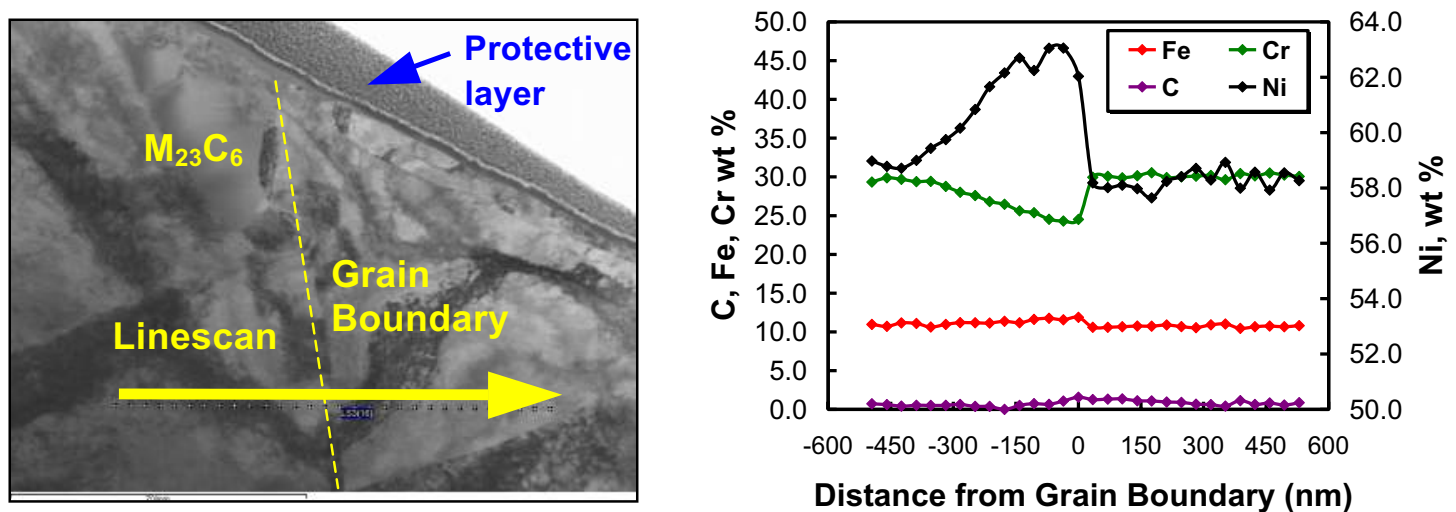

Distance from Grain Boundary (nm)

Figure 5.12 TEM brightfield micrograph and EDS linescans across a high-energy grain boundary revealing $\mathrm{Cr}$ depletion on one side of the boundary. The $\mathrm{Cr}$ concentration near the boundary drops by $\sim 6 \mathrm{wt} \%$ to $\sim 24 \mathrm{wt} \%$ and the total $\mathrm{Cr}$ depletion width is $\sim 300 \mathrm{~nm}$.
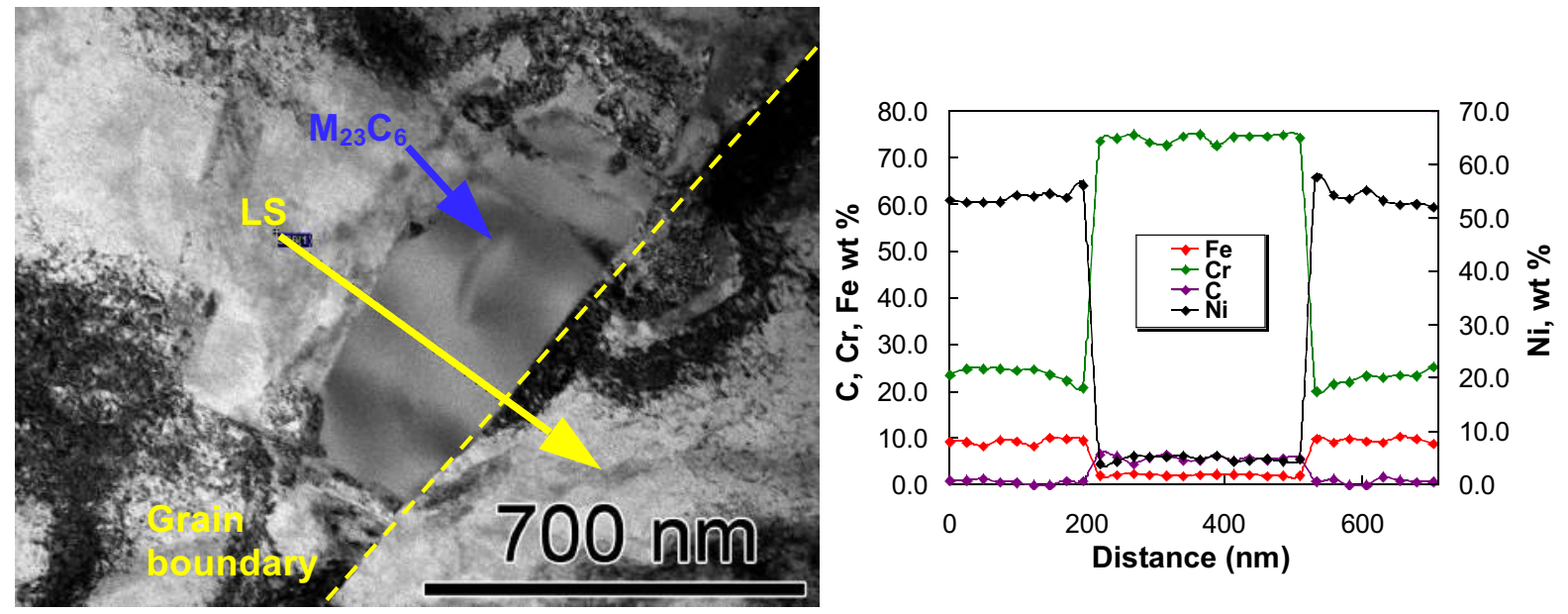

Figure 5.13 TEM brightfield and corresponding linescan across a grain boundary $\mathrm{M}_{23} \mathrm{C}_{6}$ carbide in the ANL sample. Concentration changes at the carbide-matrix interfaces show the carbide to primary $\mathrm{Cr}$ rich and the adjacent matrix is depleted by $\sim 8 \mathrm{wt} \%$ in $\mathrm{Cr}$ from the measured bulk $\mathrm{Cr}$ concentration in this region. 


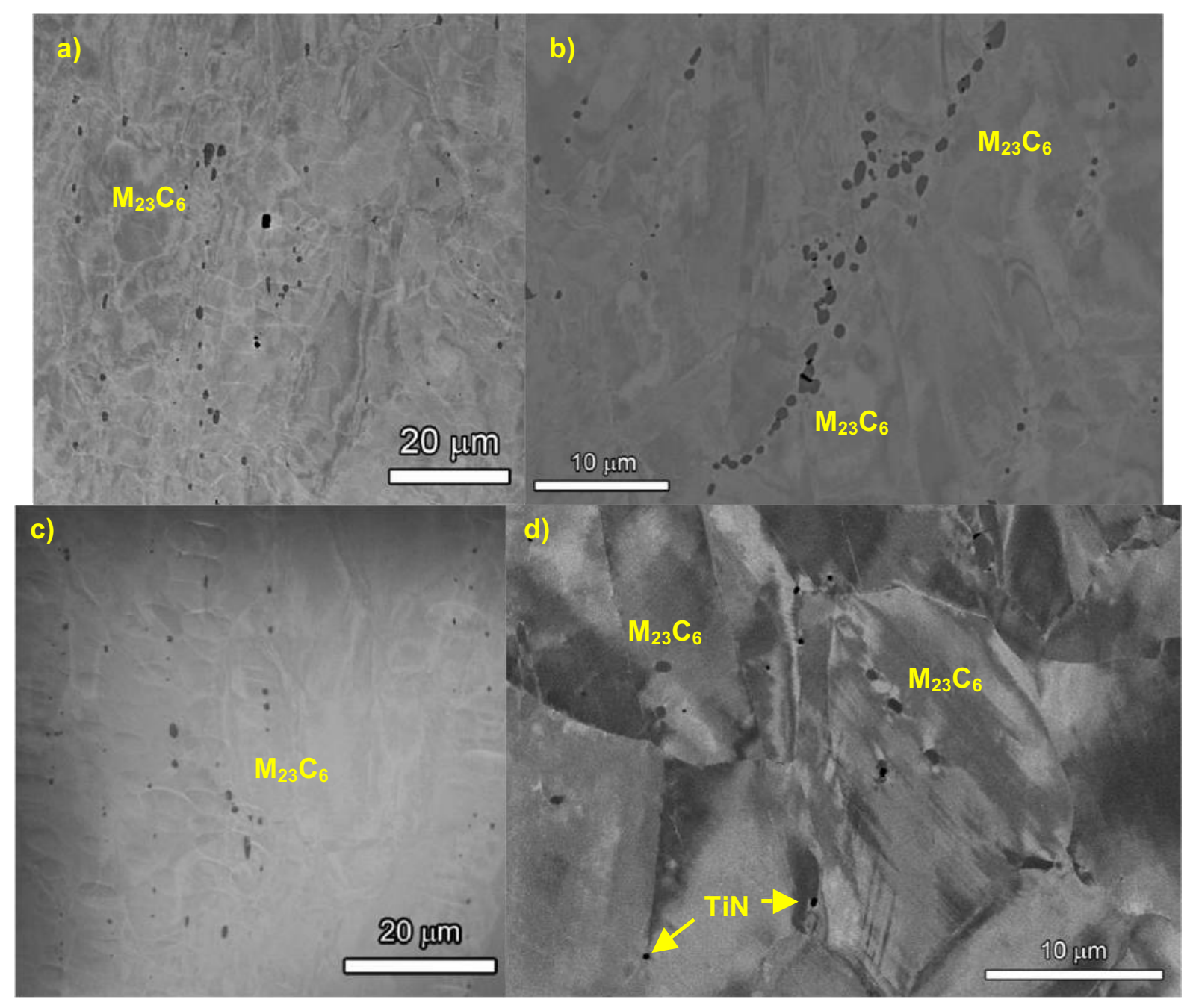

Figure 5.14 Low magnification SE and backscattered SEM images illustrating carbide distributions in $20 \%$ CR GEG alloy 690 plate (heat B25K): (a) mostly TG carbides, (b) high density of IG carbides, (c) and (d) low density of primarily TG carbides.

In general, the SEM examinations on the GEG alloy 690 plate revealed a significant variability in the precipitate microstructure across the sample thickness. This may result from compositional banding that has been seen in this material. Areas with a high density of carbides (e.g., in Figure 5.14b and 5.15d) may be within such a banded region. Lower magnification optical metallography indicated a few areas where banding was obvious as shown in Figure 5.5. The overall conclusion that most high-energy grain boundaries have a low density of well-spaced carbides does not change. 

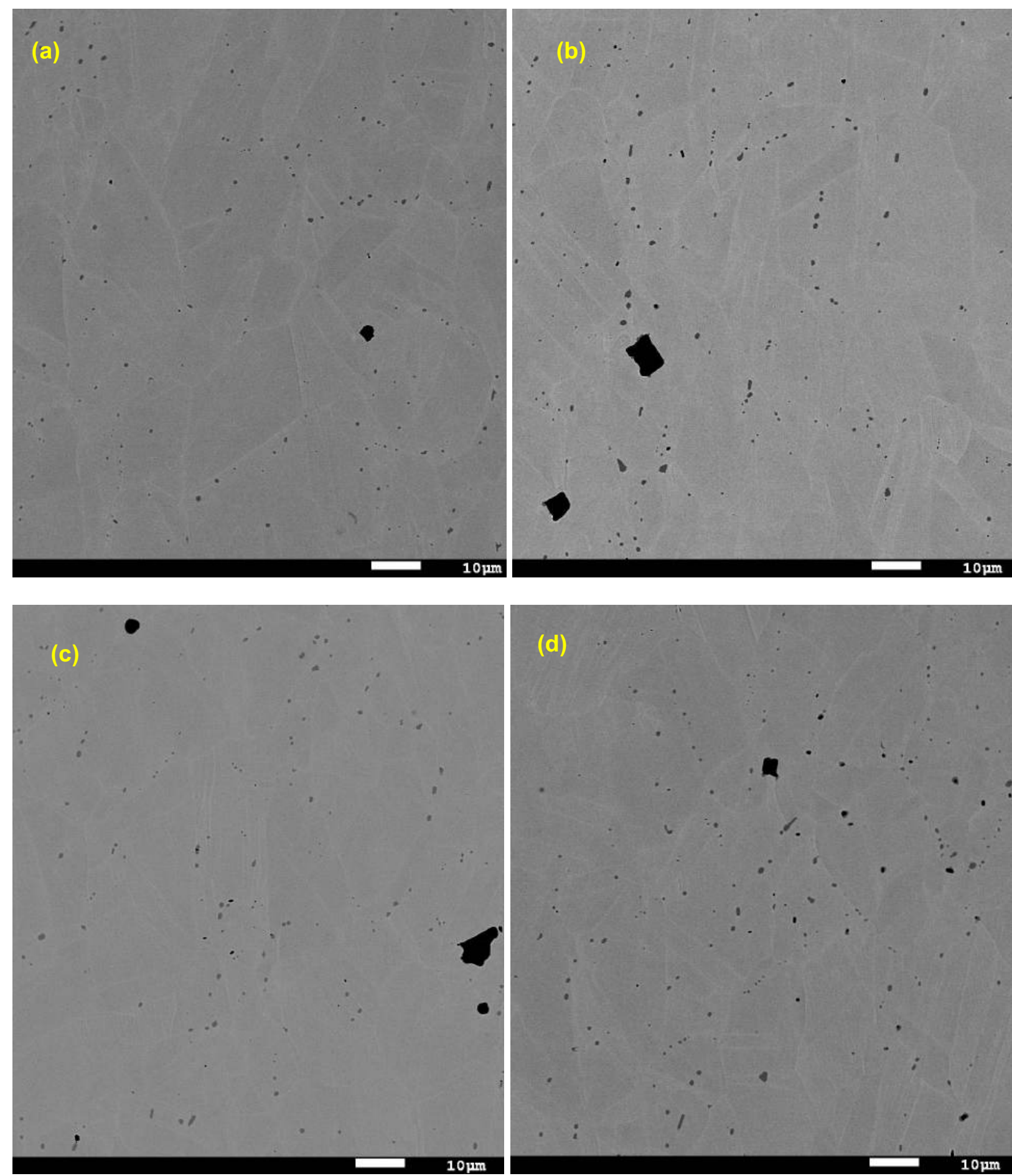

(d)

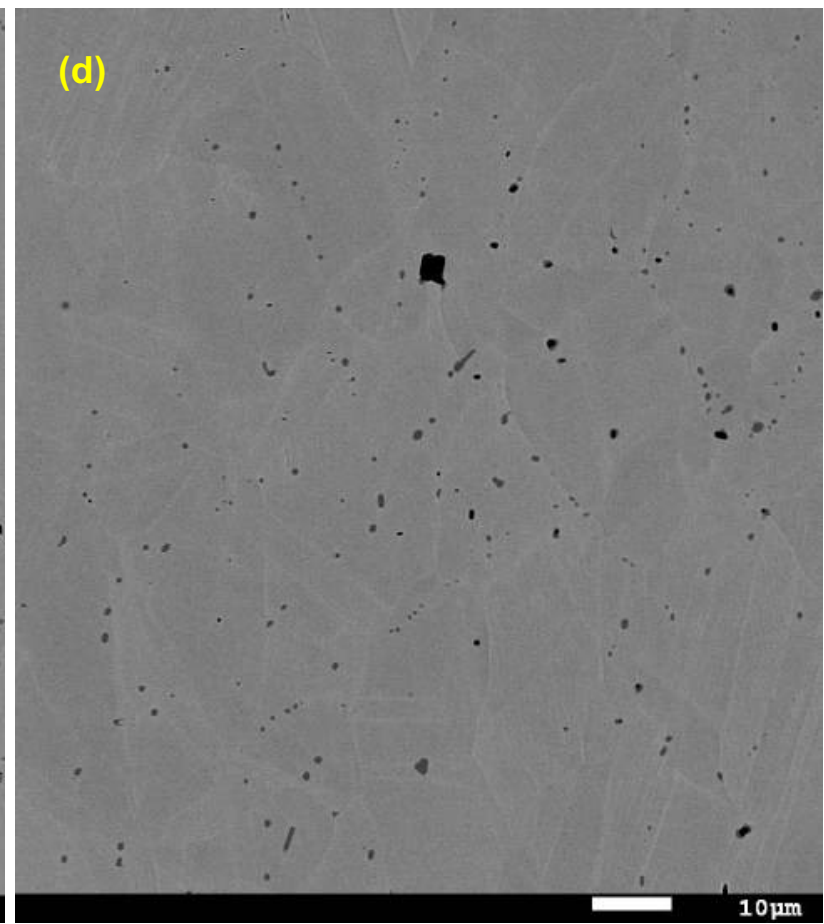

Figure 5.15 Low magnification backscattered SEM images illustrating carbide and nitride distributions in $20 \%$ CR GEG alloy 690 plate (heat B25K): (a,b,c) areas show mostly TG carbides with some aligned along prior grain boundaries and (d) area with a higher density of both TG and IG carbides. Larger Ti nitride particles can be seen in the matrix. 


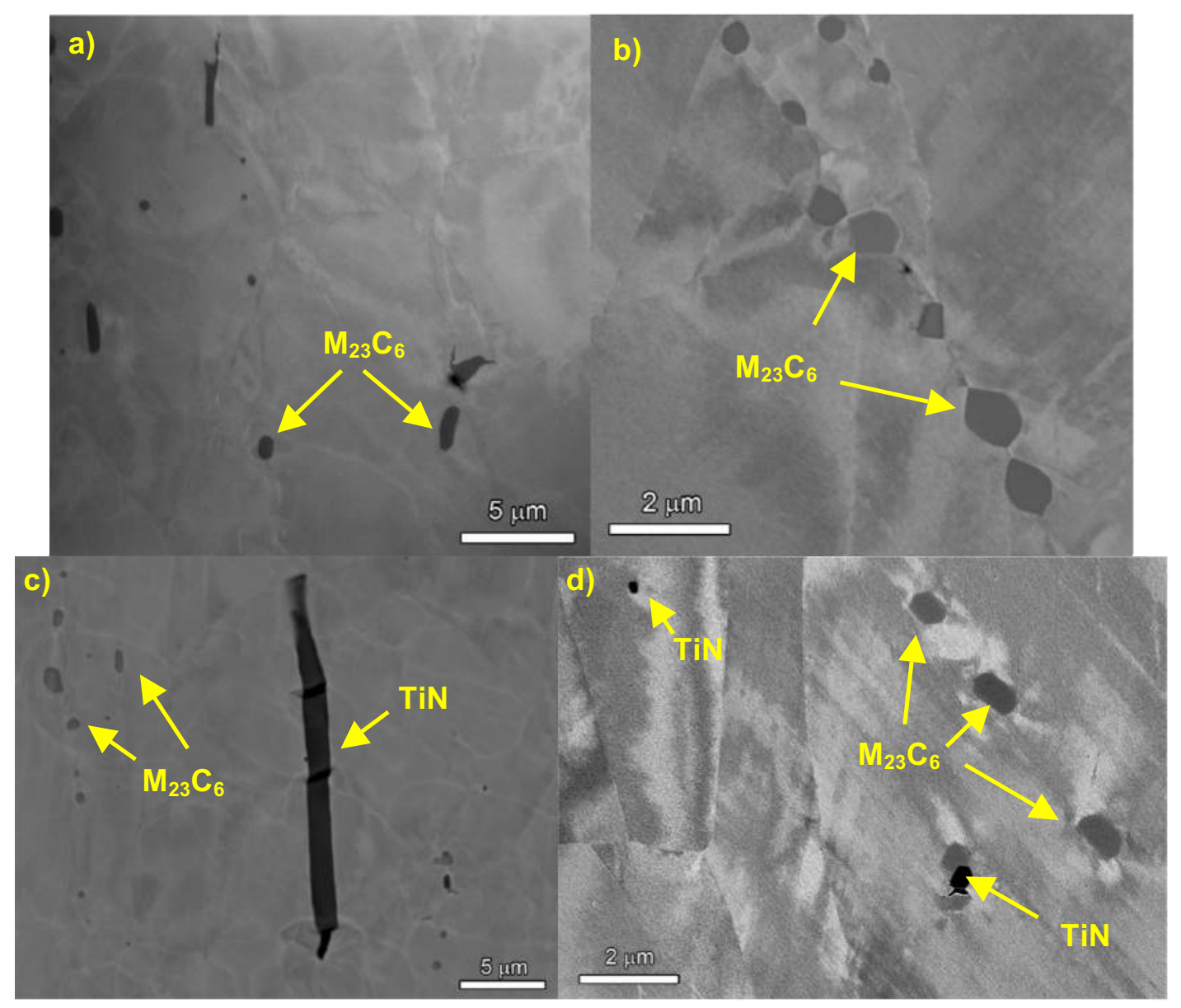

Figure 5.16 Higher magnification SE and backscattered SEM images illustrating general precipitation microstructure in 20\%CR GEG alloy 690 (heat B25K): (a) wellspaced, TG carbides; (b) high density of IG carbides; (c) well-spaced TG carbides and an elongated TiN inclusion; (d) series of TG carbides apparently formed on a prior grain boundary along with a few small TiN matrix particles.

\section{Hardness Tests on ANL 26\%CR and GEG 20\%CR Alloy 690 Plate}

Hardness measurements have also been obtained on the ANL and GEG CR alloy 690 plate materials with the most extensive examinations were performed on the $26 \%$ CR ANL plate (heat NX3297HK12). Hardness maps were obtained across the through-thickness slice from the CR plate supplied to PNNL matching the area where microstructural characterizations were performed. Thirty hardness measurements were taken across the thickness (y) in $1 \mathrm{~mm}$ steps and then repeated in 8 adjacent positions $(x)$ also $1 \mathrm{~mm}$ apart. Results were reasonably consistent as shown in Figures 5.17, 5.18 and 5.19. Slightly lower hardness $\left(285-295 \mathrm{~kg} / \mathrm{mm}^{2}\right)$ was measured at/near plate midplane and slightly higher hardness values $\left(305-315 \mathrm{~kg} / \mathrm{mm}^{2}\right)$ are found at regions closer to the top or bottom of the plate. As a result, there only appears to be a minor difference in hardness for the possible 0.5T CT sample crack-growth plane locations near the center of the plate. This suggests that the cold work produced in the multi-pass $26 \% \mathrm{CR}$ plate is reasonably uniform, however more detailed examinations by techniques such as electron backscatter diffraction are warranted to better assess strain distributions. 


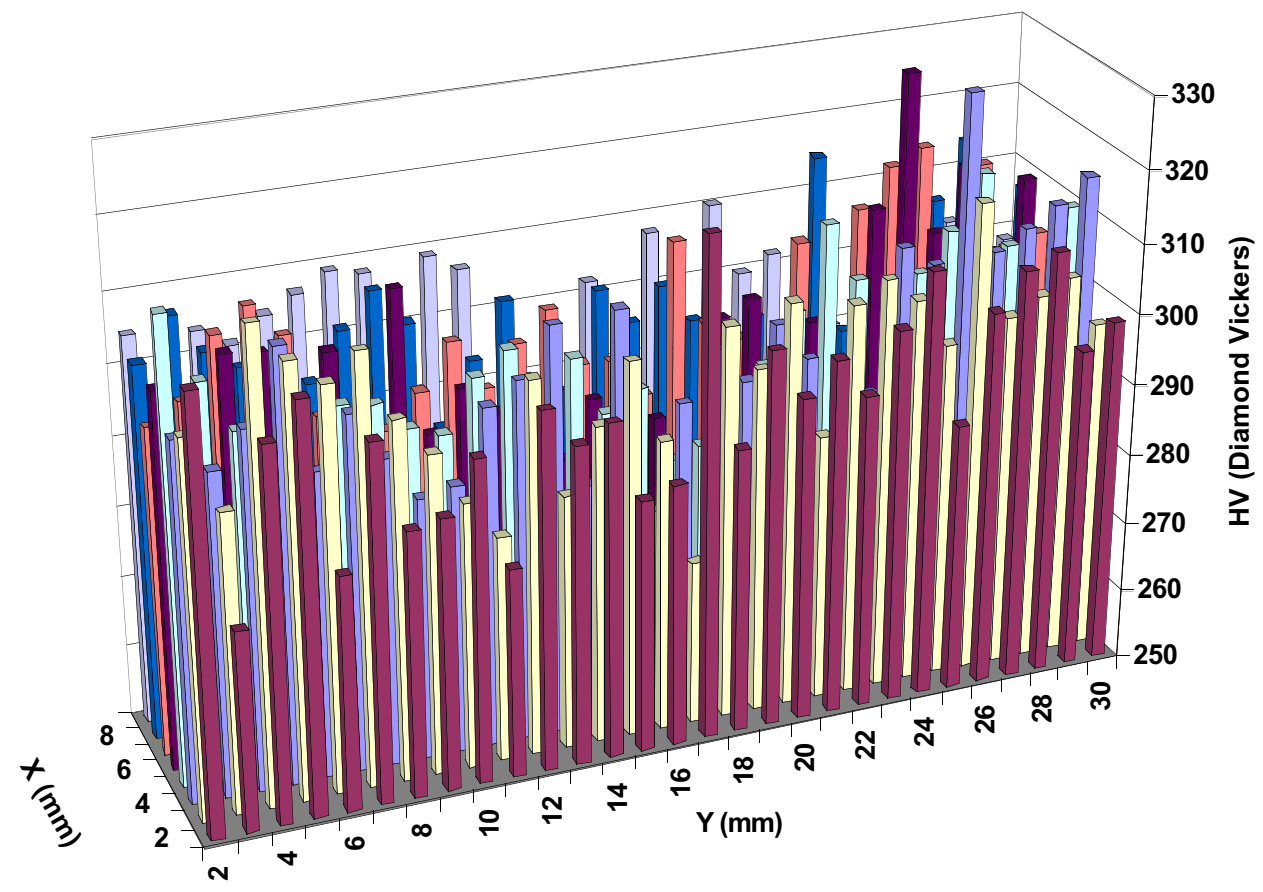

Figure 5.17 Summary of all hardness measurements for the $26 \%$ CR ANL alloy 690 plate (heat NX3297HK12), hardness units in the plots are $\mathrm{kg} / \mathrm{mm}^{2}$.

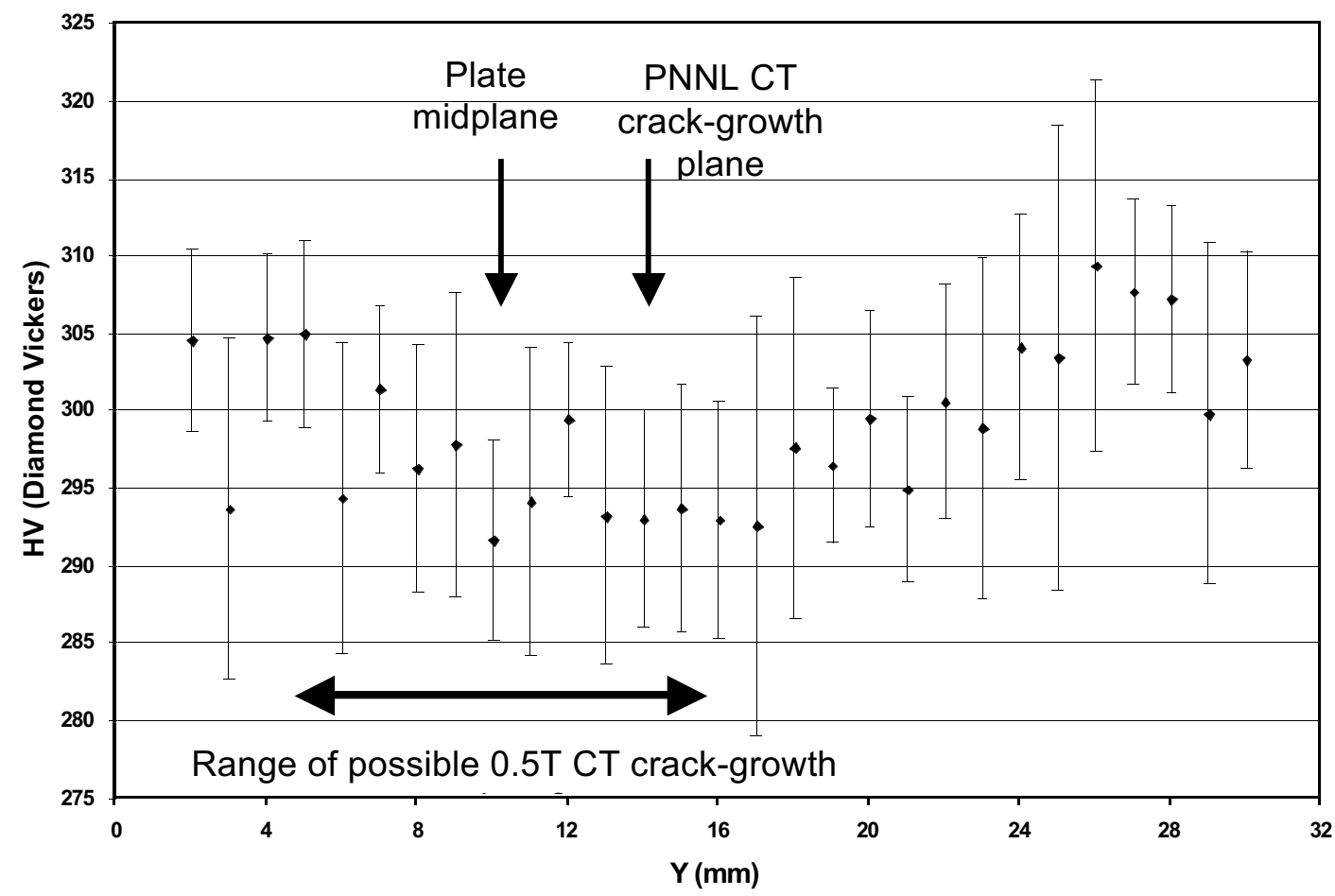

Figure 5.18 Measured through-thickness hardness for the $26 \%$ CR ANL alloy 690 plate (heat NX3297HK12), average of 8 data points in $x$ direction. Hardness units in the plots are $\mathrm{kg} / \mathrm{mm}^{2}$. 

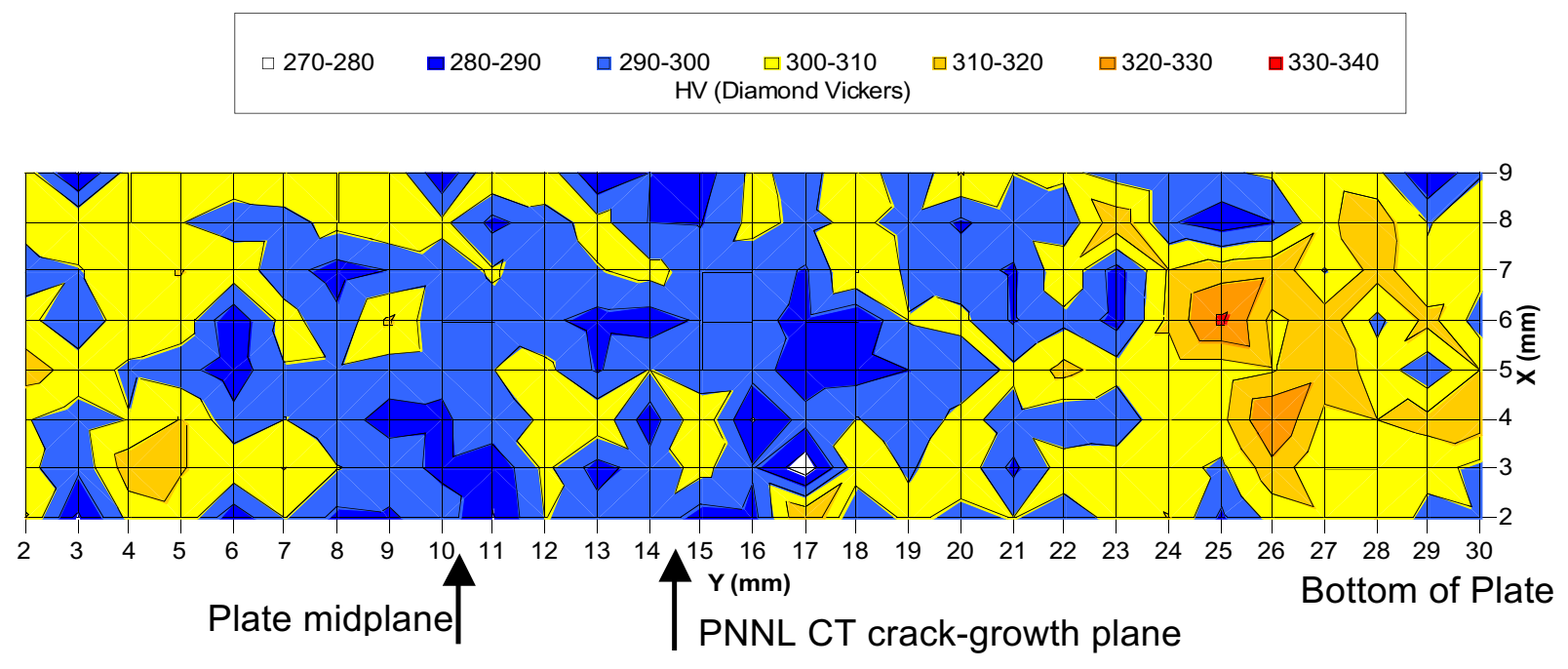

Figure 5.19 Summary of Vickers hardness measurements obtained on a cross-section sample for the $26 \%$ CR ANL alloy 690 plate (heat NX3297HK12), hardness units are $\mathrm{kg} / \mathrm{mm}^{2}$. Through-thickness measurements in the $y$ direction start at $\sim 10 \mathrm{~mm}$ below the top of the plate.

Direct hardness comparisons were also made between the $26 \%$ CR ANL specimen CT036 and the 20\%CR GEG specimen CT037 (heat B25K). Measurements were taken across polished cross-sections to assess the through-thickness hardness across the SCC crack-growth planes in the CT specimens. Somewhat surprisingly, similar hardness levels were obtained with the $26 \%$ CR ANL specimen ranging from $\sim 310$ to $330 \mathrm{~kg} / \mathrm{mm}^{2}$ and the $20 \%$ CR GEG specimen ranging from $\sim 300$ to $320 \mathrm{~kg} / \mathrm{mm}^{2}$ as shown in Figure 5.20 . It is important to note that these measurements only span a small fraction of the rolled plate thickness corresponding to the $0.5 \mathrm{~T}$ CT specimen dimension. Some changes in hardness were seen across this thickness, particularly for the GEG CT037 specimen where hardness decreased by $\sim 20 \mathrm{~kg} / \mathrm{mm}^{2}$ from one side to the other. For comparisons to the SCC response, the average hardness values at the SCC crack-growth plane locations were estimated to 315 and $307 \mathrm{~kg} / \mathrm{mm}^{2}$ for the ANL CT036 specimen and the GEG CT037 specimen, respectively. As noted above, these values suggest similar strength levels for these cold-worked plates and they are slightly higher than those measured for the 30\%CR alloy 690 CRDM tubing materials described in the previous Chapter. 


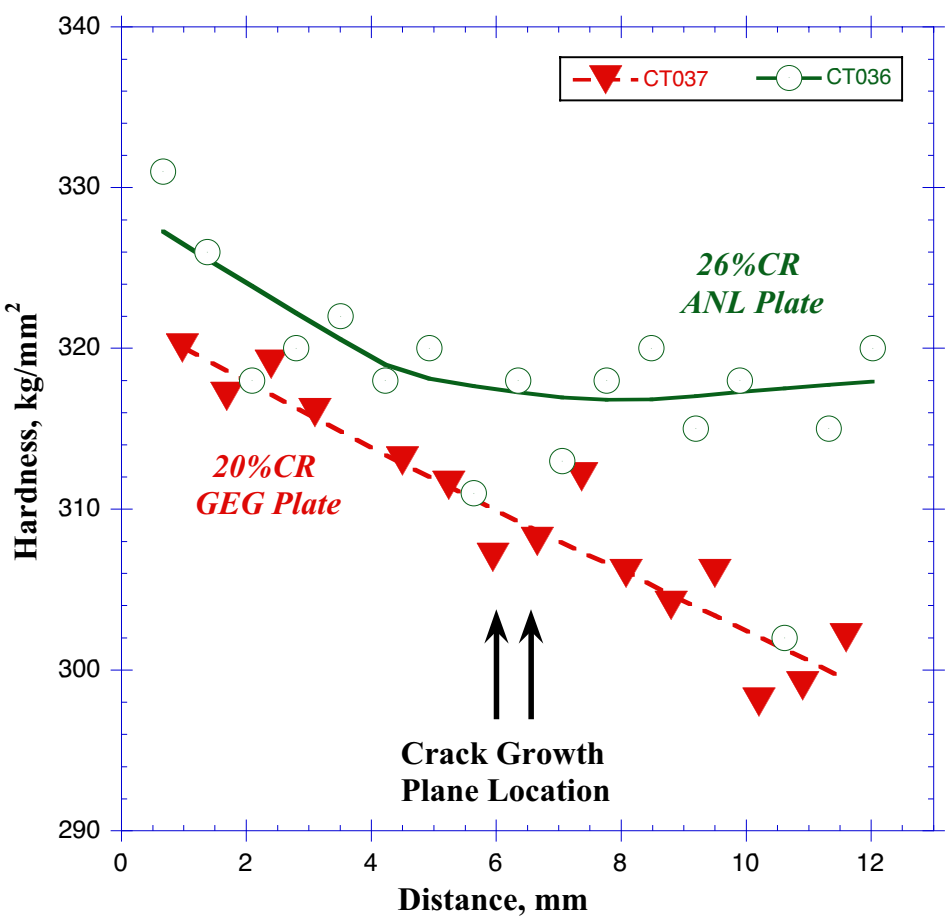

Figure 5.20 Measured through-thickness hardness for the 26\%CR ANL (heat NX3297HK12) and 20\%CR GEG alloy 690 plates, each point is an average of 3 data points in $x$ direction.

\section{Summary of General Characterization and Comparisons to CR CRDM Materials}

The examinations described in the previous subsections document key differences in the general microstructures for the ANL (heat NX3297HK12) and GEG (heat B25K) plate materials. Microstructural, microchemical and hardness measurements are briefly summarized in Table 5.2 and compared to results for the CR CRDM materials (heat RE243). The ANL plate showed a high density of $\mathrm{Cr}$-rich $\mathrm{M}_{23} \mathrm{C}_{6}$ carbides, significant $\mathrm{Cr}$ depletion and a distribution of small TiN particles on nearly all high-energy boundaries examined. Its grain boundary microstructure is most consistent with the CRDM alloy 690TT materials, but the carbide density was lower and spacing greater for the ANL plate. In addition, cellular carbide precipitation was common in the thermally treated CRDM tube while not seen in the mill annealed ANL plate.

Carbides were primarily TG in the GEG plate with the majority of grain boundaries exhibiting well-spaced carbides (and nitrides) with no measurable $\mathrm{Cr}$ depletion. The lack of grain boundary carbides and $\mathrm{Cr}$ depletion is more similar to the CRDM alloy 690CM material, however the GEG material microstructure was highly variable due to compositional banding. Selected regions did show grain boundaries with a moderate-to-high density of carbides and occasional TiN particles approaching the distributions identified for the ANL material. This variability makes a quantitative comparison impossible based on the limited examinations performed. It also illustrates the need for more detailed microstructural characterizations of material focused on the specific regions where SCC crack-growth response is evaluated. 
Table 5.2 Microstructure, microchemistry and hardness for selected CR alloy 690 materials.

\begin{tabular}{|c|c|c|c|}
\hline Sample & Microstructure & GB Microchemistry & Hardness \\
\hline $\begin{array}{c}\text { (2 - TT) PNNL } \\
\text { CRDM alloy 690TT } \\
\text { 30\%CR; Test } \\
\text { sample CT022 }\end{array}$ & $\begin{array}{c}\text { Semi-continuous (small discrete + } \\
\text { cellular) carbides on GBs, few TiN } \\
\text { at GBs and in matrix; slightly } \\
\text { elongated grains }\end{array}$ & $\begin{array}{l}\text { Cr depletion to } 21-24 \mathrm{wt} \% \text { at } \\
\text { GBs between carbides along } \\
\text { with } \mathrm{Ni} \text { enrichment, total } \\
\text { width of } 300-400 \mathrm{~nm}\end{array}$ & $\begin{array}{c}300 \\
\mathrm{~kg} / \mathrm{mm}^{2}\end{array}$ \\
\hline $\begin{array}{c}\text { (2 - CM) PNNL } \\
\text { CRDM alloy } \\
\text { 690CM 30\%CR; } \\
\text { Test sample CT023 }\end{array}$ & $\begin{array}{c}\text { Few carbides and well-spaced TiN } \\
\text { on GBs, few TiN in matrix; slightly } \\
\text { elongated grains }\end{array}$ & $\begin{array}{l}\text { No measured enrichment or } \\
\text { depletion of alloying or } \\
\text { impurity elements at GBs }\end{array}$ & $\begin{array}{c}290 \\
\mathrm{~kg} / \mathrm{mm}^{2}\end{array}$ \\
\hline $\begin{array}{l}\text { (4) GEG plate alloy } \\
69020 \% \text { CR; Test } \\
\text { sample CT037 }\end{array}$ & $\begin{array}{c}\text { Well-spaced carbides on most GBs, } \\
\text { higher density in banded areas, TiN } \\
\text { at GBs and in matrix, slightly } \\
\text { elongated grains }\end{array}$ & $\begin{array}{l}\text { No measured enrichment or } \\
\text { depletion of alloying or } \\
\text { impurity elements at GBs } \\
\text { with well-spaced carbides }\end{array}$ & $\begin{array}{c}307 \\
\mathrm{~kg} / \mathrm{mm}^{2}\end{array}$ \\
\hline $\begin{array}{l}\text { (5) ANL plate alloy } \\
69026 \% \text { CR; Test } \\
\text { sample CT036 }\end{array}$ & $\begin{array}{c}\text { Semi-continuous carbides and TiN } \\
\text { on GBs, no banding in SCC plane, } \\
\text { TiN stringers in matrix, slightly } \\
\text { elongated grains }\end{array}$ & $\begin{array}{l}\text { Cr depletion to } 22-25 \mathrm{wt} \% \text { at } \\
\text { GBs between carbides along } \\
\text { with Ni enrichment, total } \\
\text { width of } \sim 300 \mathrm{~nm}\end{array}$ & $\begin{array}{c}315 \\
\mathrm{~kg} / \mathrm{mm}^{2}\end{array}$ \\
\hline
\end{tabular}

\subsection{High-Resolution Examinations of Cold-Rolling Microstructural Damage}

Additional microstructural characterizations were performed on the CR alloy 690 plate materials to better define damage characteristics particularly at grain boundaries. These examinations using SEM (secondary and backscatter electron), brightfield TEM and elemental composition maps using energy dispersive $\mathrm{x}$-ray spectroscopy (EDS) were similar in approach to those described for the CR CRDM tubing in Section 4.3. Microstructures in the plate materials exhibited varying degrees of damage directly associated with IG or TG precipitates. TEM revealed high dislocation densities in both plate materials with evidence for most extensive localized deformation at grain boundaries in the ANL $26 \%$ CR plate. Permanent damage was different between the plate materials with much higher densities of IG cracked carbides, IG voids and TG cracked nitrides in the ANL $26 \%$ CR alloy 690 . Void formation typically took on two distinct size distributions at grain boundaries, either small (on the order of 50-75 nm) or as much larger (200-300 nm). Crack formation was observed in IG $\mathrm{M}_{23} \mathrm{C}_{6}$ carbides and IG TiN particles as well as in larger TG Ti nitride or carbonitride particles in the matrix.

\section{ANL Alloy 690 Plate}

The $26 \%$ CR ANL alloy 690, like the CRDM alloy 690TT materials, had a high density of IG $\mathrm{M}_{23} \mathrm{C}_{6}$ carbides. Even though the density of the carbides in the ANL alloy 690 was lower than that of the CRDM TT materials, the $26 \%$ CR ANL alloy 690 exhibited the highest density of cracked second-phase particles and voids among the various CR materials. Additionally, there appear to be a slightly higher density of TiN at grain boundaries in the ANL material and many more TiN inclusions in the matrix. Examples of the various types of CR-induced damage in the ANL material are presented in Figures 5.21 and 5.22. A high density of small $(50-75 \mathrm{~nm})$ voids can be seen in Figure 5.21( $a, b$ and d), typically forming at an IG carbide interface. As noted previously, small TiN precipitates can be difficult to separate from voids in the SEM without employing both backscatter and SE imaging. Lastly, cracks through $\mathrm{M}_{23} \mathrm{C}_{6}$ carbides are identified in Figures 5.21(b and d) and 5.22. Without question, the 26\%CR ANL cross-sections revealed the highest density of IG cracked carbides among all CR materials along with a similar 
density of voids as found in the $30 \% \mathrm{CR}$ alloy 690TT CRDM material. EDS elemental maps taken from various grain boundaries with carbides show the appearance of voids (Figure 5.23a), cracks (Figure 5.23b) and a combination of both (Figure 5.23c). TEM imaging and elemental mapping makes it somewhat easier to discern the differences between voids and cracks, but TEM provides a much smaller region for analysis than SEM.

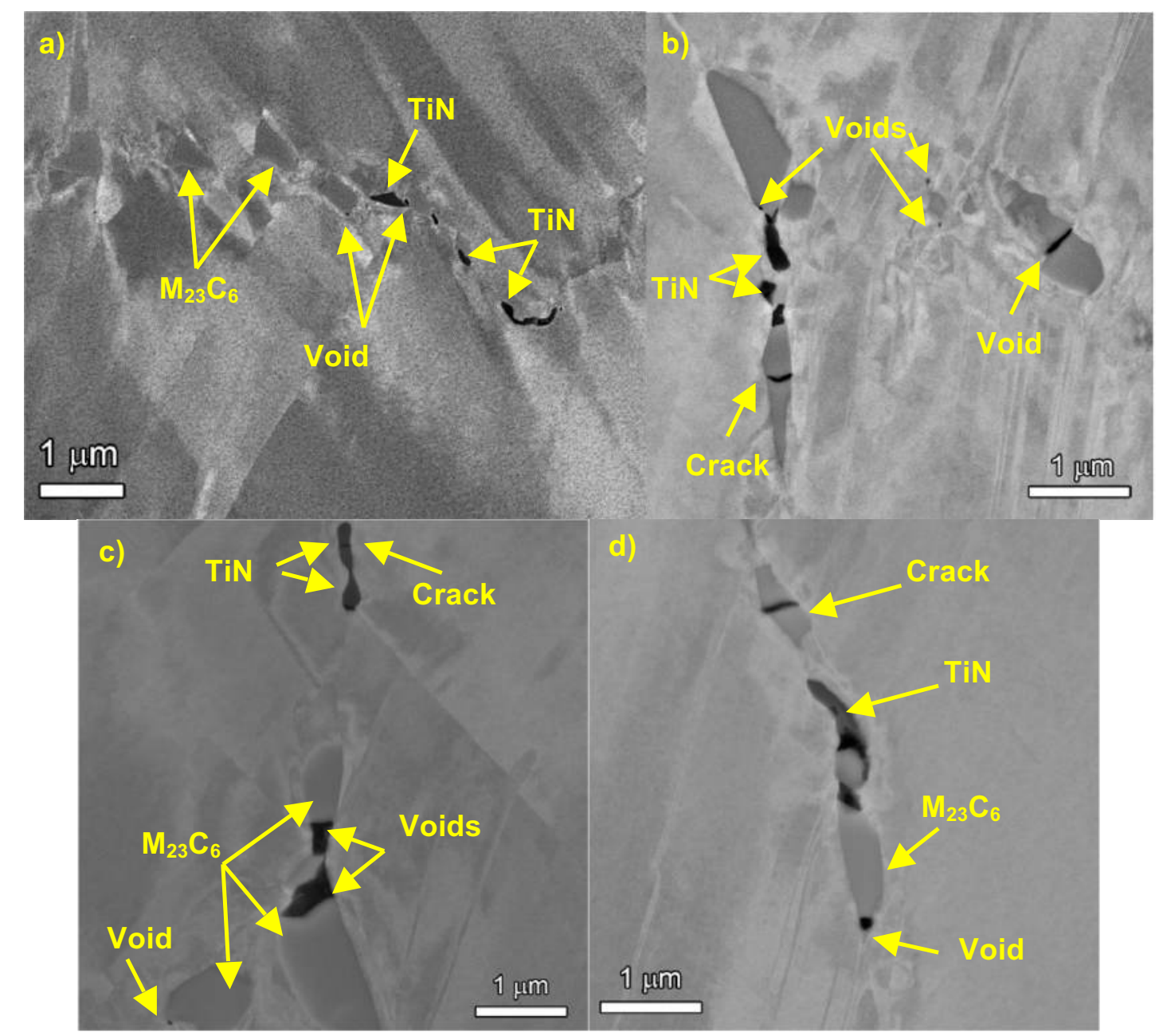

Figure 5.21 SEM backscatter micrographs illustrating grain boundary damage microstructure in 26\%CR ANL alloy 690 (heat NX3297HK12).

TiN precipitates could often be identified in these samples as opposed to voids due to the faceted nature on the interface with the matrix. In Figure 5.22(d-e), the IG TiN precipitates are often found between the $\mathrm{Cr}$ carbides. A second example is documented in Figure 5.24 with SEM images taken from a leading SCC crack-tip region in a TEM thin foil prepared by FIB (additional information is given later in this section). In the lower magnification image, it would appear that the TiN particle could be a void (Figure 5.24a). However in the higher magnification image (Figure 5.24b), the faceting of the particle clearly identified it as a TiN particle and not a void. This was also confirmed by EDS analysis. 


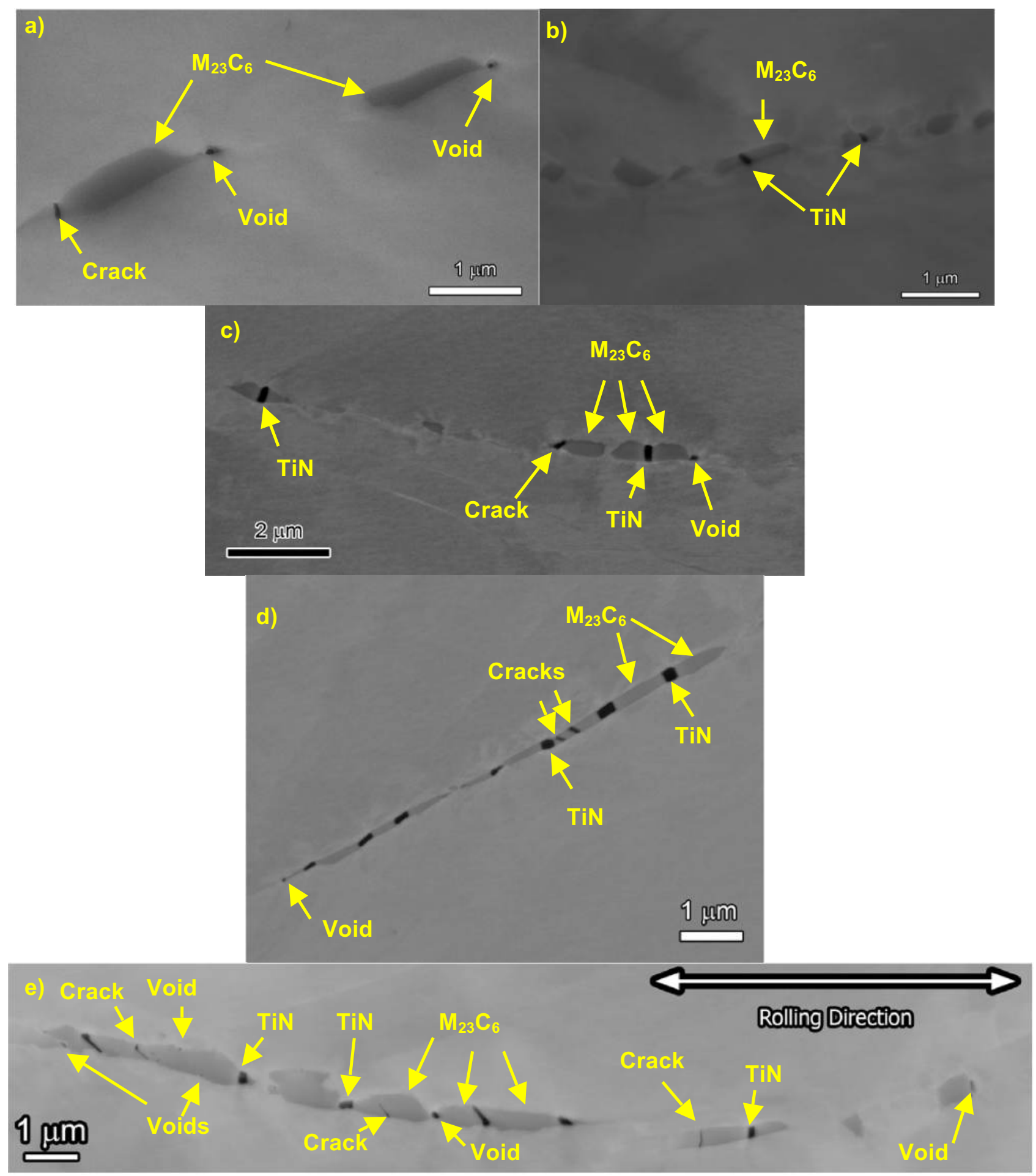

Figure 5.22 SEM micrographs illustrating general carbide damage microstructure in $26 \%$ CR ANL alloy 690 (heat NX3297HK12). 


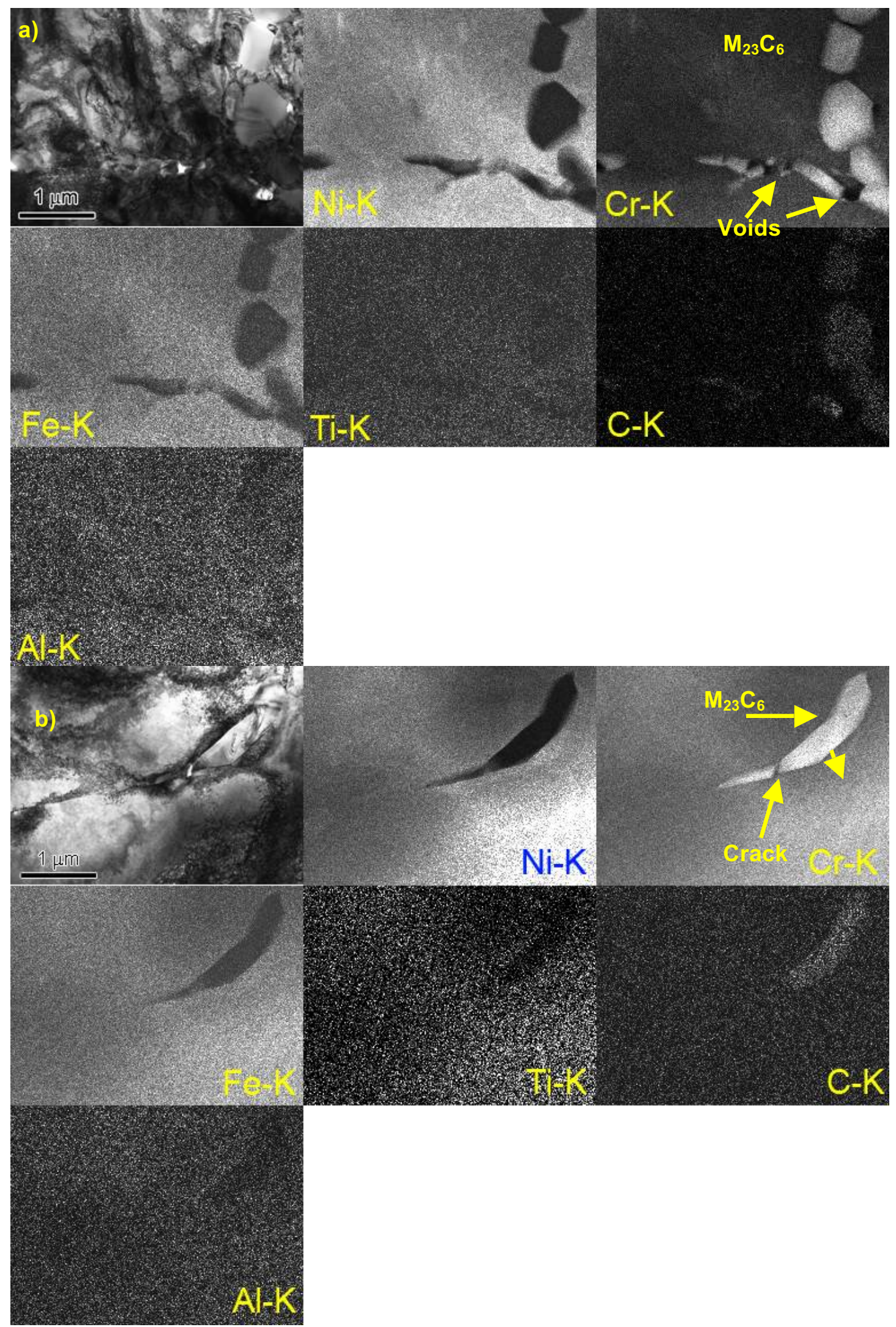

Figure $5.23(a, b)$ SEM micrographs and EDS maps $(a, b)$ illustrating general carbide microstructure in $26 \%$ CR ANL alloy 690 (heat NX3297HK12). 


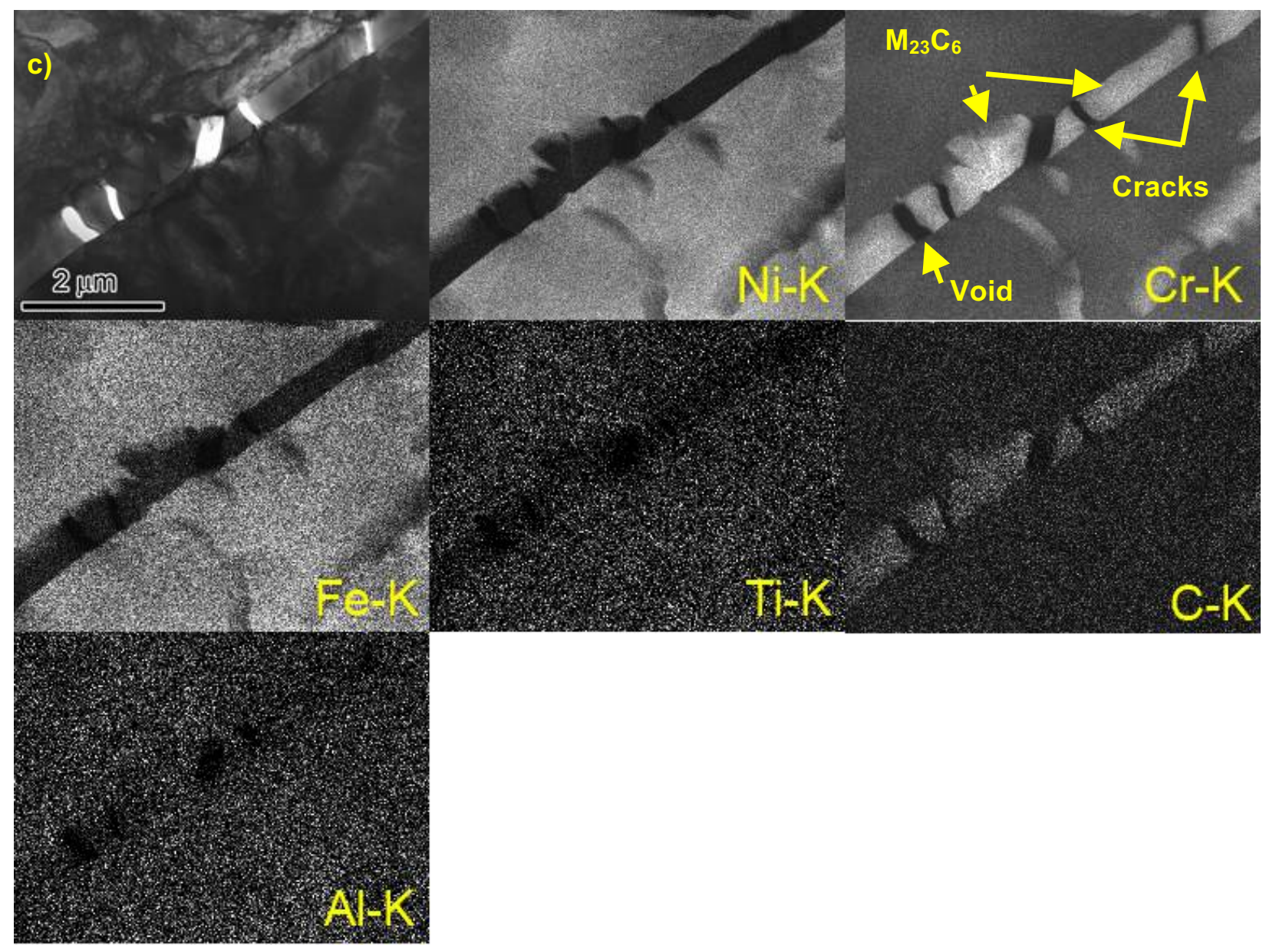

Figure 5.23 (c) SEM micrographs illustrating general carbide damage microstructure in $26 \%$ CR ANL alloy 690 (heat NX3297HK12).

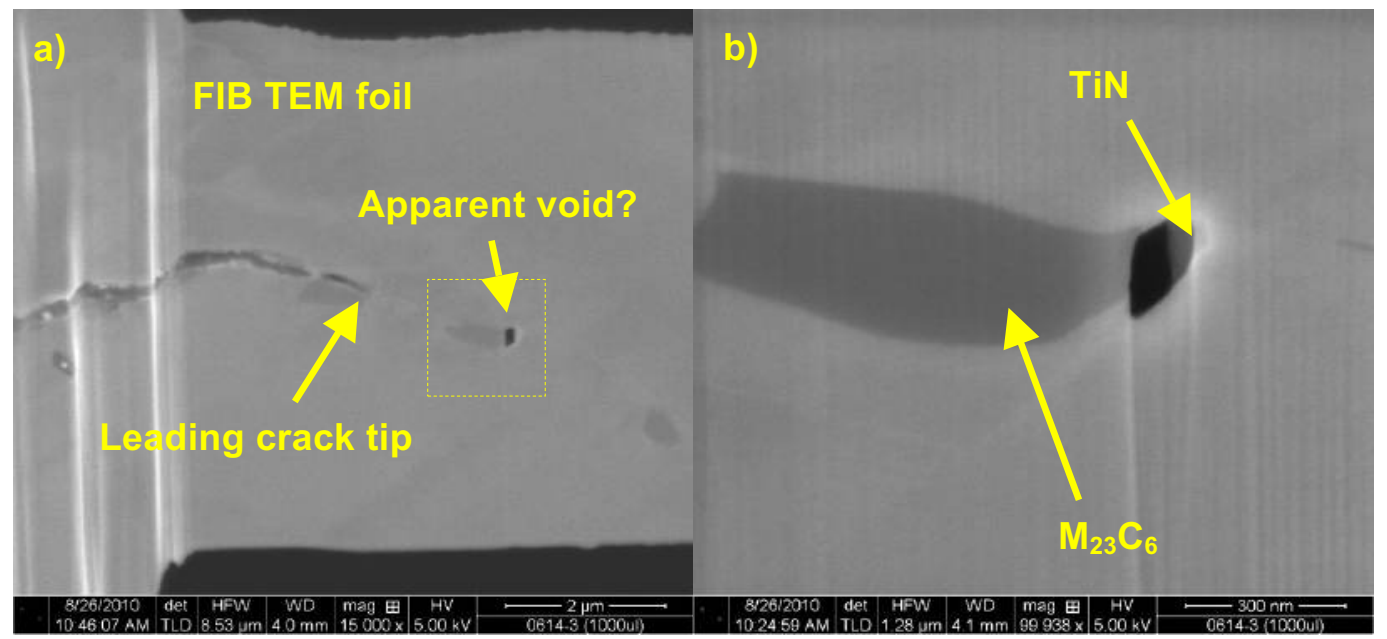

Figure 5.24 SEM micrographs of a FIB prepared plan view crack-tip sample showing differences in appearance in TiN particles in 26\%CR ANL alloy 690 (heat NX3297HK12). 
In order to more easily determine a void versus a TiN particle, secondary/backscatter electron image pairs were taken for many grain boundary regions as illustrated by the examples in Figure 5.25. Whereas in backscatter contrast it is difficult to discern the presence of material in between the carbides (Figure 5.25b), the absence of material in the SE contrast image (Figure 5.25a) highlight slightly higher yield at the edges, thus identifying it as a void. Figure 5.25 is also interesting in that it perfectly shows a crack that has not split the carbide in two pieces. Figure 5.26 highlights another region with TiN precipitate, cracks and voids in this ANL plate material. The TiN appears in much darker contrast than the carbide in backscatter imaging, and a crack can be seen emanating from the interface between the carbide and nitride. Finally, a void is observed between the TiN and $\mathrm{M}_{23} \mathrm{C}_{6}$ particles near this crack. These many examples of grain boundary structures are presented to give a representative description of the high density of cracked carbides and voids in the ANL material.

It is also important to note that there is extensive cracking of the larger TiN inclusions in the matrix and a single example is shown in Figure 5.27. The inclusions often extend many $\mu \mathrm{m}$ in length and occasionally are clustered together as short stringers. These TiN inclusions are typically cracked and occasionally have produced a TG crack extending into the matrix as in Figure 5.27. The fact these inclusions are cracked during cold rolling may help promote higher SCC growth rates by facilitating TG cracking and breaking ligaments in microstructural regions where IGSCC is more difficult.

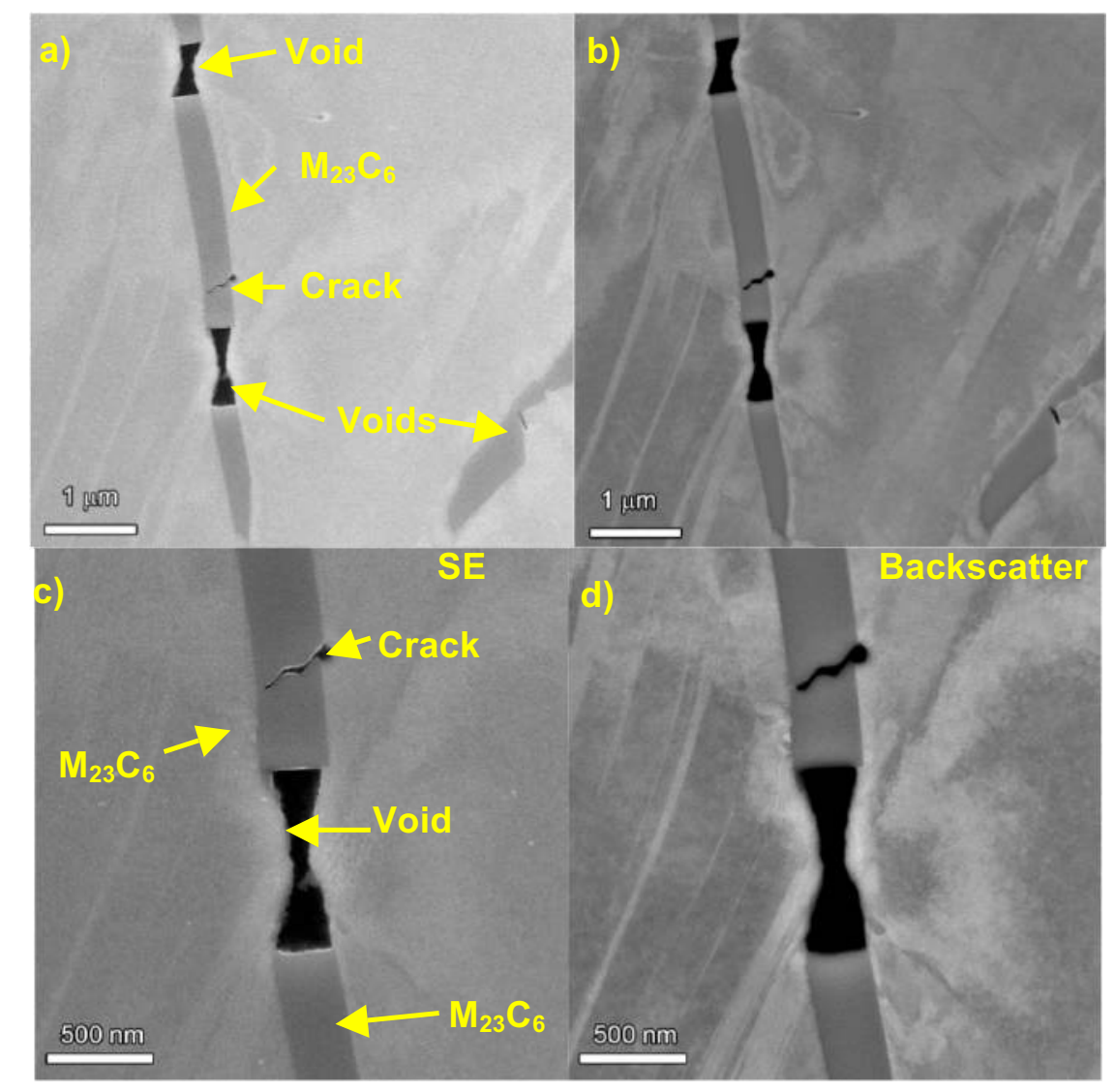

Figure 5.25 SEM Secondary/backscatter electron image micrographs illustrating general carbide damage microstructure in 26\%CR ANL alloy 690 (heat NX3297HK12). 


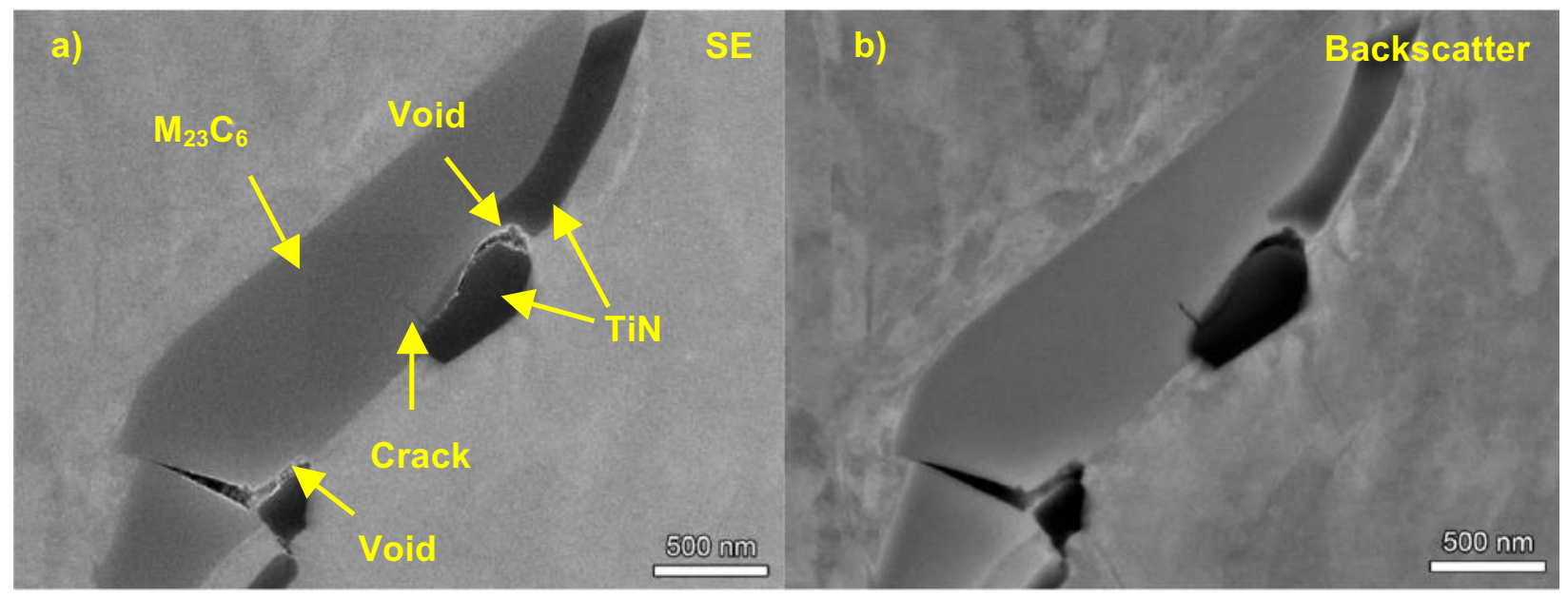

Figure 5.26 SEM micrographs illustrating general precipitate damage microstructure in 26\%CR ANL alloy 690 (heat NX3297HK12).

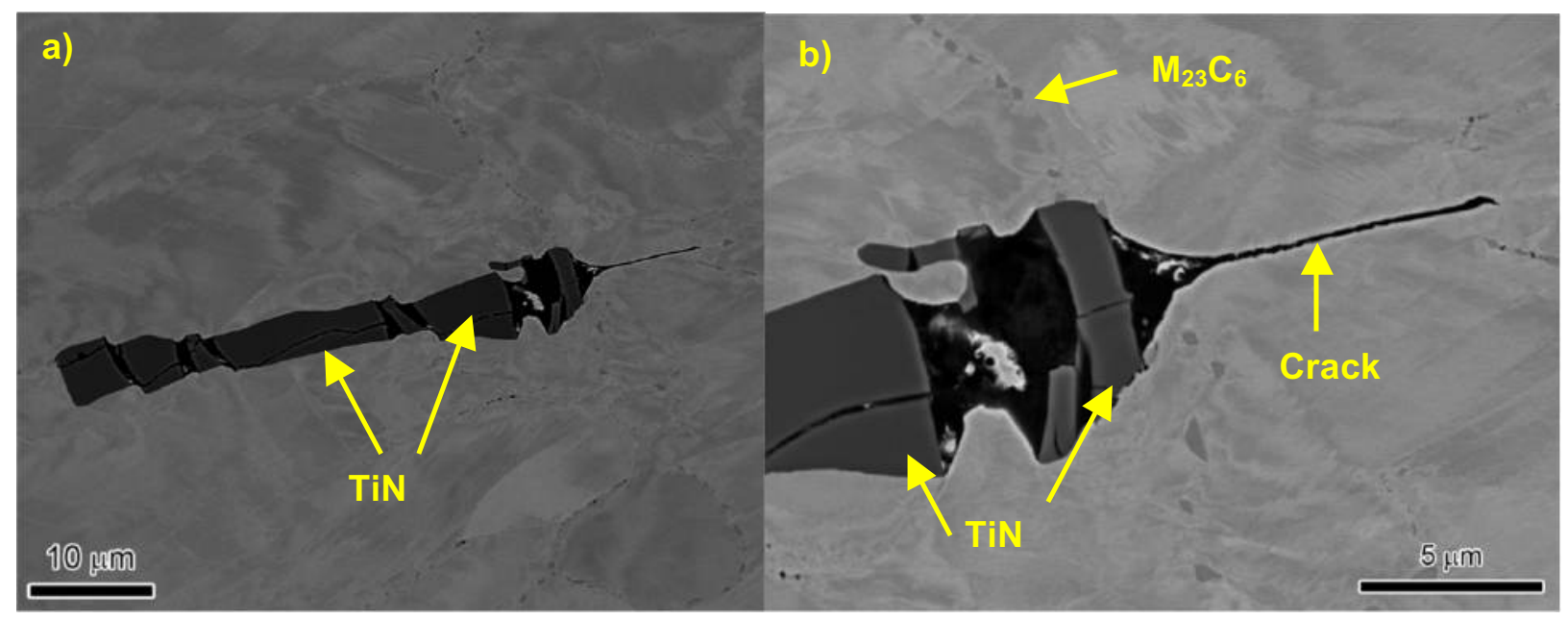

Figure 5.27 SEM micrographs further illustrating general precipitate damage microstructure in 26\%CR ANL alloy 690 (heat NX3297HK12).

The $26 \%$ CR ANL material was also characterized using electron backscatter diffraction (EBSD) techniques. As noted previously, SEM backscatter images reveal a highly strained grain structure and mottled appearance as illustrated in Figure 5.28. An EBSD pattern quality map is shown in Figure 5.29 and indicates the complexity of this deformed microstructure. The grain boundary regions are not sharply defined, a direct consequence of strain concentrated in the grain boundary regions due to the presence of IG carbides and the localized strain in the 1D rolled material. To examine the strain more thoroughly in this sample, a misorientation map was generated that presents the same area in terms of the distribution of misorientation boundaries, with a minimum misorientation of $0.75^{\circ}$ chosen as the lower limit. The results are presented in Figure 5.30, revealing a highly complex distribution of misorientation boundaries. Note that the TiN particles have rather substantial gradients of strain associated with the particles. The blue appearance of the boundaries is indicative of the region having the same rotation component with the axis of rotation parallel to the sample normal. 

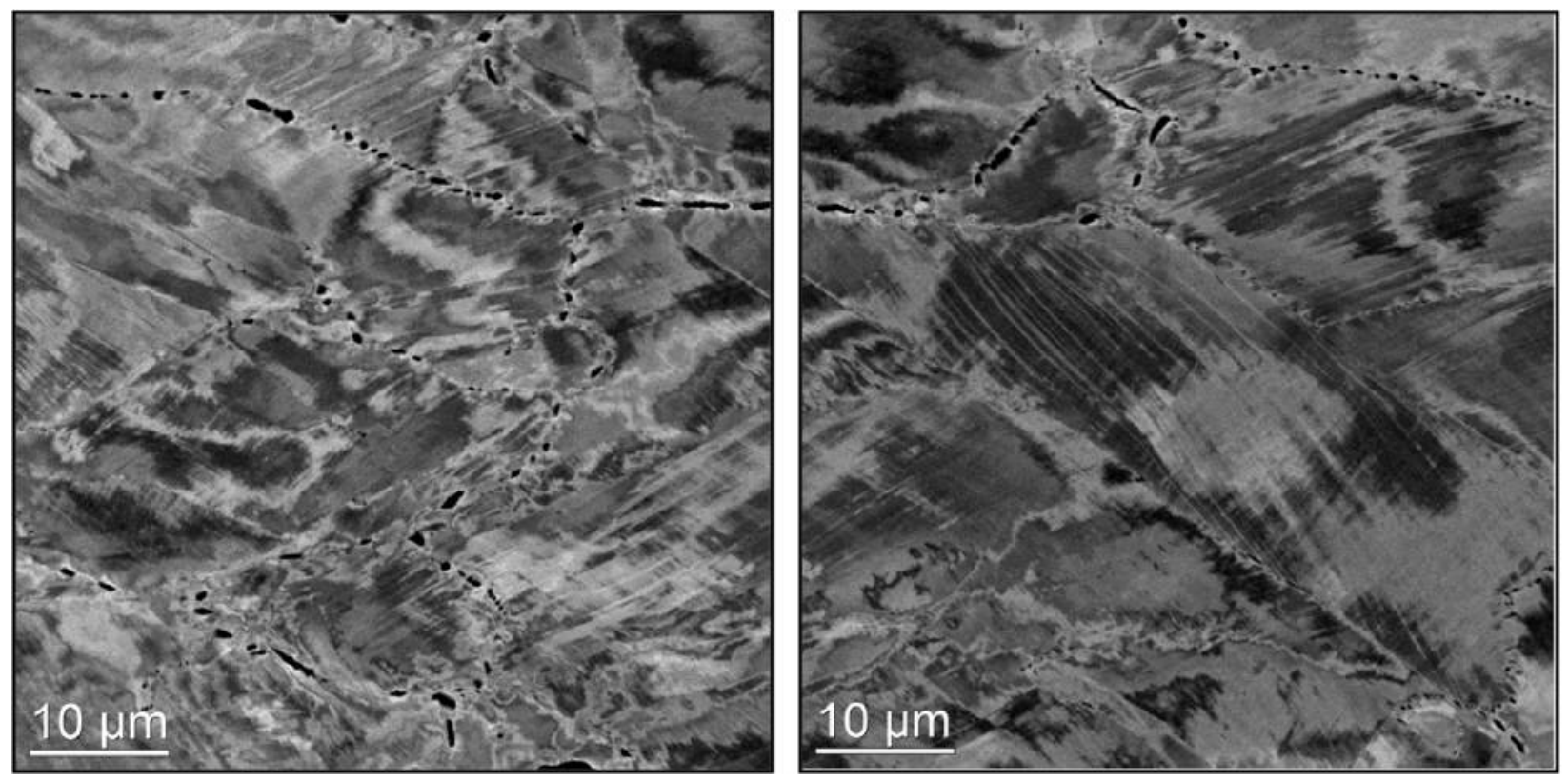

Figure 5.28 SEM backscatter images show a highly deformed grain structure with visible slip bands and high local strain at carbides on the grain boundaries.

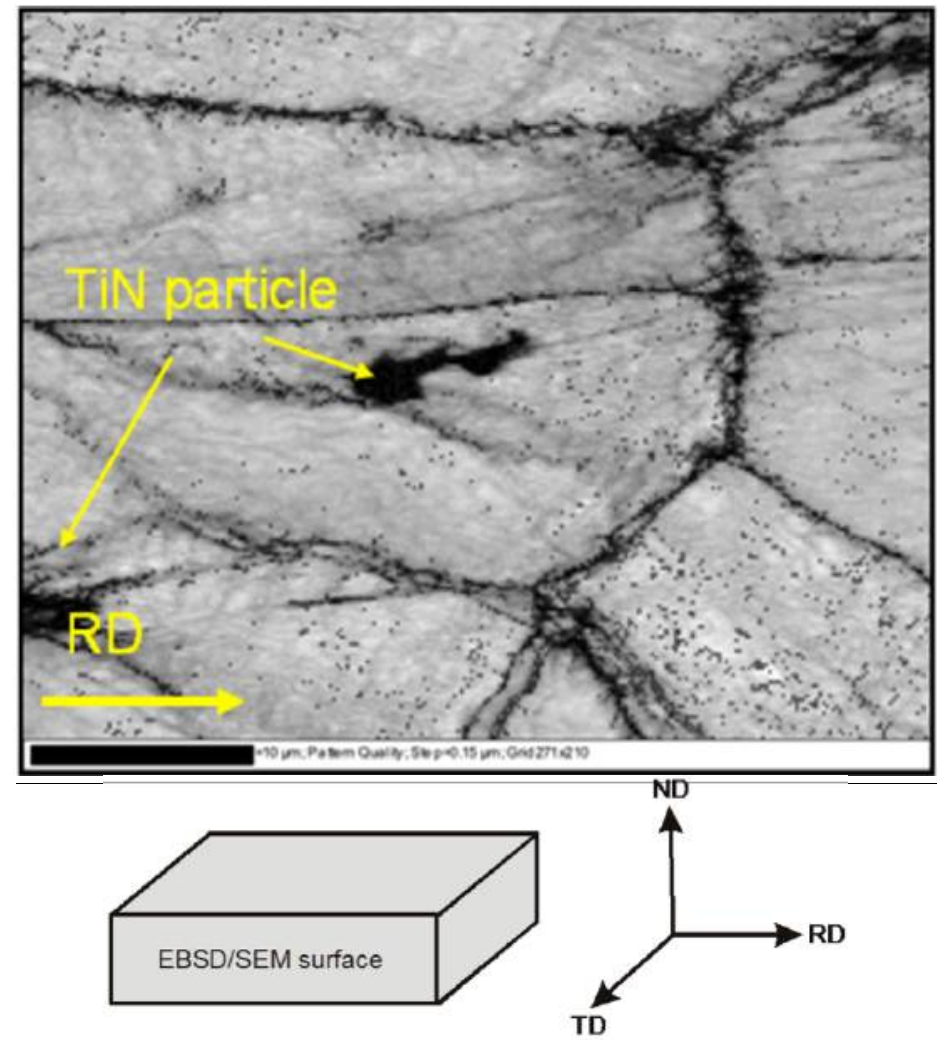

Figure 5.29 Pattern quality map show poorly indexed grain boundary regions in the ANL $26 \% \mathrm{CR}$ material because of high strain and carbides plus similar issue at TiN matrix particles. 


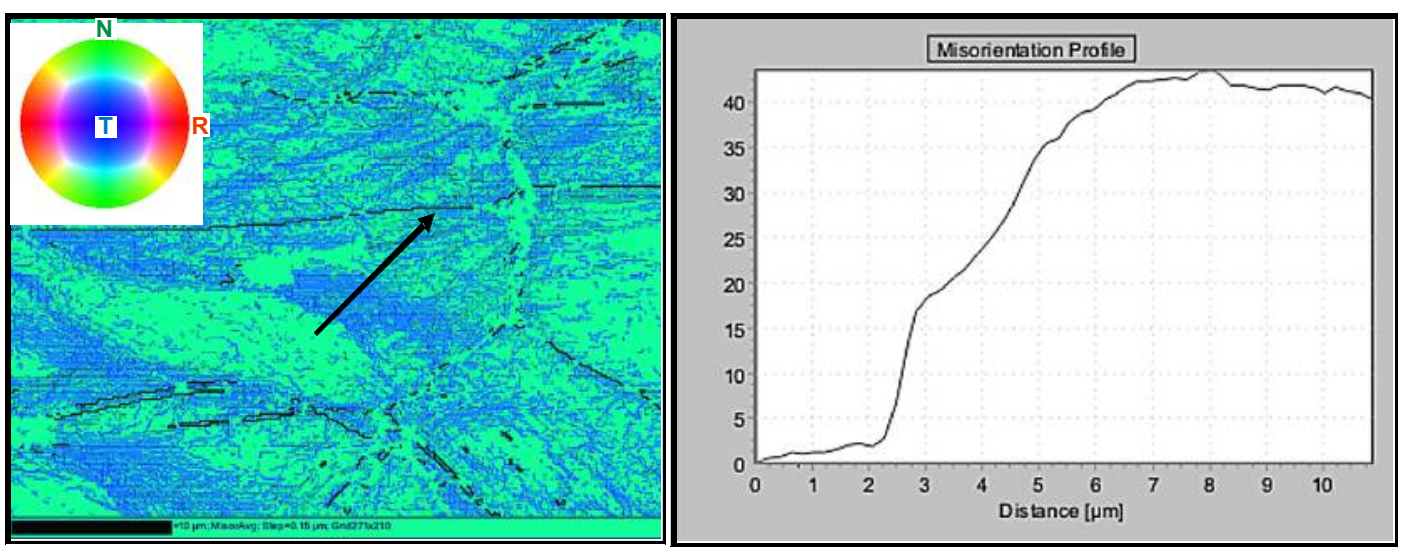

Figure 5.30 Misorientation axis map: Blue and red boundaries indicate rotation in the rolling direction, that is, axis of rotation is the sample normal $(\mathrm{N})$. Misorientation profile near TiN particle in the middle region (black arrow) shows the changing degree of misorientation.

A misorientation profile taken across the central region near the TiN particle reveals a cumulative misorientation of almost $50^{\circ}$. It was not possible to apply a strain calibration to these types of microstructures because of the gradients in the misorientation boundaries, but it is likely that the stress concentration of the TiN particles yields a strain level well in excess of $30 \%$. Figure 5.31 shows the inverse pole figure maps for the same region. In these color maps, the grains are colored according to their orientation with respect to either the rolling direction or the transverse direction. The rolling direction map has a broader range of colors than in the transverse map, probably due to the 1D rolling the sample experienced.
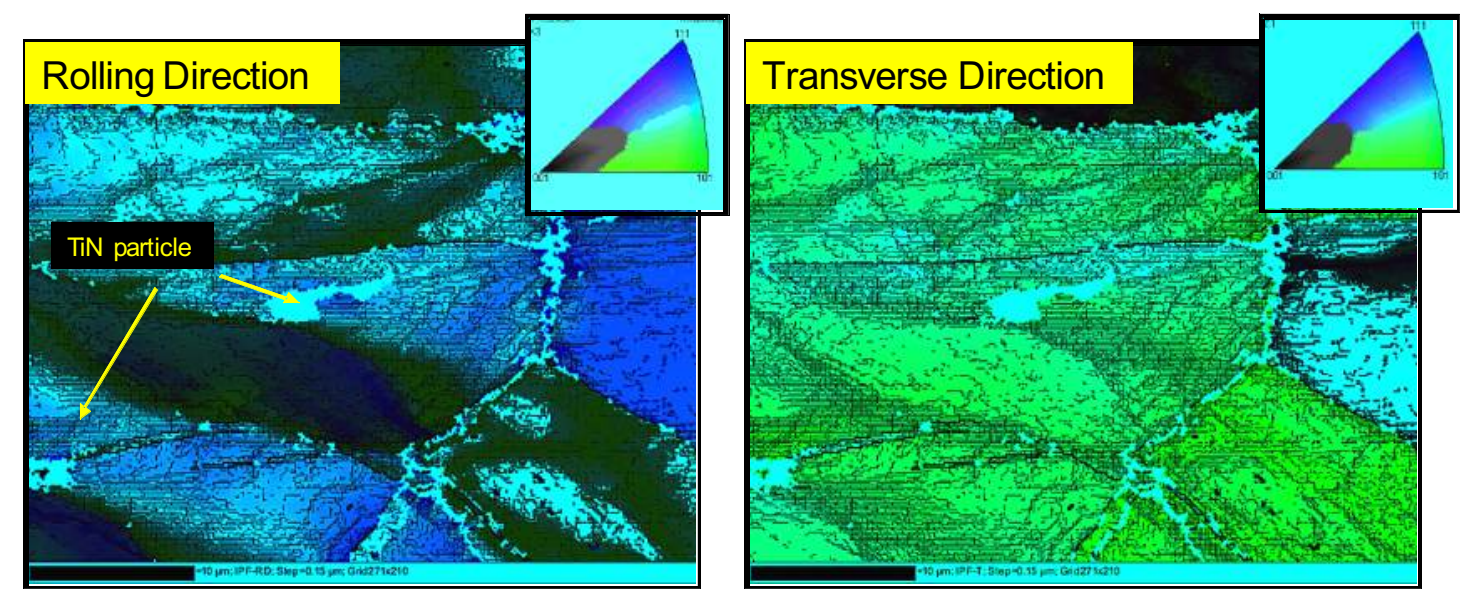

Figure 5.31 Comparison of Inverse pole figure maps (RD versus TD): Rolling direction orientation map shows a greater degree of lattice misorientation in terms of the broader range of colors present in the area, whereas from the TD, the grains are colored more uniformly. Boundary map shows boundaries with regions of greater than $>0.75^{\circ}$ misorientation. Note that the central red colored region below the $\mathrm{TiN}$ in the $\mathrm{RD}$ map is outlined by gradients in the misorientation boundaries, but inside the red region there are relatively few boundaries. 


\section{GEG Damage Microstructure}

The $20 \%$ CR GEG alloy 690 material had a significantly different microstructure with a much lower density of IG carbides and nitrides along with many TG carbides. This resulted in a much lower density of IG cracked carbides and voids for most grain boundaries. However, isolated boundary regions exhibited closely spaced carbides and more extensive permanent damage. Representative images for these isolated regions with cracked carbides and voids are presented in Figures 5.32, 5.33 and 5.34. They illustrate the presence of both cracks and voids associated with $\mathrm{M}_{23} \mathrm{C}_{6}$ carbides. Figure 5.32 shows cracking and voids on an irregularly shaped, elongated carbide. Figure 5.33 shows various IG carbides with both equiaxed shapes as well as irregular shapes with sharper facets, as well as an equiaxed, IG TiN particle. A void is observed between the carbide and nitride in Figure 5.33(a), and cracks and voids are observed on the irregularly shaped carbide in Figure 5.33(b). Figure 5.33(c) highlights cracks in another irregularly shaped carbide. Lastly, voids can be identified among a cluster of equiaxed carbides in Figure 5.34. As well, a void is observed between an equiaxed TiN and $\mathrm{M}_{23} \mathrm{C}_{6}$ precipitate at the bottom of the figure.

In summary, the low density of IG carbides in most grain boundaries for the GEG material resulted in a much lower distribution of cracked carbides and voids than for the $26 \%$ ANL material. Only local grain boundary regions on the order of $10 \mu \mathrm{m}$ in length had semi-continuous IG precipitates and more extensive permanent damage. These regions appeared to be associated with compositional banding that was oriented perpendicular to the rolling direction.
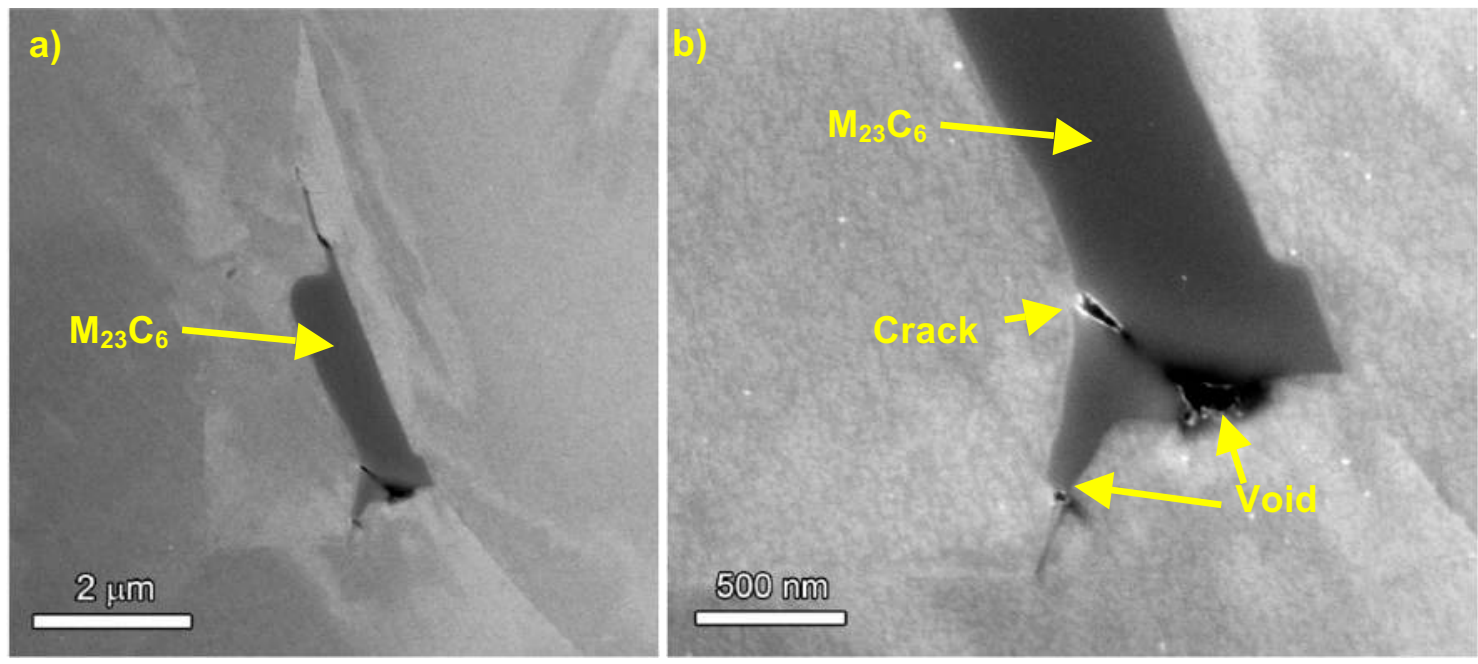

Figure 5.32 SEM micrographs illustrating general carbide damage microstructure in $20 \%$ CR GEG alloy 690 (heat B25K). 


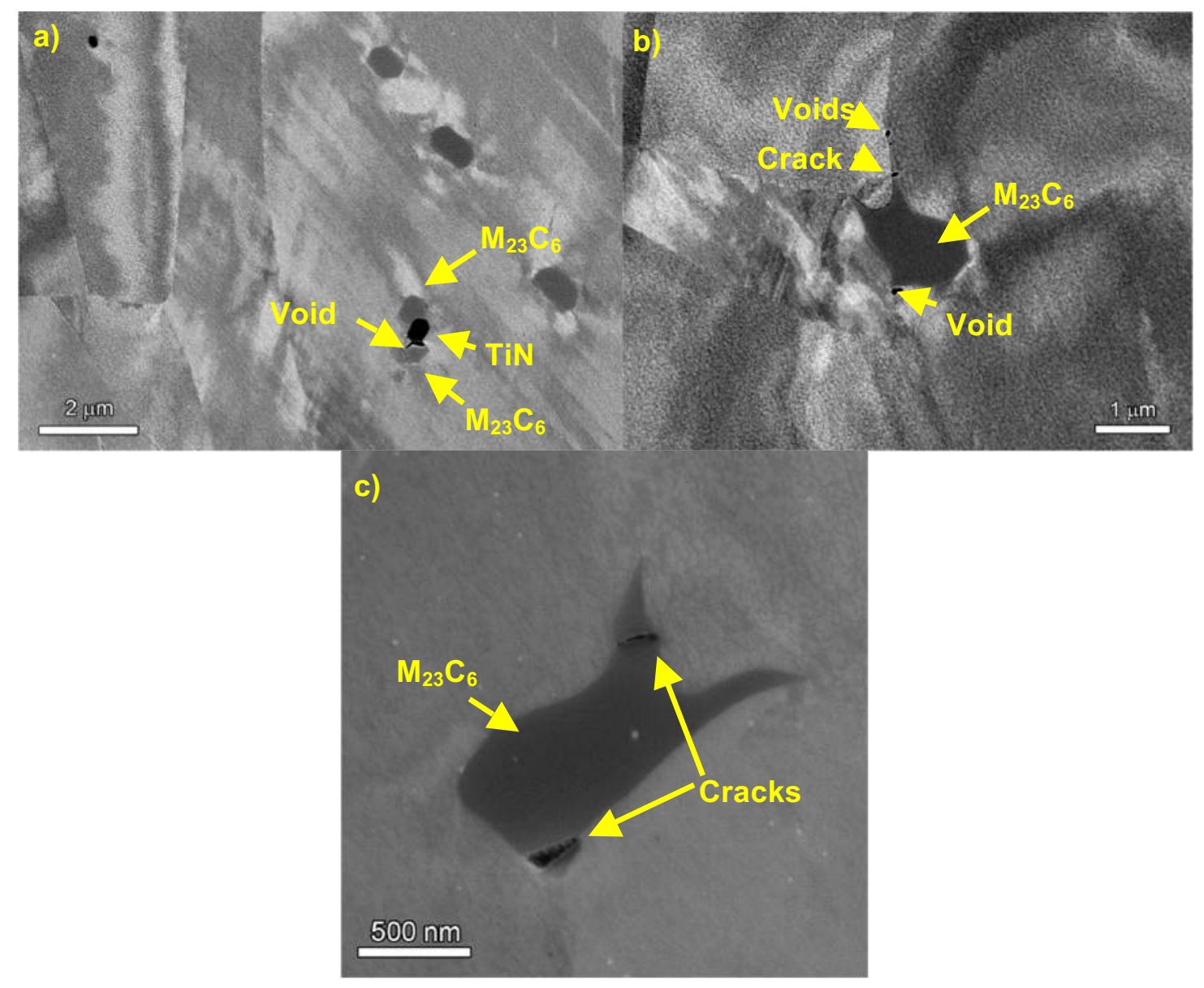

Figure 5.33 SEM micrographs illustrating general carbide damage microstructure in $20 \%$ CR GEG alloy 690 (heat B25K).

Limited EBSD characterizations were also performed on the $20 \%$ CR alloy 690 plate materials. In general, the pattern quality maps didn't show the same degree of strain as observed in the $26 \%$ CR ANL material sample, there were fewer slip bands and the grain boundaries themselves were more sharply defined. The microstructural appearance is illustrated in the SEM backscatter images of Figure 5.35 and the pattern quality map of Figure 5.36. As noted above, few carbides were present on most grain boundaries and this may improve the grain boundary resolution. It may also suggest a lower degree of plastic strain near the boundaries in this material versus the $26 \% \mathrm{CR}$ ANL material. Misorientation maps revealed strong gradients in the misorientation boundaries as shown in Figure 5.37, just as in the case for the ANL cold-rolled material. The misorientation profile included in Figure 5.37 gives an idea of the variation in plastic strain within the grain. Inverse pole figure maps are shown in Figure 5.38 along with the misorientation boundaries down to $0.75^{\circ}$ superimposed to highlight the relationship between relatively undeformed regions versus those with large strain gradients. The high density of misorientation boundaries is not surprising given the $20 \%$ cold-rolled condition of this material. 


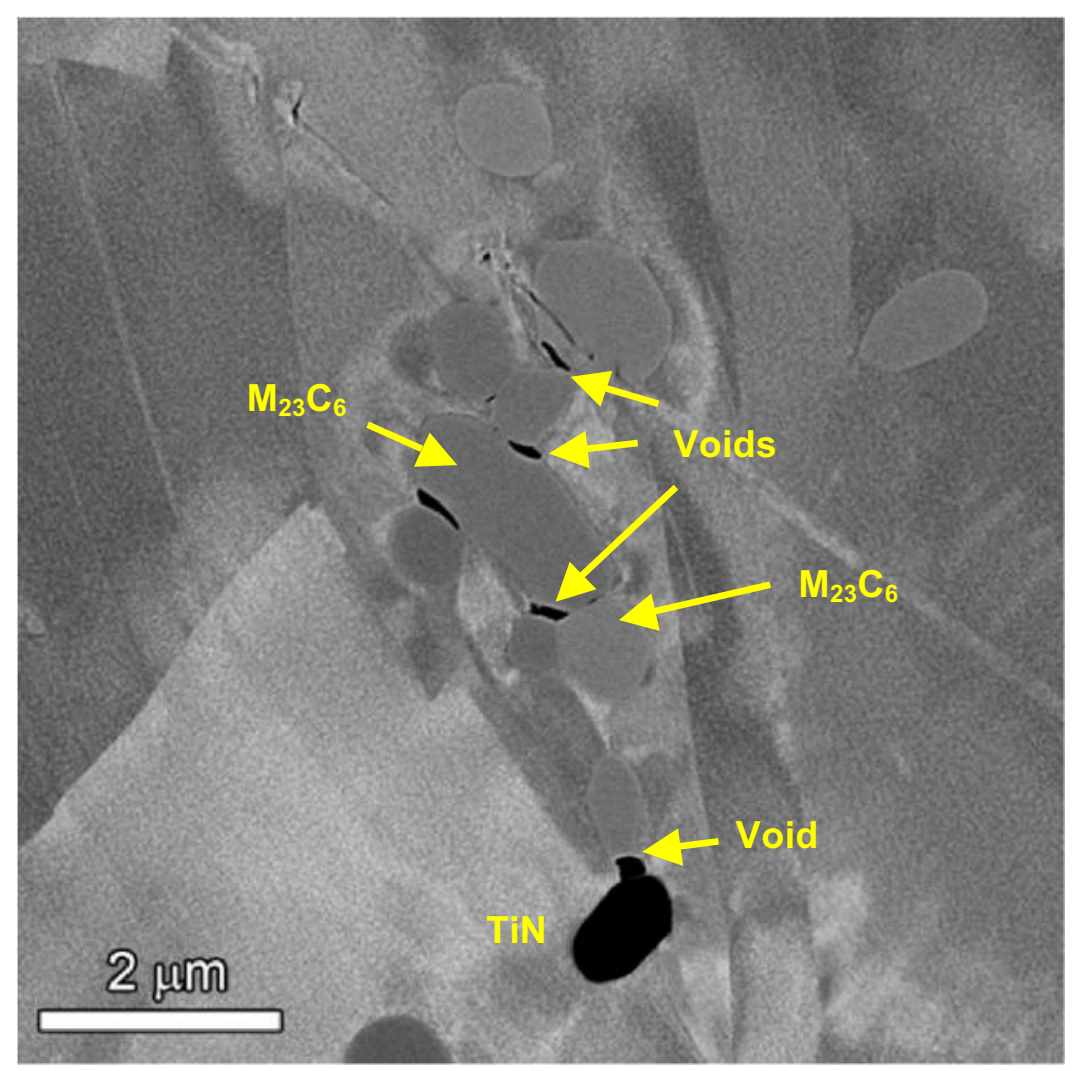

Figure 5.34 SEM micrograph showing void damage near carbides in 20\%CR GEG alloy 690 (heat B25K).
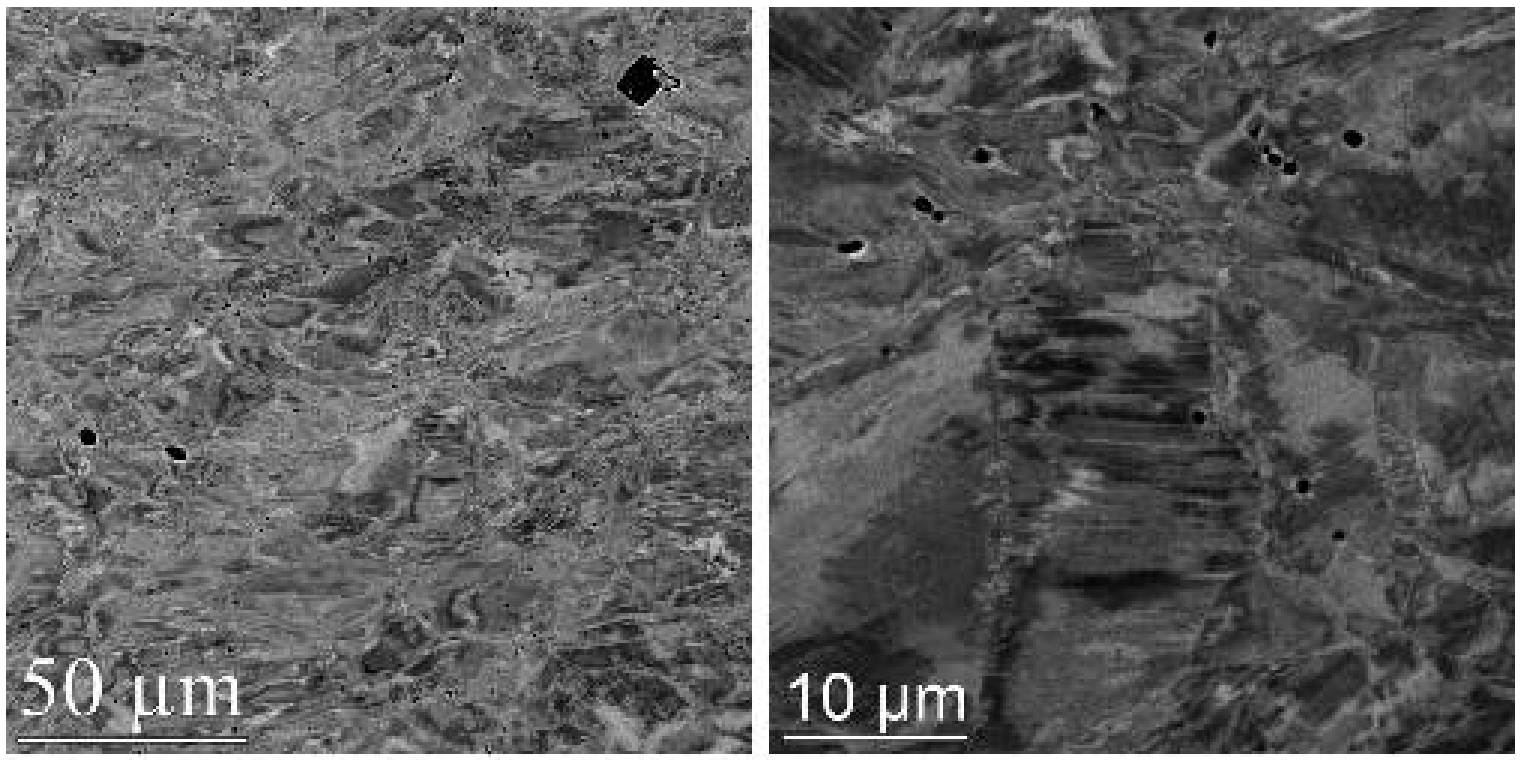

Figure 5.35 SEM backscatter images show a highly deformed grain structure with few visible carbides on the grain boundaries, but moderate density of large TiN particles, in the $20 \%$ CR GEG alloy 690 plate material (heat B25K). 

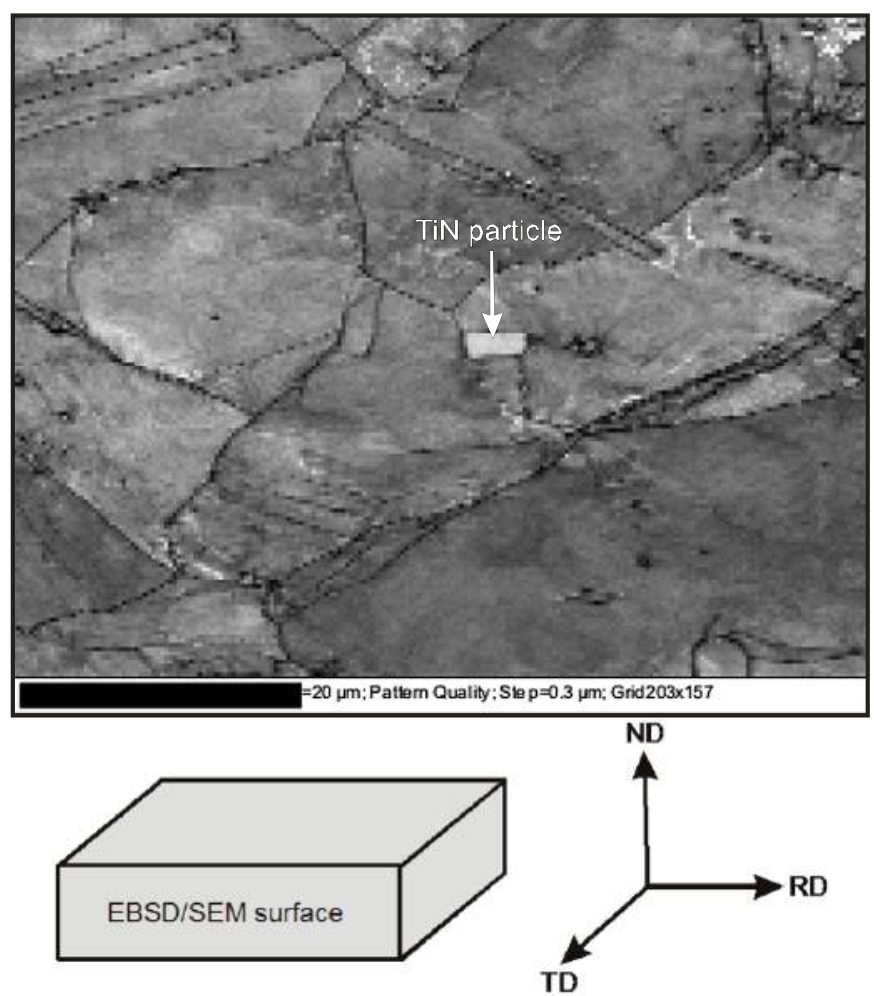

Figure 5.36 Pattern Quality map exhibits more sharply defined grain boundaries in the GEG $20 \%$ CR plate material, presumably because of the lower density of carbides on the boundaries and possible lower localized strain.
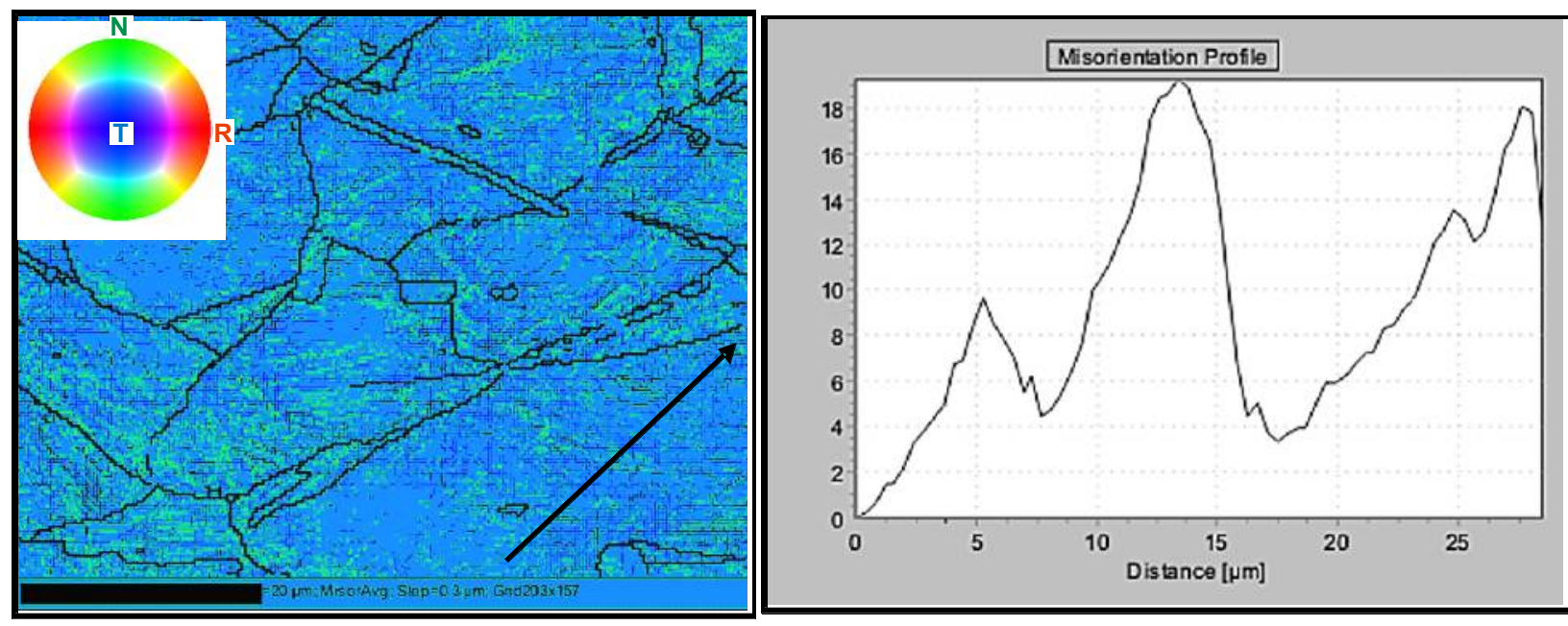

Figure 5.37 Misorientation axis map for GEG material: Blue and red boundaries indicate rotation in the rolling direction, that is, axis of rotation is the sample normal $(\mathrm{N})$. Misorientation profile across grain in lower left hand region (black arrow) shows the degree of misorientation from the less deformed matrix region to the grain boundary. 


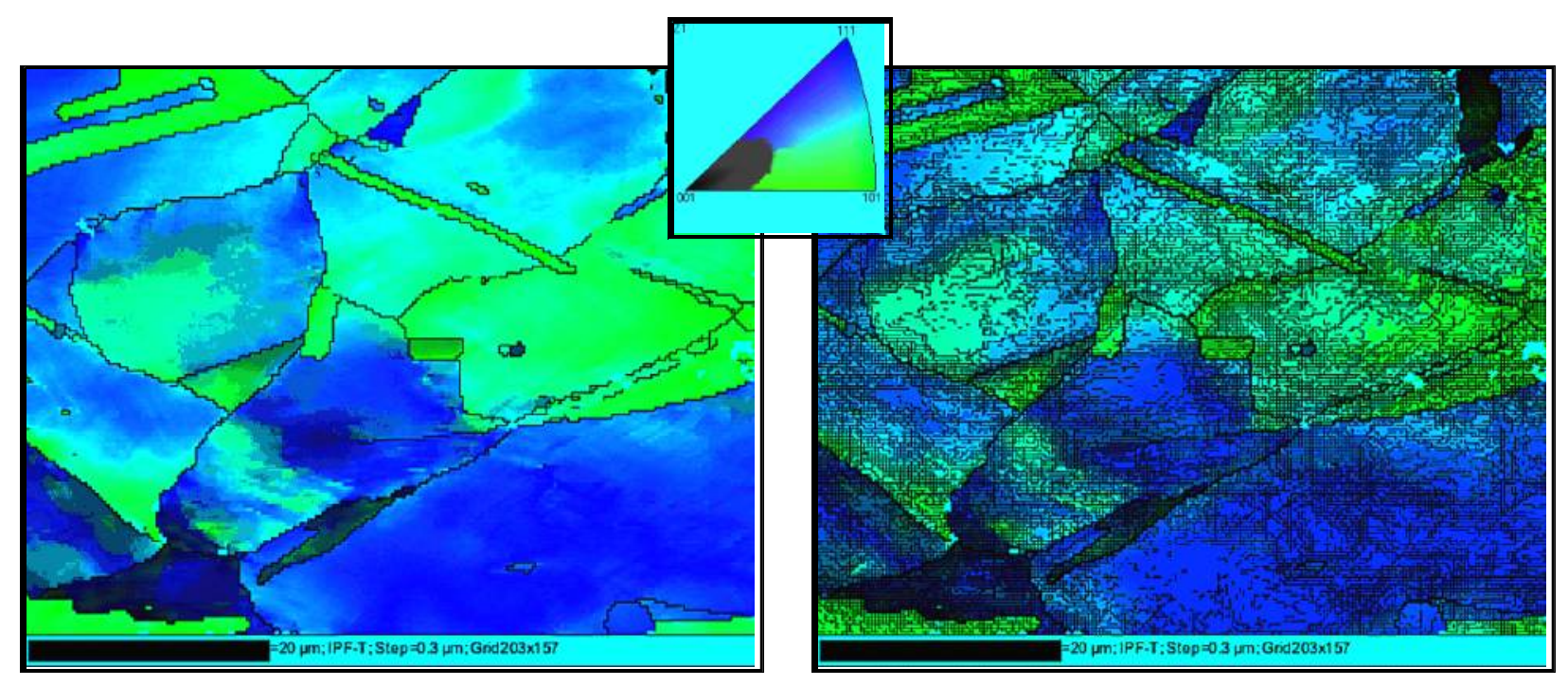

Figure 5.38 Inverse pole figure map (Transverse direction) for GEG material: Nonuniform colors indicated lattice rotation across grains. Boundary map shows boundaries with regions of greater than $>0.75^{\circ}$ misorientation.

\section{Focused Ion Beam Sample Preparation and TEM Characterization of Grain Boundary Damage}

Site-specific TEM sample preparation was accomplished using focused ion beam (FIB) milling in order to isolate grain boundary orientations in relation to the rolling direction and examine cracking along the decorated $\mathrm{M}_{23} \mathrm{C}_{6}$ carbides. Samples near the SCC fracture surface plane for the ANL and GEG cold-rolled materials were prepared to a 1- $\mu \mathrm{m}$ grit polish and then examined in the FIB (Figure 5.39a). The grain boundary contrast is apparent due to the high density of $\mathrm{M}_{23} \mathrm{C}_{6}$ carbides decorated along each boundary (5.39a and b). Grain size was $\sim 50-100 \mu \mathrm{m}$ in diameter and grains were slightly elongated with the rolling direction. In order to assess the extent of cracking and correlate it to the rolling direction, an area of interest (Figure 5.39b) was chosen across an isolated grain boundary.

Two different sample orientations (Figure 5.39c) were prepared, normal and $45^{\circ}$ to the grain boundary, in order to collect different projections of the carbides as well as examine possible cracking. A Pt strap, 1-2 $\mu \mathrm{m}$ deep, was deposited via gas injection system (GIS) (Figure 5.40a) in order to protect the sample surface during trench milling (Figure 5.40a). Trenches milled on either side of the sample using progressively smaller beam currents (from $6 \mu \mathrm{A}$ to $480 \mathrm{pA}$ ) allowed for grain boundary contrast within the sample to be observed as demonstrated in Figure 5.40 (b). As well, the mottled appearance on either side of the grain boundary suggests high strains within the material. Figure 5.40 (b) illustrates the relationship of the grain boundary orientation to the projection of the grain boundary in Figure 5.39(b). Finally, once the sample is thinned to $\sim 1-2 \mu \mathrm{m}$ thick, it is removed from the bulk by means of making a U-cut (Figure 5.40c) after which it is attached to a Cu TEM grid (Figure 5.40d) where it is milled to electron transparency. The contrast of the decorated carbides is used as a reference point for thinning. 


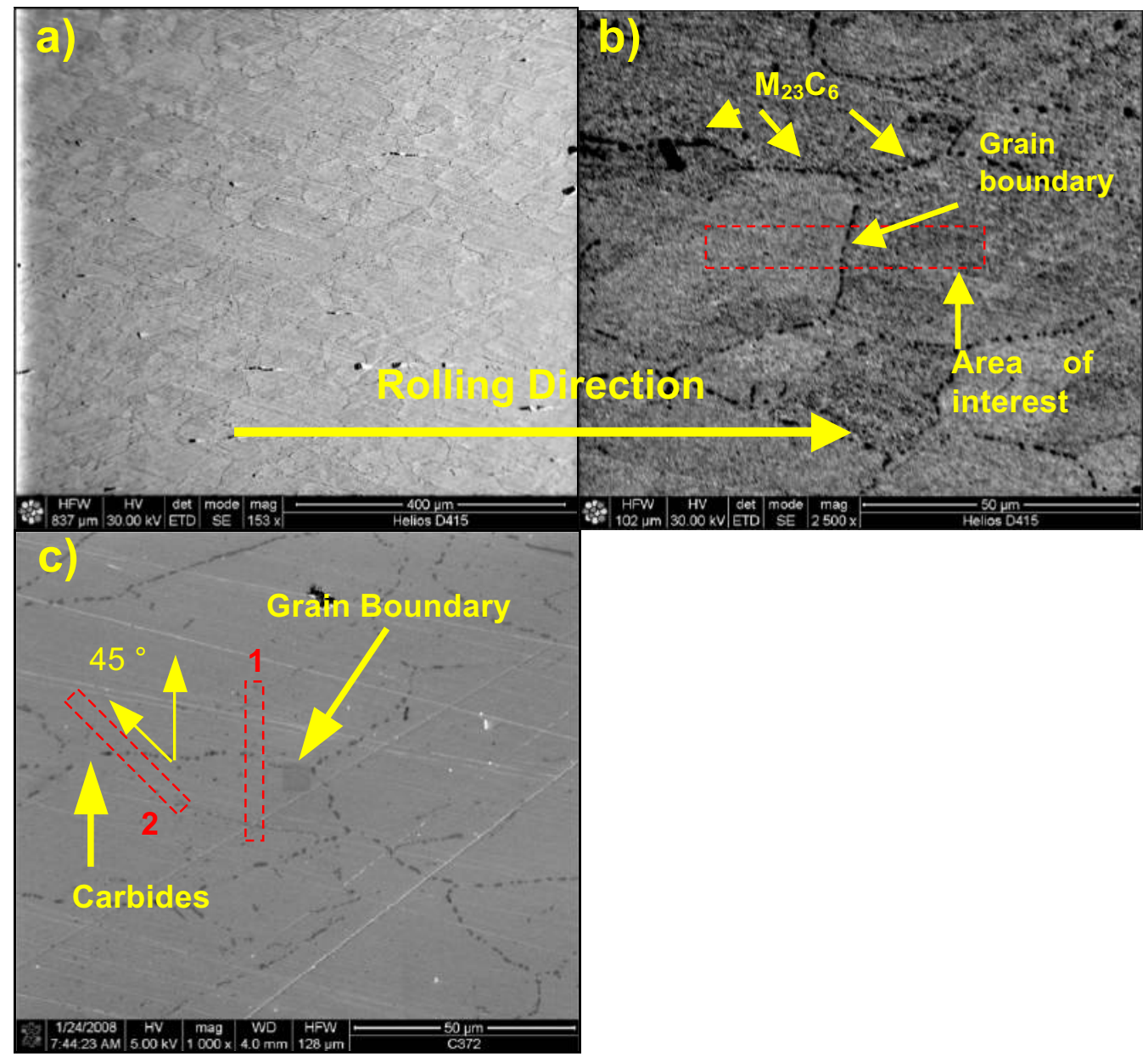

Figure 5.39 SEM micrographs of ANL $26 \%$ CR alloy 690 plate material with grain boundaries decorated with a high density of $\mathrm{M}_{23} \mathrm{C}_{6}$ carbides: (a) Low magnification image illustrating the extent of the carbide decoration throughout the sample, (b) High magnification image with dashed box indicating location of FIB sample preparation across carbided grain boundary and (c) High magnification image illustrating two different sample orientations prepared via $\mathrm{FIB}$ in order to examine cracking at $\mathrm{M}_{23} \mathrm{C}_{6}$ interfaces. Orientation 1 is normal the grain boundary and Orientation 2 is $45^{\circ}$ to the grain boundary.

The detailed characterization of rolling-induced damage by high-resolution SEM was described in the previous sections and additional SEM results on the FIB samples will not be given. It is important to note that the degree of damage varied considerably among different grain boundaries and no consistent relationship to the rolling direction was discovered. TEM was employed to investigate grain boundary damage in the cold-rolled alloy 690 at higher resolutions, however this technique limits the areas and number of boundaries that can be characterized. General conclusions were the same for the type of damage in the cold-rolled plates. Both IG voids and cracked carbides routinely observed in FIB samples of the ANL material, while very few voids and cracked carbides were seen in the GEG material. 


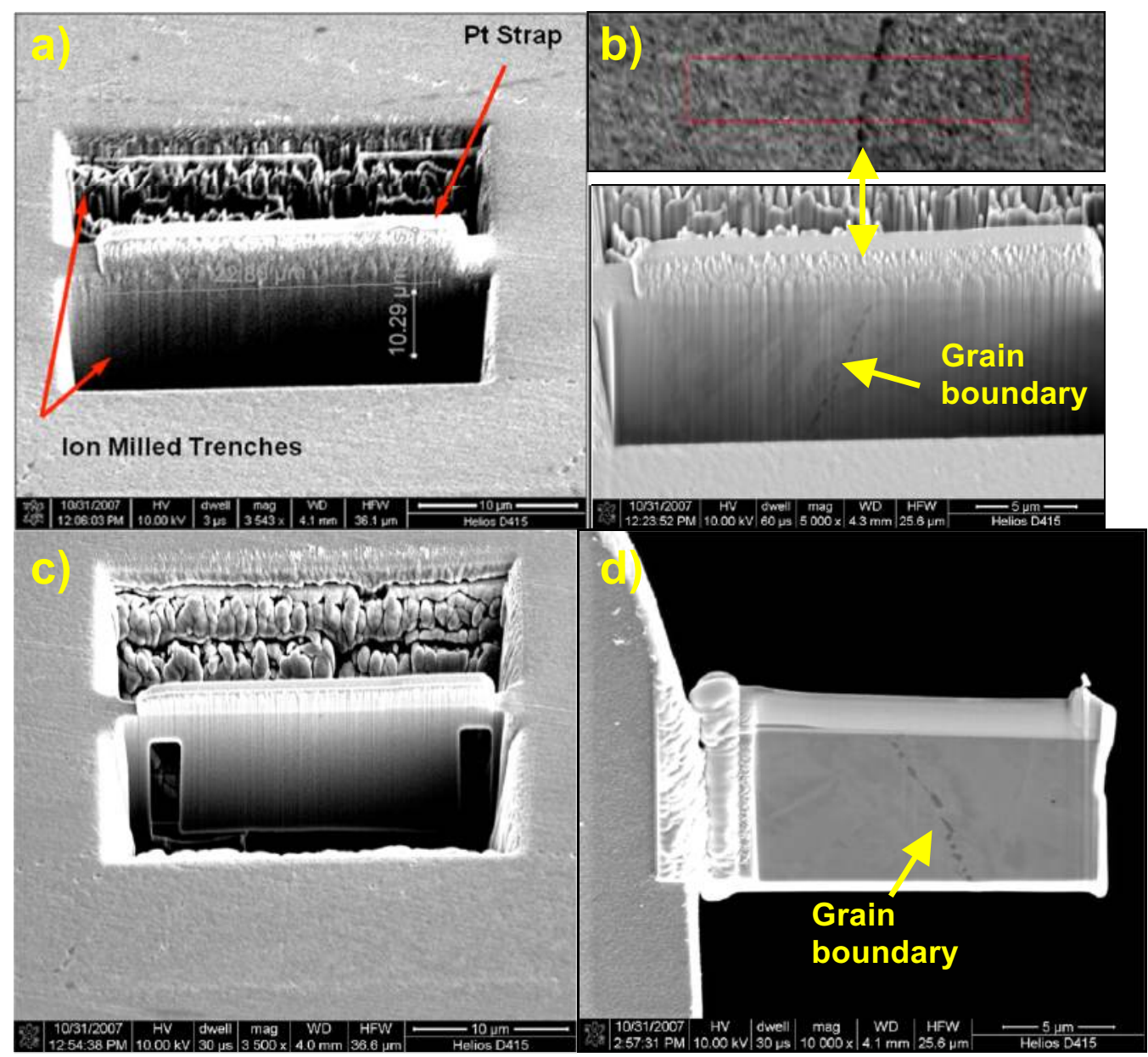

Figure 5.40 SEM micrographs of ion milled sections around selected area for TEM preparation. a) lon milling trenches illustrate how sample is isolated from remainder of the bulk. b) Composite SEM image showing surface region from Figure 5.39 overlayed with an image showing side of TEM sample which illustrates the orientation of the grain boundary in the final sample. c) $\mathrm{U}$-cut is made underneath the sample to partially free it from the bulk. d) Sample removed from bulk, rotated $180^{\circ}$ from b), and attached to a Cu TEM grid for final milling. A grain boundary decorated with carbides is present in the middle of the sample.

Typical examples for voids at the grain boundary carbide interfaces or cracks in the $\mathrm{M}_{23} \mathrm{C}_{6}$ carbides in the ANL material are shown in Figures 5.41, 5.42 and 5.43. The large amount of mottled contrast in both the bulk and carbides in Figure 5.41 also indicates large amounts of strain within the material. The carbides are coherent to the matrix (Figure 5.41b) and cracking between the carbides appears to be in-line with the rolling direction (Figure 5.42a). 


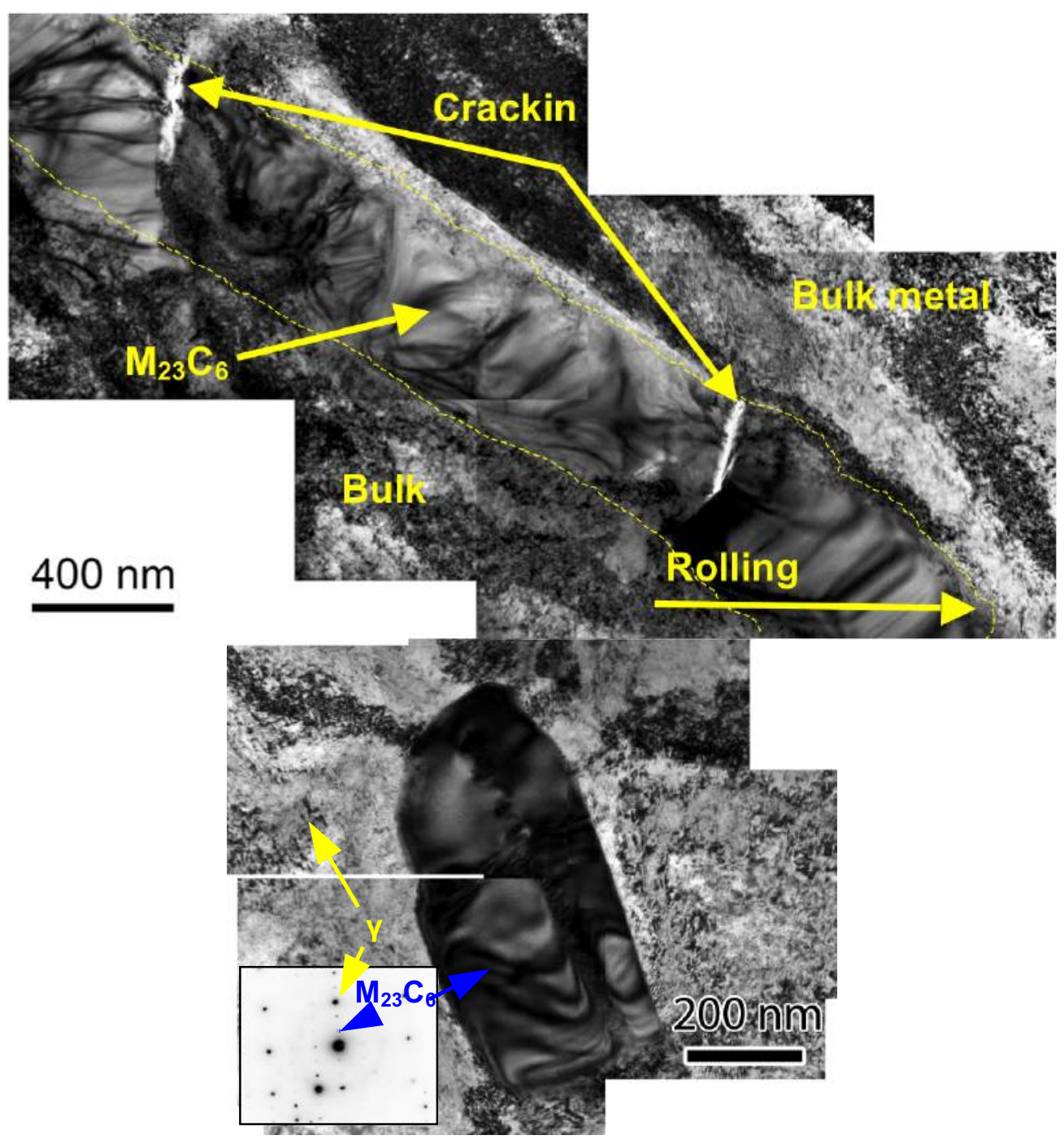

Figure 5.41 TEM micrograph montages of the 26\%CR ANL alloy 690 sample illustrating $\mathrm{M}_{23} \mathrm{C}_{6}$ carbides along a grain boundary. Top image: Sample taken normal to the grain boundary illustrating cracking between $\mathrm{M}_{23} \mathrm{C}_{6}$ carbides along the grain boundaries. Bottom image: Sample taken $45^{\circ}$ to the grain boundary showing mottled contrast in the bulk and carbide grains indicating high amounts of strain in the sample. The diffraction pattern (inset) from the selected area illustrates that the carbide is oriented in the [112] on the left grain.

Figures 5.42 and 5.43 are scanning TEM (STEM) brightfield images with accompanying elemental EDS maps of two different regions along the grain boundary illustrating two different forms of cracking. Similar to cracking in Figure 5.41, it is difficult to ascertain whether cracks are between carbides or in the carbides themselves in Figure 5.43. The STEM brightfield image in Figure 5.42 clearly illustrates that the cracking occurs within a single carbide. As noted in Figure 5.41, large amounts of strain in the STEM brightfield images in Figures 5.42 and 5.43 are observed. 


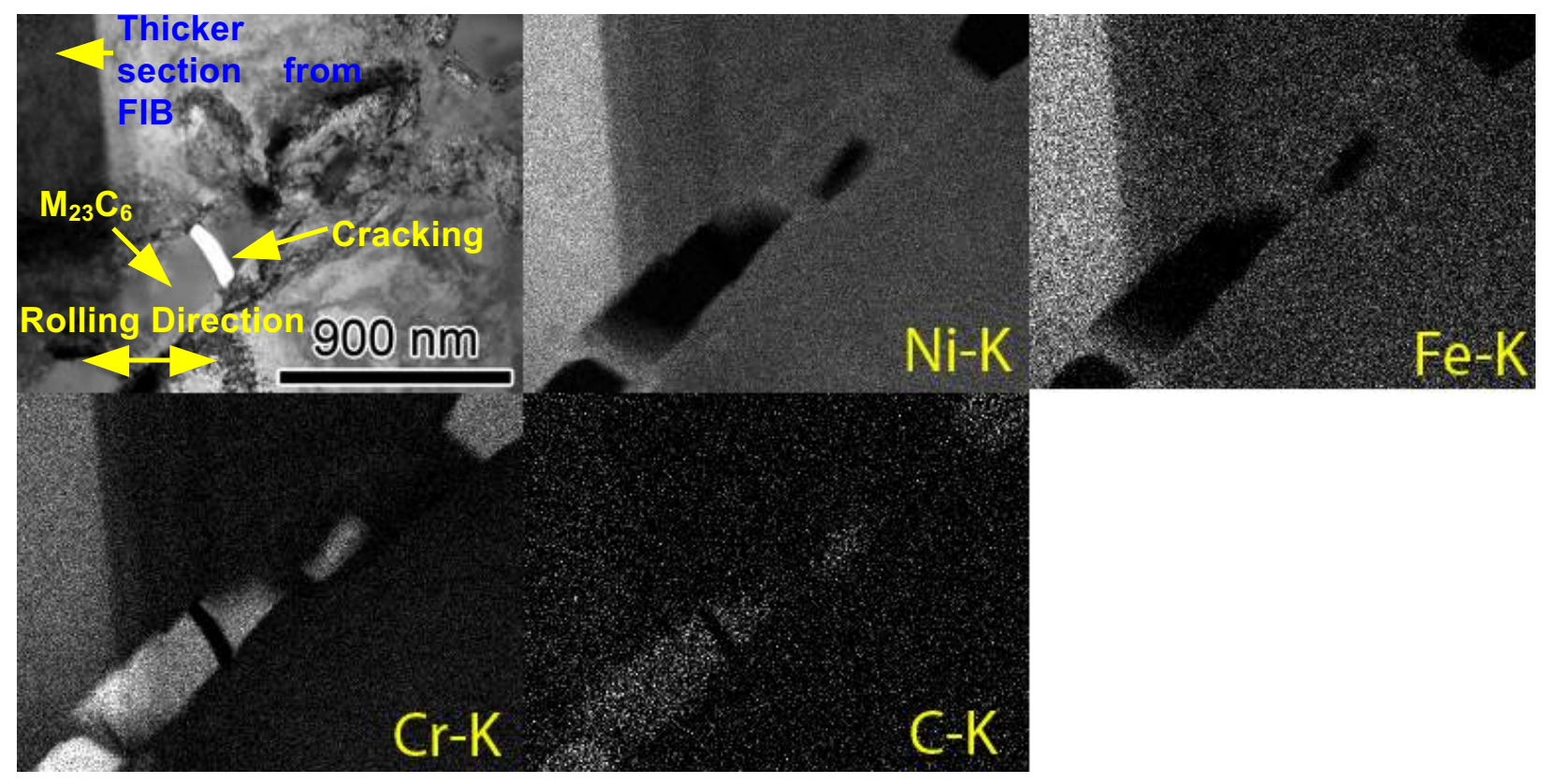

Figure 5.42 STEM brightfield micrograph and elemental maps of the $26 \%$ CR ANL alloy 690 illustrating cracks adjacent to $\mathrm{M}_{23} \mathrm{C}_{6}$ carbides that decorate the grain boundary (sample taken normal to boundary). An increased signal for most elements can be seen as a vertical line in the EDS maps as well as a dark line in the STEM image due to specimen thickness differences.

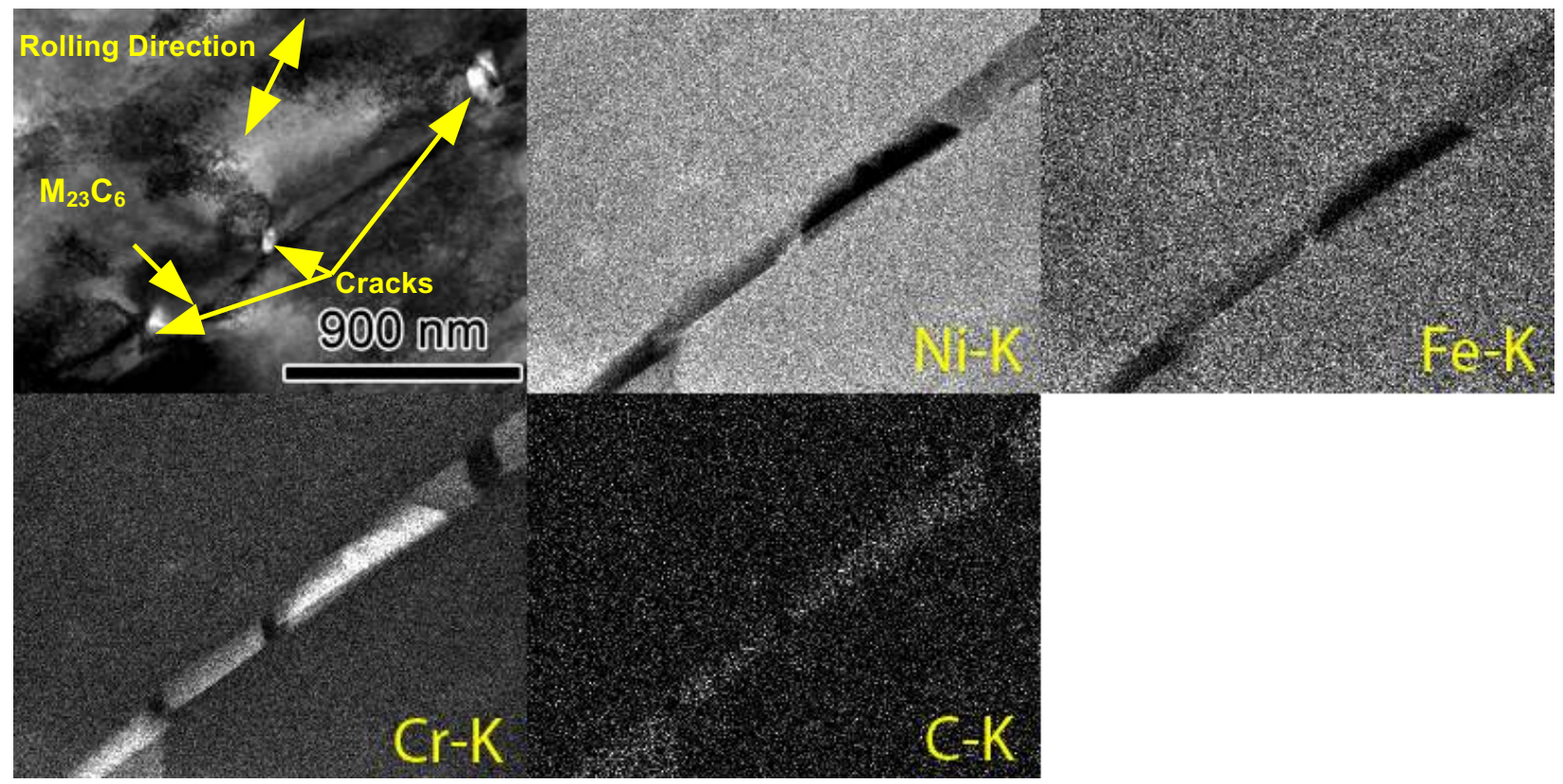

Figure 5.43 STEM brightfield micrograph and elemental maps from the $26 \% \mathrm{CR}$ ANL alloy 690 illustrating cracks adjacent to $\mathrm{M}_{23} \mathrm{C}_{6}$ carbides that decorate another grain boundary (sample taken normal to boundary). The rolling direction has been noted in the STEM image. 
The FIB TEM samples prepared from the $20 \%$ CR alloy 690 material from GEG contain only isolated IG carbides consistent with the SEM results described earlier. Although extremely high dislocation densities are present near the grain boundaries, there is no evidence for IG voids or cracks in the limited regions examined. Figure 5.44 illustrates the cross-section of a single, large carbide in the sample prepared normal to the grain boundary. The boundary was oriented along the rolling direction plane and no voids or cracks were found associated with the carbide particle. Observations from a second FIB-TEM sample prepared at $45^{\circ}$ to the grain boundary are shown in Figure 5.45. Although the FIB sample is rather thick, a thin $\mathrm{M}_{23} \mathrm{C}_{6}$ carbide was identified at the left side of the image. This is better shown in the $\mathrm{Cr}$ composition map and a very thin layer of enriched $\mathrm{Cr}$ continues for some distance along the boundary. It seems most likely that this enrichment (and matching $\mathrm{Ni}$ and $\mathrm{Fe}$ depletion) results from the presence of a $\mathrm{M}_{23} \mathrm{C}_{6}$ carbide layer. This grain boundary was inclined to the rolling direction and again no permanent damage (voids or cracks) was detected. As noted above, much more detailed TEM work is needed to properly define grain boundary characteristics in these materials but such examinations have been beyond the scope of the project. Because of the expanded interest in high-resolution characterizations of SCC crack tips within NRC project N6925, some additional work is being performed on the CR alloy 690 plate materials. Preliminary crack and crack-tip examinations are described in the following section.

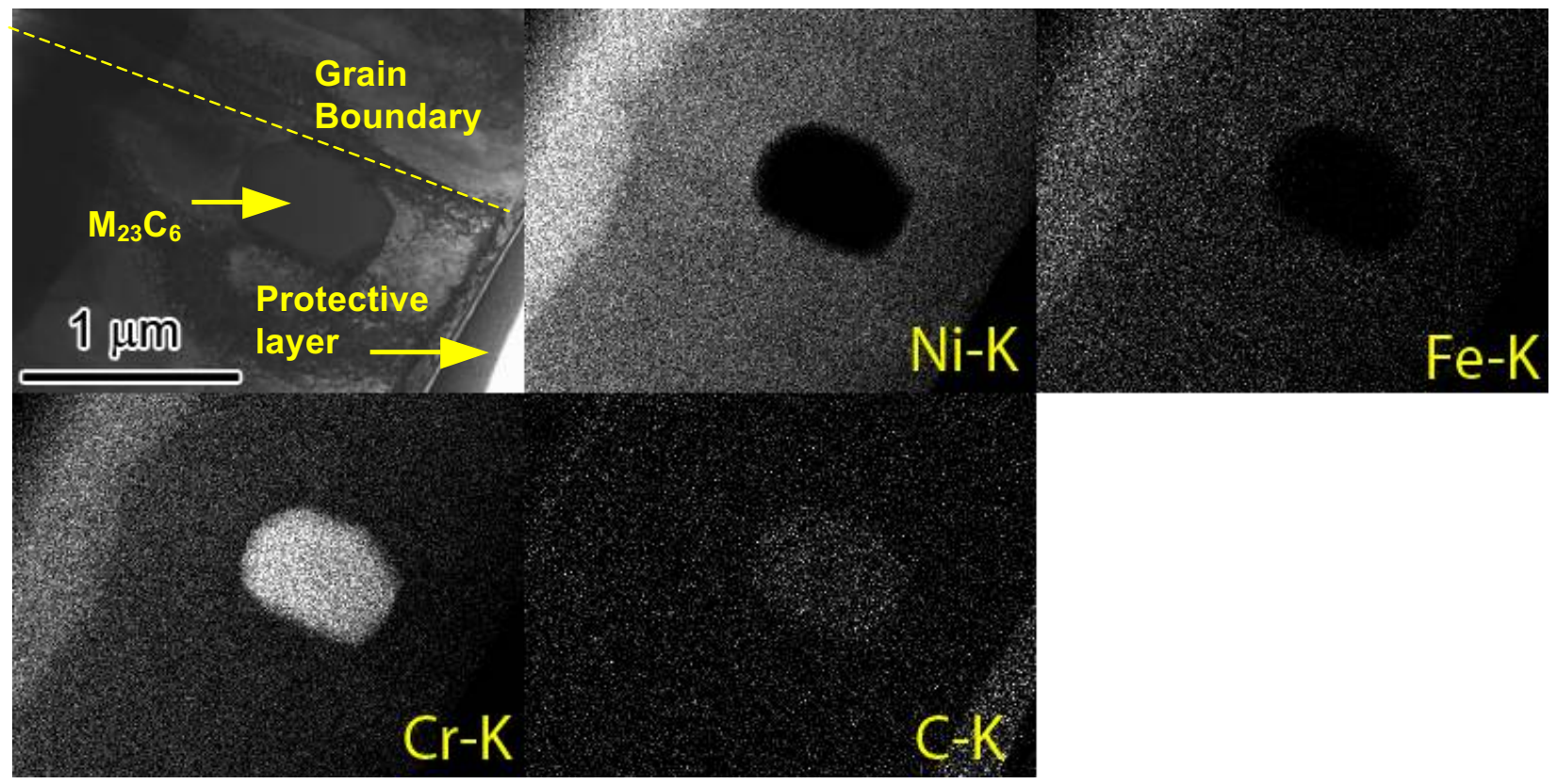

Figure 5.44 STEM image and elemental maps of a grain boundary region for FIB-TEM sample taken across a grain boundary along the rolling direction in the $20 \%$ CR GEG sample. An isolated $\mathrm{M}_{23} \mathrm{C}_{6}$ carbide is seen adjacent to the grain boundary. 


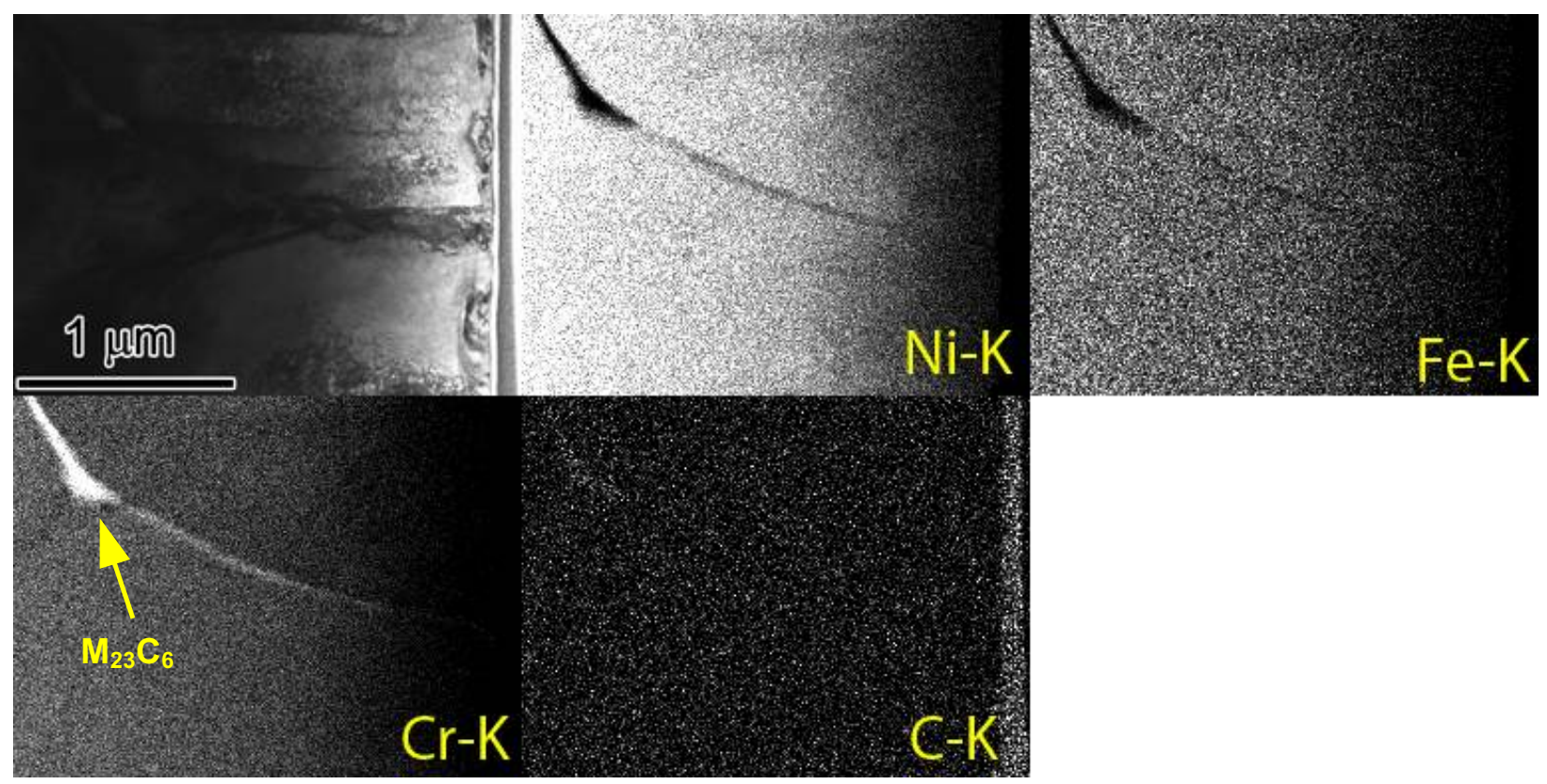

Figure 5.45 STEM image and elemental maps from a second FIB-TEM sample taken $45^{\circ}$ to a grain boundary along the rolling direction in the $20 \%$ CR GEG sample. The $\mathrm{Cr}$ composition map suggests that a thin, IG $\mathrm{Cr}$ carbide is present. High-resolution imaging was not possible due to sample thickness.

\section{Summary of CR Damage Characterizations and Comparisons to CR CRDM Materials}

Damage microstructures measured for the 26\%CR ANL (heat NX3297HK12) and 20\%CR GEG (heat B25K) plate materials are briefly summarized in Table 5.3 along with microstructure and hardness information from Table 5.2. Once again, characterization results for the $30 \% \mathrm{CR}$ alloy 690 CRDM materials (heat RE243) are added for comparison. The $26 \%$ CR ANL plate showed the highest degree of permanent damage among the CR materials examined although roughly similar to the $30 \% \mathrm{CR}$ alloy 690 TT CRDM tube. Between these two heavily damaged materials, the ANL material had more extensive cracking of IG carbides and IG/TG TiN particles along with a similar distribution of IG voids. This damage is consistent with the higher density of grain boundary carbides in these materials. The low density of well-spaced carbides on the majority of grain boundaries in the $20 \%$ CR GEG plate resulted in a much lower number of IG voids or cracked particles overall. However, selected grain boundaries with more closely spaced carbides did show significant permanent damage. The difference was simply that most grain boundaries outside a compositional banded region had a limited number of IG carbides and only isolated observations of an IG cracked particle or void. Finally, the 30\%CR alloy 690CM CRDM material exhibited the least permanent damage due to the removal of nearly all carbides from grain boundaries during the solution anneal treatment. 
Table 5.3 Microstructure, CR damage and hardness for selected CR alloy 690 materials.

\begin{tabular}{|c|c|c|c|}
\hline Sample & Microstructure & CR-Induced Damage & Hardness \\
\hline $\begin{array}{c}\text { (2 - TT) PNNL } \\
\text { CRDM alloy 690TT } \\
\text { 30\%CR; Test } \\
\text { sample CT022 }\end{array}$ & $\begin{array}{l}\text { Semi-continuous (small discrete + } \\
\text { cellular) carbides on GBs plus } \mathrm{Cr} \\
\text { depletion, few TiN at GBs and in } \\
\text { matrix; slightly elongated grains }\end{array}$ & $\begin{array}{c}\text { Moderate density of voids } \\
\text { and cracked carbides on } \\
\text { GBs, few cracked TiN in } \\
\text { matrix }\end{array}$ & $\begin{array}{c}300 \\
\mathrm{~kg} / \mathrm{mm}^{2}\end{array}$ \\
\hline $\begin{array}{c}\text { (2 - CM) PNNL } \\
\text { CRDM alloy } \\
\text { 690CM 30\%CR; } \\
\text { Test sample CT023 }\end{array}$ & $\begin{array}{c}\text { Few carbides and well-spaced TiN } \\
\text { on GBs, few TiN in matrix; slightly } \\
\text { elongated grains }\end{array}$ & $\begin{array}{l}\text { Few voids at triple points, no } \\
\text { cracked particles on GBs, } \\
\text { few cracked TiN in matrix }\end{array}$ & $\begin{array}{c}290 \\
\mathrm{~kg} / \mathrm{mm}^{2}\end{array}$ \\
\hline $\begin{array}{l}\text { (4) GEG plate alloy } \\
69020 \% \text { CR; Test } \\
\text { sample CT037 }\end{array}$ & $\begin{array}{c}\text { Well-spaced carbides on most GBs, } \\
\text { higher density in banded areas, TiN } \\
\text { at GBs and in matrix, slightly } \\
\text { elongated grains }\end{array}$ & $\begin{array}{l}\text { Low density of voids or } \\
\text { cracked particles on GBs, } \\
\text { higher density in banded } \\
\text { areas, cracked TiN in matrix }\end{array}$ & $\begin{array}{c}307 \\
\mathrm{~kg} / \mathrm{mm}^{2}\end{array}$ \\
\hline $\begin{array}{l}\text { (5) ANL plate alloy } \\
69026 \% \text { CR; Test } \\
\text { sample CT036 }\end{array}$ & $\begin{array}{c}\text { Semi-continuous carbides and TiN } \\
\text { on GBs, no banding in SCC plane, } \\
\text { TiN stringers in matrix, slightly } \\
\text { elongated grains }\end{array}$ & $\begin{array}{l}\text { Moderate density of voids } \\
\text { and cracked carbides on } \\
\text { GBs, cracked TiN in matrix }\end{array}$ & $\begin{array}{c}315 \\
\mathrm{~kg} / \mathrm{mm}^{2}\end{array}$ \\
\hline
\end{tabular}

\subsection{SCC Tests on the Cold-Rolled Alloy 690 Plate Materials}

As described in Section 5.1, alloy 690 plate was obtained from ANL in the $26 \%$ CR condition and from GEG in the $20 \%$ CR condition. Specimens CT036 and CT037 were machined so that SCC tests could be performed evaluating crack-growth response in S-L orientation. When these tests were started, some information on the expected SCC propagation response was available. In particular, GEG had reported very high growth rates during final transitioning and constant $\mathrm{K}$ for the $26 \%$ CR ANL plate and moderate rates for their own $20 \%$ CR plate. An overview of the entire PNNL test is presented in Figure 5.46 and detailed data for each phase of the test is given in Table 5.4. Similar response for the two CR plate specimens was observed during initial transitioning at $325^{\circ} \mathrm{C}$ and $29 \mathrm{cc} / \mathrm{kg} \mathrm{H}_{2}$. Measured rates during gentle cycling at $0.001 \mathrm{~Hz}$ and $\mathrm{R}=0.7$ were lower than expected for the ANL material, so $\mathrm{R}$ values were decreased first to 0.6 and then to 0.5 as shown in Figure 5.47. While the propagation rates increased with decreasing $R$ values, very little difference was detected between the ANL and GEG materials even when a hold time of $2.5 \mathrm{~h}$ was added. Additional transitioning steps were performed in phase 11 through 17 (see Table 5.4), but did not show enhanced crack growth. The decision was made to increase the test temperature to $360^{\circ} \mathrm{C}$ at $\sim 1670 \mathrm{~h}$ and adjust the dissolved hydrogen concentration to $25 \mathrm{cc} / \mathrm{kg}$ (at the predicted $\mathrm{Ni} / \mathrm{NiO}$ stability line). Increasing the temperature to $360^{\circ} \mathrm{C}$ caused an immediate $\sim 1.4 \mathrm{X}$ increase in growth rate during $0.001 \mathrm{~Hz}$ cycling $(\mathrm{R}=0.7)$. A 2.5 -h hold was subsequently added, causing the growth rate to initially drop by a factor of $5 \mathrm{X}$, but as the test progressed under cycle + hold loading, the growth rate was observed to increase from its initial value by a factor of $\sim 2 \mathrm{X}$ for both materials. The test was converted to constant $\mathrm{K}$ at $\sim 2900 \mathrm{~h}$ as shown in Figure 5.48. SCC growth rates increased slightly with time and reached corrected values of 6.3 and $4.5 \times 10^{-8} \mathrm{~mm} / \mathrm{s}$ for the ANL and GEG materials, respectively. This test was ended after $\sim 1200 \mathrm{~h}$ at constant $\mathrm{K}$ and samples were cross-sectioned for crack-tip characterizations (Chapter 6 ) and fractured for crack length and $\mathrm{K}$ corrections. 


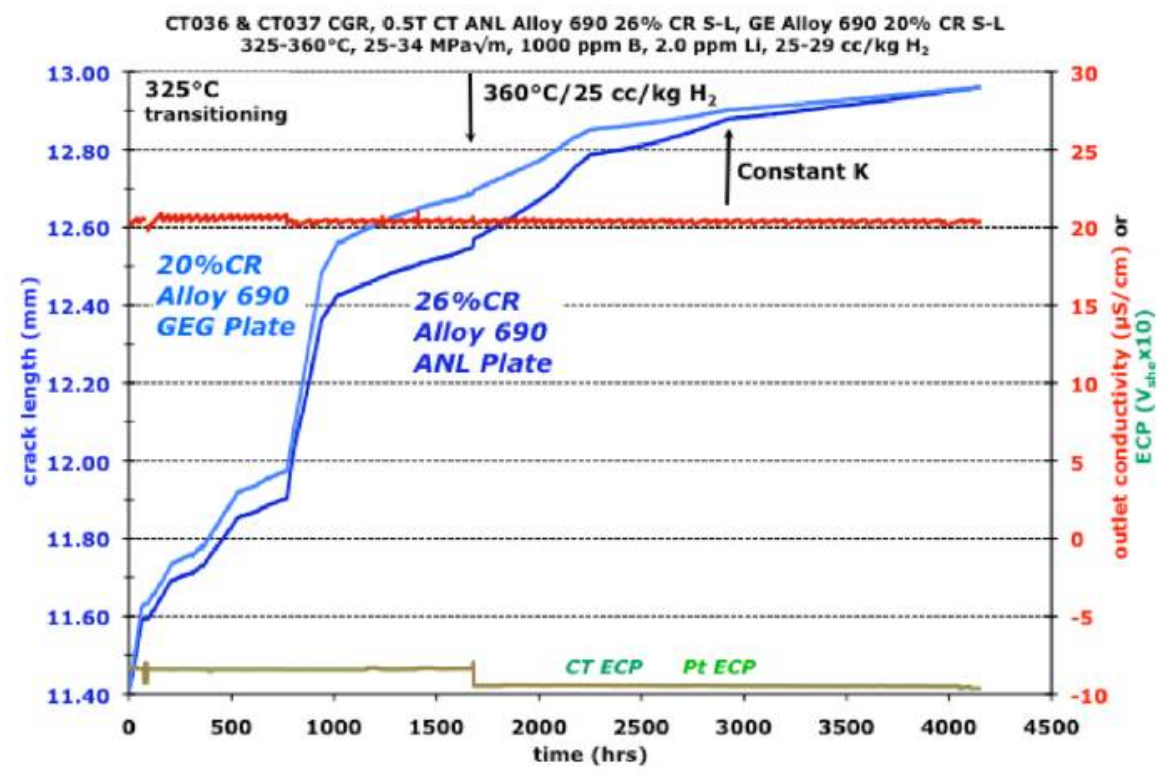

Figure 5.46 Overview of SCC test for ANL-CT036 (heat NX3297HK12) and GEG-CT037 (heat B25K) alloy 690 specimens.

Table 5.4 Corrected results for ANL and GEG 1D CR S-L alloy 690 (CT036 \& CT037).

\begin{tabular}{|c|c|c|c|c|c|c|c|c|c|c|c|c|}
\hline $\begin{array}{c}\text { Test } \\
\text { Phase } \\
\end{array}$ & $\begin{array}{c}\text { Duration } \\
\text { (h) }\end{array}$ & $\mathrm{R}$ & $\begin{array}{l}\text { Freq } \\
(\mathrm{Hz})\end{array}$ & $\begin{array}{l}\text { Hold } \\
(\mathrm{h})\end{array}$ & $\begin{array}{c}\text { Water } \\
\text { Chemistry } \\
\text { Conditions }\end{array}$ & $\begin{array}{c}\text { Temp } \\
\left({ }^{\circ} \mathrm{C}\right) \\
\end{array}$ & $\begin{array}{c}\mathrm{ANL} \\
\mathrm{Kmax} \\
(\mathrm{MPa} \sqrt{\mathrm{m}})\end{array}$ & $\begin{array}{l}\text { ANL690 } \\
26 \% \text { S-L } \\
(\mathrm{mm} / \mathrm{sec}) \\
\end{array}$ & $\begin{array}{c}\text { ANL690 } \\
\text { Extension } \\
(\mathrm{mm}) \\
\end{array}$ & $\begin{array}{c}\text { GEG690 } \\
\text { Kmax } \\
(\mathrm{MPa} \sqrt{\mathrm{m}}) \\
\end{array}$ & $\begin{array}{l}\text { GEG690 } \\
20 \% \mathrm{~S}-\mathrm{L} \\
(\mathrm{mm} / \mathrm{sec})\end{array}$ & $\begin{array}{c}\text { GEG690 } \\
\text { Extension } \\
(\mathrm{mm}) \\
\end{array}$ \\
\hline 1 & $\sim 3$ & 0.3 & 5 & 0 & air precrack & RT & 21.2 & 8.9E-05 & 0.62 & 21.0 & 7.0E-05 & 1.62 \\
\hline 2 & $\sim 2$ & 0.5 & 5 & 0 & air precrack & RT & 23.2 & 5.7E-05 & 0.41 & 23.0 & 4.7E-05 & 0.41 \\
\hline 3 & $\sim 2$ & 0.6 & 5 & 0 & air precrack & RT & 25.5 & 4.4E-05 & 0.41 & 25.1 & 3.7E-05 & 0.41 \\
\hline 4 & $\sim 3$ & 0.7 & 5 & 0 & air precrack & RT & 25.5 & $2.4 \mathrm{E}-05$ & 0.23 & 25.1 & 2.1E-05 & 0.23 \\
\hline 5 & 69 & 0.7 & 0.1 & 0 & $29 \mathrm{cc} / \mathrm{kg} \mathrm{H} \mathrm{H}_{2}$ & 325 & 25.8 & 1.3E-06 & 0.268 & 25.4 & $1.4 \mathrm{E}-06$ & 0.268 \\
\hline 6 & 145 & 0.7 & 0.01 & 0 & $29 \mathrm{cc} / \mathrm{kg} \mathrm{H} \mathrm{H}_{2}$ & 325 & 26.0 & 4.3E-07 & 0.158 & 25.7 & 3.7E-07 & 0.158 \\
\hline 7 & 103 & 0.7 & 0.001 & 0 & $29 \mathrm{cc} / \mathrm{kg} \mathrm{H}{ }_{2}$ & 325 & 26.0 & $9.8 \mathrm{E}-08$ & 0.033 & 25.9 & 1.1E-07 & 0.033 \\
\hline 8 & 50 & 0.6 & 0.001 & 0 & $29 \mathrm{cc} / \mathrm{kg} \mathrm{H}{ }_{2}$ & 325 & 26.0 & $2.0 \mathrm{E}-07$ & 0.035 & 25.9 & $1.9 \mathrm{E}-07$ & 0.035 \\
\hline 9 & 168 & 0.5 & 0.001 & 0 & $29 \mathrm{cc} / \mathrm{kg} \mathrm{H}{ }_{2}$ & 325 & 26.2 & $3.4 \mathrm{E}-07$ & 0.187 & 26.0 & 3.7E-07 & 0.187 \\
\hline 10 & 91 & 0.5 & 0.001 & 2.5 & $29 \mathrm{cc} / \mathrm{kg} \mathrm{H}{ }_{2}$ & 325 & 26.3 & 7.3E-08 & 0.026 & 26.2 & $6.5 \mathrm{E}-08$ & 0.026 \\
\hline 11 & 145 & 0.7 & 0.001 & 0 & $29 \mathrm{cc} / \mathrm{kg} \mathrm{H}{ }_{2}$ & 325 & 26.3 & 8.6E-08 & 0.052 & 26.2 & $1.0 \mathrm{E}-07$ & 0.052 \\
\hline 12 & 168 & 0.5 & 0.01 & 0 & $29 \mathrm{cc} / \mathrm{kg} \mathrm{H}{ }_{2}$ & 325 & 27.2 & 1.1E-06 & 0.717 & 26.3 & $1.2 \mathrm{E}-06$ & 0.717 \\
\hline 13 & 84 & 0.7 & 0.01 & 0 & $29 \mathrm{cc} / \mathrm{kg} \mathrm{H} 2$ & 325 & 27.3 & $3.5 \mathrm{E}-07$ & 0.106 & 27.2 & 4.0E-07 & 0.106 \\
\hline 14 & 245 & 0.7 & 0.001 & 0 & $29 \mathrm{cc} / \mathrm{kg} \mathrm{H}{ }_{2}$ & 325 & 27.4 & $9.5 \mathrm{E}-08$ & 0.082 & 27.4 & $1.0 \mathrm{E}-07$ & 0.082 \\
\hline 15 & 143 & 0.7 & 0.001 & 0 & $29 \mathrm{cc} / \mathrm{kg} \mathrm{H}_{2}$ & 325 & 27.5 & 7.0E-08 & 0.041 & 27.5 & $6.9 \mathrm{E}-08$ & 0.041 \\
\hline 16 & 147 & 0.7 & $980 / 20$ & 0 & $29 \mathrm{cc} / \mathrm{kg} \mathrm{H}{ }_{2}$ & 325 & 27.5 & $6.1 \mathrm{E}-08$ & 0.031 & 27.6 & 5.7E-08 & 0.031 \\
\hline 17 & 120 & 0.7 & 0.001 & 0 & $29 \mathrm{cc} / \mathrm{kg} \mathrm{H}{ }_{2}$ & 325 & 27.5 & 8.7E-08 & 0.038 & 27.6 & $6.5 \mathrm{E}-08$ & 0.038 \\
\hline 18 & 337 & 0.7 & 0.001 & 0 & $25 \mathrm{cc} / \mathrm{kg} \mathrm{H}$ & 360 & 28.3 & 3.3E-07 & 0.323 & 27.8 & $2.0 \mathrm{E}-07$ & 0.323 \\
\hline 19 & 119 & 0.7 & 0.001 & 0 & $25 \mathrm{cc} / \mathrm{kg} \mathrm{H}$ & 360 & $->32.1$ & 4.9E-07 & 0.180 & $->31.4$ & $3.0 \mathrm{E}-07$ & 0.180 \\
\hline 20 & 114 & 0.7 & 0.001 & 0 & $25 \mathrm{cc} / \mathrm{kg} \mathrm{H}{ }_{2}$ & 360 & 32.1 & 3.7E-07 & 0.157 & 31.4 & $2.5 \mathrm{E}-07$ & 0.157 \\
\hline 21 & 674 & 0.7 & 0.001 & 2.5 & $25 \mathrm{cc} / \mathrm{kg} \mathrm{H} \mathrm{H}_{2}$ & 360 & 33.0 & 1.6E-07 & 0.282 & 31.7 & 8.7E-08 & 0.282 \\
\hline 22 & 1225 & --- & Const $\mathrm{K}$ & --- & $25 \mathrm{cc} / \mathrm{kg} \mathrm{H} \mathrm{H}_{2}$ & 360 & 33.8 & $6.3 \mathrm{E}-08$ & 0.255 & 32.0 & $4.5 \mathrm{E}-08$ & 0.255 \\
\hline
\end{tabular}




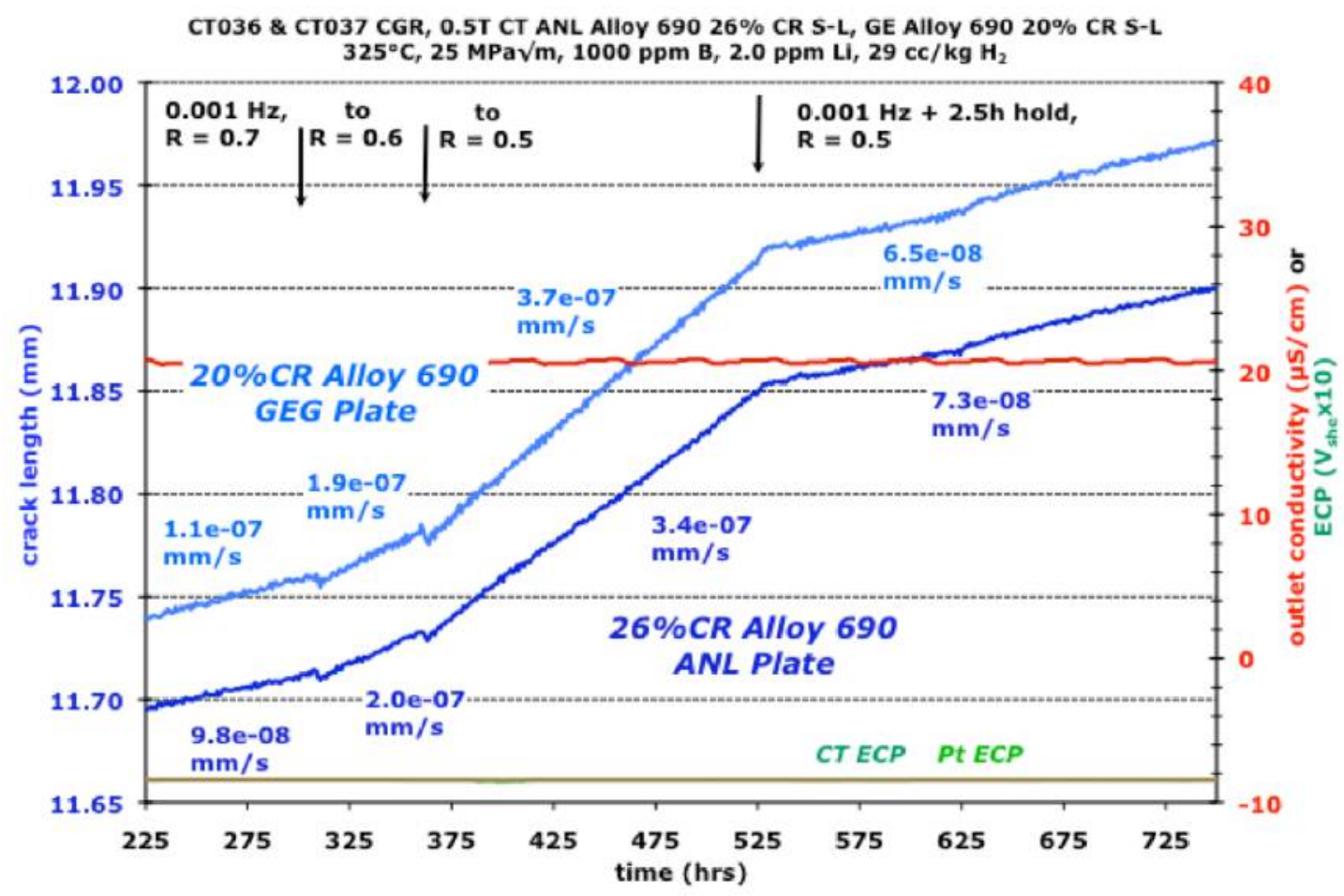

Figure 5.47 Initial transitioning for ANL (CT036) and GEG (CT037) specimens at $325^{\circ} \mathrm{C}$.

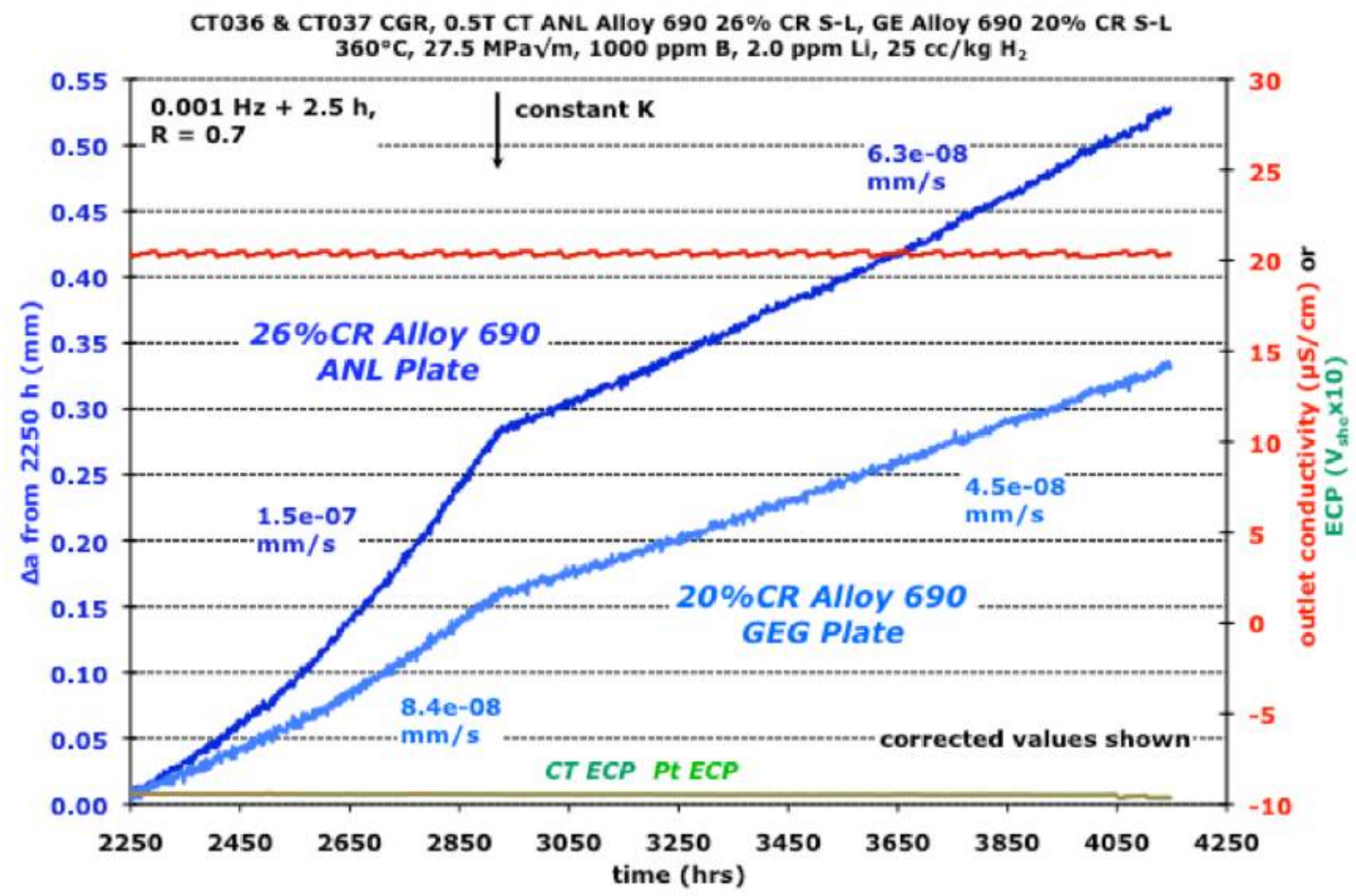

Figure 5.48 Constant $\mathrm{K}$ response for ANL 26\%CR (CT036) and GEG 20\%CR (CT037) alloy 690 plate specimens at $360^{\circ} \mathrm{C}$. 
As noted above, multi-laboratory testing has been conducted on these plate heats (26\%CR ANL and $20 \%$ CR GEG). Similar growth rates were found at GEG, SERCO and PNNL for the $20 \%$ CR GEG heat, but higher rates were documented for the $26 \%$ CR ANL heat at GEG [Ref. 17] and SERCO [Ref. 18] versus those measured at ANL [Ref. 16] and PNNL. The reported propagation rates for the $26 \%$ CR ANL heat are shown in Figure 5.49. Although the starting plate material was identical and supplied by ANL, GEG indicated [Ref. 17] that their test material exhibited compositional and microstructural banding with regions of fine grains and high carbide densities. Detailed optical and SEM characterizations on the CR ANL plate received at PNNL were described earlier in Section 5.1 to address this issue. The PNNL CT specimen (CT036) crackgrowth plane revealed a homogeneous microstructure and there was no evidence for banding in this location within the ANL plate. However, evidence for compositional and microstructural banding was found in other locations within the ANL plate thickness as shown in Figures 5.2 and 5.3. If GEG machined their 0.5T CT specimens from one of these locations, it may explain their higher measured SCC propagation rates. The importance of compositional-microstructural banding on IGSCC susceptibility of alloy 690 in PWR primary water remains unclear and additional work on well-characterized materials is needed. A summary of recent SCC crackgrowth measurements on alloy 690 materials is presented in Figure 5.50 showing the detrimental effects of unidirectional cold rolling. The original data reported by Bettis [Ref. 5] is added to the plot in Figure 5.51 illustrating that their SCC propagation rates remain consistently higher than nearly all other alloy 690 heats tested so far. It is not known at this time why certain CR heats exhibit this higher SCC susceptibility and supports the need for further research.

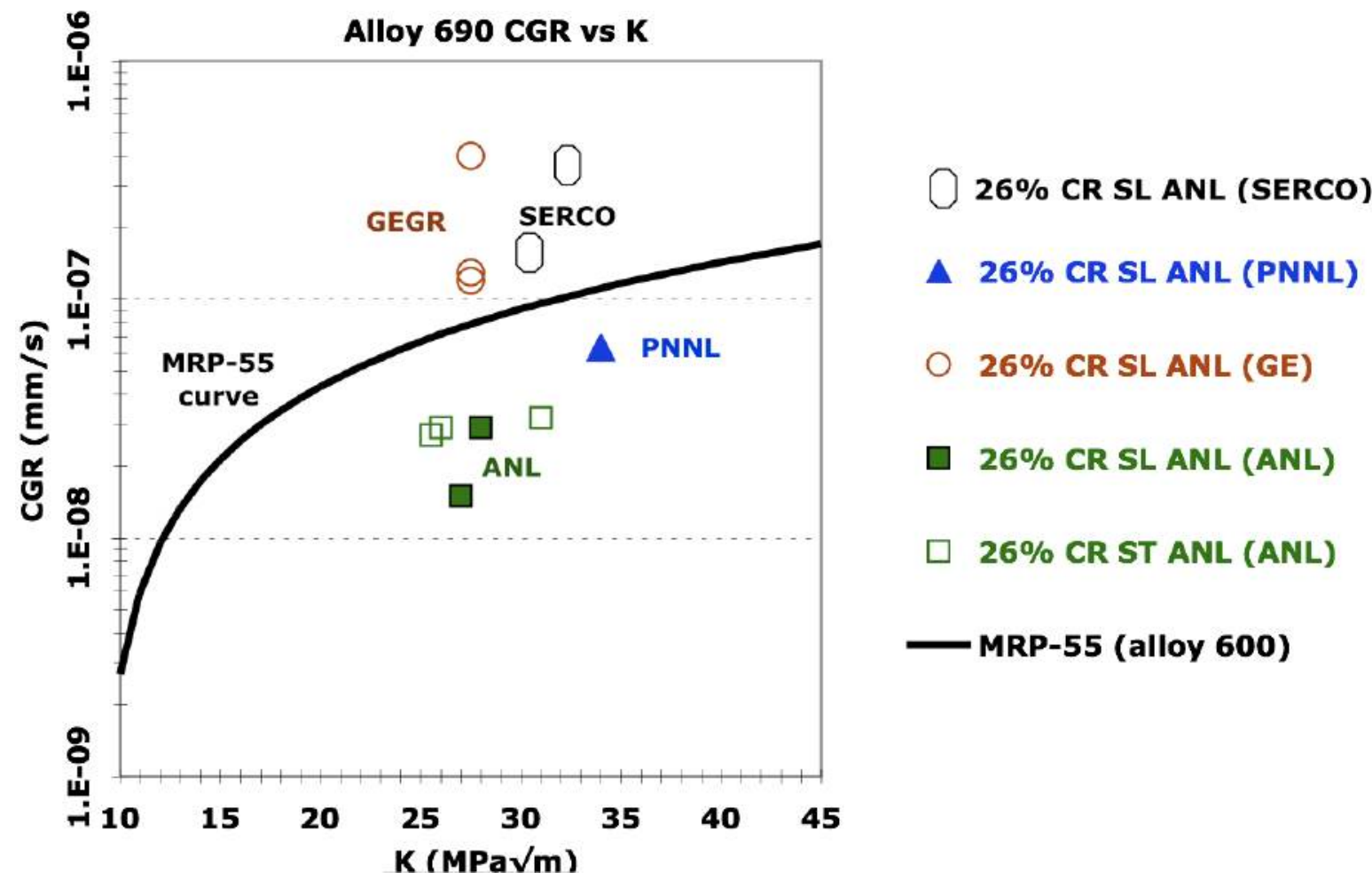

Figure 5.49 Comparison among reported SCC growth rate measurements at either constant $\mathrm{K}$ or constant load for the $26 \% \mathrm{CR}$ ANL alloy 690 plate (heat NX3297HK12). Data for ANL, GEG and SERCO is from references 16, 17 and 18 , respectively. 


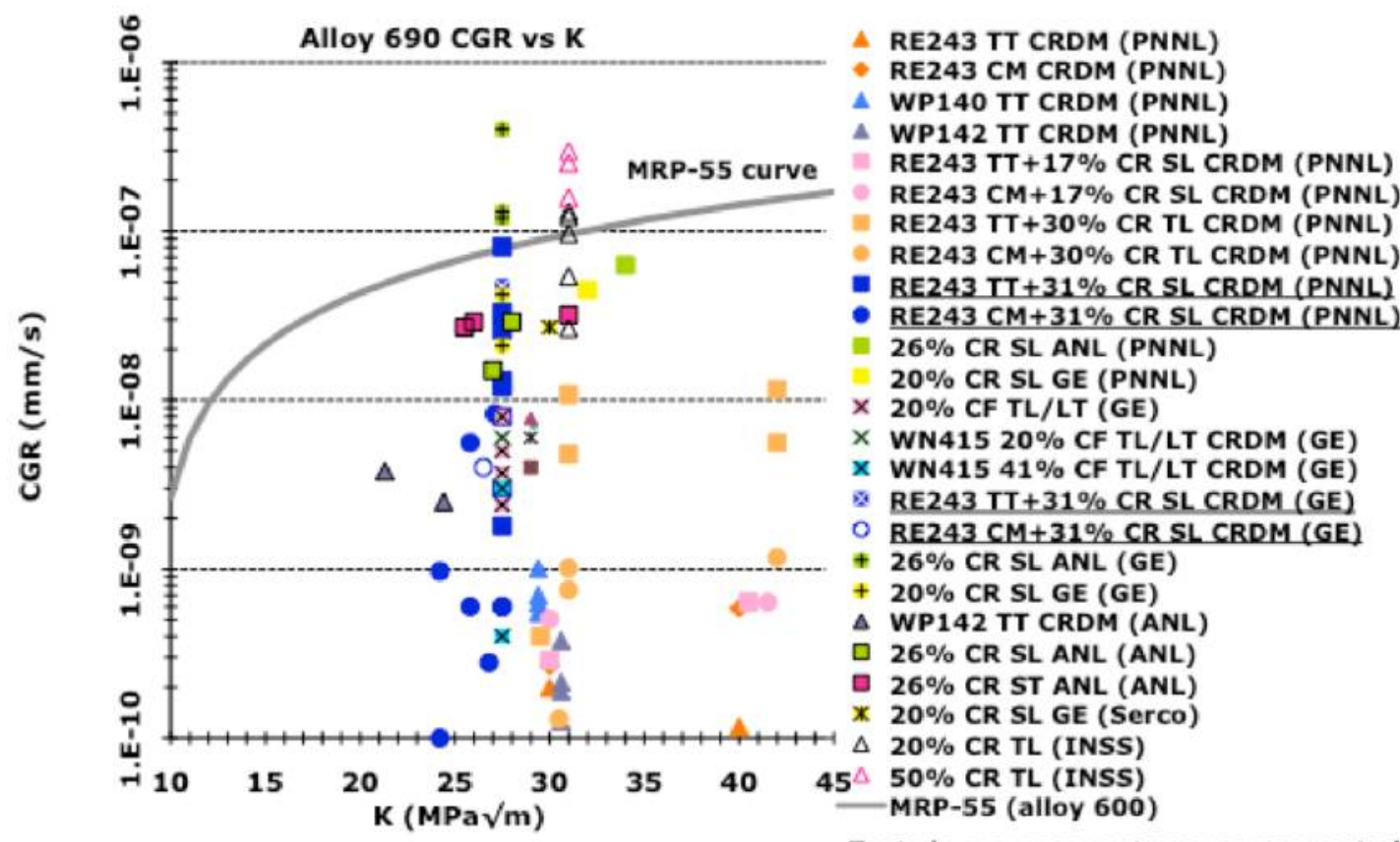

Figure 5.50 Summary of constant K crack-growth results for alloy 690 CRDM and plate heats highlighting more recent data on $1 \mathrm{D}$ cold-rolled materials. Data from ANL, GEG and SERCO are from references 16, 17 and 18, respectively.

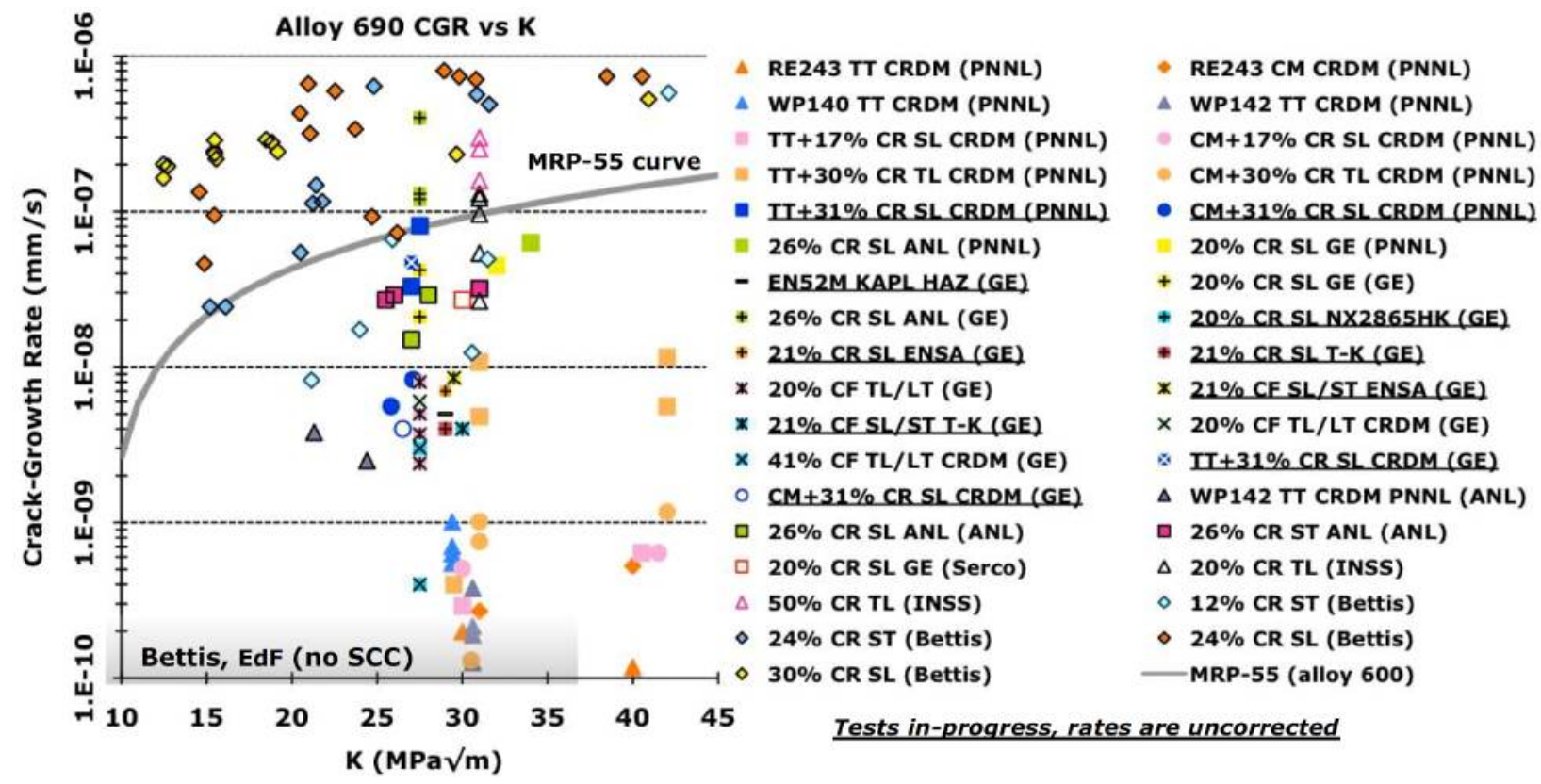

Figure 5.51 Summary of all constant K crack-growth results for alloy 690 CRDM and plate heats including the Bettis data identifying the detrimental effects of 1D rolling and tensile straining. Data from Bettis, ANL, GEG and SERCO are from references $5,16,17$ and 18, respectively. 


\subsection{Cold Rolling Effects on Microstructure and SCC}

Comparisons among the highest CR materials in Table 5.5 below can provide insights on what CR-induced microstructural features promote IGSCC in the alloy 690 material. The CR alloy $690 \mathrm{CM}$ materials exhibit a much lower density of grain boundary cracked carbides and voids simply due to the fact that the solution anneal and water quench removed nearly all IG carbides. Similar moderate-to-high SCC crack growth for the 31\%CR alloy 690TT CRDM and the ANL $26 \%$ CR alloy 690 plate materials is consistent with the high density of IG carbides (plus $\mathrm{Cr}$ depletion), grain boundary voids, and cracked carbides. However, the biggest inconsistency is the SCC response for the GEG $20 \%$ CR alloy 690 plate material. Rates are only slightly less than for the most extensively cold-worked examples, i.e., the 31\%CR CRDM and $26 \%$ CR ANL materials. The surprising aspect is that the GEG material has a very low density of grain boundary carbides, no $\mathrm{Cr}$ depletion and limited void and cracked carbide damage. Its permanent damage characteristics are most similar to the CRDM CR alloy 690CM material and far from the CRDM CR alloy 690TT and the ANL CR alloy 690 materials. Moderate-to-high SCC propagation rates in this heat do not support the potential detrimental effects of grain boundary carbides. This particular material exhibited compositional banding perpendicular to the SCC crack-growth plane and isolated boundaries sections did have IG carbides. More detailed characterization of the SCC crack morphologies and interactions with microstructural features will be presented and discussed in Chapter 6 to help develop a better understanding of factors controlling IGSCC susceptibility in CR alloy 690.

Table 5.5 Microstructure, CR damage and SCC rates for alloy 690 tested at PNNL.

\begin{tabular}{|c|c|c|c|}
\hline Sample & Microstructure & CR Damage & $\begin{array}{l}\text { PNNL } \\
\text { CGRs }\end{array}$ \\
\hline $\begin{array}{l}(2 \text { - TT) PNNL CRDM } \\
\text { alloy 690TT 30\%CR; } \\
\text { Test sample CT022 }\end{array}$ & $\begin{array}{l}\text { Semi-continuous (small discrete + } \\
\text { cellular) carbides on GBs plus Cr } \\
\text { depletion, few TiN at GBs and in } \\
\text { matrix; slightly elongated grains }\end{array}$ & $\begin{array}{l}\text { Moderate density of } \\
\text { voids and cracked } \\
\text { carbides on GBs, few } \\
\text { cracked TiN in matrix }\end{array}$ & $\begin{array}{c}1.2 \times 10^{-8} \\
\mathrm{~mm} / \mathrm{s} \\
(\mathrm{T}-\mathrm{L})\end{array}$ \\
\hline $\begin{array}{c}\text { (2 - CM) PNNL } \\
\text { CRDM alloy 690CM } \\
\text { 30\%CR; Test sample } \\
\text { CT023 }\end{array}$ & $\begin{array}{c}\text { Few carbides and well-spaced TiN } \\
\text { on GBs with no Cr depletion, few } \\
\text { TiN in matrix; slightly elongated } \\
\text { grains }\end{array}$ & $\begin{array}{l}\text { Few voids at triple } \\
\text { points, no cracked } \\
\text { particles on GBs, few } \\
\text { cracked TiN in matrix }\end{array}$ & $\begin{array}{c}1.0 \times 10^{-9} \\
\mathrm{~mm} / \mathrm{s} \\
(\mathrm{T}-\mathrm{L})\end{array}$ \\
\hline $\begin{array}{l}(3-\mathrm{TT}) \text { PNNL CRDM } \\
\text { alloy 690TT 31\%CR; } \\
\text { Test sample CT038 }\end{array}$ & As for CT022 (2 -TT) above & $\begin{array}{c}\text { As for CT022 }(2-\mathrm{TT}) \\
\text { above }\end{array}$ & $\begin{array}{c}4-8 \times 10^{-} \\
8 \mathrm{~mm} / \mathrm{s} \\
(\mathrm{S}-\mathrm{L})\end{array}$ \\
\hline $\begin{array}{c}\text { (3 - CM) PNNL } \\
\text { CRDM alloy 690CM } \\
\text { 31\%CR; Test sample } \\
\text { CT039 }\end{array}$ & As for CT023 (2-CM) above & $\begin{array}{c}\text { As for CT023 }(2-\mathrm{CM}) \\
\text { above }\end{array}$ & $\begin{array}{c}5-9 \times 10^{-} \\
9 \mathrm{~mm} / \mathrm{s} \\
(\mathrm{S}-\mathrm{L})\end{array}$ \\
\hline $\begin{array}{c}\text { (4) GEG plate alloy } \\
69020 \% \text { CR; Test } \\
\text { sample CT037 }\end{array}$ & $\begin{array}{l}\text { Well-spaced carbides on most } \\
\text { GBs with no Cr depletion, higher } \\
\text { IG and TG carbide density in } \\
\text { "banded" areas, TiN at GBs and in } \\
\text { matrix, slightly elongated grains }\end{array}$ & $\begin{array}{l}\text { Low density of voids, } \\
\text { isolated cracked } \\
\text { carbides on GBs, } \\
\text { cracked TiN in matrix }\end{array}$ & $\begin{array}{c}4.5 \times 10^{-8} \\
\mathrm{~mm} / \mathrm{s} \\
(\mathrm{S}-\mathrm{L})\end{array}$ \\
\hline $\begin{array}{c}\text { (5) ANL plate alloy } \\
69026 \% \text { CR; Test } \\
\text { sample CT036 }\end{array}$ & $\begin{array}{c}\text { Semi-continuous discrete carbides } \\
\text { and TiN on GBs plus Cr depletion, } \\
\text { TiN stringers in matrix, slightly } \\
\text { elongated grains }\end{array}$ & $\begin{array}{l}\text { Moderate density of } \\
\text { voids and cracked } \\
\text { carbides on GBs, } \\
\text { cracked TiN in matrix }\end{array}$ & $\begin{array}{c}6.3 \times 10^{-8} \\
\mathrm{~mm} / \mathrm{s} \\
(\mathrm{S}-\mathrm{L})\end{array}$ \\
\hline
\end{tabular}




\section{Characterization of SCC Cracks and Crack Tips}

\subsection{Background for SCC Crack-Tip Characterizations}

The fundamental basis for mechanistic understanding and modeling of SCC remains in question for many systems. Specific mechanisms controlling SCC can vary with changes in alloy characteristics, applied/residual stress, or environmental conditions. Local crack electrochemistry, crack-tip mechanics, and material metallurgy are the main factors controlling crack growth. The local crack conditions, especially at the tips, are difficult or impossible to measure in actively propagating cracks. Nevertheless, it is essential to quantitatively interrogate the cracktip conditions if mechanistic understanding is to be obtained. The present approach of post-test crack characterization is an attainable step in this process.

A major recent advance has been the ability to investigate SCC cracks and crack tips using analytical transmission electron microscopy (ATEM). ATEM enables the characterization of trapped solution chemistries, corrosion product compositions and structures, composition gradients, and defect microstructures along the crack walls and at the crack tip. A wide variety of methods for imaging and analyses at resolutions down to the nanometer scale and below can be used to examine the crack and corrosion film characteristics. A critical aspect of this analysis technique has been the development of sample preparation methods in which the crack corrosion products are protected during the ion-thinning process by embedding the cracks with a low-viscosity thermoplastic resin. This capability combined with modern ATEM techniques has enabled new insights into corrosion processes occurring at crack tips and is being used to identify mechanisms controlling SCC in service components. Many overview papers have been published [Refs. 19-24] and illustrate the unique information that can be produced. A key part of the work at PNNL has been direct comparisons between service components with cracks produced under complex conditions and well-controlled laboratory test samples.

Prior work at PNNL has examined cracked components removed from BWR [Refs. 25-27] (i.e., stainless steel piping, core shroud and top guide materials) and PWR [Refs. 28-36] (stainless steel baffle bolts and pressurizer, alloy 600/182 upper head penetrations and numerous alloy 600 steam generator tube materials) service. In addition, many high-resolution examinations [Refs. 23,28,29,34,37,38] have been performed on laboratory SCC samples tested in BWR and PWR environments. The objective of this section is to highlight new results focused on SCC cracks in the cold-rolled alloy 690 materials produced during laboratory crack-growth tests as part of this project. In collaboration with other projects at PNNL, extensive SEM and TEM characterizations have been performed on selected crack-growth test samples and will be reported here.

Characterization results on three SCC test samples are described: (1) CT022 - 30\%CR CRDM alloy 690TT, (2) CT036 - 26\%CR ANL alloy 690 and (3) CT037 - 20\%CR GEG alloy 690. In each case, the CT specimen was sectioned enabling metallographic cross-sections to be prepared containing the crack from the initial precracking to the final IGSCC phases of the tests. The focus for all of these cross-sections was for ATEM exams of the deepest crack tips after ion milling, but the preparation sequence enabled SEM characterizations of both primary and branched secondary cracks. These SEM crack examinations link directly with the detailed results already presented in Sections 4.3, 5.1 and 5.2 on the grain boundary damage produced by cold rolling. 


\title{
6.2 Scanning Electron Microscopy Examinations of SCC Cracks and Crack Tips
}

\author{
30\%CR CRDM alloy 690TT: Specimen CT022
}

Examples of the IG cracks observed in the 30\%CR CRDM alloy 690TT specimen cross-sections are presented in Figures 6.1 to 6.4. All of these SEM analyses were recorded from thin TEM foils being prepared to examine the leading SCC crack tips. Figure 6.1 presents a lower magnification backscatter contrast image of the leading crack tips, while higher magnification images and EDS mapping are given in Figures 6.2 and 6.3, respectively. The leading crack tips are predominately IG, with high strain contrast around the tips. Figures 6.2(a) and (b) are higher magnification images of the leading IG crack tip in Figure 6.1. The crack has propagated along the grain boundary and around the $\mathrm{M}_{23} \mathrm{C}_{6}$ carbides. It is important to note that the crack path has not been seen to link cracked carbides, but remain on the grain boundary around one side of the carbides. In most cases, the propagating IGSCC crack appears to temporarily blunt when it intersects a preexisting cracked carbide resulting in a short TG extension. The IG nature of the SCC path is illustrated in Figures 6.2(c) and (d). Figure 6.2(c) shows the crack bifurcating at a triple point and continuing on along grain boundaries, while Figure 6.2(d) shows a crack following the migrated grain boundary around cellular carbides (image is rotated from Figure 6.1). This is a good example where the SCC crack does not preferentially link preexisting cracked particles, since many of the cellular carbides are cracked but the SCC follows the grain boundary around these features.

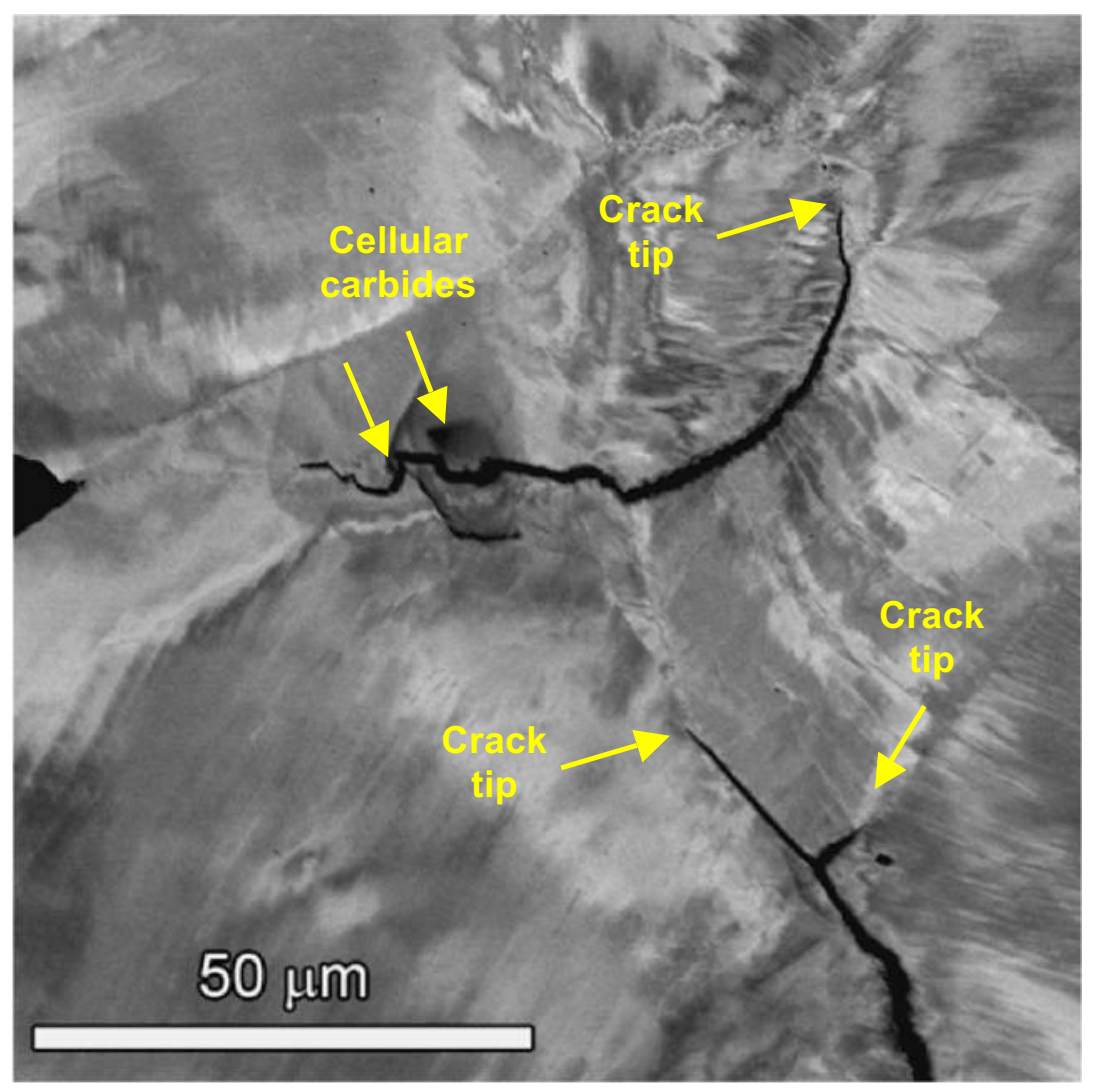

Figure 6.1 SEM backscatter micrograph of a crack-tip region in crack-growth sample CT022 for 30\%CR CRDM alloy 690TT (heat RE243). 


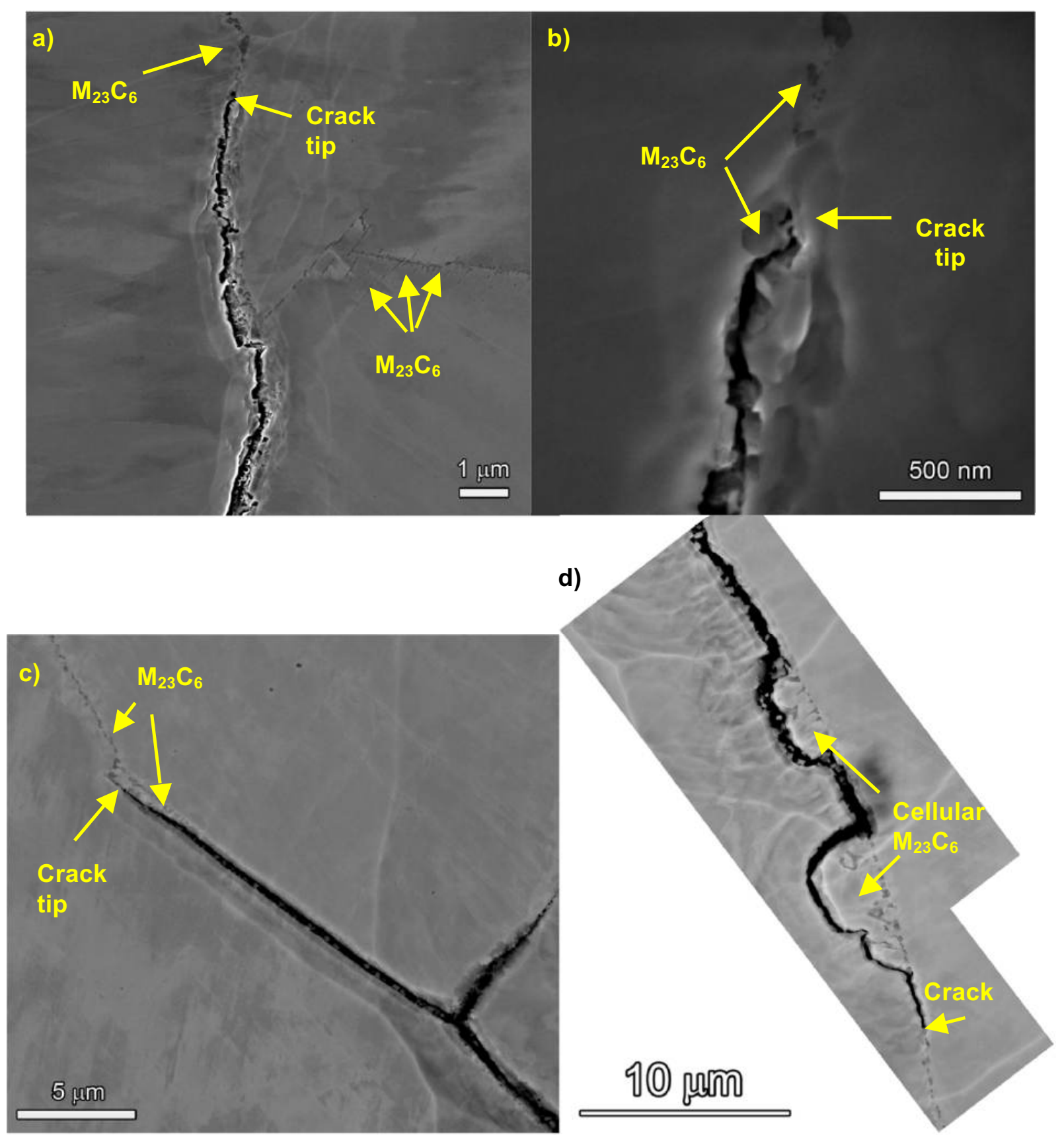

Figure 6.2 SEM micrographs (SE and backscatter) of thin TEM foil illustrating crack growth tips in 30\%CR CRDM alloy 690TT (CT022) from select regions in Figure 6.1.

Significant $\mathrm{Cr}$ depletion is observed within the cellular carbide precipitation structures. An example of the compositional variations in the cellular carbides and the SCC crack wall is illustrated in Figure 6.3. The matrix regions between the cellular $\mathrm{Cr}$ carbides were found to have $\mathrm{Cr}$ levels down to $\sim 20 \mathrm{wt} \%$. These composition maps also indicate that the crack walls contain Cr-rich, Ni/Fe-poor oxide. 


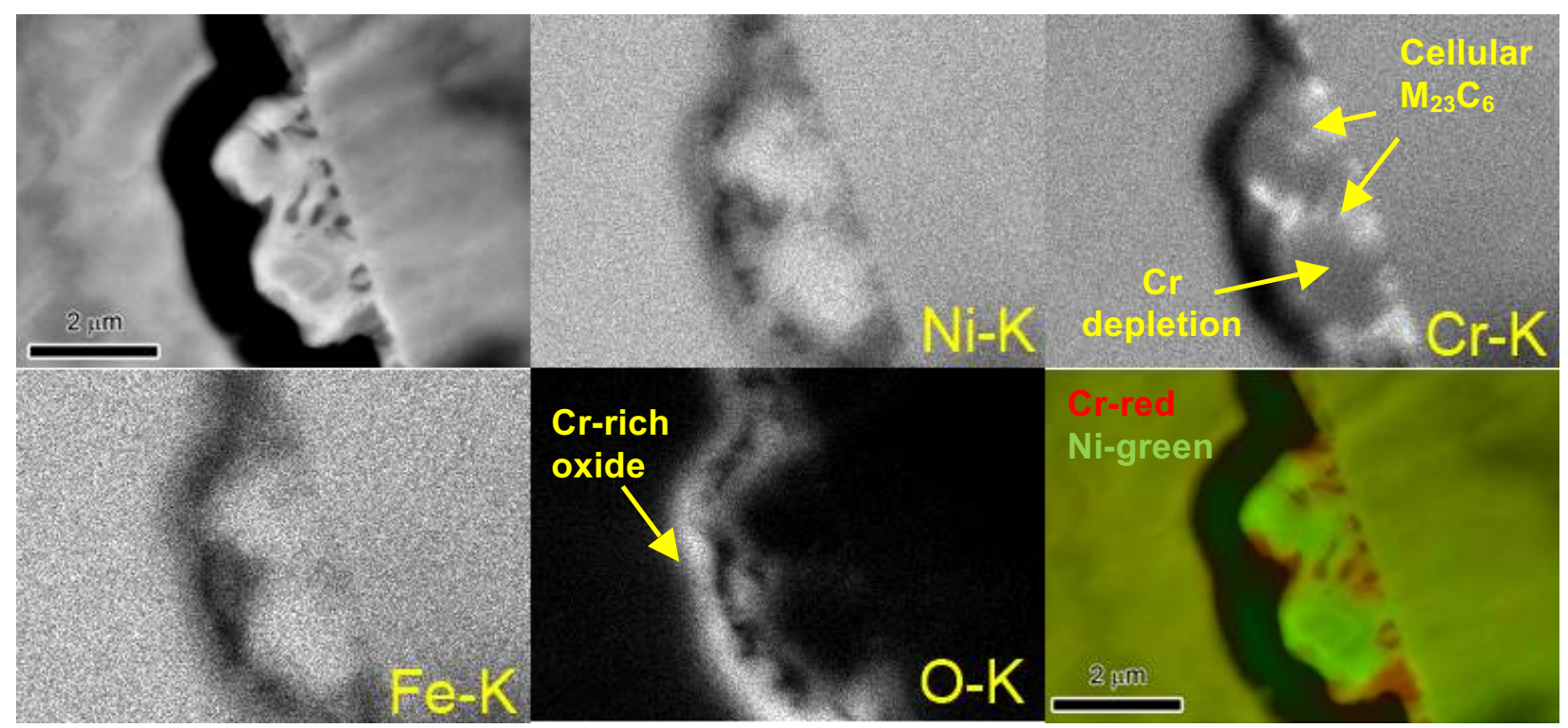

Figure 6.3 SEM elemental maps of thin TEM foil showing crack growth around a cellular carbide region in the 30\%CR CRDM alloy 690TT CT022 specimen.

High magnification SEM images of various crack tips are presented in Figures 6.4 and 6.5. These include both leading (deepest in the cross-section) and secondary SCC tips (behind the crack front). A highly complex corrosion/oxidation structure can be seen around the various crack tips. Figure 6.4(a) is a backscatter electron image of a secondary crack that ended after reaching a grain boundary triple point. Whereas the apparent open crack tip has stopped in the middle of the sample, the dark tunnel-like contrast moving around the carbides is Cr-rich oxide. Penetrative oxidation into the alloy 690 matrix is also observed off the crack walls. These SEM images were taken at low accelerating voltages (3-5 kV) and the interaction volume is very low (50-100 nm), enabling the nanometer-scale oxide filaments in the metal to be appear as mottled contrast. At higher accelerating voltages normally used, these fine structures could not be resolved due to the increased interaction volume. Figures $6.4(\mathrm{~b}, \mathrm{c})$ are leading crack tips, and also show IG growth as well as penetrative oxide attack emanating from the sidewalls (dark tunnel-like contrast) shown in Figure 6.4(c). The leading crack tip is moving along the grain boundary to one side of these carbides. Many small voids are observed next to cellular carbides, but these are not connected to the IGSCC crack path. Penetrative crack wall oxidation is found behind the leading crack tip and a shallow TG crack is formed through this region. A lower magnification image of another leading crack in the cross-section is presented in Figure 6.4(d) and it propagates around a cellular carbide region before ending at a triple point. Once again, the SCC crack is predominately IG with occasional locations where short TG extensions can be seen. A final crack-tip example for the 30\%CR CRDM alloy 690TT material is given in Figure 6.5. The higher magnification image shows the SCC crack ending in a region adjacent to a grain boundary with $\mathrm{M}_{23} \mathrm{C}_{6}$ particles. Close examination suggests the crack has propagated into the wall oxidation structure. Much more detailed characterizations of this complex crackwall oxidation structure are described in the following sections. 

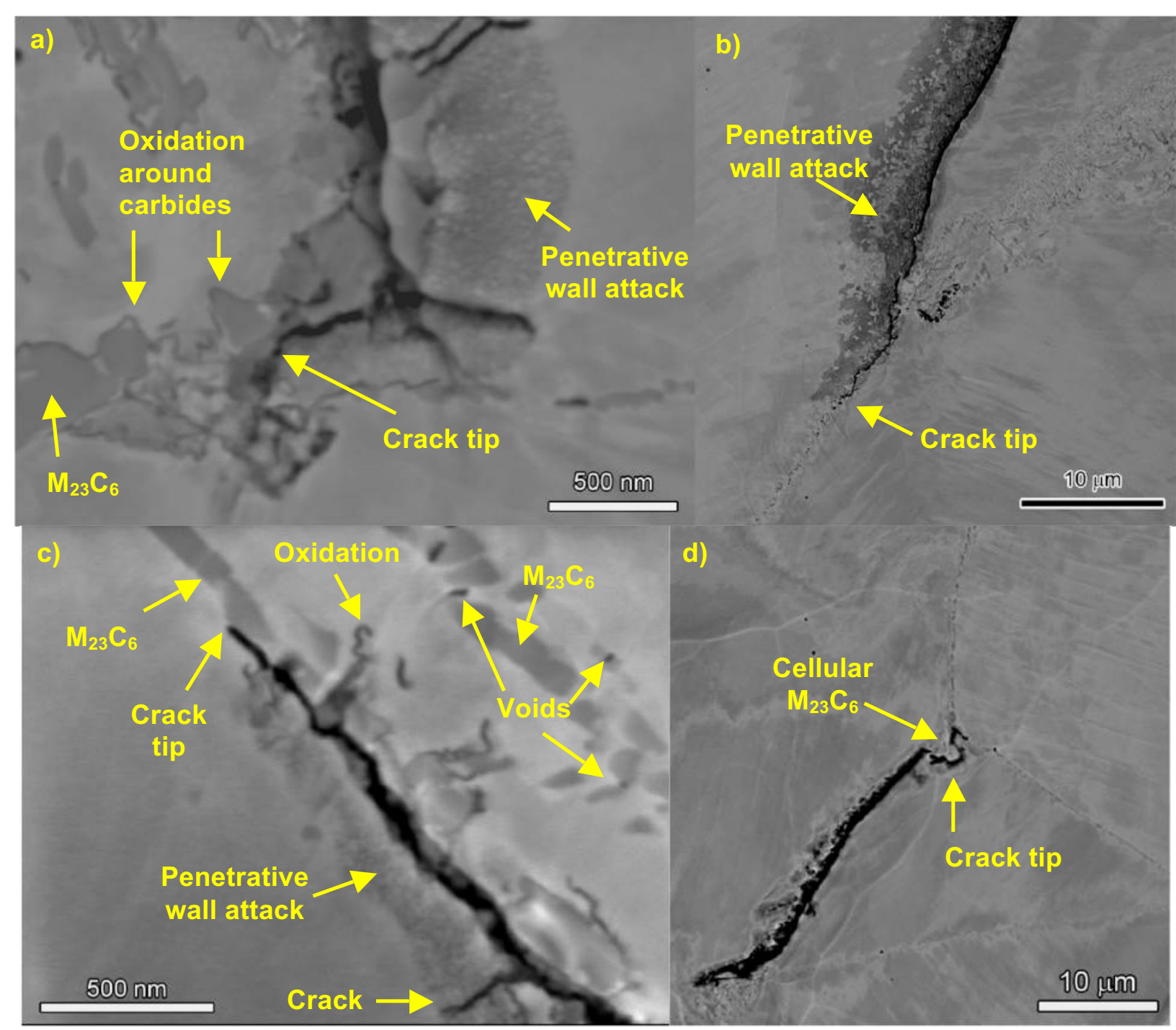

Figure 6.4 SEM backscatter micrographs of various SCC tips (secondary and primary) in 30\% CR CRDM alloy 690TT specimen CT022.

\section{6\%CR ANL Alloy 690 Plate: Specimen CT036}

Because of the high interest in the $26 \%$ CR ANL alloy 690 and testing at multiple laboratories, several cross-sections were prepared from specimen CT036 for detailed SEM and TEM characterizations of the SCC crack and crack-tip characteristics. Data was collected both from metallographically polished specimens as well as ion-milled TEM disks. Figures 6.6 to 6.10 are representative SEM (SE and backscatter) micrographs of SCC growth morphologies in the $26 \%$ CR ANL alloy 690 plate material. While IG crack growth was primarily seen during the final SCC stages of the crack-growth testing, TG cracking was also observed in these samples. As will be shown, the high density of grain boundary cracked carbides and voids in this material (described in Section 5.2) did not appear to directly influence SCC propagation. The penetrative crack wall oxidation documented in the $30 \%$ CR CRDM alloy 690 was also present along crack walls in these samples. 


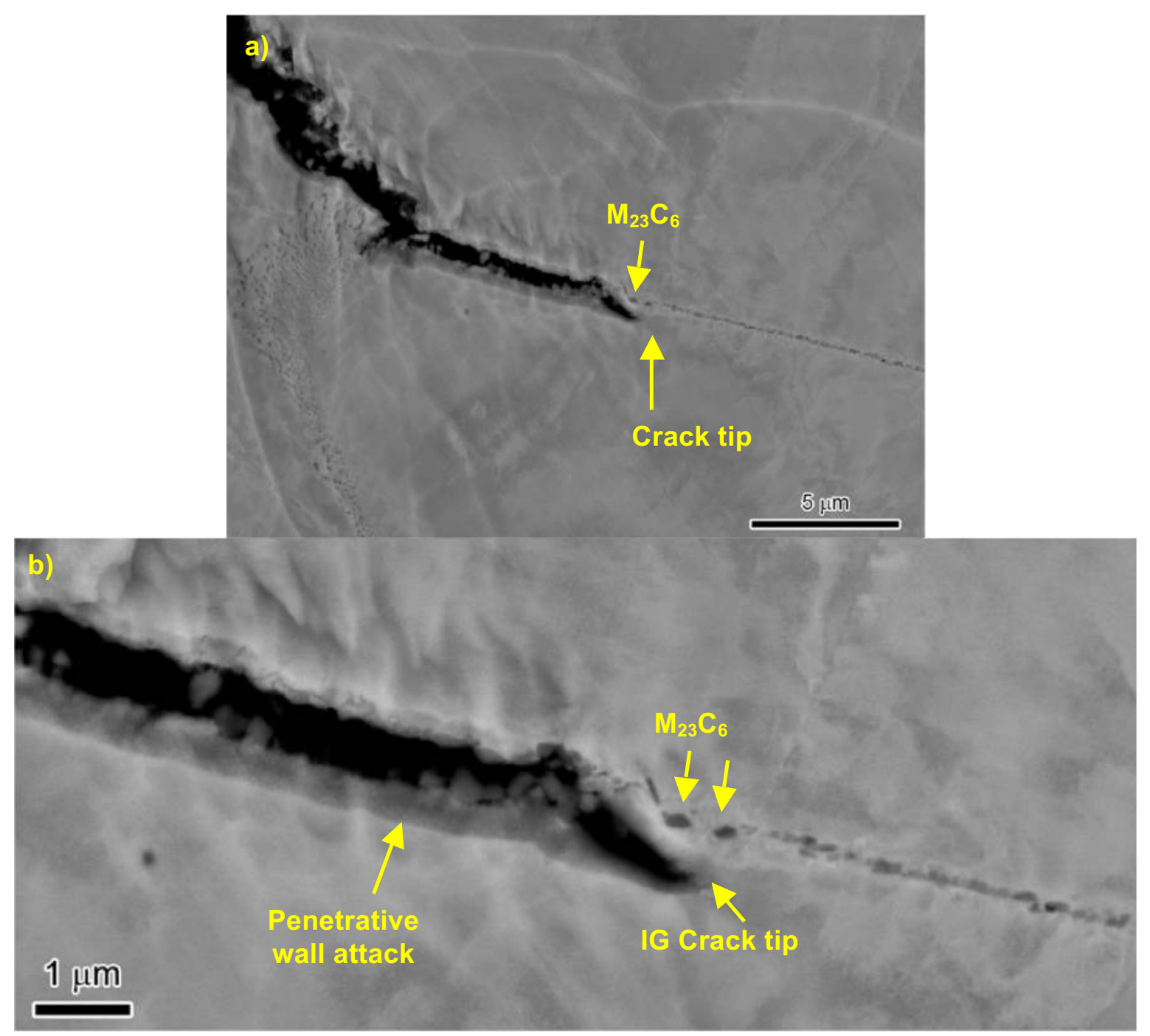

Figure 6.5 SEM backscatter micrographs of a leading SCC tip in 30\%CR CRDM alloy 690TT specimen CT022.

The backscatter micrograph montage in Figure 6.6 illustrated the highly branched SCC cracking from a leading crack tip to $\sim 500 \mu \mathrm{m}$ behind the crack front. This corresponds to the last stages of the crack-growth test under cycle + hold and constant K conditions (see Section 5.3). There is a large amount of strain contrast around the cracked regions as well as surrounding grains corresponding to the $26 \%$ CR process and deformation during SCC propagation.

The SCC growth path in most cases was IG, however minor TG cracking was found in many locations. Several areas well behind the leading crack front are shown in Figures 6.7 and 6.8 with secondary cracks appearing both as IG (Figure 6.7a) and TG (Figure 6.7b,d). Crack openings narrowed from micrometer to nanometer dimensions along the crack length to the SCC tips. The open cracks contained particulate oxides including smaller MO-structure oxide (Figure 6.8a, Ni rich) and larger oxide spinels (Figure 6.8b, Fe/Ni rich). A continuous oxide layer was not discovered on the crack walls, but penetrative oxidation is observed going into the alloy matrix from crack walls. 


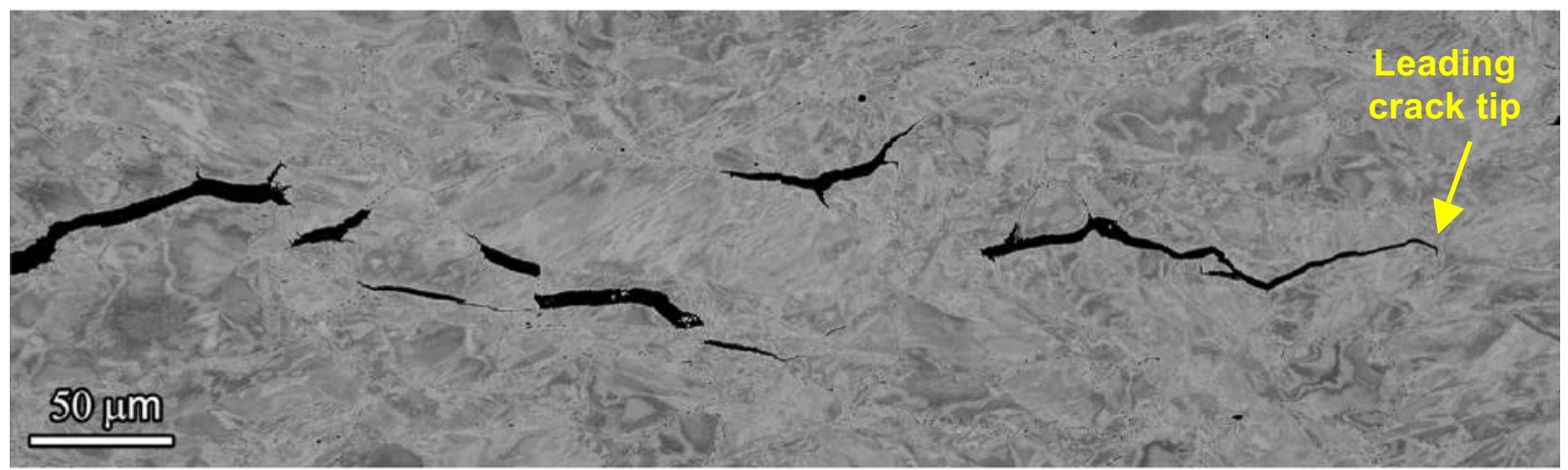

Figure 6.6 SEM backscatter micrograph montage showing SCC cracks in cross-section for the $26 \%$ CR ANL alloy 690 specimen CT036.

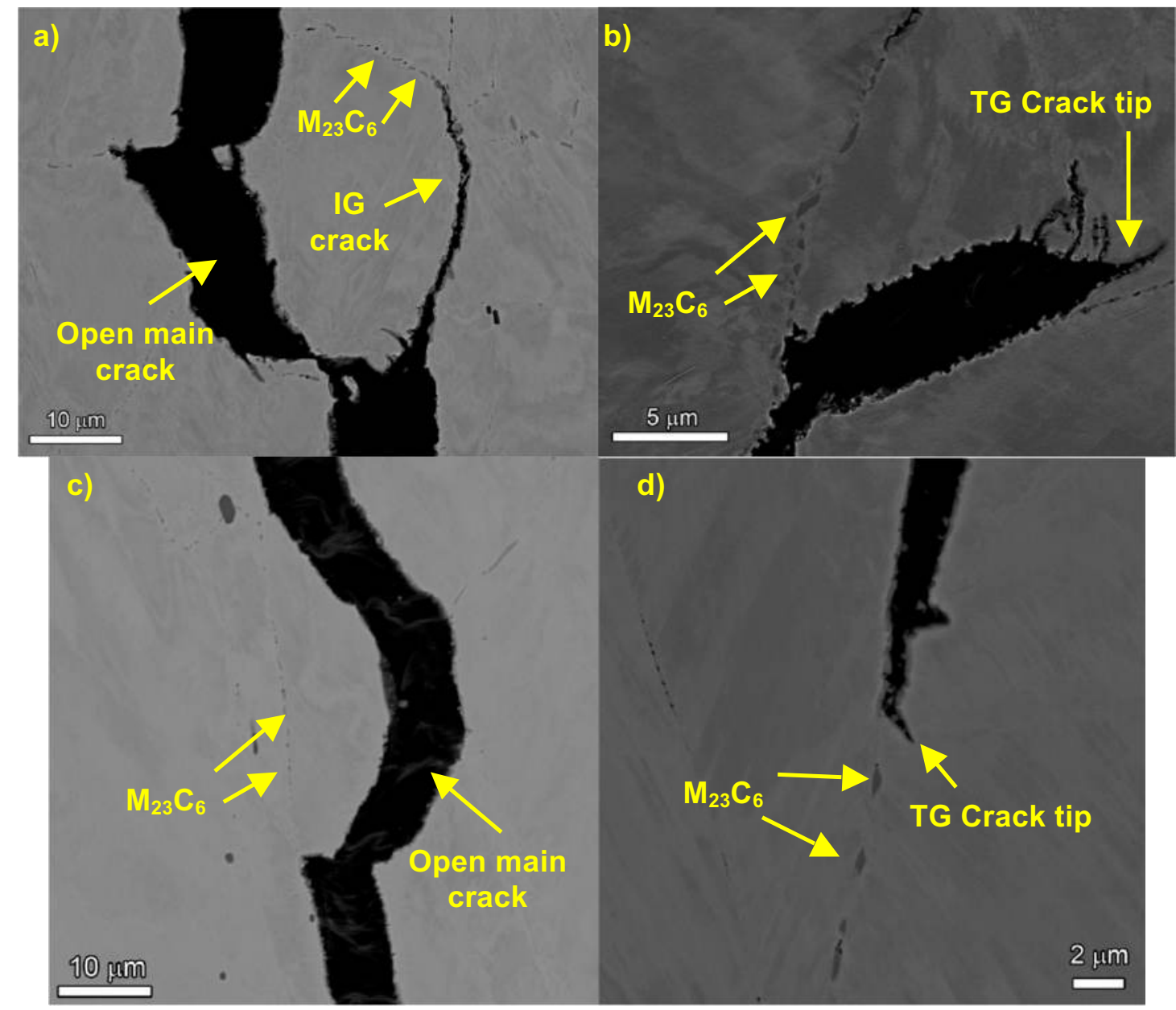

Figure 6.7 Low magnification SEM backscatter micrographs of various cracks and secondary crack tip regions in $26 \%$ CR ANL alloy 690 specimen CT036. 


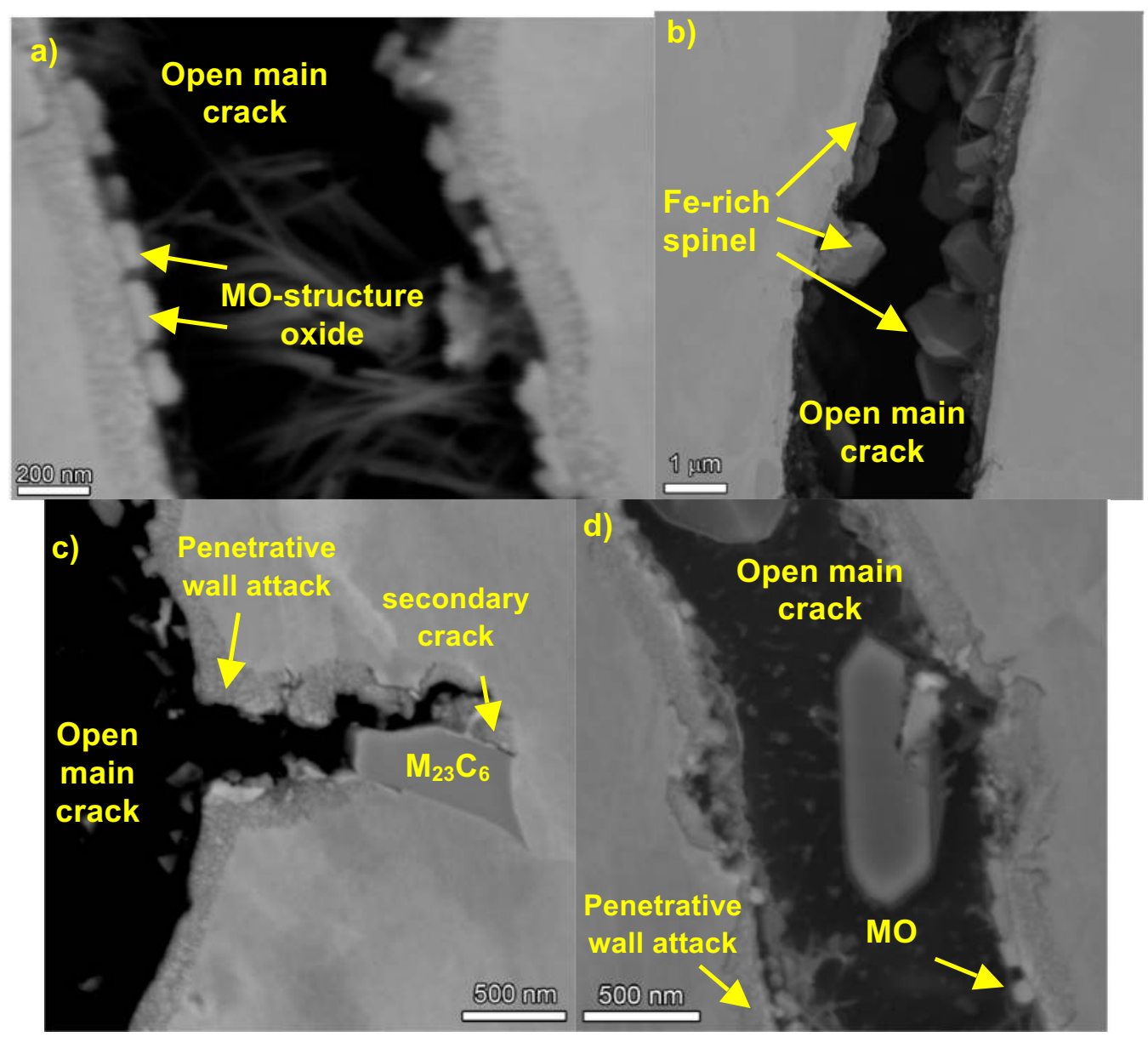

Figure 6.8 Higher magnification SEM backscatter micrographs of open cracks and crack walls in $26 \%$ CR ANL alloy 690 specimen CT036.

The interaction between propagating SCC cracks and carbides (either damaged or intact) can more clearly be visualized in Figures 6.8(c), 6.9 and 6.10. All of these images illustrate open SCC cracks intersecting carbides without significant oxidation or corrosion of the $\mathrm{Cr}$ carbide. By comparison, penetrative wall oxidation into the alloy 690 matrix can be seen. Careful examination often reveals shallow TG cracking through the wall oxidation near the carbide interfaces as shown in Figure 6.9.

The influence of pre-existing cracked carbides on IGSCC propagation is indicated by the micrograph in Figure 6.10. In the lower magnification image, carbides are all on one side of the open crack and the SCC path follows the higher energy grain boundary versus the lower energy carbide/matrix interface. This was a common observation throughout and is consistent with the previous results for the $30 \% \mathrm{CR}$ alloy $690 \mathrm{TT}$ CRDM specimen. Of more interest is the crack path illuminated in Figure 6.10(b). The SCC crack has propagated adjacent to a carbide along the grain boundary and there is no apparent interaction with pre-existing cracks in the carbides. A lower magnification image of this area, with corresponding EDS elemental maps, is observed in Figure 6.11. These images highlight the movement of the crack in relation to the distribution of $\mathrm{M}_{23} \mathrm{C}_{6}$ carbides as well as the spaced TiN particles that were present along the grain boundary in this region. The carbides and nitrides are again located on one side of the IGSCC crack. 


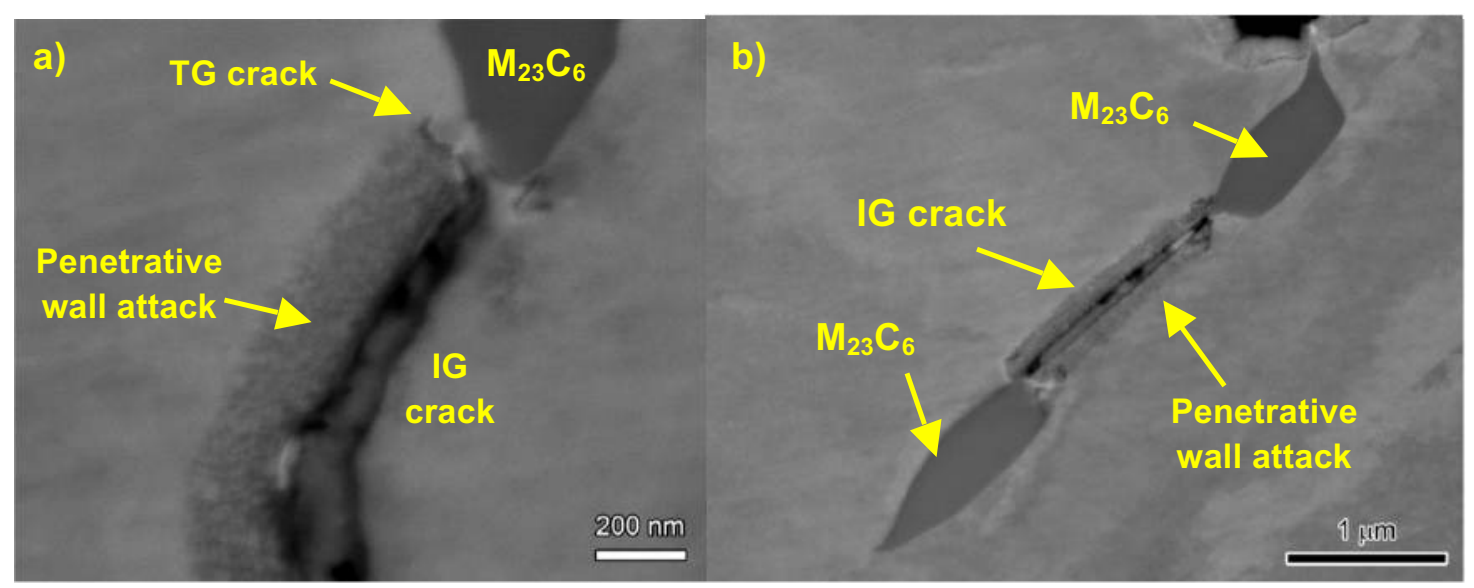

Figure 6.9 SEM backscatter micrographs of open crack walls in $26 \%$ CR ANL alloy 690.

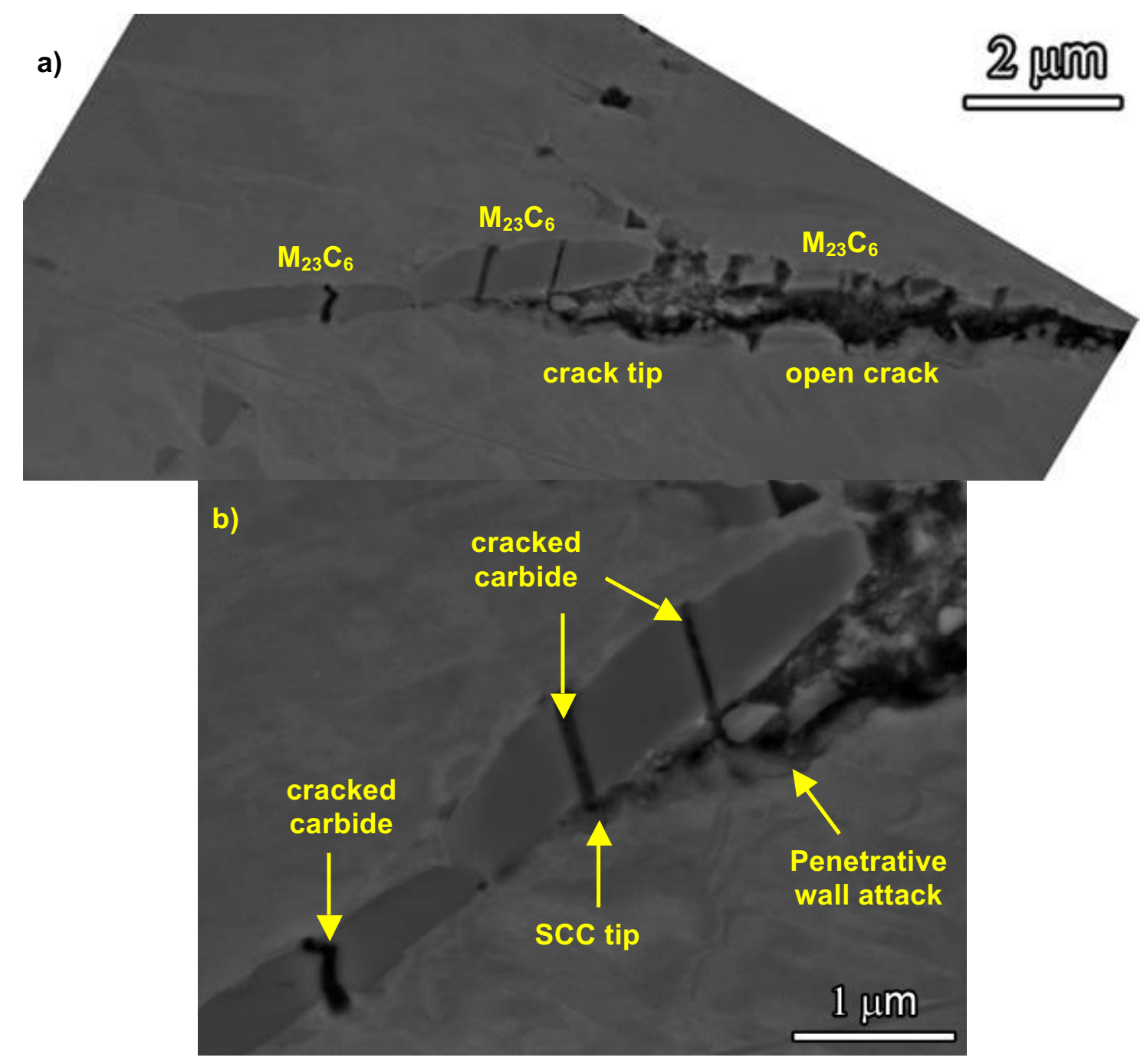

Figure 6.10 High magnification SEM backscatter micrographs of open crack walls in $26 \%$ CR ANL alloy 690 specimen CT036. 


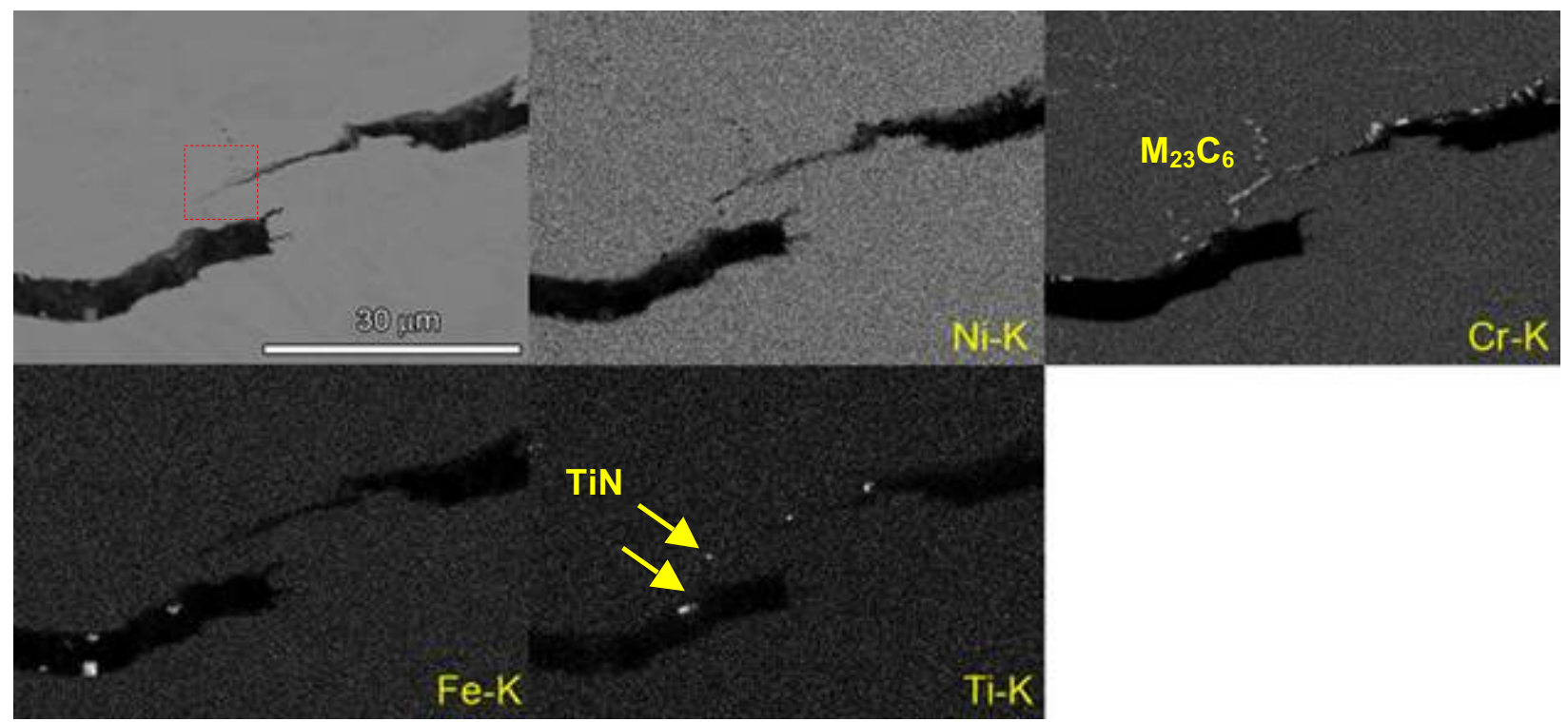

Figure 6.11 SEM backscatter micrographs of an open IGSCC crack and grain boundary precipitates along one wall in the $26 \%$ CR ANL alloy 690 specimen CT036.

The leading crack tips in the $26 \%$ CR ANL alloy 690 cross-section samples had both TG (Figures 6.12 and 6.13) and IG (Figures 6.14 and 6.15) morphologies. As was seen in the $30 \%$ CR CRDM alloy 690 specimen, cracks that appeared to be following an IG path were often observed to propagate a short distance off the grain boundary at crack tips. The first example of a TG tip is presented at higher magnifications in Figure 6.12. This crack tip appeared bifurcated and blunted in the cross-section, ending in a region of extremely high deformation/strain. The SCC crack was following an IG path until the last few micrometers and then branched TG as shown in Figures 6.12(a) and (b). This may have occurred due to the orientation of the grain boundary with respect to the growth plane for the side-grooved CT specimen. A better indication of this boundary orientation change can be seen in the lower magnification SEM/EDS elemental maps for this crack region in Figure 6.13. The $\mathrm{Cr}$ and $\mathrm{Ti}$ maps also document the grain boundary carbide and nitride distributions. Shallow penetrative oxidation is present off the IG and TG crack walls and extends to the tip region as illustrated in Figure 6.12(c).

A good example of an IGSCC crack ending in an IG tip is presented in Figure 6.14. The low magnification image demonstrates again how the crack moves along the grain boundaries with $\mathrm{M}_{23} \mathrm{C}_{6}$ carbides all to one side of the crack wall. At higher magnification (Figures 6.14b,c), the crack can be seen to have stopped in this cross-section at the carbide interface with the substantial penetrative wall oxidation to the tip region. Several shallow TG cracks have formed through the oxide depth, but no propagation is seen into the non-oxidized alloy 690 matrix. This deep penetrative wall oxidation is not observed at all SCC tips and may indicate the difference between a static, non-growing crack versus an active, rapidly growing one. The depth of wall penetrative oxidation would then scale with the time exposed to PWR primary water in the SCC crack. An example of what might be an active propagating crack is shown in Figure 6.15 where the IG crack approaching the tip is tight and ends at a grain boundary carbide. In this case, there was very little penetrative crack wall oxidation resolved by SEM even at distances several micrometers behind the tip. Differences in penetrative oxidation among various SCC tips will be discussed in more detail during TEM examinations described in Section 6.3. 

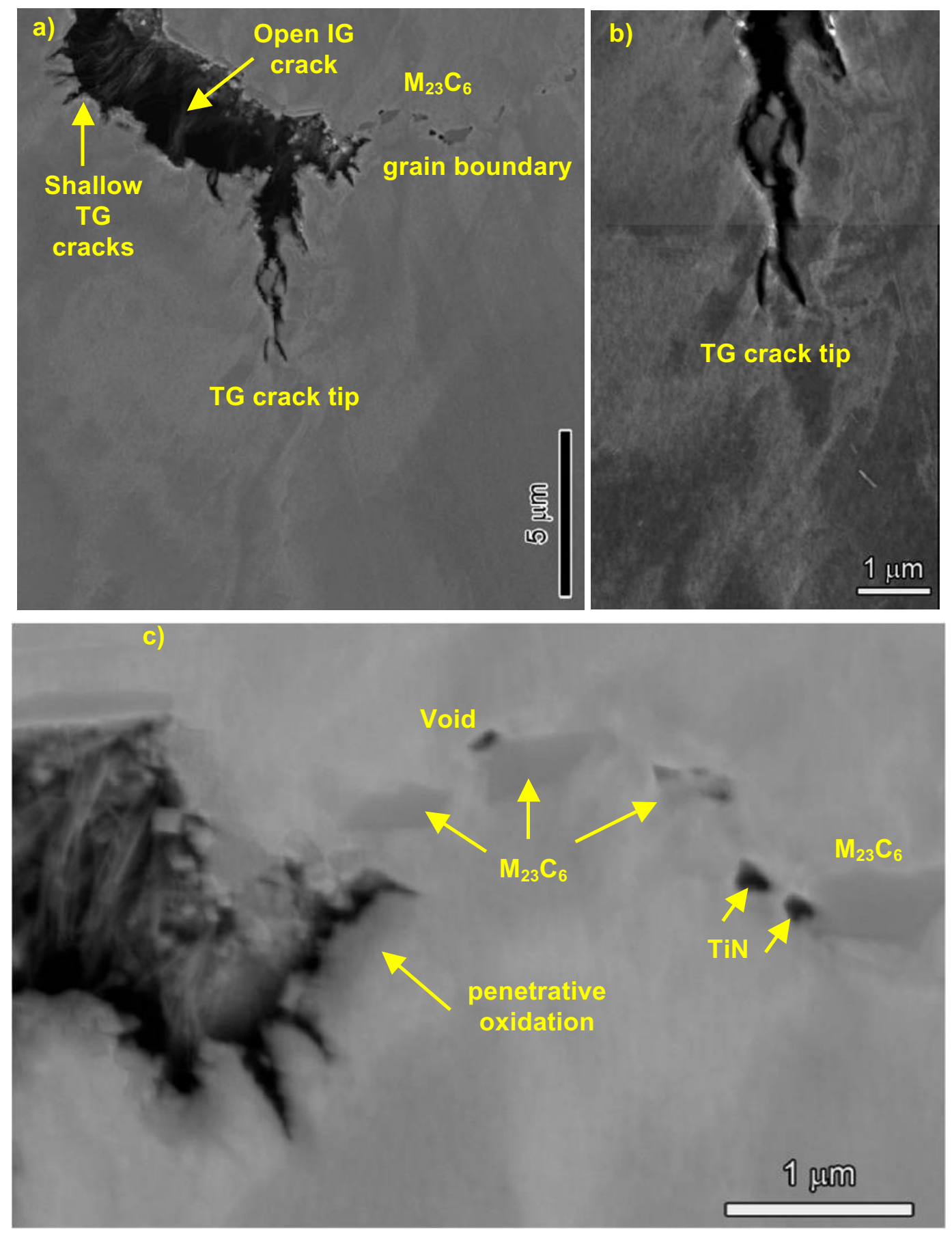

Figure 6.12 SEM backscatter micrographs of a SCC crack tip in the $26 \%$ CR ANL alloy 690 specimen CT036: (a) lower magnification showing an open IG crack ending in a highly branched tip region with a TG (b) and IG (c) characteristics. 


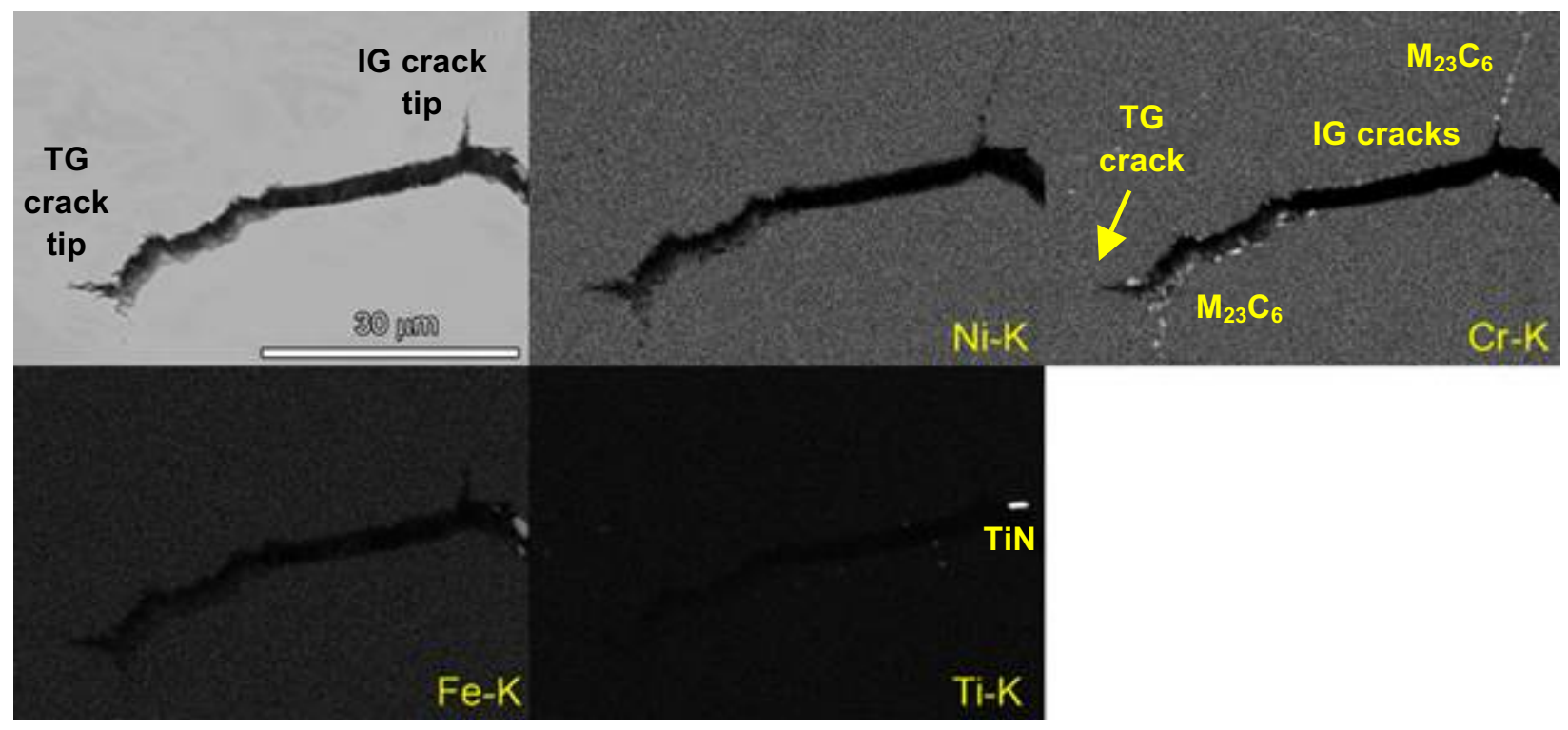

Figure 6.13 Lower magnification SEM backscatter micrograph and compositional maps showing the open IGSCC crack in specimen CT036 from Figure 6.12.

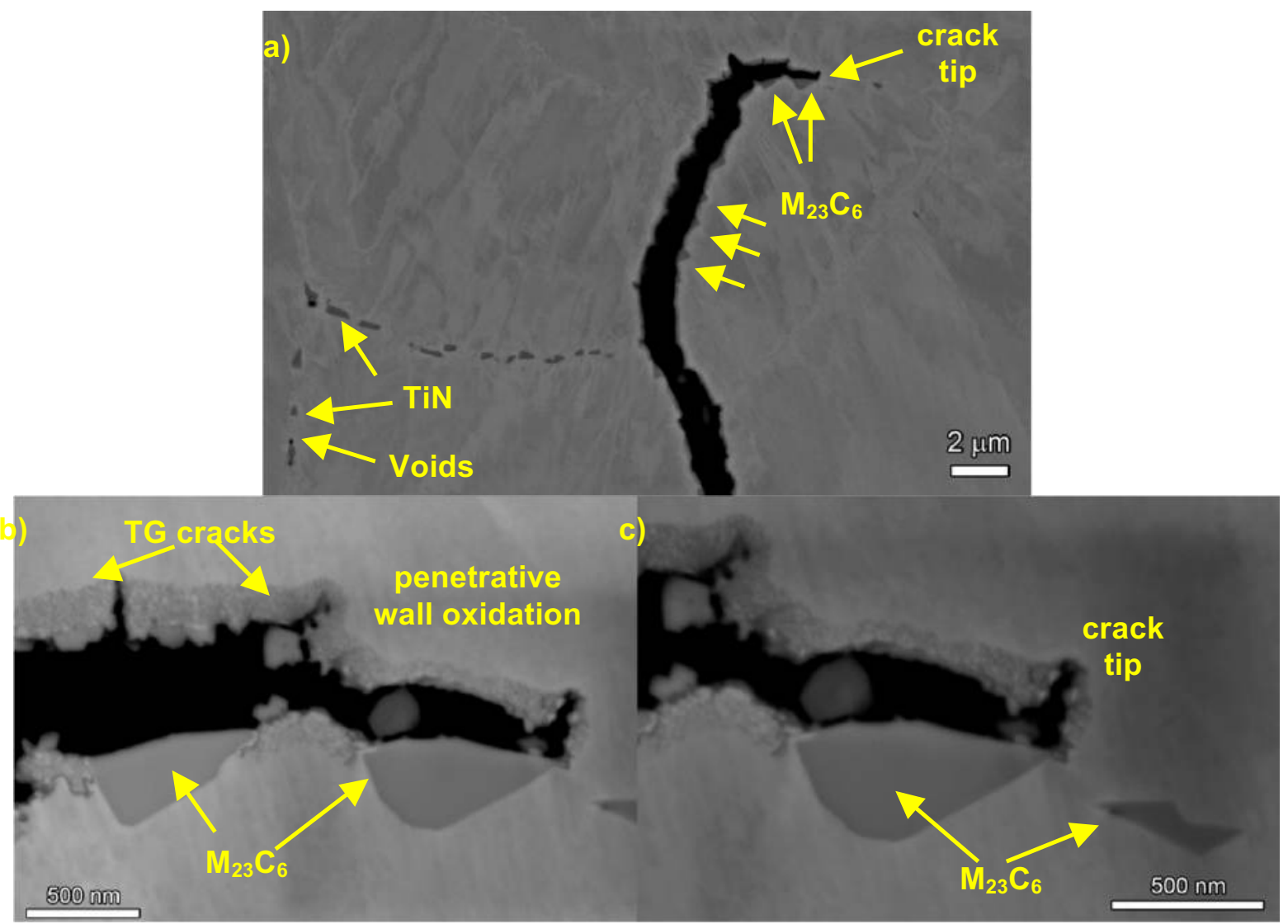

Figure 6.14 SEM backscatter micrographs of open IG crack (a) ending at a rather blunt IG crack tip (b,c) with penetrative wall oxidation in the $26 \%$ CR ANL alloy 690 specimen CT036. 


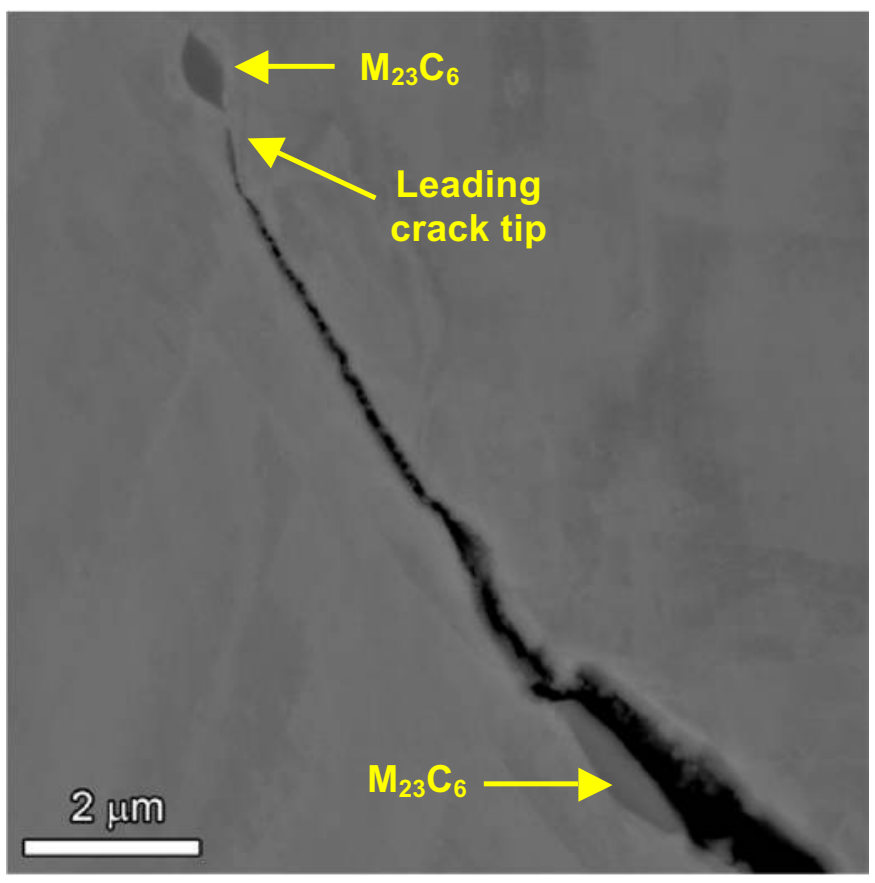

Figure 6.15 High magnification SEM backscatter micrographs of an IG crack tip in the 26\%CR ANL alloy 690 specimen CT036.

Several TEM cross-section specimens of the $26 \%$ CR ANL alloy 690 specimen CT036 were also prepared by ion milling. These thin samples often enable higher resolution SEM examinations, but exhibit areas of milling damage that must be recognized. The milling of a mechanically dimpled region ahead of the SCC crack front will produce a hole in the foil and may "open up" selected cracks. The SCC cracks can be seen to be highly branched in Figures 6.16 and 6.17, moving in and out of the cross-section plane during the final $\sim 0.5 \mathrm{~mm}$ of SCC growth. The overall crack growth morphology is IG with high amounts of strain in the surrounding matrix grains. Higher magnification micrographs of the identified crack tip regions in Figure 6.17 are examined in Figure 6.18. Regions 1 and 3 contain reasonably tight IG cracks (Figure 6.18a,c), while the center of region 2 has been opened during ion milling for TEM examination (Figure $6.18 \mathrm{~b})$. Tip region 4 is a location $\sim 200 \mu \mathrm{m}$ behind the leading crack tip and Figure $6.18(\mathrm{~d})$ shows a tight secondary crack containing oxide particles. IGSCC tips in region 2 are elucidated at higher magnifications in Figure 6.18. The dark blocky shape at the tip in Figure 6.19(b) was a hole created during final milling and suggests that the SCC crack ended at the grain boundary carbide interface. Interestingly, the other region 2 tip reveals a stepwise crack appearance along the grain boundary that is not completely IG.

One additional crack region was examined near the bottom of the CT036 TEM sample at a location $\sim 0.6 \mathrm{~mm}$ behind the leading crack front. It was found to be oxide filled with significant penetrative oxide wall attack on either side of the crack as shown in Figure 6.20. As a result of this obvious dependence of depth of wall oxidation with distance behind the crack front, a more systematic evaluation of oxidation depths was made as summarized in Figure 6.21. 


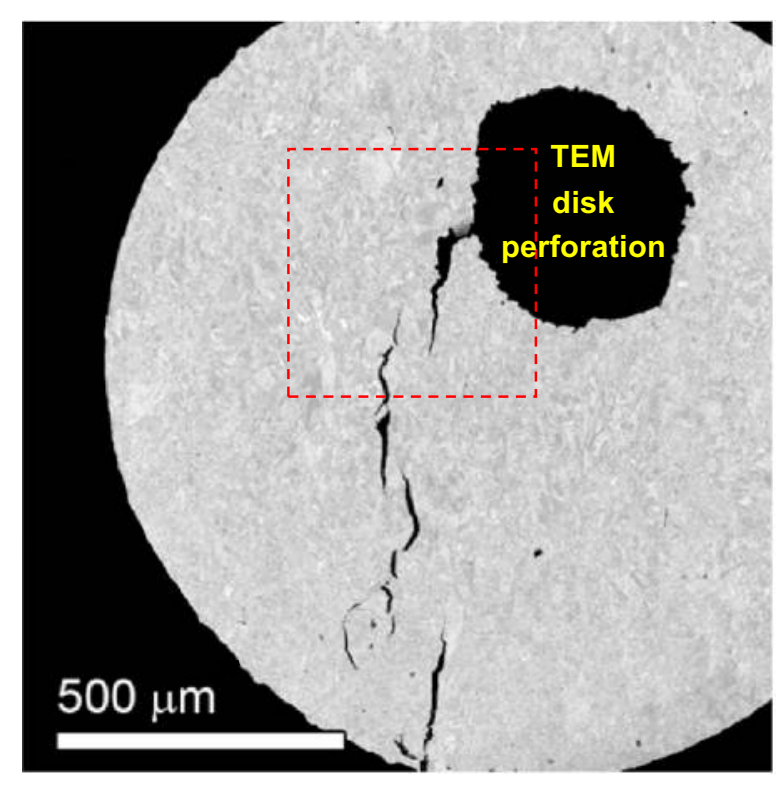

Figure 6.16 Low magnification SEM backscatter micrograph of an ion-milled TEM crosssection sample in $26 \%$ CR ANL alloy 690 specimen CT036.

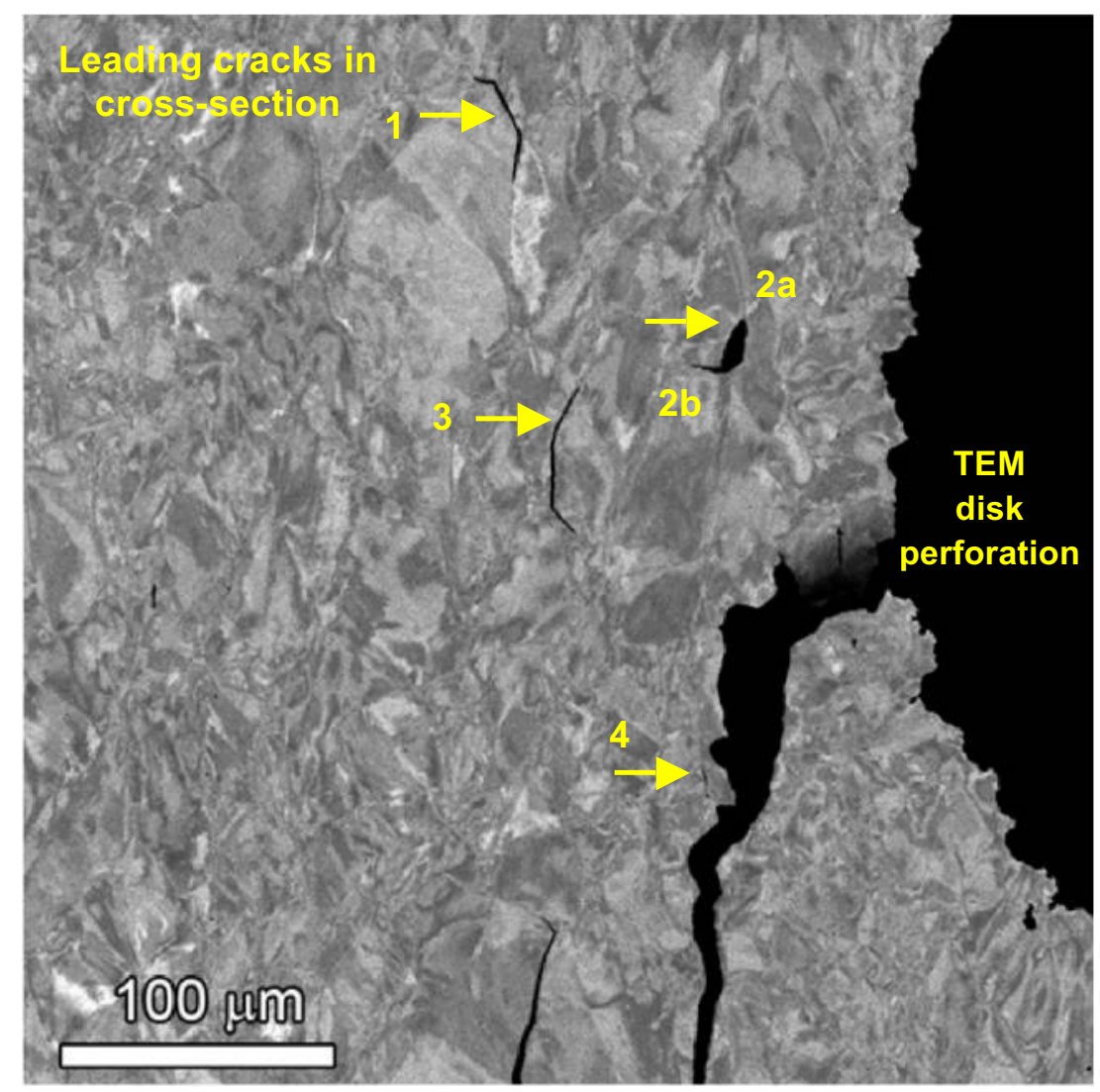

Figure 6.17 Low magnification SEM backscatter micrographs of open crack walls in 26\%CR ANL alloy 690 specimen CT036. 


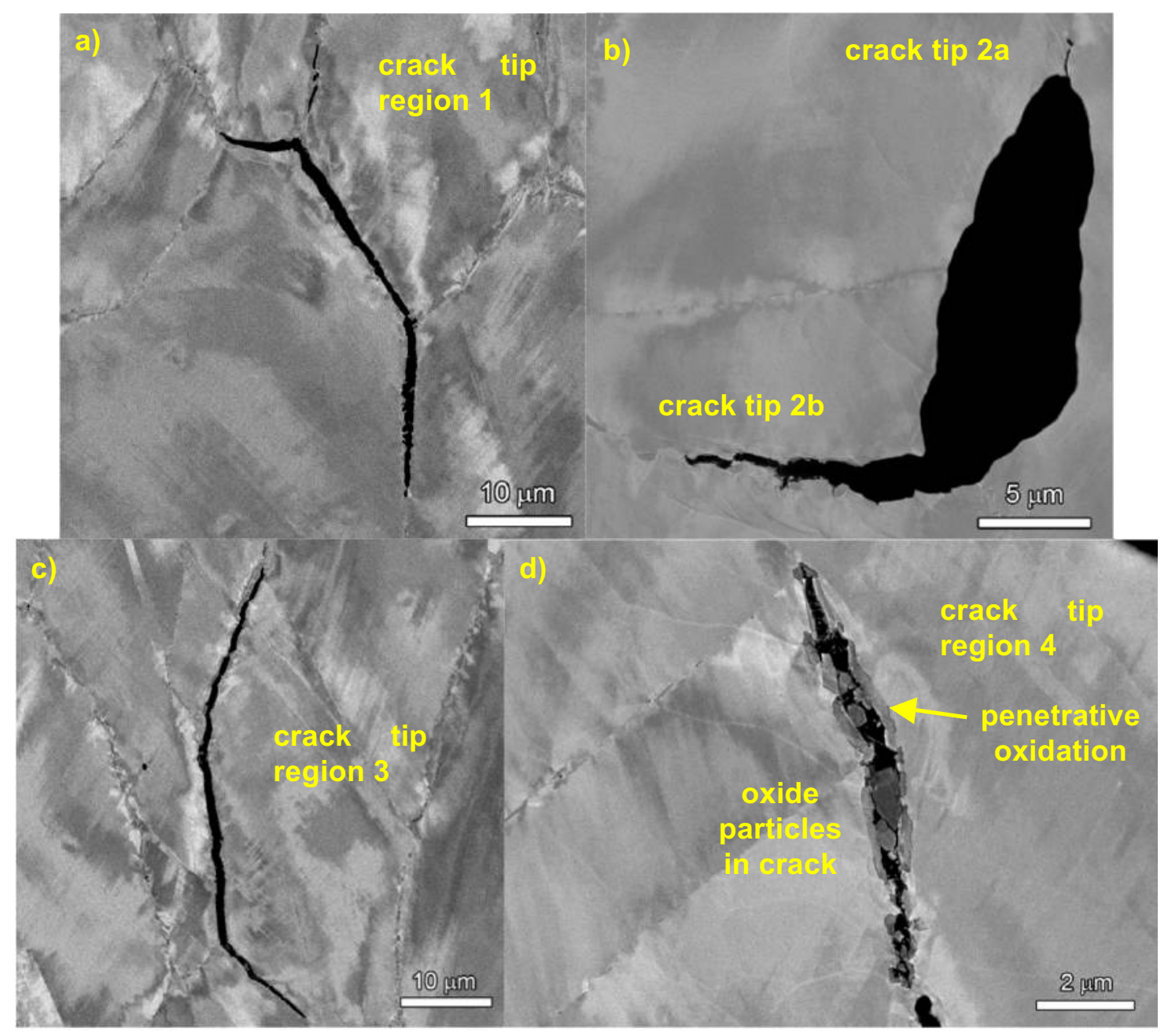

Figure 6.18 High magnification SEM backscatter micrographs of open crack walls in $26 \%$ CR ANL alloy 690 specimen CT036.

At the leading crack tips, the penetrative attack depths are $\sim 50 \mathrm{~nm}$ into the crack wall (Figure $6.21 \mathrm{a}$ ) with the oxide penetrations appearing to be $\sim 7-10 \mathrm{~nm}$ wide (Figure $6.20 \mathrm{~b}$ ). Based on the measured SCC propagation rates (Figure 6.22), the last $\mu \mathrm{m}$ of growth occurred with $\sim 50 \mathrm{~h}$ giving an estimated oxide penetration rate into the alloy 690 matrix of $\sim 1 \mathrm{~nm} / \mathrm{h}$. Moving back $\sim 125 \mu \mathrm{m}$ behind the leading crack tip, the penetration depth has nearly doubled to $100 \mathrm{~nm}$ (Figure 6.21c) corresponding to an estimated wall exposure time of $\sim 500 \mathrm{~h}$. This gives an average penetration rate of $\sim 0.2 \mathrm{~nm} / \mathrm{h}$ suggesting that the oxidation is slowing. At $250-300 \mu \mathrm{m}$ from the leading crack tip, the oxidation is observed to have penetrated to depths of $\sim 350 \mathrm{~nm}$ (Figure $6.21 \mathrm{~d}$ ) with an estimated exposure time of $\sim 1300 \mathrm{~h}$. Interestingly, this distance from the crack tip is where the oxide penetration depth stops increasing. The same approximate depth $(300-400 \mathrm{~nm})$ of wall attack is seen at distances of $\sim 600$ and $700 \mu \mathrm{m}$. It is important to note that the width of the oxide filaments increase with distance behind the crack tip and with time of exposure suggesting that remaining metal is slowly being oxidized. 


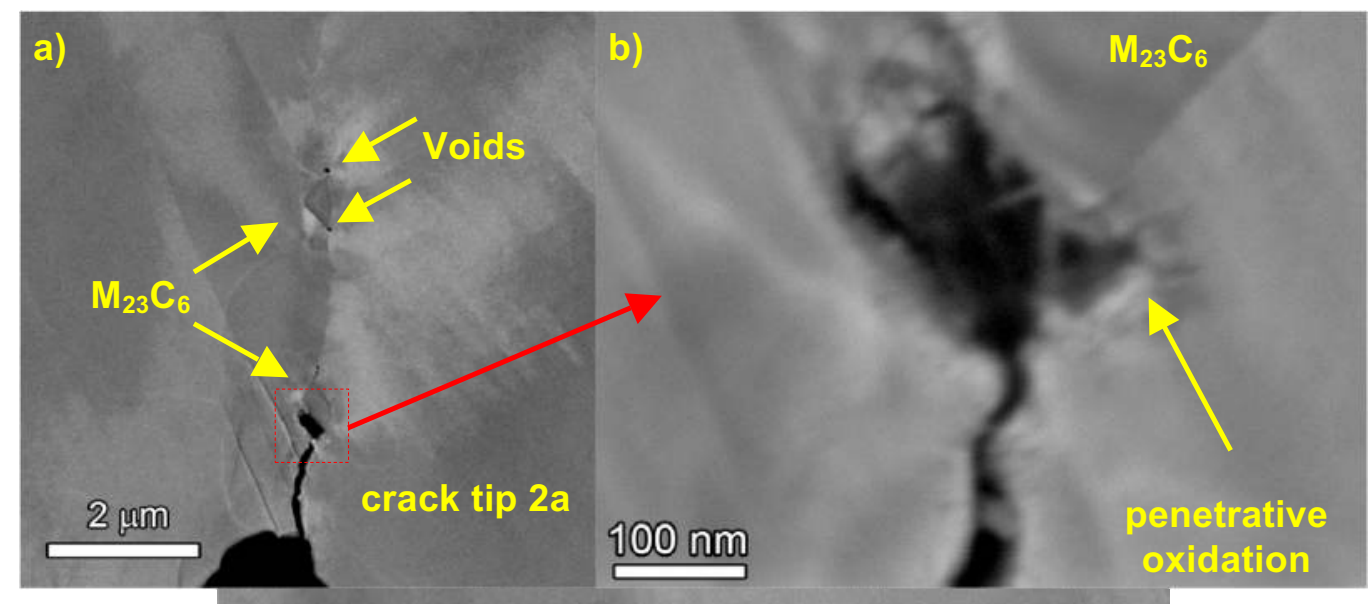

c)

crack tip $2 b$

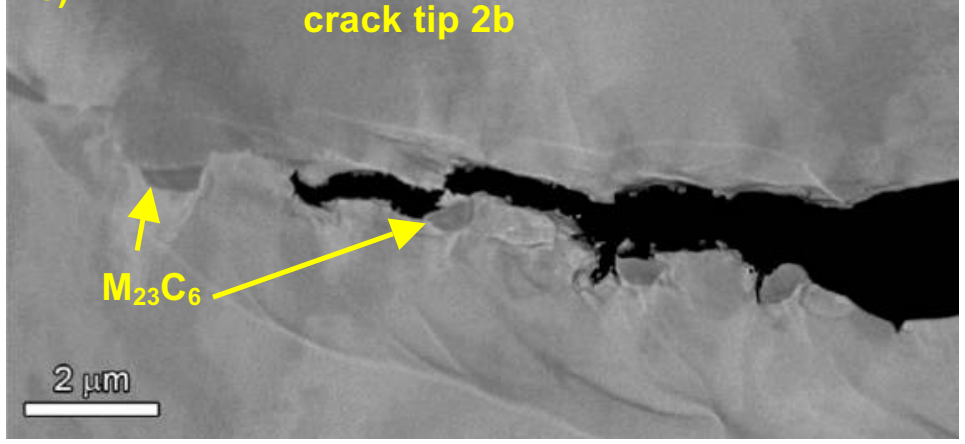

Figure 6.19 High magnification SEM backscatter micrographs of open crack walls in $26 \%$ CR ANL alloy 690 specimen CT036.

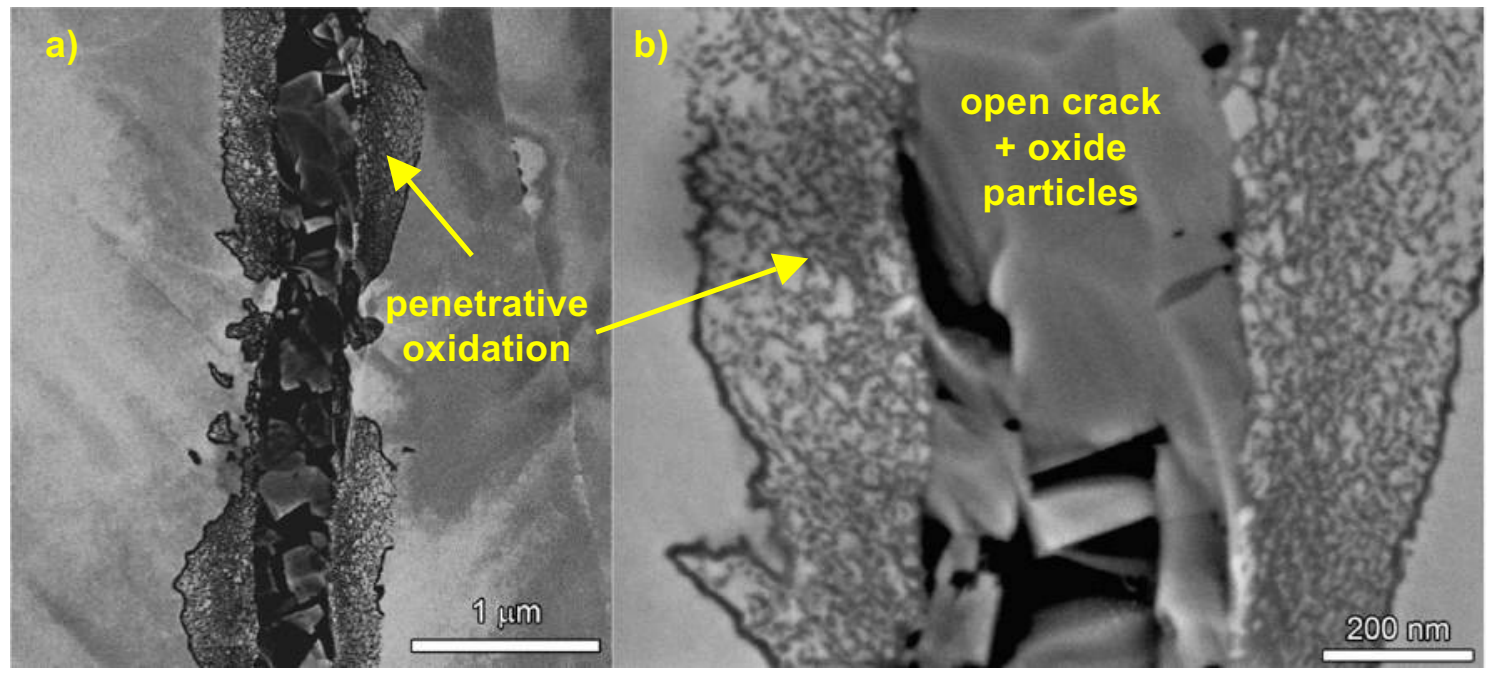

Figure 6.20 High magnification SEM backscatter micrographs of open crack walls in 26\%CR ANL alloy 690 specimen CT036. 


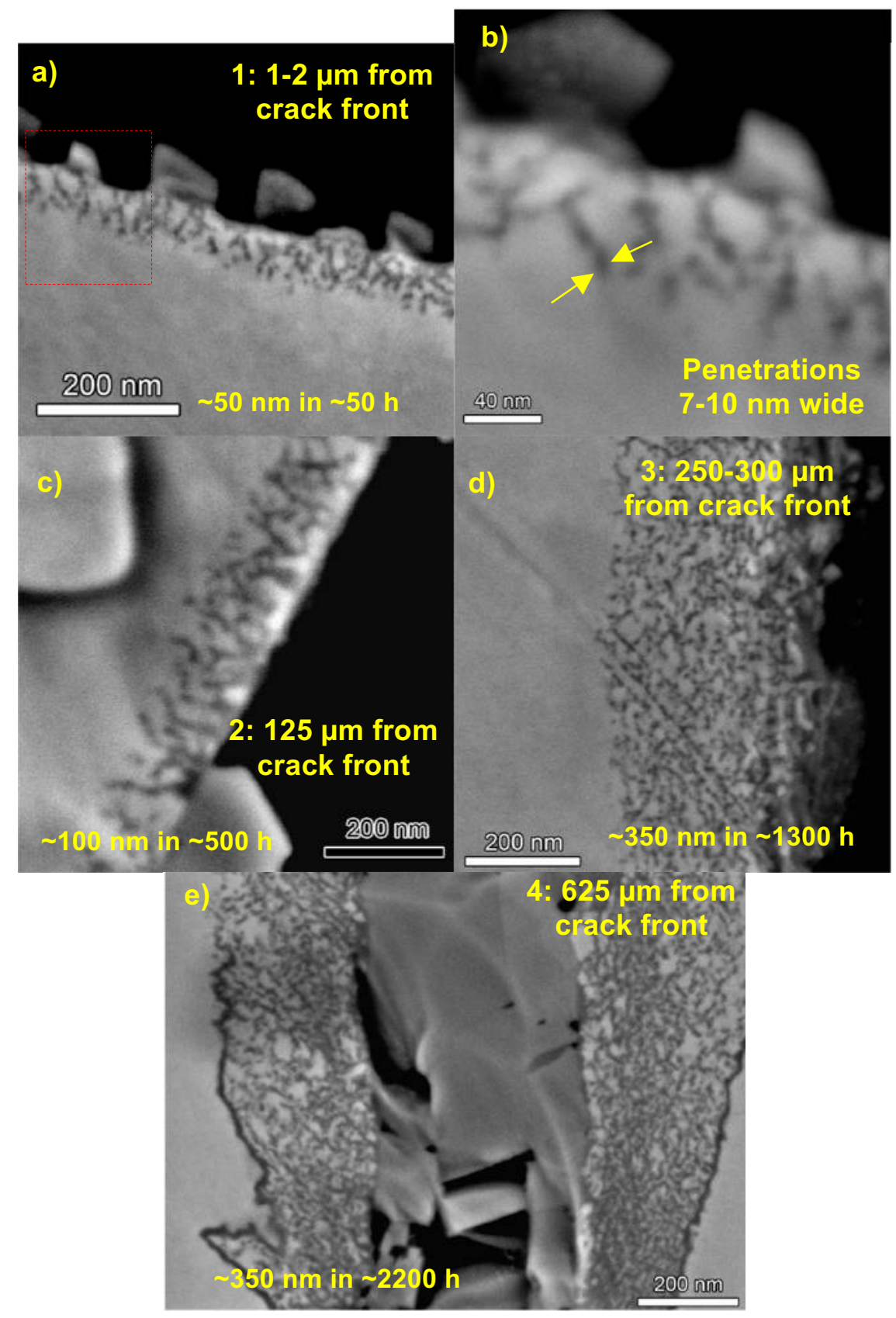

Figure 6.21 High magnification SEM backscatter micrographs of penetrative wall oxidation as a function of distance behind the SCC crack front in the $26 \%$ CR ANL alloy 690 specimen CT036.

As noted, the determined distances behind the SCC crack front in the cross-sections were used to give a rough estimate of the crack wall exposure time from the SCC crack-growth plot in Figure 6.22 (test data described in Chapter 5 and shown in Figure 5.48). Using this information, wall oxidation depth is plotted versus time in Figure 6.23 indicating the kinetics of the process and the apparent saturation depth of $\sim 350 \mathrm{~nm}$. Many additional observations would be needed to confirm and quantify this behavior in various alloy 690 specimens. 


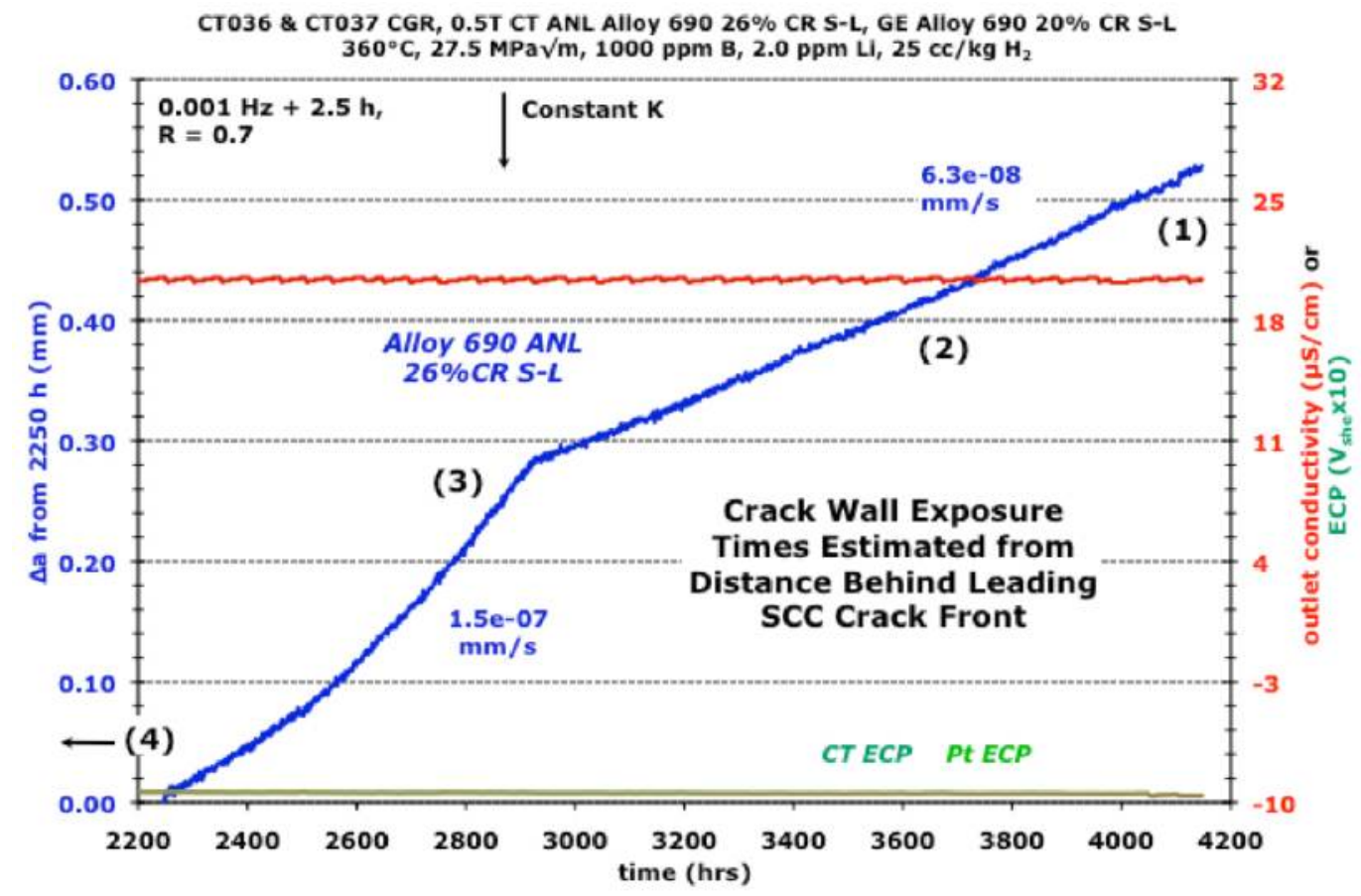

Figure 6.22 Measured crack-growth rate for 26\%CR ANL alloy 690 specimen CT036 along with specific distances where crack wall oxidation depths were determined.

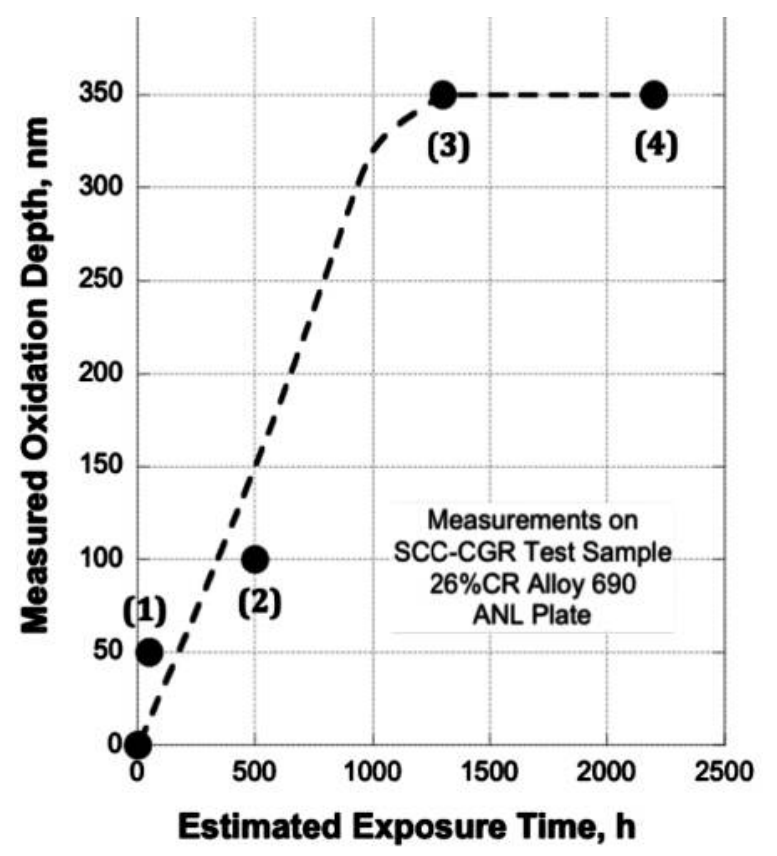

Figure 6.23 Depth of penetration oxidation off SCC crack walls as a function of the estimated time in PWR primary water. 
Cross-sections were prepared from specimen CT037 by both standard metallographic techniques for SEM exams and by ion milling for both TEM and SEM characterizations. Once again, predominately IG cracking was observed during the SCC portion of the crack-growth test and penetrative oxidation was found along crack walls. As described in some detail in Section 5.1 and 5.2, there was a low density of carbide precipitation and permanent damage (voids or cracked carbides) on most grain boundaries in the GEG material. As a result, much less time was taken examining SCC crack interactions with grain boundary carbides.

The overall crack morphology across the $20 \%$ CR GEG alloy 690 specimen CT037 was generally similar to that observed for the $26 \%$ CR ANL alloy 690 specimen CT036. This is illustrated by backscatter and SE micrograph montages in Figure 6.24 that reveal branched IG cracks (in and out of the plane of the cross-section sample) stretching $\sim 350 \mu \mathrm{m}$ behind the leading crack tip. Based on crack-growth data presented in Figure 5.48, propagation during the primary SCC portion (during cycle + hold and constant $\mathrm{K}$ loading at end of test) is estimated to be only $\sim 35 \mu \mathrm{m}$ at the very end of the test. The main crack opening appears to be a few micrometers in width before significantly narrowing as the leading SCC crack front is approached in this cross-section. While some differences were noted comparing the 3 different cross-section samples, the general morphology of the cracking was similar in each. The low magnification overviews in Figure 6.24 illustrate the larger and well-spaced TiN particles in the matrix along with the higher density of very small TG and IG $\mathrm{M}_{23} \mathrm{C}_{6}$ precipitates.

Crack morphologies and precipitate distributions were more easily resolved at higher magnifications with analyses focused on the leading SCC crack tips in the various CT037 crosssection samples. Most IG cracks propagated along grain boundaries containing few if any carbides and ended in sections without carbides as shown in Figures 6.25 and 6.26. Cracks appear to remain open to the tips and contain oxide particles that are believed to be predominately MO-structure oxide (based on TEM results reported in the following section). Penetrative oxidation is observed on the crack walls behind the tips in all cases, but certain SCC tips show little or no wall attack. Two additional crack tips are presented in Figure 6.27, which shows the deepest crack that has bifurcated along two grain boundaries with quite different precipitate structures. One of these IGSCC cracks ends in the cross-section along a carbide interface at a grain boundary triple point (Figure 6.27c). For each of the SCC crack cross-sections, grain boundary characteristics were examined at high resolution ahead of the leading crack front. As for the other CR alloy 690 crack-growth specimens, no evidence was found for enhanced void formation ahead of the SCC crack front. In summary, the $20 \%$ CR GEG alloy 690 specimen CT037 showed similar IGSCC crack features (as imaged by SEM) even though propagation occurred along grain boundaries with a much lower density of $\mathrm{Cr}$ carbides. 


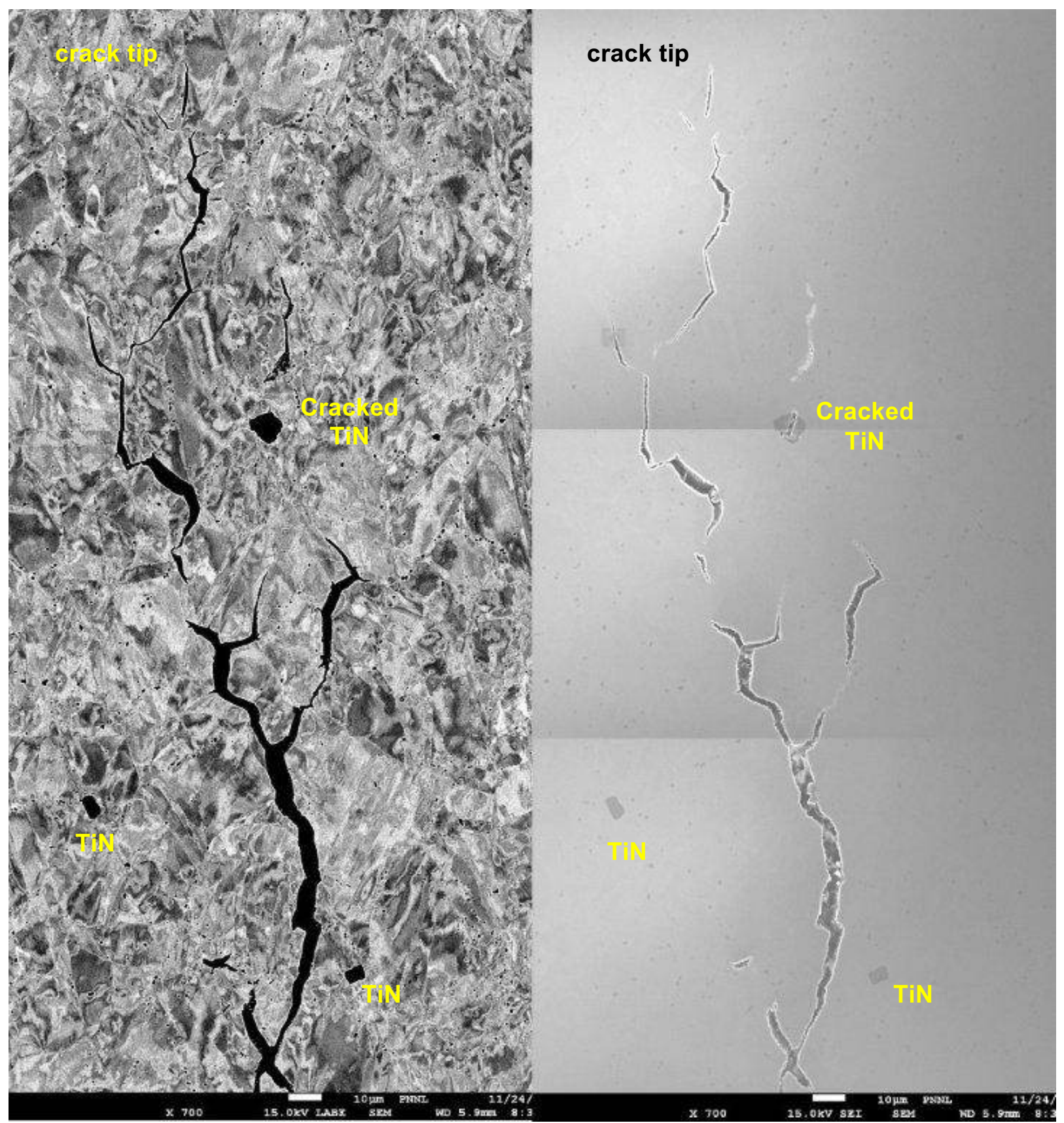

Figure 6.24 Montages of SEM backscatter (left) and secondary (right) electron micrographs at low magnifications showing the open SCC crack with branching (in and out of plane) to the crack tip in 20\%CR GEG alloy 690 specimen CT037. Several larger matrix TiN particles are identified and careful examination of the backscatter image reveals much smaller TG and IG $\mathrm{M}_{23} \mathrm{C}_{6}$ precipitates. 


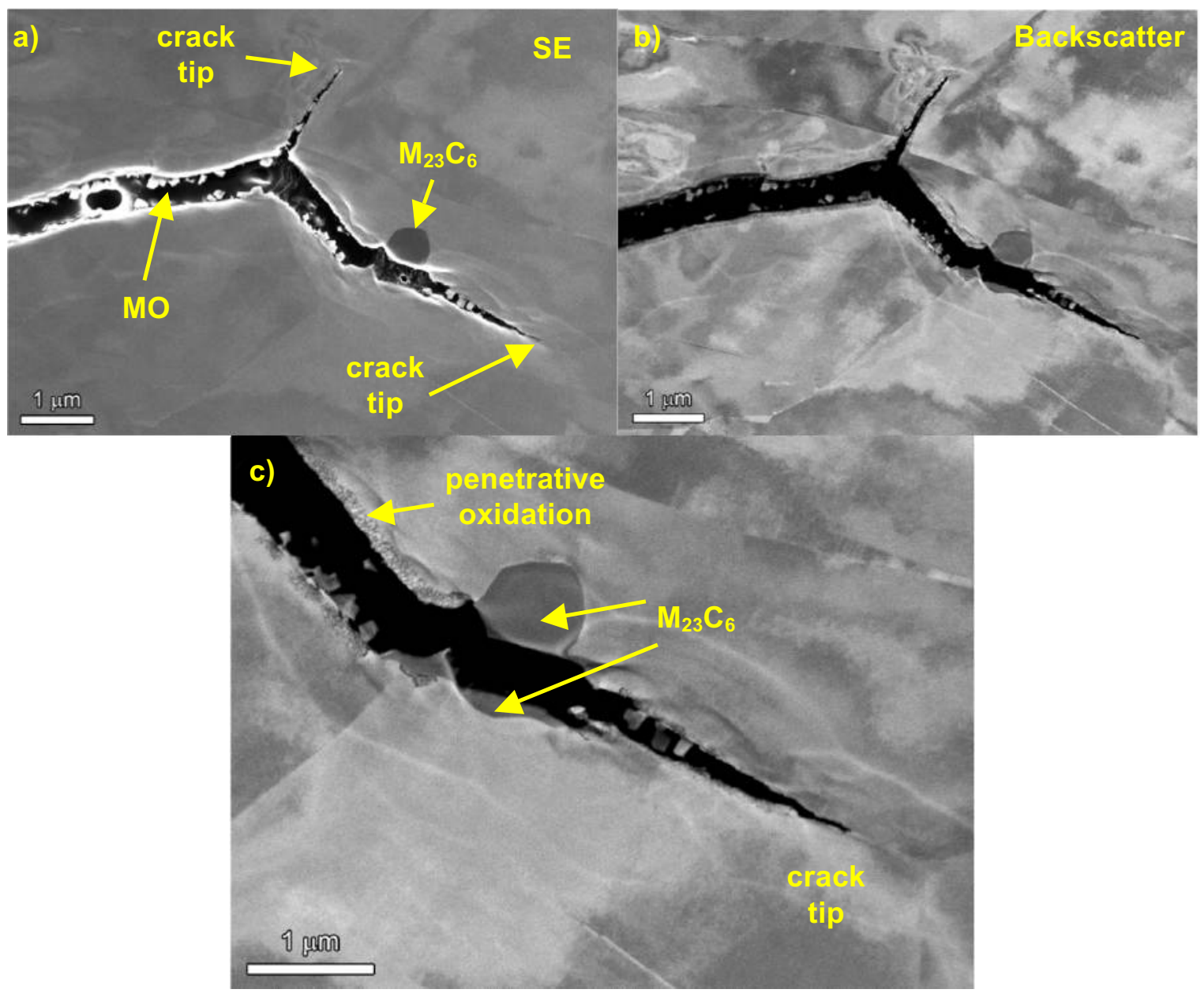

Figure 6.25 High magnification SEM SE (a) and backscatter (b,c) micrographs of open IGSCC crack ending with two IG crack tips in 20\%CR GEG alloy 690 specimen CT037.
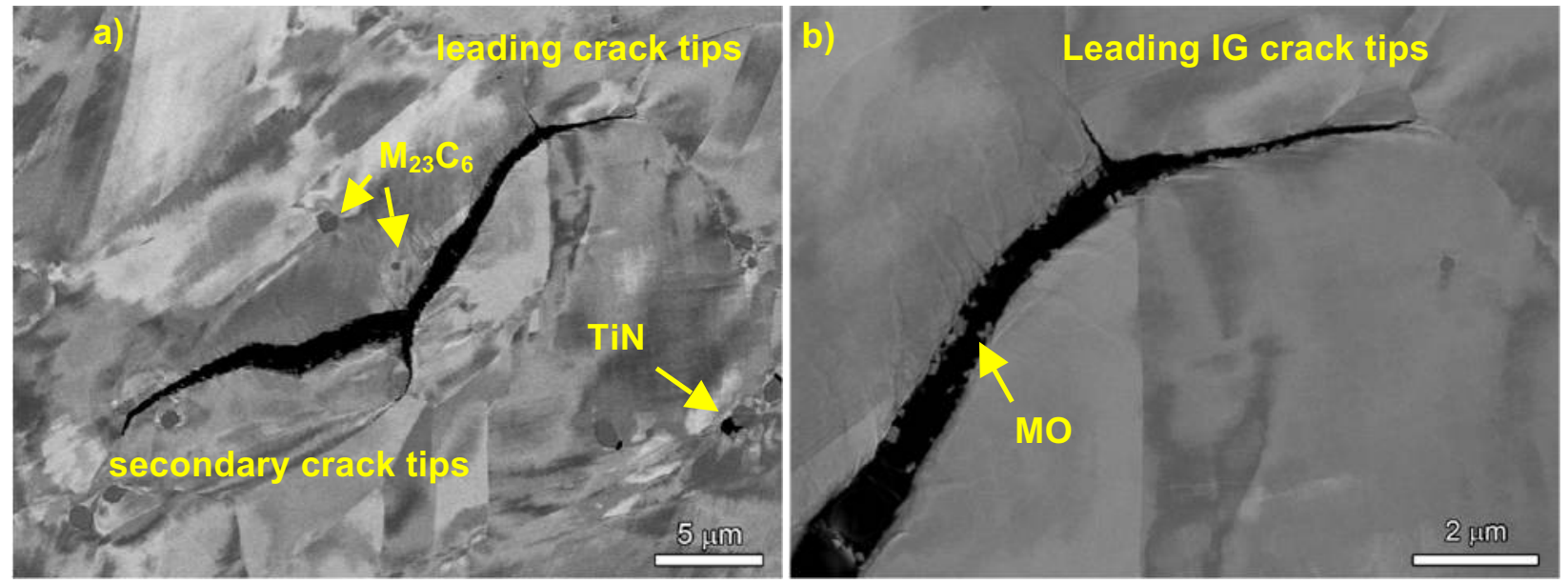

Figure 6.26 SEM backscatter micrographs showing several IGSCC crack tips in $20 \%$ CR GEG alloy 690 specimen CT037. 

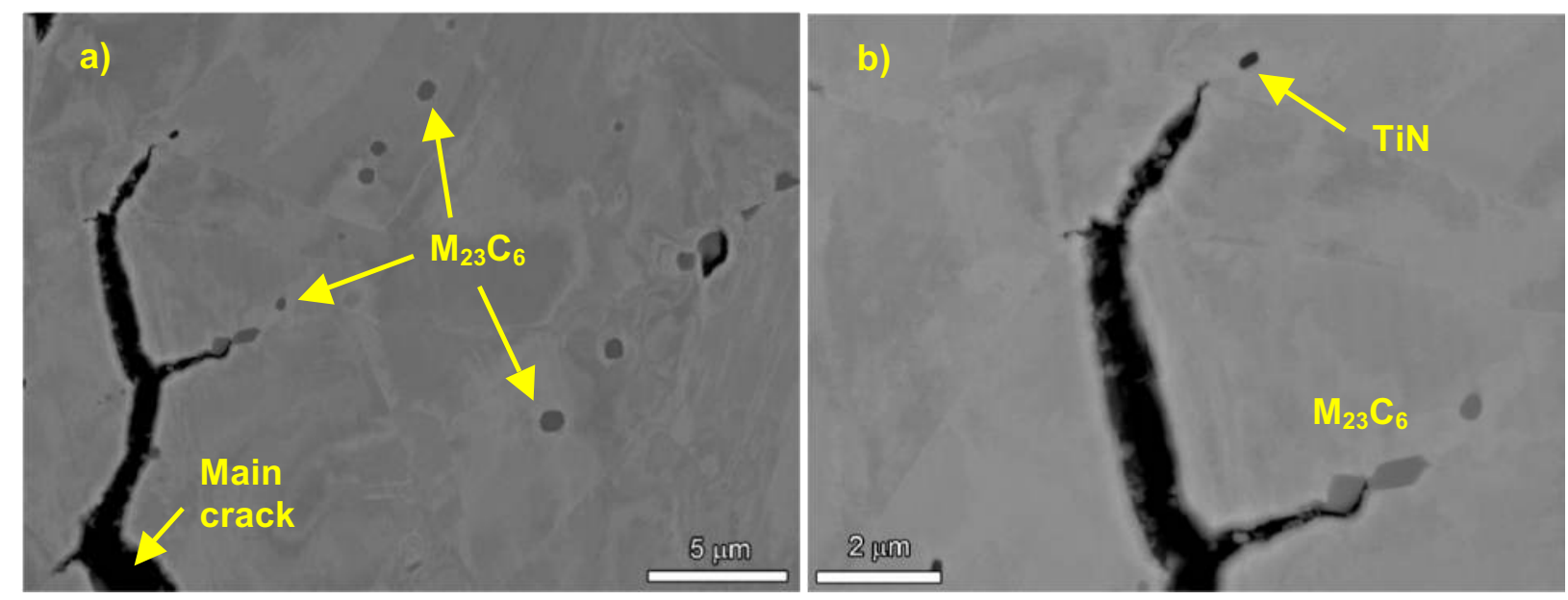

c)
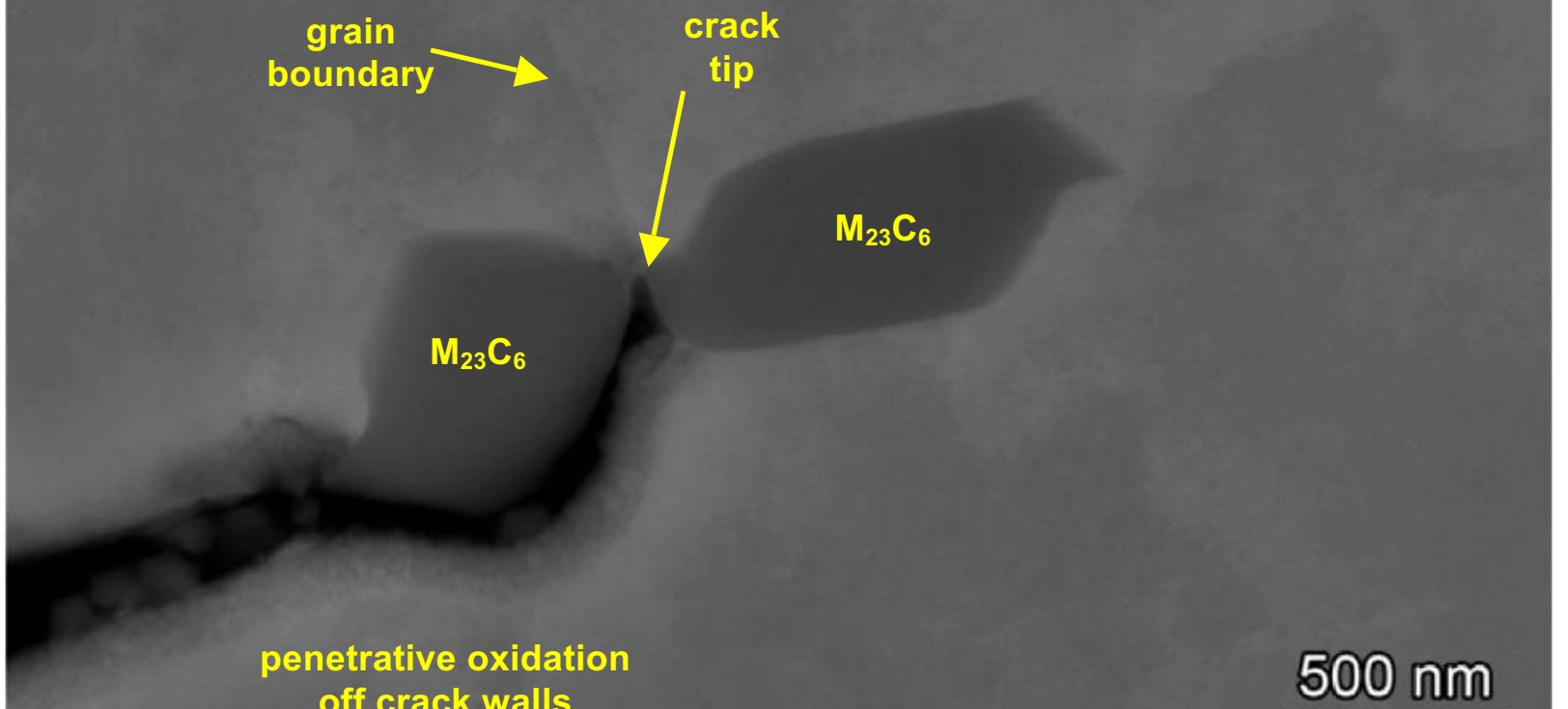

off crack walls

$M_{23} C_{6}$

Figure 6.27 SEM backscatter micrographs of leading IGSCC crack tips in 20\%CR GEG alloy 690 specimen CT037. Few grain boundary precipitates are seen off crack walls, however one of the crack branches ends at a grain boundary triple and a carbide interface. 
SEM examinations of IGSCC cracks provide insights into the influence of the CR-induced permanent damage (grain boundary cracked carbides and voids) on propagation. Overall, observations make it seem unlikely that these pre-existing defects control IGSCC response in PWR primary water. The primary interaction between these pre-existing features and the IGSCC cracks appear to be crack blunting and not an acceleration of environment-induced growth. The SCC path consistently follows the grain boundaries and does not "jump" between perpendicular cracks across carbides or between voids at carbide interfaces. For the CRDM TT materials, the most extensive carbide cracking is within the cellular precipitation regions. However, SCC propagates along the migrated grain boundary and does not typically intersect these crack carbides at all. The most significant observed interaction with the pre-existing cracked carbides is that many IGSCC cracks end at the cracked carbides. These crack-tip locations are often more open and blunted as the SCC crack hits the crack across the carbide that is oriented perpendicular to the grain boundary propagation path. As noted in Section 5.2, IG carbides clearly enhance localized grain boundary deformation and produce permanent damage. The current observations indicate that it is not the cracked carbides and voids that promote IGSCC susceptibility, but it may be the high localized interfacial stresses and strains created during cold rolling.

\subsection{Transmission Electron Microscopy Examinations of SCC Crack Tips}

Cross-section samples for ATEM characterization were prepared by removing small pieces containing selected crack tips from metallographically polished samples following vacuum impregnation with a low-viscosity thermosetting resin. The small slices were then glued to 3-mm-diameter Mo washers (the size of a TEM disk), with the crack tips at the disk centers. After trimming edges and flat polishing to $\sim 100 \mu \mathrm{m}$ total thickness, the samples were dimpleground from the washer sides and finished by low-angle ion micromilling with 2 to $5 \mathrm{KeV}$ argon ions. Repeated cycles of ion thinning and TEM were used to progressively thin and examine multiple crack-tip areas or other crack locations of interest.

ATEM characterizations were performed using a 200-kV field-emission-gun TEM with a thinwindow, energy-dispersive $x$-ray spectrometer (EDS) and a parallel-detection electron-energyloss spectrometer (PEELS) for microchemical analysis. Besides conventional brightfield and precipitate darkfield imaging, characterization methods included crystal lattice imaging with Fourier-transform diffraction analysis, fine-probe (0.7-nm diameter) compositional analysis by EDS and PEELS, and parallel-beam diffraction from selected sample areas as small as $\sim 6 \mathrm{~nm}$ in diameter. Stereoscopic TEM photographs were used to observe finely porous structures in crack oxides. A Fresnel (off-focus) image contrast method was employed to reveal fine pores and other structures as small as $1 \mathrm{~nm}$. Computer-controlled EDS mapping in a scanning transmission (STEM) mode was also extensively used to observe compositional variations along cracks and leading grain boundaries at resolutions down to $\sim 2 \mathrm{~nm}$.

Initial crack-tip examinations were performed on the 30\%CR alloy 690TT CRDM specimen CT022 tested in the less-susceptible T-L orientation. The environment was $350^{\circ} \mathrm{C}$, simulated PWR primary water with stress intensities of 30 and $40 \mathrm{MPa} \sqrt{\mathrm{m}}$ evaluated during the test. Crack and crack-tip regions examined were produced at the end of the test with a $\mathrm{K}$ of $40 \mathrm{MPa} / \mathrm{m}$. The SCC CGR results for specimen CT022 were described in Section 4.3. 
As discussed in the previous section, SEM examinations on SCC cross-section samples revealed many aspects of the matrix and grain boundary microstructures. The observations can be summarized as follows:

1. The general microstructures in this sample indicated a very heavily cold-worked material with closely spaced carbide particles along the grain boundaries. The deformation structures included high densities of tangled dislocations and occasional deformation twins apparently associated with the IG carbide particles. TEM analyses identified the IG carbides as $\mathrm{M}_{23} \mathrm{C}_{6}(\mathrm{M}=$ mostly $\mathrm{Cr}$ but also included some $\mathrm{Ni}$ and $\mathrm{Fe})$.

2. The IG carbides included blocky, nearly continuous particles $(\sim 0.1$ to $0.2 \mu \mathrm{m}$ in size $)$ along the boundary planes, as well as frequent local regions of cellular precipitation. Individual particles were sometimes separated by penny-shaped cavities ('pores') that apparently had been produced during cold working.

3. SCC propagation generally followed the grain boundaries, even in local areas where the boundaries deviated around one side of the cellular carbide colonies.

The thin central area of the TEM sample contained several branch cracks. Although the cracks appeared locally discontinuous on the section surface, they generally contained oxide to the tips, and thus had been connected to the water environment during testing. It was difficult to observe the crack tips clearly due to the heavily deformed microstructure of the material, and many cycles of thinning and examination were needed to reveal the crack microstructures.

Cracks in this sample appeared generally wide open and contained loose polishing debris. In places where the crack widths narrowed to less than $\sim 0.2 \mu \mathrm{m}$, and especially near the crack tips, the embedding resin used in sample preparation completely filled the cracks and preserved the corrosion fill products and crack-wall microstructures. Figure 6.28 shows an example of the crack microstructures in one of the protected areas. TEM analyses identified the main features as (a) loose crystallites of $\mathrm{Ni}-\mathrm{Fe}-\mathrm{Cr}$ spinel in the crack, and (b) finer polycrystalline spinel along the crack walls. EDS analyses showed that the spinel was $\mathrm{Ni}$ rich, with much lower $\mathrm{Fe}$ and $\mathrm{Cr}$ than the matrix. The cracks opened along one side of the Cr-carbide particles $\left(\mathrm{M}_{23} \mathrm{C}_{6}\right)$ in the adjacent metal matrix. A spinel crystallite indicated in the figure was observed in a [011] orientation, and easily identified from its characteristic diffraction pattern. No oriented oxide layer was found at the metal surfaces of the crack in this area.

In another crack area, shown in Figure 6.29, the crack-fill product consisted of mostly needleshaped crystallites. Electron diffraction patterns from the product poorly matched the common oxides such as spinel and $\mathrm{Cr}_{2} \mathrm{O}_{3}$, but approximately matched hydroxides such as $\mathrm{NiOOH}$ and $\mathrm{CrOOH}$. EDS analysis (Figure 6.30 and table) showed that the needle phase was Fe-rich and Cr-poor compared to the alloy.

Crack walls close to the tips showed distinctive attack, with tunnel-like structures or filaments containing oxide penetrating to $\sim 200 \mathrm{~nm}$ below the crack surfaces, and uniform oxidized 'rinds' formed between $\mathrm{Cr}$-carbide particles and the adjacent matrix. An underfocus brightfield image in Figure 6.28 shows the filaments and interfacially oxidized carbides along a crack. The protective glue in this area eroded away during ion milling. Oxide darkfield imaging (Figure 6.31 bottom) shows that the filaments contained particulate oxide with two distinct phases: $\mathrm{Cr}_{2} \mathrm{O}_{3}$ and MO-structure oxides. 
EDS maps of the same region (at 2 magnifications) are shown in Figures 6.32 and 6.33. The Crrich $\mathrm{Cr}_{2} \mathrm{O}_{3}$ appears orange in the color composite maps. Closer inspection suggests that there is also a Ni-rich oxide phase (consistent with cubic MO) that appears light blue in the maps. The higher magnification maps in Figure 6.33 also show Ni enrichment in the matrix next to the interfacial oxide on the carbides, and also minor $\mathrm{Ni}$ enrichment just below the oxide rinds on the carbide particles. EDS analysis of this region (Figure 6.34 with table) show that the $\mathrm{M}_{23} \mathrm{C}_{6}$ carbide particles contained mostly $\mathrm{Cr}$, but also included some $\mathrm{Ni}$ and $\mathrm{Fe}$. Analyses showed no significant compositional difference (apart from oxygen) between the attacked regions and the adjacent matrix.

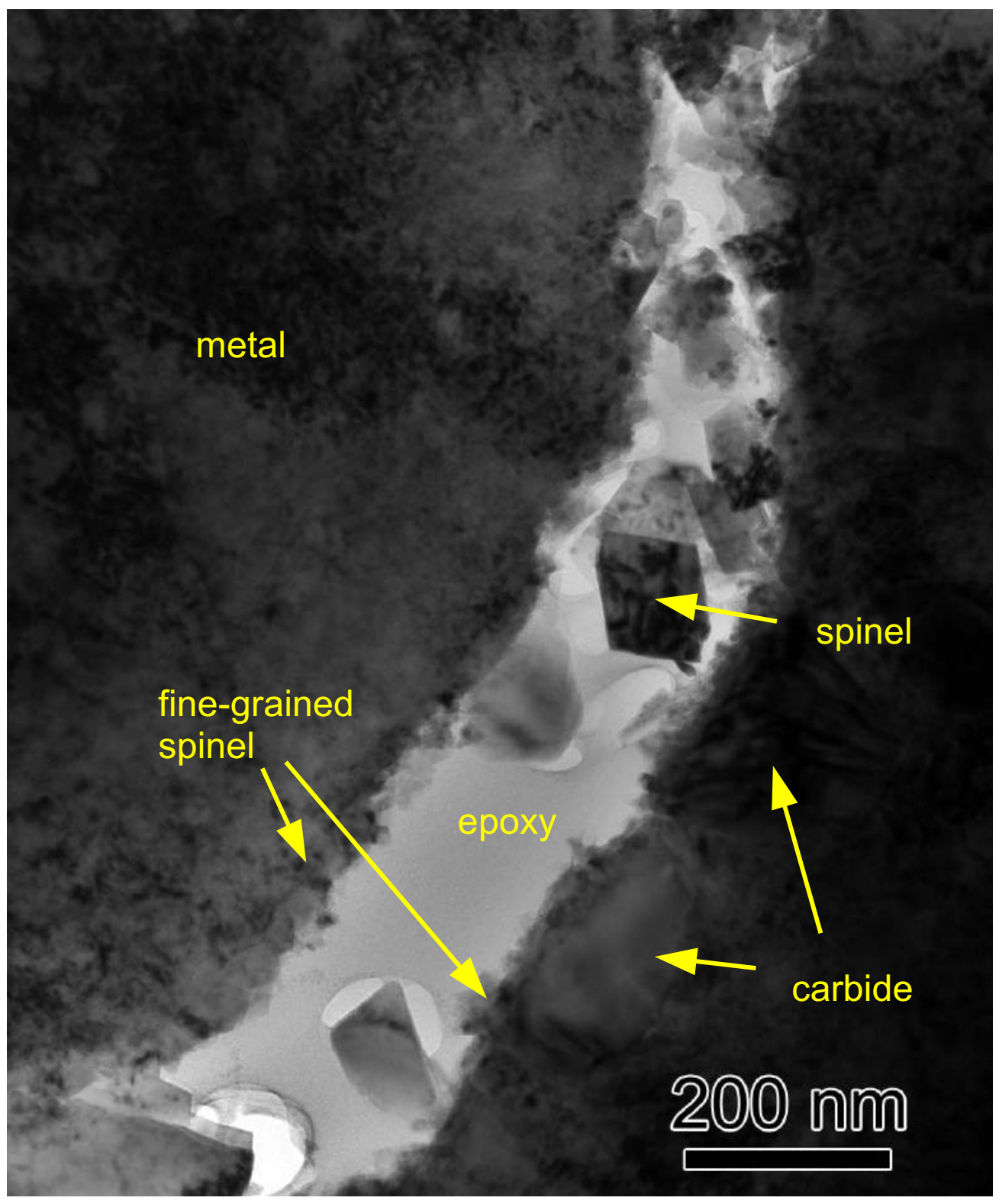

Figure 6.28 IGSCC crack partially filled with epoxy containing oxide corrosion products from 30\%CR CRDM alloy 690TT specimen CT022. 

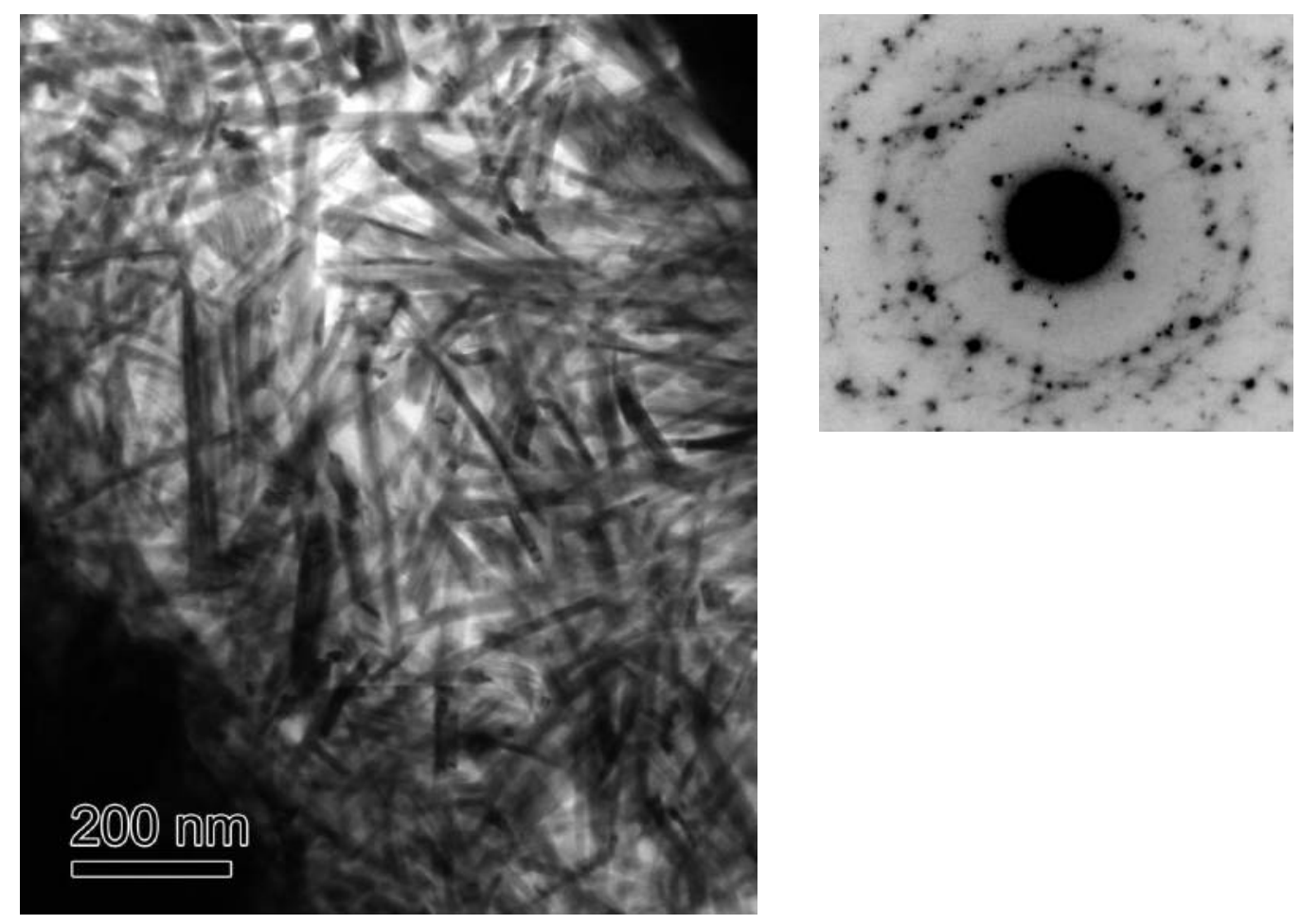

Figure 6.29 Needle-shaped crystallites are present in a crack from specimen CT022. Diffraction analysis suggests that it is a hydroxide phase, pattern gives fair match to $\mathrm{NiOOH}$ and $\mathrm{CrOOH}$ (poor match to spinel or $\mathrm{Cr}_{2} \mathrm{O}_{3}$ ).

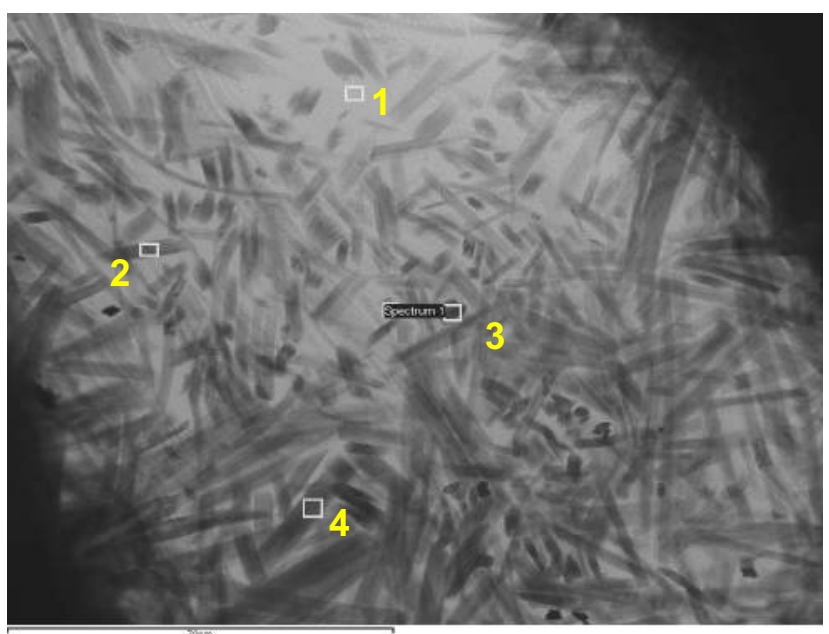

\begin{tabular}{|c|c|c|c|c|}
\hline Area & 0 & $\mathrm{Cr}$ & $\mathrm{Fe}$ & $\mathrm{Ni}$ \\
\hline 1 & 16.6 & 6.8 & 22.6 & 53.9 \\
\hline 2 & 37.9 & 6.7 & 14.5 & 40.9 \\
\hline 3 & 38.5 & 5.3 & 16.7 & 39.5 \\
\hline 4 & 37.4 & 6.0 & 16.3 & 40.2 \\
\hline
\end{tabular}

Figure 6.30 STEM image of needle-shaped corrosion product in crack along with EDS results (in wt\%) indicating that the phase is Fe-rich and Cr-poor compared to the metal matrix. 


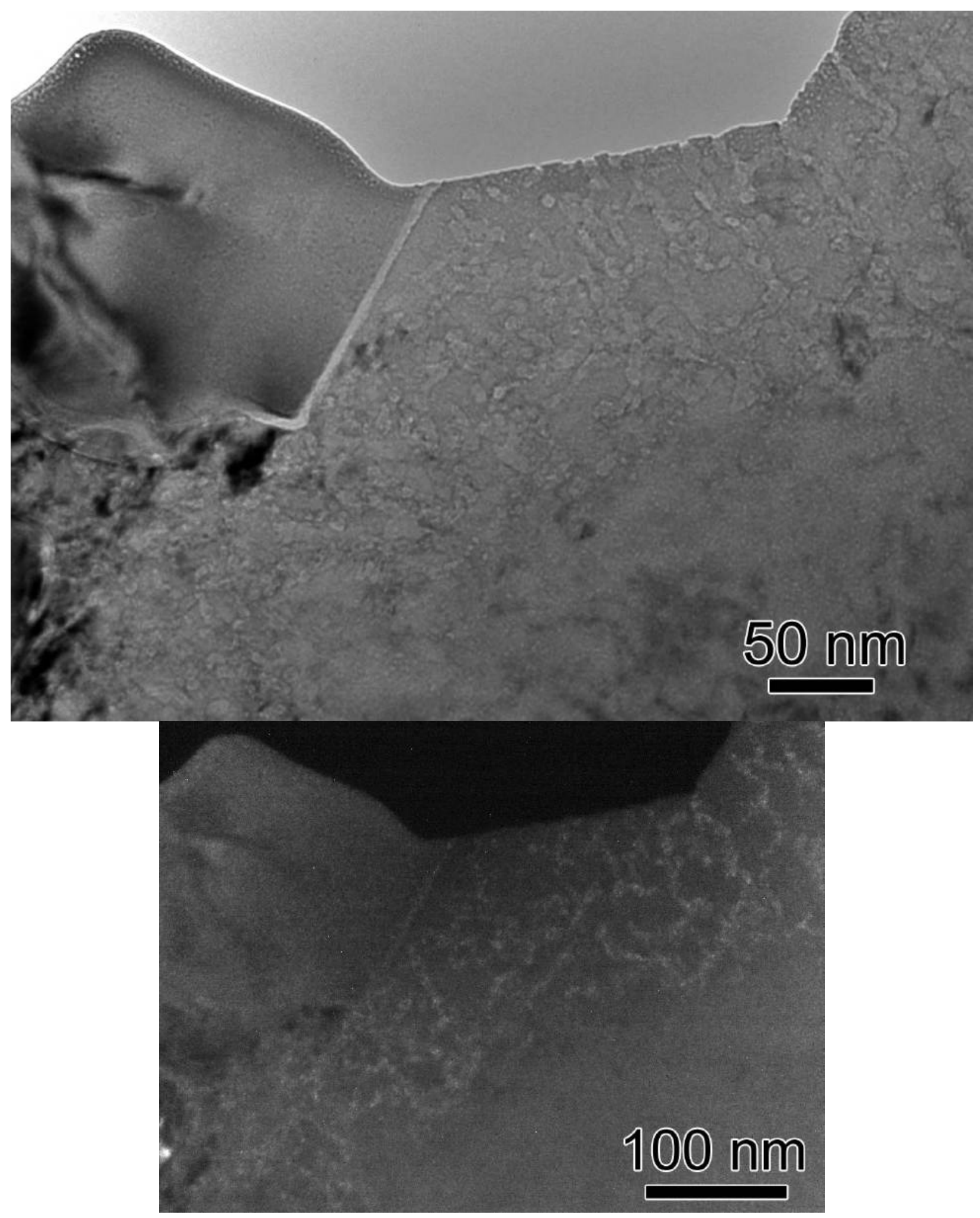

Figure 6.31 Attacked/oxidized region along edge of SCC crack in CT022. (a) brightfield underfocus image showing 'filaments' and interfacial oxidation of $\mathrm{Cr}$-carbide particle. (b) oxide darkfield image taken with $\mathrm{Cr}_{2} \mathrm{O}_{3}$ reflection, showing oxide in filaments. 


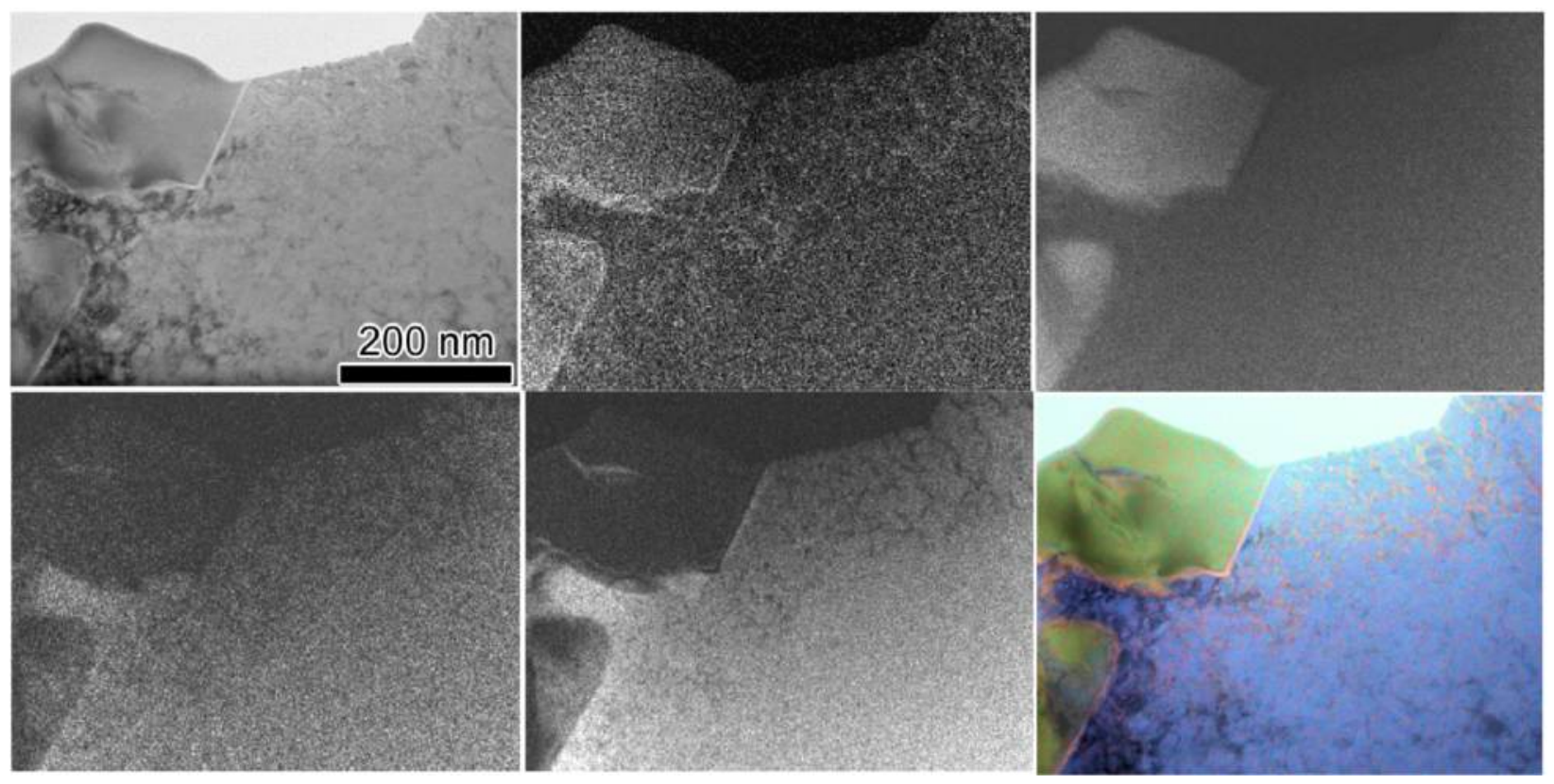

Figure 6.32 EDS maps of crack edge area in 30\%CR CRDM alloy 690TT specimen CT022 with color composite combining the $\mathrm{O}$ (red), $\mathrm{Cr}$ (green) and $\mathrm{Ni}$ (blue) maps. Cr-rich oxide at carbide interface and in filaments appears orange. Cr carbide particles appear green.

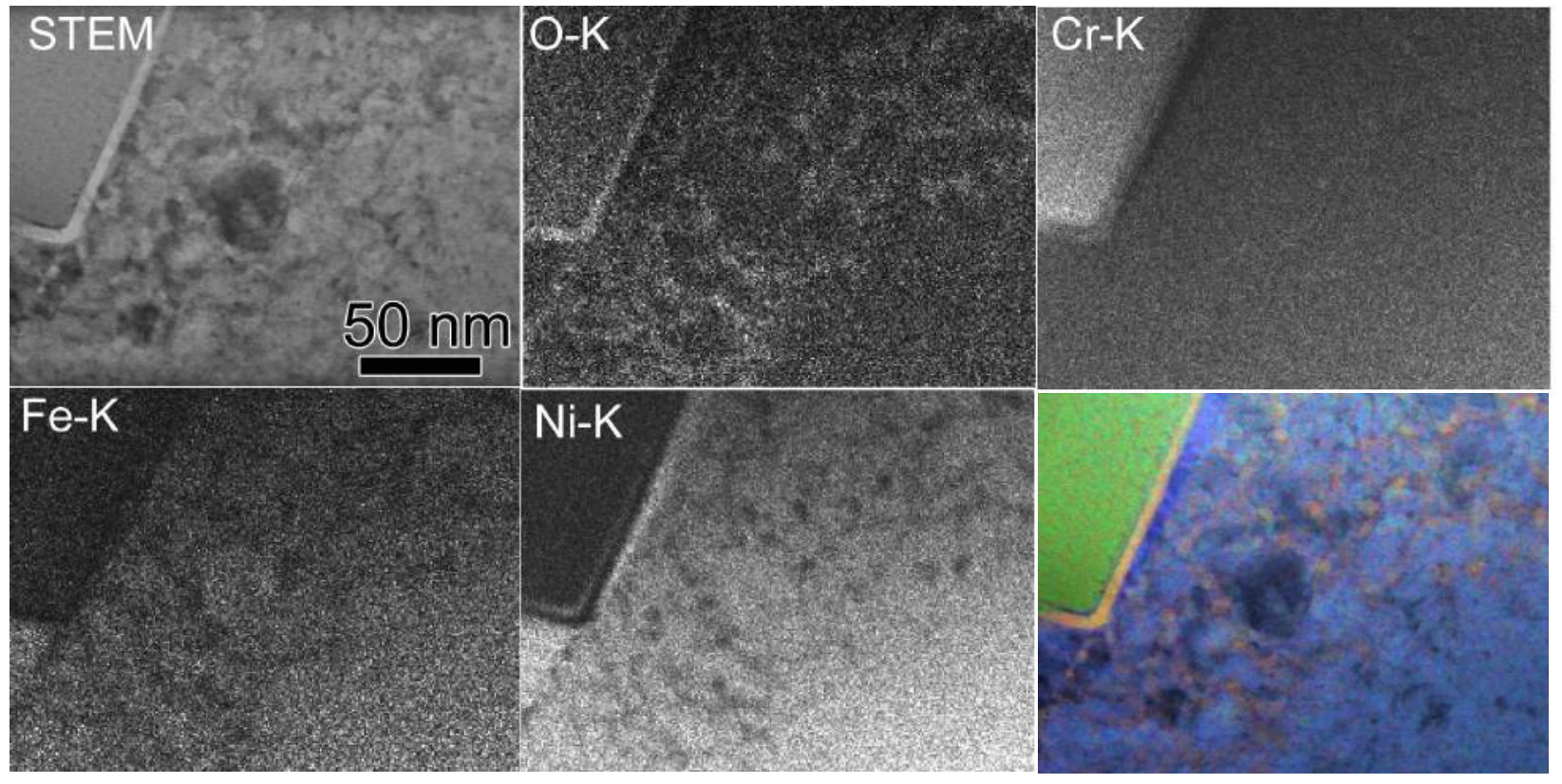

Figure 6.33 Higher magnification EDS maps of crack edge area in Figure 6.32. Color composite combines the $\mathrm{O}$ (red), $\mathrm{Cr}$ (green) and $\mathrm{Ni}$ (blue) maps. 


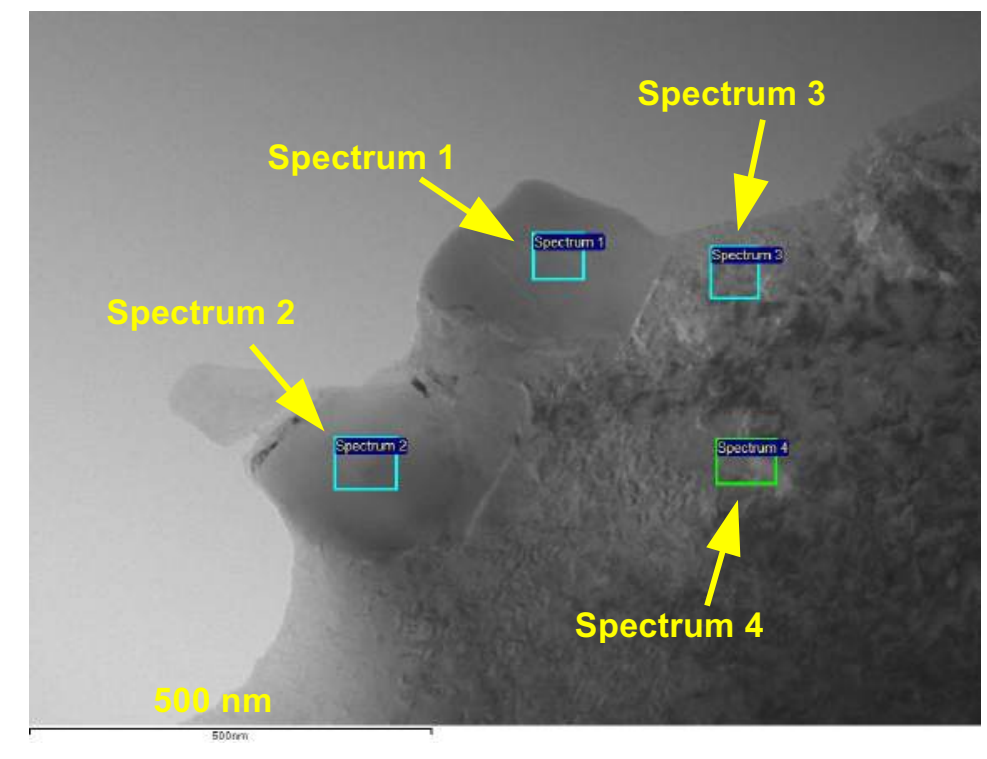

\begin{tabular}{cccccc} 
& \multicolumn{5}{c}{ Crack edge (map) area: EDS results in wt \% } \\
Spectrum & $\mathrm{Cr}$ & $\mathrm{Mn}$ & $\mathrm{Fe}$ & $\mathrm{Ni}$ & Object \\
1 & 76.4 & 0.0 & 3.9 & 19.7 & $\mathrm{M}_{23} \mathrm{C}_{6}$ particle \\
2 & 84.9 & 0.0 & 3.2 & 11.8 & $\mathrm{M}_{23} \mathrm{C}_{6}$ particle \\
3 & 27.9 & 0.9 & 9.0 & 62.2 & Matrix with filaments (O excluded) \\
4 & 29.7 & 0.0 & 10.2 & 60.1 & Adjacent matrix w/o filaments
\end{tabular}

Figure 6.34 STEM/EDS analysis of carbide particles and crack subsurface region.

Diffraction patterns identifying the two different oxides in the matrix along crack walls are given in Figure 6.35, and darkfield images taken with different oxide spots are shown in Figure 6.36. The diffraction patterns taken at a [111] matrix orientation show the parallel-oriented MO phase (intense spots just inside the matrix spots) and an apparent [0001] pattern from the trigonal $\mathrm{Cr}_{2} \mathrm{O}_{3}$ phase. However, the darkfield images taken with different $\mathrm{Cr}_{2} \mathrm{O}_{3}$ spots appear to highlight different particles, indicating the presence of multiple orientation variants. Thus, the inner pattern of sharp spots is not actually from a single zone axis. The darkfield image taken with an MO reflection also appears to highlight particles in the tunnels, but these particles appear smaller than the $\mathrm{Cr}_{2} \mathrm{O}_{3}$ particles.

Very high dislocation densities in the heavily strained material made it difficult to image the crack tips at high resolutions. In the area shown in Figure 6.37, the crack appears to have run along one side of the carbide particles, and ended with a relatively blunt tip at a carbide particle. One side of the carbide particle where the crack ended appears to show interfacial oxidation on the surface perpendicular to the crack. Progressive thinning after the first set of images was taken allowed observation of the region just ahead of the crack. No porosity was visible along the grain boundary or carbide particle interfaces leading the crack. Diffraction and EDS analyses (not included here) showed that the cracks contained $\mathrm{Cr}$-rich $\mathrm{Cr}_{2} \mathrm{O}_{3}$ to the tips. STEM/EDS maps of this region are shown in Figure 6.38. The map images indicate the presence of oxide all the way to the crack tip. In addition these images suggest that the oxidation has occurred mainly in the matrix alongside the particles. Figure 6.39 shows another tip area, where the crack ended with a blunt tip that also contained Cr-rich oxide. 


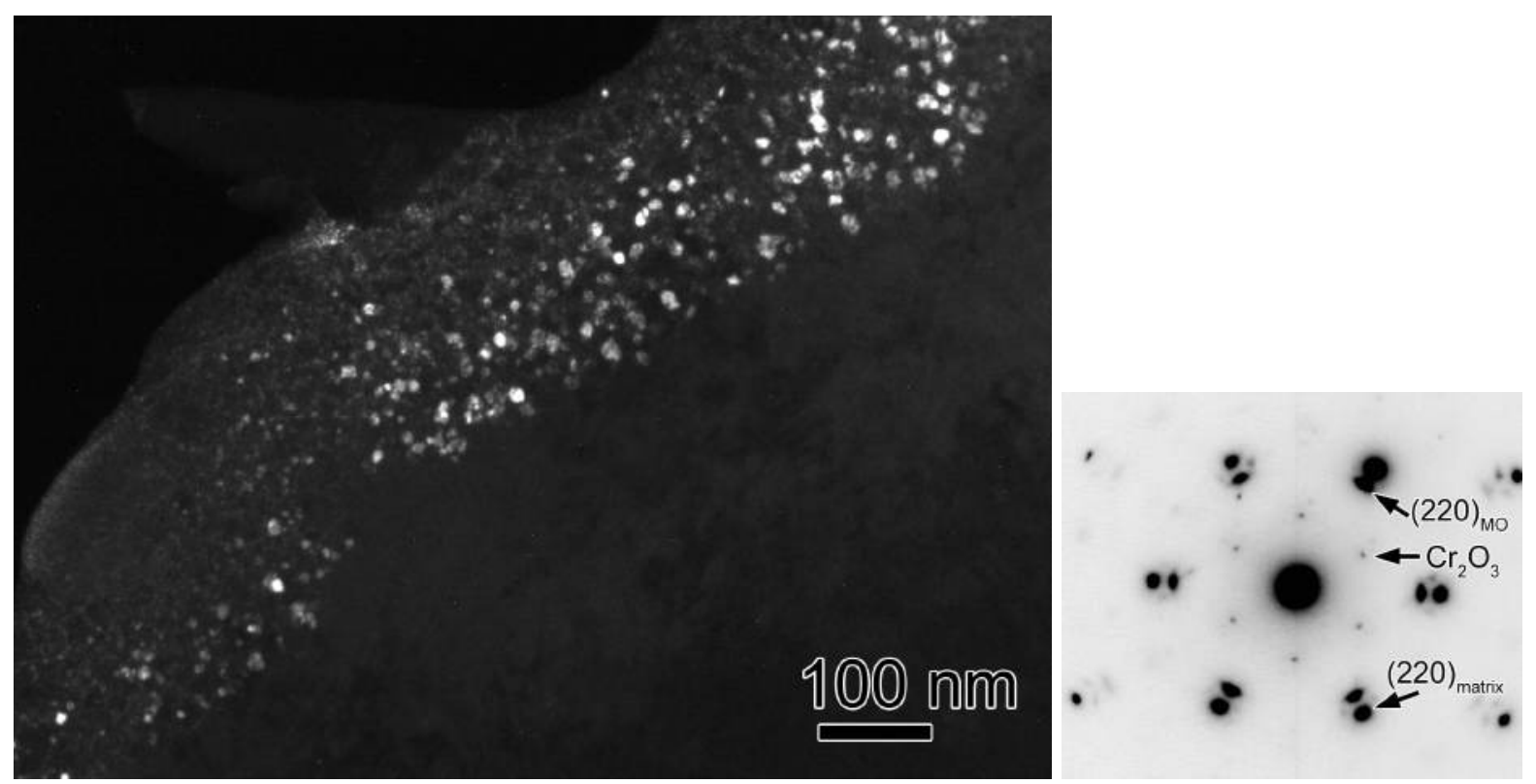

Figure 6.35 Darkfield image highlighting $\mathrm{Cr}_{2} \mathrm{O}_{3}$ particles in oxidized zone along crack wall in 30\% CR CRDM alloy 690TT specimen CT022.
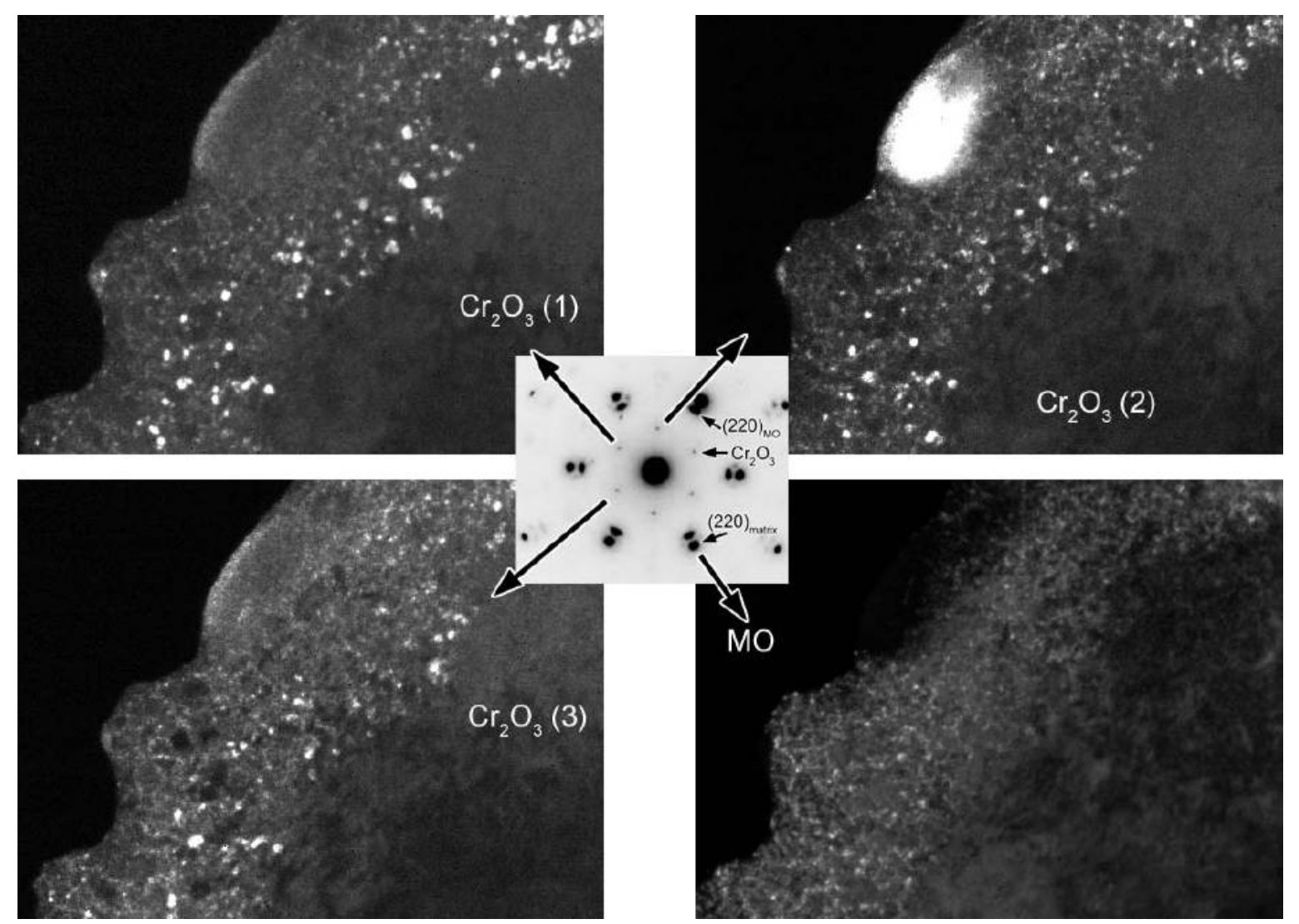

Figure 6.36 Oxide darkfield images showing particulate $\mathrm{Cr}_{2} \mathrm{O}_{3}$ and $\mathrm{MO}$-type oxide in filaments along crack wall. Different $\mathrm{Cr}_{2} \mathrm{O}_{3}$ spots appear to highlight different orientation variants. 
Preliminary TEM examinations are also being performed on the ANL 26\%CR alloy 690 specimen (CT036) and the GEG 20\%CR alloy 690 specimen (CT037). Extensive IG crack branching is seen across the crack front providing a large number of crack tips for potential analysis. As expected based on the base microstructure and the SEM results, a much higher density of $\mathrm{M}_{23} \mathrm{C}_{6}$ was present along grain boundaries and IG crack walls in the ANL material versus the GEG material. However, many leading SCC cracks exhibited large sections without carbides in the ANL specimen. Many of the same crack, crack wall and crack-tip characteristics have been observed as in the 30\%CR CRDM CT022 specimen. In general, MO-structure crystallites are seen throughout the cracks reaching the tip regions. Penetrative oxidation is again found along crack walls with $\mathrm{Cr}_{2} \mathrm{O}_{3}$ and $\mathrm{MO}$-structure oxide in tunnels. Tips themselves remain difficult to image clearly partially due to the complex and extensive deformation structure.

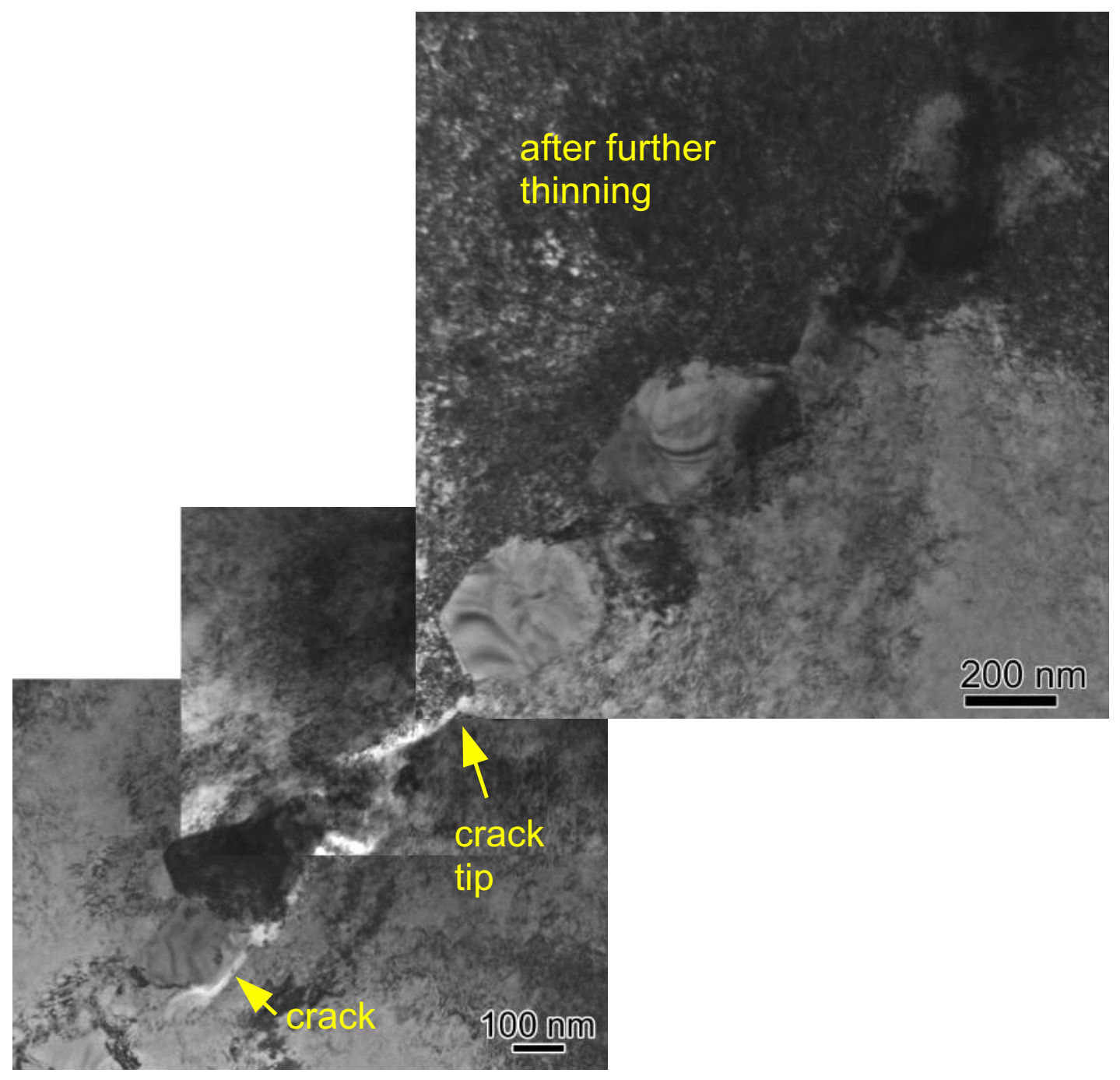

Figure 6.37 Crack-tip area in the 30\%CR CRDM alloy 690TT specimen CT022. Photo at upper right was taken after thinning was continued. Note very high dislocation density in region. No porosity is observed along grain boundary ahead of crack tip. 


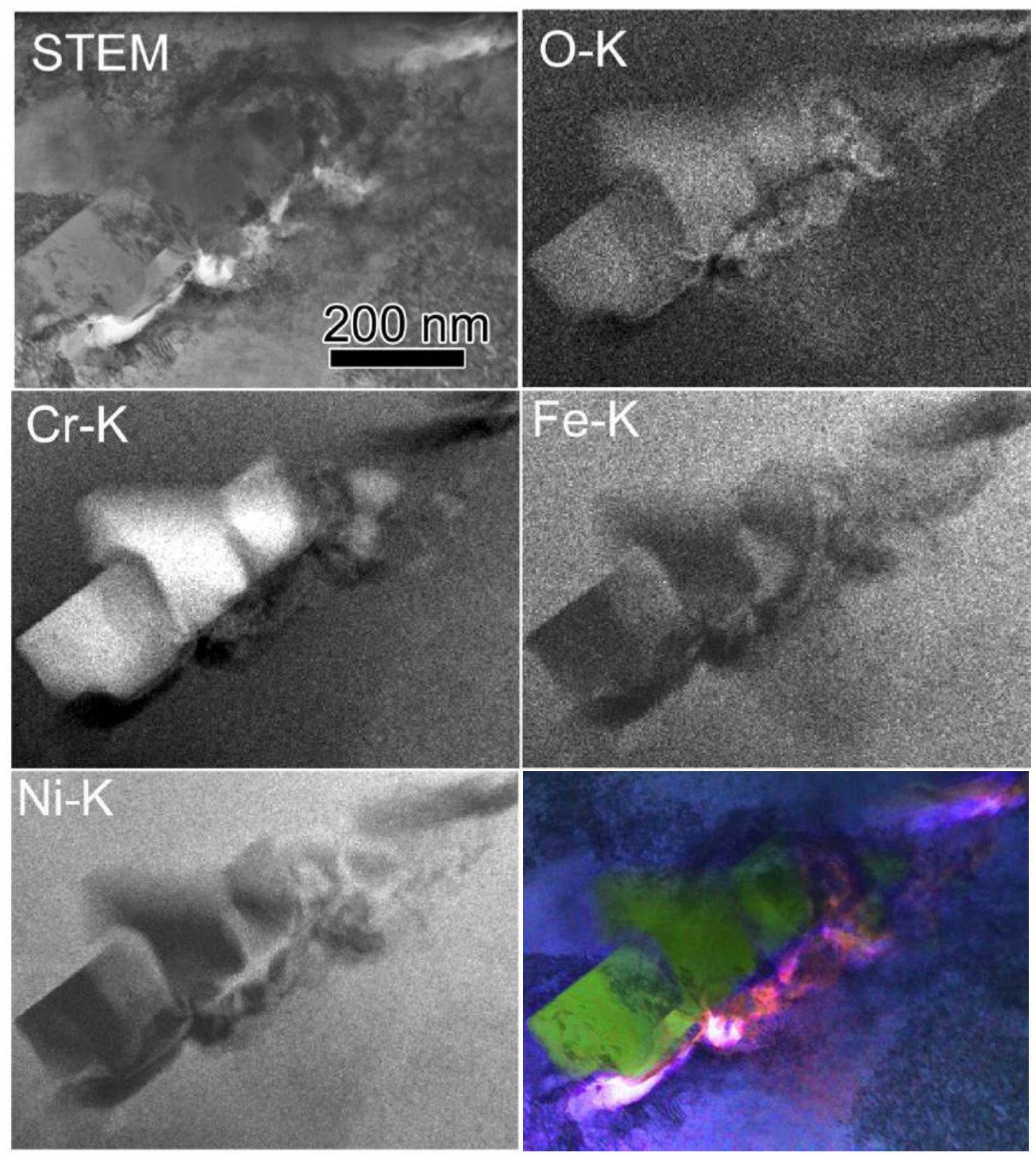

Figure 6.38 STEM/EDS maps of CT022 specimen crack tip region shown in Figure 6.36. Color composite of $\mathrm{O}$ (red), $\mathrm{Cr}$ (green) and $\mathrm{Ni}$ (blue) maps shows blocky $\mathrm{Cr}$ carbide particles (green), and Cr-rich oxide (pink-orange). White is open area of crack. Also note Ni-rich regions (dark blue) between carbide particles. 


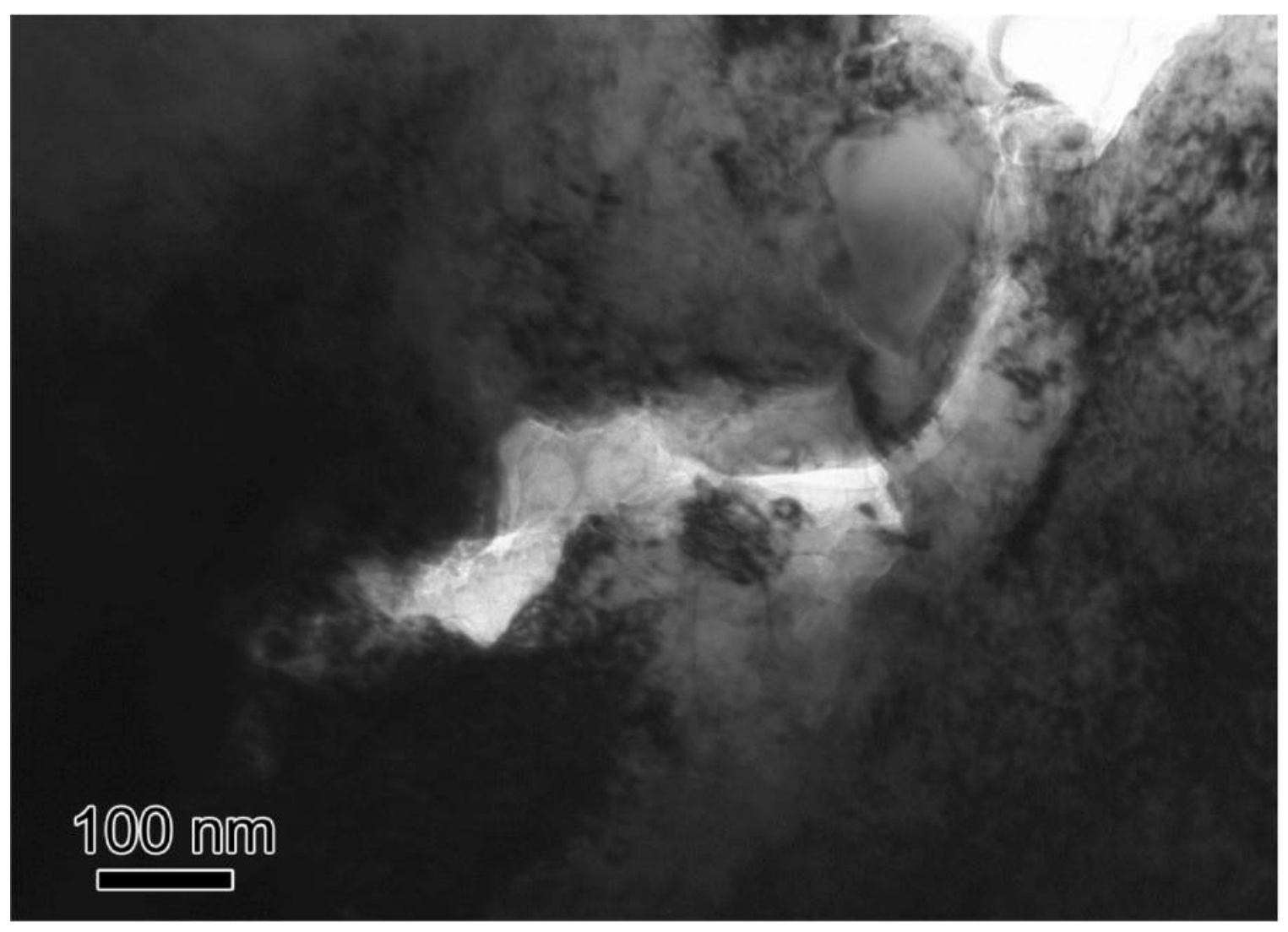

Figure 6.39 TEM brightfield image of an additional crack tip in 30\%CR alloy 690 CRDM specimen CT022.

An example of a crack-tip region is presented for the $26 \%$ CR ANL alloy 690 CT036 specimen in Figure 6.40. SEM is used to document the thin-foil surface appearance during the ion-milling preparation. TEM reveals that the crack is filled with epoxy to the SCC tip. Small, polycrystalline $\mathrm{NiO}-$ structure oxide particles are dispersed within the crack and along some wall sections. A continuous oxide layer is not observed, however penetrative oxide tunnels are again found into the alloy 690 matrix. Extremely high dislocation densities are present throughout the cold-rolled material and particularly surrounding the crack tips. Iterative ion milling is being used to obtain electron transparent regions at, and immediately ahead of, the SCC tips. Initial observations have been limited, but no evidence for grain boundary oxidation beyond the open tip has been found. NiO-structure oxide particles are detected in the tight, open crack tips.

During this iterative ion polishing, a small secondary crack well behind the SCC crack front was available for effective TEM characterization. The SEM image of this corrosion product filled crack before final ion milling and subsequent TEM EDS compositional mapping is presented in Figure 6.41. Deep wall oxidation (enriched in $\mathrm{Cr}$ ) into the alloy 690 matrix can be seen adjacent to $\mathrm{M}_{23} \mathrm{C}_{6}$ precipitates along with the formation of large $\mathrm{MO}$-structure particles in the crack. 


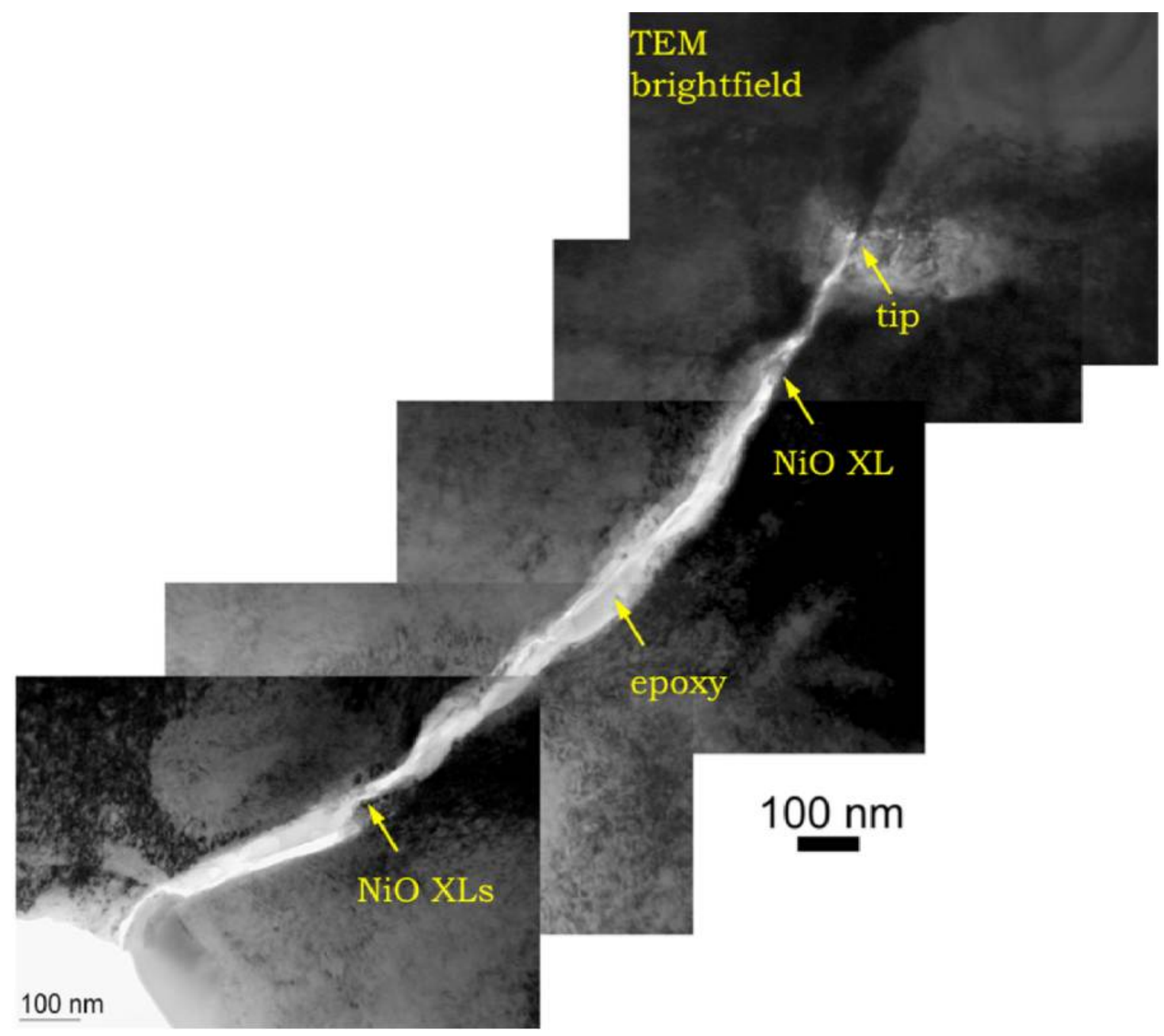

Figure 6.40 TEM image of a crack tip in the ANL $26 \%$ CR alloy 690 specimen CT036.

Figure 6.42 presents an IG crack and tip in the GEG CT037 specimen. This crack was located near the leading crack front, but was not connected to the main SCC crack in the cross-section. Oxide particles are seen in the crack itself as well as penetrative oxidation at the crack walls. The oxide darkfield images in Figure 6.43 better illustrate this corrosion structure with $\mathrm{Cr}_{2} \mathrm{O}_{3}$ in the filament-like penetrations off the crack walls. At least 6 variants must be imaged to detect the full distribution of $\mathrm{Cr}_{2} \mathrm{O}_{3}$ nanocrystals. It is interesting that this significant depth of wall internal oxidation occurs off a crack near the leading crack front. The GEG 20\%CR alloy 690 specimen CT037 exhibited a moderate-to-high growth rate $\left(>10^{-8} \mathrm{~mm} / \mathrm{s}\right)$ during the final constant $\mathrm{K}$ loading suggesting that the oxidation depth is produced rapidly (within $\sim 100 \mathrm{~h}$ ) after exposure to the crack environment. 


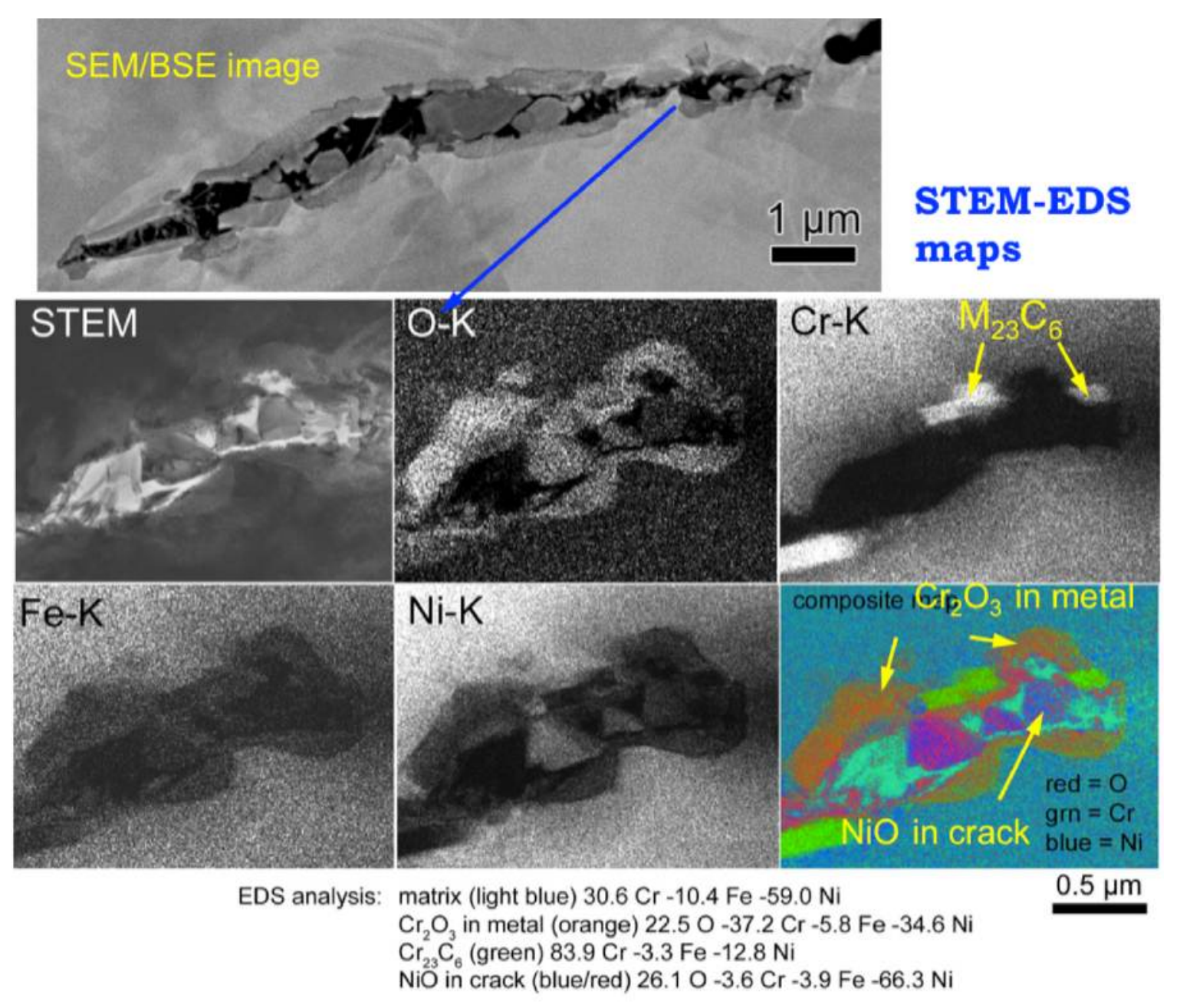

Figure 6.41 SEM and STEM images from a secondary crack region in the CT036 specimen (ANL 26\%CR alloy 690). This region is behind the SCC crack front and EDS composition maps are shown illustrating the corrosion microstructure that has developed. 

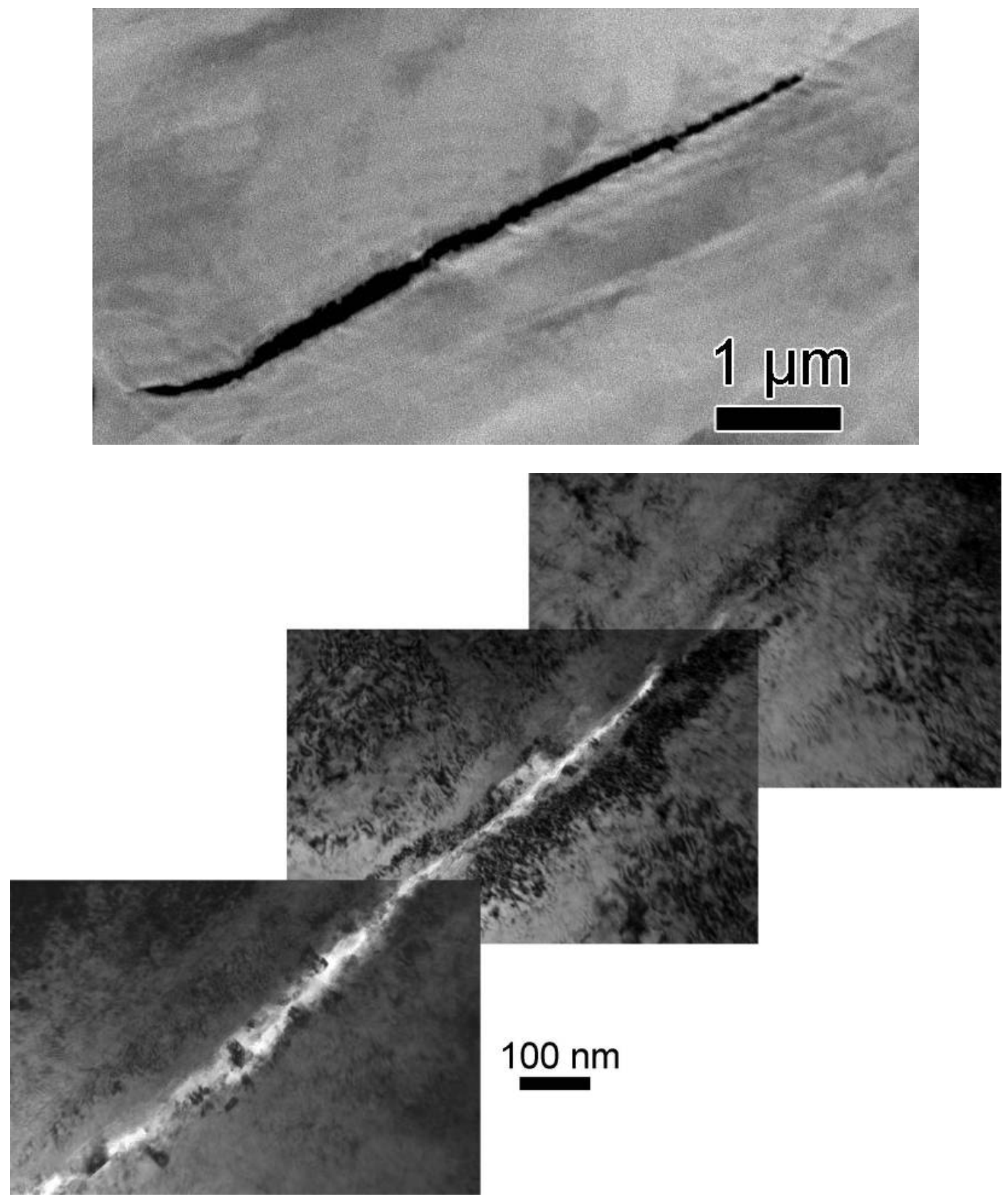

Figure 6.42 SEM (above) and TEM (below) images of a crack tip in the GEG $20 \%$ CR alloy 690 specimen CT037. 


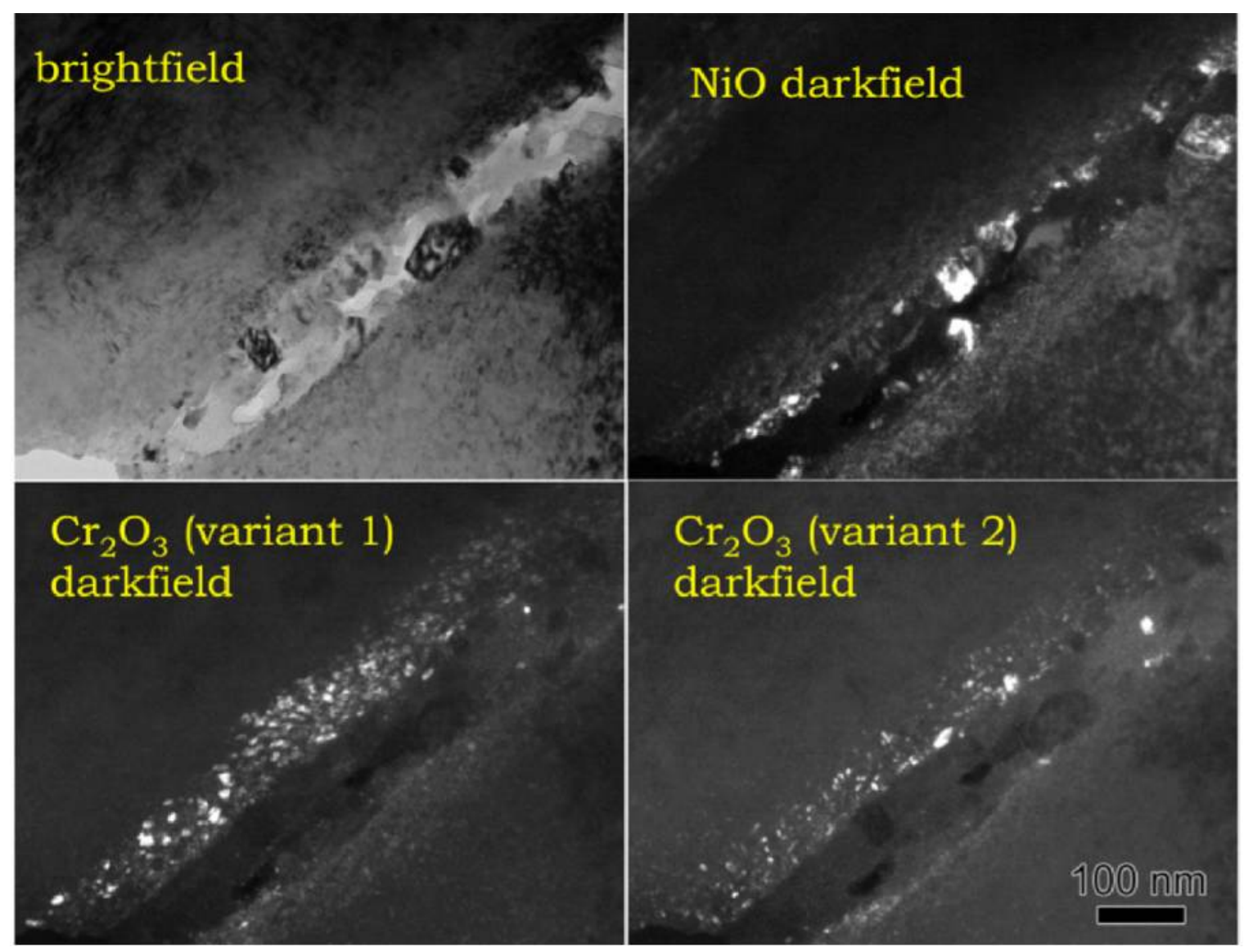

Figure 6.43 TEM brightfield and oxide darkfield images indicating wall oxidation in the crack-tip region from Figure 6.42 .

The first high-resolution examinations of IGSCC crack tips in alloy 690 have shown unexpected crack wall oxidation structures. Even though this is a high $\mathrm{Cr}$ alloy known to form a protective Cr-rich film on surfaces, a continuous film is not found on the crack walls approaching the tips. A two-phase structure of nanometer-scale penetrative oxide tunnels and the metallic alloy is detected to depths of $\sim 100 \mathrm{~nm}$ from the wall. This structure has been imaged in detail by TEM on the alloy 690 CRDM material and confirmed by high-resolution SEM techniques on the ANL and GEG plate materials. TEM observations at, and ahead of, cracks have not revealed such penetrative oxidation leading crack advance, however the high density of grain boundary carbides in the CRDM heat has made measurements difficult.

To better investigate this wall penetrative oxidation, additional examinations are being performed using high-resolution SEM techniques of crack-wall structures in various alloy 690 CRDM and plate samples along with an alloy 52M SCC test sample. All have shown evidence of this penetrative oxidation off the crack walls as documented for the CR samples in the previous section. Selected new TEM and atom-probe tomography (APT) characterizations are being made to directly compare, and better elucidate, the penetrative oxidation. 


\subsection{Insights into SCC Mechanisms from Crack Tip Characterizations}

The crack-tip observations in the previous section are the first ever performed on alloy 690 materials tested in a PWR primary water environment. Comparisons will be made in this section to prior high-resolution ATEM examinations ${ }^{18-34}$ that were performed on SCC crack tips in Niand Fe-base stainless alloys from BWR or PWR service or laboratory tested in simulated LWR environments. These characterizations have enabled direct assessments of IG cracking processes at the nanoscale. Overall, previous results have shown two distinctly different SCC crack wall and tip structures suggesting different SCC propagation mechanisms. The first example has been commonly referred to simply as IGSCC by the LWR community and starts from the extensive problems experienced for Fe-base stainless steels in BWRs. The second has often been referred to as primary water SCC specifically referring to problems with Ni-base stainless alloys (such as alloy 600 and 182) in PWRs. A very brief summary of the crack-tip results for these two LWR SCC examples are given in the following paragraphs, before comparing them to the preliminary observations on the alloy 690 materials.

Austenitic stainless steels (Type 304 or $316 \mathrm{SS}$ ) that have been stress-corrosion cracked in BWR oxidizing, BWR hydrogenated or PWR primary water all show nearly identical features. Typical examples of this type of IGSCC tip are presented in Figures 6.44 and 6.45. It is important to note that similar SCC structures are also seen for $\mathrm{Ni}-16 \mathrm{Cr}$ stainless alloys (alloy 600 and 182) tested in BWR oxidizing water. While some crack-tip aspects can be more complex among these various alloys and environmental conditions (particularly for grain boundary precipitation and $\mathrm{Cr}$ depletion in oxidizing water), the common features of an open crack, continuous wall oxide and extensive deformation at the tip are present in all cases.

SCC cracks in the cold-worked 316SS example shown in Figure 6.44 exhibited localized deformation and shear bands. Extensive strain contrast and deformation structure was present immediately ahead of the tip with shear bands intersecting the crack walls and the leading grain boundary. As noted, IGSCC tips have been evaluated in many BWR service and laboratory stainless steel samples with cracking along random, high-energy grain boundaries in highly strained metal. Both open and oxide-filled cracks contained $\mathrm{Cr}$-rich spinel films along the crack walls and Fe-rich spinel in the crack centers. Examples of both oxide-filled and open crack tips from a 316LSS core shroud are shown in Figure 6.45, with the cracks and leading grain boundaries viewed edge-on. In both cases, the oxide films tapered to only a few $\mathrm{nm}$ at the tips. The crack shown in Figure 6.45(a) was open and filled with epoxy between oxide layers all the way to the tip. The dislocation structure of the metal is not visible in this imaging condition, although slip bands can be seen intersecting the crack near the tip. The tip shown in Figure 6.45(b) contained three distinct oxide layers, with the central Fe-rich spinel layer having a different crystallographic orientation than either of the adjacent Cr-rich layers. This region also represents one of the deeper crack extensions in the shroud cross-section. STEM/EDS x-ray maps in Figure 6.45(c) show several distinctive crack-tip characteristics including a narrow zone of Ni-rich metal along the grain boundary just ahead of the last oxide. Similar Ni enrichments leading tips have been observed in most of the stainless steel service samples interrogated. Comparing the $\mathrm{Cr}, \mathrm{Fe}, \mathrm{Ni}$ and $\mathrm{O}$ maps suggests that $\mathrm{Fe} / \mathrm{Ni}$ losses cause the $\mathrm{Cr}$ enrichment of the oxide next to the metal during the oxide formation. The Mo-L x-ray map also shows the nonequilibrium Mo segregation characteristic of bulk grain boundaries in mill-annealed 316SS. 


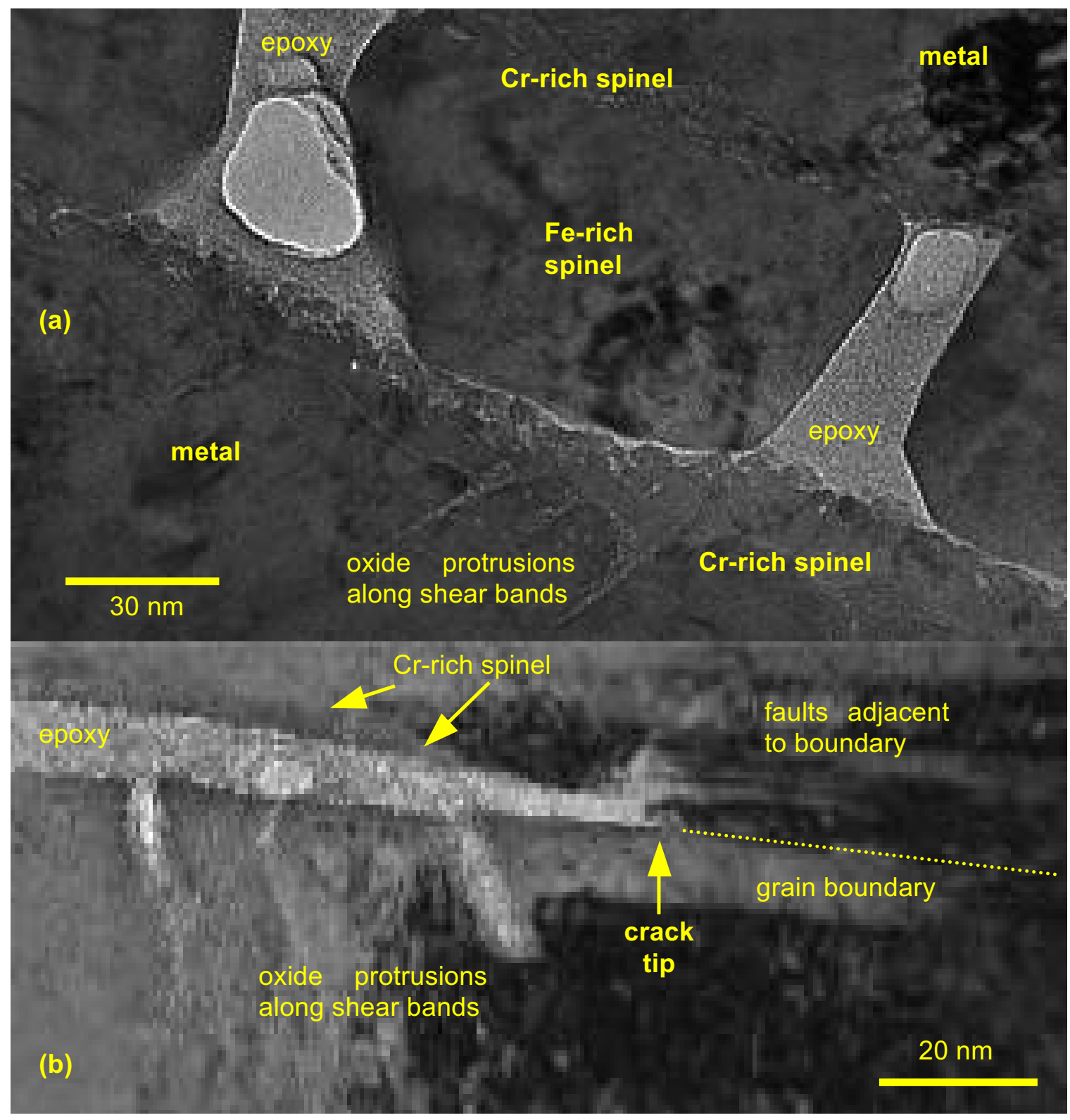

Figure 6.44 Brightfield TEM images in the CW316LSS crack-growth sample tested in BWR oxidizing water [Ref. 37]: (a) oxide- and epoxy-filled crack many micrometers behind tip and (b) highly deformed crack tip with narrow oriented spinel present on crack walls to the tip.

In summary, austenitic stainless steels (Type 304 or 316SS) show open cracks with nonporous, oriented oxide films on the crack walls to the tips and extensive deformation structures associated with the propagating IG crack. The IGSCC characteristics are generally consistent with a slip-oxidation SCC mechanism. A protective, Cr-rich oxide (spinel or MO structure) film forms on the crack walls and propagation continues by the thinning or rupture of the oxide at the tip region. While there is no evidence that localized slip is required for the disruption of the oxide at the tip, clearly extensive plasticity is occurring at the tip during SCC advance. 

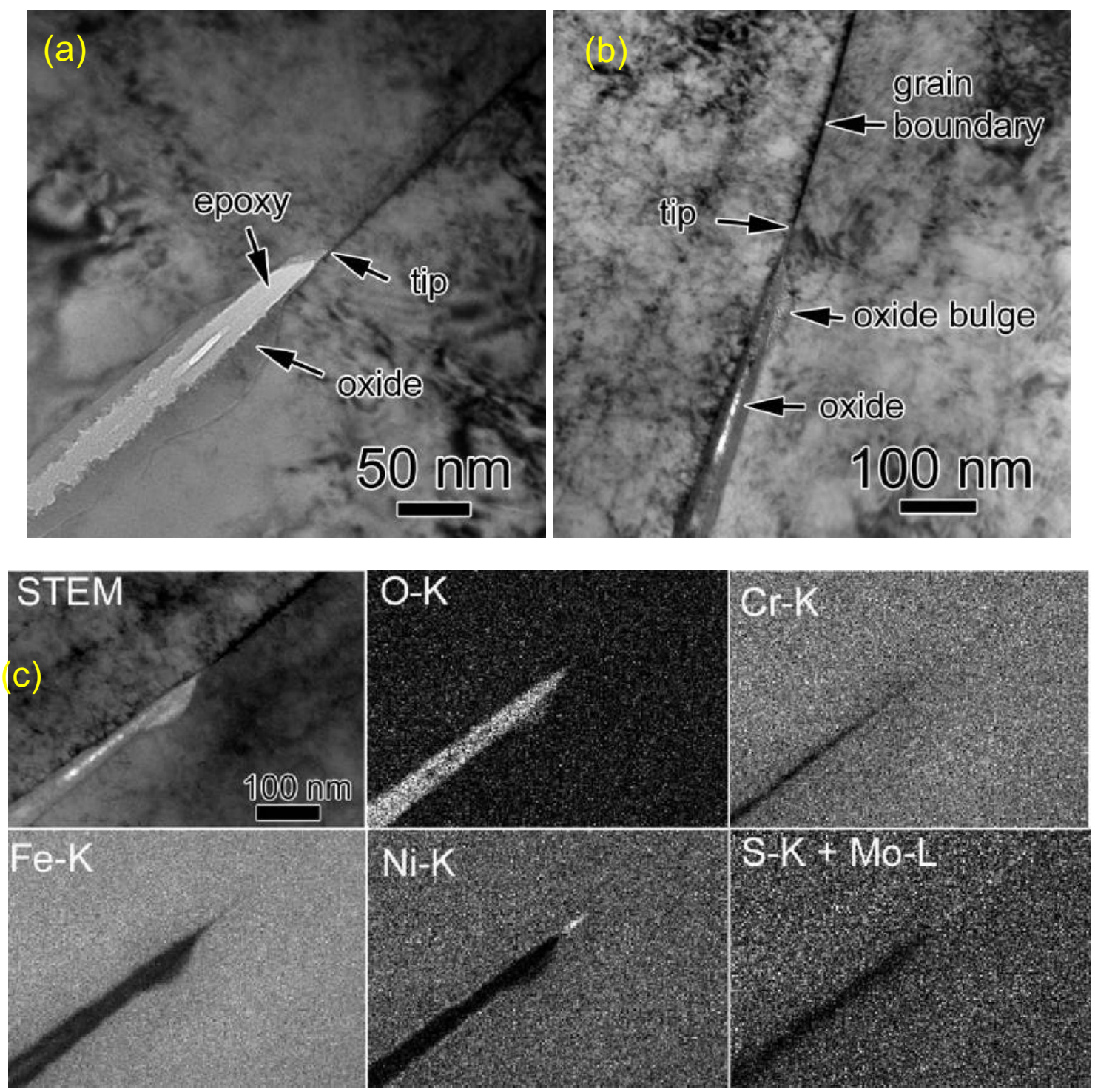

Figure 6.45 Open (a) and oxide-filled (b) crack tips in a BWR core shroud sample [Ref. 25]. EDS x-ray maps of oxide-filled tip (c) show Fe/Ni loss in oxide, $\mathrm{Ni}$ concentrated ahead of tip, and Mo segregation along the leading grain boundary.

IGSCC crack tips in mill-annealed alloy 600 have also been well characterized after exposure to PWR primary water both for laboratory tests and samples removed from service. One of the characteristic features in alloy 600 is the presence of narrow, deeply oxidized zones along grain boundaries intersected by the cracks. Nearly every intersected grain boundary in the wake of a crack was similarly attacked. An overview of one of these attacked grain boundaries is illustrated in Figure 6.46(a), with higher magnification views of the tip and mid-zone areas shown as insets. The deeply penetrative nature of the degradation is indicated by the narrow widths of the oxidized zones relative to the lengths. Actual widths determined by tilting the structures edge-on were 5-20 nm and showed little change along the entire penetrated lengths. Penetration lengths off the open SCC cracks ranged from about $100 \mathrm{~nm}$ near the deepest crack tip in the cross-section to many micrometers at distances of several grain diameters behind the 
crack tip. Narrow attacked zones contained a porous, nanocrystalline, MO-structure oxide with a $\mathrm{Ni}-\mathrm{Cr}-\mathrm{Fe}$ composition ratio similar to the metal matrix. The penetrative attack narrowed from the normal $5-20 \mathrm{~nm}$ widths to less than $3 \mathrm{~nm}$ before ending in the grain boundary plane. Fresnel imaging revealed a complex network of nm-size voids near and ahead of the tips. The underfocus image in Figure 4.46(b) shows closely spaced pores and tunnel-like features along an inclined grain boundary at the leading edge of attack. Isolated pores in the metal also appeared a short distance ahead of the last apparent oxide. Although micrographs of the penetration tips revealed fine details of the oxidation, correctly interpreting the TEM images required stereoscopic viewing to distinguish between surface and internal features. Other characteristic aspects of the IG attack were the low dislocation structure in the adjacent matrix or at the leading edge of attack, and $\mathrm{Cr}$-rich oxide at the tip led by a Ni-rich, Cr/Fe-depleted grain boundary in the metal.

Extremely narrow, penetrative IG attack was extensive in all cracked alloy 600/182 samples removed from PWR service. Detailed analysis of these corrosion-induced structures revealed them to be primarily fine-grained, porous, MO- and/or spinel-structure oxides. Examinations focused on the deepest cracks in each cross-section and found that all ended in penetrative oxidation as illustrated in Figure 6.47(a). The width of these regions was $\sim 10 \mathrm{~nm}$ and continued for many $\mathrm{mm}$ before narrowing and ending within the grain boundary plane. High-resolution EDS maps from the same region in Figure 6.47(b-d) demonstrate that the leading oxide is highly $\mathrm{Cr}$ rich and the metal is Ni rich ahead of the tip. Another key observation was the general lack of dislocation structure associated with the IG attack either along its length or at the leading edge of degradation. Occasional IG $\mathrm{Cr}_{7} \mathrm{C}_{3}$ carbides in these mill-annealed materials were attacked at their edges and oxidized to thin non-porous $\mathrm{Cr}_{2} \mathrm{O}_{3}$ film.
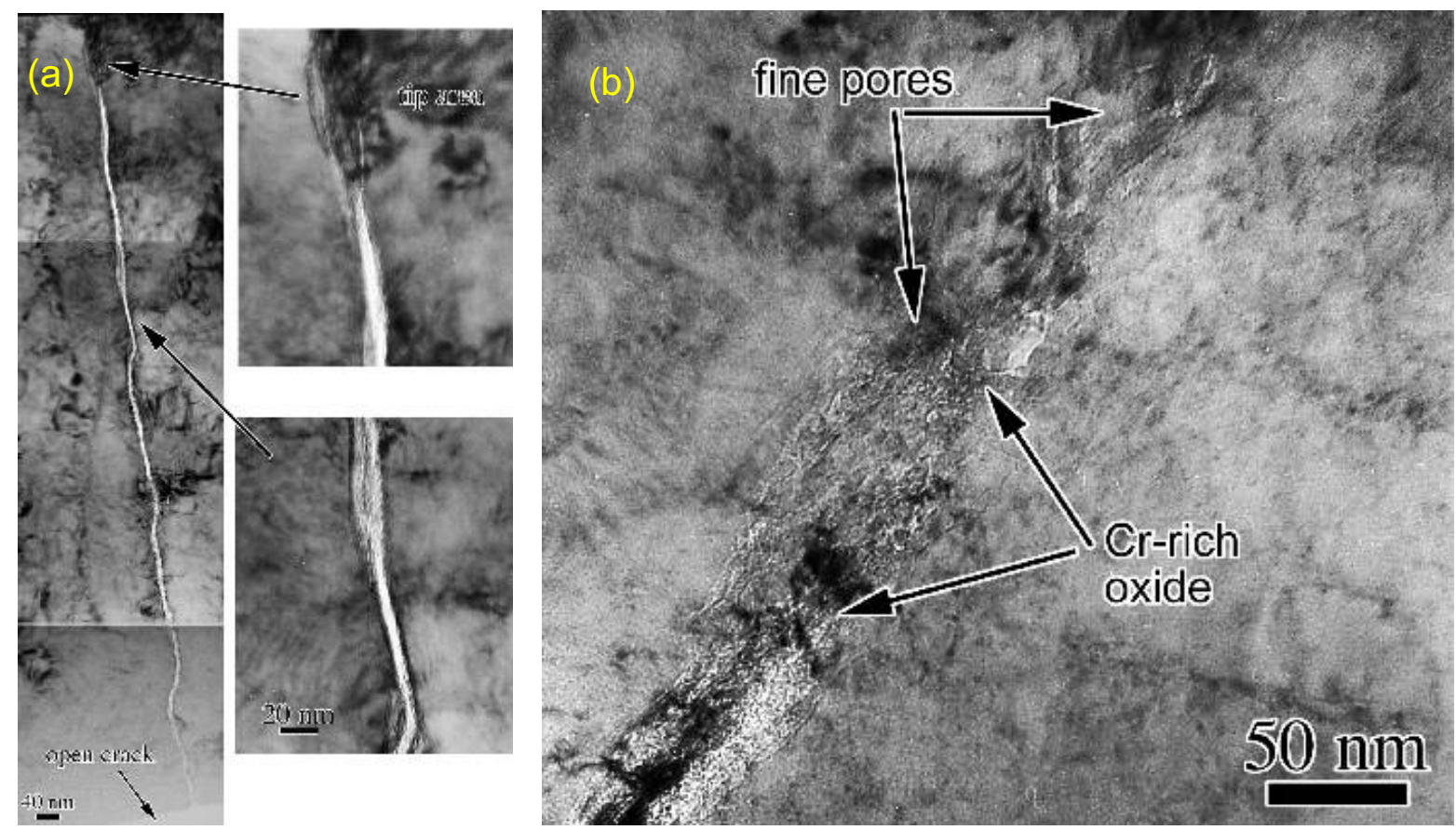

Figure 6.46 Alloy 600 IG attack in PWR primary water [Ref. 23]: (a) typical extended IG attack region filled with porous oxide and (b) leading edge of oxide penetration along grain boundary. 

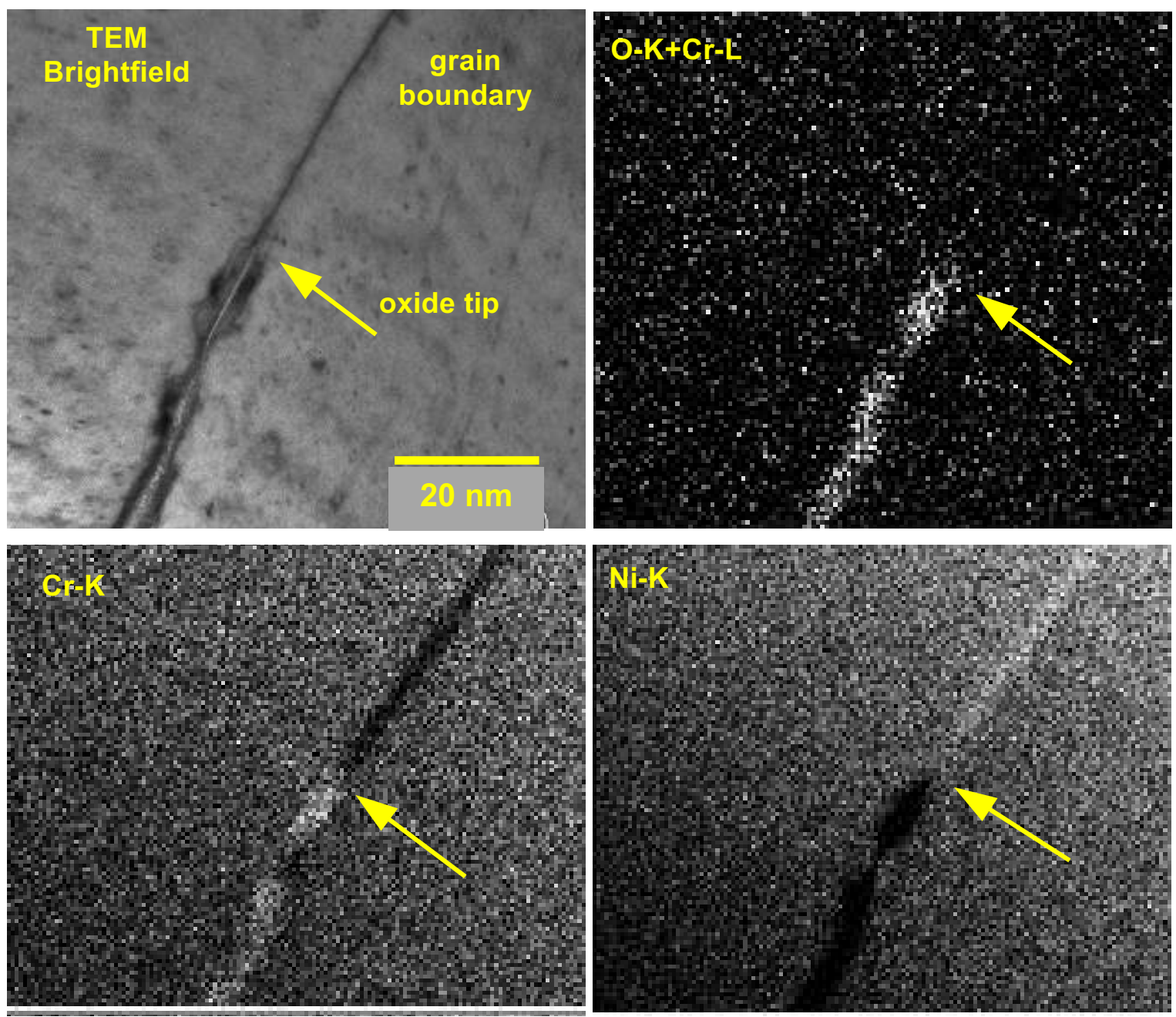

Figure 6.47 EDS maps showing the leading edge of IG attack ahead in alloy 600 [Ref. 29]. Chromium is enriched in the tip oxide and $\mathrm{Ni}$ is enriched along the boundary ahead of the tip.

Insights into the mechanism for environment-induced degradation of alloy 600 in primary PWR water can be found at the leading edge of attack along penetrated grain boundaries. Near the leading edge, the oxidized region narrowed and ended along the boundary plane. Pores and tunnel-like features were present in the leading IG oxide (best identified in the U-bend sample), and the grain boundary is altered in the metal ahead of the oxide layer. Cr-rich oxide (some $\mathrm{Cr}_{2} \mathrm{O}_{3}$ ) was found at the advancing IG attack tips, while other oxide structures (MO or spinel) were often the predominant phase just behind the tip and along most of the degraded zone. Formation of this Cr-rich oxide preferentially at the IG reaction front and the lack of evidence for significant plastic deformation during propagation represent key aspects of the degradation process. As described in some detail in previous papers [Refs. 23,39], these observations are inconsistent with many mechanisms proposed to explain primary water SCC and an active-path, stress-assisted oxidation mechanism along grain boundaries was proposed to be the most consistent with the attack morphology. Vacancy creation from selective dissolution or oxidation at the tip may promote enhanced diffusivities for the metallic alloying elements and for oxygen in the grain boundary leading to void formation. The full range of laboratory and service samples 
investigated support these same conclusions with observations of preferential Cr-rich oxide at the degradation reaction front and Ni-rich, Cr-depleted metal at the boundary immediately ahead of the tips. Scott and co-workers [Refs. 40,41] have used these observations to support the internal oxidation mechanism for primary water SCC in alloy 600.

It is very clear from all examinations that alloy 600 cracks produced in hydrogenated water have fundamentally different characteristics to the propagating tips than for stainless steels cracks produced in hydrogenated or oxidizing water. SCC cracks in stainless steels are open with a thin, epitaxial, non-porous protective oxide on walls to the tip. Crack openings taper to highly deformed tips and there is no evidence for leading boundary attack. For alloy 600 in PWR primary water, SCC cracks end in penetrative IG attack extending for $\sim 100 \mathrm{~nm}$. The corroded boundaries are filled with a porous, nanocrystalline, non-protective oxide and significant plastic deformation is not required for degradation. The Fe-base stainless steels cases suggest a slip oxidation process driving crack advance, while the Ni-base alloy 600 in hydrogenated water is more consistent with a stress-assisted oxidation process.

While the current SCC crack-tip observations on the CR alloy 690 materials are very limited, important differences can be seen particularly versus alloy 600 in PWR primary water. No evidence for penetrative IG oxidation in the alloy 690 samples has been found, while it is the defining crack-tip characteristic for alloy 600. Grain boundaries do not appear to be an activepath for oxidation in the $30 \% \mathrm{Cr}$ alloy 690 as they are in the $16 \% \mathrm{Cr}$ alloy 600 when exposed to PWR primary water environments. One interesting aspect is that $\mathrm{Cr}$ is depleted at grain boundaries in the alloy 690TT CRDM material down to levels approaching $20 \% \mathrm{Cr}$ and still these grain boundaries off the crack walls or at the crack tips are not preferentially oxidized. Surprisingly, penetrative oxidation is observed into the matrix grains off the crack walls. Results indicate that the primary mechanism promoting IGSCC in PWR primary water for alloy 690 is not an active-path, stress-assisted oxidation process along grain boundaries as proposed for alloy 600. However, the rapid penetrative oxidation into the matrix off crack walls is intriguing and suggests that localized oxidation (perhaps following a pre-existing dislocation structure) could play a role in SCC propagation. The alloy 690 SCC cracks are open to their tips similar to stainless steels in both oxygenated and hydrogenated water, however a thin, protective, Cr-rich film is not found on the crack walls to the tips for alloy 690 (as for stainless steels). Therefore, the preliminary observations do not strongly support a slip oxidation mechanism for SCC propagation as was the case for stainless steels. Extensive crack-tip plasticity does appear to be required for SCC in the alloy 690 , but simple evaluations are impossible due to the extremely high deformation of the grain boundaries during unidirectional cold rolling. Along with lack of support for these mechanisms, high-resolution measurements at and ahead of crack tips do not show the formation/growth of creep cavities as a precursor to IG crack advance. Hydrogen has also been proposed [Refs. 42,43] to play a key role in primary water SCC by promoting embrittlement or enhancing local plasticity, although little convincing evidence has been produced. The current crack-tip examinations do not offer any direct insights into possible influence of hydrogen for alloy 690. Clearly, additional experimentation and characterization is required on specimens designed to isolate critical variables controlling SCC in these alloy 690 materials. 


\section{Conclusions}

Stress-corrosion, crack-growth rates have been determined for 12 alloy 690 specimens, 11 alloy $152 / 52 / 52 \mathrm{M}$ weld metal specimens, 4 alloy 52M/182 overlay specimens and 2 alloy 52M/82 inlay specimens in simulated PWR primary water environments. The alloy 690 test materials included three different heats of extruded control-rod-drive mechanism (CRDM) tubing with variations in the initial material thermal treatment condition and degree of cold work for one heat. Two cold-rolled (CR) alloy 690 plate heats were also obtained and evaluated enabling comparisons to the CR CRDM materials. Weld metal, overlay and inlay specimens were machined from industry mock ups to provide plant-representative materials for testing. Specimens have been tested for one alloy 152 weld, two alloy 52 welds and three alloy $52 \mathrm{M}$ welds. The overlay and inlay specimens were prepared to propagate stress-corrosion cracks from the alloy 182 or 82 material into the more resistant alloy $52 \mathrm{M}$.

Important results have been obtained for alloy 690 and its weld metals establishing SCC response as a function of material and environmental parameters. As expected, the as-received and plant representative, alloy 690TT CRDM tubing heats were resistant to SCC. Steady propagation and IG cracking was observed under constant stress intensity conditions, but propagation rates were very low $\left(\leq 1 \times 10^{-9} \mathrm{~mm} / \mathrm{s}\right)$ and only isolated regions of IGSCC were produced after long tests in PWR primary water. High levels of cold work during onedimensional rolling were found to promote IGSCC and much higher ( 100X) growth rates when specimens were tested so propagation occurs in the rolling plane. These results demonstrate that extruded alloy 690 tubing with an excellent microstructure can become susceptible to IGSCC after unidirectional cold rolling similar to behavior documented for alloy 690 plate materials. It is critical to note that this level and orientation of cold work is not anticipated in lightwater-reactor service components, however these results clearly demonstrate that the high-Cr alloy 690 materials are not immune to SCC and reasons for enhanced susceptibility must be understood. To that end, the alloy 690 microstructure has been modified through heat treatment and initial data indicate that grain boundary carbides promote more severe IG damage during cold rolling and higher IGSCC growth rates. Detailed examinations of cold-rolling damage and SCC cracks have been performed using high-resolution SEM and TEM techniques. Cold rolling alloy 690 to high reductions produced extremely high dislocation densities at grain boundaries along with IG nanometer-scale voids and cracked precipitates particularly when a high density of grain boundary carbides is present. The influence of this type of permanent damage (voids and cracked precipitates) on IGSCC is unclear, since characterizations of cracks and crack tips do not show the cracked carbides or voids promoting environment-assisted crack advance. On the contrary, cracked carbides have been shown to blunt IGSCC propagation when encountered. Therefore, the local strains created at and near grain boundaries by cold working may be more important than the permanent damage. While many characterizations have been performed on the alloy 690 materials for the first time and important insights obtained, more work is needed to clarify microstructure and cold work effects on SCC susceptibility and identify the cracking mechanism.

This project has completed some of the first SCC crack-growth tests on alloy 152, 52 and 52M weld metals in PWR primary water and helped establish a basis for their behavior. Similar to the results for the as-received alloy 690 materials, the high-Cr weld metals have consistently shown a high resistance to SCC. Several different weld mockup types have been tested including Ugroove, V-groove and narrow gap welds. Some weld-to-weld CGR differences have been observed, but measured rates have been below $\sim 5 \times 10^{-9} \mathrm{~mm} / \mathrm{s}$ with most less than $2 \times 10^{-9} \mathrm{~mm} / \mathrm{s}$ 
for test temperatures from 325 to $360^{\circ} \mathrm{C}$. Examination of the crack fronts revealed varying degrees of IGSCC engagement with some having essentially no IG features and others showing considerable IG cracking. However, only a few weld metals have exhibited significant propagation along grain boundaries during long-term testing suggesting a good resistance to IGSCC. In an effort to improve IG engagement, limited testing was conducted at $50^{\circ} \mathrm{C}$ in PWR primary water. Hydrogen-induced IG crack growth and higher growth rates were promoted during cycling steps for an alloy 152 weld, but much smaller effects were seen for alloy 52 welds. The environmental cracking is believed to occur during dynamic straining and much more experimentation is needed to assess this low-temperature behavior. The increased IG engagement produced at low temperature did not promote higher SCC growth rates during subsequent constant $\mathrm{K}$ loading in high-temperature PWR primary water. The influence of preexisting weld cracks on SCC response is also being evaluated in alloy 52M with preliminary results showing no enhancement of crack growth. However, post-test examination revealed that the number of weld-induced cracks was very low in the SCC crack-growth plane limiting intersections between preexisting weld cracks and the SCC crack front. The final SCC tests on weld metals have been on industry mockups for an alloy $52 \mathrm{M} / 182$ overlay and an alloy $52 \mathrm{M} / 82$ inlay. For both mockups, initial SCC propagation rates in the lower-Cr layer (alloy 182 or 82) were less than expected with only partial IG engagement. The SCC growth rates decreased significantly as the alloy 52M interface was reached and the IGSCC propagating along selected boundaries in the lower $\mathrm{Cr}$ material intersected the higher $\mathrm{Cr}$ weld metal. A simple assessment of $\mathrm{Cr}$ concentration on propagation through the interface region was not possible without a straight crack front. Additional data was generated for alloy 52M SCC behavior from the overlay and inlay welds and the highest weld metal constant $\mathrm{K}$ propagation rates were measured within the alloy $52 \mathrm{M}$ overlay material. The most recent weld metal tests have been conducted on a $\mathrm{V}$ groove weld and two narrow gap mockup welds using the same alloy 52M weld wire. Somewhat surprisingly, the alloy $52 \mathrm{M} \mathrm{V-groove} \mathrm{weld} \mathrm{showed} \mathrm{a} \mathrm{consistently} \mathrm{higher} \mathrm{rate} \mathrm{than} \mathrm{the} \mathrm{narrow} \mathrm{gap}$ welds. This was even the case for the narrow gap weld produced with off-normal conditions to create a moderate distribution of weld defects. Post-test characterization of these final alloy 52M samples is continuing as part of follow-on research to confirm SCC growth rates and determine whether preexisting weld cracks enhance IGSCC. 


\section{References}

1. K. Smith, A. Klein, P. Saint-Paul and J. Blanchet, "Inconel 690 A Material with Improved Corrosion Resistance for PWR Steam Generator Tubes," Proc. $2^{\text {nd }}$ Int. Symp. Environmental Degradation of Materials in Nuclear Power Systems - Water Reactors, Monterey, CA, American Nuclear Society, 1986, p. 319.

2. K. Norring, J. Engstrom and H. Tornblom, "Intergranular Stress Corrosion Cracking of Steam Generator Tubing: 25,000 Hours Testing of Alloy 600 and Alloy 690," Proc. $4^{\text {th }}$ Int. Symp. Environmental Degradation of Materials in Nuclear Power Systems - Water Reactors, Traverse City, MI, National Association of Corrosion Engineers, 1990, p. 12-1.

3. F. Vaillant, J. Mithieux, O. De Bouvier, D, Vanchon, G. Zacharie, Y. Brechet and F. Louchet, "Influence of Chromium and Microstructure on Creep and PWSCC of Nickel-Base Alloys," Proc. $9^{\text {th }}$ Int. Conf. Environmental Degradation of Materials in Nuclear Power Systems - Water Reactors, Newport Beach, CA, NACE International, 1999, p. 251.

4. J.M. Boursier, F. Vaillant, P. Saulay, Y. Brechet and G. Zacharie, "Effects of the Strain Rate on the Stress Corrosion Cracking in High-Temperature Primary Water: Comparison Between Alloys 690 and 600," Proc. $12^{\text {th }}$ Int. Conf. Environmental Degradation of Materials in Nuclear Power Systems - Water Reactors, Stevenson, WA, American Nuclear Society, 2003, p. 199.

5. D.J. Paraventi and W.C. Moshier, "Alloy 690 SCC Growth Rate Testing," Proc. Workshop on Cold Work in Iron- and Nickel-Base Alloys, Toronto, Canada, EPRI, June 2007.

6. D.S. Morton, S.A. Attanasio, and G.A. Young, "Primary Water SCC Understanding and Characterization Through Fundamental Testing in the Vicinity of the Nickel/Nickel Oxide Phase Transition," Proc. 10 $10^{\text {th }}$ Int. Conf. Environmental Degradation of Materials in Nuclear Power Systems - Water Reactors, American Nuclear Society, 2001, Paper 3.

7. P.L. Andresen, L.M. Young, P.W. Emigh and R.M. Horn, "Stress Corrosion Crack Growth Rate Behavior of Ni Alloys 182 and 600 in High Temperature Water", Corrosion 2002, NACE International, 2002, Paper 02510.

8. S.M. Bruemmer, J.S. Vetrano and M.B. Toloczko, "Microstructure and SCC Crack Growth of Nickel-Base Alloy 182 Weld Metal in Simulated PWR Primary Water," Proc. $13^{\text {th }}$ International Conference Environmental Degradation of Materials in Nuclear Power Systems - Water Reactors, Canadian Nuclear Society, 2007, Paper 140.

9. T.M. Angeliu and G.S. Was, "Behavior of Grain Boundary Chemistry and Precipitates upon Thermal Treatment of Controlled Purity Alloy 690," Metall. Trans. A, 21A (1990) 2097.

10. S.M. Bruemmer, L.A. Charlot, A. Bagchi, and D.G. Atteridge, "Influence of Grain Boundary Carbides and Phosphorus Segregation on the Low-Temperature Intergranular Embrittlement of Type 316 Stainless Steel," Scripta Metall. 20, 1989, p. 1549.

11. R.H. Jones and S.M. Bruemmer, "Environment-Induced Crack Growth Processes in NickelBase Alloys," Environment-Induced Cracking of Metals, NACE International, 1989, p. 287. 
12. P.L. Andresen, "Effect of Noble Metal Coating and Alloying on the Stress Corrosion Crack Growth Rate of Stainless Steel in 288C Water," Proc. $6^{\text {th }}$ Int. Conf. Environmental Degradation of Materials in Nuclear Power Systems - Water Reactors, The Materials, Minerals and Metals Society, 1994, p. 245.

13. S.M. Bruemmer, B.W. Arey and L.A. Charlot, "Grain Boundary Cr Concentration Effects on the IGSCC and IASCC of Austenitic Stainless Steels,' Proc. $6^{\text {th }}$ Int. Conf. Environmental Degradation of Materials in Nuclear Power Systems - Water Reactors, The Materials, Minerals and Metals Society, 1994, p. 277.

14. P.L. Andresen, M.M. Morra, J. Hickling, A. Ahluwalia and J. Wilson, "PWSCC of Alloys 690, 52 and 152," Proc. 13 ${ }^{\text {th }}$ Int. Conf. Environmental Degradation of Materials in Nuclear Power Systems - Water Reactors, Whistler, B. C., Canadian Nuclear Society, 2007.

15. P.L. Andresen, P.W. Emigh, M.M. Morra and J. Hickling, "Effects of PWR Primary Water Chemistry and Dearated Water on SCC," Proc. $12^{\text {th }}$ Int. Conf. Environmental Degradation of Materials in Nuclear Power Systems - Water Reactors, The Materials, Minerals and Metals Society, 2005.

16. B. Alexandreanu, "The Stress Corrosion Cracking Behavior of Alloys 690 and 152 Weld in a PWR Environment," Proc. 14 ${ }^{\text {th }}$ Int. Conf. Environmental Degradation of Materials in Nuclear Power Systems - Water Reactors, Virginia Beach, American Nuclear Society, 2009.

17. P.L. Andresen, M.M. Morra, J. Hickling, K. Ahluwalia and J.A. Wilson, "Effect of Deformation and Orientation on SCC of Alloy 690," Proc. 14 ${ }^{\text {th }}$ Int. Conf Environmental Degradation of Materials in Nuclear Power Systems - Water Reactors, Virginia Beach, VA, American Nuclear Society, 2009.

18. D. Tice, J. Stairmand and S. Medway, "Serco/Rolls-Royce Crack Growth Program on Alloy 690 and Weldments," presentation at the EPRI Expert Panel Meeting on Alloy 690, Tampa, FL, December 2009.

19. P.L. Andresen and M.M. Morra, "SCC of Alloy 690 Base Metal and HAZ in PWR Primary Water," presentation at the NRC Alloy 690 PWSCC Research Meeting, Rockville, MD, July 2010.

20. S.M. Bruemmer and L.E. Thomas, "High-Resolution Analytical Electron Microscopy Characterization of Corrosion and Cracking at Buried Interfaces," J. Surface and Interface Analysis, 31 (2001) p. 571.

21. S.M. Bruemmer and L.E. Thomas, "Insights into Environmental Degradation Mechanisms from High-Resolution Characterization of Crack Tips," Proc. Chemistry and Electrochemistry of Corrosion and Stress Corrosion, The Materials, Minerals and Metals Society, 2001, p. 321.

22. L.E. Thomas and S.M. Bruemmer, "Insights into Environmental Degradation Mechanisms from Analytical Transmission Electron Microscopy of SCC Cracks," Proc. $9^{\text {th }}$ Int. Conf. Environmental Degradation of Materials in Nuclear Power Systems - Water Reactors, The Materials, Minerals and Metals Society, 1999, p. 41.

23. L.E. Thomas and S.M. Bruemmer, "High-Resolution Characterization of Intergranular Attack and Stress Corrosion Cracking of Alloy 600 in High-Temperature Primary Water," Corrosion J., 56-7 (2000) p. 100. 
24. S.M. Bruemmer and L.E. Thomas, "Insights into Stress-Corrosion Cracking Mechanisms from High-Resolution Measurements of Crack-Tip Structures and Compositions," 2nd Int. Conf. Environment-Induced Cracking of Materials, Volume 2, Elsevier, Oxford, 2007, p. 95.

25. L.E. Thomas, D.J. Edwards, K. Asano, S. Ooki and S.M. Bruemmer, "Crack-Tip Characteristics in BWR Service Components," Proc. $13^{\text {th }}$ International Conference Environmental Degradation of Materials in Nuclear Power Systems - Water Reactors, Canadian Nuclear Society, 2007, Paper 143.

26. D.J. Edwards, L.E. Thomas, K. Asano, S. Ooki and S.M. Bruemmer, "Microstructure, Microchemistry and Stress Corrosion Crack Characteristics in a BWR 316LSS Core Shroud Weld," Proc. $13^{\text {th }}$ International Conference Environmental Degradation of Materials in Nuclear Power Systems - Water Reactors, Canadian Nuclear Society, 2007, Paper 139.

27. L.E. Thomas, J.S. Vetrano and S.M. Bruemmer, "Microstructural and Microchemical Characterization of Intergranular Stress Corrosion Cracks in Irradiated Type 304SS Removed from a BWR Top Guide," $11^{\text {th }}$ Int. Conf. Environmental Degradation of Materials in Nuclear Power Systems - Water Reactors, American Nuclear Society, 2003, p. 1049.

28. L.E. Thomas, M.J. Olszta, B.R. Johnson, and S.M. Bruemmer, "Microstructural Characterization of Primary Water Stress-Corrosion Cracks in Alloy 182 Welds from PWR Components and Laboratory Tests," Proc.14th International Conference on Environmental Degradation of Materials in Nuclear Power Systems-Water Reactors, American Nuclear Society, 2009 , p. 409.

29. L.E. Thomas and S.M. Bruemmer, "Observations and Insights into Pb-Assisted Stress Corrosion Cracking of Alloy 600 Steam Generator Tubes," Proc. $12^{\text {th }}$ Int. Conf. Environmental Degradation of Materials in Nuclear Power Systems - Water Reactors, The Materials, Minerals and Metals Society, 2005, p. 1143.

30. L.E. Thomas, B.R. Johnson, J.S. Vetrano and S.M. Bruemmer, "Microstructural and Microchemical Characterization of Primary-Side Cracks in an Alloy 600 Nozzle Head Penetration and its Alloy $182 \mathrm{~J}$-Weld from the Davis-Besse Reactor Vessel," Proc. $12^{\text {th }}$ Int. Conf. Environmental Degradation of Materials in Nuclear Power Systems - Water Reactors, The Materials, Minerals and Metals Society, 2005, p. 567.

31. S.M. Bruemmer and L.E. Thomas, "High-Resolution Analytical Electron Microscopy Characterization of Environment-Assisted Cracks in Alloy 182 Weldments," Invited Paper, Proc. 2005 International PWSCC of Alloy 600, Electric Power Research Institute, 2005.

32. L.E. Thomas, J.S. Vetrano and S.M. Bruemmer, "High-Resolution Analytical Microscopy of Environmental Cracks in Alloy 182 Weldments," $11^{\text {th }}$ Int. Conf. Environmental Degradation of Materials in Nuclear Power Systems, American Nuclear Society, 2003, p. 1212.

33. L.E. Thomas and S.M. Bruemmer, "Analytical Transmission Electron Microscopy Characterization of Stress Corrosion Cracks in an Irradiated Type 316 Stainless Steel Core Component," Fontevraud V Int. Symp. Contribution of Materials Investigation to the Resolution of Problems Encountered in PWRs, French Nuclear Energy Society, 2003, p. 347. 
34. L.E. Thomas, P.M. Scott and S.M. Bruemmer, "Analytical TEM Comparisons of StressCorrosion-Crack Microstructures in Alloy 600 under Steam-Generator Service and Laboratory Test Conditions," Proc. Fontevraud V Int. Symp. Contribution of Materials Investigation to the Resolution of Problems Encountered in PWRs, French Nuclear Energy Society, 2003, p. 1037.

35. L.E. Thomas, V.Y. Gertsman and S.M. Bruemmer, "Crack-Tip Microstructures and Impurities in Stress-Corrosion-Cracked Alloy 600 from Once-Through and Recirculating Steam Generators," Proc. $10^{\text {th }}$ Int. Conf. Environmental Degradation of Materials in Nuclear Power Systems - Water Reactors, NACE International, 2002, Paper 26.

36. S.M. Bruemmer, V.Y. Gertsman and L.E. Thomas, "High-Resolution Comparison of Primaryand Secondary-Side Intergranular Degradation in Alloy 600 Steam Generator Tubing," Corrosion 2000, NACE International, 2000, Paper 196.

37. S.M. Bruemmer and L.E. Thomas, "High-Resolution Characterizations of Stress-Corrosion Cracks in Austenitic Stainless Steel from Crack Growth Tests in BWR-Simulated Environments," Proc. $12^{\text {th }}$ International Conference Environmental Degradation of Materials in Nuclear Power Systems - Water Reactors, The Materials, Minerals and Metals Society, 2005, p. 189.

38. S.M. Bruemmer and L.E. Thomas, "Comparison of IGSCC Crack-Tip Characteristics in BWR Oxidizing Water and BWR Hydrogen Water Chemistry Conditions," Proc. $13^{\text {th }}$ International Conference Environmental Degradation of Materials in Nuclear Power Systems - Water Reactors, Canadian Nuclear Society, 2007, Paper 144.

39. S.M. Bruemmer and L.E. Thomas, "Mechanistic Insights on IGSCC in LWR Environments from Crack-Tip Characterizations: Comparisons of Fe-Base and Ni-Base Alloys," Proc. Int. Symp. Research for Aging Management of Light Water Reactors, Institute of Nuclear Safety Systems, Fukui, Japan, 2007, Paper 11.

40. P.M. Scott and M. Le Calvar, "Some possible mechanisms of intergranular stress corrosion cracking of Alloy 600 in PWR primary water," Proc. $6^{\text {th }}$ Int. Conf. Environmental Degradation of Materials in Nuclear Power Systems - Water Reactors, The Materials, Minerals and Metals Society, 1993, p. 675.

41. P.M. Scott, "An Overview of Internal Oxidation as a Possible Explanation of Intergranular Stress Corrosion Cracking of Alloy 600 in PWRs," Proc. $9^{\text {th }}$ Int. Conf. Environmental Degradation of Materials in Nuclear Power Systems - Water Reactors, Newport Beach, CA, NACE International, 1999, p. 3.

42. G.A. Young, W.W. Wilkening, D.S. Morton, E. Richey and N. Lewis, "The Mechanisms and Modeling of Intergranular Stress Corrosion Cracking of Nickel-Chromium-Iron Alloys Exposed to High Purity Water," Proc. $12^{\text {th }}$ Int. Conf. Environmental Degradation of Materials in Nuclear Power Systems - Water Reactors, Stevenson, WA, American Nuclear Society, 2003, p. 913.

43. N. Totsuka and Z. Szklarska-Smialowska, "Hydrogen-Induced IGSCC of Ni-Containing SCC Alloys in High Temperature Water, Proc. $3^{\text {rd }}$ Int. Conf. Environmental Degradation of Materials in Nuclear Power Systems - Water Reactors, Stevenson, WA, The Materials, Minerals and Metals Society, 1987, p. 691. 